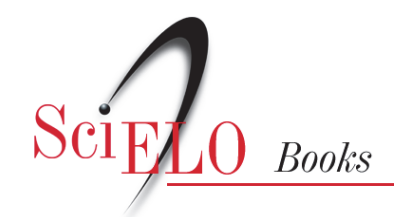

\title{
Teoria quântica: \\ estudos históricos e implicações culturais
}

\author{
Olival Freire Jr. \\ Osvaldo Pessoa Jr. \\ Joan Lisa Bromberg \\ orgs.
}

FREIRE JR, O., PESSOA JR, O., and BROMBERG, JL., orgs. Teoria Quântica: estudos históricos e implicações culturais [online]. Campina Grande: EDUEPB; São Paulo: Livraria da Física, 2011. 456

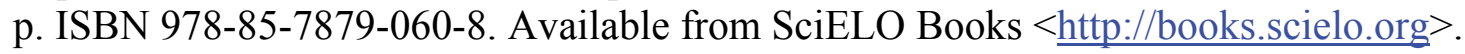

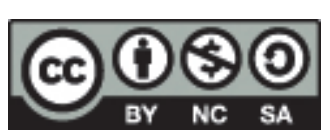

All the contents of this work, except where otherwise noted, is licensed under a Creative Commons Attribution-Non Commercial-ShareAlike 3.0 Unported.

Todo o conteúdo deste trabalho, exceto quando houver ressalva, é publicado sob a licença Creative Commons Atribuição Uso Não Comercial - Partilha nos Mesmos Termos 3.0 Não adaptada.

Todo el contenido de esta obra, excepto donde se indique lo contrario, está bajo licencia de la licencia Creative Commons Reconocimento-NoComercial-CompartirIgual 3.0 Unported. 
Olival Freire Jr. Osvaldo Pessoa Jr. Joan Lisa Bromberg

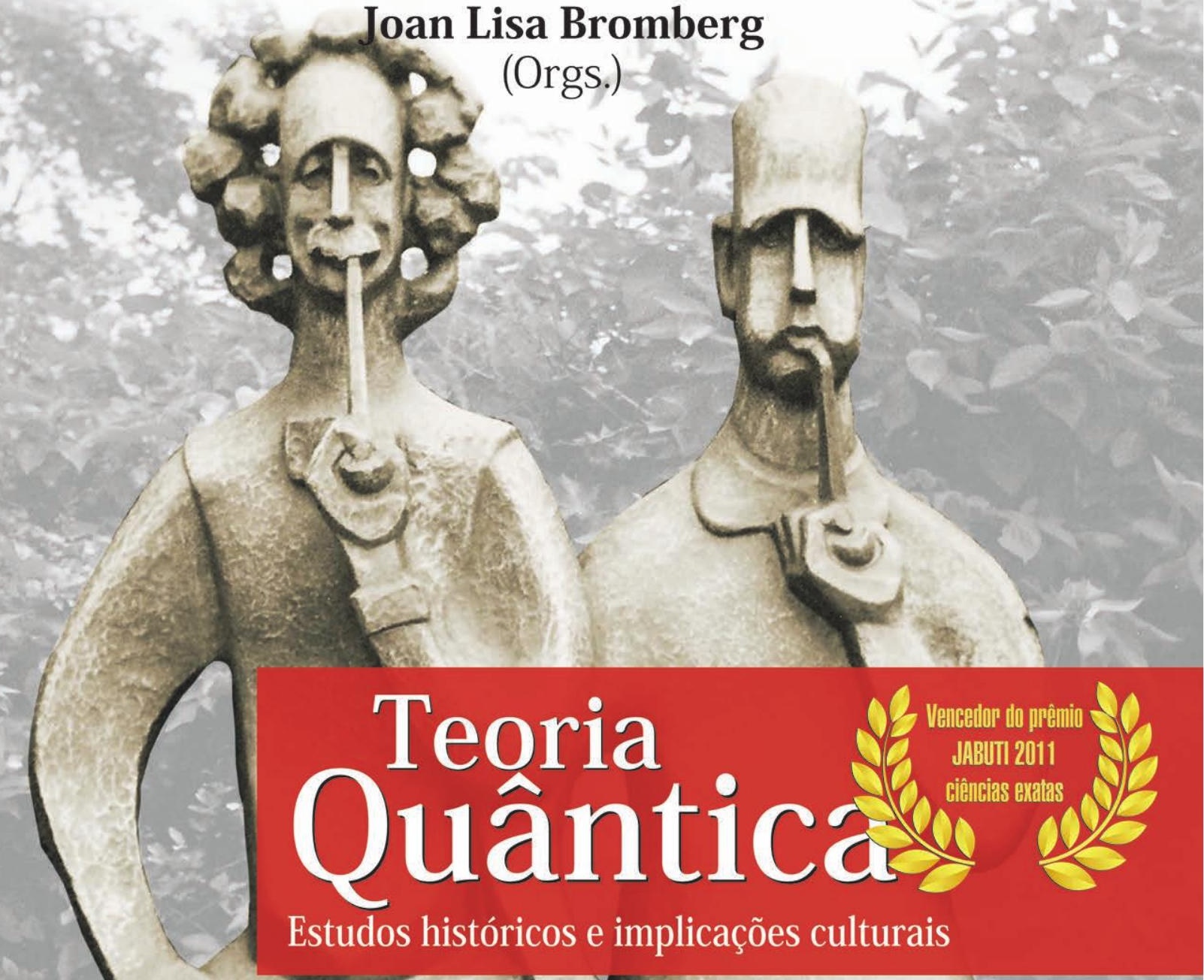




\section{Teoria Quântica: estudos históricos e implicações culturais}




\section{Universidade Estadual da Paraíba}

Profa. Marlene Alves Sousa Luna

Reitora

Prof. Aldo Bezerra Maciel

Vice-Reitor

\section{Seduepb}

Editora da Universidade

\section{Estadual da Paraíba}

\section{Diretor}

Cidoval Morais de Sousa

\section{Coordenação de Editoração}

Arão de Azevedo Souza

\section{Conselho Editorial}

Célia Marques Teles - UFBA

Dilma Maria Brito Melo Trovão - UEPB

Djane de Fátima Oliveira - UEPB

Gesinaldo Ataíde Cândido - UFCG

Joviana Quintes Avanci - FIOCRUZ

Rosilda Alves Bezerra - UEPB

Waleska Silveira Lira - UEPB

\section{Editoração Eletrônica}

Jefferson Ricardo Lima Araujo Nunes

Leonardo Ramos Araujo

\section{Capa}

Arão de Azevedo Souza

\section{Foto da capa}

Christelle Rigal

\section{Comercialização e Divulgação}

Júlio Cézar Gonçalves Porto

Zoraide Barbosa de Oliveira Pereira

\section{Revisão Linguística}

Nídia M. L. Lubisco

Normalização Técnica

Normaci Correia dos Santos 
Olival Freire Jr.

Osvaldo Pessoa Jr.

Joan Lisa Bromberg

(Organizadores)

\section{Teoria Quântica: estudos históricos e implicações culturais}

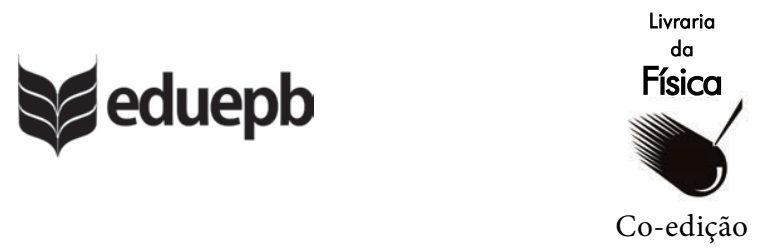

Campina Grande-PB / São Paulo-SP

2011 
Copyright $\odot 2011$ da EDUEPB

A reprodução não-autorizada desta publicação, por qualquer meio, seja total ou parcial, constitui violação da Lei nº 9.610/98.

A EDUEPB segue o acordo ortográfico da Língua Portuguesa de 1990, em vigor no Brasil, desde 2009.

$1^{\mathrm{a}}$ Reimpressão (2011).

Depósito legal na Biblioteca Nacional, conforme decreto n 1.825, de 20 de dezembro de 1907. FICHA CATALOGRÁFICA ELABORADA PELA BIBLIOTECA CENTRAL - UEPB

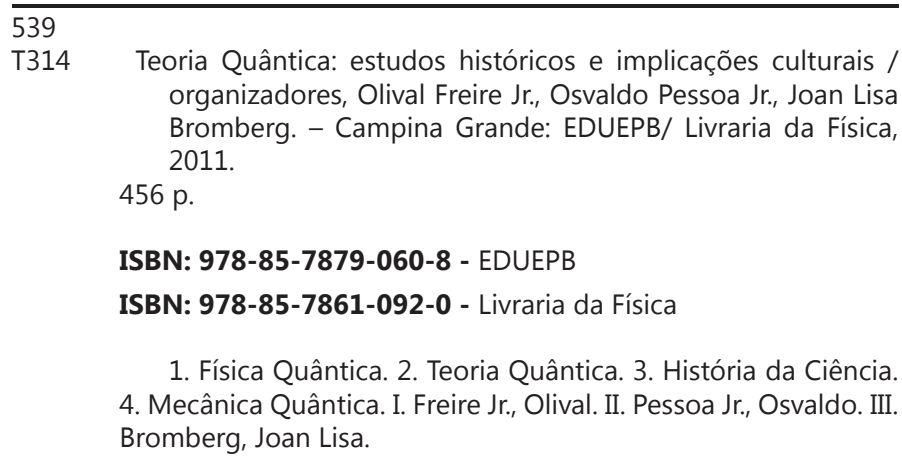

ISBN: 978-85-7879-060-8 - EDUEPB

ISBN: 978-85-7861-092-0 - Livraria da Física

1. Física Quântica. 2. Teoria Quântica. 3. História da Ciência. 4. Mecânica Quântica. I. Freire Jr., Olival. II. Pessoa Jr., Osvaldo. III. Bromberg, Joan Lisa.

21. ed. CDD

\section{EDITORA DA UNIVERSIDADE ESTADUAL DA PARAÍBA}

Rua Baraúnas, 351 - Bodocongó - Bairro Universitário - Campina Grande-PB - CEP 58429-500 Fone/Fax: (83) 3315-3381 - http://eduepb.uepb.edu.br - email: eduepb@uepb.edu.br

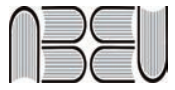

Editora filiada a ABEU 


\section{Sumário}

Apresentação Teoria Quântica: História e Cultura

\section{Parte I}

História da Teoria Quântica - desenvolvimentos e fundamentos

Problemas de pesquisa na história da Mecânica Quântica 15 Joan Lisa Bromberg

Dissidentes quânticos: pesquisa em fundamentos

da Teoria Quântica em torno de 1970.

Olival Freire Junior

A descoerência emerge: os múltiplos caminhos

de um novo fenômeno físico .65

Fábio Freitas

O itinerário científico de Louis de Broglie em busca de uma interpretação causal para a mecânica ondulatória .79

Paulo Vicente Moreira dos Santos

Sobre a cultura material dos primeiros testes experimentais do teorema de Bell: uma análise das técnicas e dos instrumentos (1972-1976) .95

Wilson Fábio de Oliveira Bispo

Denis Gilbert Francis David

Campos que interagem: Física Quântica e a transferência de conceitos entre física de partículas, nuclear e do estado sólido 107 Christian Joas 


\section{Parte II}

\section{Implicações filosóficas da Teoria Quântica}

“Construção do objeto” e objetividade na Física Quântica

Michel Paty

O realismo de Einstein e sua crítica da Mecânica Quântica

\section{Christoph Lehner}

Bohr e o problema da medição: uma solução dualista?

Stefano Osnaghi

Algumas singularidades do pensamento de Eugene P. Wigner

Frederik M. dos Santos

Fundamentações e perspectivas para a Teoria Quântica

Jhonny Alexander Castrillón Pérez

\section{Parte III}

Implicações culturais e educacionais da Teoria Quântica

O fenômeno cultural do misticismo quântico

Osvaldo Pessoa Jr.

Mecânica Quântica e a cultura em dois momentos 301

Frederico Firmo de Souza Cruz

Os princípios de complementaridade e de incerteza na obra

Copenhague de Michael Frayn: a arte e a teoria quântica

Alessandro Frederico da Silveira

Aurino Ribeiro Filho

Ana Paula Bispo da Silva

Teoria da ressonância: história e ensino

José Luis P. B. Silva

Nídia Franca Roque

Ênfase conceitual e interpretações no ensino da Mecânica Quântica ..357

Ileana M. Greca

Olival Freire Jr. 


\section{Parte IV}

Construção da Teoria Quântica - história e tendências de pesquisa

Max Planck e a Física de sistemas estocásticos

Sílvio Renato Dahmen

De Louis de Broglie a Erwin Schrödinger: uma comparação

393

Roberto de Andrade Martins

A imagem pública de Arthur Holly Compton:

um físico quântico ou clássico?

Indianara Lima Silva

Olival Freire Jr

Ana Paula Bispo da Silva

Mecânica Quântica e não-linearidade -

dificuldades e possibilidades

Aurino Ribeiro Filho

Ontologia de Fourier, análise local por onduletas e Física Quântica ...435

João Araújo

João Cordovil

José Ramalho Croca

Rui Nobre Moreira

Amaro Rica da Silva

Sobre os autores 


\section{Apresentação \\ Teoria Quântica: História e Cultura}

A Teoria Quântica, desenvolvida no primeiro quartel do século XX, é a mais bem sucedida teoria física hoje disponível. A confiança que os físicos nela depositam é de tal ordem que os desenvolvimentos teóricos ulteriores a tomam como um quadro referencial básico para pensar a Física. Desde as primeiras aplicações tecnológicas, com a invenção do transistor e do laser, até as atuais promessas no campo da informação quântica, o seu manancial de aplicações parece inesgotável. Em que pese esse sucesso científico e tecnológico, persiste entre os cientistas incertezas sobre a interpretação dos próprios fundamentos dessa teoria científica. As incertezas derivam do fato de que ela desafia as nossas intuições não só de senso comum mas mesmo aquelas enraizadas no desenvolvimento da Física nos últimos séculos. Não é de estranhar, portanto, que a segunda metade do século XX tenha presenciado um renascimento tanto da controvérsia, quanto das investigações sobre os fundamentos dessa teoria. Essa controvérsia não tem sido estéril. Hoje, compreendemos melhor a Teoria Quântica como consequência dessa controvérsia e da pesquisa que ela engendrou. A propriedade física do emaranhamento entre sistemas quânticos espacialmente separados, evidenciada no Teorema de Bell, hoje largamente aceita como um genuíno efeito quântico e colocada na base das pesquisas sobre informação quântica, tem suas raízes associadas a críticos dos fundamentos dessa própria teoria, como Albert Einstein, David Bohm, John Bell, John Clauser e Abner Shimony. No início deste ano, o prestigiado Prêmio Wolf de Física foi atribuído a John Clauser, Alain Aspect e Anton Zeilinger pelos seus experimentos com emaranhamento de fótons. O prêmio reconheceu pelo menos um físico que sempre foi um crítico dos fundamentos da Teoria Quântica, no caso John Clauser.

A controvérsia sobre os fundamentos da Teoria Quântica tem fascinado a muitos, bem além do círculo dos próprios físicos. A capa deste livro reflete essa fascinação, por estar inspirada em escultura de Albert Einstein e Niels Bohr, os principais protagonistas da controvérsia sobre os quanta, em um parque em Moscou. Imagens dos dois gigantes da Física tornaram-se ícones da Física do século XX. A controvérsia é comparada, muitas vezes, àquela que opôs Newton 
a Leibniz. Enquanto a controvérsia que está na origem da ciência moderna, no século XVII, é parte da história, a controvérsia sobre os quanta é contemporânea e estamos todos nela imersos, como partícipes.

Em 1974, o historiador Max Jammer finalizou seu The philosophy of quantum mechanics afirmando que a história dessa controvérsia é uma "história sem fim"; e acrescentou, lembrando o ensaísta francês Joseph Joubert, que "é melhor debater uma questão sem resolvê-la do que resolver uma questão sem debatê-la." Mais de 30 anos depois, as afirmativas de Jammer guardam plena atualidade.

A presente obra - Teoria quântica: estudos históricos e implicações culturais - é uma coletânea de trabalhos que exploram aspectos da história dessa teoria científica, desde sua criação aos desenvolvimentos ulteriores, incluindo a controvérsia sobre os seus fundamentos e sobre suas implicações filosóficas e culturais. Discute também problemas relacionados à pesquisa sobre o ensino e a difusão cultural dessa teoria, bem como os usos, e abusos, que aí podem aparecer.

Tanto o aparecimento deste livro, quanto o evento científico que esteve em sua origem (workshop com o mesmo nome, realizado em Campina Grande, Paraíba, entre 14 e 17 de dezembro de 2008), acontecem no Brasil em um momento oportuno. Há cerca de 15 anos vem crescendo no Brasil o número de pesquisadores dedicados a trabalhos históricos e/ou filosóficos sobre a Teoria Quântica, muitos deles autores deste trabalho, sem que se houvesse realizado até o momento um evento científico de maior envergadura integralmente dedicado ao tema. Além disso, o workshop e o livro ocorrem em um momento no qual a pesquisa sobre a história da Teoria Quântica ganha novo impulso, seja com o Projeto de História da Física Quântica, promovido pelo Instituto Max Planck de História da Ciência (Alemanha), seja com a realização de conferências internacionais sobre $o$ assunto, em especial a HQ1 (Berlim, 2007); a sessão Interpreting Quantum Mechanics - a Century of Debate, na HSS (Washington, 2007); a HQ2 (Utrecht, 2008); e a HQ3 (Berlim, 2010), todas com a participação de pesquisadores brasileiros.

O desenvolvimento da pesquisa sobre história da Teoria Quântica no Brasil também se beneficia da sua relação com a história da Física brasileira. Se é verdade que a pesquisa em Física moderna no Brasil só recebeu um momentum intelectual e institucional a partir da criação da USP, em 1934, já passada a fase áurea da criação da Teoria Quântica, também é verdade que aspectos relevantes da pesquisa e da controvérsia sobre os fundamentos dessa teoria tiveram como cenário a Física brasileira. Quando no início da década de 1950, o físico David Bohm passou três anos na Universidade de São Paulo, fugindo da perseguição do macarthismo, muito da pesquisa e dos debates sobre a interpretação causal da Teoria Quântica proposta por ele ocorreu naquela universidade. O trabalho conjunto com Jayme Tiomno e os embates com Mário Schenberg, físicos brasileiros, são parte dessa história. Mario Bunge, Jean-Pierre Vigier e Ralph Schiller 
vieram ao Brasil para trabalhar com Bohm, enquanto Léon Rosenfeld veio para estabelecer o contraponto entre a interpretação causal e a visão da complementaridade patrocinada pelo físico dinamarquês Niels Bohr. Ainda na década de 1960 foi a vez de Klaus Tausk, professor da USP, envolver-se em acirrada controvérsia com físicos italianos e com Rosenfeld sobre o problema da medição na Teoria Quântica. Pouco depois, o físico brasileiro José Leite Lopes, exilado em Estrasburgo, na França, junto com o físico francês Michel Paty, promoviam evento, que gerou o livro Quantum mechanics - a half century later, que contribuiu para criar um espaço favorável à pesquisa sobre os fundamentos da Teoria Quântica. Recentemente, os desenvolvimentos teóricos sobre o efeito descoerência e o experimento tipo "gato de Schrödinger", que testou pela primeira vez esse efeito, contam entre seus protagonistas com os físicos brasileiros Amir Caldeira e Luiz Davidovich.

Os capítulos deste livro estão organizados em quatro partes. A primeira, intitulada História da teoria quântica - desenvolvimentos e fundamentos, reúne artigos com uma abordagem eminentemente histórica sobre aspectos da pesquisa em Teoria Quântica na segunda metade do século XX. A segunda parte, Implicações filosóficas da teoria quântica, está integrada por textos essencialmente filosóficos, versando sobre a interpretação da Teoria Quântica. As Implicações culturais e educacionais da teoria quântica, terceira parte, referem-se a fenômenos, como o "misticismo quântico," a presença da quântica no teatro e o ensino dessa teoria física. Por fim, a última parte, Construção da teoria quântica: história e tendências de pesquisa, está composta por trabalhos históricos que exploram o período da construção da Teoria no início do século XX, bem como trabalhos que mesclam abordagens históricas com possibilidades atuais de desenvolvimento da pesquisa em seus fundamentos.

O livro compreende 21 capítulos e 28 autores, divididos entre brasileiros e estrangeiros, em proporções aproximadamente iguais. Reúne desde pesquisadores-sênior a estudantes de pós-graduação. Os trabalhos aqui reunidos foram apresentados em versões preliminares, no workshop que dá origem ao livro. As versões preliminares foram submetidas a um processo de arbitragem e seleção, conduzido pelos organizadores do volume, de modo que esses textos representam um esforço coletivo de discussão e elaboração que teve início naquele workshop e que se prolongou por quase um ano e meio.

Tanto o workshop que lhe deu origem, quanto o próprio livro ora publicado, foram possíveis graças ao apoio do Programa de Doutorado Interinstitucional (DINTER) em Ensino, Filosofia e História das Ciências, oferecido pela Universidade Federal da Bahia (UFBA) e Universidade Estadual de Feira de Santana (UEFS), em parceria com a Universidade Estadual da Paraíba (UEPB). A iniciativa não teria sido possível, entretanto, sem um leque de apoios, sendo o 
mais expressivo dentre eles o da UEPB, por meio de sua Reitoria e Pró-Reitoria de Pós-Graduação e Pesquisa. De fato, o apoio institucional dessa Universidade e o encorajamento recebido da sua Pró-Reitora, Profa. Dra. Marcionila Fernandes, foram essenciais para o sucesso do evento. Além da UEPB, o workshop e o livro contaram com o apoio do IQuanta (Campina Grande); do Departamento de Física da Universidade Federal de Campina Grande (UFCG); da Capes (PROCAD NF UFBA-UFSC-UFRGS); da FAPESB, do CNPq e do Instituto Max Planck de História da Ciência (Berlim). Agradecemos a Christelle Rigal a foto que serviu de base para a capa. Esta imagem já havia antes inspirado a capa do livro Quantum dialogue de Mara Beller.

Olival Freire Jr. Osvaldo Pessoa Jr. Joan Lisa Bromberg 


\section{Parte I}

\section{História da Teoria Quântica - desenvolvimentos e fundamentos}




\title{
Problemas de pesquisa na história da Mecânica Quântica ${ }^{1}$
}

\author{
Joan Lisa Bromberg
}

Uma questão surgiu no final de um artigo que publiquei em 2008 na Historical Studies in the Natural Sciences. Nele, dissera algo como o seguinte: nos anos finais do último século e na primeira década deste, os físicos realizaram mais e mais experimentos sobre a filosofia da mecânica quântica. Entre os conceitos que eles testaram estavam a ideia da complementaridade de Niels Bohr e a natureza da fronteira entre o mundo microscópico, que as leis não-intuitivas da mecânica quântica parecem governar, e o mundo sensível da nossa experiência cotidiana.

Os físicos que descrevem esses experimentos têm feito muitas afirmações sobre eles. Uma delas é de que eles lançaram uma nova luz sobre o significado da mecânica quântica. A outra é que eles abriram o caminho para testar os limites da validade dessa teoria. Eis alguns exemplos: em 1984, o presidente do comitê organizador de uma conferência, cujo título era revelador - International Symposium on Foundations of Quantum Mechanics in the Light of New Technology, fez a seguinte declaração:

Apesar do sucesso inquestionável da mecânica quântica [...] as controvérsias relacionadas à sua interpretação nunca deixaram de existir [...] mas os argumentos têm sido baseados principalmente em experimentos de pensamento idealizados e que, deste modo, dificilmente atraíram a atenção de muitos físicos os quais estavam ocupados com os seus próprios problemas mais realistas. Os recentes desenvolvimentos na tecnologia, contudo, tornaram possível a realização de muitos desses experimentos de pensamento nos laboratórios. [...] $\mathrm{Na}$ organização [desta conferência], nós pretendemos tirar

1 Tradução de Indianara Lima Silva e revisão técnica de Olival Freire Jr. 
completa vantagem deste avanço tecnológico, e emitir uma nova luz sobre aquelas velhas questões, mas, fundamentais da mecânica quântica. (NAKAJIMA, 1984)

A seguir, está uma declaração de 1992:

Na década de 1980, a tecnologia finalmente tornou possível chegar aos conceitos de medição de Bohr, von Neumann e seus colegas da década de 1930, e forçou os físicos modernos a elaborarem e estenderem aqueles conceitos. (THOME, 1992, p. xiv)

Em 1995, afirmou-se que

Nos anos recentes, surgiu um crescimento explosivo nas novas técnicas experimentais as quais podem ser adaptadas para testar algumas das predições mais estranhas da teoria quântica [...] trazendo-nos dias mais próximos de determinar os limites dessa teoria. (GREENBERGER, 1995, p. xiii-xiv)

Por fim, uma declaração feita em 2005, traduzida de um livro publicado em 1997:

Nos anos recentes, o debate sobre as questões mais relevantes da teoria moveu-se para um nível mais alto. O nosso entendimento das implicações do formalismo foi modificado devido, em particular, a algumas inovações tecnológicas importantes que tornaram possíveis muitos novos experimentos em nossos laboratórios. (GHIRARDI, 2005, p. xiv)

Eu desejei, então, testar essas afirmações. Como a condução de experimentos reais nas décadas de 1970, 1980 e 1990 afetou o que os físicos e os filósofos tinham a dizer sobre o significado da mecânica quântica? Obviamente, os experimentos de Bell tinham tido um impacto extraordinário. Mas e os experimentos realizados com os instrumentos mais recentes?

Eu me questionei se um modo de investigar sobre isso seria a partir da análise de um grupo particular de instrumentos. Nós poderíamos, por exemplo, examinar os avanços tecnológicos que os tornaram possíveis, os experimentos realizados com eles e a forma pela qual os seus resultados foram utilizados nos argumentos sobre as interpretações da mecânica quântica.

Os instrumentos escolhidos foram as cavidades de microondas, conhecidas, às vezes, como micromasers, originadas a partir da tecnologia de masers e lasers. Eles têm sido utilizados para examinar a complementaridade de Bohr e a fronteira clássico-quântica. Os micromasers têm demonstrado com sucesso a granularidade ou a natureza quântica da luz. Outros tipos de equipamento também 
foram utilizados para testar esses mesmos princípios filosóficos. E havia a estimulação mútua entre os grupos que os utilizavam e os que trabalhavam com os micromasers. No entanto, eu pensei que talvez pudéssemos compreender aquelas questões, seguindo o caminho de um tipo singular de instrumento. Comecei, então, a analisar a história dos micromasers. Ao fazê-lo, outras questões históricas interessantes começaram a surgir. Utilizarei este texto para discutir sobre a história do micromaser, mas, também, traçarei essas questões, sugerindo-as como problemas de pesquisa.

A narrativa do micromaser inicia-se com a invenção de novos tipos de lasers na década de 1960. Eles são os assim chamados lasers sintonizáveis. Os primeiros lasers tinham produzido luz em uma ou mais frequências fixas. Esses novos lasers poderiam ser sintonizados em uma faixa de frequências. Na metade da década de 1970, eles tornaram possíveis novos campos de espectroscopia. Entre eles estava a espectroscopia dos átomos de Rydberg. Esses átomos possuem um alto número quântico principal, isto é, são átomos cujo elétron da camada exterior, da valência, está tão distante do núcleo que eles se assemelham aos átomos de hidrogênio. Os átomos de Rydberg, no espaço interestelar, foram observados pelos radioastrônomos na década de 1960. Contudo, como esses átomos eram muito difíceis de fazer em laboratório através dos métodos disponíveis, os átomos terrestres de Rydberg não foram muito estudados.

Mas, a partir dos lasers sintonizáveis, isso mudou. Eles provocaram uma explosão de pesquisa sobre os átomos de Rydberg. Os editores do volume Rydberg states of atoms and molecules, publicado em 1983, puderam escrever no prefácio que

[...] mais da metade dos trabalhos publicados neste campo tem aparecido após 1975. [...] Do ponto de vista do experimentalista, [...] o campo permaneceria essencialmente adormecido até a chegada do laser sintonizável”. (STEBBINGS; DUNNING, 1983, p. ix)

Uma propriedade que diferencia os átomos de Rydberg dos seus primos em estados de menor energia é o forte efeito que os campos elétricos externos exercem sobre eles. Para os estados de menor energia, a força de Coulomb dos núcleos muito próximos é mais forte do que qualquer campo que os cientistas podem criar no laboratório. Para os átomos de Rydberg, os núcleos e os outros elétrons estão bem distantes. Isso torna possível examinar experimentalmente o modo pelo qual os campos de laboratório afetam o comportamento atômico. Essa era uma área que um grupo do MIT, sob a liderança de Daniel Kleppner, especialmente investigava. ${ }^{2}$

2 Ver, por exemplo, o artigo: Ducas e outros (1975). Ver também: Kleppner e colaboradores (1983, p. 73-116). 
Essa mesma propriedade dos átomos de Rydberg também resolveu uma difícil questão experimental. Como os átomos de Rydberg também são altamente estáveis quanto ao decaimento radiativo, o velho método para determinar o nível de energia de um átomo, através da medição do comprimento de onda da sua radiação, não podia ser usado. No MIT, e através dos trabalhos do grupo de Kleppner, "o campo de ionização" tornou-se a técnica preferida. Quanto maior a energia do átomo, menor é o campo externo que é preciso para ionizá-lo. A intensidade do campo de ionização tornou-se a medida da energia do átomo, a qual era uma medida elegante, simples e extremamente sensível. Neste caso, "Um átomo único de Rydberg em um estado bem definido pode ser detectado dessa forma" (FABRE; HAROCHE, 1983, p. 136). Isso é um exemplo impressionante de como um novo instrumento - o laser sintonizável - pôde tornar possível o estudo de uma nova classe de objetos - os átomos de Rydberg - e como, por sua vez, as propriedades desse objeto podem tornar possíveis outras novas instrumentações.

As pessoas que trabalharam com os átomos de Rydberg também conheciam as cavidades de microondas. Daniel Kleppner, por exemplo, foi um dos inventores do maser de hidrogênio. Os masers funcionam enviando moléculas ou átomos excitados para cavidades de microondas. $\mathrm{O}$ conhecimento profundo das cavidades, necessário para trazer a existência do maser de hidrogênio, incluiu a estrutura dos modos magnéticos que formam a cavidade, os meios de sintonizar a frequência desses modos, as propriedades mecânicas das cavidades, bem como as suas propriedades térmicas e magnéticas. (KLEPPNER et al., 1965)

Os outros dois homens que são fundamentais para essa narrativa tinham experiência com as cavidades de laser: Herbert Walther, da Alemanha, e Serge Haroche, da França. Walther nasceu em 1935, obteve o seu doutorado em Heidelberg, em 1962, e a sua Habilitation em Hannover, em 1968. Um das suas posições de pósdoutorado foi na Universidade do Colorado e, nessa posição, contribuiu para a invenção de uma versão inicial do laser sintonizável de corante (WALTHER; HALL, 1970). Na década de 1970, tornou-se um dos líderes na pesquisa com espectroscopia do laser, primeiro como professor na Universidade de Colônia e, em 1975, com uma posição na Universidade de Munique. (HERMANN; LECHNER, 2006)

Serge Haroche nasceu no Marrocos em 1944. Obteve o seu doutorado em 1971 na École Normale Supérieure em Paris, onde estudou com Alfred Kastler e Jean Brossel, entre outros. O orientador da sua tese foi Claude Cohen-Tannoudji. De Paris, Haroche foi realizar um pós-doutorado na Universidade de Stanford, na Califórnia, sob a orientação de Arthur Schawlow, um dos inventores do laser. Os lasers de corante também foram desenvolvidos em Standford e Haroche tornou-se um dos primeiros a aplicar essa nova ferramenta na espectroscopia (HAROCHE et al., 1973; HAROCHE, 2004). Depois, Haroche retornou a École Normale Supérieure, trazendo consigo o laser como parte do seu kit de ferramentas. 
Os primeiros masers funcionavam com aproximadamente um bilhão de moléculas de amônia em uma cavidade de microondas. De fato, obter um fluxo grande o suficiente de moléculas foi um dos obstáculos que os homens que construíram esses masers tiveram de superar (BROMBERG, 1991). No entanto, os átomos de Rydberg têm a propriedade de se acoplar muito mais fortemente com microondas do que as moléculas de amônia. Então, um maser, utilizando os átomos de Rydberg como a substância de trabalho, deveria precisar de um fluxo muito menor.

Haroche e os seus colegas produziram exatamente esse maser no final da década de 1970. O maser tinha apenas aproximadamente 500 átomos fluindo através da cavidade (GROSS et al., 1979). Eles mencionaram que o maser poderia ser utilizado na espectroscopia dos átomos de Rydberg e nos detectores sensíveis da radiação de microonda. No entanto, também é evidente o desejo de produzir um maser com ainda menos átomos. Logo, no início da década de 1980, o objetivo de obter um maser de átomo único estava claramente enunciado (HAROCHE et al., 1982, p. 659, 670-671). Deste modo, há uma década de competição entre o grupo de Walther, na região de Munique, e o grupo de Haroche em Paris. Passos na direção de um maser de átomo único se alternaram entre eles.

Antes de iniciar essa discussão, eu gostaria de sugerir um primeiro tópico de investigação, que seria um estudo comparativo desses dois grupos. Haroche e Walther trabalharam em instituições diferentes. De um lado, Walther ajudou a fundar o Max Planck Institute for Quantum Optics em Garching, próximo a Munique. Ele foi seu codiretor a partir de 1981, quando o instituto tomou forma. Do outro lado, Haroche construiu um grupo que estava dentro da École Normale e estava baseado em seus estudantes de pós-graduação.

Os equipamentos dos dois grupos também eram diferentes. Neste sentido, seria interessante investigar quais as tradições e as competências que estavam incorporadas no equipamento? Como as diferenças nos equipamentos influenciaram as diferentes direções que as suas pesquisas tomaram? Poderemos aprender mais sobre a pesquisa europeia nesta década, a partir de tal estudo? Os padrões de financiamento para a ciência na França e na Alemanha os afetaram diferentemente? E o financiamento internacional? Tanto Paris quanto Garching atraíram físicos estrangeiros. Havia diferenças na forma como esses dois locais funcionavam na condição de centros internacionais?

Como eu havia mencionado, o progresso para o maser de um átomo único alternou idas e vindas entre o grupos de Paris e o de Garching. Talvez a mais importante melhoria tecnológica tenha sido o aumento na "qualidade" da cavidade do maser, ou seja, na sua capacidade em conservar a energia eletromagnética. Os artigos do grupo da École Normale Supérieure mostraram, com riqueza de detalhes, o seu passo a passo para a melhoria da qualidade da cavidade. Em 
um artigo recebido pela Physical Review, em março de 1982, o grupo utilizou as cavidades abertas de bronze, em temperatura ambiente. Os pulsos de maser de poucas centenas de nanossegundos foram obtidos com aproximadamente 10 mil átomos de Rydberg dentro da cavidade (MOI et al., 1983). No ano seguinte, Haroche e os seus colaboradores tinham construído uma cavidade com uma qualidade aproximadamente 30 vezes maior, mudando o nióbio supercondutor e operando abaixo de 6 graus Kelvin. Ao mesmo tempo, foram capazes de aumentar o fluxo dos átomos de Rydberg para um ponto em que apenas um deles atravessava a cavidade de cada vez. Mas a qualidade da sua cavidade ainda não era boa o suficiente para obter mais do que uma ação do maser transiente. (GOY et al., 1983)

Em seguida, Garching obteve o próximo êxito. Em artigo recebido pela Physical Review Letters em agosto de 1984, os experimentadores descreveram uma qualidade de cavidade de 10 a 100 vezes maior do que aquela do grupo de Paris. A sua cavidade também foi construída a partir do nióbio supercondutor, meticulosamente processada, e eles foram capazes de realizar o experimento entre $4.3 \mathrm{e}$ 2 graus Kelvin. A operação contínua do maser, com não mais do que um átomo de cada vez, foi demonstrada e, embora eles ainda não pudessem mapeá-la, as condições estavam corretas para o átomo e para o campo, de modo a lançar um fóton para frente e para trás entre si de 5 a 20 vezes. (MESCHEDE; WALTHER; MUELLER, 1985)

O grupo de Paris iria finalmente demonstrar essa oscilação. E eles mostrariam, utilizando os campos de cavidade muito fracos, que essa oscilação revelaria a granularidade ou a natureza quântica, da luz (BRUNE et al., 1996). Ao mesmo tempo, esse grupo estava construindo e analisando um tipo diferente de maser de átomo único, a partir do qual o átomo realizava uma transição de um nível para o outro, emitindo um par de fótons ao invés de um fóton único (BRUNE et al., 1987; BRUNE; RAIMOND; HAROCHE, 1987; DAVIDOVICH et al., 1987).

Outra sugestão para um projeto em História. Poderíamos relacionar o progresso técnico que conduziu a esses resultados ao mundo mais largo do avanço tecnológico? Eu gostaria de mencionar a observação feita por Peter Galison, em Image and logic, que a instrumentação científica faz parte de um continuum de tecnologia utilizada em todo o espectro da atividade humana. (GALISON, 1997) Logo, a instrumentação acrescenta pouco valor se nós, historiadores, somente escrevermos sobre as melhorias sucessivas dos aparelhos como as cavidades. Os próprios físicos fornecem tais histórias em seus artigos de revisão. Contudo, podemos dar uma real contribuição se conseguirmos relacionar os avanços na Física com as mudanças tecnológicas em todas as ciências, bem como com as aplicações comerciais e militares. 
Mas, voltemos à narrativa. Os resultados experimentais dos micromasers não foram uma surpresa. Em meados da década de 1980, os teóricos estiveram calculando as interações entre os átomos únicos e os modos dos campos singulares por mais de duas décadas. Os cálculos originais, contudo, tinham sido realizados por razões bem distantes de comparações experimentais.

Um dos primeiros tratamentos, e um que viria a ser citado universalmente, foi publicado em 1963 pelo físico Edwin T. Jaynes, da Universidade de Washington, e pelo seu estudante Frederick W. Cummings. Jaynes estava insatisfeito com a Teoria Quântica do Eletromagnetismo (do acrônimo "QED", em inglês, ou eletrodinâmica quântica) em um nível mais fundamental. Antes da II Guerra Mundial, a QED tinha sido atormentada pelos cálculos que conduziam a respostas infinitas. Na década de 1940 e na de 1950, esse problema foi resolvido pelo programa de renormalização, o qual eliminou as infinitudes pela subtração de outras infinitudes. Jaynes não gostava da renormalização. Ele procurou, portanto, mostrar que o maser da molécula de amônia em operação poderia ser igualmente bem tratado por uma teoria que tratasse as moléculas pela mecânica quântica, mas que, ao invés de quantizar os campos tratasse os mesmos pela teoria eletromagnética clássica. Jaynes estendeu esse tratamento semiclássico e denominou a sua abordagem embelezada de Teoria Neoclássica (NCT, em inglês).

A estratégia do artigo de Jaynes-Cummings foi tratar primeiramente pela QED uma molécula única de amônia, em interação com um modo eletromagnético singular em uma cavidade idealizada sem perda. Em seguida, eles generalizaram o tratamento para o caso de muitas moléculas. Depois, eles realizaram uma análise neoclássica e compararam as suas predições com a eletrodinâmica quântica. Eles escreveram:

A teoria semiclássica, quando estendida [...] reproduz quase quantitativamente a mesma lei das trocas de energia e as propriedades de coerência como a teoria do campo quantizado. (JAYNES; CUMMINGS, 1963, p. 90)

Tendo mostrado que a NCT "[...] explica os efeitos, que todos os livros-textos padrões, descrevem como necessitando de uma quantização do campo para a sua explicação", eles dedicaram o final do seu artigo a uma aplicação da NCT para o maser de amônia. (JAYNES; CUMMINGS, 1963, p. 101-102)

Novamente, eu gostaria de fazer uma pausa para propor outro tópico de investigação. A História da Eletrodinâmica Quântica dentro da Óptica poderia nos dar uma oportunidade de unir as narrativas de duas disciplinas que são geralmente tratadas separadamente. A tentativa de Jaynes de evitar a utilização da QED seria certamente parte de tal história. Assim também seria o caso quando, no início da 
década de 1960, Roy J. Glauber invadiu a Óptica para insistir que os tratamentos clássicos da coerência fossem reformulados de acordo com a Teoria Quântica de campo. "Em última instância, não há substituto para a teoria quântica na descrição dos quanta" (GLAUBER, 1963, p. 85). E essa história poderia examinar a forma pela qual os ópticos quânticos navegaram entre o cálculo semiclássico e o quântico através do resto do século, e se poderia perguntar sobre qual o impacto dos experimentos ópticos das décadas de 1980 e 1990, os quais revelaram a granularidade da luz.

É uma das ironias da História que o modelo neoclássico de Jaynes-Cummings não tenha sido adotado. Ao invés disso, os teóricos abraçaram e exploraram, ao longo dos anos 60 e 70, as equações da Eletrodinâmica Quântica de Jaynes e Cummings. ${ }^{3}$ Mas, o que eu quero enfatizar é que este modelo da QED despertou a atenção por ser um problema que poderia ser resolvido exatamente e não por ele ser relevante para o trabalho experimental. ${ }^{4}$

Com o início da década de 1980, contudo, algo novo aconteceu. Uma aproximação iniciou-se entre essa tradição teórica e o micromaser. Os teóricos começaram a realizar cálculos diretamente relacionados com o trabalho experimental. Um exemplo é a pesquisa de Joseph Eberly e do seu grupo da Universidade de Rochester, nos Estados Unidos. Antes de 1980, partindo do modelo totalmente quantizado de Jaynes-Cummings, eles tinham derivado um resultado importante. Após 1981, Eberly tornou-se um visitante frequente de Garching e o seu grupo começou a realizar cálculos das condições experimentais por meio dos quais os fenômenos que eles calcularam poderiam ser exibidos.

Com o avanço da década de 1980 e com o micromaser tornando-se uma realidade, os teóricos seguiram novos rumos. Eles trabalharam em teorias do novo instrumento ${ }^{6}$, explorando, assim, as diferenças entre os sistemas que eram compostos por muitos átomos e os que faziam a utilização de átomos únicos. Por exemplo, eles perguntaram: - Quais eram as novas ferramentas teóricas que deveriam ser introduzidas para tratar as situações de átomo único (MEYSTRE, 1992) e sobre quais eram os novos fenômenos que poderiam ser esperados a partir deles?

3 Uma história desses artigos subsequentes é dada na primeira seção do artigo: Narozhny, Sanchez-Mondragon e Eberly (1981).

4 Ver, por exemplo, o tratamento desse modelo no seguinte artigo: Allen e Eberly (1975).

5 Compare o artigo de Eberly e outros (1980), com a seção 8, Experimental Prospects, do artigo: Yoo e Eberly (1985).

6 Por exemplo, ver o artigo: Filipowicz, Javanainen e Meystre (1986). 
Os teóricos também começaram a sugerir novos usos para o micromaser. Um exemplo de especial importância para esse trabalho foi a ideia de Marlan O. Scully de utilizar os micromasers para esclarecer a natureza da complementaridade de Niels Bohr. Mesmo antes do micromaser, Scully já tinha argumentado que a complementaridade era um princípio mais geral do que as relações de incerteza de Heisenberg (BROMBERG, 2006; CANTRELL; SCULLY, 1978; SCULLY; SHEA; MCCULLEN, 1978). Para o caso do experimento da dupla fenda, por exemplo, a complementaridade entre a informação sobre qual o caminho e sobre a interferência é frequentemente explicada sob a base das relações de incerteza. No famoso exemplo de Richard Feynman, a informação sobre qual o caminho da passagem de um elétron através de uma dupla fenda é obtida por uma fonte de luz que produz um espalhamento dos fótons pelo elétron. Essa informação da posição, no entanto, é apenas obtida através da criação da incerteza no momentum, assim, o fóton fornece ao elétron um recuo que altera o seu momentum e borra o padrão de interferência (FEYNMAN, 1963). Scully argumentou que os mecanismos baseados na incerteza eram uma forma de manter a complementaridade assegurada, mas não a única. No início de 1978 e trabalhando com vários colaboradores, ele elaborou uma série de experimentos de pensamento no qual a informação sobre o caminho era registrada pelos detectores que não perturbavam a partícula, cuja trajetória eles determinaram. ${ }^{7}$

Uma vez que o micromaser estava em operação, Scully, junto com Herbert Walther e Berthold-Georg Englert, transferiu essas ideias para o experimento com o micromaser. As partículas que emergiam das fendas eram átomos de Rydberg. Dois micromasers foram inseridos antes das fendas. O aparato foi ajustado de modo que um átomo tivesse probabilidade igual a um para emitir um fóton quando ele passasse através da cavidade. Se um fóton extra aparecesse na cavidade 1, portanto, poderíamos saber que o átomo passou através da fenda 1. Scully e os seus colaboradores sustentaram que essa informação seria obtida sem a perturbação do átomo.

Nós temos encontrado um modo [...] de determinar a informação sobre qual o caminho ou tipo de partícula sem o espalhamento ou, de outro modo, introduzindo fatores de fase largamente incontroláveis nos feixes que interferiam. Para ser claro, nós encontramos franjas de interferência que desapareceram à medida que temos a informação sobre qual o caminho, mas nós concluímos que esse desaparecimento origina-se das correlações entre o aparato de medição e o sistema que está sendo observado. O princípio da complementaridade está demonstrado, embora que a relação de incerteza da posição não desempenhe nenhum papel. (SCULLY; ENGLERT; WALTHER, 1991, p.111)

7 De modo mais proeminente, no seguinte artigo: Scully e Druehl (1982). 
Logo, os experimentos de pensamento com o micromaser focalizaram a atenção nas relações entre a complementaridade, a incerteza e as correlações (ou emaranhamentos) entre os sistemas.

Neste período, as superposições macroscópicas tornaram-se um tópico com bastante destaque. Elas são os famosos estados do gato de Schrödinger. A questão é saber se, da mesma forma que os átomos podem estar em uma superposição de dois estados diferentes, um objeto macroscópico como um gato pode estar em uma superposição, por exemplo, o estado de estar morto ou o estado de estar vivo. O grupo da École Normale Supérieure passou a estudar as superposições macroscópicas no início da década de 1990. Inicialmente, eles analisaram como criar superposições coerentes de campos eletromagnéticos dentro de uma cavidade; depois, eles passaram a se perguntar como essas superposições decaíam ou "decohere". ${ }^{8}$ A descoerência está associada à relação entre o mundo quântico e o clássico. Ela também tem relações profundas com outros aspectos da filosofia da mecânica quântica, como as ideias sobre a complementaridade propostas por Scully e os seus colaboradores. Por outro lado, a descoerência também está relacionada à computação quântica e à questão de se esse projeto de tecnologia será viável ou não. O grupo de Paris examinava a questão tanto em termos científicos, quanto tecnológicos.

O grupo debruçou-se no problema das superposições macroscópicas através do trabalho com os chamados métodos de "não-demolição" para a medição da intensidade do campo da cavidade. A maioria dos métodos de medição da intensidade do campo destroi alguns dos fótons do campo. Por exemplo, um fotomultiplicador absorve um fóton para liberar uma cascata de elétrons, a qual testemunhava a existência anterior do fóton. Os métodos de não-demolição conservam o número total de fótons do campo.

Para realizar tal medida, o grupo propôs afastar-se da situação na qual a frequência da cavidade é ressonante com a frequência da transição dos átomos de Rydberg e, assim, considerar uma interação não ressonante entre o átomo e a cavidade. Desde que ressonante significa que o átomo não pode mais trocar um fóton com o campo, essas interações conservam o número de fótons. Contudo, esses cálculos mostravam que a interação afetava, de fato, a fase do campo. Em um caso particular, no qual todos os átomos que entram com sucesso na cavidade têm a mesma velocidade, o campo deveria desenvolver uma superposição coerente de estados com fases diferentes. (BRUNE et al., 1992)

8 Dois campos eletromagnéticos são coerentes se, quando combinados, produzirem efeitos de interferência. Mais detalhes, ver Wolf (2007). NT: Em português, temos o substantivo descoerência, mas não há um verbo para descrever a perda da coerência. 
A criação real dessas superposições macroscópicas, "gatos de fases", durou alguns anos. Um número de avanços tecnológicos possibilitou a sua realização. E um deles foi criogênico. $\mathrm{O}$ grupo conseguiu resfriar essa cavidade para um valor abaixo de 0.6 graus Kelvin. Ademais, o controle das superfícies internas da sua cavidade desempenhou um papel. (HAROCHE; RAIMOND, 2006)

O grupo de Paris também tinha desenvolvido uma técnica, a qual enviava todos os átomos para a cavidade com a mesma velocidade. Esse é um dos exemplos em que é possível verificar a influência da tradição da óptica francesa. Garching tinha obtido as velocidades uniformes através da passagem de átomos pelas fendas riscadas por uma série de placas girantes 9 . Em contraste, o grupo de Paris utilizou o bombeamento óptico. Eles utilizaram um processo de três etapas baseado no fato de que os átomos com velocidades diferentes têm deslocamentos diferentes na frequência Doppler. Através do bombeamento dos átomos em vários níveis, eles conseguiram reduzir a dispersão da velocidade para 2 metros/ segundo para os átomos que viajavam a 200 metros/segundo.

Essas superposições de gatos de fase poderiam ser utilizadas para ilustrar a complementaridade entre o efeito de interferência e a informação sobre qual o caminho. Scully e o grupo de Garching tinham discutido um experimento de pensamento, no qual um átomo atravessava uma das duas fendas, e a trajetória era registrada pela presença de um fóton extra em um dos micromasers. Nos experimentos do grupo de Haroche, o átomo tinha duas "trajetórias" distintas em um sentido diferente. Ele transita do seu estado inicial excitado (e) para o seu estado final fundamental $(g)$, em duas maneiras diferentes. Ele pode ir de $e$ para $g$, passando através da cavidade no estado $g$, ou pode ir de $e$ para $g$, depois de já ter passado pela cavidade. Se a cavidade é retirada do aparato experimental, nós não conhecemos qual a "trajetória" que o átomo realizou, resultando em franjas de interferência. Se a cavidade é incluída, os seus campos fornecem-nos a informação sobre qual o caminho. Isso se deve ao fato de que o átomo que atravessa aquela cavidade no estado $e$ modifica o campo em uma fase diferente do que um que atravessou no estado $g$.

Além de criar as superposições nesses experimentos, o grupo de Paris também estava profundamente envolvido com as questões da sua fragilidade, isto é, a rapidez com a qual elas perdem a coerência. A centralidade da descoerência está refletida em títulos de artigos, tal como Observing the progressive decoherence of the 'meter' in a quantum measurement (BRUNE et al., 1996)..$^{10} \mathrm{~A}$ descoerência foi vista pelos seus partidários como uma solução para o problema da fronteira entre

9 Por exemplo, ver o artigo: Rempe, Walther e Klein (1987).

10 Para todos os parágrafos antecedentes, ver também a entrevista com Serge Haroche realizada por Olival Freire e Gilles Nogues em 2004. 
o mundo quântico e o cotidiano. Bohr insistiu que nós precisávamos de dois conjuntos de conceitos, o clássico e o quântico, para atribuir sentido aos fenômenos. Os teóricos da descoerência preferem a conjectura de que a Teoria Quântica é suficiente. A razão pela qual nós não vemos os efeitos estranhos das superposições quânticas no mundo macroscópico é simplesmente porque as superposições macroscópicas perdem a coerência quase instantaneamente. ${ }^{11}$

Essa estreita relação entre a Física e a Filosofia sugere que os experimentos sobre a descoerência poderiam ser o caminho para a resposta da questão que fiz no início deste artigo: - Os experimentos reais afetaram a filosofia da mecânica quântica? Inicialmente, nós gostaríamos de saber se eles afetaram Haroche e os seus colegas. Nós sabemos que eles aceitaram a teoria. Até onde analisei, eles pensam que a descoerência provavelmente será a solução para o problema da fronteira entre os mundos macro e micro. ${ }^{12}$ Contudo, nós não conhecemos como essa crença interagiu com o seu trabalho experimental.

Entretanto, a descoerência não foi um domínio exclusivo do grupo de Paris, embora o seu experimento tenha sido um dos primeiros a medi-la. Nos anos seguintes, a pesquisa teórica e experimental sobre a descoerência floresceu como um campo vigoroso dentro da Física. Os historiadores estão começando a estudar a evolução desse campo. Eu os instigo a dar alguma atenção à relação, ou à falta dela, entre os experimentos que foram feitos e as atitudes com respeito à descoerência dentro da literatura sobre a Filosofia da Física.

Também gostaria de mencionar sobre o trabalho aplicado do grupo de Paris. O mesmo estudo das superposições dos campos da cavidade, e da descoerência dessas superposições, conduziu o grupo de Paris à Teoria da Informação Quântica. Em um breve e interessante artigo publicado em 1993, o grupo propôs a utilização de átomos para criar e detectar os emaranhamentos entre os campos em duas cavidades separadas. O artigo também se referiu a superposições coerentes dos estados do campo que simultaneamente ocupam as duas cavidades. $\mathrm{O}$ artigo propôs fazer a medição das interferências, devido a essas superposições, e também medir as suas descoerências. Tudo isso soa como os artigos sobre a descoerência que eu já havia discutido. Mas há uma diferença semântica. Os autores estão chamando os átomos que criam as superposições de "interruptores quânticos" e eles os comparam com as portas dos circuitos lógicos. De fato, as palavras "interruptores quânticos" obtiveram um lugar de destaque, elas têm aparecido em títulos de artigos, tal como Quantum switches and non-local microwave fields. (DAVIDOVICH et al., 1993)

11 Para a Física e a filosofia da descoerência, ver o seguinte artigo: Schlosshauer (2007). Para mais detalhes sobre as ideias de Bohr quanto à relação entre os conceitos clássicos e quânticos, ver o artigo: Osnaghi, Freitas e Freire Jr. (2009), e as referências nele contidas.

12 Ver a seção 2.5 do artigo publicado por Haroche e Raimond (2006). 
Em 1994, os físicos de Paris mergulharam plenamente na Teoria da Informação Quântica. Publicaram uma proposta para a teleportação da informação... mais especificamente, para a informação sobre o estado quântico de um átomo. Neste artigo, os autores traduziram para os termos do seu próprio equipamento um esquema que Charles Bennett da IBM, em colaboração com um grupo internacional de coautores, havia desenvolvido em 1993. Eles estão argumentando que o equipamento deles fornece capacidades realistas para a realização das ideias do grupo de Bennett (DAVIDOVICH et al., 1994). Depois disso, um número de artigos apareceu com títulos como A simple cavity-QED two-bit universal quantum logic gate: quantum memory with a single photon in a cavity e Coherent operation of a tunable quantum phase gate in cavity $Q E D .^{13}$

Como todos sabem, na década de 1980 e na de 1990, estávamos realizando uma fusão da Física com a Ciência da Informação. E isso conduz imediatamente à outra questão para os historiadores. Gostaríamos de compreender como os conceitos dos físicos, incluindo a interpretação da mecânica quântica, podem estar se modificando por causa disso. É verdade que Haroche e os seus colaboradores mais próximos são céticos quanto à ideia de que a computação quântica passará a ser uma tecnologia viável (HAROCHE; RAIMOND, 1996). ${ }^{14}$ Não obstante, nós podemos nos perguntar se uma análise dos artigos do grupo de Paris poderia ser uma forma de analisar a fusão dos conceitos da Física e aqueles dirigidos à computação. Por fim, esse é o problema de pesquisa final que eu quero apresentar a vocês. Como essa união com a Ciência da Informação afetou a Física?

Para resumir, sugeri cinco tópicos, passíveis de investigação. Dois reunindo campos da História da Física, os quais estão frequentemente separados. O primeiro é a História da Eletrodinâmica Quântica dentro da Óptica. O segundo é o impacto recíproco entre a Ciência da Informação e a Física. Dois tópicos referem-se à história do micromaser. Primeiro, eles são uma comparação entre a pesquisa sobre o micromaser desenvolvida pela École Normale Supérieure e pelo Max Planck Institute for Quantum Optics; e, segundo, um estudo que analise qual a tecnologia utilizada para a construção dos micromasers dentro de uma visão ampla do desenvolvimento do criogênico e de outras tecnologias, no final do século XX. Finalmente, há um problema com o qual eu iniciei: se e como a transição dos experimentos de pensamento para os experimentos reais afetaram a Filosofia da mecânica quântica. Apesar de eu ter iniciado a discussão, colocando-o como um problema, não finalizarei este artigo com uma solução. Responder a essa indagação continua a ser uma das tarefas da História.

13 Ver Domokos et al (1995) e Rauschenbeutel et al (1999).

14 Ver também Haroche e Raimond (2006) para uma análise das ideias mais recentes desses dois autores. 


\section{Referências}

ALLEN, L; EBERLY, J. H. Optical resonance and two-level atoms. New York: John Wiley, 1975.

BROMBERG, J. L. Device physics vis-a-vis fundamental physics in cold war America: the case of quantum optics. Isis, v. 97, n. 2, p. 237-259, 2006.

. The Laser in America, 1950-1970. Cambridge, MA: The MIT, 1991.

. New instruments and the meaning of quantum mechanics. Historical

Studies in the Natural Sciences, v. 38, n. 3, p. 325-352, 2008.

BRUNE, M. et al. Manipulation of photons in a cavity by dispersive atomfield coupling: Quantum nondemolition measurements and generation of "Schroedinger cat" states. Phys. Rev. A, v. 45, n. 7, p. 5193-5214, 1992.

BRUNE, M. et al. Observing the progressive decoherence of the 'meter' in a quantum Measurement'. Phys. Rev. Lett., v. 77, n. 24, p. 4887-4890, 1996 b.

BRUNE, M. et al. Realization of a two-photon maser oscillator. Phys. Rev. Lett., v. 59, n. 17, p. 1899-1902, 1987.

BRUNE, M. et al. Quantum rabi oscillation: a direct test of field quantization in a cavity. Phys. Rev. Lett., v. 76, n. 11, p. 1800-1803, 1996 a.

BRUNE, M.; RAIMOND, J. M.; HAROCHE, S. Theory of the Rydberg-atom two-photon 'micromaser'. Phys. Rev. A, v. 35, n. 1, p. 154-163, 1987.

CANTRELL, C. D.; SCULLY, M. O. The EPR paradox revisited, Phys. Reports, v. 43, n. 13, p. 499-508, 1978.

DAVIDOVICH, L. et al. Quantum switches and non-local microwave fields. Phys. Rev. Lett., v. 71, n. 15, p. 2360-2363, 1993.

DAVIDOVICH, L. et al. Quantum theory of a two-photon 'micromaser'. Phys. Rev. A, v. 36, n. 8, p. 3771-87, 1987.

DAVIDOVICH, $\mathrm{L}$ et al. Teleportation of an atomic state between two cavities using nonlocal microwave fields. Phys. Rev. A, v. 50, n. 2, p. R895-R898, 1994. Part A. 
DOMOKOS, P. et al, A Simple Cavity-QED two-bit universal quantum logic gate: principle and expected performances, Phys. Rev. A, v. 52, p. 3554, 1995.

DUCAS, T. W. et al. Stark ionization of high-lying states of sodium. Phys. Rev. Lett., v. 35, n. 6, p. 366-369, 1975.

EBERLY, J. H et al. Periodic spontaneous collapse and revival in a simple quantum model. Phys. Rev. Lett., v. 44, n. 20, p. 1323-1326, 1980.

FABRE, C; HAROCHE, S. Spectroscopy of one- and two-electron Rydberg atoms. In: STEBBINGS, R. F.; DUNNING, F. B. (Ed.). Rydberg States of Atoms and Molecules, Cambridge: Cambridge Univ., 1983. p. 117-164.

FEYNMAN, R. P. The Feynman lectures on physics. Reading, MA: AddisonWesley, 1963. v. I, p. 37-7 e v. III, p. 1-7.

FILIPOWICZ, F.; JAVANAINEN, J.; MEYSTRE, P. Theory of a microscopic maser. Physical Review, v. 34, n. 4, p. 3077-3087, oct. 1986.

GALISON, P. L. Image and logic: a material culture of microphysics. Chicago: Univ. of Chicago, 1997.

GLAUBER, R. J. Photon Correlations. Physical Review Letters, v. 10, n. 3, p. 84-86, 1963.

GHIRARDI, G. Sneaking a look at God's cards. Trad. Gerald Malsbary. Princeton: Princeton Univ., 2005.

GOY, P et al. Observation of cavity-enhanced single-atom spontaneous emission. Phys. Rev. Lett., v. 50, n. 24, p. 1903-06, 1983.

GREENBERGER, D. M. Fundamental Problems in Quantum Theory. Annals of the New York Academy of Sciences, v. 177, p. xiii-xiv, 1995.

GROSS, M. et al. Maser oscillation and microwave superradiance in small systems of rydberg atoms. Phys. Rev. Lett., v. 43, n. 5, p. 343-346, 1979.

HAROCHE, S. Entrevista concedida a Olival Freire Jr. e Gilles Nogues. Niels Bohr Library \& Archives, American Institute of Physics, College Park, MD USA, 10 fev. 2004. 
HAROCHE, $S$ et al., Exploration of radiative properties of very excited atoms. Phil. Transactions Royal Soc., London A 307, p. 659-672, 1982.

HAROCHE, S. et al. Hyperfine quantum beats observed in Cs vapor under pulsed dye laser excitation. Phys. Rev. Lett., v. 30, n. 20, p. 948-951, 1973.

HAROCHE, S.; RAIMOND, J. M. Exploring the Quantum: atoms, cavities, and the quantum. Oxford: Oxford University, 2006.

Quantum computing: dream or nightmare? Physics Today, v. 49, p. 51-52, Aug. 1996.

HERMANN, I.; LECHNER, R. (Ed.). In memoriam, Prof. Herbert Walther. Max Planck-Institut fuer Quantenoptik, 2006.

JAYNES, E. T.; CUMMINGS, F. W. Comparison of quantum and semiclassical radiation theories with application to the beam Maser. Proceedings of the IEEE, v. 51, p. 89-109, 1963.

KLEPPNER, D. et al. Hydrogen-Maser principles and techniques. Phys. Rev., v. 138, n. 4A, A972-A983, 1965.

KLEPPNER, D. et al. Rydberg atoms in strong fields. In: STEBBINGS, R. F; DUNNING, F. B. (Ed). Rydberg states of atoms and molecules. Cambridge: Cambridge University, 1983. p. 73-116.

MESCHEDE, D; WALTHER, H; MUELLER, G. One-Atom Maser. Phys. Rev. Letters, v. 54, n. 6, p. 551-554, 1985.

MOI, L. et al. Rydberg-atom masers. I. A theoretical and experimental study of super-radiant systems in the millimeter-wave domain. Phys. Rev. A, v. 27, n. 4, p. 2043-2064, 1983.

MEYSTRE, P. Cavity Quantum Optics and the Quantum Measurement Process. In: WOLF, E. (Ed.). Progress in Optics XXX. Amsterdam: Elsevier Science, 1992. p. 262-355

NAKAJIMA, S. Preface. In: INTERNATIONAL SYMPOSIUM ON THE FOUNDATIONS OF QUANTUM MECHANICS IN THE LIGHT OF NEW TECHNOLOGY, Tokyo, 1984. Proceedings... Tokyo: Physical Society of Japan, 1984. 
NAROZHNY, N. B.; SANCHEZ-MONDRAGON, J. J.; EBERLY, J. H. Coherence vs. incoherence: collapse and revival in a simple quantum model. Phys. Rev., v. l. a 23, n. 1, p. 236-247, 1981.

OSNAGHI, S.; FREITAS, F.; FREIRE JR., O. The origin of the everettian heresy. Studies in History and Philosophy of Modern Physics, v. 40, p. 97-123, 2009.

RAUSCHENBEUTEL, A. et al, Coherent Operation of a tunable quantum phase gate in Cavity QED, Phys. Rev. Lett. v. 83, p.5166, 1999.

REMPE, G.; WALTHER, H.; KLEIN, N. Observation of quantum collapse and revival in a one-atom maser. Phys. Rev. Lett., v. 58, n. 4, p. 353-356, 1987.

SCHLOSSHAUER, M. Decoherence and the quantum-to-classical transition. Berlin: Springer-Verlag, 2007.

SCULLY, M. O.; DRUEHL, K. Quantum eraser: a proposed photon correlation experiment concerning observation and 'delayed choice' in quantum mechanics. Phys. Rev., v. A 25, n. 4, p. 2208-2212, 1982.

SCULLY, M. O; ENGLERT, B. G; WALTHER, H. Quantum optical tests of complementarity. Nature, v. 351, p. 111-116, 1991.

SCULLY, M. O; SHEA, R; MCCULLEN, J. D. State reduction in quantum mechanics: a calculational example. Phys. Reports, v. 43, n. 13, p. $485-498$, 1978.

STEBBINGS, R. F.; DUNNING, F. B. (Ed.). Rydberg states of atoms and molecules. Cambridge: Cambridge Univ., 1983.

THOME, K. S. Editor's foreword, quantum measurement. Cambridge: Cambridge Univ., 1992.

WALTHER, H; HALL, J. L. Tunable Dye Laser with Narrow Spectral Output. Applied Phys. Lett., v. 17, n. 6, p. 239-242, 1970.

WOLF, E. Introduction o the theory of coherence and polarization of light. Cambridge: Cambridge University, 2007.

YOO, H. I; EBERLY, J. H. Dynamical theory of an atom with two or three levels interacting with quantized cavity fields. Phys. Reports, v. 118, n. 5, p. 239-337, 1985. 



\title{
Dissidentes quânticos: pesquisa em fundamentos da Teoria Quântica em torno de 1970.
}

\author{
Olival Freire Junior
}

\section{Introdução}

A florescente pesquisa em fundamentos da Teoria Quântica, no final do século $\mathrm{XX}$, não foi nem a consequência de uma evolução gradual, desde as origens dessa teoria científica em meados da década de 1920, nem apenas o resultado de novas técnicas que permitiram a efetiva realização de experimentos concebidos inicialmente como experimentos mentais. De fato, vários são os fatores que podem ter desempenhado um papel na evolução da controvérsia sobre os fundamentos dessa teoria física. Entre esses fatores, devem ser considerados preconceitos profissionais, questões filosóficas e ideológicas, mudanças culturais e geracionais e a diversidade de ambientes sociais e profissionais nos quais a Física foi praticada ao longo do século. Ao lado desses fatores, houve avanços teóricos e conceituais, inovações técnicas e sucessos em experimentos mentais e reais, bem como expectativas de aplicações tecnológicas. Contudo, nem todos esses fatores atuaram simultaneamente; de fato, em cada corte diacrônico dessa história apenas alguns desses fatores podem ser encontrados. O papel do historiador deve ser então o de discernir a influência de cada fator em cada contexto local e temporal.

Na segunda metade do século XX, um ponto de virada na história da pesquisa sobre os fundamentos da mecânica quântica pode ter sido o ano de 1970. Dados cientométricos parecem indicar que, a partir desse ano, ocorreu um alto crescimento quantitativo de publicações científicas dedicadas aos fundamentos dessa teoria (FREITAS; FREIRE, 2003; KAISER, 2007). Um número significativo de físicos intensificou a sua pesquisa nesse tema. Eles fundaram revistas especializadas, como a Foundations of Physics; organizaram encontros, como a Escola 
de Verão de Varenna de 1970; e publicaram artigos em revistas de circulação mais ampla, como a Physics Today. Desse modo, alguns deles ajudaram a deslocar os fundamentos da Teoria Quântica das margens da pesquisa em Física - uma "controvérsia filosófica", como ela era considerada por muitos na década de 1950 - para o terreno da Física normal, ainda que com um apelo filosófico (FREIRE, 2004). As particularidades dos eventos em torno de 1970 ficam mais claras quando comparadas como o que aconteceu mais tarde, principalmente a partir do final da década de 1970 e início da de 1980. De fato, embora a mudança em torno de 1970 tenha sido acelerada pela promessa dos primeiros experimentos sobre o teorema de Bell, os quais seriam os primeiros experimentos reais a serem introduzidos na controvérsia sobre os fundamentos da Teoria Quântica, a referida mudança foi até certo ponto independente do aparecimento do próprio teorema de Bell e de seus experimentos. Em contraste, e prosseguindo na cronologia, na década seguinte, vários experimentos foram sugeridos ou realizados (BROMBERG, 2006, 2008) e a interação entre teoria e experimento tornou-se a força impulsionadora dessa pesquisa. Na década de 1990, foi a promessa de aplicações tecnológicas relacionadas ao uso da Teoria Quântica em computação que provavelmente dinamizou ainda mais essa pesquisa.

Para compreender o que aconteceu com a pesquisa em fundamentos, minha estratégia é produzir um perfil biográfico coletivo dos físicos que foram os protagonistas dessa pesquisa em torno de 1970. Essa estratégia foi inspirada no que os historiadores profissionais chamam de prosopografia (KRAGH, 1978; STONE, 1971); contudo, uso métodos qualitativos no lugar de quantitativos para a produção desse perfil coletivo. Não discutirei os pais fundadores que querelaram entre si entre o final dos anos 1920 e o início dos anos 1950, nem a nova geração de físicos, tais como David Bohm, Jean-Pierre Vigier e Hugh Everett, que começaram a criticar a interpretação padrão da mecânica quântica na década de 1950. Pela mesma razão, não incluo nesse perfil biográfico coletivo aqueles físicos que começaram a pesquisar nesse campo mais tarde, a partir da segunda metade da década de 1970, a exemplo de Alain Aspect, Leonard Mandel, Anthony Leggett, Amir Caldeira, Anton Zeilinger e Marlan Scully. Focalizando sobre os físicos que foram ativos na pesquisa em fundamentos da mecânica quântica, em torno de 1970, e assumindo a arbitrariedade inerente à escolha de uma amostra de personagens para pesquisa histórica, selecionei os seguintes nove casos: Heinz Dieter Zeh (1932-), John Bell (1928-1990), John Clauser (1942-), Abner Shimony (1928-), Eugene Wigner (1902-1995), Léon Rosenfeld (1904-1974), Bernard d'Espagnat (1921-), Franco Selleri (1936-) e Bryce DeWitt (1923-2004).

Formulei as seguintes questões sobre esses personagens: Quais foram seu treinamento profissional e sua carreira inicial, antes de abordar os fundamentos da Teoria Quântica? Quais foram suas realizações em fundamentos da Teoria Quântica e em outros campos da Física? Quando e onde começaram suas 
preocupações com a mecânica quântica? Por que eles foram atraídos para a pesquisa em fundamentos? Eles enfrentaram obstáculos profissionais ao trabalhar com fundamentos? Foram críticos do que percebiam como sendo a interpretação de Copenhague sobre a mecânica quântica? Como eles avaliavam o pensamento de Bohr sobre as questões epistemológicas relacionadas a essa teoria física? Eles obtiveram êxito em suas carreiras trabalhando com fundamentos? Que tipo de redes eles desenvolveram ao trabalhar com fundamentos da Teoria Quântica?

Antecipando conclusões, meu argumento é que o esboço de uma biografia coletiva desses personagens pode ser obtido notando-se que, exceto Rosenfeld, todos eles foram dissidentes, ou melhor, dissidentes quânticos. Mover a pesquisa em fundamentos para o terreno da física usual requereu não apenas boas ideias teóricas, habilidades experimentais e aprimoramentos tecnológicos, mas também uma mudança na atitude da comunidade da Física quanto ao estatuto dos fundamentos da Teoria Quântica como tema para a pesquisa em Física. Esses físicos lutaram contra a atitude dominante na comunidade dos físicos da época, segundo a qual questões de fundamentos da Teoria Quântica já haviam sido equacionadas pelos pais fundadores da disciplina. Desse modo, eles desafiaram o preconceito contra a pesquisa em fundamentos e muitos deles fora críticos acirrados sobre o que eles identificavam como a interpretação da complementaridade. Suas crenças comuns, entretanto, eram mínimas, e estavam concentradas apenas na importância da pesquisa em fundamentos da Teoria Quântica. Eles foram críticos entre si, apoiaram interpretações distintas para essa teoria física e escolheram temas e abordagens diferentes em suas pesquisas. Uma das fontes de sua força foi o fato de sua plataforma comum ter sido a análise crítica, tanto teórica quanto experimental, dos fundamentos da Teoria Quântica, mais do que o desenvolvimento de apenas uma interpretação alternativa ou mesmo a defesa de seu credo filosófico. A prática desses físicos é uma história de sucesso, no seu todo, na medida em que a pesquisa em fundamentos, ou pelo menos uma parte, foi incorporada ao corpo principal dos resultados e das pesquisas em Física. Eu fiz essa sugestão anteriormente (FREIRE, 2006), com base em um número mais limitado de casos (Clauser, Shimony e Bell) e pretendo agora consubstanciá-la em um estudo mais amplo.

Esse trabalho está organizado da seguinte maneira. Na seção 2, discuto os casos do físico alemão H. D. Zeh, suas contribuições ao que hoje chamamos de "efeito descoerência" e como o preconceito existente contra a pesquisa em fundamentos prejudicou o desenvolvimento de sua carreira. A seção 3 é dedicada aos físicos que trouxeram o experimento idealizado conhecido como EPR para as bancadas dos laboratórios - Bell, Clauser e Shimony - e como eles lidaram com o estigma existente contra a questão das variáveis escondidas. Na seção 4 , analiso o modo como dois físicos da velha guarda, Wigner e Rosenfeld, contribuíram, o primeiro intencionalmente e o segundo involuntariamente, para colocar 
a pesquisa em fundamentos na agenda da Física. A seção 5 é dedicada a três físicos - d'Espagnat, Selleri e DeWitt - que contribuíram, embora de diferentes maneiras, para a mesma agenda. Nesta seção, também analiso suas presenças na Escola de Verão de Varenna, em 1970, e a ressonância dessa Escola na emergente comunidade dedicada aos fundamentos da Física Quântica. As conclusões são apresentadas na última seção.

\section{Zeh e os tempos sombrios da descoerência}

“Tempos sombrios" foi o termo usado por H. D. Zeh para descrever o período entre seu primeiro contato com o problema da medição no final dos anos 1960 e o início dos anos 1980, quando abordagens análogas foram desenvolvidas por W. H. Zurek e foram mais bem recebidas. Tempos sombrios, contudo, podem ter sido a consequência das circunstâncias profissionais e culturais envolvendo a conversão da atenção de Zeh na direção dos fundamentos da Teoria Quântica. Em 1967, o físico nuclear teórico, então um professor assistente (Privatdozent) em Heidelberg, voltou sua atenção para o problema da medição, chegando à conclusão que as interações entre corpos macroscópicos e seu ambiente nos impede de descrevê-los, do ponto de vista da Teoria Quântica, como sistemas fechados. Isto significa que o sistema acoplado - objeto quântico mais o aparato de medição - não evolui de acordo com a equação de Schrödinger. Ele também notou quão distante essa abordagem estava de duas outras abordagens concorrentes, sobre as quais comentaremos adiante: a amplificação termodinâmica sugerida pelos físicos italianos Daneri, Loinger e Prosperi e a abordagem mentalista formulada por Wigner. As ideias de Zeh foram sistematizadas e submetidas, em forma de artigo, à revista italiana Nuovo Cimento. Ele não desenvolveu completamente as implicações de suas sugestões, mas logo em seguida notou a conexão entre suas ideias e a interpretação dos estados relativos formulada por Hugh Everett em 1957. Esta conexão, explicitada em uma segunda versão de seu artigo, foi finalmente publicada em Foundations of Physics (ZEH, 1970). Os acontecimentos nos bastidores da avaliação desse artigo esclarecem os obstáculos enfrentados à época pela pesquisa sobre os fundamentos da Teoria Quântica.

$\mathrm{O}$ artigo foi rejeitado por várias revistas. Franco Bassani, vice-diretor de Nuovo Cimento, por exemplo, recusou o artigo baseado na opinião de um árbitro que havia afirmado: "[...] o artigo é totalmente sem sentido. É claro que o autor não compreendeu completamente o problema e as contribuições anteriores para esse campo." O editor de Die Naturwissenschaften, F. Boschke, polidamente recusou o artigo justificando que alguns de seus argumentos não estavam claros 
para os não especialistas ${ }^{1}$. Além da recusa do artigo, Zeh começou a enfrentar problemas em sua alma mater, a Universidade de Heidelberg. Como Zeh (2006) relembraria,

[...] foi absolutamente impossível à época discutir essas ideias com colegas, ou mesmo publicá-las. Um influente Prêmio Nobel de Heidelberg me informou, com franqueza, que qualquer atividade adicional sobre esse tema finalizaria minha carreira acadêmica!

O Prêmio Nobel era Hans D. Jensen, como Zeh (2006) mais tarde confirmaria, acrescentando que

[...] quando eu escrevi esse artigo que foi publicado em 1970

[...] [Jensen] disse que ele não entendia aquilo, e enviou uma cópia, infelizmente, para Rosenfeld em Copenhague. [...] Ele [Rosenfeld] escreveu uma carta para Jensen, a qual Jensen nunca me mostrou, na qual ele deve ter sido muito cínico sobre o que eu tinha dito, e eu me lembro que Jensen contou aquilo para alguns outros colegas; então, quando eu notei, eles estavam falando entre si, eles estavam sorrindo. Mas ele nunca me disse com precisão o que estava naquela carta. [...] Então Jensen me disse que eu não deveria continuar esse trabalho e nossa relação deteriorou. ${ }^{2}$

Recentemente, essa carta foi desenterrada dos Arquivos Rosenfeld e seu conteúdo expressa as dificuldades enfrentadas por Zeh: "Eu estabeleci uma regra em minha vida de nunca pisar nos dedos do pé de alguém, mas um preprint que recebi, escrito por certo "dedo do pé" [Zeh, em alemão] do seu instituto, me faz desviar daquela regra. Eu tenho todas as razões do mundo para assumir que tal concentrado de selvagem nonsense não está sendo distribuído pelo mundo com a sua benção, e eu penso estar prestando-lhe um serviço ao chamar sua aten-

1 A versão original - Probleme der Quantentheorie, em alemão - pode ser encontrada em <http:// www.rzuser.uni-heidelberg.de/ as3/>. Franco Bassani para H. D. Zeh, em 3 de outubro de 1968, com um relatório anexado; Boschke para Zeh, em 3 de outubro de 1968. Agradeço a gentileza de H. D. Zeh e F. Freitas o acesso a essas cartas.

2 H. D. Zeh, 2008, entrevista com Fábio Freitas. 
ção para esse infortúnio.”’ Desde o início da década de 1970, Zeh praticamente abandonou a Física Nuclear, dedicando-se em tempo integral aos fundamentos da Teoria Quântica. Em retrospectiva, Zeh (2008) vê aquela mudança como consequência dos obstáculos profissionais que enfrentou ao abordar o tema dos fundamentos:

Eu me concentrei naquelas questões porque eu tinha decidido que minha carreira tinha sido destruída. De qualquer modo, eu nunca chegaria ao posto máximo como professor universitário por causa daquelas coisas que tinham ocorrido, aí então eu disse, agora eu posso fazer exatamente o que eu gosto e não tenho que tentar mais obter qualquer posição ou algo similar. ${ }^{4}$

De fato, apenas na década de 1980 o trabalho de Zeh sobre fundamentos ganharia novo impulso, dessa vez com a colaboração de seu estudante E. Joos. ${ }^{5}$

Tendo em vista esses acontecimentos, não surpreende que Zeh não tenha mantido uma alta estima pelo que ele considerava ser a interpretação de Copenhague da Teoria Quântica, associada como ela estava aos nomes de Rosenfeld, Bohr, Heisenberg, Pauli e suas conexões com Jensen. Nesse contexto, é que se pode compreender o ressentimento que ele expressou para John Archibald Wheeler, uma década depois daqueles incidentes:

Eu sempre percebi com amargura o modo pelo qual a autoridade de Bohr junto com o sarcasmo de Pauli matou qualquer discussão sobre os problemas fundamentais dos quanta. [...] Eu espero que a interpretação de Copenhague seja algum

3 "Ich mach es zu einer Lebensregel, so weit vermeidlich auf keinen Zeh zu treten, aber der Empfang eines von einem gewissen Dr. Zeh aus Ihrem Institut verfassten preprint veranlasst mich von dieser Regel abzuweichen. Ich habe allen Grund anzunehmen, dass ein solches Konzentrat wildesten Unsinnes nicht mit Ihrem Segen in die Welt verbreitet ist, und ich glaube Ihnen von Dienst zu sein, indem ich Ihre Aufmerksamkeit auf dieses Unglück richte.” L. Rosenfeld para J. H. D. Jensen, 14 Fevereiro 1968. Em seguida, Jensen tentou atenuar a reação de Rosenfeld, temendo pelas suas consequências: "Eu espero, que ele não tenha sua reputação arruinada," Jensen para Rosenfeld, 1 mar. 1968. Rosenfeld então considerou o caso de uma maneira levemente mais favorável, embora ainda considerando o trabalho de Zeh "mais como uma reivindicação de monopólio da mais alta sabedoria" do que "como um convite para uma discussão factual," Rosenfeld para Jensen, 6 mar. 1968. O caso ocupou mais três cartas entre Rosenfeld e Jensen: Jensen para Rosenfeld, 10 abr. 1968; 9 maio 1968; Rosenfeld para Jensen, 25 abr. 1968. Rosenfeld Papers, Niels Bohr Archive, Copenhague. Sou grato a Anja Jacobsen e Felicity Pors pela recuperação dessas cartas e a Christian Joas pela tradução do alemão.

4 Entrevista concedida por H. D. Zeh, em 2008..

5 Sobre reflexões ulteriores de Zeh sobre a Teoria Quântica, ver Camilleri (2009). 
dia chamada de o maior sofisma da história da ciência, mas eu consideraria uma terrível injustiça se - quando algum dia uma solução seja encontrada - algumas pessoas sustentem que "isso é certamente o que Bohr sempre quis dizer", somente porque ele foi suficientemente vago. ${ }^{6}$

Alguns anos antes dessa carta, o historiador David Edge havia lhe perguntado: "Você sente que físicos que sustentam visões não ortodoxas sobre a mecânica quântica têm qualquer grande dificuldade para realizar seu trabalho?" Sua resposta foi: "dificuldades excepcionais." Perguntado "se um jovem físico começa sua vida profissional trabalhando nesse campo, sua carreira pode enfrentar obstáculos?" ele respondeu "certamente." Zeh também reconheceu que o número de físicos interessados em fundamentos da mecânica quântica estava crescendo e ele atribuiu ao declínio da injustificada autoridade de N. Bohr, W. Pauli e outros pragmatistas. $^{7}$

$\mathrm{Na}$ fase inicial de sua pesquisa em fundamentos, Zeh (2006) não encontrou apenas adversários. A suprema ironia é que o seu maior apoio veio de um físico que havia partilhado o Nobel de Física de 1963 com Jensen. Eugene Wigner, a quem retornaremos adiante, recebeu uma cópia do mesmo artigo que havia sido recusado por Nuovo Cimento. Embora ele não concordasse com a abordagem de Zeh, pois Wigner sustentava à época que a mente humana desempenha um papel no processo de medição, ele apoiou a publicação do artigo em Foundations of Physics, revista recém criada e da qual ele era membro do corpo editorial. Wigner também o convidou para uma palestra na Escola de Verão, a ser realizada em Varenna em 1970, organizada pela Sociedade Italiana de Física e dirigida por Bernard d'Espagnat. Na palestra de abertura, Wigner introduziu o problema da medição, apresentando a proposta de Zeh como uma das seis possíveis soluções para esse problema (FREIRE, 2007). Em Varenna, Zeh conheceu Bell e sentiu que ele apoiava seu trabalho, mesmo não concordando com a abordagem feita. De fato, Bell não gostava da interpretação de Everett à qual a proposta de Zeh estava associada; Bell favorecia a ideia de onda-piloto de Bohm e estava completamente envolvido com os debates teóricos e experimentais sobre a questão da localidade. Zeh não estava pois em sintonia com Bell, pois considerava que o princípio da superposição tinha validade irrestrita, o qual estava na base da não localidade quântica. Zeh achou Bell

[...] muito interessado e sempre perguntando questões adequadas. Era importante que existisse alguém critico sobre a

6 H. D. Zeh para J. A. Wheeler, em 30 de outubro de 1980, Wheeler Papers, Series II, Box Wo-Ze, folder Zeh, American Philosophical Society, Philadelphia.

7 Questionário enviado a Zeh por David Edge, em 1976. Sou grato a H. D. Zeh e F. Freitas por me permitirem a consulta a esse documento. 
tendência dominante e que colocava seu dedo nas questões certas. Apenas poucas pessoas faziam aquilo. ${ }^{8}$

Zeh convidou Bell duas vezes para discutir em Heidelberg questões de fundamentos, o que diminuiu seu próprio isolamento naquela universidade.

\section{O estigma contra as variáveis escondidas - Bell, Clauser e Shimony ${ }^{9}$}

John Bell, John Clauser e Abner Shimony são os responsáveis pela introdução do EPR, originalmente um experimento de pensamento, nos laboratórios. Esse empreendimento abriu as portas para um dos mais intrigantes efeitos quânticos: o emaranhamento entre sistemas espacialmente separados, propriedade física que é um dos pilares da atual pesquisa em informação quântica. Em 1964, Bell compreendeu que o requisito da localidade adotado por Einstein (medição sobre um sistema não deve alterar o estado de outro sistema distante do primeiro) implicava em uma desigualdade que seria violada pelas predições da Teoria Quântica. Cinco anos mais tarde, Clauser e Shimony, com contribuições essenciais de Michael Horne e Richard Holt, adaptaram a desigualdade obtida por Bell para um experimento viável em ótica e concluíram que nenhum experimento anteriormente realizado podia contrastar teorias de variáveis escondidas locais com a mecânica quântica. ${ }^{10}$ Três anos mais tarde Clauser e Stuart Freedman publicaram os resultados do experimento pioneiro sobre esse tema, com resultados confirmando as predições da Teoria Quântica (BELL, 1964; CLAUSER et al., 1969; FREEDMAN; CLAUSER, 1972). A história dessa aventura é, talvez, a melhor ilustração de como a pesquisa em fundamentos saiu das margens da Física para o estatuto de "boa física", e daí para o mainstream dessa ciência. Não por acaso, A. Van Raan (REDNER, 2005) denominou de "belas adormecidas" artigos como o de Einstein de 1935, com a proposta do experimento idealizado EPR, ou trabalhos clássicos ressuscitados, pois este artigo não obteve mais que algumas dezenas de citações até 1980, saltando para mais de mil atualmente. Efetivamente, experimentos e teoria sobre o EPR só se tornaram temas bem valorizados na Física depois da publicação dos resultados dos experimentos de Alain Aspect em 1982 (FREIRE,

8 H. D. Zeh em 2008, entrevista.

9 Para referências não citadas, ver Freire (2006), trabalho no qual esta seção está baseada.

10 Teorias de variáveis escondidas são tentativas de completar a Teoria Quântica com mais variáveis que aquelas usualmente admitidas por essa teoria. A mais destacada dessas tentativas foi aquela sugerida por David Bohm em 1952. Uma teoria de variáveis escondidas locais pressupõe, adicionalmente, a localidade. 
2006), mas esse é um tópico fora do escopo deste artigo. Trazer os experimentos idealizados EPR para as bancadas de laboratório não foi feito sem perdas, como o caso de Clauser irá exemplificar.

Façamos um resumo das carreiras científicas de nossos três personagens. Bell, em sua carreira, cedo começou a refletir sobre os fundamentos da Teoria Quântica. Antes de começar seus estudos de doutoramento em Birmingham, Reino Unido, ele foi atraído pelo artigo de David Bohm de 1952, sugerindo uma interpretação causal da mecânica quântica em termos de variáveis escondidas. Debateu a questão com Franz Mandl, tentando compreender como a proposta de Bohm era possível se existia uma prova matemática, elaborada por John von Neumann, contra a existência de tais variáveis. As interações com Rudolf Peierls foram úteis para sua carreira em Física de altas energias, mas não o ajudaram com a questão das variáveis escondidas, pois Peierls não estava interessado no assunto. No início da década de 1960, já trabalhando na Organização Européia para a Pesquisa Nuclear, o CERN, em Genebra, e tendo construído uma carreira de sucesso com aceleradores de partículas e Física de altas energias, ao assistir seminários nos quais Josef Jauch apresentou uma versão reforçada da prova de von Neumann, ele se sentiu desafiado a retomar suas investigações iniciais. Em 1964, em Stanford, durante uma licença do CERN, Bell retomou seu trabalho inicial com as variáveis escondidas, como meio para completar a mecânica quântica, e produziu um par de artigos que se tornariam referência nos fundamentos da Teoria Quântica. Clauser deslocou sua atenção para a pesquisa em fundamentos quando concluía, em 1969, seu doutoramento na Columbia University, sob a orientação de Patrick Thaddeus, sobre medidas de precisão da radiação cósmica de fundo. Esse era um tema que despertava muito interesse devido à descoberta de Arno Penzias e Robert Wilson, em 1964, de uma radiação uniforme de microondas que chegava à Terra, uma descoberta logo relacionada à teoria do Big Bang. A mudança de foco de Clauser resultou de pelo menos três diferentes fatores: a) uma duradoura insatisfação com a Teoria Quântica desde o seu tempo de aluno de graduação; b) a excitação gerada pela sua descoberta do teorema de Bell e de suas implicações (ele foi o primeiro a escrever para Bell sugerindo experimentos viáveis para testar a localidade); c) o ambiente político da época, como ele relembra (CLAUSER, 2002):

A guerra do Vietnã dominou o pensamento político de minha geração. Como um jovem estudante vivendo naquela era de pensamento revolucionário, eu naturalmente queria "sacudir o mundo." Como eu já acreditava que variáveis escondidas de fato existiam, eu pensei que esse seria o experimento crucial para revelar sua existência. 
Os fundamentos da ciência e suas implicações filosóficas têm sido desde sempre o assunto acadêmico preferido de Shimony. Depois de obter seu doutorado em Filosofia da Probabilidade em Yale, ele foi para Princeton fazer um segundo doutorado, agora em Física, mais especificamente sobre os fundamentos da mecânica estatística, sob a orientação de Wigner. Pouco antes de concluí-lo, foi atraído pelo interesse de Wigner no problema da medição. De Wigner ele também recebeu o apoio de um físico muito prestigiado, que ganharia o Nobel em 1963, para sua entrada no campo dos fundamentos da Teoria Quântica e publicou seu primeiro artigo sobre o tema, exatamente em 1963. Trabalhar nesse campo não se constituiu um obstáculo para a carreira de Shimony. Depois de um contrato do departamento de Filosofia do Massachusetts Institute of Technology (MIT), ele cruzou o rio Charles para uma afiliação dupla, em Filosofia e em Física, na Boston University. De todo modo, ele nunca dependeu exclusivamente de suas credenciais em Física para uma carreira acadêmica. Na Boston University, ele sugeriu a Michael Horne estudar o teorema de Bell como um assunto para o seu doutoramento em Física. Essa colaboração gerou um trabalho que não foi publicado, mas foi incorporado ao trabalho conjunto com Clauser e Holt, publicado em 1969. Para Horne, o seu doutoramento levou-o a uma duradoura carreira de dedicação aos fundamentos da Teoria Quântica. Ao longo da década de 1970, Bell, Clauser e Shimony foram, juntamente com d'Espagnat, os principais promotores da pesquisa teórica e experimental sobre localidade e mecânica quântica e construíram uma rede que levaria à ampliação das fronteiras dessa teoria física (FREIRE, 2006). Shimony atuou como um editor informal de Epistemological Letters, uma revista concebida como um permanente simpósio impresso sobre as "variáveis escondidas e a incerteza quântica;" Bell e d'Espagnat organizaram o Erice Thinkshop sobre Física dedicado ao tema, em 1976; e Clauser e Shimony publicaram, em 1978, o primeiro artigo de revisão sobre os experimentos relacionados ao teorema de Bell.

Bell, Clauser e Shimony eram críticos do que eles compreendiam como a interpretação da complementaridade de Bohr e apoiaram formas levemente diferentes do realismo científico, mas tiveram expectativas distintas sobre os resultados dos experimentos sobre a desigualdade de Bell. ${ }^{11}$ Clauser e Bell foram mais otimistas do que Shimony sobre as possibilidades de se obter resultados violando a mecânica quântica; e Clauser, de longe o mais otimista entre eles, fato revelador do nível de confiança de cada um deles no formalismo da Teoria Quântica. Bell tinha poucas expectativas de um resultado experimental que fosse um grande avanço na Física:

11 Ver Shimony (1993a) e Bell (2004). Para a defesa de Clauser do papel das imagens nas teorias físicas e seu apoio às ideias de Bohm e de Broglie, ver Oral history interview with John Clauser, American Institute of Physics, College Park, MD, 2002. 
Em vista do sucesso, em geral, da mecânica quântica, é muito difícil para mim duvidar do resultado desses experimentos. Contudo, eu preferiria que esses experimentos, nos quais os conceitos cruciais são testados muito diretamente, tenham sido feitos e os resultados registrados. Além disso, há sempre uma chance pequena de um resultado inesperado, o que abalaria o mundo. ${ }^{12}$

O otimismo de Clauser está revelado em uma carta que Shimony lhe enviou:

Incidentalmente, eu estou muito surpreso com suas estimativas das probabilidades dos possíveis resultados do experimento. Eu estimaria um milhão para um em favor da função de correlação mecânico quântica. Não há necessidade de frisar que eu espero estar errado nisso.

Shimony recentemente relembrou as expectativas de Clauser, dizendo

[...] ele estava absolutamente convencido que o experimento iria resultar favoravelmente às teorias de variáveis escondidas locais e contra a mecânica quântica, e que seria um desses experimentos que marca uma época. ${ }^{13}$

Ao final, o otimismo de Clauser revelou-se infundado.

Bell e Shimony estavam conscientes do estigma que a comunidade dos físicos havia associado à pesquisa sobre variáveis escondidas em mecânica quântica; um estigma herdado da década de 1950 (FREIRE, 2005, 2006). Contudo, foi Clauser que mais sofreu os efeitos do preconceito. Na mesma época em que publicou seus dois artigos seminais, Bell também publicou um terceiro, sobre o problema da medição em mecânica quântica, em coautoria com Michael Nauenberg. Nesse trabalho, eles criticaram a visão partilhada pela maioria dos físicos:

Nós enfatizamos não somente que nossa visão [que a mecânica quântica é, no melhor caso, incompleta] é a de uma minoria mas também que o interesse atual em tais questões é pequeno. O físico típico sente que elas [questões sobre fundamentos] foram há muito respondidas, e que ele compreenderá completamente se puder reservar vinte minutos para pensar sobre elas.

12 Mais informações, ver Freire (2006).

13 Bell para Clauser, 5 de março 1969; Shimony para Clauser, 20 de abril 1969; entrevista de história oral com Abner Shimony, 2002, citados em Freire (2006). 
Dez anos mais tarde, em que pese os experimentos já realizados sobre a desigualdade que havia formulado, Bell tinha a mesma sensação de um estigma associado ao tema. Em 1975, Alain Aspect teve um encontro com Bell para discutir sua proposta de novos experimentos sobre as desigualdades de Bell; Bell perguntou-lhe: "Você tem uma posição permanente?" Depois da resposta positiva de Aspect, Bell calorosamente encorajou-o a publicar a ideia, mas o alertou que o tema era considerado pela maioria dos físicos um assunto para excêntricos ou loucos. Como Shimony (1993a, p.xii) mais tarde lembraria,

[...] a preponderância da comunidade da física àquela época aceitava alguma variante da interpretação de Copenhague da mecânica quântica e acreditava que soluções satisfatórias já haviam sido dadas para o problema da medição, o problema de Einstein-Podolsky-Rosen e outras dificuldades conceituais.

As realizações de Clauser na década de 1970 foram notáveis. Ele compreendeu todas as consequências do teorema de Bell, realizou dois experimentos chave sobre ele, um dos quais foi o primeiro desse tipo a ser realizado, e ampliou nossa compreensão do tema com um artigo de revisão. Ademais, ele usou o conhecimento requerido para os experimentos com as desigualdades de Bell para contribuir com o debate entre os que apoiavam teorias semiclássicas da radiação, notavelmente Edwin Jaynes, e os que apoiavam um tratamento quântico integral para a radiação. Contudo, não obstante essas realizações, Clauser nunca obteve uma posição permanente em Física no mundo acadêmico. Para se entender o fracasso de Clauser em obter uma posição é preciso ter em conta que o início da década de 1970 foi um tempo de restrição ao financiamento público da ciência nos Estados Unidos e que essa circunstância teve consequências nas oportunidades de emprego para os jovens físicos. Contudo, a documentação disponível mostra que alguns dos físicos que decidiram não contratar Clauser foram influenciados pelo preconceito de que experimentos sobre variáveis escondidas não eram "física verdadeira." Seu antigo orientador. P. Thaddeus, escreveu cartas alertando as pessoas a não contratarem Clauser para fazer experimentos sobre variáveis escondidas em mecânica quântica porque isso era "ciência sem valor," uma visão partilhada por outros potenciais empregadores. Shimony lhe relatou que

[...] quando eu vi d'Espagnat na última semana ele tinha uma carta do chefe do departamento em San José inquirindo se o que você estava fazendo era "realmente física." Seria desnecessário lhe dizer que ele escreverá uma forte carta respondendo a questão em seu favor. Eu lamento, dessa evidência, saber que a sua situação de trabalho continua não resolvida. 
Retrospectivamente, Clauser admite que ele não foi esperto o suficiente para contornar potenciais preconceitos sobre as desigualdades de Bell quando na procura de um emprego. "Eu fui um tipo jovem ingênuo e esquecido de tudo isso. Eu tinha de reconhecer quanto estigma havia, e simplesmente escolhi ignorá-lo. Eu estava me divertindo e achava que era uma física interessante." ${ }^{14}$

\section{Uma cisão dentro da ortodoxia - Wigner e Rosenfeld ${ }^{15}$}

Diferentemente de nossos outros protagonistas, Wigner e Rosenfeld haviam começado suas carreiras científicas bem antes da Segunda Guerra. Embora eles não pertençam à geração dos pais fundadores da Teoria Quântica, eles podem ser considerados uma "velha guarda" no perfil biográfico que estou construindo. O trabalho que assegurou a Wigner o Prêmio Nobel de Física de 1963 - Contribuições para a teoria do núcleo atômico e as partículas elementares, particularmente através da descoberta e aplicação de princípios fundamentais de simetria - foi realizado no final da década de 1930. O trabalho de Rosenfeld com Bohr sobre a mensurabilidade dos campos eletromagnéticos, uma peça de referência nos debates sobre os fundamentos da Teoria Quântica, foi produzido no início da década de 1920. Na década de 1960, nosso foco de atenção, Wigner já tinha ativamente participado do Projeto Manhattan, tinha uma posição permanente em Princeton e era um vencedor do Nobel. Rosenfeld tinha uma carreira acadêmica bem estabelecida, tendo trabalhado sucessivamente em Copenhague, Utrecht, Manchester e, de novo, Copenhague, dessa vez no Instituto Nórdico para Física Teórica (NORDITA), na maior parte desse tempo servindo como assistente de Bohr para temas epistemológicos.

Rosenfeld estava bem mais envolvido com a controvérsia sobre a interpretação da Teoria Quântica do que Wigner, mas este não era insensível à existência de problemas relevantes nos fundamentos dessa teoria. Na década de 1950, Rosenfeld havia criticado fortemente a interpretação causal de Bohm (FREIRE, 2005) e atentamente seguido os debates em Copenhague sobre a interpretação dos "estados relativos" de Everett (OSNAGHI; FREITAS; FREIRE, 2009). No início dos anos 1960, ele era, certamente, considerado dos mais fieis intérpretes do princípio da complementaridade de Bohr. Wigner havia contribuído para a análise que John von Neumann fizera do problema da medição e no início dos anos 1950 introduziu

14 Shimony para Clauser, em 8 de agosto de 1972; Oral history interview with John Clauser (2002), citado em Freire (2006).

15 Exceto para as referências explicitamente indicadas, todas as outras são retiradas de Freire (2007), trabalho que é a base desta seção. 
o conceito de regras de superseleção para ter em conta as limitações que havia identificado na questão da mensurabilidade (FREIRE, 2007, p. 206). Enquanto Rosenfeld apoiava as ideias de Bohr, Wigner era mais simpático à apresentação da mecânica quântica feita por von Neumann. Embora uma análise lógica hoje possa identificar diferenças entre as apresentações dessa teoria por Bohr e por von Neumann, seria um anacronismo enfatizar o reconhecimento dessas diferenças no período em consideração. Efetivamente, tanto Rosenfeld quanto Wigner se consideravam alinhados, à época, com diferenças menores em relação ao que eles consideravam a interpretação ortodoxa ou usual da Teoria Quântica. Na década de 1960, contudo, essa concordância tácita evaporaria quando cada um toma seu rumo na controvérsia sobre o problema da medição quântica.

No início da década de 1960, Wigner decidiu participar mais ativamente no crescente debate sobre o chamado problema da medição quântica (WIGNER, 1961, 1963), e ousou sugerir que a ação da mente humana era responsável pelas medições quânticas. Essa abordagem mentalista, bizarra nos dias atuais, apresentava, contudo, coerência lógica. Wigner tomava como ponto de partida a análise da evolução do estado que descreve um sistema quântico feita por von Neumann, em 1932. John von Neumann havia afirmado que um estado quântico pode evoluir através de dois diferentes processos: no primeiro, sofre uma evolução linear e determinística, governada pela equação de Schrödinger; no segundo, o estado geralmente descrito por uma superposição de autoestados, subitamente pula para um desses estados, em um processo que von Neumann descreveu, matematicamente, com o recurso a um operador de projeção e sugeriu ser a descrição adequada de um processo de medição quântica. Wigner argumentou que o último processo não podia ser finalizado sem ambiguidade sem o recurso da introspecção, isto é, a interferência da mente humana no processo físico.

Ao analisar o problema da medição, contudo, Wigner tomou sua solução mentalista como uma evidência das limitações da mecânica quântica por causa de sua incapacidade para lidar com fenômenos da vida, como a consciência. Além disso, ele foi cauteloso na defesa da solução mentalista e aceitou a possibilidade de outras soluções para o problema da medição. Sua posição foi claramente afirmada na sua conferência de abertura da Escola de Verão de Varenna, em 1970, dedicada aos fundamentos da Teoria Quântica. Ele reconheceu a existência de pelo menos seis diferentes abordagens do problema (WIGNER, 1971). Elas incluíam a proposta de Everett de um "vetor de estado de todo o universo"; a ideia de que "instrumentos de medição devem ser descritos classicamente," por ele considerada "mais concisamente articulada" por V. A. Fock e não por Niels Bohr; a proposta de von Neumann da introdução do colapso do vetor de estado como um novo axioma no formalismo quântico; e a proposta de Zeh de mudar o tratamento do problema da medição, passando a considerar que os aparatos, como corpos macroscópicos, não podem ser mantidos em um estado de isolamento. Além destas quatro alternativas, Wigner incluiu mais duas outras propostas, 
ambas levando à conclusão de que a "validade das leis lineares da mecânica quântica é limitada." Uma dessas propostas fora introduzida por G. Ludwig e sugeria que "todos os objetos macroscópicos estão situados fora dos limites de validade da mecânica quântica", enquanto a outra, claramente conectada com a proposta mentalista inicial do próprio Wigner, implicava que a fronteira de validade dessa teoria física fosse colocada "onde a vida e a consciência começam a desempenhar um papel." Desse modo, ao tempo em que Wigner sustentava uma visão aberta para diferentes soluções em relação ao problema da medição, incluindo a visão relacionada à complementaridade de Bohr, também afirmava que a Teoria Quântica era uma teoria ainda incompleta e inclinava-se pela mudança da equação de Schrödinger para uma equação não-linear. Estas implicações, em si mesmas, colocavam Wigner em rota de colisão com todos aqueles que consideravam a Teoria Quântica uma teoria física completa, em particular com os bohrianos.

Antes de comentar o confronto de Wigner com os bohrianos, eu gostaria de mencionar que a ideia de mudar a linearidade da mecânica quântica para equações não-lineares prosperou em outras mãos que não as de Wigner. Embora a ideia não fosse nova, bastando ver, por exemplo, as propostas de Louis de Broglie no início da década de 1950 (DE BROGLIE, 1960), ela só teve impulso a partir do final da década de 1970. Por isso, quando Max Jammer escreveu, no início da década de 1970, o seu abrangente livro sobre a filosofia da mecânica quântica (JAMMER, 1974), ele não incluiu um capítulo sobre mecânica quântica não-linear, embora tenha dedicado capítulos à teoria e às interpretações de variáveis escondidas e estocásticas. Mais tarde, Pearle (1989), Ghirardi, Rimini e Weber (1986), além de Gisin (1984, 1989), entre outros, sugeriram formas modificadas da equação de Schrödinger. Abner Shimony (1993b) tem servido como uma espécie de consciência crítica dessas propostas, apoiando-as, mas ao mesmo tempo procurando dados derivados de resultados experimentais que possam restringir as hipotéticas equações de Schrödinger não-lineares (BIALYNICKI-BIRULAB; MYCIELSKI, 1976; SHIMONY, 1979; SHULL et al., 1980). Com o passar do tempo, Wigner, contudo, tornou-se mais cético a respeito dessa abordagem. Como escrevera a Shimony, em 1977,

[...] existe somente um aspecto das "visões de Abner" com a qual eu não concordo. É a implicação de que tudo que é necessário é produzir equações de movimento não-lineares. $\mathrm{Eu}$ acredito que mudanças muito mais fundamentais serão necessárias - análogas ao que aconteceu quando o eletromagnetismo foi introduzido ou quando a física microscópica, isso é, mecânica quântica, foi criada. ${ }^{16}$

16 Eugene Wigner para Abner Shimony, em 12 de outubro de 1977, Wigner Papers, Box 83, folder 7, Princeton University Library. Agradeço a Frederik Santos por chamar minha atenção para essa carta. 
No início da década de 1960, os físicos italianos Daneri, Loinger e Prosperi (1962) desenvolveram um tratamento do problema da medição no qual trataram os aparatos de medição macroscópicos como sistemas termodinâmicos. Através da descrição de uma medição quântica, como uma amplificação termodinâmica de um sinal resultante da interação entre os sistemas quânticos e os aparelhos de medição, eles forneceram uma explicação referente à causa de os processos de medição levarem a resultados bem definidos. Rosenfeld então decidiu valorizar ainda mais o argumento formulado pelos italianos, afirmando que incompreensões "que remontam às deficiências no tratamento axiomático de von Neumann" tinham sido "[...] completamente removidas pela profunda e elegante discussão dos processos de medição em mecânica quântica realizada por Daneri, Loinger e Prosperi" (ROSENFELD, 1965). Rosenfeld estava se reportando à apresentação da Teoria Quântica feita por von Neumann, anteriormente referida, na qual são postulados dois tipos de evolução para o vetor que descreve o estado quântico. Rosenfeld (1965) já havia, bem antes, considerado a apresentação de von Neumann uma Rosenfeld já havia, bem antes, considerado a apresentação de von Neumann uma "infeliz apresentação da questão da medição na teoria quântica" porque ela dispensava os conceitos clássicos que Bohr, Rosenfeld, e em geral os bohrianos, consideravam um requisito necessário para descrever medições quânticas. Como nós sabemos, os bohrianos consideravam esses conceitos inevitáveis porque eles estavam enraizados na linguagem da "experiência usual," a qual era necessária para a comunicação dos resultados de experimentos que assegura a objetividade na Física. ${ }^{17}$ A controvérsia foi então aquecida quando os italianos deram sequência ao debate, afirmando que "nenhum deles [Wigner, estudantes de Wigner como Shimony e Yanase, Jauch, Moldauer] dá novas contribuições que sejam essenciais para o assunto" (DANERI; LOINGER; PROSPERI, 1966). Esse artigo foi contestado por Jauch, Wigner e Yanase (1967) e recebeu a tréplica por Rosenfeld (1968) e Loinger (1968).

Está fora do escopo deste trabalho revisar essa disputa e seus subprodutos, o que tem sido objeto de outros trabalhos (FREIRE, 2007; PESSOA; FREIRE; DE GREIFF, 2008). Nossa discussão pode, contudo, concluir que, pela primeira vez na história da mecânica quântica, uma cisão apareceu não entre os apoiadores da ortodoxia na interpretação dessa teoria e seus críticos, mas entre os apoiadores do que era então considerada a ortodoxia sobre o tema. A cisão foi suficiente para atrair a atenção de certo número de físicos. Pela primeira vez, na literatura especializada, o termo "escola de Princeton" foi utilizado para diferenciar as visões de Wigner e von Neumann daquelas de Bohr e de Rosenfeld.

17 Léon Rosenfeld. Parecer sobre Louis de Broglie, La théorie de la mesure en mécanique ondulatoire, publicado em Paris, por Gauthier-Villars em 1957; e Rosenfeld para Saul Bergmann, em 21 de dezembro 1959. Esses documentos estão nos Rosenfeld Papers, Niels Bohr Archive (Copenhague) e são citados em Osnaghi, Freitas e Freire (2009, p. 99, 117). 
Conforme Ballentine (1970, p. 360), existiam "várias versões da interpretação de Copenhague," e, "embora ambas identifiquem-se como ortodoxia, parece agora existir uma diferença de posições entre o que pode ser chamada a escola de Copenhague, representada por Rosenfeld, e a escola de Princeton, representada por Wigner." Desde então, referências às escolas de Copenhague ou de Princeton, bem como a distinção entre Bohr e Wigner no que diz respeito ao problema da medição, tornaram-se comuns na literatura sobre o tema. (HOME; WHITAKER, 1992; LEGGETT, 1987)

Os dois polos da disputa, entretanto, não desempenharam papeis análogos no apoio à pesquisa em fundamentos da mecânica quântica. Tanto Wigner quanto Rosenfeld tomaram partido na disputa e apoiaram pesquisadores mais jovens trabalhando no tema; Wigner, contudo, apresentou uma mentalidade mais aberta do que Rosenfeld e apoiou iniciativas institucionais para a pesquisa em fundamentos. Wigner apoiou Zeh, mesmo não concordando com sua abordagem, como já vimos, e o mesmo pode ser dito do seu apoio a Shimony, na medida em que este era cético em relação à conjectura mentalista de Wigner. Rosenfeld tratava como não merecedoras de consideração qualquer visão conflitante com a posição de Bohr (FREIRE, 2005; JACOBSEN, 2007; OSNAGHI; FREITAS; FREIRE, 2009; PESSOA; FREIRE; DE GREIFF, 2008). Em 1970, quando Wolfgang Yourgrau e Henry Margenau criaram uma nova revista, significativamente denominada Foundations of Physics, Wigner emprestou o seu prestígio à iniciativa integrando seu comitê editorial. No mesmo ano, ele participou ativamente da Escola de Verão de Varenna, dedicada aos fundamentos da Teoria Quântica, e foi o responsável pela conferência de abertura. Pode ser dito que Wigner intencionalmente apoiou um amplo debate sobre os fundamentos da Teoria Quântica, enquanto Rosenfeld contribuiu para a abertura de tal debate, mas sem intencionalidade, na medida em que considerava não existir problemas a serem resolvidos nos fundamentos dessa teoria científica.

\section{D'Espagnat, Selleri e Dewitt - mudanças nas agendas de pesquisa}

O físico teórico Bernard d'Espagnat interessou-se tanto por Filosofia como por Ciência desde os tempos de escola secundária. Ele obteve o Baccalauréat francês [grau de estudos secundários] em Matemática e Filosofia, mas logo compreendeu que investigações na Filosofia da Ciência no século XX requereriam treinamento científico, o que o levou aos estudos superiores em Física. Em meados da década de 1960, em paralelo à sua carreira em Física de Altas Energias no CERN, ele foi sendo gradualmente atraído pelo interesse crescente em fundamentos da Teoria 
Quântica. Em 1965, publicou Conceptions de la physique contemporaine - les interprétations de la mécanique quantique et de la mesure, o qual seria seguido dez anos depois pelo influente Conceptual foundations of quantum mechanics, os quais integram hoje sua série de livros muito elogiados (D’ESPAGNAT, 1965, 1976). No CERN ele se aproximou de Bell quando ambos reconheceram que partilhavam o mesmo interesse em fundamentos da Teoria Quântica. Uma contribuição destacada de d'Espagnat para a pesquisa em fundamentos requereu, entretanto, não apenas a sua formação científica e a sua inclinação filosófica, mas também suas habilidades diplomáticas. ${ }^{18}$

Quando o conselho da Sociedade Italiana de Física aceitou uma proposta de Franco Selleri de dedicar uma de suas escolas de verão realizadas no resort de Varenna, situada à beira do Lago de Como, ao tema dos fundamentos da Teoria Quântica, ele estava tomando uma decisão polêmica sobre um tema por si mesmo objeto de controvérsia. Desde o fim da Segunda Guerra, essa Escola de Verão tinha sido um espaço privilegiado para treinar físicos jovens e promissores em temas fronteiriços da Física. Contudo, uma questão surgia: como treinar cientistas em questões sobre as quais não existe consenso? Ademais, a edição de 1970 dessa escola foi realizada em uma época em que as universidades italianas e a comunidade dos físicos corriam riscos de cisão, como resultado das manifestações políticas estudantis generalizadas, características do final da década de 1960. Toraldo di Francia, presidente da sociedade, buscou alguém que pudesse aglutinar físicos com diferentes posições sobre a interpretação da Teoria Quântica e, além disso, capaz mais de unir do que dividir os físicos italianos. Sua escolha por Bernard d'Espagnat não poderia ter sido mais adequada. ${ }^{19}$

A Escola de Verão de Varenna naquele momento foi pacífica e cercada de êxito nas discussões científicas e filosóficas, a despeito de distúrbios em um evento social por causa de discordâncias relacionadas à Guerra do Vietnã. Seus 84 participantes, a qualidade de suas palestras, a edição de suas atas (D'ESPAGNAT, 1971), os primeiros debates sobre o teorema de Bell e seus experimentos, e a diversidade de seus conferencistas, incluindo Bell, Bohm, Wigner, de Broglie, Jauch, Shimony, Zeh, Selleri e DeWitt, criaram um clima de excitação em torno da pesquisa em fundamentos. Seu sucesso, contudo, não foi independente das habilidades de d'Espagnat na sua organização. Na carta-convite, ele estabeleceu os padrões de conduta que os cientistas deveriam adotar para intervenções nesse tema controvertido e essas regras incluíam (D’ESPAGNAT, 1971):

18 Oral history interview with Bernard d'Espagnat (2001), American Institute of Physics, College Park, MD, USA.

19 Oral history interviews with Toraldo di Francia (2003), Franco Selleri (2003), American Institute of Physics, College Park, MD, USA. 
1) Nós não devemos ter como nosso objetivo a conversão do herético mas sim um melhor entendimento de seu ponto de vista. 2) Nós não devemos sugerir que consideramos alguém na audiência um louco estúpido (a não ser que os loucos estúpidos apareçam no final claramente como sendo nós mesmos!). 3) Nós devemos tentar nos apegar aos fatos. 4) Apesar disso, nós devemos estar preparados para ouvir sem indignação visões não muito conformistas que não tenham implicações imediatas sobre fatos.

Após a Escola de Varenna, o crescente interesse em fundamentos na década seguinte absorveu quase toda a energia de d'Espagnat. Em 1977, ele visitou os Estados Unidos como Professor Visitante da Universidade do Texas, em Austin, instituição que John Archibald Wheeler tinha, exitosamente, estabelecido como uma grande instituição universitária norte-americana, dedicada à pesquisa em fundamentos da Relatividade Geral e da Teoria Quântica. D’Espagnat chegou aos Estados Unidos, continuando sua cruzada pela "tolerância de pontos de vista diferenciados," como observado por Wheeler. Contudo, discussões ali realizadas com Wheeler, Everett, DeWitt, Henry Stapp, George Sudarshan e James Hartle levaram d'Espagnat a rever sua percepção anterior sobre o interesse dos físicos norte-americanos sobre questões de fundamentos. Como ele escreveu para Wheeler,

[...] de fato, essas três semanas fizeram-me descobrir tanto problemas específicos muito atrativos como também alguns aspectos da tendência geral de ideias nos Estados Unidos que eram novos para mim, e que podem talvez corresponder a uma genuína evolução. ${ }^{20}$

Ao final, d'Espagnat abandonou a Física de altas energias e seguiu seus sonhos primeiros de uma carreira integralmente dedicada à pesquisa em Ciência e Filosofia, agora sempre relacionada ao tema dos fundamentos da mecânica quântica.

Em 1958, Franco Selleri obteve seu doutorado em Física em Bolonha, onde se graduara como físico sob a influência de Giampietro Puppi. Nos dez anos seguintes, Selleri desenvolveu com êxito uma carreira em Física de Altas Energias, para a qual incluiu contribuições originais como o modelo de troca de um pion (onepion exchange model). Essas realizações contribuíram para lhe assegurar uma posição na Universidade de Bolonha, quando retornou de uma série de estágios com bolsas na Suíça, França e Estados Unidos. ${ }^{21}$ Desencantado com o ambiente

20 D’Espagnat para Wheeler, em 27 de abril de 1977, Wheeler Papers, Series 2 - Box DE, folder d'Espagnat. "tolerância de pontos de vista diferenciados" e referências às discussões estão no caderno de anotações de Wheeler, p. 145-149. Wheeler Papers, Series 5, Notebook oct. 1976/ dec. 1977.

21 Tarozzi e van der Merwe (2004). As citações e informações sobre Selleri nesta seção foram obtidas com a Oral history interview with Franco Selleri (2003), American Institute of Physics. 
político e cultural no Departamento de Física da Universidade de Bolonha, e atraído por um convite para iniciar o ensino e a pesquisa em Física teórica em uma nova universidade, ele se mudou para Bari em 1968, onde permanece até hoje. Selleri tinha se frustrado com a escassa quantidade de realismo físico que se podia atribuir às abordagens utilizadas em Física de Partículas e começou a ver "- $[. .$.$] os problemas em física das partículas elementares como derivados$ do fato de que a mecânica quântica é pouco entendida e é, de todo modo, uma ideia muito abstrata." Ele deslocou sua atenção para problemas em fundamentos da mecânica quântica, sugeriu a organização da Escola de Verão de Varenna e, finalmente, tornou-se um pesquisador dedicado integralmente aos fundamentos da Teoria Quântica e mais recentemente à Teoria da Relatividade. Durante essa transição, foi muito influenciado pela leitura do livro de d'Espagnat que havia sido publicado em 1965, Conceptions de la physique contemporaine, quando ele compreendeu que diferentes interpretações podiam ser acomodadas ao mesmo formalismo quântico.

Selleri desenvolveu uma abordagem singular ao problema dos fundamentos, combinando sua desconfiança quanto ao formalismo quântico com uma agenda de pesquisa voltada para propor novos experimentos relacionados ao tema. Efetivamente, ele passou a discordar da interpretação da complementaridade não apenas por razões filosóficas, mas também por pensar que o espaço de Hilbert, como estrutura matemática da Teoria Quântica, seria finalmente considerado errôneo e seria substituído por uma descrição nas coordenadas normais do espaço-tempo. Ele foi dos primeiros a sugerir experimentos para testar a representação de onda e partícula, sugerida por Louis de Broglie, posteriormente conhecida como "onda vazia"; a expor possibilidades de evasão das conclusões (loopholes) nos primeiros experimentos com o teorema de Bell; e a sugerir testes com esse teorema em Física de Partículas em altas energias. Os resultados experimentais até os dias atuais têm frustrado suas expectativas, na medida em que têm confirmado as predições da Teoria Quântica. Contudo, seu papel, como uma espécie de consciência crítica dos experimentos com o teorema de Bell, provavelmente tem sido responsável pela sua elevada consideração nesse campo de pesquisa. Adicionalmente, Selleri tem mesclado sua defesa do realismo na Teoria Quântica com preocupações sociais mais amplas. ${ }^{22} \mathrm{Na}$ década de 1980, ele foi responsável pelo estabelecimento de uma ponte entre os físicos críticos da mecânica quântica e o filósofo Karl Popper, que estava interessado nessa teoria, trazendo assim a

22 "Eu sempre pensei [...] que é nosso dever construir uma ciência que possa ser comunicada a todos. Naquela época, eu estava pensando em termos de classes trabalhadoras, em pessoas que trabalham. Dito de outro modo, se o único meio de entender o que eu estou fazendo é estudar equações diferenciais ou espaço de Hilbert, [...] então existe um limiar muito elevado. Se, pelo contrário, eu construo a física no espaço tridimensional e no tempo, em acordo com as regras da causalidade, então eu posso comunicar os meus resultados." Oral history interview with, Franco Selleri (2003). 
controvérsia sobre os fundamentos da Teoria Quântica para um público maior. O seu livro, Die Debatte um die Quantentheorie, publicado em alemão em 1983 e imediatamente traduzido em várias línguas, foi parte desse seu empreendimento voltado para leitores não especializados no tema.

A conversão de sua pesquisa para temas de fundamentos não trouxe maiores prejuízos para a carreira profissional de Selleri. Embora sua titularidade como professor tenha sido adiada por dez anos (até 1980), explicada por ele como consequência de sua conversão, ele nunca encontrou obstáculos profissionais maiores a esse tema de pesquisa: "Eu tenho sido tratado justamente. Não tenho sido discriminado pela atividade que eu desenvolvi." O fato de sair de um grande e tradicional centro para trabalhar em um mais novo, Bari, com físicos mais jovens, também atenuou potenciais obstáculos, como ele próprio reconheceu: "Em Bolonha teria sido mais difícil." Em retrospectiva, Selleri (ver nota 20) também considera que o ambiente da Física italiana também contribuiu para a nova etapa de sua carreira, "[...] de todo modo, eu tenho o sentimento de que a Itália é mais tolerante do que outros países em relação à pesquisa em fundamentos da mecânica quântica," uma característica que ele atribui a um fator ainda não estudado pelos historiadores: as críticas de Enrico Fermi à mecânica quântica. Contudo, no início da década de 1970, ele não pensava da Itália do mesmo modo:

[...] por algum tempo Paris parecia como o mais interessante lugar do planeta para o meu tipo de pesquisa, porque de Broglie estava vivo. Existia a Fundação de Broglie, existia Vigier, existia d'Espagnat. Existiam jovens esquerdistas como Paty e Lévy-Leblond interessados em questões fundamentais, assim a cidade parecia um paraíso.

Este ambiente favorável não durou por muito tempo:

Eu presenciei, com o passar do tempo, o paraíso derreter-se completamente, lentamente, porque ao final de Broglie morreu, a Fundação de Broglie depois de sua morte seguiu um perfil de baixa atividade e não foi mais uma instituição de defesa efetiva das ideias de Broglie, d'Espagnat mudou completamente sua filosofia. Com Vigier era muito difícil de se chegar a um acordo porque já como partida ele se considerava um realista não-local, uma posição cuja motivação ainda hoje tenho dificuldade para compreender. [...] E, por fim, os jovens esquerdistas também se converteram à linha ortodoxa de pensamento; então com o tempo nada restou, e Paris desapareceu de meu horizonte. 
O rumo dos acontecimentos em Paris foi para ele um indicador de uma característica negativa da ciência à época. Ele relembra que entre os pais fundadores da mecânica quântica existiam dois campos de igual tamanho em conflito, e depois se tornaram "99 a 1" em favor da visão da complementaridade entre aqueles ativos na pesquisa. Ele suspeita que o dogmatismo tenha sido a causa da mudança. "Como foi possível? Através de repressão e controle de publicações? Então existe também uma grande quantidade de dogma. As pessoas não ousam opor ideias importantes." ${ }^{23}$

Diferente de d'Espagnat e de Selleri, o relativista norte-americano Bryce Seligman DeWitt nunca se dedicou inteiramente aos fundamentos da Teoria Quântica, mas desempenhou um papel significativo ao ressuscitar a interpretação da mecânica quântica de Everett, no final da década de 1960. Embora conhecesse o trabalho de Everett desde o seu início, apenas dez anos mais tarde ele passou a valorizá-lo de maneira muito expressiva, quando desenvolvia o seu próprio trabalho de quantização da gravidade e notou a ressonância entre as ideias de Everett e seu próprio trabalho. A história das origens da tese de Everett é exemplar para se entender as vicissitudes que a pesquisa em fundamentos atravessava na década de 1950; mas, para essa história, remetemos o leitor a outros trabalhos: Byrne (2007), Freire (2004) e Osnaghi, Freitas e Freire (2009). O fato é que até a década de 1960 o trabalho de Everett estava virtualmente desconhecido, o que levou o historiador da Física, Max Jammer (1974, p. 509), a se referir a ele como "um dos mais bem guardados segredos desse século." Quando DeWitt começou a trabalhar com a interpretação de Everett, ele já era um físico com reputação destacada. Formado em Harvard, onde obteve seu doutorado com Julian Schwinger, o prestigiado relativista era então professor na Universidade da Carolina do Norte, em Chapel Hill, onde liderava um influente programa de pesquisa em relatividade. No primeiro de uma trilogia de artigos (DEWITT, 1967) sobre a quantização da gravitação, muito bem citados, no qual apareceu o que é agora conhecido como "equação de Wheeler-DeWitt", ele considerou a interpretação de Everett como necessária para dar sentido à tentativa de quantização de uma equação que descrevesse todo o universo, na medida em que essa interpretação dispensa do apelo a um "observador externo" para realizar medições. Conforme DeWitt (1967, p. 1141), "é muito natural adotar em Teoria Quântica da gravitação a visão do mundo de Everett, pois nessa teoria se está acostumado a falar sem embaraços da 'função de onda do universo'. É possível que a visão de Everett seja não apenas natural, mas essencial."

A defesa da interpretação de Everett feita por DeWitt foi muito efetiva. Além do uso em seu próprio trabalho científico, ele alistou um estudante de doutorado, Neil Graham, para revisar o artigo original e, apoiado por Hobart Ellis e Harold

23 Oral history interview with Franco Selleri, 2003. 
Davies, editores da revista Physics Today, ele apresentou as ideias de Everett para um público mais amplo e desencadeou um aquecido debate nas páginas dessa tradicional revista do American Institute of Physics. A própria existência desse debate já era um sinal dos tempos, como foi observado por um dos leitores que escreveu para Physics Today:

Os [debates] exemplificam os modos altamente sutis e complexos pelos quais a opinião científica pode mudar. Quando eu era um estudante de graduação, estudando Física 20 anos atrás, [...] a linha de Copenhague era 'científica', qualquer outra coisa era sem sentido, conversa vazia ou, na melhor hipótese, errada. (HAMMERTON, 1971)

Na Escola de Verão de Varenna, DeWitt apresentou as ideias de Everett, para as quais ele cunhou a expressão "interpretação dos muitos mundos"; em seguida, providenciou que a longa tese original fosse publicada e escreveu, com seu aluno Graham, a primeira revisão bibliográfica abrangente sobre fundamentos da mecânica quântica.

Não faz sentido discutir possíveis obstáculos que DeWitt tenha enfrentado ao apresentar as ideias de Everett porque ele não se dedicou ao tema dos fundamentos, nem integral nem permanentemente. Contudo, DeWitt estava sensível e consciente da existência de preconceitos profissionais contra a pesquisa em fundamentos da Teoria Quântica. Além disso, era crítico do que ele entendia como sendo a "interpretação de Copenhague." Em carta a Wheeler, ao deslanchar sua campanha em defesa da interpretação de Everett, ele escreveu:

[...] os cutucões na Escola de Copenhague não eram para inclusão na versão publicada. [...] Eu devo confessar que dei esses cutucões, de modo levemente malicioso, para seu próprio benefício. [...] (Sobre meu uso da palavra "rígida" ao me referir à "doutrina de Copenhague", como você descreveria a atitude de Rosenfeld sobre $\mathrm{o}$ assunto?). ${ }^{24}$

Ao citar Rosenfeld, DeWitt certamente estava reagindo ao ceticismo das críticas do primeiro (ROSENFELD, 1963) acerca do projeto de quantização da relatividade geral, o qual era tão apreciado tanto por DeWitt quanto por Wheeler. 


\section{Conclusões}

As realizações científicas dos nossos protagonistas, no período em estudo, são verdadeiramente impressionantes e isto pode ser evidenciado pelos dados cientométricos. ${ }^{25}$ Mais convincente, contudo, é a lista das suas realizações. Os avanços maiores foram obtidos por Bell, Clauser e Shimony, que contrastaram a localidade com a mecânica quântica e contribuíram para o estabelecimento do emaranhamento como um novo efeito físico quântico. Não obstante, a pesquisa sobre o que agora chamamos de "descoerência" apenas emergiu mais tarde e Zeh pode ser corretamente considerado o seu precursor. DeWitt contribuiu para a quantização da gravitação, embora esse desafio continue sem solução. Wigner, d'Espagnat, Zeh, Shimony e Rosenfeld ampliaram o entendimento do que é o problema da medição, embora nem todos eles, como foi o caso de Rosenfeld, tenham reconhecido que exista um problema da medição quântica. Selleri alimentou a corrida por melhores experimentos melhores e trouxe a controvérsia quântica ao alcance de um público mais vasto.

Nenhum dos nossos protagonistas foi treinado para a pesquisa em fundamentos da mecânica quântica e, exceto Clauser que foi para o teorema de Bell logo depois do seu doutorado, todos eles mudaram para os fundamentos em um estágio posterior das suas carreiras. Deste modo, eles administraram e minimizaram possíveis perdas em suas carreiras. Foram atraídos para os fundamentos a partir de áreas muito diferentes, incluindo partículas, nuclear, relatividade e os próprios fundamentos. Alguns deles, tal como Zeh e Selleri, reconheceram a existência de problemas não resolvidos em fundamentos, quando mudavam para esse campo; outros, como Bell e Clauser, tinham se preocupado com essas questões desde a sua formação inicial. Para alguns deles, como Selleri e Clauser, o clima político da década de 1960 influenciou suas decisões para empreender a pesquisa em fundamentos.

Considerando essa diversidade de perfis profissionais e pessoais, pode-se perguntar o que esses personagens tinham em comum, além do tema de pesquisa que escolheram? Exceto Rosenfeld, eles foram dissidentes, dissidentes quânticos. Quase todos foram críticos do que percebiam como a interpretação da complementaridade, a interpretação de Copenhague ou a interpretação usual da Teoria

25 Oito artigos de nossos protagonistas, todos com uma incidência direta sobre os fundamentos da Teoria Quântica, atingiram mais de 500 citações, em janeiro de 2009. Os artigos são de Bell (1964, 1966), Clauser, Horne, Shimony e Holt (1969), Clauser e Shimony (1978), Clauser e Horne (1974), Joos e Zeh (1985), Greenberger, Horne, Shimony e Zeilinger (1990) e DeWitt (1967). 
Quântica, termos que designavam a interpretação mais difundida dessa teoria. ${ }^{26}$ No entanto, eles não compartilharam uma única interpretação alternativa para a mecânica quântica. Compartilharam, sim, atitudes profissionais e intelectuais, segundo as quais as questões dos fundamentos da mecânica quântica eram relevantes o suficiente de serem investigadas como parte de uma carreira profissional em Física; e que negar isso seria uma atitude dogmática. Essa foi a característica principal da dissidência entre eles, pois a maioria dos físicos, à época, não concordava com isso. Em uma visão compartilhada com Rosenfeld, os físicos pensavam que problemas de fundamentos já tinham sido resolvidos por Bohr, Heisenberg e Pauli. Nos casos de Bell, d'Espagnat, Wigner, DeWitt, Zeh e Clauser, encontramos evidências de quão sensíveis eles foram àquele preconceito e quão forte ele foi. Em retrospectiva, Shimony e Selleri também pensam o mesmo. Ademais, as carreiras de Clauser e Zeh foram prejudicadas por tais preconceitos profissionais.

A literatura sobre a mecânica quântica convida ao uso metafórico do termo dissidência, comum em política e em religião, para lidar com as controvérsias científicas. De fato, Heilbron (2001) escreveu sobre os Missionários do espírito de Copenhague, Rosenfeld utilizou "heresia" para se referir às ideias de Everett (OSNAGHI; FREITAS; FREIRE, 2009, p. 240), Wigner (1963) apresentou a sua própria ideia como a ortodoxia na mecânica quântica e Jammer (1974, p. 250) escreveu sobre a "monocracia incontestada da Escola de Copenhague na filosofia da mecânica quântica", ao analisar os debates sobre a interpretação, no início da década de 1950, apenas para citar alguns exemplos. A metáfora é atrativa. Como muitos dos dissidentes da segunda metade do século XX - tal como Mandela, Lula ou Martin Luther King -, eles, ou as causas que eles abraçaram, ganharam, pelo menos no médio prazo. Os fundamentos da mecânica quântica tornaram-se finalmente um campo respeitável de pesquisa. Contudo, a metáfora nem sempre funciona. As expectativas de quebrar a mecânica quântica ou de revelar os seus limites não foram realizadas. O dictum Hamletiano de Bell - "a mecânica quântica está apodrecida" - tem ainda de ser confirmado. A mecânica quântica padrão entra no século XXI ainda mais corroborada experimentalmente.

Finalmente, esse perfil biográfico responde a certo número de questões, mas sugere outras. Trato agora de algumas dessas questões sugeridas. A história da ciência tem se enriquecido pela tomada em consideração do papel dos contextos locais na produção da ciência. Nossos casos são evidências que Paris, Berkeley, Heidelberg, Itália ou Estados Unidos podem ter tido nessa história papeis bem diferentes. A própria existência de um ambiente favorável à investigação em fundamentos, nos Estados Unidos, demanda explicação, pois ela desafia a literatura histórica disponível que enfatiza o pragmatismo e a Guerra Fria como fatores que

26 A despeito da presente dificuldade em identificar o que era a "interpretação de Copenhague". (CAMILLERI, 2009; HOWARD, 2004) 
conformaram a Física norte-americana contra pesquisas filosoficamente inclinadas e a favor de pesquisas aplicadas. ${ }^{27}$ Contudo, como Bromberg (2006) tem mostrado, a Física aplicada não foi contraditória com a Física de fundamentos, no caso da Ótica Quântica nos Estados Unidos. Kaiser, em American physics and the cold war bubble, livro em preparação, explora como períodos diferentes da Guerra Fria interagiam diferentemente com a Física norte-americana. A segunda questão diz respeito às premissas filosóficas de nossos protagonistas. Exceto, talvez, para Rosenfeld e Wigner, nossos protagonistas, pelo menos na época considerada, estavam comprometidos com uma ou outra variante do realismo científico. Isto parece ter sido uma grande mudança quando comparada com as tendências filosóficas influentes na construção da mecânica quântica. Em artigo mais antigo, Brush (1980) tentou explicar essa mudança sugerindo a existência de oscilações cíclicas entre períodos "românticos" e "realistas" na ciência e na cultura do Ocidente. Por fim, a metáfora da dissidência pode ser um conceito útil em períodos outros da história da mecânica quântica do que esse em torno de 1970? A literatura sugere que ela pode ser adequada a casos anteriores, como os de David Bohm e Hugh Everett, na década de 1950 (FREIRE, 2005; OSNAGHI; FREITAS; FREIRE, 2009). É menos certo que ela possa se revelar útil em períodos posteriores porque, nesses momentos mais recentes, pode ter crescido o número de físicos teóricos e experimentais trabalhando em fundamentos da mecânica quântica e, ao mesmo tempo, apoiando a interpretação da complementaridade. Ademais, as promessas de aplicações tecnológicas no campo da informação quântica têm mudado o cenário do campo de pesquisas em fundamentos. Todas essas questões requerem mais pesquisa histórica.

\section{Agradecimentos}

Traduzido pelo próprio autor, a partir de Quantum dissidents: research on the foundations of quantum theory circa 1970, Studies in history and philosophy of modern physics (n. 40, p. 280-289, 2009), com permissão de Elsevier. Versões preliminares foram apresentadas: na HQ2 Conference on the History of Qantum Physics, 14 a 17 de julho, Utrecht; no Workshop Teoria Quântica: estudos históricos e implicações culturais, 15 a17 de dezembro de 2008, Campina Grande; e no Instituto Max Planck para a História da Ciência, 17 de julho de 2009, Berlim. Esta pesquisa foi apoiada pelo Conselho Nacional de Desenvolvimento Científico e Tecnológico (CNPq) e Fundação de Amparo à Pesquisa do Estado da Bahia (FAPESB). Agradeço a Joan Bromberg e Fábio Freitas, por seus comentários, e a dois árbitros anônimos da revista, pela cuidadosa análise crítica desse artigo.

27 Ver Schweber (1986) e referências em Bromberg (2006, nota 1). 


\section{Referências}

BALLENTINE, L. The statistical interpretation of quantum mechanics. Reviews of Modern Physics, v. 42, n. 4, p. 358-381, oct. 1970.

BELL, J. S. On the Einstein Podolsky Rosen paradox. Physics, v. 1, n. 3, p. 195200, 1964.

. On the problem of hidden variables in quantum mechanics. Reviews of Modern Physics, v. 38, n. 3, p. 447-452, 1966.

. Speakable and unspeakable in quantum mechanics - collected papers on quantum philosophy. Cambridge: Cambridge University, 2004.

BIALYNICKI-BIRULAB, I.; MYCIELSKI, J. Nonlinear wave mechanics. Annals of Physics, v. 100, n. 1-2, p. 62-93, 1976.

BROMBERG, J. L. Device physics vis-à-vis fundamental physics in Cold War America: the case of quantum optics. ISIS, v. 9, n. 2, p. 237-259, 2006.

. New instruments and the meaning of quantum mechanics. Historical Studies in the Natural Sciences, v. 38, n. 3, p. 325-352, 2008.

BRUSH, S. The chimerical cat: philosophy of quantum mechanics in historical perspective. Social Studies of Science, v. 10, n. 4, p. 393-447, 1980.

BYRNE, P. The many worlds of Hugh Everett. Scientific American, p. 98-105, dec. 2007.

CAMILLERI, K. Constructing the myth of the Copenhagen interpretation. Perspectives on Science, v. 17, n. 1, p. 26-57, 2009a.

. A history of entanglement: decoherence and the interpretation problem. Studies in History and Philosophy of Modern Physics, v. 40, issue 4, p. 290-302, 2009b.

CLAUSER, J. F. Early history of Bell's theorem. In: BERTLMANN, R. A.; ZEILINGER, A. (Ed.). Quantum [un]speakables: from Bell to quantum information. Berlin: Springer, 2002. p. 61-98. 
CLAUSER, J. F.; HORNE, M. A. Experimental consequences of objective local theories. Physical Review D, n. 10, p. 526-535, 1974.

CLAUSER, J. F. et al. Proposed experiment to test local hidden-variable theories. Physical Review Letters, v. 23, n. 15, p. 880-884, 1969.

CLAUSER, J. F.; SHIMONY, A. Bell's theorem: experimental tests and implications. Reports on Progress in Physics, n. 41, p. 1882-1927, 1978.

DANERI, A.; LOINGER, A.; PROSPERI, G. M. Further remarks on the relations between statistical mechanics and quantum theory of measurement. Nuovo Cimento,B44, p. 119-128, 1966.

Quantum theory of measurement and ergodicity conditions. Nuclear Physics, v. 33, p. 297-319, 1962.

DE BROGLIE, L. Non-linear wave mechanics. Amsterdam: Elsevier, 1960.

D'ESPAGNAT, B. Conceptions de la physique contemporaine -les interprétations de la mécanique quantique et de la mesure. Paris: Hermann, 1965.

Conceptual foundations of quantum mechanics. $2^{\text {nd }}$. ed. Reading: W.A. Benjamin, 1976. A primeira edição data de 1971.

. (Ed.). Foundations of quantum mechanics: proceedings of the International School of Physics 'Enrico Fermi’. New York: Academic, 1971.

DEWITT, B. S. Quantum theory of gravity. I - The canonical theory. Physical Review, v. 160, n. 5, p. 1113-1148, 1967.

FREEDMAN, S. J.; CLAUSER, J. F. Experimental test of local hidden-variable theories. Physical Review Letters, v. 28, n. 14, p. 938-941, 1972.

FREIRE, O. The historical roots of "foundations of quantum mechanics" as a field of research (1950-1970). Foundations of Physics, v. 34, n. 11, p. 1741-1760, 2004.

. Orthodoxy and heterodoxy in the research on the foundations of quantum physics: E.P. Wigner's case. In: SANTOS, B. S. (Ed.). Cognitive justice in a global world - prudent knowledges for a decent life. Lanham, MD, USA: Lexington Books, 2007. p. 203-224. 
. Philosophy enters the optics laboratory: Bell's theorem and its first experimental tests (1965-1982). Studies in History and Philosophy of Modern Physics, v. 37, p. 577-616, 2006.

. Science and exile: David Bohm, the cold war, and a new interpretation of quantum mechanics. Historical Studies in the Physical and Biological Sciences, v. 36, n. 1, p. 1-34, 2005.

FREITAS, F. H. A.; FREIRE, O. Sobre o uso da Web of Science como fonte para a história da ciência. Revista da SBHC, v. 1, n. 2, p. 129-147, 2003.

GHIRARDI, G. C.; RIMINI, A.; WEBER, T. Unified dynamics of microscopic and macroscopic systems. Physical Review D, n. 34, p. 470-491, 1986.

GISIN, N. Quantum measurement and stochastic processes. Physical Review Letters, v. 52, n. 19, p. 657-1660, 1984.

. Stochastic quantum dynamics and relativity. Helvetica Physica Acta, n. 62, p. 363-371, 1989.

GOTTFRIED, K. Does quantum mechanics carry the seeds of its own destruction?. Physics World, v. 4, issue 10, p. 34-90, oct. 1991.

GREENBERGER, D. et al. Bell theorem without inequalities. American Journal of Physics, v. 58. n. 12, p. 1131-1143, 1990.

HAMMERTON, M. Carta. Physics Today, v. 24, n. 10, p. 11-13, 1971.

HEILBRON, J. The earliest missionaries of the Copenhagen spirit. In:

GALISON, P.; GORDIN, M.; KAISER, D. (Ed.). Science and society - the history of modern physical science in the twentieth century. New York: Routledge, 2001. v. 4, p. 295-33.

HOME, D.; WHITAKER, M. A. B. Ensemble interpretations of quantum mechanics: a modern perspective. Physics Reports, v. 210, n. 4, p. 223-317, 1992.

HOWARD, D. Who invented the "Copenhagen interpretation"? A study in mythology. Philosophy of Science, n. 71, p. 669-682, 2004. 
JACOBSEN, A. Léon Rosenfeld's Marxist defense of complementarity. Historical Studies in the Physical and Biological Sciences, v. 37, p. 3-34, mar. 2007. Supplement.

JAMMER, M. The philosophy of quantum mechanics: the interpretations of quantum mechanics in historical perspective. New York: Wiley, 1974.

JAUCH, J. M., WIGNER, E. P.; YANASE, M. M. Some comments concerning measurements in quantum mechanics. Nuovo Cimento, B48, v. 1, p. 144-151, 1967.

JOOS, E.; ZEH, H. D. The emergence of classical properties through interaction with the environment. Zeitschrift fur Physik B, v. 59. n. 2, p. 223-243, 1985.

KAISER, D. Comments on "Interpreting quantum mechanics: a century of debate". HSS Session, Washington, nov. 2007. Não publicado.

KAISER, D. American physics and the cold war bubble. Chicago: Chicago University, [201-]. No prelo

KRAGH, H. An introduction to the historiography of science. New York: Cambridge University, 1987.

LEGGETT, A. J. Reflections on the quantum measurement paradox. In: HILEY, B. J.; Peat, F. David (Ed.). Quantum implications: essays in honour of David Bohm. London: Routledge, 1987. p. 85-104.

LOINGER, A. Comments on a recent paper concerning the quantum theory of measurement. Nuclear Physics v. 108, issue 2, p. 245-249, feb. 1968

OSNAGHI, S.; FREITAS, F.; FREIRE, O. The origin of the Everettian heresy. Studies in History and Philosophy of Modern Physics, v. 40, p. 97-123, 2009.

PEARLE, P. Combining stochastic dynamical state-vector reduction with spontaneous localization. Physical Review, A 39, p. 227-239, 1989.

PESSOA, O.; FREIRE, O.; DE GREIFF, A. The Tausk controversy on the foundations of quantum mechanics: physics, philosophy, and politics. Physics in Perspective, v. 10, n. 2, p. 136-162, 2008. 
REDNER, S. Citation statistics from 110 years of Physical Review. Physics Today,v. 58, n. 6, p. 49-54, jun. 2005.

ROSENFELD, L. The measuring process in quantum mechanics. Progress of Theoretical Physics, p. 222-235, 1965. Supplement.

. On quantization of fields. Nuclear Physics, v. 40, p. 353-356, 1963.

Reimpresso em R. S. Cohen e J. J. Stachel (Ed), sob o título Selected papers of Léon Rosenfeld, editado em Dordrecht por D. Reidel, em 1979. p. 442-445.

. Questions of method in the consistency problem of quantum mechanics. Nuclear Physics, A108, p. 24-244, 1968.

SCHWEBER, S. The empiricist temper regnant: theoretical physics in the United States 1920-1950. Historical Studies in the Physical Sciences, n.17, p.55-98, 1986. Part 1.

SELLERI, F. Die debatte um die quantentheorie. Braunschweig: Vieweg, 1983.

SHIMONY, A. Desiderata for a modified quantum dynamics. In: SHIMONY, A (Ed.). Search for a naturalistic world view: natural science and metaphysics. New York: Cambridge University, 1993b. v. 2

. Proposed neutron test of some nonlinear variants of wave mechanics. Physical Review A, v. 20, n. 2, p. 394-396, 1979.

. Search for a naturalistic world view scientific method and epistemology. New York: Cambridge University, 1993. v. 1

SHULL, C. G. et al. A. Search for a nonlinear variant of the Schrödinger equation by neutron interferometry. Physical Review Letters, v. 44, n. 12, p. 765-768, 1980.

STONE, L. Prosopography. Daedalus, v. 100, n. 1, p. 46-79, 1971.

TAROZZI, G.; MERWE, A. van der. For Franco Selleri on his seventieth birthday. Foundations of Physics, v. 34, n. 11, p. 1613-1615, 2004.

WIGNER, E. P. The problem of measurement. American Journal of Physics, v. 31, p. 6-15, 1963. 
Remarks on the mind-body question. In: GOOD, I. J. (Ed.). The scientist speculates. London: W. Heinemann, 1961. p. 284-302.

The subject of our discussion. In: D'ESPAGNAT, B. (Ed.). Proceedings of the International School of Physics "Enrico Fermi": Course IL -Foundations of quantum mechanics. New York: Academic, 1971. p. 1-19.

$\mathrm{ZEH}, \mathrm{H}$. D. On the interpretation of measurement in quantum theory. Foundations of Physics, n. 1, p. 69-76, 1970.

Roots and fruits of decoherence. Quantum Physics, v. 2,8 mar. 2006.

Disponível em: $<$ http://arxiv.org/abs/quant-ph/0512078v2S, 2006 $>$. Acesso em: 5 jun. 2010. 


\title{
A descoerência emerge: os múltiplos caminhos de um novo fenômeno físico
}

\author{
Fábio Freitas
}

\section{Introdução}

A Teoria Quântica encontra-se numa situação única na história da ciência. Desde seu estabelecimento formal, em fins da década de 1920, sua aplicação nos mais diversos domínios tem se mostrado absolutamente bem sucedida, mesmo nas mais extremas situações, e seu desenvolvimento permitiu a chamada revolução da informação em fins do século XX, de modo que inquestionavelmente é a teoria física mais bem sucedida de todos os tempos e com maior impacto social e tecnológico. Todavia, nesses mais de 80 anos, desenvolveu-se uma controvérsia, às vezes mais branda, porém muitas vezes extremamente intensa, sobre qual o significado dessa teoria, que imagem de mundo ela nos permite formar ou, mesmo, se nos permite formar alguma imagem de mundo ${ }^{1}$. Essa controvérsia, ademais, também tem características únicas. Não é a primeira vez que se discute, ao longo dos anos, o significado de uma teoria, porém é raro o caso de uma controvérsia gerar frutos tão importantes para o próprio desenvolvimento da teoria. $\mathrm{Na}$ busca de se compreender melhor os fundamentos dessa teoria, $\mathrm{o}$ desenvolvimento de resultados formais levou à identificação e ao evidenciamento experimental de dois novos fenômenos: o emaranhamento e a descoerência. Este trabalho, cujos resultados preliminares são aqui apresentados, concentra-se em desenvolver a história de um deles, a descoerência ${ }^{2}$, focando nos diversos caminhos através dos quais se chegou ao seu estudo. Mas antes de explicar melhor a sua importância, vamos traçar um panorama histórico do desenvolvimento do campo da controvérsia.

1 Confira Freire Jr. e Freitas (2006).

2 Na literatura, em língua portuguesa, também se usa o termo decoerência. 


\section{Breve histórico da controvérsia sobre os fundamentos da Teoria Quântica}

O primeiro destes dois fenômenos, o emaranhamento entre sistemas quânticos, também conhecido como ação fantasmagórica a distância, seguindo a terminologia de Einstein, tem prometido aplicações em criptografia quântica e o desenvolvimento de computadores quânticos. Tendo suas origens nas críticas de Einstein à incompletude da Teoria Quântica, em 1935, foi somente cerca de três décadas depois, por meio das mãos de John Bell e posteriormente mergulhando nos experimentos, que o emaranhamento começou a se estabelecer como uma propriedade efetiva do mundo quântico. (BELL, 1964; EINSTEIN; PODOLSKY; ROSEN, 1935) Do ponto de vista clássico, essa característica é tão surpreendente que, recentemente, a escritora Louisa Guilder batizou seu livro sobre a história da Mecânica Quântica de Age of entanglement: when quantum physics was reborn. De fato, esse fenômeno, que emerge na década de 60 , tem sua história já razoavelmente bem estudada, desde as motivações que levaram os físicos a prestar mais atenção a essas propriedades, até os caminhos que levaram à efetivação dos experimentos realizados, e à análise desses resultados experimentais, que terminariam por confirmar a Mecânica Quântica em testes extremamente rígidos. ${ }^{3}$

O segundo resultado teórico também tem suas origens em críticas de um dos pais fundadores da Mecânica Quântica, o austríaco Erwin Schrödinger. No mesmo ano de 1935, seguindo o debate gerado com o trabalho de Einstein, Schrödinger desenvolve o seu caricatural experimento de pensamento do gato que leva o seu nome e é tradicionalmente visto como um símbolo da própria Teoria Quântica. ${ }^{4}$ Em sua crítica, ele enfatiza o problema da aplicação da teoria a sistemas macroscópicos, problema que quando enfrentado posteriormente leva à proposição do mecanismo da descoerência. Todavia, sua história é bastante diferente daquela do emaranhamento. Enquanto o emaranhamento apareceu como carro-chefe do ressurgimento e institucionalização da pesquisa em fundamentos da Física, durante as décadas de 60 e 70, a descoerência permaneceu fora dos circuitos principais de debate até fins da década de 80 , tendo seu nome atual sido cunhado para o grande público da Física apenas em 1991. Mas a principal diferença é o processo pelo qual o estudo da descoerência se consolidou. Ao invés de pesquisadores trabalhando em contato e colaborando uns com os outros sobre os avanços da pesquisa, o estudo da descoerência surgiu (e ressurgiu) a partir de três

3 Para a história do emaranhamento, ver Freire Jr. (1999), Freire Jr. (2004), e, especialmente, Freire Jr. (2006). Para o livro de Gilder, ver Gilder (2009).

4 Para o texto original, ver Schrödinger (1980). Ver ainda, Moore (1994). 
diferentes grupos de modo independente, cada qual com formações específicas e enfrentando problemas físicos distintos. ${ }^{5}$

\section{Descoerência}

A descoerência, por si só, não é exatamente algo novo. Sua ideia básica está relacionada ao fato de que um sistema quântico que não esteja isolado do meioambiente terá propriedades completamente distintas daquelas de um sistema isolado, mais especificamente perdendo o comportamento dito quântico, que exibiria interferências, e passando para um comportamento clássico, cujas propriedades tipo posição e trajetória ${ }^{6}$ estariam simultaneamente bem definidas. Como alguns pesquisadores já argumentaram, é possível identificar, em diversos momentos na História da Quântica, sugestões de que a interação de um sistema com o meio-ambiente, ou em outras palavras, o fato de trabalharmos com um sistema aberto, levaria a tais consequências. ${ }^{7}$ Todavia, foi somente após os trabalhos de Dieter Zeh e posteriormente de Wojciech Zurek, além de Anthony Leggett e Amir Caldeira, que este tema de fato mereceu a atenção da comunidade dos físicos. ${ }^{8}$ Atualmente, o seu papel em fundamentos da Física é bastante amplo, indo desde o problema da medição, a transição quântico-clássico até

5 Todavia, aparentemente essa situação não é única na história da ciência. Evelyn Fox Keller, em um par de artigos, sugere uma nova abordagem à história da emergência do conceito de auto-organização na ciência. Em sua descrição, esse conceito teria passado por três fases ou caminhos distintos entre si: um primeiro caminho ocorreu dentro da Biologia, sendo seguido pelas pesquisas em Engenharia e Cibernética e, por fim, emergindo dentro da Física, caminho pelo qual esse conceito se estabeleceu contemporaneamente. (KELLER, 2008, 2009).

6 Mas não exclusivamente estas. (Cf. SCHLOSSHAUER, 2007)

7 Castagnino, Laura e Lombardi, por exemplo, identificam van Kampen, van Hove e Daneri, Loinger e Prosperi como pioneiros nessa abordagem nas décadas de 50/60. Stamp, por sua vez, aproxima essas ideias das origens da teoria propriamente dita ao incluir London e Bauer, e Von Neumann na década de 30. Por fim, Bacciagaluppi nos remete à década de fundação da Teoria Quântica, em 1929, com o trabalho de Mott sobre trajetórias de partículas alfa numa câmara de bolhas. A respeito, ver Castagnino, Laura e Lombardi (2008), Stamp (2006), Bacciagaluppi (2007).

8 Em relação a Zeh como pioneiro de facto, não parece haver muita discordância, bem como ao papel desempenhado por Zurek. Ver, por exemplo, Bacciagaluppi (2007). Porém, em relação ao papel de Caldeira e Leggett, estes são tradicionalmente desconsiderados, ainda que mais recentemente esse panorama parece ter mudado. Para trabalhos que não citam Caldeira e Leggett, explicitamente na história da descoerência, ver Auletta, (2001) e Schlosshauer e Fine (2007). Para trabalhos que já mencionam explicitamente Caldeira e Leggett, ver Stamp (2006) e Camilleri (2009). Todavia, esse último trabalho é concentrado nos personagens Zeh e Zurek, indicando que uma história extensiva da descoerência permanece por ser escrita. 
temas ligeiramente mais afastados, como a direção preferencial da seta do tempo. Todavia, a profundidade do papel da descoerência nestes debates ainda permanece um tema controverso. ${ }^{9}$

O primeiro destes pesquisadores foi o alemão H. Dieter Zeh. Em um contexto no qual a Alemanha tentava se restabelecer no cenário científico internacional, após o fim da II Guerra, o tema central para tal desenvolvimento dentro da Física foi o estudo da estrutura nuclear, especialmente importante por questões energéticas e mesmo bélicas. Esse tema também era central pela presença de Hans Jensen, agraciado com o prêmio Nobel por seu trabalho nesse campo, em 1963, e que durante a guerra desenvolveu pesquisas que teriam sido utilizadas nos esforços de construção da bomba atômica alemã (WALKER, 1989). Jensen era professor na Universidade de Heidelberg, alma matter de Zeh. Tendo terminado o seu doutorado e sua habilitação em Física nuclear, em 1961 e 1966 respectivamente, ambas em Heidelberg, Zeh começa um processo de transição da pesquisa aplicada para o campo de Fundamentos da Física. Como consequência de seu trabalho de 1966, Zeh imaginou um núcleo que fosse tão grande, com tantos graus de liberdade, que ele mesmo pudesse se observar ou, em outras palavras, que o próprio núcleo pudesse registrar "propriedades" dele mesmo, servindo como objeto e sistema de medição. Essa situação hipotética servia para tentar compreender, a partir de novas bases, o problema do colapso de função de onda, como exemplificado pelo Gato de Schrödinger. A partir deste panorama, Zeh pôde criticar as diversas abordagens a esse problema, inclusive a desenvolvida pelos físicos italianos Adriana Daneri, Angelo Loinger e Giovanni Maria Prosperi, conhecida na literatura como DLP. Essa abordagem levava o apoio do físico belga Léon Rosenfeld, que dedicara grande parte de sua carreira aos Fundamentos da Física, servindo como assistente filosófico de Niels Bohr, pai da interpretação ortodoxa da Teoria Quântica. ${ }^{10}$ Quando terminou o manuscrito do artigo, Zeh o entregou para seu professor, Jensen. Como Jensen nunca se dedicara às questões de fundamentos, enviou para o editor da Nuclear Physics, que também era seu amigo: Léon Rosenfeld.

Tendo em vista o passado de Rosenfeld, que em outras oportunidades se envolveu fortemente para coibir críticas à interpretação dominante da Teoria Quântica ${ }^{11}$, não vem a ser grande surpresa que este não tivesse dado apoio ao trabalho de Zeh, muito pelo contrário. Na resposta de Rosenfeld para Jensen, Rosenfeld disse que tinha todos os motivos para acreditar que, com referência ao

9 Ver Stamp (2006), Bacciagaluppi (2007), Schlosshauer (2004) e Pessoa Jr., (1998).

10 Para mais detalhes sobre a história da abordagem DLP e controvérsias anteriores nas quais ela esteve envolvida, ver Pessoa Jr., Freire Jr. e Greiff (2008).

11 Ver Pessoa Jr., Freire Jr. e Greiff (2008, nota 9) e Osnaghi, Freitas, Freire Jr., (2009). 
manuscrito de Zeh, "[...] tamanha concentração da mais absurda falta de senso"12 não fora escrita com o consentimento de Jensen e que tinha certeza que este não permitiria que esse tipo de coisa continuasse a acontecer em Heidelberg. De fato, Jensen se empenhou em impedir que isso acontecesse em seu instituto. $\mathrm{Na}$ medida em que Zeh continuasse a publicar sobre Física Nuclear, ele seria mais do que bem vindo, porém não deveria insistir nessas faltas de sentido. Todavia, Zeh insistiu. Apesar de o manuscrito ter sido recusado em duas revistas, mediante a intervenção do então prêmio Nobel, Eugene Wigner (que curiosamente havia compartilhado o prêmio com Jensen), o artigo foi finalmente aceito por uma recém-lançada revista, Foundations of Physics. ${ }^{13}$ Em função desse episódio, a carreira de Zeh seria fortemente afetada pela perda do apoio do físico mais poderoso de Heidelberg. De fato, Zeh declararia, posteriormente, que sua transição definitiva para o campo de fundamentos só veio a acontecer quando ele percebeu que não mais teria como desenvolver uma carreira, portanto, passaria a se dedicar ao que ele gostava. Durante os anos seguintes permaneceu publicando em boletins e em revistas com baixo prestígio, de modo que sua importância no campo somente seria reconhecida após sua aposentadoria.

O segundo caminho pelo qual o tema da descoerência aparece na comunidade científica é pelas mãos do brasileiro Amir Caldeira, junto com seu orientador, Anthony Leggett. Graduou-se em Física nos áureos tempos da Pontifícia Universidade Católica do Rio de Janeiro (PUC-RJ), onde ingressou em 1970 com o objetivo de tornar-se engenheiro; porém, o contato com o ambiente de pesquisa e a sua aptidão para o campo levaram-no a desviar para a área de Física. Em 1976, ele terminou o mestrado na mesma instituição, sob a orientação de Nicim Zagury, trabalhando sobre o efeito de dissipação em sistemas quânticos. Este trabalho em Física básica não apresentava nenhuma relação direta com o campo de fundamentos. Todavia, a habilidade que desenvolveu no estudo de efeitos de dissipação serviu, mais tarde, como uma luva nos projetos de Leggett, professor na Universidade de Sussex, Inglaterra, onde Caldeira decidiu ir fazer o seu doutorado. Em 1977, quando ingressou em Sussex, Leggett já era um físico renomado, tendo resolvido o problema da superfluidez do hélio 3, trabalho pelo qual ganharia o prêmio Nobel em 2003. Além de ser um talentoso físico teórico, Leggett tinha uma faceta menos conhecida: era um ferrenho crítico da Teoria Quântica, que acreditava se mostraria inadequada quando aplicada a novos domínios. O seu já

12 Carta de Léon Rosenfeld para Hans Jensen, 14 de fevereiro de 1968. Niels Bohr Archives. Essa carta foi identificada a partir de entrevista realizada com H. Dieter Zeh, em julho de 2008, pelo autor e recuperada por Anja Jacobsen. As informações subsequentes sobre a carreira de Zeh estão presentes nesta entrevista.

13 Para o papel de Wigner na controvérsia sobre fundamentos da Teoria Quântica, ver Freire Jr. (2007). Ver ainda Pessoa Jr., Freire Jr. e Greiff (2008, nota 9), para o papel de Wigner em um debate anterior envolvendo a abordagem DLP. Para o artigo de Zeh, ver Zeh (1970). 
mencionado trabalho sobre o hélio 3 , que mais tarde se mostrou ser uma das mais impressionantes confirmações do poder heurístico da Teoria Quântica, tinha na sua origem a busca de falhas nessa mesma teoria. Leggett conta que a fase superfluida do hélio 3 era uma situação extrema e rara e que a Teoria Quântica nunca havia sido testada em tais condições. Quando começou a enfrentar o problema, ele tinha certeza de que a Mecânica Quântica não conseguiria explicar fenômeno tão específico. Claramente, como mostrou seu trabalho, suas expectativas iniciais não se concretizaram, porém o espírito de manter-se buscando situações em que a Teoria Quântica falharia permeou o resto de sua carreira e ainda hoje está presente em suas motivações ${ }^{14}$.

Um ano após ter chegado a Sussex, em 1978, Leggett sugeriu um problema de pesquisa para Caldeira. Ele propôs que fosse examinada a ocorrência de mudança de estados no fluxo magnético em um dispositivo squid ${ }^{15}$ devido à flutuação térmica. Esse problema era perfeito para Caldeira, pois como havia trabalhado com dissipação no seu mestrado, agora aplicaria as mesmas técnicas, mas em um problema distinto. De fato, isso foi extremamente frutífero, pois os resultados encontrados, após dois anos de cálculos, indicaram que o efeito definitivo de um banho termodinâmico era a supressão do efeito de tunelamento na junção Josephson, um dos elementos do squid. Em termos mais simples, o que Caldeira e Leggett haviam encontrado era que o meio-ambiente servia para fazer desaparecer as propriedades quânticas do sistema, aproximando-o de um sistema clássico. Leggett, com seu interesse em fundamentos da Teoria Quântica e em mostrar que essa teoria apresentava limitações, logo percebeu que esse fenômeno teórico se assemelhava ao famoso paradoxo do gato de Schrödinger, no qual um gato é colocado em um estado de sobreposição quântica e por um ato de medição deveria voltar a se tornar um gato clássico, vivo ou morto. Leggett notou que o papel exercido pelo meio-ambiente poderia se assemelhar a um ato de medição, pois seus efeitos eram idênticos: transformar um sistema essencialmente quântico em um sistema clássico ${ }^{16}$.

14 Essas informações constam em entrevista realizada com Amir Caldeira em janeiro de 2009, pelo autor e Olival Freire Jr., e entrevista realizada com Anthony Leggett, em fevereiro de 2009, pelo autor e Osvaldo Pessoa Jr.

15 Squid, acrônimo do inglês para Dispositivos Supercondutores de Interferência Quântica, são pequenos dispositivos de medida de campos magnéticos extremamente sensíveis. Os primeiros Squids foram construídos em fins da década de 1960, baseados no efeito Josephon, teoricamente previsto em 1962, que previa a ocorrência de tunelamente de um par de Cooper em uma junção de semicondutores separados por uma fina barreira isolante.

16 Ver, por exemplo, “[...] a minimum condition is that the system be not 'observed' over a time at least of the order of the period of the resonance oscillation, and macroscopic systems such as SQUIDS, in strong distinction to atoms, interact so strongly with their environment that this condition is by no means trivial to realize." (LEGGETT, 1980, p. 80-100). 
Em 1996, um dos mais importantes grupos experimentais do mundo em Óptica Quântica, liderado por Serge Haroche, da École Normalle Supérieure, Paris, anunciou que conseguiu medir o tempo de perda de coerência, isto é, em quanto tempo um sistema deixa de apresentar propriedades tipicamente quânticas para começar a se comportar classicamente, após estar imerso em um meio com o qual interage de modo incontrolável. Para desenvolver a teoria concernente a este experimento, Luiz Davidovich, físico brasileiro e responsável pelo desenvolvimento teórico no grupo, utilizou um resultado que estava presente em um dos artigos oriundos da interação entre Caldeira e Leggett, publicado em 1985. ${ }^{17}$ Todavia, entre o surgimento do resultado teórico e o seu uso em experimentos, foi necessário convencer a comunidade de físicos sobre a importância do tema, o que ficou a cargo do terceiro "descobridor" da descoerência, o físico polonês Wojciech Zurek.

Zurek graduou-se em Física na Polônia, sem nenhum interesse particular em fundamentos da Teoria Quântica. ${ }^{18}$ Após a graduação, ele decidiu fazer doutorado nos Estados Unidos. Dos muitos centros de excelência na Física americana, ele decidiu por Austin por um motivo peculiar: seus pais, que eram médicos, tinham amigos na universidade. Essa escolha terminou sendo um grande golpe de sorte, pois, durante o doutorado, Zurek se interessaria por três temas: Termodinâmica, tema no qual completaria sua tese de doutoramento, Cosmologia e Fundamentos da Teoria Quântica. O interesse nesses dois últimos temas o levaria a se aproximar de John Archibald Wheeler, então aposentado da Universidade de Princeton e já atuando na Universidade do Texas, em Austin, onde montou o seu Instituto de Física Teórica. Wheeler havia conquistado seu prestígio, inicialmente, por trabalhos em Física Nuclear, em especial pelo seu modelo do núcleo, desenvolvido em parceria com Niels Bohr. Posteriormente, durante as décadas de 50 e 60, ele viria a se dedicar à Cosmologia, tendo sido responsável pelo aumento do prestígio desse campo junto à comunidade de físicos. Ao ingressar na Universidade do Texas, Wheeler passou a se dedicar ao campo de Fundamentos de Física, em especial ao problema da medição. Em 1978, ministrou um curso sobre esse problema, revisitando a literatura clássica e os novos desenvolvimentos conceituais e técnicos. Esse curso, que continuaria a ser ministrado nos anos seguintes, viria a dar origem ao volume Quantum Theory and Measurement, no qual foram republicados alguns dos mais importantes artigos e textos em fundamentos da Teoria Quântica. Para organizar o volume, Wheeler contou com a ajuda de um estudante da disciplina: Wojciech Zurek. De fato, o envolvimento de Zurek foi muito além da organização do volume. Quando aluno na primeira turma do curso, Zurek

17 Para maiores informações, ver Davidovich e outros $(1993,1996)$. O artigo original é Caldeira e Leggett (1985).

18 Essas informações constam na entrevista realizada com Wojciech Zurek, fevereiro de 2009, pelo autor. 
desenvolveu como ensaio de conclusão uma ideia na qual ele tentava resolver o problema do Gato de Schrödinger. Ao fazer um átomo de prata passar por um dispositivo do tipo Stern-Gerlach, Zurek imaginou um "demônio" que observaria por qual trajeto quântico possível o átomo passou e quais seriam os efeitos da presença deste demônio nos resultados possíveis do experimento. Efetivamente, esse demônio imaginado, que deu origem ao artigo de Zurek de 1981, é um experimento de pensamento equivalente aos trabalhos de Zeh e Caldeira e Leggett. ${ }^{19}$ Todavia, viria a ser Zurek quem publicaria a peça "publicitária" definitiva para o estabelecimento do meio-ambiente como observador no mundo quântico: um artigo na revista Physics Today. ${ }^{20}$

Editada pelo American Institute of Physics, a referida revista funciona como um instrumento de comunicação não (super) especializado da Física americana e mundial. Como, hoje em dia, os campos de pesquisa estão cada vez mais distantes entre si, os esforços desenvolvidos em um campo específico são comunicados aos pesquisadores de outros campos por meio de revistas como esta, sendo a Physics Today a mais importante ${ }^{21}$. Um bom artigo nela publicado pode servir para estabelecer algo no imaginário dos físicos e foi isso que Zurek conseguiu fazer com seu artigo de 1991: estabelecer uma aplicação da Mecânica Quântica como sendo um fenômeno com autonomia própria e merecedor das manchetes, dos pesquisadores e de trabalhos experimentais. A partir de então, o termo descoerência tornou-se parte integrante da Física, diretamente relacionado ao problema da medição, à emergência das propriedades clássicas e à seta do tempo, além de, naturalmente, à sua aplicação mais importante: os computadores quânticos.

O projeto cujos resultados preliminares apresentamos aqui tem como objetivo delinear o desenvolvimento da pesquisa sobre o efeito descoerência ou, melhor dizendo, traçar os diversos caminhos por meio dos quais a relação entre sistemas quânticos distintos, um sendo o meio-ambiente e outro o sistema quântico tradicional, começou a ser estudada; e como esse tipo de estudo pôde estabelecer um novo fenômeno, com nome e campo de pesquisa próprios. Além disso, tendo-se que cada um destes caminhos ocorreu em ambientes distintos - o primeiro na Alemanha dos anos 60/70, o segundo na Inglaterra/Brasil dos anos 70/80 e o último nos Estados Unidos dos anos 80 -, este estudo pretende compreender o impacto que estes diferentes ambientes de pesquisa tiveram sobre

19 Zurek, W. Measurement as a phenomenon. Ms. 1978. Folder PHY394T Quantum Theory of Measurement, BOX CDL 3 9.7/2008-164/13, Wheeler's Papers, Center for American History. e Zurek (1981).

20 Para o livro, ver Wheeler e Zurek (1984). Para o artigo, ver Zurek (1991).

21 O fator de impacto da Physics Today é 5.1. Em termos de comparação, é a segunda colocada; Physics World, editada pelo Institute of Physics da Grã-Bretanha, tem fator de impacto de 0.8 . 
o desenvolvimento e a carreira de cada um desses pesquisadores ${ }^{22}$. Outro ponto importante desse projeto se refere ao imaginário dos físicos e como estes constroem as imagens que descrevem a evolução e formação do seu campo. Apesar dos artigos de Caldeira e Leggett acumularem mais citações que a soma dos artigos dos outros pioneiros do campo e de seus resultados teóricos serem referidos diretamente quando da realização dos primeiros experimentos, seus nomes não constam normalmente no imaginário da história da descoerência, sendo suas contribuições, de certo modo, ignoradas na área de Fundamentos da Física. Neste estudo, pretendemos compreender porque suas contribuições foram excluídas desse imaginário, mesmo sendo, um deles, um prêmio Nobel em Física. Um último ponto importante é verificar de que modo essa história está de acordo com a descrição historiográfica do campo de pesquisa em Fundamentos da Física na segunda metade do século XX, contrastando em especial com as descrições de Freire e Bromberg. ${ }^{23}$

\section{Referências}

AULETTA, G. Foundations and Interpretations of Quantum Mechanics: in the light of a critical-historical analysis of the problems and of a synthesis of the results. Singapore: World Scientific, 2001.

BACCIAGALUPPI, G. Probability, arrow of time and decoherence. Studies in History and Philosophy of Modern Physics, v. 38, issue 2, p. 439-456, jun. 2007.

BACCIAGALUPPI, G. The role of decoherence in quantum mechanics. Stanford Encyclopedia of Philosophy, 23 aug. 2007. Disponível em: <http://plato.stanford. edu/entries/qm-decoherence/>.

BELL, J. On the Einstein Podolsky Rosen Pardox. Physics, v. 1, n. 3, p. 195-200, 1964.

BROMBERG, J.L. Device physics vis-a-vis fundamental physics in Cold War America: the case of quantum optics. ISIS, v. 97, n. 2, p. 237-259, 2006.

22 Para discussão do papel do ambiente de pesquisa, ver Forman (1971). No contexto da pesquisa em fundamentos da Teoria Quântica, ver Freire Jr. (2005). Harvey (1980, 1981), Kaiser (2007) e Olwell (1999).

23 Para as descrições de Freire sobre o desenvolvimento do campo na segunda metade do século XX, ver além das obras citadas, Freire Jr. (2009). Para Bromberg, ver seus textos de 2004 e 2006. Ver ainda Freitas e Freire Jr. (2003) e Pinch (1977). 
The rise of experimental metaphysics' in late twentieth century physics. 2004. Unpublished manuscript.

CALDEIRA, A.; LEGGETT, A. Influence of damping on quantum interference: An exactly soluble model. Physical Review A, v. 31, p. 1059-1066, 1985.

CAMILLERI, K. A history of entanglement: decoherence and the interpretation problem. Studies In History and Philosophy of Science Part B: Studies In History and Philosophy of Modern Physics, v. 40, issue 4, p. 290-302, dec. 2009.

CASTAGNINO, M.; LAURA, R.; LOMBARDI, O. A general conceptual Framework for decoherence in closed and open systems. Philosophy of Science, v. 74, n. 5, p. 968-980, 2008.

DAVIDOVICH, L. et al. Mesoscopic quantum coherences in cavity QED: preparation and decoherence monitoring schemes. Physical Review A, v. 53, p. 1295-1309, 1996.

Quantum Switches and nonlocal microwave fields. Physical Review Letters, v. 71, p. 2360-2363, 1993.

EINSTEIN, A.; PODOLSKY, B.; ROSEN, N. Can Quantum-Mechanical Description of Physical Reality Be Considered Complete?. Physical Review, n. 47, p. 777-780, 1935.

FORMAN, P. Weimar culture, causality, and quantum theory, 1918-1927: adaptation by German physicists and mathematicians to a hostile intellectual environment. In: McCORMMAC, Russel (Ed.). Historical Studies in the Physical Sciences. Philadelphia: university of Pennsylvania, 1971. v.3, 1-115.

FREIRE, O. David Bohm e a controvérsia dos quanta. Campinas: CLE, 1999.

FREIRE JR, O. The historical roots of 'foundations of Quantum Physics' as a field of research (1950-1970). Foundations of Physics, v. 34, issue 11, p. 1741-1759, 2004.

Orthodoxy and heterodoxy in the research on the foundations of quantum physics: E. P. Wigner'case. In: SANTOS, B. S. (Org.). Cognitive justice in a global world. Lanhan: Lexington, 2007. 
. Philosophy enters the optics laboratory: Bell's theorem and its first experimental tests (1965-1982). Studies in History and Philosophy of Modern Physics, v. 37, p. 577-616, 2006.

FREIRE JR., O. Quantum Dissidents: research on foundations of quantum theory circa 1970. Studies In History and Philosophy of Science Part B: Studies In History and Philosophy of Modern Physics, v. 40, issue 4, p. 280-289, dec. 2009.

. Science and exile: David Bohm, the cold war, and a new interpretation of quantum mechanics. Historical Studies in the Physical and Biological Sciences, v. 36, n. 1, p. 1-34, 2005.

FREIRE JR., O.; FREITAS, F. H. A. Controvérsia Octogenária. Scientific American, São Paulo: Duetto, p. 90-97, 1 dez. 2006. (Gênios da Ciência: Quânticos - os homens que mudaram a física, n. 13).

FREITAS, F. H. A.; FREIRE JR., O. Sobre o uso da web of science como fonte para a história da ciência. Revista da Sociedade Brasileira de História da Ciência, v. 2, n. 1, p. 129-147, 2003.

GILDER, L. The age of entanglement: when quantum physics was reborn. New York: Knopf, 2009.

HARVEY, B. The effects of social context on the process of scientific investigation: experimental tests of quantum mechanics. In: KNORR, K. D.; KROHN, R.; WHITLEY, R. (Ed.). The social process of scientific investigation. Dordrecht: Reidel, 1980. p. 139-163.

. Plausibility and the Evaluation of Knowledge: a case-study of experimental quantum mechanics. Social Studies of Science, v. 11, p. 95-130, 1981.

KAISER, D. American physics and the cold war bubble. Chicago: Chicago University, 2007.

KELLER, E. F. Organisms, machines, and thunderstorms: a history of SelfOrganization, part one. Historical Studies in the Natural Sciences, v. 38, n. 1, p. 45-75, 2008.

. Organisms, machines, and thunderstorms: a history of Self-

Organization, part two. Historical Studies in the Natural Sciences, v. 39, n. 1, p. 1-31, 2009. 
LEGGETT, A. Macroscopic Quantum Systems and the Quantum Theory of Measurement. Progress of Theoretical Physics, v. 69, p. 80-100, 1980.

MOORE, W. A life of Erwin Schrödinger. Cambridge: Cambridge University, 1994.

OLWELL, R. Physical Isolation and Marginalization in Physics - David Bohm's Cold War Exile. ISIS, v. 90, p. 738-756, 1999.

OSNAGHI, O.; FREITAS, F.; FREIRE JR., O. The origin of Everettian Heresy. Studies in History and Philosophy of Modern Physics, v. 40, p. 97-123, 2009.

PESSOA JR., O. Can the decoherence approach help to solve the measurement problem? Synthese, v. 113, issue 3, p. 323-346, 1998.

PESSOA JR., O.; FREIRE JR., O.; GREIFF, A. de. The Tausk Controversy on the Foundations of Quantum Mechanics: physics, philosophy and politcs. Physics in Perspective, v. 10, n. 2, p. 138-162, jun. 2008.

PINCH, T. What does a proof do if it does not prove? A study of the social conditions and metaphysical divisions leading to David Bohm and John von Neumann failing to communicate in quantum physics. In: MENDELSOHN, E. Weingart, P.; Whitley, R. D. (Ed). The Social Production of Scientific Knowledge. Dordrecht: Reidel, 1977. p. 171-216. (Sociology of Science, 1).

SCHLOSSHAUER, M. Decoherence and the Quantum-to-Classical Transition. Berlin: Springer. 2007 . Decoherence, the measurement problem, and interpretations of quantum mechanics. Reviews of Modern Physics, v. 76, issue 4, p. 1267-1305, 2004.

SCHLOSSHAUER, M.; FINE, A. Decoherence and the foundations of quantum mechanics. In: EVANS, J.; THORNDIKE, A. S. (Ed.). Quantum mechanics at the crossroads. Berlin: Springer, 2007.

SCHRÖDINGER, E. The present situation in Quantum Mechanics: a translation of Schrödinger's "Cat Paradox" Paper. Proceedings of the American Philosophical Society, v. 124, p. 323-38, 1980.

STAMP, P. C. E. The decoherence puzzle. Studies in History and Philosophy of Modern Physics, v. 37, p. 467-497, 2006. 
WALKER, M. German National Socialism and the Quest for Nuclear Power. Cambridge: Cambridge University, 1989.

WHEELER, J.; ZUREK, W. (Org.). Quantum Theory and Measurement. Princeton: Princeton University, 1984.

ZEH, H. D. On the interpretation of measurement in quantum theory. Foundations of Physics, v. 1, p. 69-76, 1970.

ZUREK, W. Decoherence and the transition from quantum to classical. Physics Today, v. 44, p. 36-44, 1991.

. Pointer basis of quantum apparatus: Into what mixture does the wave packet collapse? Physical Review D, v. 24, p. 1516-1525, 1981. 



\title{
O itinerário científico de Louis de Broglie em busca de uma interpretação causal para a mecânica ondulatória
}

\author{
Paulo Vicente Moreira dos Santos
}

\section{Introdução}

A tese de doutorado de Louis de Broglie, defendida em 1924, constitui um marco na história da Teoria Quântica. No entanto, ela costuma ser lembrada entre os físicos somente por atribuir a uma partícula material um comportamento ondulatório, com frequência $\boldsymbol{v}=\boldsymbol{E} / \boldsymbol{h}$ e comprimento de onda $\boldsymbol{\lambda}=\boldsymbol{h} / \boldsymbol{p}$. Para Bacciagalupi e Valentini (2006), o trabalho desenvolvido por de Broglie durante a década de 1920 tem sido subestimado, mal representado e largamente ignorado, não somente pelos físicos, mas também por historiadores.

Em relação à vida e obra de de Broglie, Pestre (1988) afirma que, do ponto de vista historiográfico, existe muito a ser feito e aponta três grandes estudos que podem ser realizados: a) refinar as características, origens e efeitos das bases culturais e intelectuais de Louis de Broglie entre 1910 e 1930, partindo de fontes originais, dando continuidade ao trabalho de Bruce Wheaton, em seu livro The tiger and the shark, Cambridge, 1983; b) investigar os trabalhos dos membros da escola formada por de Broglie entre 1930 e 1970, suas linhas de pesquisa, métodos, e buscar compreender as razões que levaram este trabalho à marginalização; c) considerar os modos institucional e intelectual, por meio dos quais outra espécie de Física teórica entrou na França, entre os anos 1940 e 1950. Pestre não aponta o trabalho desenvolvido por de Broglie após 1952 como constituindo uma possível área de interesse para a história da ciência.

Após consulta às bases de dados Web of Science e ISIS não encontramos obra de história da ciência que discutisse as novas ideias apresentadas por de 
Broglie após seu retorno à busca de uma interpretação causal para a mecânica ondulatória. As fontes históricas disponíveis são os artigos originais, notas autobiográficas, livros e a biografia publicada por Georges Lochak, a quem de Broglie confiou toda a sua obra.

Neste artigo faremos uma breve apresentação da trajetória de Louis de Broglie, desde sua formação inicial até as motivações que o levaram a abandonar o programa de pesquisa em busca de uma interpretação causal para a Mecânica Ondulatória. Em seguida, apresentaremos os principais aspectos da obra de de Broglie após 1951, quando ele retomou seu programa de pesquisa em torno da Teoria da Dupla Solução e propôs a não-linearidade da equação das ondas de matéria.

Finalizaremos, citando alguns trabalhos de outros autores que também pensaram no desenvolvimento de um formalismo não-linear para a Teoria Quântica, como uma alternativa aos formalismos desenvolvidos por Schrödinger, Heisenberg e Dirac, que são essencialmente lineares.

\section{O nascimento da mecânica ondulatória}

Louis Victor Pierre Raymond de Broglie, príncipe francês, nasceu em 15 de outubro de 1892. Aos 18 anos obteve o título de Licenciado em História, porém, logo depois, se interessou pela Física, particularmente pela Física Quântica e a Relatividade. Louis de Broglie teve seus primeiros contatos com os fenômenos envolvendo os quanta de luz no laboratório particular de espectroscopia e difração de raios-X do seu irmão, o físico Louis Cesar Victor Maurice de Broglie (1875-1960) (ROSA, 2004).

O interesse de Louis de Broglie pela Física aumentou após ler as atas do primeiro Congresso Solvay, realizado em 1911, editadas por Paul Langevin e com a colaboração do seu irmão Maurice. Em 1913, ele obteve o título de Licenciado em Ciências e, em outubro do mesmo ano, ingressou no serviço militar, servindo durante a I Guerra Mundial na companhia de telegrafia, onde se familiarizou com os conceitos envolvendo fenômenos ondulatórios. Após a guerra, retomou os estudos que tinham despertado seu interesse pela Física, dedicando-se ao trabalho experimental com raios-X, em colaboração com seu irmão (ROSA, 2004).

Os primeiros trabalhos de de Broglie, em relação aos quanta de luz, foram publicados em 1922, porém foi somente em 1923 que ele tentou fazer uma síntese entre as teorias ondulatória e corpuscular da luz. De Broglie propôs estender 
para as partículas materiais a dualidade onda-partícula que Einstein havia proposto para a luz, em 1905. Para de Broglie, as condições de quantização de Bohr-Sommerfeld para as órbitas eletrônicas somente poderiam ser entendidas em termos de ondas estacionárias e foi esta observação que o levou a postular a existência das ondas de matéria (DE BROGLIE, 1929).

Os trabalhos ${ }^{1}$ publicados em 1923 constituíram a base da sua tese de doutoramento, defendida em 1924, na Sorbonne, em Paris, com o título Recherches sur la théorie des quanta ${ }^{2}$, sob orientação de Paul Langevin. A importância deste trabalho foi logo reconhecida por Einstein, que, ao fazer referência em seu segundo trabalho sobre a Teoria Quântica do gás ideal ${ }^{3}$, chamou atenção dos outros pesquisadores para a ideia que iria revolucionar a Teoria Quântica (JAMMER, 1966).

Para Bacciagalupi e Valentini (2006), pouca atenção é dada ao tema central da tese de Broglie, que consistia em desenvolver uma nova dinâmica onde a velocidade da partícula seria determinada por ondas-guia. Esta concepção se baseia na unificação dos princípios variacionais de Maupertuis e o de Fermat, produzindo uma teoria capaz de sintetizar os dois conceitos aparentemente contraditórios, onda e partícula. Para MacKinnon (1976), o fato de que o princípio de Maupertuis pudesse ser escrito em um formato que descrevesse o movimento de ondas ou partículas não constituía nenhuma novidade, isto já havia sido proposto por Hamilton no século XIX. ${ }^{4}$

A hipótese de de Broglie, ao associar cada partícula com uma onda, influenciou o alemão Erwin Schrödinger a escrever a equação de propagação das ondas de matéria. Para Schrödinger, a forma como de Broglie foi capaz de explicar as condições de quantização de Bohr-Sommerfeld sugeria a ideia que a quantização pudesse ser tratada como um problema de autovalor, muito comum no estudo das ondas (JAMMER, 1966). O formalismo desenvolvido por Schrödinger fez muito sucesso entre os físicos quânticos, pois eles estavam acostumados a resolver equações de onda ao invés de diagonalizar matrizes infinitas, tal como aparecia no formalismo de Heisenberg (DARRIGOL, 2003).

Schrödinger, ao escrever a equação de propagação das ondas de matéria proposta por de Broglie, eliminou o conceito de trajetória da partícula ao descrever

1 Ondes et quanta. Comptes Rendus de l'Académie des Sciences de Paris, v. 177, p. 507-510, 1923. 2) Quanta de lumière, diffraction et interférences. Comptes Rendus de l'Académie des Sciences de Paris, v. 177, p. 548-550, 1923. 3) Les quanta, la théorie cinétique des gaz et le principe de Fermat. Comptes Rendus de l'Académie des Sciences de Paris, v. 177, p. 630-632, 1923.

2 Pesquisa sobre a teoria dos quanta (DE BROGLIE, 2004).

3 Einstein (1925).

4 Para uma análise crítica da tese de doutorado de Louis de Broglie, veja MacKinnon (1976). 
seu movimento utilizando ondas contínuas. O alemão Max Born, ao utilizar o formalismo de Schrödinger para investigar o espalhamento de partículas após sofrer uma colisão, deu origem à interpretação probabilística da função de onda. Como os resultados obtidos por Schrödinger e a interpretação de Born tinham boa concordância com os dados experimentais, de Broglie acreditava que esta interpretação era correta para um feixe de partículas e, por esta razão, deveria ser mantida, porém este formalismo não seria capaz de dar conta de fenômenos individuais. Para de Broglie, a mecânica ondulatória tinha uma natureza abstrata, por considerar a função de onda $\Psi$ propagando-se em um espaço de configuração de $3 \mathrm{~N}$ dimensões, que é um espaço abstrato. Para explicar os fenômenos ondulatórios que ocorrem com as partículas materiais, tais como interferência e difração, seria necessário considerar uma onda se propagando no espaço tridimensional (DE BROGLIE, 1960).

Em 1926, de Broglie publicou o artigo The wave mechanics and the atomic structure of matter and of radiation ${ }^{5}$, no qual apresentou, pela primeira vez, o que chamou de "princípio da dupla solução". Consistia em considerar que a equação de propagação das ondas de matéria deveria admitir duas soluções, uma sendo a onda $\Psi$, de caráter probabilístico, responsável por descrever o comportamento de um feixe de partículas, e a outra solução seria uma onda-u que, por conter uma singularidade, seria responsável por descrever cada partícula individualmente (DE BROGLIE, 1927).

Devido às dificuldades matemáticas em provar a existência das duas ondas e a relação existente entre elas, ao final do artigo de Broglie propôs uma versão simplificada, que chamou de "teoria da onda piloto", na qual assumiu a existência da partícula material e da onda contínua, representada por $\Psi$, como tendo realidades distintas, e postulou que o movimento da partícula é determinado como uma função da fase da onda $\Psi$ através da sua fórmula-guia, isto é, a onda contínua seria responsável por dirigir o movimento da partícula, seria uma onda piloto (DE BROGLIE, 1927).

O citado artigo de 1927 chamou atenção de Wolfgang Ernst Pauli, que, numa carta a Niels Bohr datada de 6 de agosto de 1927, disse: "[...] é muito rico em ideias e muito inteligente, e num nível muito mais elevado que o artigo infantil de Schrödinger"6 (PAULI, 1979 apud BACCIAGALUPI; VALENTINI, 2006, p. 73). Pauli sugeriu a Bohr que se referisse ao artigo de de Broglie na palestra que

5 A mecânica ondulatória e a estrutura atômica da matéria e da radiação.

6 "[...] it is very rich in ideas and very sharp, and on a much higher level than childish paper by Schrödinger." 
ele faria em Como, na Itália. ${ }^{7}$ No entanto, Bohr caracterizou o trabalho de de Broglie como uma tentativa de reconciliar os dois lados aparentemente contraditórios dos fenômenos quânticos, que ele já havia tinha, supostamente, resolvido com seu princípio da complementaridade. Além disso, Bohr considerava que a tentativa de resgatar a descrição determinística, ao propor que as partículas ou os quanta de luz seriam singularidades em uma onda estendida, estaria baseada em conceitos clássicos e não ajudava a resolver as dificuldades fundamentais. (VALENTINI, 2006)

Para Bacciagalupi e Valentini (2006), este artigo de de Broglie, que tem sido ignorado por físicos e historiadores, assume uma maior importância, do ponto de vista histórico, nos dias atuais do que no passado, pois dele nasceu a teoria da onda piloto, que foi aperfeiçoada pelo físico americano David Bohm (1917-1992), reiniciando a busca de uma interpretação causal para a Teoria Quântica.

De Broglie, ao ser convidado para apresentar seu trabalho no V Congresso Solvay, de 1927, optou por usar somente a teoria da onda piloto em sua comunicação intitulada: La nouvelle dynamique des quanta ${ }^{8}$. Esta comunicação não recebeu apoio da maioria dos presentes ao congresso, nem mesmo daqueles que ainda insistiam em encontrar uma interpretação causal para a mecânica ondulatória (Einstein, Langevin, Schrödinger e Lorentz). O grupo liderado por Bohr e Born defendia a interpretação puramente probabilista que eles haviam desenvolvido e se recusaram a discutir o ponto de vista adotado por de Broglie (1960). Uma notável exceção foi Pauli, que apresentou críticas à teoria apresentada por de Broglie, ao citar o exemplo do rotor de Fermi, que podia muito bem ser explicado pela interpretação puramente probabilista, mas que encontrava dificuldades na proposta causal de de Broglie. Nesta época, de Broglie não tinha claro entendimento de todos os aspectos da teoria da onda piloto, muitos dos quais só foram desenvolvidos por Bohm em 1952 (BACCIAGALUPI; VALENTINI, 2006).

Em 1928, ao ser indicado para professor da Faculté des Sciences de Paris, de Broglie resolveu abandonar a sua teoria, pois não podia ensinar um ponto de vista que não tinha condições de justificar. De Broglie afirmou que não foram as objeções de Pauli que o fizeram abandonar a teoria da onda piloto, pois ele já havia encontrado uma maneira de superá-las. As razões foram publicadas em seu primeiro livro, Introduction à l'étude de la mécanique ondulatoire, publicado em 1930 (DE BROGLIE, 1960). Dentre estas razões, duas são fundamentais9?: a)

7 Congresso Internacional de Física em homenagem ao centenário da morte de Alessandro Volta, realizado em setembro de 1927.

8 A nova dinâmica dos quanta.

9 Ver de Broglie (1960, p.183-185) e Bacciagalupi e Valentini (2006, p. 254). 
a partícula, concebida como uma realidade física, não pode ser guiada pela onda $\Psi$ - que possui um caráter subjetivo (uma mera representação de probabilidades) e é condicionada pelo conhecimento do observador; b) mesmo no caso de uma partícula simples, cujo movimento é guiado por uma onda $\Psi(\mathrm{x}, \mathrm{y}, \mathrm{z}, \mathrm{t})$, as coordenadas $(\mathrm{x}, \mathrm{y}, \mathrm{z})$ não representam pontos no espaço físico, e sim as possíveis posições da partícula nesse espaço. O movimento da partícula guiada pela onda $\Psi$ dependeria não somente da posição que a partícula tinha originalmente, como também de todas as posições que ela poderia ter ocupado, mas realmente não ocupa. Estes paradoxos convenceram de Broglie de que a teoria da onda piloto não constituía uma forma de retornar às concepções clássicas de causalidade. (DE BROGLIE, 1960)

Após 1930, Nye (1997) destaca que Michel Eberhardt sentia que Louis de Broglie "era um homem solitário, quase marginal, que se preocupava mais com fazer palestras do que fazer uma escola". O físico nuclear francês Anatole Abragam disse que seus discípulos, com poucas exceções, "não eram aqueles com alta capacidade intelectual e nem sempre de alta honestidade intelectual", eles assumiram uma postura de adulação reivindicando o termo "mecânica ondulatória" ao invés de "mecânica quântica". ${ }^{10}$

\section{O retorno à busca por uma interpretação causal}

Em 1951, Louis de Broglie recebeu o pre-print do artigo de David Bohm ${ }^{11}$ que viria a ser publicado no The Physical Review em janeiro de 1952. Em comunicação datada de 17 de setembro de 1951, sob o título Remarques sur la théorie de l'onde pilote $^{12}$, de Broglie relembrou as razões que o fizeram abandonar a tentativa de interpretação causal da mecânica ondulatória. Ele acreditava que o trabalho de Bohm encontraria dificuldades insuperáveis ao atribuir uma realidade física para a onda $\Psi$.

10 de Broglie comparou os autores que preferiam o termo "mecânica quântica" ao invés de "mecânica ondulatória" como "crianças pequenas que desconhecem seus pais", pois, para ele, esta última seria a responsável por todo o desenvolvimento matemático da moderna Teoria Quântica (DE BROGLIE, 1962, p.156).

11 Bohm admitiu, em seu primeiro artigo, que não conhecia a proposta de de Broglie ao elaborar a sua interpretação causal. Porém, após tomar conhecimento das críticas feitas por Pauli e as objeções feitas, posteriormente, pelo próprio de Broglie, ele escreveu seu segundo artigo com o objetivo de responder a estas objeções (BOHM, 1952). Para a disputa de prioridades entre Bohm e de Broglie ver Freire (2005).

12 Notas sobre a teoria da onda piloto (DE BROGLIE, 1951). 
Este retorno imediato de de Broglie às suas ideias da juventude, tão logo recebeu o pre-print de Bohm, parece indicar que ele nunca aceitou completamente a interpretação puramente probabilista, tendo convivido com ela somente enquanto não encontrou uma outra alternativa de interpretação para a mecânica ondulatória. Uma análise apressada poderia atribuir esta reviravolta no pensamento de de Broglie unicamente ao trabalho de Bohm. Porém, conforme pode ser verificado em suas notas, de Broglie não concordava com Bohm em um aspecto essencial: a atribuição de uma realidade física para a onda $\Psi$, tal como é assumida na teoria da onda piloto.

O pensamento de de Broglie já estava se preparando para esta mudança nos anos que antecederam o artigo de Bohm. Isto pode ser comprovado através da análise do livro publicado em 1982, mas cujos manuscritos datam de 19501952, intitulado Les incertitudes d'Heisenberg et l'interpretation probabiliste de la mécaniqueondulatoire ${ }^{13}$. De Broglie havia confiado sua obra a Georges Lochak; dentre o material entregue havia um manuscrito com a tarja $A$ ne pas publier ${ }^{14}$. Este manuscrito chamou a atenção de Lochak que, após analisá-lo, persuadiu de Broglie a torná-lo público, alegando que este material não pertencia a ele, mas à história da ciência. Segundo Lochak (1982), estes manuscritos seriam uma ótima oportunidade para o público em geral ver como a ciência funciona realmente. Depois de alguns meses, de Broglie autorizou a publicação, desde que fosse acompanhada de uma introdução para situar o livro dentro de sua obra geral, bem como a adição de notas suplementares ao longo do texto.

Segundo Lochak (1982), estes manuscritos foram elaborados por de Broglie com o objetivo de convencer a si mesmo sobre a interpretação usual da mecânica ondulatória e, na forma de notas, ele expressava as suas críticas. O livro publicado em 1982 divide o manuscrito em duas partes: a primeira teria sido escrita entre 1950-1951, sob o título Sur les incertitudes d'Heisenberg et l'interprétation probabiliste de la mécanique ondulatoire; e a segunda, teria sido escrita entre 1951-1952, sob o título Sur l'interprétation probabiliste de la mécanique ondulatoire et sur diverses questions qui s'y rattachent.

Esta súbita reviravolta no pensamento de de Broglie não foi bem aceita no Instituto Henri Poincaré, onde ele trabalhava como professor. Segundo Lochak (1982), as pessoas sussurravam pelos corredores do Instituto e agiam como se de Broglie tivesse contraído uma espécie de doença e do qual seria mais sábio manter distância.

13 As incertezas de Heisenberg e a interpretação probabilística da Mecânica Ondulatória (DE BROGLIE, 1982).

14 Não publicar. 


\section{Uma tentativa de interpretação causal e não-linear}

Numa nota intitulada Sur la possibilité d'une interprétation causale et objective de la mécanique ondulatoire ${ }^{15}$, datada de 14 de janeiro de 1952, de Broglie reconheceu que a interpretação causal de Bohm tinha diversos pontos que mereciam atenção, principalmente no que se refere à análise dos procedimentos das medições que podem ser realizadas no nível quântico, e buscou uma alternativa para conciliar o seu ponto de vista com o de Bohm.

Na citada nota, de Broglie sugeriu pela primeira vez que a onda-u, responsável pela descrição objetiva da partícula material, deveria obedecer a uma equação de propagação não-linear, sendo esta a direção que sua pesquisa seguiu ao longo de toda a década de 1950. À medida que novas ideias foram surgindo, ele as registrava na forma de notas no periódico Comptes Rendus. As notas publicadas entre 1951 e 1954 constituíram a base do livro publicado em 1956, sob o título Une tentative d'interprétation causale et non linéaire de la mécanique ondulatoire - la théorie de la double solution. ${ }^{16}$

Este livro é dividido em duas partes. Na primeira, de Broglie apresenta o desenvolvimento da Mecânica Ondulatória, partindo das suas ideias iniciais, passando pela contribuição de Schrödinger e o estabelecimento da interpretação puramente probabilista que foi desenvolvida sob a liderança de Bohr e colaboradores, em Copenhague. Após apresentar as objeções a esta interpretação feita por alguns cientistas, a exemplo de Einstein, Schrödinger e ele próprio, ele chama a atenção para a única tentativa feita para evitar a interpretação puramente probabilista e desenvolver uma teoria causal e determinista, isto é, a tentativa que ele fez em 1927, a teoria da dupla solução.

Na segunda parte, de Broglie reapresenta a teoria da dupla solução, refinada em certos pontos, rediscute as objeções levantadas por Pauli em relação à teoria da onda piloto e assume que a teoria da dupla solução não parece apresentar as mesmas dificuldades. No entanto, ele introduz uma hipótese que considera fundamental: a de que a onda-u, responsável pela descrição objetiva da partícula, deveria obedecer a uma equação de propagação não-linear. Esta hipótese é levantada após J. P. Vigier chamar a atenção para o fato de que a dedução da fórmula-guia era semelhante à demonstração de Einstein e Georges Darmois para o movimento de uma partícula na Relatividade Geral, que obedecem a equações não lineares. E então, por analogia, deveria ocorrer o mesmo para as ondas de matéria.

15 Sobre a possibilidade de uma interpretação causal e objetiva da Mecânica Ondulatória (DE BROGLIE, 1952).

16 Uma tentativa de interpretação causal e não linear da mecânica ondulatória - A teoria da dupla solução (1956). Traduzido para o inglês sob o título Non-linear wave mechanics - a causal interpretation (1960). Neste artigo utilizamos a versão em inglês. 
De Broglie propôs que a equação de propagação não-linear a ser obedecida pela onda-u, na ausência de qualquer campo e numa aproximação não relativística, teria a seguinte forma:

$$
-\frac{\hbar}{i} \frac{\partial u}{\partial t}=-\frac{\hbar^{2}}{2 m} \nabla \mathrm{u}+\mathrm{N}(\mathrm{u}, \ldots)
$$

Ou seja, seria a equação de Schrödinger generalizada. Ele acreditava que a introdução de convenientes termos não-lineares $\mathrm{N}$ permitiria a existência de soluções sem espalhamento. De modo que a não-linearidade da equação de onda admitiria a concepção de grupos de ondas sem espalhamento, em oposição ao espalhamento natural dos trens de onda que ocorrem na teoria linear. Os termos não lineares para a equação da onda-u seriam desprezíveis na parte externa da região do trem de onda e somente se tornariam importantes na região de fronteira. De Broglie não conseguiu levar adiante a sua hipótese por desconhecer os termos não-lineares que deveriam ser introduzidos na equação de propagação das ondas de matéria.

A dificuldade encontrada por de Broglie em dar prosseguimento a sua hipótese de não-linearidade das equações de propagação das ondas de matéria é facilmente compreendida, pois, conforme ele mesmo reconhece, até aquela época ainda não havia métodos confiáveis para resolver equações diferenciais não lineares. Porém, ele mesmo já tinha sinalizado que a hipótese dos grupos de ondas não deformadas poderia ser comparada com a teoria das "ondas solitárias" da Hidrodinâmica ${ }^{17}$.

Vale ressaltar que a hipótese da mecânica quântica vir a ser substituída por uma teoria que fosse fundamentalmente não-linear não foi descartada nem mesmo por Heisenberg, um dos maiores defensores da interpretação ortodoxa. Em 1967, ele declarou que

[...] a não linearidade é tão fundamental na natureza que seria possível que mesmo uma teoria tão fundamentalmente linear como a Teoria Quântica viesse a ser substituída por outra que fosse não linear. (HEISENBERG, 1967)

Tanto para de Broglie, quanto para Heisenberg, o sucesso em obter uma Teoria Quântica não-linear estaria completamente ligado ao desenvolvimento de métodos matemáticos para a resolução das equações dos sistemas dinâmicos não lineares.

17 "The theory of these non-deformed wave groups may be compared to the theory of "solitary waves" in Hydrodynamics, which exhibits certain similarities to it." (DE BROGLIE, 1960, p. 251). 
De Broglie, ao concluir o citado livro Non-linear wave mechanics, admitiu não ter completo desenvolvimento para suas sugestões em virtude das dificuldades matemáticas colocadas desde o princípio. Ele esperava que jovens talentosos com boa percepção física e habilidade matemática se interessassem por suas sugestões para construir a verdadeira microfísica do futuro.

Rosenfeld (1958) criticou o livro publicado por de Broglie em 1956, afirmando que um argumento fraco não se torna forte por repetição. Para Rosenfeld, o livro não traz nenhuma evidência que justifique reconsiderar a impossibilidade de descrever os processos quânticos em termos clássicos e conclui:

[...] a teoria da dupla solução sofre de uma falta de originalidade na determinação dos termos não lineares da equação de onda, que a coloca em pé de igualdade com o modelo do éter do século passado. (ROSENFELD, 1958)

\section{A termodinâmica da partícula isolada}

De Broglie, ao tentar encontrar uma síntese entre os comportamentos ondulatório e corpuscular, comparou a expressão do quantum de energia com a expressão da energia de repouso, na Teoria da Relatividade, para obter a frequência da onda de matéria $\left(v=m_{\mathrm{o}} c^{2} / h\right)$. Ao assumir uma equivalência entre os princípios de Fermat e Maupertuis, de Broglie propôs que o movimento da partícula seria descrito através da fase da onda equivalente.

Na década de 1960, de Broglie desenvolveu uma nova ideia, que denominou de termodinâmica da partícula isolada, na qual pretendia fazer uma comparação entre três princípios fundamentais da Física: os de Fermat, Maupertuis e Carnot. Ele comparou a expressão do quantum de energia $(E=h v)$ com a expressão da energia na termodinâmica $(E=k T)$ para encontrar a relação entre a frequência do movimento ondulatório e a temperatura da partícula. Esta ideia foi baseada na sugestão de Bohm e Vigier sobre a existência de um meio subquântico responsável por imprimir, nas partículas, um movimento aleatório capaz de justificar as leis de probabilidade. Para de Broglie, este meio subquântico se comportaria como uma reunião de termostatos escondidos, cuja interação com a partícula seria capaz de produzir uma espécie de movimento browniano.

De Broglie apresentou estas ideias numa nota publicada em 1961, intitulada Sur la thermodynamique du corpuscule isolép ${ }^{18}$, cujo objetivo principal era encontrar uma relação entre o princípio da mínima ação da mecânica com o segundo

18 Sobre a termodinâmica da partícula isolada. (DE BROGLIE, 1961) 
princípio da termodinâmica. Ele escreveu que estes dois princípios estão relacionados através da seguinte expressão,

$$
\frac{S}{k}=\frac{A}{h}
$$

em que $S$ é a entropia, $A$ a grandeza ação e $k$ a constante de Boltzmann. Em outro artigo, de Broglie interpretou estes resultados, identificando o princípio da mínima ação como um caso particular da segunda lei da termodinâmica em que os estados estacionários dos sistemas quantizados correspondem aos estados de máxima entropia (DE BROGLIE, 1967).

De Broglie considerava que seu trabalho constituía apenas sugestões para o desenvolvimento de uma nova interpretação para a mecânica ondulatória. Devido à idade avançada, ele não tinha esperança de ver até onde estas ideias poderiam levar. Ele admitiu contar com a ajuda de poucos pesquisadores que se interessaram por suas sugestões e esperava que eles pudessem dar continuidade ao seu trabalho.

\section{Considerações finais}

Conforme vimos, o trabalho desenvolvido por de Broglie, após seu retorno à busca por uma interpretação causal, constituiu em sugerir duas linhas de pesquisa; a) a não linearidade das equações das ondas de matéria; e b) a termodinâmica da partícula isolada. A investigação sobre como estes trabalhos influenciaram outros pesquisadores, e até onde eles foram desenvolvidos, pode constituir um importante tema de pesquisa na história dos fundamentos da Teoria Quântica. Até o presente, supomos que estas sugestões podem ter sido seguidas por estudantes de doutorado da Faculdade de Ciências de Paris que estavam sob a orientação de de Broglie. (SILVA; PEREIRA, 1970)

Em 1979, Shimony publicou um artigo no qual propôs um aparato experimental, com o objetivo de testar se a mecânica ondulatória linear seria válida ou deveria ser substituída pela sugestão dada por de Broglie, de que em dimensões inferiores a $10^{-12} \mathrm{~cm}$ seria necessária a utilização de uma teoria não-linear (SHIMONY, 1979). O aparato experimental consiste em um interferômetro de nêutrons. Este teste foi realizado por R. Gähler, A. G. Klein e A. Zeilinger, em 1981, que chegaram à conclusão de que os termos não-lineares não apareciam no limite estabelecido por Shimony e outros autores. Porém, eles afirmaram que os resultados não eram definitivos e que novos testes deveriam ser realizados. (GÄHLER; KLEIN; ZEILINGER, 1981) 
Segundo Pierre Lochak (1984), os desenvolvimentos matemáticos obtidos nas duas décadas anteriores, na resolução de certas classes de equações diferenciais não-lineares, permitiram reviver a ideia de uma "física quântica não linear", cuja origem está nas ideias de de Broglie. Estes desenvolvimentos permitiram a aplicação da mecânica quântica em sistemas físicos não-lineares, a exemplo de supercondutores, superfluidos (hélio líquido), ferromagnetismo e outros (RIBEIRO FILHO; VASCONCELOS, 2006). No entanto, os chineses Pang e Feng (2005) advogam que a não-linearidade vai além dos problemas de aplicação e podem ter grande influência sobre as controvérsias que ainda permanecem em torno dos fundamentos da Teoria Quântica. Se o formalismo usual da mecânica quântica será substituído por um formalismo que seja essencialmente não linear, isto ainda é uma questão em aberto na Física.

Ainda que estas ideias não tenham progresso na Física, resgatar o extenso trabalho de Louis de Broglie durante o período que ele chamou de "o mais belo de sua vida"19 constitui uma tarefa para os historiadores da ciência e para aqueles interessados em psicologia dos cientistas. Conforme o próprio de Broglie (1962) registrou, "[...] a história da ciência pode ensinar muitos fatos importantes sobre a natureza da inteligência humana".

\section{Referências}

BACCIAGALUPI, G.; VALENTINI, A. Quantum theory at the crossroads: reconsidering the 1927 Solvay Conference. Cambridge: Cambridge University, 2006.

BOHM, D. A suggested of the quantum theory in terms of "hidden" variables. Physical Review, v. 85, n. 2, p. 166-193, 1952. Artigos 1 e 2.

DARRIGOL, O. Quantum theory and atomic structure, 1900-1927. In: NYE, Mary Jo. The modern physical e mathematical sciences. Cambridge: Cambridge University, 2003. p. 331-349. (The Cambridge History of Science, v. 5).

DE BROGLIE, L. Les incertitudes d'heisenberg et l'interpretation probabiliste de la mécanique ondulatoire. Paris: Gauthier-Villars, 1982.

19 "Je me suis souvent demandé, dans ces dernières années, si la période qui a suivi mes 70 ans n’a pas été, du point de vue intellectuel, la plus belle de ma vie”. (DE BROGLIE, 1982, p. xv) 
. On the theory of quanta. Traduzido por A. F. Kracklauer. Paris: AFK, 2004. Título original: Recherches sur la theorie des quanta, 1925, Ann. de Phys., $10^{a}$ série, t. III. Disponível em: <http://www.ensmp.fr/aflb/LDB-oeuvres/De_ Broglie_Kracklauer.pdf $>$. Acesso em: 2 jul. 2009

. The new dynamics of quanta. In: BACCIAGALUPI, G.; VALENTINI, A. Quantum theory at the crossroads: reconsidering the 1927 Solvay Conference. Cambridge: Cambridge University, 2006. p. 374-407.

. A new interpretation concerning the coexistence of waves and particles. In: YOURGRAU, W.; MERWE, A. van. der (Ed.). Perspectives in Quantum Theory. New York: Dover, 1967.

. New perspectives in physics. Traduzido por A. J. Pomerans e Oliver \& Boyd. New York: Basic Books, 1963.

. Non-linear wave mechanics: a causal interpretation. Trad. por Arthur J. Knodel e Jack C. Miller. Amsterdam: Elsevier, 1960. Original: Une tentative d'interprétation causale et non linéaire de la mécanique ondulatoire (la théorie de la double solution). 1956.

. Une nouvelle démonstration de la formule du guidage dans la théorie de la double solution, C. R. Acad. Sci., n. 239, p. 737-739, 1954.

. Remarques sur la théorie de l'onde pilote. C. R. Acad. Sci, n. 233, p. 641-644, 1951.

Sur l'interprétation causale et non linéaire de la mécanique ondulatoire. C. R. Acad. Sci., n. 237, p. 441-444, 1953.

Sur la possibilité d'une interprétation causale et objective de la mécanique ondulatoire. C. R. Acad. Sci., n. 234, p. 265-268, 1952.

. Sur la thermodynamique du corpuscule isolé. C. R. Acad. Sci., n. 253, p. 1078-1081, 1961.

. The value of the History of Science. In: OLIVER; BOYD. New Perspectives in Physics. 1962. p. 227-230.

. The wave mechanics and the atomic structure of matter and of radiation. In: DE BROGLIE, L.; BRILLOUIN L. Selected papers on wave mechanics. 
London: Blackie \& Son, 1928. p.113-138. Publicado originalmente no Le Journal de Physique et le Radium, n. 8, p. 255, 1927.

The wave nature of the electron. Nobel Lecture, $12 \mathrm{dec} .1929$.

Disponível em: <http://nobelprize.org/nobel_prizes/physics/laureates/1929/ broglie-lecture.pdf >. Acesso em: 12 jul. 2009.

EINSTEIN, A. Teoria quântica do gás ideal monoatômico - segundo tratado. $R B E F$, v. 27, n. 1, p.113-120, 2005. Traduzido de Quantentheorie des einatomigen idealen gases: Zweite Abhandlung, publicado nos Sitzungsberichte der Preussischen Akademie der Wissenschaften I, 3-14, 1925.

FREIRE JR., O. Science and exile: David Bohm, the cold war, and a new interpretation of quantum mechanics. Historical Studies in the Physical and Biological Sciences, v. 36, n. 1, p. 1-34, 2005.

GÄHLER, A.; KLEIN, A. G.; ZEILINGER, A. Neutron optical tests of nonlinear quantum mechanics. Physical Review A, v. 23, n. 4, p. 1611-1617, 1981.

HEISENBERG, W. Nonlinear problems in physics. Physics Today, v. 20, n. 5, p. 27-32, 1967.

JAMMER, M. The conceptual development of quantum mechanics. New York: McGraw-Hill, 1966.

LOCHAK, G. The evolution of ideas of Louis de Broglie on the interpretation of wave mechanics. Foundations of Physics, v. 12, n. 10, 1982.

Louis de Broglie: un prince de la science. Paris: Flammarion, 1992.

LOCHAK, Pierre. Could solitons be adiabatics invariants attached to certain non linear equations. In: DE BROGLIE, Louis; DINER, Simon (Ed.). The waveparticle dualism: a tribute to Louis de Broglie on his 90th birthday. Reidel, 1984. p. $173-214$.

MACKINNON, E. De Broglie's thesis: a critical retrospective. American Journal of Physics, v. 44, n.11, 1976.

NYE, M. J. Aristocratic culture and the pursuit of science: the de Broglies in modern France. ISIS, v. 88, n. 3, p. 397-491, 1997. 
PANG, X. F.; FENG, Y. P. Quantum mechanics in nonlinear systems. Singapore: World Scientific, 2005.

PESTRE, D. Louis de Broglie: un itineraire scientifique by Louis de Broglie, Georges Lochak. ISIS, v. 79, n. 4, p. 740-741, 1988.

RIBEIRO FILHO, A.; VASCONCELOS, D. S. Aspectos matemáticos em sistemas não lineares na mecânica quântica e mecânica clássica moderna. Cadernos de Ciências Humanas, v. 9, n. 16, p. 397-410, 2006.

ROSA, P. S. Louis de Broglie e as ondas de matéria. 80 p. 2004. Dissertação (Mestrado em Física) - Instituto de Física, Universidade Estadual de Campinas, Campinas. Disponível em: <http://ghtc.ifi.unicamp.br/Teses/Pedro-Sergio-Rosa. pdf $>$. Acesso em: 24 nov. 2008.

ROSENFELD, L. Une tentative d'interprétation causale et non linéaire de la mécanique ondulatoire (la théorie de la double solution) by Louis de Broglie. The British Journal for the Philosophy of Science, v. 9, n. 34, p. 167-168, 1958.

SHIMONY, A. Proposed neutron interferometer test of some nonlinear variants of wave mechanics. Physical Review A, v. 20, n. 2, p. 394-396, 1979.

SILVA, J. Andrade e; PEREIRA, J. Vassalo. On another formulation of the de Broglie's hidden thermodynamics. International Journal of Theoretical Physics, v. 3, n. 1, p. 67-76, 1970. 



\title{
Sobre a cultura material dos primeiros testes experimentais do teorema de Bell: uma análise das técnicas e dos instrumentos (1972-1976)
}

\author{
Wilson Fábio de Oliveira Bispo \\ Denis Gilbert Francis David
}

\section{Introdução}

Albert Einstein, Boris Podolsky e Nathan Rosen publicaram um artigo, em 1935, que balançou os alicerces da mecânica quântica (MQ). Através de um experimento de pensamento (Gedankenexperiment), esse artigo, hoje conhecido como EPR, supostamente mostrava que a MQ era uma teoria incompleta. $\mathrm{O}$ argumento apresentado no EPR tinha como alicerce a seguinte premissa: considere duas partículas que interagiram e estão correlacionadas em suas posições e momentos lineares; se essas duas partículas forem afastadas por certa distância e efetuarmos a medida da posição ou momento em uma dessas partículas, isso não deve modificar o "elemento de realidade" associado à outra partícula (e muito menos o resultado de uma medição na outra). Esta premissa, também conhecida como "localidade" ou "separabilidade", faz parte do que seriam denominadas teorias de variáveis ocultas locais (TVOL).

David Bohm, quando publicou seu livro Quantum theory, em 1951, propôs uma mudança no experimento de pensamento apresentado no artigo EPR, a qual consistia, em suma, em utilizar variáveis bivalentes como, por exemplo, componentes de spin de duas partículas correlacionadas, ao invés de posição e momento. Essa mudança trouxe maior simplicidade matemática à descrição teórica do experimento, além de ter sido utilizada por John Bell no desenvolvimento de um teorema hoje denominado Teorema de Bell. 
O teorema de Bell - considerado por John F. Clauser (2002, p. 61) e por Alain Aspect (1999) um dos resultados mais profundos da Física do século XX - é uma desigualdade matemática que mostra uma incompatibilidade entre a MQ e quaisquer TVOL. Seu surgimento ocorreu em 1964, quando Bell derivou uma de suas desigualdades, satisfeita por quaisquer TVOL, mas violada pela mecânica quântica. ${ }^{1}$ De um lado estava a $\mathrm{MQ}$, com certa ideia de "não localidade"; de outro, as TVOL, com a separabilidade (ou localidade). Uma possível solução para resolver esse impasse apareceu com o artigo publicado por Clauser, Horne, Shimony e Holt em 1969, onde, a partir da generalização das desigualdades de Bell e de algumas modificações no experimento de Kocher e Commins (1967), eles propuseram um experimento realizável que poderia testar as desigualdades de Bell, surgindo ulteriormente os primeiros experimentos que as testaram.

Analisamos aqui a cultura material dos primeiros experimentos, com fótons polarizados, que testaram as desigualdades de Bell, i.e., os experimentos realizados por Freedman e Clauser (1972), Clauser (1976) e Fry e Thompson (1976). Eles confirmaram as previsões da mecânica quântica, violando as desigualdades de Bell e foram muito influentes no desenvolvimento da pesquisa sobre fundamentos da física quântica. Nesta análise, procuramos entender como eram os aparatos, como funcionavam e quais seus papeis nos experimentos, além de explicar as técnicas de excitação, detecção e contagem utilizadas, bem como seus desenvolvimentos de um experimento para outro. Fazemos ainda uma análise histórica dos instrumentos cruciais para a realização desses experimentos, com o intuito de verificar se eles já poderiam ter sido realizados anteriormente e com isso tentar entender como a Ciência se desenvolveu naquele período e contexto.

A análise histórica dos instrumentos está baseada na abordagem historiográfica focada na história dos instrumentos. (PESTRE, 1996) Atualmente, a história dos instrumentos está bem estabelecida na história das ciências, seja pela Scientific Instruments Commission (organização filiada à International Union of the History and Philosophy of Science, que busca encorajar estudantes na pesquisa em história de instrumentos, preservação, documentação e coleção de instrumentos, bem como seu uso na história da ciência) ou pelos trabalhos de Peter Galison, mais precisamente aqueles relacionados à ideia de cultura material (GALISON, 1997, 1999). Cultura material é tudo aquilo que o homem cria (ou concebe) e que utiliza na sua vida quotidiana, de modo a extrair do meio envolvente tudo de que necessita. (NOGUEIRA, 2000, p. 192) Em outras palavras, o conjunto de objetos - tecidos, utensílios, ferramentas, adornos, meios de transporte, moradias, armas - que formam o ambiente concreto de determinada sociedade.

1 Sobre as desigualdades de Bell ver Pessoa Jr (2006, cap. 27). Para um maior aprofundamento ver Pessoa Jr. (2006, cap. 28); Bell (1964) ou Freire Jr. (1991). 


\section{Componentes da cultura material dos experimentos}

Este estudo está baseado numa análise dos instrumentos que compõem os experimentos. O principal objetivo desses experimentos foi testar o teorema de Bell, ou seja, verificar se os resultados experimentais encontrados estavam de acordo com as previsões teóricas da MQ ou das TVOL. Nessa verificação, media-se o coeficiente de correlação de polarização linear (grandeza que indica se um fóton está correlacionado em polarização com o outro) de dois fótons emitidos de uma cascata de cálcio ou mercúrio. Discutiremos agora mais detalhadamente os instrumentos referentes a cada experimento, nos tópicos que seguem.

\section{1 Experimento realizado por Freedman e Clauser}

Indica-se abaixo o esquema experimental apresentado por Freedman e Clauser, no artigo que descreve este experimento:

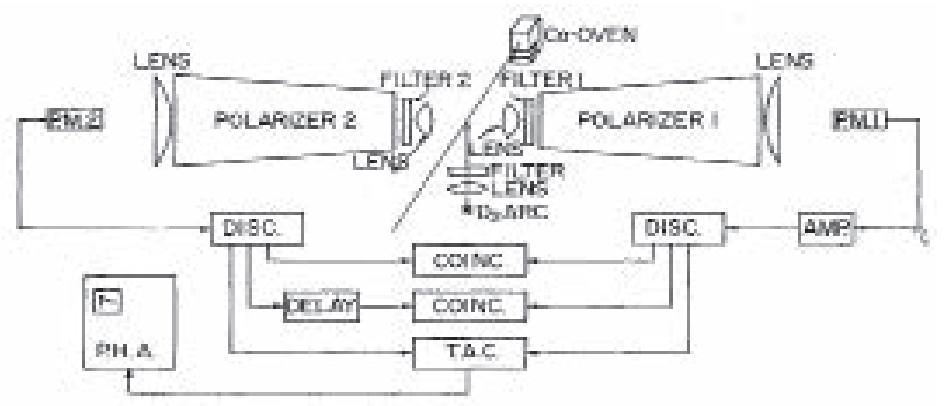

Figura 1: Esquema do experimento

Fonte: Freedman e Clauser (1972)

O forno de tântalo emitia um feixe de cálcio na forma de vapor, o qual era excitado, através do fenômeno da absorção por ressonância, pela luz de uma lâmpada de arco de deutério (também chamada lâmpada de descarga). Após a excitação, no decaimento que segue, pares de fótons eram emitidos e selecionados por filtros de interferência (ou interferômetros de Fabry-Pérot). Com a necessidade de concentrar esses fótons no menor volume possível, aproveitando-os ao máximo e aumentando assim a acumulação de dados, foram usadas lentes primárias (ou seja, as primeiras a receber a luz vinda da fonte) anaesféricas (afastam-se do formato esférico, com o intuito de reduzir as aberrações esféricas; devido a esse efeito, onde se deveria ver um ponto, vê-se uma mancha).

2 DISC (Discriminadores), T.A.C. (Conversor Tempo Amplitude), P.H.A. (Analisador de Altura de Pulso), P.M. (Fotomultiplicadores). 
Houve também a necessidade de selecionar as polarizações (paralela ou perpendicular ao plano dos polarizadores) dos fótons correlacionados e, para tanto, foram usados polarizadores do tipo pilha de placas (pile-of-plates). Estes eram dez lâminas de vidro inclinadas, próximas ao ângulo de Brewster. Em cada lâmina ocorriam duas reflexões, uma em cada face, onde parte da luz que tinha certa polarização era refletida e a outra, com outra polarização, era transmitida. Um mecanismo com dois eixos paralelos interligados por uma cruz de Malta e por dois discos, chamado Mecanismo Geneva, girava os polarizadores num incremento de $27,5^{\circ}$, para evidenciar melhor uma violação das desigualdades de Bell, já que os ângulos de maior violação eram os de $27,5^{\circ}$ e $67,5^{\circ}$.

A detecção era realizada através do tubo fotomultiplicador (fototubo) que, ao absorver a luz incidente, emitia elétrons (devido ao efeito fotelétrico) e os multiplicava por emissão secundária. O primeiro fototubo foi criado em 1930 por Koller e Campbell ${ }^{3}$, contudo, os fototubos utilizados pelos autores - chamados "quanticons" (fototubos que faziam contagem de fotons únicos) - foram mais sofisticados. Estes fototubos só foram aperfeiçoados no início da década de 1970, conforme afirmou o próprio Freedman, quando "[...] fazer boas contagens de fotons únicos tinha acabado de ser desenvolvido". (GILDER, 2008, p. 266)

A contagem dos fótons era feita por meio do circuito de coincidência, um aparato eletrônico cuja finalidade consistia em verificar se o par detectado, de fato, era o par correlacionado, sendo esta verificação feita através da janela de coincidência (tempo em que os dois detectores permanecem abertos simultaneamente) que, neste experimento, era de 8,1ns. Os precursores da contagem de coincidência, ainda sem o uso da eletrônica, foram Bothe e Geiger, em 1924 ${ }^{4}$, no entanto, o circuito de coincidência foi desenvolvido por Bruno Rossi, em 1930, trabalhando com física de raios cósmicos em Arcetri, Universidade de Florença. ${ }^{5}$ Apesar de ter sido desenvolvido em 1930, o circuito de coincidência só poderia ser utilizado nos experimentos com a mesma precisão alcançada na década de 1950, devido ao desenvolvimento do transistor, que proporcionou um tempo de resposta para o circuito da ordem do nano segundo.

\subsection{Experimento realizado por Clauser}

Os filtros de interferência, polarizadores, fototubos e circuito de coincidência já foram explicados anteriormente. Nesse experimento, havia um terceiro fototubo, ligado a um laço de realimentação (servo loop), usado para estabilizar a

3 Ver PHOTOMULTIPLIER tubes... (1999).

4 Para maiores detalhes, ver Bothe (1955).

5 Physics Today, 34-10, Oct. 1981, p. 35-36. 
corrente do feixe de elétrons excitador, de modo que, se a emissão de fótons fosse baixa, o sinal do fototubo aumentava a corrente, o que fazia com que aumentasse a emissão de fótons; caso contrário, o sinal do fototubo diminuía a corrente, diminuindo assim a emissão de fótons.

Para evitar a influência do campo magnético terrestre sobre os níveis excitados, os autores utilizaram bobinas na posição de Helmholtz, criando um campo magnético oposto, de maneira a anular ou manter esse campo com intensidade menor que 50mG. Estas são duas bobinas circulares, planas, contendo $\mathrm{N}$ espiras percorridas por correntes no mesmo sentido, que produzem um campo magnético uniforme sobre um volume relativamente grande, cobrindo a zona de excitação.

\subsection{Experimento realizado por Fry e Thompson}

Forno, lentes, filtros, polarizadores e fototubos já foram explicados anteriormente. Um canhão solenoidal de elétrons bombardeava o mercúrio com o intuito de excitá-lo, realizando assim o primeiro passo da excitação. O segundo passo era feito por absorção de ressonância de um laser de corante sintonizável. Este emitia um feixe mono-modo (de modo único, isto é, possuindo uma linha única de emissão espectral), com comprimento de onda de 5461 ̊́ na faixa do visível. Os primeiros lasers foram colocados em operação em 1960 (BROMBERG, 2006, p. 240), porém o laser sintonizável só foi desenvolvido em 1965, por Peter Sorokin e John Lankard. De fato, eles desenvolveram o material principal para que este laser fosse constituído, embora o mesmo tenha sido terminado alguns anos depois. (FREIRE JR., 2006, p. 601)

\section{Sobre as técnicas utilizadas nos experimentos}

Podemos dividir os experimentos aqui analisados em três técnicas: de excitação, de detecção e de contagem. A primeira é caracterizada pela excitação dos átomos e emissão dos fótons correlacionados; a segunda técnica é caracterizada pela seleção, detecção e transformação dos fótons em pulsos elétricos; e, por fim, a terceira foi a da contagem de coincidência (ou técnica de coincidência), caracterizada pela contagem dos pares correlacionados. Comentaremos agora sobre as particularidades de cada uma dessas técnicas nos seus respectivos experimentos, bem como a diferença e desenvolvimento de cada uma delas de um experimento para outro, caso haja. 


\subsection{Experimento realizado por Freedman e Clauser (1972)}

Na técnica de excitação, um feixe de cálcio, oriundo de um forno de tântalo, era excitado através do processo de absorção de ressonância, onde uma lâmpada de arco de deutério emitia um feixe contínuo de luz ultravioleta, com comprimento de onda de $227,5 \mathrm{~nm}$. Antes de excitar o átomo de cálcio, a luz da lâmpada de deutério passava por lentes e filtros, para colimar e selecionar o feixe. A região de interação - local onde o cálcio interagia com a luz para realizar a excitação consistia de um cilindro de vidro pirex de $5 \mathrm{~mm}$ de altura e $3 \mathrm{~mm}$ de diâmetro, onde a densidade de cálcio era $10^{10}$ átomos $/ \mathrm{cm}^{3}$. Os átomos de cálcio passavam do nível fundamental $4 s^{21} S_{0}$ (nesta notação, a primeira parte, $4 s^{2}$, representa o estado eletrônico; e a segunda parte, ${ }^{1} S_{0}$, foca o estado de spin) para o nível excitado $3 d 4 p^{1} P_{1}$. Dos átomos que não decaíam diretamente para o estado fundamental, apenas $7 \%$ decaía para o estado $4 p^{21} S_{0}$, a partir do qual ocorria mais dois decaimentos, passando pelo estado intermediário $4 p 4 s^{1} P_{1}$, dando origem ao par de fótons correlacionados em polarização, emitidos de uma cascata $\mathrm{J}=0, \mathrm{~J}=1, \mathrm{~J}=0$ (onde J é o momento angular total). Assim, a quantidade de dados coletados foi relativamente baixa, comparada ao total de fótons emitidos. Como estes eram experimentos estatísticos, a quantidade de dados era fator fundamental. A duração do experimento foi de $200 \mathrm{~h}$. Abaixo o esquema do decaimento em cascata apresentado pelos autores:

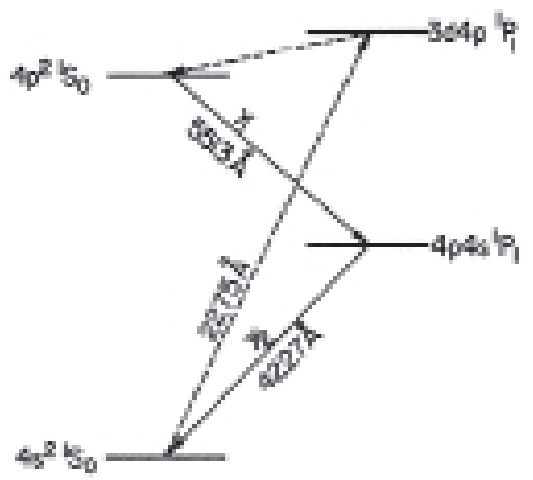

Figura 2 - Decaimento em cascata

Fonte: Freedman e Clauser (1972).

A técnica de deteç̧ão não se caracteriza apenas pela detecção em si, mas também pelas condições ideais para que ela ocorresse. Essas condições estão relacionadas à seleção dos fótons, com o devido comprimento de onda e a devida polarização, e à manutenção do ambiente com baixa luminosidade e baixa intensidade do campo magnético. Como as emissões ocorriam em diversas direções, 
foram usadas lentes colimadoras com grande ângulo de aceitação, aumentando a eficiência do experimento e reduzindo a possibilidade de um dos detectores contar um fóton pertencente ao par e o outro detector, de não contar o outro fóton pertencente ao referido par, perdendo assim a medida. Outra necessidade era a de escolher os fótons que realmente pertenciam ao par correlacionado. A primeira seleção era feita com os filtros de interferência, onde só passavam os fótons com os devidos comprimentos de onda; a segunda, pelos polarizadores, onde se escolhia a polarização correta dos fótons. Se a polarização coincidisse com o inverso da outra, a contagem era efetuada; caso contrário, não. Como a maior violação das desigualdades de Bell ocorre nos ângulos $\varphi$ (ângulo entre as orientações dos dois polarizadores) iguais a $22,5^{\circ}$ e $67,5^{\circ}$, os polarizadores giravam num incremento de $22,5^{\circ}$, para suprir esta necessidade. A detecção era concluída com a chegada dos fótons nos fototubos, resfriados com o intuito de reduzir a contagem de eventos aleatórios de origem térmica.

$\mathrm{Na}$ técnica de contagem, cada fototubo estava ligado a um discriminador e estes, por sua vez, estavam ligados a dois contadores de coincidência e a um conversor tempo-amplitude. O primeiro contador fazia a contagem de todas as coincidências. $\mathrm{O}$ segundo tinha um atraso em um dos canais de 50ns, para contar coincidências acidentais, as quais posteriormente seriam subtraídas das coincidências totais, obtendo-se assim a coincidência real. Um conversor tempoamplitude estava ligado a um analisador de altura de pulso, e esse conjunto media o tempo de atraso do espectro de dois fótons, sendo que o resultado indicava o tempo de vida do estado intermediário, $\sim 5 \mathrm{~ns}$ (tempo que o átomo permanece no estado excitado). A taxa de coincidência dependia do feixe e da intensidade da lâmpada, a qual foi decrescendo gradualmente durante o experimento. $\mathrm{O}$ tempo de resolução de todo sistema foi de 1,5ns. O curto tempo de vida do estado intermediário permitiu uma estreita janela de coincidência de 8,1ns. Só foi possível fazer contagens de coincidências com uma janela tão estreita, depois do desenvolvimento do transistor, em $1947^{6}$, isto porque, anteriormente, a eletrônica baseada no uso de válvulas não era tão eficiente nesse aspecto, pois a maioria das válvulas trabalhava na frequência do mega hertz $\mathrm{z}^{7}$ (tempo de resposta da ordem do microssegundo $)^{8}$.

6 Disponível em: <http://pt.wikipedia.org/wiki/Trans\%C3\%ADstor>. Acesso em: 09 set. 2009.

7 Disponível em: <http://www.fazano.pro.br/port62.html>. Acesso em: 21 set. 2009.

8 Apesar do magnetron de cavidade (válvula de alta frequência, usada nos primeiros radares e em fornos de micro ondas, que atingia até $3,33 \mathrm{GHz}$ ) já existir em 1943, esta válvula não é um tubo capaz de amplificar um sinal, é um oscilador (um espécie de pequeno acelerador circular de elétrons), logo não era possível fazer um circuito de coincidência a partir dele. 


\subsection{Experimento realizado por Clauser}

A técnica de excitação foi realizada através de bombardeamento de elétrons, onde o choque destes com o átomo de mercúrio excitava a amostra, ocorrendo assim um decaimento em cascata $(\mathrm{J}=1 \rightarrow \mathrm{J}=1 \rightarrow \mathrm{J}=0)$. Toda a fonte estava encerrada em um bulbo de pirex, contendo $91 \%$ de $H g^{202}, 2,1 \%$ de $H g^{199}$ e 2,2\% de $H g^{201}$. Um feixe de elétrons de $135 \mathrm{eV}$ foi focalizado no bulbo por furos colimadores de $2 \mathrm{~mm}$ de diâmetro. Os fótons correlacionados por polarização eram emitidos da cascata $9^{1} S_{1} \rightarrow 7^{3} S_{1} \rightarrow 6^{3} P_{0}$, com comprimentos de onda iguais a $\lambda_{1}=5676 \AA$ e $\lambda_{2}=$ $4046 \AA$. Com o objetivo de manter uma corrente de $125 \mathrm{nA} \pm 1 \%$, um terceiro fototubo foi colocado externo à região de interação, o qual dirigia um servo loop (laço de realimentação) que estabilizava a corrente. As condições para excitação eram mais trabalhadas do que no experimento anterior. Além de manter a corrente estabilizada, era necessário manter um baixo campo magnético (menor que 50mG), evitando a ação do campo magnético terrestre sobre os níveis de energia. O tempo de realização do experimento foi de $412 \mathrm{~h}$.

A técnica de detecção utilizada foi similar a do experimento realizado por Freedman e Clauser, contudo, agora os fótons foram emitidos de uma cascata de mercúrio, o que fez com que os filtros, lentes e polarizadores fossem diferentes, já que os comprimentos de onda foram diferentes, bem como os detectores (fototubos).

A técnica de coincidência foi a mesma explicada no experimento anterior. (FREEDMAN; CLAUSER, 1972)

\subsection{Experimento realizado por Fry e Thompson}

A técnica de excitação foi diferente dos experimentos anteriores; neste caso, o mercúrio foi excitado em dois passos, que ocorreram em locais físicos diferentes. O primeiro, por bombardeamento de elétrons, onde um feixe deles de $135 \mathrm{eV}$ excitava o mercúrio para o nível $6^{\rightarrow 3} \mathrm{P}_{2}$, um fototubo gerenciava um servo loop para estabilizar a corrente em $125 \mathrm{~mA}$, com um desvio de $\pm 1 \%$. O segundo passo era por absorção de ressonância de um laser sintonizável de comprimento de onda de $\lambda=5461 \AA$, onde o mercúrio era excitado para o nível $7^{3} S_{1}$. O decaimento em cascata que originava o par de fótons correlacionados era do nível $7^{3} S_{1}$ para o nível $6^{3} P_{1}$, emitindo um fóton com comprimento de onda de $4358 \AA$, e do nível $6^{3} P_{1}$ para o nível $6^{1} S_{0}$, emitindo outro fóton com comprimento de onda de $2537 \AA ̊$. O laser sintonizável interceptava o feixe de mercúrio em dois locais diferentes. O primeiro, antes da região de interação, para verificar a fluorescência da fonte garantindo que esta seja máxima; e o segundo, na região de interação (onde o nível $7^{3} S_{1}$ era povoado). Nesta não ocorria outro estado de decaimento em cascata, 
além do que originava os fótons correlacionados, por isso existia uma relação de um decaimento para cada par de fótons, o que evitava possíveis contagens que não fossem do par de fótons correlacionados. Com isto, foi obtido um resultado bastante satisfatório na acumulação de dados, em relação aos dois experimentos realizados anteriormente. A grande novidade surgida nesta técnica foi o uso do laser sintonizável no segundo passo da excitação, pois, além de ter melhorado a acumulação de dados e ter evitado possíveis contagens não válidas, reduziu o tempo de realização do experimento para $80 \mathrm{~min}$, enquanto que no experimento realizado por Freedman e Clauser foi de aproximadamente 200h e no realizado por Clauser, $412 \mathrm{~h}$.

As técnicas de detecção e de contagem de coincidência foram similares a dos experimentos anteriormente analisados.

\section{Conclusão}

A análise histórica dos aparatos nos mostra que quase todos os aparatos utilizados nos experimentos já tinham sido criados desde 1930, exceto os quanticons, o laser e o transistor. Contudo, a análise das técnicas nos diz que apenas o desenvolvimento de alguns desses aparatos, no período entre o pós-guerra e o final da década de 1960, permitiu a realização de experimentos testando as desigualdades de Bell. A técnica de excitação para os dois primeiros experimentos analisados já estava desenvolvida desde 1930; contudo, para o terceiro experimento só esteve disponível a partir de 1965, devido ao uso do laser sintonizável. A técnica de detecção só estava desenvolvida a partir do final da década de 1960, devido ao uso dos quanticons. A técnica de contagem de coincidência só estava desenvolvida, a ponto de ser utilizada com a mesma precisão, na década de 50, devido ao desenvolvimento do transistor. Com isto, podemos afirmar que, apesar de os aparatos já terem surgidos anteriormente, os experimentos analisados não poderiam ter sido realizados antes da década de 1970, já que havia a necessidade de se fazer contagens de fótons únicos com boa precisão estatística e os quanticons só estavam desenvolvidos no início da década de 1970, sendo este um fator determinante para o sucesso desses experimentos. Notemos também que o desenvolvimento de uma técnica estava intimamente ligado ao desenvolvimento ou a criação de um novo dispositivo ou aparato, como no exemplo do laser sintonizável; logo,

[...] a prática e o desenvolvimento das ciências só podem ser estudados sem se separar jamais o conceitual, o material ou o instrumental do técnico ou do político. Sempre misturadas, a lógica de uns redefine permanentemente a dinâmica dos outros. (PESTRE, 1996, p. 21-22) 


\section{Referências}

ASPECT, A. Bell's inequality test: more ideal than never. Nature, v. 398, 18 mar. 1999.

BELL, J. S. On the Einstein, Podolsky and Rosen paradox. Physics, n. 1, p. 195200, 1964.

BOTHE, W. Coincidence method. Science, v. 122, n. 3175, nov. 1955.

BROMBERG, J. L. Device physics vis-a-vis fundamental physics in cold war America: the case of quantum optics. Isis, v. 97, p. 237-259, 2006.

CLAUSER, J. F. Early history of Bell's theorem. In: BERTLMANN, R.A; ZEILINGER, A. (Org.). Quantum [un]speakables: from bell to quantum information. Berlin: Springer, 2002, p. 61.

CLAUSER, J. F. et al. Proposed experiment to test local hidden variable theories. Physical Review Letters, v. 24, issue 10, p. 549, 1969.

CLAUSER, J. F. Experimental Investigation of Polarization Correlation Anomaly. Physical Review Letters, n. 36, p. 1221-1226, 1976.

EINSTEIN, A.; PODOLSKY, B.; ROSEN, N. Can Quantum Mechanical Description of Physical Reality Be Considered Complete? Physical Review Letters, n. 47, p. 777, 1935.

FREEDMAN, S. J.; CLAUSER, J. F. Experimental tests of local hidden-variable theories. Physical Review Letters, v. 28, n. 14, p. 938-941, 1972.

FREIRE JR., O. David Bohm e a controvérsia dos quanta. Campinas (SP): UNICAMP, 1999.

FREIRE JR., O. Philosophy enters the optics laboratory: Bell's theorem and its first experimental tests (1965-1982). S.H.P.M.P., v. 37, p. 577-616, 2006.

FREIRE JR., O. Sobre as desigualdades de Bell. Caderno Catarinense de Ensino de Física, Florianópolis, v. 8, n. 3, p. 212-26, dez. 1991.

FRY, E. S.; THOMPSON, R. L. C. Experimental Tests of Local Hidden Variable Theories. Physical Review Letters, v. 37, n. 8, p. 465-468, 1976. 
GALISON, P. Culturas etéreas e culturas materiais. A ciência tal qual se faz. In: FERNANDO, G. Lisboa: Edições João de Sá, 1999. p. 395-414.

Image and logic: the material culture of microphysics. Chicago:

University of Chicago, 1997.

GILDER, L. The age of entanglement: when the quantum physics was reborn. New York: Alfred A. Knopf2008.

KOCHER, C. A.; COMMINS, E. D. Polarization correlation of photons emitted in an atomic cascade. Phy. Rev. Let., v. 18, n. 15, p. 575-577, 1967.

PHOTOMULTIPLIER tubes: basics and applications. $3^{\text {rd }}$. ed. [S.l]: Hamamatsu, 2006? Disponível em: <http://sales.hamamatsu.com/assets/applications/ETD/ pmt_handbook_complete.pdf $>$. Acesso em: 2010.

NOGUEIRA, Sandra. A tanoaria no Concelho do Cartaxo. In: PROGRAMA Nacional de Bolsas de Investigação para Jovens Historiadores e Antropólogos. 3. ed. Lisboa; Porto: Fundação da Juventude, 1996/1997. p. 184-293. 2000, v. 3, p. 192.

PESSOA JR., O. Conceitos de física quântica. São Paulo: Editora Livraria da Física, 2006. v. 2, cap. 27 e 28.

PESTRE, D. Por uma nova história social e cultural das ciências: novas definições, novos objetos, novas abordagens. Cadernos IG, São Paulo, Unicamp, v. 6, n.1, 1996. 



\title{
Campos que interagem: Física Quântica e a transferência de conceitos entre física de partículas, nuclear e do estado sólido ${ }^{1}$
}

\author{
Christian Joas
}

\section{Introdução}

Yoichiro Nambu foi recentemente agraciado com metade do prêmio Nobel de 2008, pela sua "descoberta do mecanismo de quebra de simetria espontânea na física subatômica". Nambu (1960b) propôs que a quebra espontânea de simetria, ideia derivada da física do estado sólido e usada na teoria de transição de fases, pode também ser um conceito útil na Teoria Quântica de Campos de partículas elementares. Ele baseou uma nova teoria do vácuo em uma analogia com o estado supercondutor da matéria e mostrou como partículas podem adquirir massa através de um mecanismo similar ao da formação do gap de energia em supercondutores (NAMBU; JONA-LASINIO, 1961a, 1961b). Este ponto de vista engenhoso foi provado frutífero por anos a fio e até hoje permeia todas as teorias, envolvendo o assim chamado modelo-padrão da física de partículas elementares: simetria quebrada espontaneamente possui um papel fundamental no mecanismo de Anderson-Higgs para explicar por que partículas elementares possuem massa. ${ }^{2}$ As ideias de Nambu foram consideravelmente facilitadas

1 Traduzido por Leyla Joaquim e Fábio Freitas. O autor é membro do Projeto sobre História e Fundamentos da Física Quântica, uma colaboração do Instituto Max Planck de Historia da Ciência e do Instituto Fritz Haber da Sociedade Max Planck em Berlim. O artigo foi desenvolvido a partir de uma palestra realizada em dezembro de 2008, no workshop Teoria Quântica: estudos históricos e implicações culturais, na Universidade Estadual da Paraíba, em Campina Grande, Brasil.

2 Sobre a importância da quebra espontânea de simetria no modelo-padrão, ver Brown e outros (1997). Pickering (1984, p. 168-173) relata a história da apropriação do conceito de quebra espontânea de simetria por partículas físicas. Kibble (2009) fornece uma abordagem técnica da história convoluta do mecanismo de Anderson-Higgs e sua conexão com a teoria do estado sólido. Ver também Shirkov (2009). 
por sua familiaridade com a teoria do estado sólido, devido ao seu trabalho prévio neste campo - particularmente na teoria da supercondutividade - no qual o conceito de quebra de simetria já havia sido desenvolvido no final da década de 50 (NAMBU, 1995). Ele forneceu uma derivação teórica quântica de campos da teoria de supercondutividade de Bardeen-Cooper-Schrieffer (BARDEEN; COOPER; SCHRIEFFER, 1957a, 1957b), baseando-se na invariância de calibre e na teoria da perturbação de Feynman-Dyson, técnica emprestada da eletrodinâmica quântica. ${ }^{3}$

Tanto a transferência dos métodos teóricos quânticos de campos (tais como o uso dos diagramas de Feyman), das físicas nuclear e de partículas elementares para a física do estado Sólido, quanto a transferência do conceito de simetria quebrada espontaneamente da teoria de sólidos (de Nambu) para a teoria de partículas elementares, são belos exemplos do estabelecimento de elos surpreendentes entre campos de pesquisa aparentemente distantes. Os campos da física do estado sólido, da física nuclear e da física de partículas elementares (ou física da matéria condensada e física de altas energias, para usar seus nomes modernos) ${ }^{4}$ são frequentemente apresentadas como campos amplamente desconectados, compartilhando pouco mais que suas bases conceituais - inicialmente a Mecânica Quântica, e, a partir dos meados da década de 50, também da Teoria Quântica de Campos. ${ }^{5}$ No presente artigo, mostrarei que, ao contrário, a física do estado sólido, a física nuclear e a física de partículas elementares são profundamente emaranhadas, tanto em seus respectivos desenvolvimentos históricos, quanto conceituais. Irei estudar a história das interações entre estes campos desde os primórdios da Mecânica Quântica período no qual a física do estado sólido, a física nuclear e a física de partículas

3 Antes mesmo de Nambu, Gorkov (1958) derivou a teoria BCS usando a teoria da perturbação diagramática (para uma exposição, ver ABRIKOSOV; GOR'KOV; DZYALOSHINSKI, 1965).

4 Estes nomes devem ser usados com cautela quando se fala do início da história destes campos (ver, por exemplo, a discussão em HUGHES, 2003, p. 370-374).

5 Os físicos do estado sólido da segunda metade do século XX muitas vezes afirmaram perceber uma falta de apreciação pela sua área: a física do estado sólido é comumente considerada inferior em algum aspecto em relação a outros mais "fundamentais" ramos da física. Para uma expressão inicial deste sentimento de inferioridade por um pesquisador do campo da física do estado sólido, ver Pippard (1961). Wolfgang Pauli, supostamente, referiu-se à física de semicondutores como "física suja" (schmutzphysik) e Murray Gell-Mann, com desprezo, apelidou a física do estado-sólido de "física do estado esquálido". É interessante notar que, quando procurou por confirmações destes enunciados famosos, o autor se deparou com o fato de que os físicos do estado sólido, quase que exclusivamente, referem-se a eles, mesmo quando defendem a relevância de seu próprio campo e não fornecem referências. A história dos debates sobre a prioridade entre a física de partículas e física do estado sólido é um assunto interessante e essencialmente não estudado, sendo abordado apenas superficialmente no presente artigo. (ver, por exemplo, a nota de rodapé 40) 
estavam longe de serem estabelecidas como subdisciplinas da Física - até a década de 60 em diante. Este estudo enfatizará que a história das interações, como a esboçada acima, está intimamente conectada com a história do século XX. Ao longo do curso desse século, os modos de interação entre os campos evoluíram. Esta evolução não se reflete somente nos desenvolvimentos conceituais em Física, como o advento da Mecânica Quântica ou Teoria Quântica de Campos, mas também em fatores externos, como emigrações na década de 30, a Segunda Guerra Mundial ou a Guerra Fria. Estes fatores tiveram efeitos diferentes nos campos em emergência e também nos modos de interação entre eles. Fases de interações mútuas frutíferas foram interrompidas por fases de desenvolvimentos isolados e houve uma fase particularmente interessante na primeira metade da década de 50, na qual a transferência de conceitos e ideias era predominantemente unidirecional.

O artigo é organizado da seguinte maneira: a seção 2 situa a pré-história das atuais físicas de altas energias e da matéria condensada no contexto do advento da Mecânica Quântica: ao contrário de muitas abordagens, que relatam a história da física do estado sólido, nuclear e de partículas, como exemplos de aplicação da Mecânica Quântica a domínios de pesquisa fora da física atômica, irei argumentar que estas (proto-) disciplinas formam parte da gênese complexa da Mecânica Quântica e, somente em retrospecto, em grande parte devido a razões contingentes, aparecem como sendo meramente fenômenos secundários relativos à física atômica. A importância dos campos emergentes para a contínua negociação a respeito da Mecânica Quântica, nos anos de 1925-1926, será enfatizada. A seção 3 oferece um breve relato das dinâmicas iniciais e da consolidação das subdisciplinas emergentes da Física. Espero, assim, esclarecer os paralelos e diferenças em suas evoluções até o final da Segunda Guerra Mundial e comentarei sobre os efeitos que isto teve nas interações entre eles. A seção 4 trata de um obstáculo específico encontrado tanto pela física nuclear quanto pela física do estado sólido, o chamado "problema de muitos-corpos". A necessidade de encontrar abordagens teóricas para lidar com este problema é um dos componentes-chave da interação entre os campos. $\mathrm{Na}$ seção 5, são discutidos os modos de interação entre a física de partículas elementares e a física do estado sólido, baseados fortemente na análise da influência da Mecânica Quântica e da Teoria Quântica de Campos em ambos os campos. A seção 6 se constitui mais como um epílogo do que como uma conclusão. Ali, reflito sobre alguns aspectos mais gerais da institucionalização sob a luz do advento de teorias de unificação, tais como a Mecânica Quântica e a Teoria Quântica de Campos. O presente artigo constitui-se um trabalho em desenvolvimento. 


\section{A mecânica quântica além do átomo}

As narrativas da história da Mecânica Quântica frequentemente se baseiam na história da Espectroscopia Atômica e de vários tópicos isolados da Física Estatística, como radiação do corpo negro ou da estatística de gases ${ }^{6}$. As teorias do estado sólido, da ligação química ou do subatômico são apresentadas como meras "aplicações" do novo formalismo a novos domínios. Entretanto, tanto a velha teoria quântica dos anos anteriores a 1925 quanto a Mecânica Quântica dos anos posteriores são entendidas muito além da busca por uma explicação apropriada do espectro do átomo de hidrogênio. As tendências historiográficas são devidas ao fato, ao menos parcialmente, de que outras linhas de desenvolvimento, como o estudo dos sólidos ou do núcleo atômico, não foram estabelecidas como campos propriamente definidos da Física, até décadas posteriores à gênese da Mecânica Quântica em 1925-1927, enquanto que a espectroscopia atômica já era um ofício bem estabelecido. No início do século, os teóricos e com isso também os pais da Mecânica Quântica estavam interessados em uma ampla gama de fenômenos físicos, alguns dos quais, retrospectivamente, podem aparecer como desvios de um caminho reto até a Mecânica Quântica. Werner Heisenberg, ao mesmo tempo em que trabalhava e publicava sobre da Teoria Quântica, escreveu uma dissertação sobre a estabilidade e turbulência de fluidos que fluem (CASSIDY, 1992, p. 150-154). Max Born publicou extensivamente sobre a teoria atômica e as dinâmicas de estruturas cristalinas (ver, por exemplo, BORN, 1915). ${ }^{7}$ Erwin Schrödinger, nos anos de 1910 e 1920, publicou sobre tópicos tais como relatividade, radiação atmosférica, radioatividade e a condução elétrica e estabilidade dos sólidos. ${ }^{8}$ Tanto Einstein $(1924,1925)$, quanto Schrödinger (1924), ao trabalharem com estatística de gases, tentaram extrair de suas teorias sobre degeneração de gases - as quais Hanle $(1971,1979)$ identificou como uma importante raiz da mecânica ondulatória - conclusões sobre o comportamento conhecido de metais, o qual não podia ser explicado por nenhuma teoria contemporânea (ECKERT; SCHUBERT; TORKAR, 1992, p. 39-40). Estes poucos exemplos, dentre muitos outros, demonstram que os fenômenos exteriores ao domínio da Física Atômica não estavam nem na periferia da atenção dos físicos teóricos anteriormente ao advento da Mecânica Quântica, nem foram irrelevantes para a sua gênese.

6 Confira, por exemplo, Hendry (1984) e Beller (1999). Ver também Darrigol (2009).

7 Eckert, Schubert e Torkar (1992) fornecem uma abordagem do trabalho de Born com cristais e observa: "[...] Foi precisamente o seu interesse sobre propriedades físicas de cristais que levaram Born primeiro à Mecânica Quântica (leia-se Teoria Quântica) e mais tarde à física atômica, e finalmente ao [...] Dreimänerarbeit."

8 Assim que novas ideias sobre a estrutura dos sólidos foram possibilitadas pelos experimentos de difração de raio-X de Friedrich, Knipping e Laue, (1912) apresentou uma teoria ambiciosa sobre a estrutura e estabilidade dos sólidos como sua tese de habilitação (Joas e Katzir, não publicado). 
A Mecânica Quântica forneceu uma estrutura coerente para que, eventualmente, se construísse uma fundação unificada aos campos nascentes da física do estado sólido, nuclear e de partículas elementares. Pode-se argumentar que as ideias adquiridas na teoria quântica do espectro atômico, assim que eram condensadas na nova mecânica, poderiam finalmente ser empregadas na construção de teorias sobre fenômenos fora do domínio do átomo. Eu pretendo ir além e argumentar que a própria Mecânica Quântica e a interpretação do formalismo quanto-mecânico foram negociadas e moldadas em um diálogo progressivo, que derivou não somente do conhecimento empírico sobre o espectro atômico, mas também do conhecimento daquelas áreas de pesquisa que seriam mais tarde chamadas de física do estado sólido, nuclear e de partículas. A ideia de que a fundação quanto-mecânica da física do estado sólido, de partículas e nuclear não passa de uma mera apropriação de métodos da Mecânica Quântica, por grupos de pesquisadores que trabalhavam na periferia do desenvolvimento, é enganadora. Muito pelo contrário, a história da gênese e interpretação da Mecânica Quântica é fortemente conectada aos problemas que surgiram em diferentes correntes de desenvolvimento, eventualmente combinadas pelos novos campos emergentes, e os protagonistas da gênese da Mecânica Quântica se tornaram frequentemente figuras proeminentes também nos campos nascentes da física do estado sólido, química quântica e física nuclear e de partículas.

Nós já vimos que os pais da Mecânica Quântica, ao mesmo tempo em que ponderavam questões relacionadas aos espectros atômicos, estavam também se dedicando a problemas exteriores à espectroscopia atômica, apesar do papel limitado que estes problemas tiverem no desenvolvimento de fato da nova mecânica. Enquanto o tumulto dos anos 1925-1926 certamente levou a uma parada temporária na maioria das atividades relacionadas aos fenômenos externos à física atômica, o conhecimento empírico e teórico sobre estes fenômenos informou os criadores da Mecânica Quântica e a busca pela explicação destas áreas logo ganhou de novo a atenção dos físicos teóricos. A história da teoria quantomecânica de elétrons em metais é uma ilustração disto: em 1926, após conhecer a nova estatística de um gás de partículas obedecendo ao princípio de exclusão de Pauli', Heisenberg (1926) observou que a Mecânica Quântica admitia duas classes mutuamente exclusivas de autoestados em sistemas com mais de uma partícula e relacionou este fato a - então ainda dúbia - hipótese do spin do elétron. Mais tarde naquele ano, Wolfgand Pauli (1926) aplicou a estatística de FermiDirac do gás ideal monoatômico à condução de elétrons em metais, com o intuito de explicar seus comportamentos paramagnéticos. Arnold Sommerfeld (1927), então, aplicou a nova estatística na tentativa de explicar a condutividade de metais em uma extensão da teoria clássica de Paul Drude (1900a, 1900b, 1904). Somente

9 Atualmente, esta nova estatística é chamada estatística de Fermi-Dirac, em homenagem aos seus dois descobridores independentes. 
quando Felix Bloch (1928) levou em consideração satisfatoriamente a presença de estrutura iônica, “a maquinaria completa da Mecânica Quântica, desenvolvida em 1925 e 1926, tornou-se importante para os sólidos" (HODDESON; BAYM; ECKERT, 1992, p. 89). Muitos ingredientes-chave da moderna física da matéria condensada e de altas energias, bem como da Química Quântica moderna ${ }^{10}$, de fato derivaram do trabalho dos protagonistas da Mecânica Quântica que foram produzidos, não depois, mas durante a gênese da Mecânica Quântica. A inspeção mais próxima do conteúdo destas contribuições iniciais revela que conceitos importantes da própria Mecânica Quântica (e. g., a conexão entre spin de elétron e a estatística quântica de férmions e bósons, ou a natureza das forças de troca da Mecânica Quântica) resultaram da pesquisa conduzida na época da consolidação da Mecânica Quântica. Adicionalmente, a Mecânica Quântica, em 1927, não foi vista como uma teoria definitiva por seus criadores. Mais notavelmente, a questão da sua extensão relativística confundiu profundamente físicos teóricos e os fez suscetíveis ao estudo de problemas externos à física atômica. Esta questão, de modo amplo, foi negociada com base na Teoria Quântica do núcleo ${ }^{11}$. Descrever os primórdios da teoria da física do estado sólido ou da física nuclear como meras “aplicações da Mecânica Quântica” é, então, enganador. Conforme será argumentado na seção 5, o fato de que a própria história da Mecânica Quântica está entrelaçada com a história inicial das subdisciplinas emergentes da Física permite desenvolver valiosas ideias sobre os modos de interação entre estes campos em um estágio no qual eles não tinham nenhuma identidade institucional.

\section{Campos emergentes: a institucionalização da física nuclear, da física de partículas elementares e da física do estado sólido}

Foi somente nas décadas seguintes ao advento da Mecânica Quântica que a física nuclear, a de partículas elementares e a do estado sólido emergiram como campos de pesquisa institucionalizados. ${ }^{12}$ Durante a década de 30, alguns físicos gradualmente passaram a se autodenominar "físicos nucleares" (HUGHES,

10 O artigo de "ressonância" de Heisenberg (1926) também possui um papel na história da teoria da ligação homopolar adiantada por Heitler e London (1927) (GAVROGLU, 1995, p. 45). Conforme Hoddeson, Baym e Eckert (1992, p. 108) apontam, o artigo de Heitler e London motivou diretamente Bloch (1928) a se apoiar na ideia de "[...] que Heitler e London usaram em seus diferentes tratamentos da molécula de hidrogênio, de construir funções de ondas de elétrons a partir da base de orbitais do estado-fundamental de átomos-individuais nãoperturbados."

11 Ver nota de rodapé 15.

12 Para a fisica nuclear, ver Stuewer (1979) e Aaserud (1990); para a física do estado sólido, ver Hoddeson e colaboradores (1992a). 
2003). Somente depois da Segunda Guerra, outros físicos começaram a considerar-se "físicos de partículas" ou "físicos do estado sólido". No caso da física do estado sólido, Weart (1992, p. 617) descreveu este processo da seguinte maneira:

Em 1930 a física do estado sólido não existia. O termo era desconhecido, e não havia qualquer entidade intelectual ou social para a qual o termo poderia ser aplicado. Certamente uma série de especialidades prosperaram, tais como a teoria do elétron em metais e estudos experimentais de ligas magnéticas, as quais eventualmente caíram no campo da física do estado sólido, mas não havia nenhum campo como um todo, não havia nenhuma razão que justificasse uma distinção entre os físicos que estudavam sólidos e o grupo de físicos que estudavam gases, radioatividade ou qualquer outra coisa. Em 1960 a situação mudou completamente. O termo "física do estado sólido" não somente se tornou familiar como poderiam também ser associado a algumas instituições: posições acadêmicas, conferências, periódicos, grupos de pesquisa, mecanismos de financiamentos, até mesmo construções inteiramente destinadas à disciplina. Estas instituições foram unidas em uma comunidade mundial da física do estado sólido. Como um espelho, esta entidade social refletia uma entidade intelectual, o estudo da física do estado sólido.

Nas décadas seguintes ao advento da Mecânica Quântica, áreas aparentemente desconectadas, nos primórdios da pesquisa, tornaram-se progressivamente integradas e consagradas (dialogando com Weart) em entidade social e intelectual e passaram a ser consideradas campos de pesquisa diferentes. Os campos emergentes foram construídos sob intuições de base empírica que já haviam sido alcançadas bem antes que eles pudessem ser considerados subdisciplinas da física por si próprios ${ }^{13}$. Estas intuições empíricas foram encapsuladas em teorias e modelos ${ }^{14}$, as quais teriam papéis importantes no estabelecimento dos novos campos emergentes. Antes do advento da Mecânica Quântica, havia nos campos emergentes uma falta de base sistemática, adquirida apenas no curso de apropriação e conseqüente extensão dos métodos mecânicos quânticos que

13 Por exemplo, conhecimentos sobre raio-X ou sobre espalhamento de partículas alfa em átomos para a física nuclear; conhecimento sobre estruturas cristalinas, condutividade elétrica, magnetismo ou calores específicos para a física do estado sólido.

14 O modelo de Rutherford do átomo e modelos nucleares anteriores podem servir como exemplos para a física nuclear. Para a física do estado sólido, a teoria de Laue-Ewald da difração de raios-X em sólidos, a teoria do magnetismo de Curie-Weiss-Langevin e a teoria de Drude da condução elétrica são casos exemplares de teorias anteriores que forneceram intuições empíricas cruciais. 
começaram nos anos de 1925-1927. Anteriormente, os fenômenos e teorias mencionados acima não eram vistos, nem apresentados, como elementos coerentes de uma visão unificada. Já durante a sua formulação, a Mecânica Quântica passou a ser vista como um possível formalismo unificado para estas novas áreas de pesquisa. No final da década de 1920 e início da década de 1930, colaboradores dos campos emergentes, embora oriundos de diferentes contextos intelectuais, frequentemente trabalhavam com problemas derivados de diversas áreas que atualmente, em retrospecto, seriam considerados bastante distantes. Tanto a física nuclear inicial quanto a física do estado sólido inicial se baseavam fortemente na mecânica ondulatória e apenas em uma extensão menor, em outras formulações da Mecânica Quântica. O domínio dos métodos da mecânica ondulatória permitiu, assim, que os físicos penetrassem em questões sobre sólidos ou sobre o núcleo, essencialmente com o mesmo arsenal de métodos (por exemplo, teoria da perturbação, efeito tunelamento, estatística quântica). De modo interessante, a dinâmica de institucionalização dos campos emergentes, no entanto, mostrou fortes diferenças em escala, ritmo e implicações sociais, especialmente com respeito aos efeitos da emigração na Europa na década de 1930, da Segunda Guerra Mundial e da era pós-Guerra. Nos seguintes parágrafos, será delineada a história das físicas nuclear e de partículas e da física do estado sólido, a partir de suas origens no início do século XX até as décadas de 1950 e 1960.

\subsection{A física nuclear e de partículas}

O início da história da física nuclear e de partículas pode ser dividido, grosso modo, em três fases (PAIS, 1986). No início do século XX, os físicos estudaram materiais radioativos e raios cósmicos, focando as propriedades qualitativas da radiação. Nos anos seguintes, a radioatividade foi essencialmente uma ciência experimental, complementada com teorias fenomenológicas simples (HUGHES, 1998). Esta primeira fase, que Pais (1986, p. 297) denomina “[...] física nuclear sem núcleo [...]", terminou com a análise de Rutherford, em 1911, dos experimentos de espalhamento de partículas a em termos de um modelo atômico que incluía um núcleo. $\mathrm{O}$ modelo de Rutherford rapidamente se tornou aceito e provocou investigações sobre as propriedades do núcleo, bem como pesquisas sobre processos nucleares. O terceiro estágio da história inicial do campo coincide com os primórdios da Mecânica Quântica. Este pode ser datado aproximadamente entre 1926-1932. Esta assim chamada "era do paradoxo" foi dominada pela crise do modelo próton-elétron do núcleo e testemunhou as primeiras descrições bem sucedidas dos processos nucleares com os meios da Mecânica Quântica, tais como as teorias de emissões a e $\gamma$ de Gurney e Condon $(1928)^{15}$ e de Gamow

15 Condon $(1926,1928)$ também trabalhou extensivamente em problemas de física molecular no mesmo período. 
(1928), com base na mecânica ondulatória. Logo após o advento da Mecânica Quântica, mesmos os experimentais sentiram necessidade de se tornar familiarizados com a mecânica ondulatória (HUGHES, 1998). O chamado annus mirabilis da física nuclear em 1932, com a descoberta do nêutron por James Chadwick, iniciou os "felizes anos 30" (BETHE, 1979). O ano de 1932 marca o ponto de virada da emancipação da física nuclear como um campo distinto de pesquisa: o estudo do núcleo se tornou mais e mais sistematizado, baseado na Mecânica Quântica, e apareceram os primeiros livros e séries de artigos seguindo este programa. ${ }^{16}$ Em 1932, Douglas Hartree avaliou a situação neste campo do seguinte modo (HARTREE, 1932):

O considerável avanço recente em nosso conhecimento das propriedades e estrutura do núcleo atômico se deve primeiramente ao desenvolvimento brilhante de idéias e experimentos por Rutherford e outros, e segundo ao passo fundamental, dado independentemente e quase simultaneamente por Gamow e Gurney e Condon, de aplicar os conceitos e métodos da Mecânica Quântica - e particularmente aquela formulação da Mecânica Quântica para a qual o termo mecânica ondulatória é aplicado - no fenômeno nuclear, em primeira instância para aqueles de radioatividade e desintegração artificial.

Da metade em diante da década de 1930, a física nuclear teve sucesso em combinar várias linhas de desenvolvimento do início do século XX, tais como a radioatividade, pesquisa sobre raios cósmicos e aspectos da espectroscopia atômica (por exemplo, a estrutura hiperfina dos espectros atômicos). Ela começa a tomar forma como um campo de pesquisa distinto e de crescimento acelerado. ${ }^{17}$ Durante a Segunda Guerra Mundial, torna-se uma disciplina chave na pesquisa do período de guerra, especialmente através do Projeto Manhattan, e foi amplamente responsável por um prestígio sem precedentes da Física como um todo, que por sua vez levou a um rápido crescimento do tamanho da comunidade acadêmica, após a guerra. Foi somente no pós-guerra que a física de partículas

16 Ver Gamow (1931), Heisenberg (1932a, 1932b, 1933), Bethe e Bacher (1936); Bethe (1937); Livingston e Bethe (1936). Os três últimos artigos ficaram conhecidos como "a bíblia de Bethe". Aaserud (1990, p. 54-55) observa sobre o primeiro artigo da trilogia de Heisenberg: "Como Bohr, [Heisenberg] apresentou o decaimento beta como evidência contra a conservação de energia e a favor da necessidade de uma física quântica relativística completamente nova. Mesmo no artigo clássico de Heisenberg, então, o os problemas mais básicos do núcleo eram ainda parte de uma busca mais ampla por uma nova física quântica relativística. A física nuclear teórica não era ainda um campo de investigação por si mesmo."

17 De acordo com Henry Small, citado por Weiner (1972), a proporção de publicações relacionadas à física nuclear na Physical Review subiu de 8\% em 1932 para 43\% em 1940. (BROWN; HODDESON, 1983) 
elementares (ou física de altas energias) se consolidou como um campo distinto de pesquisa (PICKERING, 1984). Sua história inicial está intimamente conectada com aquela da física nuclear, frequentemente retratada como sua precursora direta. Entretanto, a física nuclear não sofreu uma mudança de nome na década de 1950; ao invés disto, persistiu ao lado da física de partículas elementares, da qual havia se dividido, principalmente devido ao advento dos aceleradores de partículas e as grandes instalações de pesquisa tais como o Centro Europeu de Pesquisas Nucleares (CERN). Os físicos de partículas e nucleares nas décadas de 1950 e 1960 estavam interessados em questões diferentes: enquanto os físicos de partículas investigavam os constituintes dos núcleons, os físicos nucleares estudavam o comportamento coletivo de núcleons e processos nucleares (HUGHES, 2003, p. 370-374). Nesse contexto, os físicos nucleares encararam o que passou a ser conhecido como o "problema de muitos-corpos", isto é, o tratamento das interações de um grande número de partículas. Este problema constituiu-se em um gargalo para um tratamento mecânico quântico do núcleo ${ }^{18}$. Retornaremos ao problema de muitos-corpos na seção 4 .

\subsection{A física do estado sólido}

Enquanto em princípio seja ainda mais antiga, na medida em que abrange conhecimento de metalurgia e cristalografia (ECKERT; SCHUBERT, 1986; SMITH, 1965), a física do estado sólido durante o século XX combinou diferentes correntes da física do século XIX e início do século XX, tais como a físico-química, criogenia, teoria da elasticidade, cristalografia, eletrodinâmica e termodinâmica, bem como ideias gerais sobre a estrutura e estabilidade da matéria. No século XIX e início do século XX, teorias dos sólidos foram baseadas na Mecânica, na Termodinâmica e no Eletromagnetismo, e estiveram no centro dos debates fervorosos sobre atomismo e a estrutura da matéria. De um lado, havia teorias fenomenologicamente bem sucedidas, descrevendo vários aspectos do comportamento dos sólidos; de outro lado, a teoria cinética era aplicada com bastante sucesso a diversos aspectos isolados. A teoria cinética de metais de Drude (1900a, 1900b, 1904) e a teoria de condução elétrica dela resultante, baseada na identificação de elétrons por J. J. Thomson como carregadores de corrente, é o primeiro exemplo do sucesso da teoria cinética. Outro exemplo é a teoria de Curie-

18 Fischer (1993, p. 141), em um estudo bibliométrico, observa um declínio na física nuclear teórica já no final da década de 1930 e início de 1940. Ele atribui esta queda ao fato de que, apesar dos numerosos esforços, não havia nenhuma Mecânica Quântica do núcleo satisfatória: “[...] embora talvez invisível aos participantes ou observadores medianos, a frente da pesquisa teórica já havia começado a mudar para o que viria a se tornar a 'física de altas energias' na década de 50. Com a falta de máquinas para altas energias, contudo, ainda se estava confinado ao estudo dos efeitos das partículas de alta energia que ocorrem naturalmente, tais como raios cósmicos." 
Langevin-Weiss que, explicitamente, usou as ideias de Bolztman para explicar o para- e o ferromagnetismo, ao assumir a existência de moléculas magnéticas dipolares. A óptica ondulatória do século XIX foi a base para a teoria de óptica de cristais de von Laue e Ewald, que seguiu os experimentos de difração de raio-X de Friedrich e Knipping (Cf. FRIEDRICH; KNIPPING; LAUE, 1912). Logo depois da formulação de Planck sobre a hipótese quântica em 1900, o calor específico dos sólidos apresentou uma oportunidade de estender o domínio explicativo das novas hipóteses e formular teorias quânticas do calor específico dos sólidos (EINSTEIN, 1907, 1911a, 1911b) e da dinâmica de estruturas cristalinas (BORN; KARMAN, 1912; DEBYE, 1912b), baseando-se apenas nos graus de liberdade iônicos. ${ }^{19}$ Entretanto, durante a velha teoria quântica, a teoria quântica não era necessariamente vista como uma ferramenta indispensável para a descrição dos sólidos e muitos dos pioneiros da física teórica do estado sólidos demonstraram, de certo modo, uma atitude oportunista em relação ao uso das hipóteses quânticas em suas teorias ${ }^{20}$. Este quadro mudou com o advento da Mecânica Quântica, especialmente com as proposições relacionadas ao princípio de exclusão de Pauli e a natureza fermiônica dos elétrons. Arnold Sommerfeld (1927) estendeu a teoria clássica da condução eletrônica de Drude, levando em consideração o que é atualmente conhecido como estatística de Fermi-Dirac. Contudo, sua teoria falhou em explicar a suposição do movimento eletrônico quase livre. Este mistério foi resolvido quando Bloch (1928) apresentou sua teoria da condução do potencial periódico, explicando o alto caminho médio dos elétrons em metais, ao usar a maquinaria da mecânica ondulatória e intuições do campo emergente da química quântica. Hoddeson e Baym (1980, p. 19) afirmam que:

$\mathrm{O}$ artigo de Bloch foi seguido por uma série de desenvolvimentos rápidos na teoria "moderna" dos sólidos entre 1928 e 1933, na qual os fenômenos básicos foram explicados um após outro. Conforme Peierls examinou o estado da teoria dos metais em seu artigo de 1932 (Peierls, 1932): "pode-se ter a impressão de que o problema, de explicar as condições típicas de metais a partir de propriedades moleculares, e derivar as leis quantitativas que existem, está, com exceções [...] resolvido".

19 Até o advento da Mecânica Quântica, a teoria de Drude-Lorentz, baseada somente no movimento eletrônico (quase livre), e a teoria Einstein-Debye-Born-von Karman, baseada no movimento térmico dos íons e negligenciando os elétrons, permaneceram abordagens essencialmente desconectadas à natureza dos sólidos (HODDESON; BAYM, 1980)

20 Apenas um mês antes de seu trabalho sobre calor especifico dos sólidos, Debye (1912a) havia publicado uma teoria de isolantes que se apoiava na mecânica estatística e não fazia nenhum uso da hipótese quântica. Ver também Joas e Katzir, [200?]. 
O crescimento do número de artigos sobre conceitos teóricos novos referentes a sólidos, no final da década de 1920 e início da década de 1930, não foi limitado à teoria de metais, mas abrangeu muitos outros aspectos, tais como magnetismo e supercondutividade ${ }^{21}$, condução térmica em sólidos não metálicos e a teoria de bandas, bem como a teoria de estruturas (por exemplo, defeitos pontuais). Na metade da década de 1930, um número impressionante de artigos de revisão apareceu sobre esses assuntos ${ }^{22}$. Em contraste com o desenvolvimento da física nuclear, entretanto, o momentum destes anos iniciais não durou até a segunda metade da década de 1930 e a Guerra. Vários fatores levaram a uma desaceleração, de fins dos anos 1930 em diante. Primeiramente, sucessos no campo emergente da física nuclear impulsionaram os físicos para fora da teoria dos sólidos: tantas descobertas fundamentalmente novas foram feitas na física nuclear durante a década de 1930 que o estudo dos sólidos, para cuja prospecção só existia um arsenal de técnicas experimentais um tanto quanto limitadas, tornou-se menos atrativo para os físicos. Esta tendência foi amplificada pelos efeitos da emigração da Alemanha nazista que afetou grande parte dos pioneiros da teoria quântica inicial dos sólidos. Alguns dos personagens principais, quando emigraram para a Grã-Bretanha e outros lugares, começaram a confinar suas atenções à física nuclear ${ }^{23}$. Ainda, o centro da teoria de sólidos durante a década de 30 , sob a influência da emigração, moveu-se da Alemanha para a Grã Bretanha. O esforço de Guerra reduziu o número de pesquisadores ativos no campo, apesar de que alguns aspectos da física dos sólidos (por exemplo, pesquisa de radar e microondas, semicondutores) foram fortemente investigados devido à sua relevância em implicações militares (ECKERT, 2003). Após a Guerra, o interesse por sólidos cresceu lentamente, mas de modo contínuo, principalmente devido aos avanços tecnológicos e às novas técnicas experimentais para o estudo dos sólidos, resultantes da pesquisa do período de

21 O fenômeno da supercondutividade, entretanto, evadiu aqueles ávidos a seguir a nova abordagem, apesar da esperança levantada pelo sucesso da teoria quântica de metais (JURKOWITZ, 1995; MATRICON; WAYSAND, 2003). Hoddeson, Baym e Eckert (1992, p. 141) escreveram: “[...] entre 1929 e 1933, mais do que uma dúzia de físicos teóricos - incluindo Bohr, Pauli, Heisenber, Bloch, Landau, Brillouin,W. Elsasser, Frenkel e Kronig - armados com os sucessos da teoria quântica de metais e novas observações, estavam otimistas que a nova ferramenta também os ajudaria a explicar supercondutividade".

22 Hans Bethe, por exemplo, cuja "Bíblia de Bethe" em física nuclear já nos deparamos (nota de rodapé 15), escreveu um influente texto de referência ( $\mathrm{N}$ do T: Handbuch) de mais de 300 páginas com Arnold Sommerfeld. (SOMMERFED; BETHE, 1933)

23 Ao menos parcialmente, isto se deve à tradição da pesquisa nuclear e de radioatividade na Grã-Bretanha e às oportunidades resultantes para físicos procurando emprego após serem forçados a emigrar. Rudolf Peierls, por exemplo, deixou de trabalhar quase exclusivamente com sólidos para trabalhar em física nuclear, quando ele emigrou para a Grã-Bretanha. Hans Bethe é outro exemplo (ver seção 5). 
guerra. ${ }^{24}$ As técnicas novas ou refinadas levaram a uma abundância de novas proposições dentro da rica fenomenologia dos sólidos. Ao contrário da física nuclear, os experimentos eram baratos e podiam ser conduzidos por grupos pequenos. Alguns daqueles que, antes da Guerra, dedicaram tempo a problemas relacionados à física dos sólidos, optaram por retornar aos seus estudos, sob a luz dos experimentos refinados. Outros, treinados em física durante a Guerra, começaram a participar de novas instituições - tanto na academia quanto na indústria - que lidavam com tópicos relacionados aos sólidos. ${ }^{25}$ Adicionalmente, o número total de físicos cresceu tremendamente nos anos pós-guerra, devido ao aumento de apoio à ciência instigado pelo papel que a Física teve durante a Guerra. Durante a década de 1950 e 1960, a física do estado sólido se tornou, possivelmente, a maior subdisciplina da Física e permaneceu assim desde então, transformando profundamente a tecnologia e exercendo um impacto de longo alcance na sociedade moderna (MOYER, 1985; ECKERT; SCHUBERT, 1986). ${ }^{26}$ Mesmo físicos que permaneceram no campo durante a Guerra não anteciparam este desenvolvimento. Em sua autobiografia, Frederick

24 Exemplos são as novas técnicas de microondas da pesquisa em radar, métodos de espalhamento térmico de nêutrons devido à disponibilidade de reatores nucleares, técnicas de preparação de amostra de semicondutores desenvolvidas durante a Guerra, a disponibilidade em larga escala de isótopos químicos para dopagem, a partir da separação de isótopos, novos métodos de computação e técnicas de baixa temperatura mais sofisticadas. Ver, por exemplo, Braun, (1992) e Forman (1995)

25 O mais famoso exemplo sendo o grupo de pesquisa do laboratório Bell do qual Bardeen, Shockley e Herring participaram na década de 1940 (HODDESON; DAITCH, 2002). Sua descoberta do transistor de ponto de contato em 1947 marcou o começo da era da moderna eletrônica do estado sólido (RIORDAN; HODDESON, 1998) e começou um "crescimento rápido da pesquisa do estado sólido, tanto em laboratórios industriais, quanto em departamentos universitários" (ECKERT, 2003, p. 422). Ver também Kevles (1995).

26 O termo "física do estado sólido" foi cunhado na década de 1940 (WEART, 1992, p. 629-640). O nome moderno - "física da matéria condensada" - que também inclui o estudo dos líquidos e dos sistemas desordenados, supostamente vem desde P. W. Anderson, que nomeou seu grupo de pesquisa em Cambridge (Mass.), quando ele se uniu ao corpo docente em 1967 (comunicação privada, maio 2009). Weart (1992, p. 651), entretanto, encontrou evidências desse "recente nome popular" já em 1962. Comparada com outros ramos da física do século XX, a física da matéria condensada recebeu pouca atenção de historiadores e filósofos da ciência. Existem, comparativamente, poucos estudos relativos à história da física do estado sólido; e a história da física do estado sólido no pós-guerra permanece essencialmente não estudada. Isto não se deve à falta de fontes. Durante a década de 1980, o Projeto Internacional da História da Física do Estado Sólido localizou um número impressionante de fontes relacionadas à história deste ramo da física (WARNOW-BLEWETT; TEICHMANN, 1992). O projeto também conduziu um grande número de entrevistas orais gravadas, que estão depositadas (muitas delas como transcritos inteiros) na biblioteca Niels Bohr do American Institute of Physics, em College Park (MD). O principal resultado do projeto é o livro clássico de história da física do estado sólido (HODDESON et al. 1992a). A maior parte dos trabalhos sobre história da física do estado sólido do autor se constroi baseada nestes recursos. 
Seitz (1994, p. 179), autor de um dos primeiros livros textos sobre a teoria quântica dos sólidos (SEITZ, 1940), comentou:

Se, durante a parte final da Segunda Guerra Mundial, alguém tivesse me perguntado o que aconteceria finalmente com o campo da física do estado sólido, eu teria conjecturado que ele teria sido incorporado no que foi então o campo mais geral da físico-química. Na verdade, em certo sentido, aconteceu o oposto. Muitos físico-químicos se tornaram físicos e entraram em departamentos de física ou grupos interdisciplinares. O campo da físico-química for permanentemente transformado e, em certo nível, reduzido. No meio tempo, a física do estado sólido se tornou parte do amplo campo da física da matéria condensada.

\section{O problema de muitos-corpos}

Do ponto de vista de um físico teórico, tanto a física do núcleo como a física dos sólidos se preocupam com um grande número de partículas ${ }^{27}$. Uma solução exata (ou mesmo uma solução numérica aproximada) para a equação de Schrödinger de muitas-partículas revela-se algo impossível ${ }^{28}$. Em ambos os campos, o sucesso inicial baseado no uso da Mecânica Quântica apoiava-se na validade (e na "eficiência irracional", tomando emprestado uma expressão cunhada por Wigner para descrever a eficiência da matemática na descrição do nosso mundo) das aproximações para partículas individuais e para valores médios dos campos. Isto é, eram abordagens que negligenciavam a interação das partículas entre si, ou apenas as incluíam como aproximações um tanto quanto cruas $^{29}$. Tais modelos funcionam surpreendentemente bem em alguns casos ${ }^{30}$, apesar da presença de fortes interações entre as partículas, mas falham comple-

27 O número de partículas (núcleons) em um núcleo atômico é bem menor que aquelas envolvidas em um sólido. Entretanto, na física de partículas que interagem, qualquer número maior que dois deve ser considerado grande, como ilustra a história da teoria quântica do átomo de hélio.

28 Em sólidos, o número de partículas envolvidas é da ordem de grandeza de $10^{23}$. É a interação coulombiana entre as partículas, por exemplo, os elétrons em um gás, que é responsável por uma "catástrofe combinatória" ou "catástrofe de dimensão".

29 De modo resumido, o teórico assume que o comportamento de uma partícula individual somente depende do valor médio do campo criado por todas as outras partículas de uma maneira estatística.

30 Nós já havíamos encontrado a teoria de Sommerfeld-Drude de elétrons em metais e a teoria da banda de sólidos, bem como a teoria de Weiss do campo molecular em imãs. 
tamente em algumas outras ${ }^{31}$. O que motivou este fato só foi compreendido nos anos 1950, após o advento da eletrodinâmica quântica.

Superar as abordagens de partículas individuais requereu o desenvolvimento de métodos que atacavam o problema de muitos corpos e forneciam meios para tratar as correlações entre as partículas em um sistema de muitos-corpos que interagem. Esse era um gargalo essencial para o desenvolvimento tanto da teoria nuclear como do estado-sólido e, após a Guerra, um número crescente de físicos começou a desenvolver um interesse mais amplo nesse problema, buscando por novas técnicas que permitiriam abordá-lo. Conyers Herring (1980, p. 71-72) recorda:

Ainda que as pessoas soubessem desde os primórdios da Mecânica Quântica que a verdadeira função de onda do estado-fundamental de um sistema de muitos-elétrons devesse ser de uma forma mais complicada que um determinante das funções de onda de um elétron, e ainda que a importância da correção da "energia de correlação" para um cálculo com a teoria de banda da energia coesiva de um metal tenha sido claramente reconhecida por Wigner e Seitz em 1933 e $1934^{32}$, a dimensão e o papel da energia de correlação permaneceram compreendidos inadequadamente em uma parte considerável da comunidade do estado-sólido por muitos anos. Talvez a complicação do importante artigo de $1934^{33}$ de Wigner, que continha uma estimativa surpreendentemente boa da energia de correlação de um gás de elétrons-livres, criou a esperança enganadora na direção de julgar tais efeitos como sendo menores do que havia sido estimado.

Durante quase duas décadas, a expansão perturbativa da energia de correlação, desenvolvida por Wigner, que Herring menciona na citação acima, permaneceu como o estado-da-arte no problema prototípico de muitos-corpos do gás de elétrons livres. Wigner, entretanto, deixou de notar que a contribuição

31 Por exemplo, a supercondutividade ou o cálculo da energia coesiva de metais (HODDESON et al., 1992b).

32 O trabalho de Wigner e Seitz (1933) sobre o sódio metálico é possivelmente o primeiro exemplo de uma aplicação bem sucedida quantitativamente dos métodos quanto-mecânicos ao comportamento de materiais reais (em oposição aos mais antigos modelos idealizados).

33 Neste artigo, Wigner (1934) estuda a interação de elétrons em um gás de elétrons livres através de uma abordagem variacional (ver, por exemplo, PINES, 1961). A "energia de correlação" introduzida por Wigner é uma contribuição puramente quanto-mecânica para a energia de ligação de elétrons em sólidos (HODDESON et al., 1992b, p. 491). Enquanto, inicialmente, ele apenas conseguiu fornecer estimativas para essa energia de correlação nos limites de baixadensidade (Cristal de Wigner) e alta-densidade, Wigner (1938) posteriormente estendeu sua teoria ao interpolar os dois limites extremos. 
da próxima ordem para sua expansão perturbativa da energia de correlação (ver nota 32) é logaritimicamente divergente, devido à natureza de longo alcance da interação coulombiana. De acordo com David Pines (apud HODDESON et al., 1992b, p. 587), essa divergência desencorajadora "[...] atrasou a aplicação sistemática da teoria perturbativa do gás de elétrons por cerca de 20 anos" ${ }^{34}$ Devido à natureza de longo alcance da interação de Coulomb e das divergências resultantes, as abordagens perturbativas, tão bem sucedidas em outras áreas onde a Mecânica Quântica foi usada, tinham que ser complementadas com aproximações um tanto quanto cruas, que resolviam a blindagem da carga eletrônica de um elétron pelos outros elétrons. ${ }^{35} \mathrm{O}$ conceito de blindagem de carga remonta ao trabalho de Debye e Hückel (1923a, 1923b) sobre plasmas clássicos e emergiu no contexto das tentativas de compreender o comportamento de eletrólitos. A física dos plasmas - gases neutros, mas altamente ionizados - era um campo ativo de pesquisa já no início da década de 1920 e ganhou enorme importância durante e após a Guerra, principalmente por sua relevância para separação de isótopos e fusão termonuclear controlada (ECKERT, 2003) ${ }^{36}$. A inclusão da blindagem de carga em teorias de sólidos, entretanto, permaneceu um tanto ad hoc e, até após a guerra, os físicos eram incapazes de fornecer uma explicação microscópica para o funcionamento do mecanismo.

David Bohm, após receber seu doutorado em Física com J. Robert Oppenheimer em 1943, havia trabalhado em física dos plasmas no Radiation Laboratory da Universidade da Califórnia durante os últimos anos da Guerra. (HODDESON et al., 1992b, p. 534-541) Nos anos do pós-guerra, em Princeton, ele continuou seu trabalho sobre plasmas e ficou particularmente interessado no que chamou plasmas quânticos - plasmas muito mais densos que aqueles encontrados em descargas gasosas - a respeito dos quais Bohm tinha esperanças de que pudessem fornecer um modelo para a compreensão do comportamento de elétrons em metais (PINES, 1987). Ele posteriormente afirmou que na conferência de Pocono, em 1948, quando ele ficou sabendo da eletrodinâmica quântica renormalizada de Schwinger, também com raízes no período da Guerra, ele percebeu que a blindagem dinâmica em um plasma quântico

34 Na teoria do calor específico dos sólidos, primeiro Paul Dirac (1930) e posteriormente John Bardeen (1936), um ex-estudante de pós-graduação de Wigner, encontraram divergências logarítimicas similares, decorrentes da mesma fonte (HODDESON et al., 1992b). O artigo de Bardeen é muito importante para a história posterior da supercondutividade.

35 Blindagem é o nome dado ao mecanismo "[...] pelo qual cada elétron mantém os outros distantes de si e assim previne que seu campo coulombiano afete mais de que seus vizinhos imediatos". (PIPPARD, 1995, p.1361)

36 A física do plasma passou por um processo similar de institucionalização aos da física nuclear e do estado-sólido e desenvolveu muitas interações tanto com a física nuclear como com a do estado sólido. 
[...] é basicamente a mesma da renormalização [da carga] na teoria das partículas elementares - quer dizer, a carga real de um elétron é infinita de acordo com aquela teoria, mas ele se encerra em uma nuvem que a torna finita (SCHWEBER, 1994 apud HODDESON et al., 1992b, p. 536);

e que os métodos teóricos quânticos de campos empregados em eletrodinâmica quântica poderiam ser úteis também em teorias do plasma quântico. Pois o advento da eletrodinâmica quântica, em fins da década de 1940, trouxe uma surpresa para os teóricos de partículas: a eletrodinâmica quântica, de certa forma, era também um problema de muitos corpos. $O$ vácuo quântico-eletrodinâmico não é vazio como o vácuo clássico, mas preenchido com uma corrente de pares partículas-antipartículas (AICHISON, 1985). A eletrodinâmica quântica não apenas fornecia os métodos teóricos para lidar com essa polarização do vácuo, mas também técnicas poderosas para lidar com os complicados cálculos perturbativos, que também se inspiraram na interpretação do novo formalismo. (KAISER, 2005)

Durante os anos 1950, a compreensão da conexão entre renormalização da carga, na eletrodinâmica quântica, e a blindagem dinâmica, em sistemas quânticos de muitos corpos, levou Bohm e outros a estabelecer analogias para a Teoria Quântica de Campos das partículas elementares que, no final, ajudaram a resolver o quebra-cabeça da interação de longo alcance coulombiana na teoria de sólidos. Um exemplo para a transferência de métodos teóricos quânticos de campos é o uso de coordenadas coletivas (permitindo a separação de coordenadas através de transformações canônicas), que apareceram de modo independente durante os anos 1950, tanto na teoria de Bohm-Pines do gás de elétrons, como na teoria dos núcleos de Bohr e Mottelson (1953). A separação de variáveis em ambos os casos permitiu o tratamento simultâneo de aspectos coletivos e individuais do comportamento de muitos-corpos e o estudo de suas relações. ${ }^{37}$ Outro

37 Em sua palestra do Nobel, Mottelson lembra que: “A situação em 1950 [...] era caracterizada pelo fato inescapável que o núcleo às vezes exibia fenômenos característicos do movimento de partículas independentes, enquanto outros fenômenos, tais como o processo de fissão e momentos quadripolos grandes, claramente envolviam um comportamento coletivo do núcleo inteiro." (MOTTELSON, 1976, p. 375). A teoria de Bohr-Mottelson explicava o espectro de baixa energia do núcleo, através do uso simultâneo de coordenadas coletivas e de partículas individuais. Pines (1987, p.74) escreve sobre a teoria de Bohm-Pines (BOHM; PINES, 1950, 1951; PINES; BOHM, 1952; BOHM; PINES, 1953; PINES, 1953): “A teoria era baseada no nosso reconhecimento de que, assim como no caso clássico, a interação coulombiana entre os elétrons fez surgir as oscilações do plasma. Nós percebemos que as oscilações tinham um papel decisivo [...]. Era necessário, primeiro, encontrar as variáveis coletivas que descreviam as ondas de plasma e, segundo, derivar um formalismo matemático no qual tanto as variáveis coletivas e de partículas individuais aparecessem.” Em ambos os casos, evidência experimental recente foi instrumental para o reconhecimento da importância dos modos coletivos. Ver também Hughes (2006). Kojevnikov (2002) constrói um paralelo entre as ideias coletivistas de David Bohm tanto na Física quanto em sua vida política. 
exemplo é a técnica dos diagramas de Feynman (1949), adotada gradualmente em ambos os campos ao longo dos anos 1950. Do início até meados da década de 1950, da mesma forma que nos anos que sucederam o advento da Mecânica Quântica, teóricos equipados com o arsenal dessas novas técnicas de muitoscorpos foram capazes de semear tanto o campo da física do estado sólido, como o da física nuclear, e as interações entre teóricos neste período eram frequentes. Em fins da década de 1950, a engenhosa transferência de métodos teóricos quânticos de campo desenvolvidos na física de partículas e nuclear despertou uma mudança fundamental na abordagem teórica à física dos sólidos. ${ }^{38}$ De repente, teorias macroscópicas receberam uma justificativa microscópica. A eficiência irracional de modelos de partículas individuais foi explicada ao se adotar ideias de renormalização da Teoria Quântica de Campos. A emergência de teorias efetivas descrevendo sólidos em termos de novas entidades fictícias (quasipartículas e excitações coletivas) era dirigida pelo desejo de se ater ao modelo de partículas individuais. ${ }^{39} \mathrm{O}$ crescimento notável da física do estado sólido como campo de pesquisa, despertado pelos desenvolvimentos experimentais durante a guerra, foi amplificado pelo desenvolvimento de um ponto de vista unificado em relação a

38 Muito do mencionado acima é focado nos desenvolvimentos ocidentais no pós-guerra. Desenvolvimentos similares aconteceram na União Soviética, de modo mais notável no grupo de Landau, representando o caso intrigante de um grupo de pesquisa que vinha trabalhando continuamente em problemas tanto de física de altas-energias, como de matéria condensada, desde fins da década de 1930. Nos primeiros anos da Guerra Fria, as interações entre o Ocidente e Oriente eram raras e o acesso às publicações era severamente limitado (na melhor das hipóteses, traduções mimeografadas de artigos de pesquisa soviéticos estavam disponíveis no Ocidente), se não impossível devido à confidencialidade. Grandes desenvolvimentos, tais como o artigo de Ginzburg e Landau (1950), passaram despercebidos no Ocidente durante anos. Foi somente em meados da década de 1950 que o intercâmbio científico entre Ocidente e Oriente aumentou e, em 1955, o American Institute of Physics iniciou o Soviet Physics JETP, tradução de um jornal russo comparável ao Physical Review em escopo e relevância (KAISER 2006; AMBEGAOKAR, 2008). Isso teve efeitos no desenvolvimento de teorias de muitos-corpos que vão além do escopo do presente texto. Para uma discussão do espalhamento dos diagramas na União Soviética, ver Kaiser e outros (2004). Da segunda metade de 1950 em diante, o intercâmbio científico no campo da física do estado sólido acelerou a passos rápidos.

39 Esse desejo era alimentado não apenas pela complexidade desafiante de cálculos diretos para problemas de muitos-corpos, a partir das equações de movimento de seus constituintes básicos, mas também da percepção empírica de que muitas propriedades dos sólidos, ainda que se refiram a sistemas de muitos-corpos que interagem, devem de qualquer forma ser descritíveis em termos de entidades independentes ou "excitações elementares". Pines (1958, p. 347) escreve: “Todos nós sabemos o quão crua é a aproximação para um elétron em sólidos; nós também sabemos o quanto ela é bem sucedida. De fato, o experimento pede que haja algo muito parecido com uma excitação de partícula independente como evidenciado, por exemplo, pelo efeito Haas-van Alphen em metais e ressonância cyclotron em semicondutores. Entretanto, a questão é se, à luz do nosso conhecimento atual da interação do elétron nos sólidos, nós podemos entender os elétrons efetivos.” Ver também Hughes (2006). 
problemas de muitos-corpos em Teoria Quântica de Campos $^{40}$ e de uma nova heurística intuitiva (a imagem de quasipartículas), que permitiu essencialmente manter os modelos de partículas individuais que haviam sido desenvolvidos anteriormente. ${ }^{41}$

\section{Campos de interação}

Ao longo do século XX, ocorreram interações importantes e fertilizações cruzadas entre física nuclear, de partículas e do estado sólido, desde antes de suas institucionalizações até o presente. Nesta seção, discutirei os modos de interação entre os campos, com ênfase em suas dinâmicas históricas. Um estudo das interações entre física de partículas, nuclear e do estado sólido revela pelo menos dois mecanismos:

a) Compartilhamento de protagonistas: o treinamento em Mecânica Quântica ou Teoria Quântica de Campos possibilitou que alguns físicos trabalhassem em ambos os campos simultaneamente. Esse mecanismo foi particularmente poderoso em fins de 1920 e início de 1930 e na era pós-guerra, isto é, nos anos após a formulação das teorias fundamentais correspondentes.

40 Ver, por exemplo, Martin e Schwinger (1959).

41 Essa nova heurística iniciou debates sobre as relações interteóricas da física de partículas e do estado-sólido. Muitos físicos mas também alguns historiadores e filósofos da física aceitam um esquema reducionista no qual a física de altas-energias é a teoria fundamental da qual a física atômica e, por sua vez, a física do estado sólido são derivadas ou pelo menos, em princípio, poderiam ser derivadas. Outros desafiaram essa visão e assumem a posição de que não há uma clara relação interteórica (ver ANDERSON, 1972 para a mais famosa exposição de uma visão antirreducionista e HUGHES, 2006, p.515-518, para uma breve discussão). O conceito de emergência em Física, de modo geral, nega à física de altas energias seu papel fundamental na hierarquia de teorias e, pelo contrário, sugere a existência de "camadas" de realidade e teorias físicas em diferentes escalas de energias, ambas independentes em essência. (LAUGHLIN; PINES, 2000) Teorias do estado sólido, de fato, tendem a não ser derivadas do nosso conhecimento sobre partículas elementares contidas em sólidos (elétrons e núcleons) e suas interações básicas. (LEGGETT, 1992) Este não é o espaço para revisar os diferentes argumentos ou a intrigante história dos debates sobre reducionismo e emergência em Física (HOWARD, 2003; KUZEMSKY, 2008; MORRISON, 2006; SCHWEBER, 1993) e em ciência em geral (KIM, 1999), os quais não apenas pertencem às questões básicas sobre a unidade da ciência (CAT, 1998), mas também têm consequências mais amplas em políticas de pesquisa, tais como as relacionadas com o financiamento de colisores de partículas supercondutores. (KEVLES, 1995, p. ix-xlii) Ver também Hartmann (2001). 
b) Fronteiras permeáveis: os métodos e conceitos desenvolvidos em um campo podiam ser transferidos e adaptados para outros, frequentemente por meio do estabelecimento de analogias formais entre dois problemas diferentes.

\subsection{Compartilhamento de protagonistas}

Nos anos seguintes ao advento da Mecânica Quântica, os campos emergentes da física nuclear e do estado sólido interagiram fortemente através do compartilhamento de protagonistas. Muitos dos pais da Mecânica Quântica e seus estudantes procuravam estender o domínio explicativo da Mecânica Quântica para fenômenos fora do campo da física atômica, com a esperança de que, levando em consideração a rica fenomenologia dos sólidos e do núcleo, poder-se-ia ajudar a avançar a Teoria Quântica ao se testar as limitações da Mecânica Quântica e ao fornecer novas pistas para sua extensão. O conhecimento da velha Teoria Quântica sugeriu a aplicabilidade da Mecânica Quântica a um domínio mais amplo de fenômenos do que aqueles da espectroscopia atômica; e o conhecimento da Mecânica Quântica, especialmente da mecânica ondulatória de Schrödinger, permitiu aos físicos formular novas teorias, tanto para o subatômico como para os agregados de átomos, isto é, moléculas e sólidos. Físicos teóricos dispunham de um conjunto comum de ferramentas e técnicas que poderiam facilmente ser empregadas para o estudo dos núcleos e dos sólidos - o mesmo vale, numa extensão menor, para os experimentais. Experimentais, por outro lado, foram levados um tanto naturalmente para os campos emergentes, já que a espectroscopia não se encerrava nas séries do átomo de hidrogênio. A questão da estrutura hiperfina dos espectros atômicos forçou os físicos a pensar o papel do núcleo. ${ }^{42} \mathrm{Na}$ outra ponta do espectro, experimentais estavam interessados nos espectros de moléculas e, assim, tinham que considerar os graus de liberdade rotacionais e vibracionais, bem como as questões de ligação que formaram uma ponte natural para o estudo dos sólidos. Em física teórica, protagonistas das origens tanto da física nuclear como do estado sólido, em fins da década de 1920 e 1930, incluíam nomes tais como Heisenberg, Pauli, Debye, Bloch, Condon, H. London, F. London, Bethe, Wigner, Peierls, Landau, Seitz, Mott, Heitler e Fröhlich. Durante a década de 1930, muitos dos físicos, laborando em ambos os campos simultaneamente, começaram a abandonar um campo ou o outro (ver seção 3). Enquanto parcialmente motivados pela necessidade de acompanhar uma crescente quantidade de literatura especializada nos campos emergentes, o processo de especialização

42 Em fins dos anos 1920, por exemplo, Samuel Goudsmit, um dos descobridores do spin do elétron, foi levado naturalmente de experimentos em espectroscopia atômica para experimentos no que hoje nós consideraríamos como física nuclear, guiado por seu interesse em estrutura hiperfina. 
frequentemente era reforçado pelas restrições à emigração e pela Guerra, o que levou à prevalência da física nuclear. O treinamento especializado da geração do pós-guerra reduziu ainda mais a permeabilidade das fronteiras disciplinares para cientistas individuais. Entretanto, após a Guerra, alguns dos físicos que já haviam trabalhado em sólidos, em meados da década de 1930, decidiram retornar ao campo e físicos mais jovens gradualmente os acompanharam. Junto de si, eles levaram novas ferramentas - Teoria Quântica de Campos - que eventualmente seria aplicada com sucesso também à teoria dos sólidos.

Um exemplo de compartilhamento de protagonistas entre o início da física do estado sólido e a física nuclear é Hans Bethe. Estudante de Sommerfeld em Munique, Bethe escreveu uma dissertação, em 1926-28, explicando os experimentos de Davisson-Germer, utilizando ideias da teoria de Ewald de óptica em cristais. Após ser agraciado com uma Rockfeller fellowship em 1930, ele passou um tempo com Fowler em Cambridge, com Fermi em Roma e como assistente em Tübingen. Em 1933, junto com Sommerfeld, escreveu seu famoso artigo de referência (Handbuch) sobre Teoria Quântica dos metais (SOMMERFELD; BETHE, 1933). Emigrou em 1933 e entrou no grupo de Bragg, em Manchester, posteriormente indo para o grupo de Mott em Bristol, em 1934, tornando-se professor em Cornell em 1935. Nesses anos, ele desistiu de seu trabalho em sólidos e focou-se em física nuclear. Posteriormente lembrou:

[...] Eu imagino que provavelmente, após mais alguns anos, eu também teria sido cativado pela física nuclear. Mas aconteceu mais cedo porque eu entrei em contato com pessoas que estavam fazendo física nuclear. A Inglaterra estava cheia de física nuclear quando eu cheguei lá em 1933 e eu acho que isso teve muito a ver com o que aconteceu. De fato, Mott e eu apenas trocamos nossos papeis naquela época. Ele estava em teoria de colisões, colisões de altas energias, efeitos relativísticos em colisões e agora ele havia mudado para estado sólido. E eu fiz o contrário. ${ }^{43}$

Em 1936-37, Bethe publicou uma série de artigos de revisão sobre física nuclear, que vieram a ser conhecidos como a "Bíblia de Bethe" por uma geração subsequente de físicos. ${ }^{44} \mathrm{O}$ trabalho dele durante a Guerra estava relacionado com o radar e, principalmente, com o desenvolvimento de armas nucleares dentro do Projeto Manhattan. Após a Guerra, o físico nuclear contribuiu para a eletrodinâmica quântica, por exemplo, através de sua explicação de 1947 do desvio

43 Entrevista com Hans A. Bethe por Lillian Hoddeson, em 29 de abril de 1981, Niels Bohr Library \& Archives, American Institute of Physics, College Park, MD USA . Disponível em: $<$ http://www.aip.org/history/ohilist/4505.html>

44 Ver nota 15. 
Lamb no hidrogênio. Na década de 1950, Bethe trabalhou em teorias de muitoscorpos do núcleo (com Keith Brueckner e Jeffrey Goldstone). Posteriormente em sua vida, Bethe foi para a astrofísica e tornou-se um advogado dos movimentos de cientistas contra armas nucleares. Enquanto Bethe nunca retornou à teoria do estado sólido, suas contribuições para a teoria nuclear de muitos-corpos foi de relevância imediata também para a teoria do estado sólido.

Um colaborador próximo de Bethe nos anos 1930, Rudolf Peierls, em suas memórias descreve sua re-entrada no campo que ele havia abandonado, devido à pesquisa relacionada com a Guerra, do seguinte modo:

Antes da Guerra, a maior parte do meu trabalho havia sido em física do estado-sólido, mas havia acontecido uma grande expansão do trabalho em minha área, então eu me senti desatualizado [...] Recuperei minha conexão com a física do estado sólido de um modo incomum. Em 1953 proferi uma série de palestras em física do estado sólido na escola de verão em Les Houches [...] Isso exigiu, de uma vez, notas de aula por escrito, que eu decidi transformar em um livro. Ao escrever as notas, e posteriormente ao revisá-las para o livro, me dei conta que muitos dos problemas que eu considerava em aberto quinze anos atrás permaneciam sem solução. Esses estavam relacionados particularmente a problemas em teoria da condutividade. Eu, assim, decidi retornar a estes problemas e comecei discussões com colegas no departamento. Geoffrey Chester, que ao chegar em 1956 havia trabalhado com hélio líquido (tradicionalmente tratado junto com problemas do estado sólido, ainda que não seja muito sólido!) tornou-se interessado, e da mesma forma Armin Thellung, um visitante da Suíça, e Sam Edwards, que havia vindo em 1953 com experiência em teoria de campos e física nuclear. De seus trabalhos e de vários de seus estudantes resultaram importante esclarecimentos. (PEIERLS, 1985, p. 229)

Ambas as biografias exemplificam a tendência geral de 1930 a 1950: nos anos 1930 e durante a Guerra, o estudo dos núcleos ganhou momentum, enquanto o estudo dos sólidos perdeu o apelo, para ser retomado nos anos do pós-Guerra, fomentado pelos avanços consideráveis tanto no experimento como na teoria.

\subsection{Fronteiras permeáveis}

As fronteiras entre a física de partículas, a nuclear e a do estado sólido eram não somente permeáveis a cientistas individuais, mas também a um número 
de conceitos e técnicas importantes, especialmente com o advento da Teoria Quântica de Campos em fins da década de 1940. O conhecimento sobre métodos teóricos quânticos de campos não viajava facilmente de teórico para teórico (KAISER, 2005). Muito pelo contrário, "tecnologias teóricas" tinham que ser aprendidas em contato com aqueles que já as dominavam ou trazidas por alguém para um novo campo de pesquisa ${ }^{45}$. No início da década de 1950, a transferência de conceitos e métodos era principalmente unidirecional, de física de partículas e nuclear para física do estado sólido ${ }^{46}$. Isso só mudaria em fins da década de 1950. Não somente técnicas formais eram transferidas, mas também a heurística da física do estado sólido era influenciada pelo advento da eletrodinâmica quântica: a abordagem heurística de Feynman (GALISON, 1998), tão bem sucedida em eletrodinâmica quântica, era baseada em evitar equações fundamentais do movimento (por exemplo, a formulação hamiltoniana da eletrodinâmica quântica), em favor de uma abordagem de soluções orientadas espacialmente (por exemplo, usando funções de Green). Uma mudança semelhante no estilo de raciocínio também aconteceu na teoria do estado sólido em fins da década de 1950: o ponto de partida das descrições microscópicas para o comportamento de sólidos se afastou de abordagens construtivas baseadas na equação de Schrödinger de muitos corpos para o uso de propagadores efetivos de partículas individuais. Os novos métodos se espalharam rapidamente e revolucionaram a física do estado sólido. Abrikosov, Gordov e Dzayloshinksi, no prefácio ao seu livro de 1961, Methods of quantum field theory in statistical Physics47, descreveram esse processo do seguinte modo:

Nos últimos anos, um sucesso notável tem sido alcançado na física estatística, devido ao uso extensivo de métodos emprestados da Teoria Quântica de Campos. O fato de esses métodos serem frutíferos está associado com novas formulações da teoria da perturbação, primariamente ligada com a aplicação dos "diagramas de Feynman". A vantagem básica da técnica do diagrama está em seu caráter intuitivo: operando com conceitos de partículas únicas, nós podemos usar a técnica para determinar a estrutura de qualquer

45 Ver, por exemplo, a discussão do trabalho de Andrew Warwick e Ursula Klein (KAISER et al., 2004, p. 880-881). Ver ainda Ramsey (2000).

46 Métodos importados de teoria nuclear de muitos corpos (por exemplo, a teoria de muitos corpos de Brueckner) também foram crucialmente importantes para a química quântica. Ver Löwdlin (1995) para uma discussão da história do problema da correlação do elétron em Química.

47 O trabalho Abrikosov, Gor'kov e Dzyaloshinski (1965) é conhecido como AGD para muitos teóricos do estado sólido. Ele possivelmente se constitui como a primeira monografia sobre as novas técnicas teóricas quânticas de campo e foi rapidamente traduzido para o inglês em 1963. 
aproximação [...]. Esse novos métodos tornaram possível não somente resolver um grande número de problemas que não se rendiam à antiga formulação da teoria, mas também obter muitas novas relações de caráter geral. ${ }^{48}$

A blindagem dinâmica de cargas em sólidos era explicada microscopicamente usando os métodos de renormalização de carga da eletrodinâmica quântica, principalmente a teoria da perturbação diagramática de Feynman (1949), e se apoiando em esquemas perturbativos, inventados para a aplicação desses métodos em problemas de física nuclear. Keith Brueckner (1955) havia introduzido uma "expansão de núcleos-ligados" para o tratamento da matéria nuclear (ver, por exemplo, BETHE, 1956) e Jeffrey Goldstone (1957), introduzindo a técnica perturbativa e utilizando diagramas como os de Feynman. Com essa abordagem, ele conseguiu mostrar que a expansão de núcleos-ligados de Brueckner é exata para o estado fundamental de energia de um sistema de muitos férmions interagindo, o que permite o tratamento "do estado fundamental de partículas independentes como um 'estado de vácuo"” (GOLDSTONE, 1957, p. 268), colocando assim a analogia à eletrodinâmica quântica em bases ainda mais firmes. Ao mesmo tempo, Murray Gell-Mann, um teórico de partículas, juntamente com Brueckner, que estava predominantemente interessado em teorias de matéria nuclear, atacaram diagramaticamente o problema do limite de alta densidade de um gás de elétrons os quais interagem entre si e resolveram o quebra-cabeça das divergências que ocorriam em todas as abordagens anteriores para a energia de correlação no gás de elétrons (GELL-MANN; BRUECKNER, 1957). Seu trabalho conjunto, publicado no início de 1957, resultou de uma cooperação com um projeto RAND em fusão termonuclear (HODDESON et al., 1992b, p. 538-539). Eles notaram que as divergências na energia de correlação do gás de elétrons, contida em teorias anteriores, eram consequência de uma soma incompleta das séries de perturbação. Uma soma completa gerava uma série geométrica e as divergências eram canceladas ${ }^{49}$. O trabalho deles e o já mencionado artigo de Goldstone (1957) podem ser considerados como os primeiros exemplos da aplicação de métodos diagramáticos do tipo Feynman em uma área explicitamente conectada à teoria do estado sólido. Hoje, diagramas de Feynman são comuns no campo (ver, por exemplo, MATTUCK, 1967). A teoria da perturbação diagramática é um dos

48 Prefácio dos autores à edição russa de 1961, citado em Abrikosov; Gor’kov; Dzyaloshinski (1965).

49 Usando a teoria da perturbação diagramática, eles provaram que a divergência logarítmica que aparece na ordem mais baixa da expansão perturbativa da energia de correlação é cancelada por divergências similares, em termos de alta ordem e, assim, é uma consequência de não somar as contribuições até a infinitésima ordem. Isso permitiu derivar uma expressão para o estado de energia fundamental do gás de elétrons os quais interagem no limite de alta densidade. Ver, por exemplo, Falicov e Heine (1961, p. 75). 
vários elementos que se originaram na Teoria Quântica de Campos de partículas elementares que iniciaram uma mudança fundamental na Teoria Quântica de sólidos. Um grande conjunto de aplicações dos novos métodos teóricos quânticos de campos a problemas em física do estado sólido apareceu rapidamente ${ }^{50}$.

Em fins da década de 1950 e começo de 1960, os métodos teóricos quânticos de campos em física do estado sólido foram estendidos e desenvolvidos, frequentemente de modo independente da física de partículas. Desde então, a física da matéria condensada se tornou uma fonte de novos modelos, métodos e conceitos em Teoria Quântica de Campos em geral. A rica fenomenologia da física do estado sólido - quando comparada à física de partículas e nuclear - implicou em numerosas abordagens engenhosas e uma diversidade de novos conceitos, cujo potencial fertilizou de volta a física de altas energias. Frequentemente, ideias originárias da física de partículas, através de sua adoção na teoria do estado sólido, passaram por refinamento em suas interpretações físicas; e o estabelecimento de analogias entre física de altas energias e da matéria condensada, hoje em dia, é visto geralmente como uma fonte de inovação em ambos os campos. Nós já havíamos mencionado a história do conceito de quebra espontânea de simetria na introdução deste artigo. Um exemplo próximo datado do fim da década de 1950, ressaltando a interação intensa entre teóricos nucleares e do estado sólido baseados na teoria de muitos corpos, é o artigo de Bohr, Mottelson e Pines (BOHR et

50 O artigo de Gell-Mann e Brueckner foi imediatamente seguido por um cálculo do calor específico do gás de elétrons de alta densidade, desenvolvido por Gell-Mann (1957). No mesmo ano, Hubbard (1957a, 1957b), ao introduzir uma interação modificada entre as partículas, seguindo "um processo análogo à eliminação das partes de auto-energia do fóton da matriz S eletrodinâmica", refinou o tratamento diagramático para incluir os modos coletivos, tais como os plasmons. Sawada, Brueckner, Fukada e Brout demonstraram que a abordagem de Gell-Mann e Brueckner de fato continha as oscilações do plasma que Bohm e Pines (1953) haviam calculado e que a aproximação de fase aleatória de Bohm e Pines é exata no limite da alta densidade (SAWADA et al., 1957). Wentzel (1957), usando as novas técnicas, mostrou que "o diamagnetismo de um gás de elétrons denso é o mesmo que o de elétrons que não interagem", excluindo assim a explicação da supercondutividade (isto é, o efeito MeissnerOchsenfeld), baseada somente nas propriedades de um gás de elétrons que interagem (a teoria BCS havia acabado de ser apresentada há cerca de meio ano, mas apenas a nota curta (BARDEEN; COOPER; SCHRIEFFER, 1957a) havia sido publicada). Galitski e Midgal (1958) trataram a teoria da constante dielétrica com uma abordagem de muitos corpos. Já em fins de 1957, Bogoliubov (1958a, b) e Valatin (1958. p. 846, nota) propuseram independentemente uma técnica de transformação canônica, anteriormente desenvolvida por Bogoliubov (1947) para a teoria de superfluidos, para a supercondutividade. Logo após, Gor'kov (1958) e posteriormente Nambu (1960a) desenvolveram a abordagem teórica de campos para a supercondutividade. Beliaev (1958a, 1958b) e Heugenholtz e Pines (1959) estenderam o formalismo para bósons que interagem. Luttinger e Nozières (1962a, 1962b), posteriormente, foram bem sucedidos ao fornecer uma derivação diagramática da teoria de Landau para Líquidos de Fermi (LANDAU, 1956). Muitas das referências nesta nota de rodapé podem ser encontradas como reprints em Pines (1961). 
al., 1958), que estabeleceu uma analogia entre a supercondutividade e o espectro de baixa energia do núcleo. Em sua palestra do prêmio Nobel, Mottelson (1976, p. 377) lembrou:

Foi uma circunstância afortunada para nós que David Pines passasse um período de diversos meses em Copenhague no verão de 1957, durante o qual ele nos introduziu aos excitantes novos desenvolvimentos da teoria da supercondutividade. Através de discussões com ele, a relevância desses conceitos para o problema da correlação de pares em núcleos se tornou aparente (Bohr et al., 1958). Um componente importante dessas discussões era o fato de que evidências experimentais haviam sido acumuladas para a existência de um gap de energia no espectro de excitação do núcleo reminiscente daquele observado em supercondutores.

Outro exemplo relacionado e particularmente intrigante de fertilização cruzada é a abordagem de grupo de renormalização (SHIKOV, 1993, 2009). Originário dos trabalhos iniciais de Teoria Quântica de Campos em partículas elementares (GELL-MANN; LOW, 1954; STÜCKELBERG; PETERMAN, 1953), o grupo de renormalização só chegou à proeminência, na década de 1970, quando Kenneth G. Wilson (1971) e outros, baseados em ideias desenvolvidas em trabalhos anteriores sobre teoria da matéria condensada por Leo Kadanoff (1966) - renormalização em blocos de spin - aplicaram de modo bem sucedido esta à teoria da transição de fases e fenômenos críticos e, posteriormente, ao problema de Kondo (WILSON, 1975). O trabalho de Wilson, conforme (SCHWEBER, 1993, p. 150), “[...] deixou claro que a renormalização não era um dispositivo técnico para eliminar divergências, 'mas uma expressão da variação da estrutura das interações físicas com mudanças na escala do fenômeno sendo testado' (Gross, 1985)". O método de grupo de renormalização teve um impacto tremendo em física da matéria condensada e estatística (por exemplo, grupo de renormalização de matriz densidade), mas também em física de altas energias e no modelo padrão (por exemplo, a ideia de usar constantes acopladas), e mesmo na interpretação e desenvolvimento posterior da própria Teoria Quântica de Campos (HARTMANN, 2001; SCHWEBER, 1993, 2007). ${ }^{51}$ Este está no coração de debates efervescentes sobre o reducionismo na Física. ${ }^{52} \mathrm{O}$ impacto da física da matéria condensada em questões fundamentais da Física tem, entretanto, sur-

51 Um projeto sobre a história das técnicas de escalonamento e da interação entre física de altas energias e da matéria condensada no início dos anos 1970, chamado "Física da escala", tem sido conduzido, porém, até onde o autor sabe, infelizmente nunca foi concluído. Atualmente, está disponível em: $<$ http://authors.library.caltech.edu/5456/1/hrst.mit.edu/hrs/renormalization/public/index.html>.

52 Ver nota 40. 
preendido a físicos de altas energias. Até hoje, interações e fertilizações cruzadas entre física de altas energias e da matéria condensada são frequentes e analogias entre a Teoria Quântica de Campos de partículas elementares e fenômenos em física da matéria condensada são abundantes. ${ }^{53}$

\section{Epílogo: mecânica quântica e o crescimento e diversificação da física moderna}

Durante o século XX, a Física não somente passou por mudanças conceituais revolucionárias, mas também cresceu significativamente como disciplina científica. Kragh (1999, p. 440-441) estima um aumento por cerca de um fator 100 no número de físicos e na quantidade de publicação ao longo do último século. Isto transformou profundamente o modo pelo qual a pesquisa física é desenvolvida. Exemplos de tais transformações são as mudanças na divisão de trabalho entre teoria e experimento, a emergência da big science e da pesquisa em equipe, questões de relevância militar e tecnológica da Física e a diversificação da Física teórica em subdisciplinas especializadas. Enquanto a Física não está sozinha em sua expansão, seu crescimento certamente foi amplificado pelo espalhamento da Mecânica Quântica e pela relevância crescente da Física para o domínio militar e tecnológico ${ }^{54}$. A Mecânica Quântica, e posteriormente a Teoria Quântica de Campos, transformou-se numa estrutura unificadora para a maioria dos físicos. Ingenuamente, é possível esperar que o advento de teorias unificadoras, tais como a Mecânica Quântica e a Teoria Quântica de Campos, levaria a uma integração dos temas, não a uma diversificação acelerada. Entretanto, como foi visto, o completo oposto permanece verdadeiro: em Física, a unificação intelectual não implica integração institucional, mas o contrário - ao longo do século XX, a Física se dividiu em subdisciplinas. ${ }^{55}$ Teria então a Mecânica Quântica agido como uma semente para a diversificação? E, em caso afirmativo, quais mecanismos estavam por trás desse processo?

53 Teorias de campos conforme, estatística aniônica e teoria de campos Chern-Simons para sistemas Hall quânticos, áxions em isolantes topológicos, férmions de Dirac em grafenos, apenas para citar alguns exemplos mais recentes. Ver Fradkin (1991) e Altland e Simons (2006).

54 Ver, por exemplo, Kaiser (2002) para um estudo sobre o aumento da "mão-de-obra" científica nos Estados Unidos no pós-Guerra.

55 John H. van Vleck chamou isso de "balcanização" da Física. Seitz (1994, p. 85) recorda: “Como ele acreditava firmemente que o campo da Física era bastante unificado, van Vleck ficou bastante perturbado quando a American Physical Society começou a desenvolver divisões associadas com suas especialidades. Ele chamou isso de "balcanização" da Física e se esforçou ao máximo para retardar esse processo. Infelizmente, o enorme crescimento da sociedade eventualmente requereu algum tipo de quebra organizacional em categorias." 
Uma forma de responder a essa questão é negar que ela esteja bem colocada. Perceber a Mecânica Quântica como um formalismo unificante, desprovido de seu conteúdo, de fato é um exercício sem sentido. A Mecânica Quântica de fato integrou correntes aparentemente desconexas de desenvolvimento da Física do século XIX e início do século XX e assim levou à integração da, digamos, pesquisa em radioatividade e raios cósmicos sob o telhado da física nuclear. A Mecânica Quântica usada em física nuclear não é um conjunto fixo de ferramentas, desenvolvido em física atômica e aplicado ao domínio do núcleo, pois a própria Mecânica Quântica se desenvolveu quando fenômenos nucleares e de outras áreas foram incluídos no seu domínio explicativo. Entretanto, em uma perspectiva histórica, não pode ser negado que a subdivisão ou diversificação da Física começou mais ou menos ao mesmo tempo do advento da Mecânica Quântica. A aparente contradição pode ser removida ao se notar que os pais da Mecânica Quântica não eram simplesmente "físicos atômicos" ou espectroscopistas que haviam formulado uma teoria fundamental para descrever a riqueza de fenômenos encontrados nesta área particular da Física. Pelo contrário, muitos dos "mecânicos quânticos" iniciais eram, acima de tudo, físicos teóricos, ao invés de atômicos, nucleares ou do estado sólido. Colocar etiquetas desse tipo sobre os físicos do início do século XX é algo comum, mas altamente problemático. Enquanto o primeiro sucesso da Mecânica Quântica veio com a descrição do espectro atômico, a tradição da velha Teoria Quântica sugeria um alcance explicativo muito mais amplo. Equipados com a confiança no poder da Mecânica Quântica quanto à descrição do espectro atômico, os primeiros mecânicos quânticos começaram a estendê-la para o subatômico (isto é, física nuclear e de partículas) e para agregados de átomos (isto é, física molecular e do estado sólido, Química e, posteriormente, até mesmo Biologia Molecular).

Avanços na experimentação, frequentemente dependentes da Mecânica Quântica, tiveram um papel crucial nas décadas seguintes ao advento da mesma e forneceram uma abundância de fenômenos a serem explicados, tornando extremamente difícil para qualquer indivíduo manter-se a par de todos os desenvolvimentos. Após a Guerra, o crescimento sem precedentes no número absoluto de físicos amplificou essa tendência. Os primeiros protagonistas da "aplicação" da Mecânica Quântica a fenômenos fora do domínio do átomo eram móveis por que tinham um passado na construção da Teoria Quântica que ia bem além das questões de espectroscopia atômica. Em fins dos anos 1920 e início dos anos 1930, eles frequentemente seguiram o desenvolvimento em vários dos campos emergentes. As gerações subsequentes não tinham essa vantagem. A permeabilidade das fronteiras das disciplinas emergentes para pessoas, e também para ideias e conceitos individuais, diminuiu. O modo pelo qual a Física - Mecânica Quântica - era ensinada mudou (ver, por exemplo, KAISER, 2007). Vagarosamente, mas de maneira contínua, campos tais como a física nuclear, de partículas e do estado sólido se consolidaram como subdisciplinas bem definidas da Física em seu próprio direito. 
Só o advento da Teoria Quântica de Campos em fins dos anos 1940, suplantando - ou melhor, complementando - a Mecânica Quântica como o formalismo unificador para os campos emergentes durante os anos 1950, aproximou novamente as trajetórias da física nuclear, de partículas e do estado sólido entre si. Conceitos e métodos desenvolvidos para solucionar as aparentes contradições na Mecânica Quântica, quando esta se aproximou do acoplamento ao campo eletromagnético, foram transferidos de física de partículas para física nuclear e do estado sólido. A rica fenomenologia e a fácil acessibilidade experimental dos sólidos levaram a novos conceitos e técnicas que, em fins dos anos 1950 e início dos anos 1960, começaram a fertilização cruzada de volta para a física de partículas e nuclear. Desde então, interações entre os campos são frequentes e férteis. As interações, algumas esboçadas no presente texto, de fato refletem certa integração intelectual devido à Mecânica Quântica e à Teoria Quântica de Campos. Mas elas também se beneficiaram da diversidade de contextos, onde a física quântica é aplicada e estendida. Ao invés de concorrer para uma falta de unidade ou coerência na Física, a diversidade que brota da desintegração institucional da Física durante o século XX parece garantir sua estabilidade e não destruí-la. As origens da divisão fundamental entre os estilos de pensamento em física de altas energias e da matéria condensada e seus efeitos nas interações entre os dois campos, necessitarão de estudos históricos adicionais.

\section{Agradecimento}

O autor agradece a Olival Freire Jr. e a todos os organizadores desta conferência, pela hospitalidade, e a Finn Aaserud, Gordon Baym, Silvio Dahmen, Lillian Hoddeson, Don Howard, Anja Skaar Jacobsen, Jeremiah James, Ed Jurkowitz, Leo Kadano, Shaul Katzir, Christoph Lehner, Ben Mottelson, Felix von Oppen, Ingo Peschel, Jürgen Renn, Sam Schweber, Georges Waysand, Spencer Weart, pela suas observações e críticas que auxiliaram os vários estágios deste projeto em andamento sobre o advento dos métodos teóricos quânticos de campo em física da matéria condensada. $\mathrm{O}$ autor agradecidamente reconhece concessão de suporte do Friends of the Center for History of Physics, American Institute of Physics.

\section{Referências}

AASERUD, F. Redirecting science: Niels Bohr, philanthropy and the rise of nuclear physics. Cambridge: Cambridge University, 1990. 
ABRIKOSOV, A. A.; GOR'KOV, L. P.; DZYALOSHINSKI, I. E. Quantum field theoretical methods in statistical physics. Oxford: Pergamon, 1965.

AITCHISON, I. J. R. Nothing's plenty: the vacuum in modern quantum field theory. Contemporary Physics, v. 26, p. 333-391, 1985.

ALTLAND, A.; SIMONS, B. Condensed matter field theory. Cambridge: Cambridge University, 2006.

AMBEGAOKAR, V. The Landau school and the American Institute of Physics translation program. Physics Uspekhi, v. 51, n. 12, p. 1287-1290, 2008.

ANDERSON, P. W. More is different. Science, New Series, v. 177, p. 393-396, 1972.

BARDEEN, J. Electron exchange in the theory of metals. Physical Review, v. 50, p. 1098-1099, 1936.

BARDEEN, J.; COOPER, L. N.; SCHRIEFFER, J. R. Microscopic theory of superconductivity. Physical Review, v. 106, p. 162-164, 1957a.

$1957 b$.

. Theory of superconductivity. Physical Review, v. 108, p.1175-1204,

BELIAEV, S. T. Application of the methods of quantum field theory to a system of bosons. Soviet Physics JETP, v. 7, p. 289-299, 1958a.

. Energy spectrum of a non-ideal Bose gas. Soviet Physics JETP, v. 7, p. 299-307, 1958b.

BELLER, M. Quantum dialogue. The making of a revolution. Chicago: University of Chicago, 1999.

BETHE, H. A. The happy thirties. In: STUEWER, R. H. (Ed.). Nuclear physics in retrospect. Proceedings of a symposium on the 1930s. Minneapolis: University of Minneapolis, 1979. p. 11-26.

1956.

. Nuclear many-body problem. Physical Review, v. 103, p. 1353-1390, 
Nuclear physics. B. Nuclear dynamics, theoretical. Reviews of Modern Physics, v. 9, p. 69-244, 1937.

BETHE, H. A.; BACHER, R. Nuclear physics. A. Stationary states of nuclei. Reviews of Modern Physics, v. 8, p. 82-229, 1936.

BLOCH, F. Über die Quantenmechanik der Elektronen in Kristallgittern. Zeitschrift für Physik, v. 52, p. 555-600, 1928.

BOGOLIUBOV, N. N. On the theory of superfluidity. Journal of Physics (USSR), v. 11, p. 23-32, 1947.

. A new method in the theory of superconductivity. I. Soviet Physics JETP, v. 7, p. 41-46, 1958a.

. On a new method in the theory of superconductivity. Il Nuovo Cimento, v. 7, p. 794-805, 1958 b.

BOHM, D.; PINES, D. A collective description of electron interactions. I. Magnetic interactions. Physical Review, v. 82, p. 625-634, 1951.

. A collective description of electron interactions: III. Coulomb interactions in a degenerate electron gas. Physical Review, v. 92, p. 609-625, 1953.

. Screening of electronic interactions in a metal. Physical Review, v. 80, p. $903-904,1950$.

BOHR, A.; MOTTELSON, B. R. Collective and individual-particle aspects of nuclear structure. Kongelige Danske Matematisk-fysiske Meddelelser, v. 27, n.16, p. 1-174, 1953.

BOHR, A.; MOTTELSON, B. R.; PINES, D. Possible analogy between the excitation spectra of nuclei and those of the superconducting metallic state. Physical Review, v. 110, p. 936-938, 1958.

BORN, M. Dynamik der Kristallgitter. Berlin: Teubner, 1915.

BORN, M.; KARMAN, T. von. Über Schwingungen in Raumgittern.

Physikalische Zeitschrift, v. 13, p. 297-309, 1912. 
BRAUN, E. Selected topics from the history of semiconductor physics and its applications. In: HODDESON, L. et al. (Ed.). Out of the crystal maze: chapters from the history of solid-state physics. Oxford: Oxford University, 1992. p. 443488, 1992.

BROWN, L. M. et al. Panel session: spontaneous breaking of symmetry. In: HODDESON, L., et al. (Ed.). The rise of the Standard Model: particle physics in the 1960s and 1970s. New York: Cambridge University, 1997. p. 478-522.

BROWN, L. M.; HODDESON, L. (Ed.). The birth of particle physics: based on a Fermilab symposium. Cambridge: Cambridge University, 1983.

BUECKNER, K. A. Many-body problem for strongly interacting particles. II. Linked cluster expansion. Physical Review, v. 100, p. 36-45, 1955.

CASSIDY, D. C. Uncertainty: the life and science of Werner Heisenberg. New York: Freeman, 1992.

CAT, J. The physicists' debate on unification at the end of the 20th century. Historical Studies in the Physical and Biological Sciences, v. 28, p. 253-300, 1998.

CONDON, E. U. A theory of intensity distribution in band systems. Physical Review, v. 28, p. 1182-1201, 1926.

Nuclear motions associated with electron transitions in diatomic molecules. Physical Review, v. 32, p. 858-872, 1928.

DARRIGOL, O. A simplified genesis of quantum mechanics. Studies in History and Philosophy of Modern Physics, v. 40, p. 151-166, 2009.

DEBYE, P. Einige Resultate einer kinetischen Theorie der Isolatoren. Physikalische Zeitschrift, v. 13, p. 97-100, 1912a. 789-839, $1912 b$. Zur Theorie der spezifischen Wärmen. Annalen der Physik, v. 39, p.

DEBYE, P., HÜCKEL, E. Zur Theorie der Elektrolyte. I. Gefrierpunktserniedrigung und verwandte Erscheinungen. Physikalische Zeitschrift, v. 24, p. 185-208, 1923a. 
Zur Theorie der Elektrolyte. II. Das Grenzgesetz für die elektrische Leitfähigkeit. Physikalische Zeitschrift, v. 24, p. 305-328, 1923b.

DIRAC, P. A. M. Note on exchange phenomena in the Thomas atom. Proceedings of the Cambridge Philosophical Society, v. 26, p. 376-385, 1930.

DRUDE, P. Optische Eigenschaften und Elektronentheorie. I. Teil. Annalen der Physik, v. 14, p. 677- 725, 1904.

Zur Elektronentheorie der Metalle: 1. Teil. Annalen der Physik, v. 1, p. 566-613, 1900a;

. Zur Elektronentheorie der Metalle: 2. Teil. Annalen der Physik, v. 3, p. 369- 402, 1900b.

. Zur Elektronentheorie der Metalle: Berichtigung. Annalen der Physik, v. 7, p. 687-692, 1902.

ECKERT, M. Plasmas and solid-state science. In: NYE, Mary Jo (Ed.). The Cambridge history of Science, 2003. p. 413-428. (The modern physical and mathematical sciences, v. 5).

ECKERT, M.; SCHUBERT, H. Kristalle, elektronen, transistoren: von der Gelehrtenstube zur Industrieforschung. Reinbek bei Hamburg: Rowohlt, 1986.

. Crystals, electrons, transistors: from scholar's study to industrial research. Trans. by Thomas Hughes.Berlin: Springer, 1990.

ECKERT, M.; SCHUBERT, H.; TORKAR, G. The roots of solid-state physics before quantum mechanics. In: HODDESON, L. et al. (Ed.). Out of the crystal maze: chapters from the history of solid-state physics. Oxford: Oxford University, 1992. p. 3-87.

EINSTEIN, A. Die plancksche theorie der strahlung und die theorie der spezifischenw"arme. Annalen der Physik, v. 22, p. 180-190, 1907.

. Eine Beziehung zwischen dem elastischen Verhalten und der spezifischen Wärme bei festen Körpern mit einatomigem Molekül. Annalen der Physik, v. 34 , p. $170-174,1911$ a. 
. Elementare Betrachtungen über die thermische Molekularbewegung in festen Körpern. Annalen der Physik, v. 35, p. 679-694, 1911b.

Quantentheorie des einatomigen idealen Gases. Sitzungsberichte der Preussischen Akademie der Wissenschaften. Physikalisch-Mathematische Klasse, 1924. p. 261-267.

Quantentheorie des einatomigen idealen Gases. Zweite Abhandlung. Sitzungsberichte der Preussischen Akademie der Wissenschaften. PhysikalischMathematische Klasse, v. 23, p. 3-14, 18-25, 1925.

FALICOV, L. M.; HEINE, V. The many-body theory of electrons in metal or has a metal really got a Fermi surface? Advances in Physics, v. 10, p. 57-105, 1961.

FETTER, A. L.; WALECKA, J. D. Quantum theory of many-particle systems. New York: McGraw-Hill, 1971.

FEYNMAN, R. P. The theory of positrons. Physical Review, v. 76, p. 749-759, 1949.

FISCHER, K. Changing landscapes of nuclear physics: a scientometric study on the social and cognitive position of German-speaking emigrants within the nuclear physics community 1921-1947. Berlin: Springer, 1993.

FORMAN, P. Swords into ploughshares: breaking new ground with radar hardware and technique in physical research after World War II. Reviews of Modern Physics, v. 67, p. 397-455, 1995.

FRADKIN, E. Field theories of condensed matter systems. Redwood City, CA: Addison-Wesley, 1991.

FRIEDRICH, W.; KNIPPING, P.; LAUE, M. von. Interferenz-Erscheinungen bei Röntgenstrahlen. Sitzungsberichte der Mathematisch-Physikalischen Classe der Königlich-Bayerischen Akademie der Wissenschaften zu München, p. 303-322, 1912.

GALISON, P. Feynman's war: modelling weapons, modelling nature. Studies in History and Philosophy of Science Part B: Studies In History and Philosophy of Modern Physics, v. 29, p. 391-434, 1998. 
GALITSKII, V.; MIGDAL, A. Application of quantum field theory methods to the many body problem. Soviet Physics JETP, v. 7, p. 96-104, 1958.

GAMOV, G. Constitution of atomic nuclei and radioactivity. Oxford: Clarendon, 1931.

. Zur Quantentheorie des Atomkernes. Zeitschrift f"ur Physik, v. 52, p. 204-212, 1928.

GAVROGLU, K. Fritz London: a scientific biography. Cambridge: Cambridge University, 1995.

GELL-MANN, M. Specific heat of a degenerate electron gas at high density. Physical Review, v. 106, p. 369-372, 1957.

GELL-MANN, M; BRUECKNER, K. A. Correlation energy of an electron gas at high density. Physical Review, v. 106, p. 364-368, 1957.

GELL-MANN, M.; LOW, F. Quantum electrodynamics at small distances. Physical Review, v. 95, p. 1300-1312, 1954.

GINZBURG, V. L.; LANDAU, L. D. On the theory of superconductivity. Zhurnal Eksperimental'noi i Theoreticheskoi Fiziki, v. 20, p. 1064-1082, 1950.

GOLDSTONE, J. Derivation of the Brueckner many-body theory. Proceedings of the Royal Society, A239, p. 267-279, 1957.

GOR'KOV, L. P. On the energy spectrum of superconductors. Zhurnal Eksperimental'noi $i$ Theoreticheskoi Fiziki, v. 34, p. 735-739, 1958. Translation in: Soviet Physics JETP, v. 7, p. 505-508, 1958.

GROSS, D. On the uniqueness of physical theories. In: DETAR, C.; FINKELSTEIN, J.; TAN, C.-I. (Ed.). A passion for physics. Singapore: World Scientific, 1985.

GURNEY, R. W.; CONDON, E. U. Wave mechanics and radioactive disintegration. Nature, v. 122, p. 439, 1928.

HANLE, P. A. The coming of age of Erwin Schr"odinger: His quantum statistics of ideal gases. Archive for the History of the Exact Sciences, v. 17, p. 165-192, 1971. 
. The Schrödinger-Einstein correspondence and the sources of wave mechanics. American Journal of Physics, v. 47, n. 7, p. 644-648, 1979.

HARTMANN, S. Effective field theories, reductionism and scientific explanation. Studies in History and Philosophy of Modern Physics, v. 32, p. 267-304, 2001.

HARTREE, D. W. Review: The constitution of atomic nuclei and radioactivity by G. Gamow. The Mathematical Gazette, v. 16. n. 220, p. 284-285, 1932.

HEILBRON, J. L.; SEIDEL, R. W. Lawrence and his laboratory: a history of the Lawrence Berkeley Laboratory. Berkeley: University of California, 1989. v. 1

HEISENBERG, W. Mehrkörperproblem und Resonanz in der Quantenmechanik. Zeitschrift für Physik, v. 38, p. 411-426, 1926.

1932a.

. Über den Bau der Atomkerne. I. Zeitschrift für Physik, v. 77, p. 1-11, . Über den Bau der Atomkerne. II. Zeitschrift für Physik, v. 77, p. 156164, p. 1932 b. 596, 1933.

Über den Bau der Atomkerne. III. Zeitschrift für Physik, v. 80, p. 587-

HEITLER, W.; LONDON, F. Wechselwirkung neutraler Atome und homöopolare Bindung nach der Quantenmechanik. Zeitschrift für Physik, v. 44, p. 455-472, 1927.

HENDRY, J. The creation of quantum mechanics and the Bohr-Pauli dialogue. Dordrecht: Reidel, 1984.

HERRING, C. Recollections. Proceedings of the Royal Society of London. Series A: Mathematical and Physical Sciences, n. 371, (1744), p. 67-76, 10 jun. 1980.

HODDESON, L. et al. (Ed.). Out of the crystal maze: chapters from the history of solid-state physics. Oxford: Oxford University, 1992a.

HODDESON, L. et al. Collective phenomena. In: HODDESON, L. et al. (Ed.). Out of the crystal maze: chapters from the history of solid-state physics. Oxford: Oxford University, 1992c. p. 489-616. 
HODDESON, L., BAYM, G. The development of the quantum mechanical electron theory of metals, 1900-28. In: MOTT, N. F. (Ed.). The beginnings of solid state physics. London: The Royal Society: Cambridge University, 1980. p. 8-23.

HODDESON, L.; BAYM, G.; ECKERT, M. The development of the quantum mechanical electron theory of metals, 1926-1933. In: HODDESON, L. et al. (Ed.). Out of the crystal maze: chapters from the history of solid-state physics. Oxford: Oxford University, 1992b. p. 88-181).

HODDESON, L.; DAITCH, V. True genius: the life and science of John Bardeen. Washington, D. C.: Joseph Henry, 2002.

HOWARD, D. Reduction and emergence in the physical sciences: some lessons from the particle physics-condensed matter physics debate. 2003. Unpublished manuscript, available online: $<$ http://www.nd.edu/ dhoward1/Papers.html $>$

HUBBARD, J. The description of collective motions in terms of many-body perturbation theory. Proceedings of the Royal Society, A239, p. 267-279, 1957a.

. The description of collective motions in terms of many-body perturbation theory. II. The correlation energy of a free-electron gas. Proceedings of the Royal Society, A243, p. 336-352, 1957b.

HUGENHOLTZ, N. M.; PINES, D. Ground-state energy and excitation spectrum of a system of interacting bosons. Physical Review, v. 116, p. 489-506, 1959.

HUGHES, J. Modernists with a vengeance": Changing cultures of theory in nuclear science, 1920-1930. Studies in History and Philosophy of Modern Physics, v. 29, p. 339-367, 1998.

. Radioactivity and Nuclear Physics. In: NYE, Mary Jo (Ed.). The Cambridge history of Science. Cambridge: Cambridge University, 2003. p. 350374. (The modern physical and mathematical sciences, v. 5).

HUGHES, R. I. G. Theoretical Practice: the Bohm-Pines quartet. Perspectives on Science, v. 14, p. 457-524, 2006.

JOAS, C.; KATZIR, S. Analogy, extension, and novelty: Young Schrödinger on electric phenomena in solids. [200?]. Submitted for publication to Studies in History and Philosophy of Modern Physics. Unpublished. 
JURKOWITZ, E. P. Interpreting superconductivity: the history of quantum theory and the theory of superconductivity and superfluidity, 1933-1957. 1995, Thesis (Doctor) - University of Toronto, 1995.

KADANO, L. P. Scaling laws for Ising models Near Tc. Physics, v. 2, p. 263, 1966.

KAISER, D. Drawing theories apart: the dispersion of Feynman diagrams in postwar physics. Chicago: University of Chicago, 2005.

. The physics of spin: Sputnik politics and American physicists in the 1950s. Social Research, v. 73, p. 1225-1252, 2006.

Scientific manpower, cold war requisitions, and the production of American physicists after World War II. Historical Studies in the Physical and Biological Sciences, v. 33, p. 131-159, 2002.

Turning physicists into quantum mechanics. Physics World, 20, p. 28-33, may 2007.

KAISER, D.; ITO, K.; HALL, K. Spreading the tools of theory: Feynman diagrams in the USA, Japan, and the Soviet Union. Social Studies of Science, v. 34, p. 879-922, 2004.

KEVLES, D. J. The physicists: the history of a scientific community in modern America. 2nd ed. Cambridge: Harvard University, 1995.

KIBBLE, T. W. B. Englert-Brout-Higgs-Guralnik-Hagen-Kibble mechanism. Scholarpedia, v. 4, n. 1, p. 8741, 2009.

KIM, J. Making Sense of Emergence. Philosophical Studies, v. 95, p. 3-36, 1999.

KOJEVNIKOV, A. David Bohm and collective movement. Historical Studies in the Physical and Biological Sciences, v. 33, p. 161-192, 2002.

KRAGH, H. Quantum Generations. Princeton: Princeton University, 1999.

KUZEMSKY, A. L. Works by D. I. Blokhintsev and the development of quantum physics. Physics of Particles and Nuclei, v. 39, p. 137-172, 2008.

LANDAU, L. D. The theory of a Fermi liquid. Zhurnal Eksperimental'noi $i$ Theoreticheskoi Fiziki, v. 30, p. 1058-1064, 1956. 
LAUGHLIN, R. B. A different universe: reinventing physics from the bottom down. New York: Basic Books, 2005.

LAUGHLIN, R. B.; PINES, D. The theory of everything. Proceedings of the National Academy of Science,USA, v. 97, p. 28-31, 2000.

LEGGETT, A. J. On the nature of research in condensed-state physics.

Foundations of Physics, v. 22, p. 221-233, 1992.

LIVINGSTON, M. S.; BETHE, H. A. Nuclear physics. C. Nuclear dynamics, experimental. Reviews of Modern Physics, v. 9, p. 245-390, 1936.

LÖWDIN, P.-O. The historical development of the electron correlation problem. International Journal of Quantum Chemistry, v. 55, p. 77-102, 1995.

LUTTINGER, J. M.; NOZI'ERES, P. Derivation of the Landau theory of Fermi liquids. I. Formal preliminaries. Physical Review, v. 127, p. 1423-1431, 1962a.

. Derivation of the Landau theory of Fermi liquids. II. Equilibrium properties and transport equation. Physical Review, v. 127, p. 1431-1440, 1962b.

MARTIN, P. C.; SCHWINGER, J. Theory of many-particle systems. I. Physical Review, v. 115, p. 1342-1373, 1959.

MATRICON, J.; WAYSAND, G. Cold wars: a history of superconductivity. New Brunswick, NJ: Rutgers University, 2003.

MATTUCK, R. D. A guide to Feynman diagrams in the many-body problem. London: McGraw-Hill, 1967.

MIGDAL, A. Interaction between electrons and lattice vibrations in a normal metal. Soviet Physics JETP, v. 7, p. 996-1001, 1958.

MORRISON, M. Emergence, reduction, and theoretical principles: rethinking fundamentalism. Philosophy of Science, v. 73, p. 876-889, 2006.

MOTTELSON, B. Elementary modes of excitation in the nucleus. Reviews of Modern Physics, v. 48, p. 375-383, 1976.

MOYER, M. History of physics. Osiris, 2nd series, v. 1, p. 163-182, 1985. 
NAMBU, Y. Axial vector current conservation in weak interactions. Physical Review Letters, v. 4, p. 380-382, 1960 b.

Quasi-particles and gauge invariance in the theory of superconductivity. Physical Review, v. 117, p. 648-663, 1960a.

. Research in elementary particle theory. In: EGUCHI, T.; NISHIJIMA, K. (Ed.). Broken symmetry. Singapore: World Scientific, 1995. Selected papers of Y. Nambu, p. vii-xiv.

NAMBU, Y.; JONA-LASINIO, G. Dynamical model of elementary particles based on an analogy with superconductivity. I. Physical Review, v. 122, p. 345-35, 1961a.

. Dynamical model of elementary particles based on an analogy with superconductivity. II. Physical Review, v. 124, p. 246-254, 1961b.

NOZI'ERES, P.; PINES, D. A dielectric formulation of the many body problem: Application to the free electron gas. Il Nuovo Cimento, v. 9, p. 470-490, 1958.

PAIS, A. Inward bound: of matter and forces in the physical world. Oxford: Clarendon, 1986.

PAULI, W. Über Gasentartung und Paramagnetismus. Zeitschrift für Physik, v. 41, p. 81-102, 1926.

PEIERLS, R. Bird of passage: recollections of a physicist. Princeton: Princeton University, 1985.

. Elektronentheorie der Metalle. Ergebnisse der exakten

Naturwissenschaften, v. 11, p. 264-321, 1932.

PICKERING, A. Constructing quarks: a sociological history of particle physics. Edinburgh: Edinburgh University, 1984.

PINES, D. A collective description of electron interactions: IV: electron interaction in metals. Physical Review, v. 92, p. 625-636, 1953.

The collective description of particle interactions: from plasmas to the Helium liquids. In: HILEY, B. J.; PEAT, F. D. (Ed.). Quantum implications: essays in honour of David Bohm. Henley-on-Thames: Routledge, 1987. p. 66-84. 
Supplemento 2,

. The many-body problem. Reading, Mass.: Addison-Wesley, 1961.

PINES, D.; BOHM, D. A collective description of electron interactions: II: collective vs individual particle aspects of the interactions. Physical Review, v. 85, p. 338-353, 1952.

PIPPARD, A. B. The cat and the cream. Physics Today, p. 38-41, nov. 1961.

. Electrons in solids. In: BROWN, L. M.; PAIS, A.; PIPPARD, A. B. (Ed.). Twentieth century physics. New York: Institute of Physics Publishing, 1995. v. 3, p. $1279-1383$

RAMSEY, J. Of parameters and principles: producing theory in twentieth century physics and chemistry. Studies in History and Philosophy of Modern Physics, v. 31, p. 549-567, 2000.

RIORDAN, M.; HODDESON, L. Crystal fire. The invention of the transistor and the birth of the information age. New York: W. W. Norton, 1998.

SAWADA, K. et al. Correlation energy of an electron gas at high density: plasma oscillations. Physical Review, v. 108, p. 507-514, 1957.

SCHRÖDINGER, E. Gasentartung und freie Wegl"ange. Physikalische Zeitschrift, v. 25, p. 41-45, 1924.

Studien über Kinetik der Dielektrika, den Schmelzpunkt, Pyround Piezoelektrizit" at. Sitzungsberichte der kaiserlichen Akademie der Wissenschaften in Wien. Mathematisch-naturwissenschaftliche Klasse, Abteilung 2a, v. 121, p. 1937-1972, 1912.

SCHWEBER, S. S. Changing conceptualization of renormalization theory. In: BROWN, L. M. (Ed.). Renormalization: from Lorentz to Landau (and beyond). New York: Springer, 1993. p. 135-166.

. Postscript. In: GAVROGLU, K.; RENN, J. (Ed.). Positioning the history of science. Dordrecht: Springer, 2007. p. 185-188.

. QED and the men who made it. Princeton: Princeton University, 1994. 
SEITZ, F. The modern theory of solids. New York: McGraw-Hill, 1940. . On the frontier: my life in science. New York: AIP, 1994.

SHIRKOV, D. V. Historical remarks on the renormalization group. In: BROWN, L. M. (Ed.). Renormalization: from Lorentz to Landau (and beyond). New York: Springer, 1993. p. 167-186.

Sixty years of broken symmetries in quantum physics (from the Bogoliubov theory of superfluidity to the Standard Model). Physics Uspekhi, v. 52, p. 549-557, 2009.

SMITH, C. S. The prehistory of solid state physics. Physics Today, v. 18, n. 12, p. 18-30, 1965.

SOMMERFELD, A. Zur Elektronentheorie der Metalle. Die Naturwissenschaften, v. 15, p. 825-832, 1927.

SOMMERFELD, A.; BETHE, H. A. Elektronentheorie der Metalle. In: GEIGER, H.; SCHEEL, K. (Ed.). Handbuch der Physik. Berlin: Springer, 1933. v. 24, part 2, p. 333-622.

STÜCKELBERG, E. C. G.; PETERMAN, A. La normalisation des constantes dans la th'eorie des quanta. Helvetica Physica Acta, v. 26, p. 499-520, 1953.

STUEWER, R. H. (Ed.). Nuclear physics in retrospect: proceedings of a symposium on the 1930s. Minneapolis: University of Minnesota, 1979.

VALATIN, J. G. Comments on the theory of superconductivity. Il Nuovo Cimento, v. 7, p. 843-857, 1958.

WARNOW-BLEWETT, J.; TEICHMANN, J. International catalog of sources for history of physics and allied sciences, report no. 6: Guide to sources for history of solid state physics. New York: Center for History of Physics/ American Institute of Physics, 1992.

WEART, S. R. The Solid Community. In: HODDESON, L. et al. (Ed.). Out of the crystal maze: chapters from the history of solid-state physics. Oxford: Oxford University Press, 1992. p. 617-669. 
WEINER, C. 1932-Moving into the new physics. Physics Today, v. 25, p. 40-49, 1972.

WENTZEL, G. Diamagnetism of a dense electron gas. Physical Review, v. 108, p. 1593-1596, 1957.

WIGNER, E. Effects of the electron interaction on the energy levels of electrons in metals. Transactions of the Faraday Society, v. 38, p. 678-685, 1938.

. On the interaction of electrons in metals. Physical Review, 46, 10021011, 1934.

WIGNER, E.; SEITZ, F. On the constitution of metallic sodium. Physical Review, v. 43, p. 804-810, 1933.

WILSON, K. G. The renormalization group: critical phenomena and the Kondo problem. Reviews of Modern Physics, v. 47, p. 773-840, 1975.

Renormalization group and critical phenomena. I. Renormalization group and the Kadanoff scaling picture. Physical Review B, v. 4, p. 3174-3183, 1971. 



\section{Parte II}

\section{Implicações filosóficas da Teoria Quântica}





\title{
“Construção do objeto” e objetividade na Física Quântica1
}

\author{
Michel Paty
}

\section{Introdução}

Habitualmente, a Física Quântica dá ao público, aos filósofos, mas também aos próprios físicos, a impressão de ser totalmente construída pelo pensamento e, até mais, por dispositivos experimentais, do que de ser dada pela natureza; ou, pelo menos, aparenta tratar menos diretamente desta, como geralmente concebemos que fazem as outras teorias mais clássicas da Física. Na mecânica quântica, fala-se de "preparação de estados", de "teoria da medição", de intervenção irredutível do observador sobre o objeto observado etc.; na física das partículas e dos campos quânticos, insiste-se sobre o lado "artificial" e a aparência de jogos de construção (Matemática) das partículas fundamentais, a partir de teorias de grupos de simetrias, de números quânticos ou do conceito de gauge (calibre). Tal como os quarks, com suas estranhas propriedades de cargas elétricas e bariônicas não-inteiras, seu "confinamento", sua "liberdade assintótica", seus "sabores" e suas "cores"... Atendo-nos às expressões inventadas pelos físicos por necessidade de causa, pareceria, à primeira vista, que tais elaborações teóricas corresponderiam antes a um jogo formal que à descrição dos fenômenos da natureza e das propriedades objetivas (das propriedades dos objetos), as quais se imporiam naturalmente. Mas, em verdade, estas construções não são gratuitas, a julgá-las pelas experiências efetuadas neste domínio, que revelam ou criam fenômenos que essas construções permitem analisar e caracterizar de maneira circunstanciada e precisa. A formulação dos conceitos mencionados resulta de tais análises e as experiências correspondem, de alguma forma, às respostas da natureza às questões que lhe são postas em tais termos.

1 Traduzido do original francês por Geovana Monteiro e revisado pelo autor. 
Além disso, problemas de interpretação se mostram há muito tempo de tal modo que colocam a questão da relação entre oformal, subentendido matemático ("funções de estado", definidas sobre os espaços matemáticos de Hilbert, grandezas "observáveis" como "operadores hermitianos não comutativos" operando sobre tais espaços etc.), e o físico, sob benefício de se entenderem acerca do que este último qualificativo significa exatamente: o empírico, o "dado aos sentidos", o mensurável, o natural (physis), dado em uma relação; e qual relação? (para não dizer cruamente o real, relativo a certo domínio). Certamente, é sabido que os fenômenos são aproximados "indiretamente", que eles são incompletamente dados pela observação ou pela medida, que são determinados apenas de maneira probabilística etc.

Mencionamos, entre outros problemas de interpretação, o da natureza da teoria e de seu objeto (este último sendo supostamente descrito por aquela); o problema das propriedades atribuíveis ou não a sistemas físicos, a eventualidade de completar a teoria por "variáveis ocultas" suscetíveis de restabelecer o determinismo clássico; a possibilidade de conceber ou de recusar a "não-localidade" (mais precisamente, a "não-separabilidade local") para subsistemas correlatos; e, ainda, a reconciliação entre o domínio quântico e o domínio clássico, este último que corresponde a objetos e propriedades de objetos de concepção mais direta...

Contudo, todos os conceitos que caracterizam os fenômenos quânticos se organizam em uma teoria coerente e potente, a qual parece corresponder bem à "necessidade dos fenômenos", de modo que estes não ficam tão distantes quanto parecia da objetividade. Como, então, se caracterizaria melhor o método de acesso ao conhecimento desse domínio da Física: por construção ou conforme a objetividade? Como estes dois métodos se conciliam no trabalho dos físicos e na operacionalização dos resultados obtidos? $\mathrm{E}$ como isto se dá no tocante às concepções epistemológicas correspondentes: construtivismo ou objetivismo? Qual é o lugar da teoria e da experiência, respectivamente, nestas duas perspectivas? E, finalmente, o que se pode dizer da natureza da teoria de tal domínio: ela é fundamentalmente matemática e aplicada ou propriamente física? (É necessário, então, por outro lado, precisar o que se compreende por este último termo, ou seja, a particularidade de conceitos, e de sistemas de conceitos, físicos).

Notamos ainda que, em Física, é possível distinguir dois tipos de proposições capazes de se situarem diferentemente uma do outra com relação ao "construtivismo": aquelas referentes aos modelos teóricos, que se "se ajustam aos fenômenos" (ou seja, que tentam segui-los nos detalhes), e aquelas que exprimem antes de tudo propriedades fundamentais, ligadas a traços estruturais destes fenômenos através de sua representação e que são de alcance mais geral (propriedades reunidas, por exemplo, na formulação de princípios físicos, tais como princípios de simetria e de invariância). O resultado da elaboração teórica recebe, pelos dois modos de 
pensamento (por modelos e teórico, propriamente dito), um estatuto de verdade diferente (parcial e pragmático para o primeiro, holista e universalizante, e até mais normativo, para o segundo). Podemos também questionar se o critério da adequação entre a representação teórica e o representado (o "objeto físico real") basta para esgotar a noção de verdade.

Tendo posto essas considerações preliminares - como tantos questionamentos -, chegamos ao ponto que se trata aqui de esclarecer, sobre "a objetividade e o construtivismo". Distingo aí, no que concerne ao domínio científico do qual pretendo falar (a Física, e mais particularmente, a Física Quântica), três aspectos que abordarei sucessivamente. O primeiro aspecto é este de saber se os conceitos científicos (para nós, os da Física, mais particularmente, os da Física Quântica) correspondem a uma realidade objetiva ou a qualquer que seja que se possa qualificar de objetivo. Este aspecto corresponde ao debate "tradicional" entre físicos e filósofos sobre a interpretação na Física Quântica; sendo o objeto deste debate precisamente qualificar esse "qualquer que seja": realidade física propriamente dita ou entidade mista "físico-observacional"? Tal aspecto conduz diretamente ao que podemos, de fato, encontrar na prática intelectual desse campo disciplinar quanto à forma e ao conteúdo dos conhecimentos e, em definitivo, quanto a sua significação.

O segundo aspecto corresponde aos processos pelos quais esta representação é obtida, que podemos reunir sob o qualificativo de "construção". Trata-se de uma construção não somente intelectual, mas também social - historiadores e filósofos falam neste sentido, há muitos anos, de "construtivismo". A questão posta sobre a "objetividade" de tal construção não coincide necessariamente com a questão precedente, a que se atinha às formas e conteúdos. Levando em consideração os processos, as práticas efetivas e os contextos, fazemos intervir outros esclarecimentos que mostram certo grau mínimo de contingência desses conteúdos de conhecimento elaborados e construídos. Esta contingência faz, para alguns, se esvair a pertinência de uma referência trans-histórica ou trans-social para representações que supostamente dizem respeito à natureza: a esta altura, a ciência seria apenas o reflexo de sua própria atividade (essencialmente social) e não nos diria nada sobre o mundo. Os cientistas (e outros como eles, que sabem distinguir raciocínio e sofisma) dificilmente admitirão uma posição tão extrema, que não diferencia os diversos gêneros da atividade humana, sem consideração para as significações correspondentes. Seu bom senso - o mesmo que acompanha sua própria prática e inteligência de sua ciência - lhes faz recusar justificadamente este reducionismo antropossociológico que ignora os conteúdos de sentido.

Descartadas tais aberrações, resta, entretanto, que os elementos de contingência, derivados das circunstâncias sociohistóricas da produção dos conhecimentos, não podem ser ignorados ou subestimados. Considerá-los e refletir sobre eles constitui o terceiro aspecto da questão aqui posta. Este aspecto refere-se ao 
próprio valor do conhecimento como esforços e conteúdos. Perguntar-nos-emos, particularmente, em que medida ainda podemos falar de "objetividade" para uma construção de representação de um "objeto natural" suposto e mesmo visado, mas cujos materiais e modalidades seriam contingentes por natureza. Seremos levados a examinar o sentido exato que podemos dar, para a Física (entre as ciências), a idéia de "construção de objetividade"; e em que medida ela corresponde a uma "construção de objetos" que não seja factícia e ilusória.

\section{Os conceitos científicos (físicos, quânticos) correspondem a uma objetividade?}

Os conceitos da Física e, de um modo geral, os conceitos científicos, correspondem a algo de objetivo? Quero dizer (... mas é para dizer?) a uma realidade objetiva? E, secundariamente, de que maneira se vinculam nesta correspondência: certamente, de maneira abstrata, é o que todos admitem. Mas, em seguida, essa espécie de vinculação admitida por todos torna-se (ou não?) "direta", "concreta", "intuitiva”... É isto que está em discussão.

Consideremos primeiramente a modalidade "abstrata" da correspondência. Einstein via na Teoria da Relatividade geral a marca de um grau de abstração mais elevado de conceitos e teorias que anteriormente. Para ele, havia ali uma distância que iria crescente entre a representação teórica e os dados empíricos. Tal distanciamento (consequência lógica após a crítica da indução, de Hume até Mach ou Poincaré) obrigava a efetuar um ato de criação ${ }^{2}$. Todavia, esses elementos inicialmente abstratos eram, em seguida, objetos de apropriação pelo pensamento e por isso tornavam-se, de certa forma, concretos. É o que Paul Langevin (1934), que via ali uma constante na história das ciências, exprimia, a sua maneira, dizendo: "O concreto é o abstrato tornado familiar pelo uso". Ocorreria o mesmo com a Física Quântica? Voltaremos a esta questão.

Consideremos, em seguida, a modalidade "direta" da correspondência. Eu a compreendo no sentido de um ajustamento da descrição teórica que adere ao máximo ao que ela descreve. Mas não poderia ser o contrário? No primeiro caso, é o "dado", de origem empírica (mas não somente), que governa o movimento de elaboração de uma descrição teórica. Tal fora, efetivamente, um dos momentos da constituição da Teoria Quântica, quando os fenômenos da Física atômica e da radiação revelaram características que escapavam à teoria (clássica) disponível. Tais características foram o objeto de uma organização teórica sistemática com a formulação (por volta de 1926) das mecânicas ondulatória e quântica, como

2 Sobre esta reflexão de Einstein afirmada por várias vezes, ver Paty (1993a, cap. 9). 
quadro conceitual e teórico e seus prolongamentos na dinâmica, com a teoria da difusão e a teoria quântica dos campos. O sucesso destas formulações teóricas devia-se à sua coerência e à confirmação de suas primeiras previsões pela experiência. Era, então, a descrição teórica que aderia o mais próximo das características não-clássicas dos fenômenos que ela se propunha descrever.

Mas, em seguida, vem o momento (constantemente renovado) de testar a teoria assim constituída e é então o segundo caso que é efetivo, o da proposição inversa àquela que acabamos de ilustrar, se isto que é descrito (o "objeto" da descrição) se mostra bem ajustado e como que moldado à sua descrição pela teoria. Devemos então considerar que o objeto, tal como é descrito, é de fato dado em uma representação teórica prévia às experiências pelas quais esforçamo-nos em descrever. Os fenômenos inicialmente desconhecidos e não previstos anteriormente, e mesmo impensáveis segundo os cânones dos conhecimentos precedentes, resultam, pela lógica da forma, do arranjo teórico. Este último teria revelado, estruturando conceitualmente os traços específicos indicados (pondo em forma as relações de conceitos como as relações entre as grandezas correspondentes, de expressão matemática), que sua coerência em profundidade implicava os fenômenos assim previstos e doravante constatados.

Dito dessa forma, esse parece ser um aspecto geral das teorias físicas e não somente da Teoria Quântica. Mas a Teoria Quântica o ilustra em grau bem maior que qualquer outra teoria física conhecida, pois é possível dizer, a propósito dela, deixando de lado as diferenças, tomando as palavras ao pé da letra, que o que é descrito (em uma ordem caracterizada de fenômenos) adere ao máximo à sua descrição pela teoria. Por exemplo, que as partículas quânticas "interferem consigo mesmas" - segundo a expressão de Dirac (1930) -, que elas são indiscerníveis de qualquer outra partícula idêntica a elas e que obedecem (por esta mesma razão) à "estatística quântica", que elas são não-separáveis localmente, que seu comportamento é governado pelo "princípio de superposição linear" de suas funções de estado etc., sendo todas estas características constatadas, mas que não poderiam ter sido concebidas e pensadas sem a teoria que as comporta e a elas obriga.

O ajustamento do objeto pela teoria parece, pois, ser o caso na Física Quântica mais ainda que em qualquer outra descrição teórica de "objetos" pela Física: porém, ocorre também que tais “objetos", se existem, se mostram na Física Quântica sob modalidades bastante surpreendentes para o senso comum e até mesmo para os cientistas habituados a outros comportamentos. Eventualmente, pode-se ainda dizer: estes "objetos" têm "propriedades" surpreendentes. Em verdade, não tão surpreendentes, uma vez que podemos deduzi-las racionalmente pela teoria: cabe a nós, portanto, admiti-las, explicitando sua significação, estendendo a linha de seu caráter inteligível do qual a teoria precisamente nos assegura, ao preço, como veremos, de transformações da nossa "intuição comum". Contudo, com o início da 
frase precedente pretendíamos insistir sobre a expressão "estes 'objetos' têm 'propriedades"', embora fossem estas à primeira vista surpreendentes. Vejamos: toda a questão epistemológica fundamental sobre a mecânica quântica remete à questão sobre a natureza de um objeto e de suas propriedades. Há, pois, uma relação estreita, e, neste sentido, "direta", ilustrada pela previsibilidade, entre a descrição e o que ela descreve, isto é, seu "objeto", no sentido lógico e não ontológico do termo. Tal sentido de "direto" elimina a significação vaga frequentemente ligada a este adjetivo, em termos de imagens ou de analogias de forma: mas a evolução das ideias científicas já havia permitido denunciar o caráter ilusório das aparências primeiras.

Após os esclarecimentos sobre a modalidade "direta” (ou não) da descrição teórica, deveremos em seguida nos perguntar se é possível (ou não) qualificá-la como "concreta", após o momento da abstração. Eu a compreendo no sentido da correspondência aos efeitos tangíveis, ocasionados ou produzidos pelos "objetos" (esta palavra ainda sendo aqui tomada no sentido relativamente neutro de "objetos da representação"). A resposta não parece ser duvidosa se pensarmos em todas as realizações obtidas, com acúmulo de conhecimentos, em todos os domínios da Física onde a Teoria Quântica constitui o quadro do pensamento conceitual. E, em primeiro lugar, a realização fenomenal da previsão teórica é bem a marca do "concreto". Concreto é o mundo dos fenômenos e, particularmente, a produção de fenômenos.

Enfim, será essa teoria intuitiva ou, ao menos, é possível concebê-la e praticá-la como tal? Entendo por intuitiva que dispomos, por ela, de uma penetração intelectual sintética do conteúdo de significação (no sentido da Física, isto é, da concepção dos fenômenos físicos ou dos "sistemas físicos" que os engendram) deste "conceito-objeto" ou que adquirimos, progressivamente, aquela penetração. A resposta, ainda aqui, encontra-se na realidade efetiva do trabalho dos físicos, ou seja, em sua prática de pensar os fenômenos deste campo disciplinar: um pensamento que se torna efetivo em termos de fenômenos, um pensamento que se comprova nos fenômenos através da experiência (a síntese sendo aqui o pensamento do fenômeno, o qual reúne e resume as proposições teóricas). A resposta à questão sobre o caráter "intuitivo" da teoria é, pois, positiva, tal como para as duas outras. Voltaremos a este ponto.

Essas questões referem-se ao conhecido "debate quântico" (ao menos, do qual todos já ouviram falar, embora sem sempre ter dele uma ideia muito clara e precisa). Entretanto, as respostas positivas que mencionei não prejulgam, até então, da resposta à questão sobre a "realidade física objetiva" que corresponderia aos conceitos: concordaremos sobre a "objetividade" e discutiremos ainda eventualmente sobre a "realidade".

Tanto em sua prática, quanto em suas convicções epistemológicas sobre a Física, os físicos do domínio quântico não têm nenhuma dúvida sobre a objetividade do conhecimento que produzem e é assim, por força da reprodutibilidade 
das experiências, pelos controles múltiplos dos resultados, pela ampliação dos efeitos (por exemplo: uma vez descobertas, as "partículas quânticas", inicialmente raras, são doravante produzidas em feixes de alta intensidade - milhões e até bilhões de indivíduos - dos quais é possível controlar os parâmetros a vontade: feixes de neutrinos, "usinas" de bósons intermediários...).

A prática dos físicos admite, pois, uma objetividade sem que esta seja, até então, necessariamente associada a um objeto no sentido estrito. Mas o que isto quer dizer? Uma objetividade sem objeto no sentido habitual da noção de objeto, isto é, de uma entidade possuidora de propriedades; ou ainda, mais precisamente, porque se trata de uma questão física, uma objetividade sem objetos físicos, tais como os descrevem e os concebem as teorias mais clássicas... Podemos, então, seja concluir que não há mais objetos, embora reste a objetividade (mas poderemos então perguntar a que reportar tal objetividade: e a resposta dada comumente será, por exemplo, aos procedimentos de observação ou de produção dos fenômenos); seja declarar que tal objetividade corresponde ainda a "objetos", mas segundo uma outra caracterização teórica dos objetos que escaparia à mecânica quântica e necessitaria de reformá-la ou completá-la. Essas duas respostas transcrevem as duas posições antagônicas e principais do debate sobre a interpretação da Física quântica, tal como era tradicionalmente apresentado há duas ou três décadas atrás. A questão filosófica fundamental em jogo nesse debate, direcionado em torno das posições respectivas de Niels Bohr e de Albert Einstein, era a do estatuto da realidade física, ou seja, da pertinência ou não, para a nova ciência que era a Física Quântica, da categoria de pensamento "realidade física", geralmente considerada como dependendo da "ontologia" (e recusada junto à "metafísica"). (Esta situação de fato pôde ser por vezes mascarada sob as considerações relativas à causalidade e ao determinismo, postas preferencialmente à frente por outros protagonistas. Wolfgang Pauli foi um dos primeiros comentadores a sublinhar com força que o que verdadeiramente estava em jogo no debate entre Einstein e Bohr era, sim, o realismo) $)^{3}$.

A primeira resposta, no que concerne aos procedimentos de observação, sob os quais se evanesceria a noção de realidade física, isto é, a noção de sistema físico real existindo independentemente de suas condições de observação (e até mesmo, concebivel independentemente destas condições $\left.{ }^{4}\right)$, corresponde à posição

3 Ver sua intervenção na discussão entre Einstein e Max Born, publicada com a correspondência entre estes últimos (EINSTEIN; BORN, 1969); ver Paty ([no prelo]).

4 A escolha desses termos corresponde à formulação por Einstein de sua exigência realista: todas as nuances (raramente percebidas) do realismo crítico se atêm à distinção entre existir e conceber (legitimamente) a existência: o que podemos dizer não escapa ao espaço do pensamento, mas se refere, entretanto, a alguma coisa que é exterior a ele, o mundo físico, a matéria, caracterizando-a de uma maneira precisa, conceitual (PATY, 1988). 
conhecida como sendo a da Escola de Copenhague (que abriga de fato certa diversidade de posições) e cuja forma atenuada recente é o "antirrealismo"క. A segunda, mantendo a definição habitual do objeto físico real, considera que a mecânica quântica é uma teoria incompleta e esta resposta compreende diversas direções para conceber uma teoria como completa: uma, em termos de restauração do determinismo pelo acréscimo de variáveis ocultas suplementares de tipo clássico, com Louis de Broglie, o "primeiro" David Bohm, Jean-Pierre Vigier, Franco Selleri...'; uma outra, mantém a noção de estado físico real para objetos físicos individuais, localizados, mas considerando uma refundação teórica sobre conceitos outros que os conceitos "mecânico-quânticos", os quais poderiam ser obtidos por uma via indireta, a mecânica quântica sendo reencontrada no limite clássico: tal era a perspectiva reivindicada por Einstein. ${ }^{7}$

Ainda que as posições presentes no debate sobre a interpretação da Física Quântica tenham sido frequentemente reduzidas às duas direções indicadas, é possível conceber uma terceira eventualidade, que de fato já existe, qual seja, admitir sem restrição a teoria quântica enquanto teoria física do domínio considerado, aprofundando meta-teoricamente (de fato, epistemologicamente) as categorias de pensamento que a subtende, notadamente as próprias noções de objeto físico e de propriedade física, admitindo que elas seguem tendo um sentido - e, ainda, que elas são necessárias para pensar fisicamente -, mas sob a condição de se dar uma nova definição, alargada, de tais noções gerais, desenvolvendo as lições da novidade dos conceitos e da teoria quântica a este respeito.

Essa terceira posição (ou melhor, esse terceiro grupo de posições) não corresponde sempre a uma terceira resposta única para a questão acerca do objeto e suas propriedades, pois ela compreende em suas variantes, tanto uma direção filosoficamente cética ou indecisa, quanto uma direção francamente realista (realista crítica). Ela recebeu menos comentários porque é mais recente (ainda que seus elementos tenham sido sugeridos anteriormente ${ }^{8}$ ) e porque aceita a mecânica quântica como teoria completa, criticando ou rejeitando suas interpretações filosóficas dominantes, observacionais e não-realistas; e ainda, talvez, porque ela é suspeitada (ao menos como direção realista) de ingenuidade, como se iam tomando por garantidas, isto é, por físicas entidades que até então só eram concebidas como matemáticas, deixando assim na sombra o que faz a diferença

5 Bohr (1958), Rosenfeld (1979). Sobre o antirrealismo, ver Fine (1986), van Frassen (1991).

6 Bohm (1952, 1980), De Broglie (1953), Vigier (1983), Selleri (2007).

7 Einstein (1948, 1949), Paty (1993a, 1993b, 1995, 2001a, 2001b).

8 Por exemplo: Dirac (1926a, 1926b), Langevin (1934). 
entre uma grandeza física e uma grandeza matemática ou se abstendo de justificar o que poderia identificá-las, se é isto que seus defensores pretendem. ${ }^{9}$

Demoremo-nos um instante, antes de retomar certas questões epistemológicas encontradas, notadamente a última (acerca da relação das entidades de expressão matemática com os fenômenos físicos), pois ela me parece corresponder ao problema epistemológico fundamental. E voltemos o olhar, durante esta pausa, para o problema posto no início: objetividade ou construtivismo?

No mínimo, um resultado já está claramente alcançado, aquele concernente ao primeiro termo: qualquer que seja a direção de sua própria interpretação epistemológica, os físicos afirmam (e realizam) a objetividade no conhecimento de seu domínio. Este é um resultado que podemos, com efeito, generalizar: não há, aos olhos dos físicos, Física sem objetividade e satisfazer a objetividade é precisamente o objetivo de todo o seu trabalho. A dificuldade e as divergências de pontos de vista recaem sobre a possibilidade de qualificar esta objetividade em termos de objetos (caracterizados por suas propriedades).

Resta analisar o segundo termo: senão o construtivismo, ao menos a construção...

\section{Que relação há entre o debate sobre a interpretação da Física Quântica e a disputa objetividade-construtivismo?}

Se há uma relação entre o debate epistemológico sobre a mecânica e a Física Quânticas e a controvérsia atualmente diagnosticada nos debates sobre o conhecimento científico, sobretudo aqueles suscitados pelos estudos acerca da "construção social" das ciências ${ }^{10}$, o mínimo que se pode dizer é que tal relação não é nem absolutamente evidente, nem necessariamente pertinente. Parece mesmo que os dois tipos de debate são bastante estranhos um ao outro. O que não impede (sob inclinação devida ao pensamento dominante e pretensamente hegemônico) de forçar essa aproximação, atualmente, vendo, no segundo, a

9 Organizarei nessa categoria, malgrado as nuances por vezes bastante consideráveis, as concepções que vão de "realismo velado" para uma "objetividade fraca" (d'Espagnat) à um realismo de princípio solicitando uma reinterpretação, porém sem solução evidente em vista (Bell), e a um "realismo quântico" (os outros, ainda com variantes): Bell (1981), Bunge (1973), d'Espagnat (1994), Lévy-Leblond (1977), Cini e Lévy-Leblond [1990], Omnès (1994), Paty (1988, 1999, 2000a, 2003).

10 Ver Hacking (1999). 
forma "pós-moderna"11 do primeiro. Mas isto não aconteceria sem deformação de argumentos e distorções de raciocínios. Temos já, em todo caso, um primeiro elemento que impede a identificação entre as duas formas de debate: no debate quântico e na prática dos físicos, a constatação da objetividade é unânime.

Por outro lado, a maior parte dos físicos não se intimida em qualificar de construções as elaborações conceituais e teóricas, como as da Física Quântica, mas no sentido de construções intelectuais. Para eles, trata-se de uma necessidade de princípio: é necessário construir representações abstratas deste domínio da natureza que escapa aos sentidos, com o custo de dever, em seguida, torná-las concretas, fazendo com que elas correspondam estreitamente às características dos fenômenos físicos (tal foi, já nos primórdios, o sentido das primeiras aproximações do domínio quântico com a ajuda das probabilidades concebidas como instrumento matemático $)^{12}$.

Se considerarmos as realizações adquiridas ou empreendidas, esse caráter de construção é totalmente evidente para as teorias de grupos de simetrias tal como estas são atualmente utilizadas na física fundamental (por exemplo, as simetrias unitárias das partículas elementares ou os campos quânticos de interações de calibre unificado ou em processo de unificação); porém, a conclusão seria análoga se remontássemos aos primórdios da elaboração da Física Quântica (por exemplo, a construção de operadores para exprimir as variáveis dinâmicas, impulsão, energia, momento angular etc., a partir de geradores infinitesimais, de tipo clássico). Dir-se-á, porém, que estas são construções matemáticas e não físicas, e o foi dito, justamente, atenuando por isto mesmo o alcance da dimensão construtiva deste trabalho do pensamento. $\mathrm{O}$ que nos remete à evocação das concepções da Escola de Copenhague sobre este tema, para a qual essas construções matemáticas são puramente instrumentais e auxiliares para a Física que, por sua vez, seria dada na experiência. E também, acrescenta, pensada na e pela experiência (e não somente pensada em relação à experiência).

A Escola de Copenhague, representando a interpretação dominante (sobretudo na bela época da aparição da mecânica quântica e de suas primeiras consolidações), deixava à Matemática as grandezas matemáticas, abstratas e "formais", tais como os vetores ou funções de estado, definidos em espaços de Hilbert, e seu princípio de superposição, e as variáveis dinâmicas, expressas por operadores não-comutativos agindo sobre tais funções (e denominadas, neste contexto observacionalista, "observáveis"). E dava à Física o que concernia à observação, ou seja, o que resultava da medida que, por sua vez, efetuava-se necessariamente com o auxílio de aparelhagens cujos resultados eram, no final

11 Por mais que esta expressão tão em moda tenha um sentido...

12 Ver Paty (2002). 
das contas, lidos (atingindo os sentidos) por intermédio dos processos da Física clássica. Essa escola concebia como grandezas físicas somente aquelas que poderiam ser postas em correspondência direta com os resultados da medida, o que significa grandezas de tipo clássico (os aparelhos de medida sendo de tipo clássico, por definição). Estava, pois, subentendido que as grandezas deveriam ser expressas, nesta perspectiva, como funções de valores numéricos. A especificidade dos fenômenos quânticos obrigava, assim, segundo esta concepção e guardando a referência às grandezas clássicas (as únicas das quais é possível falar, para Niels Bohr), a suprimir daquelas grandezas sua significação física direta pela descrição dos fenômenos ou dos "sistemas" quânticos. Não se poderia alcançar ou descrever "objetos quânticos", mas apenas efeitos de medida sobre aqueles sistemas, restituídos pelas grandezas clássicas, únicas a atingirem os dados da percepção. Porém, podemos perguntar, este não é um efeito de ilusão? As próprias grandezas clássicas não correspondiam, quando foram formuladas na elaboração da Física clássica, a uma evidência dos dados dos sentidos; elas resultaram de construções intelectuais que estavam longe de parecer evidentes ou diretamente correspondentes às experiências dos sentidos.

Na concepção da Escola de Copenhague, as grandezas "matemáticas" do formalismo teórico não poderiam, pois, ser concebidas como "diretamente" físicas: elas só se reportariam aos fenômenos e às grandezas físicas por meio das regras de interpretação (tais como a interpretação probabilística da função de onda ou do vetor de estado, a das grandezas observadas como valores próprios dos operadores, o enunciado do princípio de superposição, a redução efetiva, na operação de medida, do vetor de estado a apenas um dos componentes da superposição linear que ele constitui, etc.). Entre essas regras, algumas correspondem às definições da significação física de grandezas por sua colocação em relação aos conteúdos físicos e são neutras filosoficamente: elas pertencem à Teoria Quântica no seu sentido estrito e são comumente aceitas com a mecânica quântica, independentemente de qualquer outra interpretação. Outras regras, ao contrário, exprimem uma conviç̧ão filosófica sobre o conhecimento, como, por exemplo, o observacionalismo ou a complementaridade, segundo Bohr, e a afirmação correlata da necessidade de se recorrer sempre aos conceitos clássicos, inclusive no domínio quântico, onde eles são afetados por limitações de validade, compensadas pela consideração de conceitos ou grandezas complementares; ou, ainda, a concepção do vetor de estado como sendo o catálogo de conhecimentos de um sistema e não a representação teórica de seu estado físico.

Todavia, essa posição filosófica, associada ao segundo gênero ("filosófico") de regras, aparece limitada por um tipo de naturalismo que lhe faz considerar, de maneira privilegiada, a percepção como tendo um papel direto no acesso ao conhecimento. Uma concepção do conhecimento como elaboração intelectual, no sentido explícito de construção pelo entendimento, permite, ao contrário, 
conceber uma relação mais abstrata e feita de maneira indireta, no momento da construção (estes dois adjetivos, abstrata e indireta, têm, contudo, um sentido relativo, como acabamos de ver), mas que consegue integrar em um esquema teórico-conceitual de conhecimento os elementos de origem empírica dados na percepção. Elementos de origem empírica são, certamente, indispensáveis a qualquer conhecimento físico, porém, eles são sempre retomados no conhecimento, segundo o entendimento, que é aquele da compreensão, para serem transformados em conceitos e grandezas suscetíveis de se relacionarem a outros e de serem inteligíveis ${ }^{13}$. Nenhuma limitação em sua forma é imposta, a priori, em tal concepção, aos elementos de conhecimento salvo de serem relacionais como o são de maneira privilegiada as grandezas matemáticas.

Paradoxalmente, uma vez que o conhecimento dos fenômenos atômicos e infra-atômicos pareciam inicialmente necessitar de processos construtivos, distanciados dos dados empíricos imediatos (porque o mundo dos átomos e das radiações, dos quanta, escapa à percepção dos sentidos), certa prudência, de inspiração empirista, teria acompanhado e marcado a acumulação de seus sucessos no plano teórico. Como se a exigência de objetividade e de racionalidade para o conhecimento do domínio quântico houvesse tido, como contrapartida, a desconfiança (para não dizer rejeição) no tocante às construções intelectuais abstratas, efetuadas segundo as formas matemáticas. Estas últimas sendo, neste caso, adotadas como um simples "formalismo", sem dúvida poderoso, mas, no final das contas, auxiliar. Ao invés disso, uma teoria física, tal como era geralmente concebida até então, da Física clássica à relatividade geral, constituía a instância mesma da inteligibilidade do domínio fenomenal considerado. Esta ideia não teria verdadeiramente mais nenhuma pertinência para o domínio quântico? É sobre isto que nos propomos discutir agora, interrogando-nos sobre o gênero de construção que é a Teoria Quântica.

\section{Em que sentido é possível falar de construção?}

Os conceitos e as teorias são construções intelectuais na modalidade do pensamento simbólico, característico da presença e do lugar do homem na natureza, meio de sua compreensão da natureza e de sua comunicação com seus semelhantes. É razoável à primeira vista, pois, considerar que tais construções não são apenas de pensamentos individuais, mas que elas têm uma dimensão social. Há algum tempo, a ideia de "construção social" das ciências tornou-se

13 Um exemplo que trata deste conhecimento em dois níveis, um perceptivo, o outro intelectual, é a diferença entre o espaço representativo e o espaço geométrico, descrita por Poincaré (1902, cap. 4). 
um dos cavalos-de-batalha de uma nova socioantropologia das ciências que se ocupa do comportamento social dos cientistas em grupo, de suas redes, de suas estratégias de poder, visíveis notadamente nos modelos de fundamentação da big-science. Entretanto, esse interesse exclusivo, que pretende se estender a todo o conjunto da história das ciências, desenvolve-se infelizmente à custa do abandono e do esquecimento dos aspectos propriamente intelectuais do movimento do conhecimento. Falam-nos, por exemplo, da "construção social dos quarks"14 (partículas quânticas fundamentais das teorias dinâmicas atuais da matéria, na teoria quântica dos campos) e até mesmo de "construção social" da racionalidade ou da verdade. ${ }^{15}$ Estas novas doutrinas se interessam muito pouco pelo trabalho racional efetivo dos físicos e pela perspectiva de objetividade que os guia e que eles reivindicam. Para o construtivismo social radical, os conceitos e as teorias dos físicos são artefatos construídos socialmente que só devem sua aceitação ao consenso dos atores e manipuladores das redes, muito mais ocupados com jogos de poder do que com a preocupação em saber como o mundo é feito; este seria um objetivo ilusório, uma aura ideológica secretada por seu meio sociocultural, para justificar sua atividade a seus próprios olhos e aos olhos do restante da sociedade; os pesquisadores que se imaginam trabalhar na (e para) a objetividade, são apenas, de fato, agentes produtores de construções sociais que dão a ilusão da objetividade ${ }^{16} \ldots$ O objetivo e os motivos que eles invocam de preferência, a saber, a solução de problemas pela descrição ou representação ou, pior ainda, a explicação do mundo fenomenal ou do mundo real, recobririam atividades de natureza menos nobres e muito mais prosaicas.

Felizmente, outras perspectivas mais equilibradas e respeitosas da dimensão intelectual do pensamento humano são possíveis. Considerar a produção das ciências do ponto de vista da construção social apresenta seguramente um interesse quanto às condições efetivas da produção dos conhecimentos nas sociedades e quanto a sua relação com outras atividades humanas, como elas inscritas na história. Porém, isto não impede de também prestar atenção às lições da epistemologia, ponto de vista que se interessa pelos conteúdos de conhecimento, o único a permitir entrar na inteligibilidade de tais conteúdos. Tomá-los conjuntamente, porque a realidade efetiva da produção dos conhecimentos na sociedade e na história o exige, é precisamente a posição do grande (e saudoso) sociólogo Pierre Bourdieu, que descreve, por sua parte, a tarefa da sociologia das ciências como sendo a de elucidar as "condições sociais ou sócio-epistêmicas de possibilidade dos conhecimentos científicos". Ela não se substitui de forma alguma

14 Pickering (1984).

15 Shapin (1994).

16 Cofira, p. ex., Latour (1989). Para as críticas a estes pontos de vista, ver Gingras (1995), Shinn (2000), Bourdieu (2001) e Paty (2001b). 
à perspectiva da epistemologia: as duas se esclarecem de fato mutuamente para compreender o conhecimento como o resultado de uma atividade do homem, ser eminentemente social.

Do ponto de vista da epistemologia da construção racional objetiva, os conceitos científicos devem sua legitimidade a um processo de caracterização racional, capaz de ser retraçado ou reencontrado pela análise tanto dos contextos sociohistóricos e culturais, quanto dos elementos cognitivos relacionados a sua inteligibilidade, assim como as representações conceituais e teóricas de tais fenômenos ou entidades físicas, a significação das experiências em relação a estes esquemas teóricos e à possibilidade de pensá-los e criá-los tecnicamente. Numerosos exemplos, tomados na história ou também contemporâneos, poderiam ser examinados nessa perspectiva: da elaboração da mecânica quântica à descoberta das correntes neutras, à evidenciação dos quarks ou dos bósons intermediários (em breve, talvez, dos bósons de Brout, Englert e Higgs) ${ }^{17}$.

Andrew Pickering acreditou ter decifrado (em sua obra mencionada) a "construção social dos quarks" e reduzido assim a produção dos quarks à fabricação de um "consenso" ao cabo de "negociações"18. Em suma, ele poderia dizer isto mesmo nesta altura da construção dos quanta, subtraindo o "confinamento" e os últimos aspectos da big science. Os quanta e suas "partículas" (quânticas) idênticas indiscerníveis (tão pouco familiares, tão pouco pensáveis inicialmente) não são menos construídos que os quarks.

Tomemos por um instante os quarks. Sigamos as elaborações racionais que os constituíram em relação aos dados empíricos sobre as propriedades das partículas elementares (hadrônicas). Distinguimos, particularmente, nestas elaborações, tais que possamos segui-las em seu desenvolvimento ${ }^{19}$, dois tempos ou duas faces de sua colocação em evidência (ou de sua produção conceitual e efetiva). É, com efeito, em primeiro lugar, uma elaboração matemática, que implica a teoria dos grupos de simetria para as grandezas quânticas representantes das "propriedades" das partículas (operadores dos diversos "sabores", isospin, estranheza etc.): deste ponto de vista, as partículas, remetidas a seus números quânticos, são constituídas de quarks "matemáticos". Vêm, em seguida, num segundo tempo, os resultados das experiências de difusão penetrante de partículas (léptons, fótons) sobre outras (prótons, nêutrons) que põem em evidência centros duros de difusão nestes últimos, cujas propriedades em termos quânticos se confirmam como as dos quarks precedentes ("matemáticos"). Daí a identificação dos dois, os quarks

17 Paty (2003, cap. 7, p. 116, 218).

18 Pickering (1984).

19 Paty (1988, cap. 9); Paty (2003, cap.7). 
"matemáticos" (de início puramente formais) e os quarks "físicos", inicialmente apenas empíricos. Deve-se também mencionar um terceiro passo da construção, no qual intervêm as teorias de simetria de calibre dos campos de interação que incorporam os quarks, em razão de suas propriedades ${ }^{20}$, a título de "objetosfonte" dos campos (quânticos) de interação: é a construção da "cromodinâmica quântica"21.

Seguir os traços dos processos dessas elaborações, dessas construções teóricas, tal como foram propostas, aprofundadas e testadas, impede de reduzi-las a puras práticas sociais, instrumentais, de decisão. Tais práticas, certamente, se deixam constatar que são a marca da dimensão social desses processos de elaboração ou de construção, ou seja, do contexto social no qual elas foram produzidas, do meio onde se alimentou socialmente e culturalmente a atividade dos pesquisadores científicos que as formularam em seu pensamento (na atividade de seu pensamento). Evidentemente, as ideias não nascem diretamente de um "meio social", mas de indivíduos e de pensamentos singulares viventes neste meio. As "negociações" e persuasões que levam à aceitação mais ou menos rápida de tal enunciado de conhecimento, longe de abolir a exigência da inteligibilidade segundo a racionalidade, que corresponde aos pensamentos singulares, devem tê-la em conta, ao contrário, fazendo dessa exigência sua regra: esta assume a tarefa de uma condição de credibilidade, à qual as falsas construções não resistirão muito tempo. Bourdieu (2001) fala justamente a esse respeito de "condição sócio-transcendental".

Estas ideias foram constituídas intelectualmente em vista de um sentido e o que lhe dá este sentido, e que guia o pensamento de seus inventores, é uma cadeia de considerações racionais, ordenadas pelo pensamento racional, segundo as modalidades deste (quais sejam, as modalidades conceituais, teóricas e ligadas aos dados da experiência), que pertencem a um campo disciplinar dado, constituindo-o intelectualmente. Tais elaborações são formadas por processos de pensamento que recaem sobre o pensamento simbólico e, ao mesmo tempo, o concreto de pensamento, esta última expressão designando conteúdos físicos, referindo-se a objetos ou a fenômenos efetivamente atestados (e por isto mesmo

20 Notadamente sua "liberdade assintótica" a mínimas distâncias, que torna possível a aproximação em termos de campos quantificados mesmo para a interação forte, pois ela pode, desde então, ser tratada em série de perturbação da constante de acoplagem (esta, sendo pequena em mínimas distâncias, pode ser associada a uma série convergente).

21 Teoria dinâmica do campo quântico da "cor" (a "cor" é um número quântico caracterizando os quarks), considerado como o campo fundamental das interações nucleares fortes. A terminologia, fantasiosa e por vezes gratuita, intervém talvez, tomada superficialmente, contra a consideração do caráter objetivo e "real" destas entidades; por outro lado, ela torna diretamente manifesto que se trata de construções. 
controláveis) que não seguem as conveniências da moda, ou das circunstâncias orçamentárias, e não dependem do relaxamento e das reconfigurações das "redes". Os "objetos de pensamento" assim constituídos são estáveis através das transformações sociais, assim como através dos discursos retóricos ou outros pronunciamentos sobre eles.

O campo disciplinar, concebido também como campo social, legitimamente, como o "campo científico" de Pierre Bourdieu (1976, 2001), não pode apagar ou negar a asseidade deste "concreto-de-pensamento": por outro lado, neste último caso, como acabamos de afirmar, longe de negá-lo ou ignorá-lo, ele o leva em conta no estudo das modalidades de sua inscrição social, contribuindo assim para esclarecer as circunstâncias de sua formação ou de seu funcionamento. O estudo dos comportamentos sociais, concebido desta maneira (também racional e científica), não se propõe a reduzir aos últimos a racionalidade específica que opera na construção intelectual estudada; ao contrário, ele a leva em consideração e ao mesmo tempo a re-situa nas condições concretas, históricas e sociais, de sua elaboração ou de seu emprego e caracteriza as linhas de força que a acompanham nesta ordem. Concebida desta maneira, a aproximação sociológica da atividade científica pode então, legitimamente, se apresentar como o estudo das condições sociais de possibilidade de tal conhecimento científico ${ }^{22}$, ou de tal tipo de racionalidade, e longe de concorrer ou de recusar a aproximação filosófica e epistemológica dos objetos intelectuais do campo, ela a completa ao fornecer esta dimensão, esclarecedora ao seu nível.

Contudo, é provável que os aspectos contingentes, ligados a uma cultura particular do grupo de especialistas do domínio, desenvolveram um papel nãoneutro nesta elaboração, tanto para a Física Quântica quanto para os quarks, ou os neutrinos, ou as correntes neutras etc., conseguindo que uma interpretação (ou uma via de pesquisa) e não outra seja predominante durante certo tempo. Seria seguramente interessante estudar tais efeitos, combinando aqui a análise epistemológica e a investigação sociológica. ${ }^{23}$

22 Esta expressão de Bourdieu, já evocada acima, faz ver, por sua referência implícita a Kant, que ela não nega a preocupação com o racional, mas a completa pela contextualização.

23 Este seria um gênero de investigação na direção dos estudos de Peter Galison (1987, 1997); Ver a análise proposta em Darrigol (1998) e as de Terry Shinn sobre a "pesquisa-tecnologia". (SHINN, 1993, 1999, 2000; JOERGES; SHINN,2001) 


\section{Prática do pensamento dos conceitos e inteligibilidade: um aspecto "sociocognitivo" da interpretação da mecânica quântica}

O longo domínio da interpretação observacionalista da mecânica quântica, por exemplo, está inegavelmente ligado à pressão de uma "escola" (a de Bohr, a Escola dita de Copenhague), estrategicamente influente por razões que podemos aqui descrever. Ela obteve a adesão quase geral da "comunidade" dos físicos quânticos, mas com alguns "dissidentes", o mais irredutível entre eles sendo Einstein, que recusava transigir sobre a questão da realidade física como sendo, a seus olhos, o próprio objeto da teoria física. (Einstein invocava a ideia de uma "realidade física" de uma forma que ultrapassava o simples posicionamento "metafísico" ou "ontológico", relacionando-a a critérios cognitivos próprios às determinações da Física: segundo ele, a Física descreve os "elementos da realidade física” individuados, existindo independentemente de sua observação ${ }^{24}$ ).

Os físicos quânticos desenvolveram, assim, em torno de Niels Bohr, uma “ortodoxia" que teve, com efeito, suas vantagens: ela lhes permitiu não se deixar distrair pelas insatisfações, quanto aos fundamentos, e a continuar seguindo adiante nas construções da física atômica e subatômica (nuclear e subnuclear). Mas essa ortodoxia não foi finalmente mantida a favor e contra tudo; as ideias se esclareceram com o tempo e com a experiência adquirida, dissociando, particularmente, as considerações ligadas à interpretação filosófica e aos enunciados puramente físicos. Estes últimos, para além de toda obediência “ortodoxa”, continuam participando da bagagem de todo físico quântico e constituem "invariantes", enquanto que as posições gerais como o observacionalismo e a complementaridade, no sentido filosófico (bohriano), foram bem desfeitas no decorrer das décadas: restam hoje sobretudo os resíduos fossilizados no vocabulário ("incerteza", "indeterminação", “observáveis"...) que, doravante, não são mais do que os vestígios testemunhais de circunstâncias contingentes (de natureza sociocultural) das elaborações iniciais.

Mas aqui houve um efeito interessante, o qual nos permite estimar que, malgrado as distorções indicadas de origem social e cultural, malgrado os efeitos de "construção social", o pensamento científico é movido por um encadeamento bem mais determinante que permite ultrapassá-los e cuja força permanece relacionada ao jogo da atividade racional e da natureza (compreendida como physis, o mundo externo ao pensamento e à sociedade), havendo entre os dois o exercício de uma prática do pensamento físico, teórico e experimental, pelos físicos dos laboratórios de pesquisa. Ocorre que, no fim das contas, tendo ido adiante, estes físicos vieram, por assim dizer, naturalmente a pensar os sistemas físicos os quais

24 Paty (200?). 
eles tratam como "objetos" (isto é, como entidades físicas que possuem propriedades), enquanto que tal "simplificação" lhes tinha sido inicialmente impedida.

Se a partir de então eles puderam agir dessa forma não foi porque transgrediram o impedimento nas boas razões que existiam (de não reduzir o quântico ao clássico), mas porque contornaram o impedimento: eles mantiveram a exigência de pensar os sistemas quânticos diferentemente dos objetos clássicos anteriores, uma vez que não deixaram de aplicar o modelo de aproximação teórico-quântico, que não é outro senão o da Teoria Quântica, com suas grandezas (ditas) matemáticas (vetores de estado, operadores...) trazidas de fato (sem que isto seja explicitamente dito) à posição de conceitos físicos, e seu "formalismo" próprios. Este último aparenta não ser outra coisa em seu pensamento efetivo que a própria forma da teoria (no sentido de teoria física para um campo de fenômenos). Eles, os físicos, integraram este modo de aproximação (teórico-quântica) ao que concebiam de fato, na prática de seu trabalho, como sendo "objetos físicos" e "propriedades" de tais objetos, estes últimos ganhando seu sentido a partir da própria teoria ${ }^{25}$. Eles têm este modo tão bem integrado que conceberam e realizaram suas experiências em função dele. Eles materializaram (ou concretizaram), por assim dizer, nos próprios dispositivos experimentais, os conceitos e a teoria quântica, fazendo-os tomar corpo ao realizar o que Bachelard chamava uma "fenomenotécnica" ${ }^{26}$.

Façamos, quanto a isso, duas observações. A primeira, que a integração em questão se fez por assimilação e interiorização. A segunda, que é possível, agindo de tal forma, afinar nossa concepção de "objetos" e de "propriedades" (por extensão de sentidos, de tipo categorial). De fato, a ideia de assimilar guarda uma ligação com a ideia de remodelar categorias (tais como as categorias de grandeza física, objeto e propriedade física) ${ }^{27}$.

Notemos, além disso, acidentalmente, que se poderia estudar sob esse ângulo, em uma investigação ao mesmo tempo epistemológica e sociológica, a atividade efetiva dos pesquisadores em física atômica, nuclear ou das partículas elementares, tanto dos teóricos "fenomenólogos" (próximos da experiência), quanto dos experimentadores que trabalham sobre a análise dos dados, ou concebendo e realizando as aparelhagens, os aceleradores, os feixes de partículas quânticas e os detectores. E entre tais físicos, em particular, aqueles (físicos atômicos e ópticos quânticos) que se dedicam a "fabricar" e a estudar fisicamente os fenômenos mais

25 Paty (1999).

26 Bachelard (1934, p. 5, 13) falava da "realização do racional na experiência física". Ver também Bachelard (1949).

27 Ver, a propósito das "grandezas físicas” em geral, Paty (2001a]) e sobre a assimilação no sentido indicado: Paty (2005b). 
simples e mais "fundamentais" do ponto de vista das bases conceituais e teóricas da Física Quântica, isto é, os fenômenos "não clássicos"; a saber, a interferência de uma partícula quântica consigo mesma, a condensação de Bose-Einstein, a descoerência etc., dos quais relembraremos um pouco mais à frente.

No entanto, as pesquisas existentes de história das ciências ou de socioepistemologia sobre os domínios ligados à Física Quântica não têm evidenciado, segundo tenho conhecimento, essa perspectiva; e seus autores não estão interessados até aqui no problema preciso que podemos designar: as implicações epistemológicas da prática científica e social da Física Quântica. Este seria, entretanto, um ponto muito original de encontro e de confrontação entre as questões fundamentais da epistemologia (aqui, a epistemologia da mecânica quântica) e o estudo sociohistórico do trabalho dos físicos que operam nesses domínios. Fato é que este encontro de domínios não teve ainda lugar, pois os epistemólogos do debate quântico permanecem relegados às aproximações puramente filosóficas, ou pretensamente filosóficas, ao passo que os sociólogos e socioepistemólogos se interessam mais por outros problemas de "construção" da física contemporânea do que por aqueles relativos à própria mecânica quântica. Gostaria de ressaltar, todavia, os recentes estudos originais de Olival Freire e de seus alunos acerca da institucionalização da dimensão epistemológica da Física no campo disciplinar da Física Quântica, que homologou a legitimidade do debate sobre os fundamentos e a interpretação. ${ }^{28}$

Ao menos teve lugar a experiência, feita regularmente pelos físicos em seu trabalho de pesquisa, de que os conceitos teóricos da mecânica quântica constituem de fato o quadro de pensamento por meio do qual eles atingem os sistemas e problemas físicos (quânticos) estudados. Praticando o exercício do pensamento físico neste quadro, este transforma-se em uma segunda natureza, ou ainda, este quadro de pensamento é transformado em propriamente "intuitivo"; e ele perdia, por isto mesmo, toda necessidade de ser interpretado da maneira antiga ("ortodoxa"), que relacionava o quântico ao clássico, ora sem reduzi-lo, mas tomando o modelo clássico de pensar e de observar como referência indispensável.

Dito de outra forma, tais físicos inventaram, ou codificaram, assim, uma outra maneira de pensar esses sistemas quânticos como objetos, tornando-lhes concretos, diretos, intuitivos, em um sentido outro que aquele relativo aos objetos das concepções anteriores; tendo sido tal sentido insuflado em seu pensamento (racional) em física por sua prática da Física Quântica (prática teórica ou experimental, por vezes as duas juntas). Eles conceberam de outra forma o que é um objeto físico, e o fazem funcionar

28 Freire (1999, 2003, 2004, 2005, 2006, 2007). Devemos mencionar igualmente os esforços e as realizações referentes à mecânica quântica de base, as quais têm em conta as lições do debate sobre a interpretação: Bohm (1951), Diu, Cohen-Tannoudji e Laloë (1973); Lévy-Leblond e Balibar (1984) etc. 
praticamente, em seu pensamento, sem necessariamente ter dele uma consciência explícita. Frequentemente, apesar de contrariar assim por meio de seu "pensamento prático" às regras de interpretação ortodoxa, eles repetem certos elementos do credo. Em outros termos, sua epistemologia expressa não é sempre conforme à prática de seu pensamento conceitual e teórico do domínio quântico (e ainda, que me perdoem por ousar tal julgamento, ela permanece bem aquém deste).

$\mathrm{Na}$ necessidade encontrada de formular os objetos correspondendo à objetividade que eles perseguem, esses físicos não somente exploraram esse domínio com proveito, revelando novas propriedades, ainda objetivas, da matéria física, como fabricaram em laboratório tais objetos, impensáveis sem a teoria quântica. E, em particular, esses "objetos" que são os mais simples de descrever no quadro da teoria quântica, nisso que correspondem exatamente às características ditas "matemáticas" (transpostas em "representação de sistemas e propriedades físicas") das entidades teóricas da mecânica quântica, tais como o vetor de estado para representar e descrever o próprio estado físico (esta "função de onda sem onda" do início da teoria) e os operadores não comutativos (matrizes, diferenciação, etc.) para representar e descrever as propriedades de tais sistemas e de seus estados.

Tais objetos desse tipo de simplicidade são os sistemas quânticos individuais que engendram por si mesmos os fenômenos especificamente quânticos, precedentemente concebidos apenas de maneira estatística (difração e interferência consigo mesmo de elétrons, de fótons, de nêutrons, de átomos, produzidos individualmente, interações de átomos individuais com seu próprio campo eletromagnético etc.); ou os sistemas quânticos idênticos indiscerníveis, simétricos ou antissimétricos pela permutação de dois deles, dando a condensação de Bose-Einstein em um caso, o princípio de exclusão de Pauli no outro, com consequências físicas consideráveis (constatadas) nos dois. Tais fenômenos que não teriam sido pensáveis sem a Teoria Quântica e suas grandezas, fazem-nos como que "tocar com o dedo" o vetor de estado (ou a função de onda) pelo sistema quântico "simples" correspondente, o qual engendra diretamente tais efeitos.

De algum modo, há um encerramento do que é físico (os estados de sistemas quânticos) pela descrição teórica com suas grandezas próprias, que são a expressão de seus conceitos. Estes conceitos, intelectualmente construídos, podem ser vistos, em sua própria expressão matemática, como novas modalidades de descrição ou de qualificação da "realidade física", no sentido em que as grandezas que transcrevem ou expressam os conceitos fornecem, por suas relações, a descrição exata das propriedades destes sistemas. Podemos ver neles uma extensão de sentido da noção de grandeza física, para além do puramente numérico e do diretamente mensurável, uma vez que a concepção de Bohr impedia por princípio tal visão (porque para ele só havia conceito físico que fosse clássico) ${ }^{29}$.

29 Ver Paty (1999, 2000b, 2001a, 2002, 2003). 
Supondo que este seja efetivamente o caso, não se trataria mais que de uma regra do jogo que muda, alguns vão dizer. Isso nos leva de volta ao "construído social" e a sua retórica fechada! Mas isto seria uma visão muito limitada das coisas e suprimiria toda a espessura, do ponto de vista cognitivo, da atividade prática deste pensamento que interiorizou a mudança (sempre com o recurso à experiência como pedra de toque do possível para o real): ao passo que também essa atividade prática tornou concreto esse pensamento, pela produção de efeitos físicos, materiais e, desta forma, imediatamente inteligíveis. Pois, parece bem necessário, para identificar e receber a novidade (em uma descoberta) e para assimilá-la, que a racionalidade, a operar no trabalho do pensamento, se alargasse para dar-lhe um lugar e incluí-la, para integrá-la, enquanto que esta novidade que assim se apresenta era anteriormente impossível de conceber, nos quadros anteriores muito estreitos do pensamento.

Esses alargamentos da racionalidade teriam, provavelmente, sido impossíveis fora da existência de uma "comunidade", de um grupo social de indivíduos intercambiando pensamentos (pela educação, pesquisa, comunicação, transmissão etc.). Mas, nesses alargamentos do racional (das formas de racionalidade), o que penetra o racional para transformá-lo não é o social, no caso aqui considerado da Física; é antes alguma coisa do mundo exterior, pela ocasião do dado empírico que necessitava ser entendido, compreendido, ou seja, ser integrado racionalmente. $\mathrm{O}$ que se operou aqui, de um ponto de vista fundamental, foi que o racional se nutriu do empírico para se transformar em alguma coisa que permanece ainda fundamentalmente racional, um racional mais largo, como um organismo que cresce e se complexifica, preservando a constituição de seu meio interno, as tendências de sua estruturação própria. (PATY, 2005b)

Resta que, nessa assimilação-transformação de alguma coisa empiricamente dada em algo racional diretamente inteligível, que resulta (ou deveria resultar) em uma mudança da interpretação, correspondendo a um outro pensamento do conteúdo físico da teoria, a prática dos físicos (como atividade individual e social) assume, seguramente, um papel considerável, o qual seria interessante analisar mais adiante ${ }^{30}$. Mas de forma alguma se trata de uma redução do conteúdo do pensamento científico ao do "construído socialmente".

A fraqueza congênita da explicação dos conhecimentos científicos pela "construção social" está em querer ignorar a especificidade do racional, a capacidade de autoconsistência e de alargamento do pensamento racional, a presença e a resistência do mundo exterior (o "real", a "natureza") e a objetividade dos diferentes campos científicos. Em outras palavras, o social não é um dissolvente da objetividade e da racionalidade, mas ele é o meio-ambiente no

30 Paty (2010). 
seio do qual certa objetividade é produzida por construção, a partir da experiência do mundo, segundo os modos do racional. Relativamente a isto, todo discurso de exterioridade e de pura retórica é vão e só constrói, na melhor das hipóteses, sofismas.

\section{Referências}

BACHELARD, Gaston. La formation de l'esprit scientifique. Paris: Vrin, 1938. Le nouvel esprit scientifique. 9. ed. Paris: Alcan, 1934. Também publicado em Paris: Presses Universitaires de France, 1966.

.. Le racionalisme appliqué. Paris: Press Universitaires de France, 1949.

BELL, John S. Speakable and unspeakable in quantum mechanics. Cambridge: Cambridge University Press, 1987.

BEN-DOV, Yoav. Versions de la mécanique quantique sans réduction de la fonction d'onde, Tese de dourado (Doctor) - Université de France, Paris, 1988.

BOHM, David. Quantum Theory. Englewood Cliffs, USA: Prentice Hall, 1951. . A suggested interpretation of the quantum theory in terms of « hidden variable s». Physical Review, v. 85, p. 166-179, 1952. Retomado em Bohm [1980].

1980. . Wholeness and the implicate order. London: Routledge and Kegan Paul,

BOHR, Niels. Atomic physics and human knowledge. New York: Wiley, 1958. Trad. fr. por Edmond Bauer e Roland Omnès, Physique atomique et connaissance humaine, Paris, Gauthier-Villars; nova ed. estabelecida por Catherine Chevalley, Paris: Gallimard, 1991.

BOURDIEU, Pierre. Science de la science et réflexivité, Paris : Raison d'Agir, 2001.

La science du champ scientifique et la réflexivité. Paris, 2001. Curso do Collège de France, Cátedra de sociologia, jan./abr. 2001. Anotações tomadas no curso por M.P. 
BUCHWALD, J. (Ed.). Scientific Practice: theories and stories of doing physics. Chicago: Chicago University Press, Chicago, 1995.

BUNGE, Mario. Philosophy of physics. Dordrecht: Reidel, 1973. Trad. fr., Philosophie de la physique. Paris: Seuil, 1975.

CINI, Marcello; LÉVY-LEBLOND, Jean-Marc (Ed.). Quantum theory without reduction. London: Adam Hilger, 1990.

DARRIGOL, Olivier. From c-Numbers to q-Numbers. The classical Analogy in the History of Quantum Theory. Berkeley: University of California Press, 1992.

Toward a new topology of scientific practice. Historical Studies in the Philosophical Sciences, v. 28, n. 2, p. 337-351, 1998.

DE BROGLIE, Louis. La physique quantique restera-t-elle indéterministe? Paris: Gauthier-Villars, 1953a.

DIRAC, Paul A. M. The principles of quantum mechanics. Oxford: Clarendon, 1930. Trad. fr. por Alexandre Proca e Jean Ullmo, Les principes de la mécanique quantique. Paris: Presses Universitaires de France, 1931.

. On quantum algebra. Proceedings of the Cambridge Philosophical Society, v. 23, p. 412-418, 1926b.

. Quantum mechanics and a preliminary investigation of the hydrogen atom, Proceedings of the Royal society of London, A 110, p. 561-579, 1926a. Repr. parcial em Waerden [1967], p. 417-427.

DIU, Bernard; COHEN-TANNOUDJI, Claude; LALOE, Franck. Mécanique quantique. Paris: Hermann, 1973. 2 v.

EINSTEIN, Albert. Oeuvres choisies. Trad. fr. pelo grupo de trad. do ENS Fontenay-St-Cloud et al. Edição sob a dir. de Françoise Balibar. Paris: Seuil/ CNRS, 1989-1993. $6 \mathrm{v}$.

Quantenmechanik und Wirklichleit. Dialectica, v. 2, p. 35-39, 1948. Trad. fr., Mécanique quantique et réalité, in Einstein, A. Oeuvres choisies, p. 244-249. 
. Reply to criticism. Remarks concerning the essays brought together in this cooperative volume. Schilpp, p. 663-693, 1949.

EINSTEIN, Albert; BORN, Max. Briefwechsel 1916-1955. München:

Nymphenburger Verlagshandlung GmbH, 1969. Trad. fr. por Pierre Leccia, Correspondance 1916-1955, commentée par Max Born. Paris: Seuil, 1972.

D’ESPAGNAT, Bernard. Le réel voilé. Analyse des concepts quantiques. Paris: Fayard, 1994.

FINE, Arthur. The shaky game. einstein realism and the quantum theory. Chicago: The University of Chicago, 1986.

FRASSEN, Baas van. Quantum Mechanics, an empiricist view. Oxford: Oxford University Press, 1991.

FREIRE, Olival. David Bohm e a Controversia dos Quanta. Campinas, SP: Unicamp, 1999. (Coleção CLE, n, 27).

. The historical roots of "foundations of quantum physics" as a field of research (1950-1970). Foundations of Physics, v. 34, p. 1741-1760, 2004.

Orthodoxy and heterodoxy in the research on the foundation of quantum physics: E.P. Wigner's case. In: SANTOS, Boaventura de Souza (Ed.). Cognitive justice in a global world. prudent knowledges for a decent life. Lanham: LexingtonBooks, Rowman \& Littlefield, 2007. p. 203-209.

Philosophy enters the optics laboratory: Bell's theorem and its first experimental tests (1965-1982). Studies in History and Philosophy of Modern Physics, v. 37, p. 577-616, 2006.

Science and Exile: David Bohm, the cold war, and a new interpretation of Quantum Mechanics, Historical Studies in the Physical Sciences, v. 36, p. 1-34, 2005.

A story without an ending: The quantum physics controversy 1950 1970. Science \& Education, v. 12, p. 573-58, 2003.

GALISON, Peter. How experiment end. Chicago: Chicago University Press, 1987. 
. Image and Logic: a material culture of microphysics. Chicago: Chicago University Press, 1997.

GINGRAS, Yves. Un air de radicalisme. Sur quelques tendances récentes en sociologie de la science et de la technologie. Actes de la recherche en sciences sociales, n. 108, 3-17, jun. 1995.

. Constructing a Tokamak. Social Studies of Science, v. 23, n. 1, p. 5-36, 1993.

. Mathématisation et exclusion: Socio-analyse de la formation des cités savants. In: WUNENBURGER, Jean-Jacques (Ed.). Bachelard et l'épistémologie française. Paris: PUF, 2001. (Débats philosophiques).

HACKING, Ian. The social construction of what? Cambridge, Mass: Harvard Universiy Press, 1999.

JAMMER, Max. The philosophy of quantum mechanics: the interpretations of quantum mechanics in historical perspective. New York: Wiley and sons, 1974.

JOERGES, Bernward; SHINN, Terry (Ed.). Instrumentation between science, state and industry. Dordrecht: Kluwer, 2001.

LANGEVIN, Paul. La notion de corpuscules et d'atomes. Paris: Hermann, 1934.

LATOUR, Bruno. La science en action. Paris: La Découverte, 1989.

LEITE LOPES, José; PATY, Michel (Ed.). Quantum Mechanics, a Half Century Later, Dordrecht: Reidel, 1977.

LÉVY-LEBLOND, Jean-Marc. Towards a proper quantum theory. In: LEITE LOPES, José; PATY, Michel (Ed.). Quantum Mechanics, a Half Century Later, Dordrecht: Reidel, 1977. p. 172-205.

LÉVY-LEBLOND, Jean-Marc; BALIBAR, Françoise. Quantique: rudiments. Paris: CNRS-Interéditions, 1984.

MEHRA, Jagdish; RECHENBERG, Helmut. The Historical Development of Quantum Theory. New York: Verlag; Berlin: Springer, 1992. 
OMNĖS, Roland. The Interpretation of Quantum Mechanics. Princeton: Princeton University Press, 1994.

PATY, Michel. Are quantum systems physical objects with physical properties?, European Journal of Physics, v. 20, p. 373-388, nov. 1999.

. The concept of quantum state: new views on old phenomena. In:

ASHTEKAR, Abhay et al (Ed.). Revisiting the Foundations of Relativistic Physics: Festschrift in Honor of John Stachel. Dordrecht: Boston Studies in the Philosophy and History of Science: Kluwer Academic, 2003. p. 451-478.

La connaissance scientifique comme pensée symbolique. [in Bachta, A. (éd.), Michel Paty, philosophe et historien des sciences, Paris : Hermann, 2010

Des fondements vers l'avant. Sur la rationalité des mathématiques et des sciences formalisées. Philosophia Scientice, Paris: Univ. Nancy 2, v. 9, n. 2, p. 109-130, 2005b.

. Einstein philosophe. Paris: Universitaires de France, 1993a.

prelo.

. Einstein, les quanta et le réel (critique et construction théorique). No

. Intelligibilité et historicité (Science, rationalité, histoire). In:

SALDAÑA, Juan José (Ed.). Science and cultural diversity: filling a Gap in the History of Science. México, 2001c. p. 59-95. (Cadernos de Quipu 5)

Interprétations et significations en physique quantique, Revue Internationale de Philosophie, n. 212, p. 17-60, 2000a.

La matière dérobée. L’appropriation critique de l'objet de la physique contemporaine. Paris: Archives contemporaines, 1988.

. The nature of Einstein's objections to the Copenhagen interpretation of quantum mechanics. Foundations of Physics, v. 25, n. 1, p. 183-204, jan. 1995.

Paty, Michel. La notion de grandeur et la légitimité de la mathématisation en physique, in Espinoza, Miguel (éd.), De la science à la philosophie. Hommage à Jean Largeault, Paris : L'Harmattan, 2001, p. 247-286. Trad. Inglesa: The idea of quantity at the origin of the legitimacy of mathematization in phy- 
sics. In: GOULD, Carol (Ed.). Constructivism and Practice: Towards a Historical Epistemology. Lanham: Rowman \& Littlefield, 2003. p. 109-135.

. La physique quantique ou l'entraînement de la forme mathématique sur la pensée physique. In: MATAIX, Carmen; RIVADULLA, Andrés (Ed.). Física cuantica y realidad: quantum physics and reality. Madrid: Complutense, 2002. p. 97-134.

. The problem of the physical interpretation of theoretical quantities and the intelligibility of the quantum world. In: DEBRU, Claude; PATY, Michel (Ed.). Changes in interpretation and conceptual contents. Changements dans l'interprétation et contenus conceptuels. In: SALDAÑA, Juan José (Ed.). Science and Cultural Diversity. In: International Congress of History of Science, 20., 2001, Mexico. Proceedings..., Mexico: Universidad Autónoma de México \& Sociedad Mexicana de Historia de la Ciencia y de la Tecnologia, 2005a. v. 37, p. 2774-2793. CD-Rom.

. The quantum and the classical domains as provisional parallel coexistents. Synthese, Dordrecht;Boston: Kluwer, v. 125, n.1-2, p. 179-200, out.-nov. 2000b. Editores: Steven French; Décio Krause e Francisco Doria, In honour of Newton da Costa, on the occasion of his seventieth birthday.

. Sur les variables cachées de la mécanique quantique: Albert Einstein, David Bohm et Louis de Broglie. La Pensée, n. 292, p. 93-116, mar./abr. 1993b.

- Uma visão "antropológica" do conhecimento científico (resenha de "Bruno Latour. Ciência em Ação. Como seguir cientistas e engenheiros sociedade afora. São Paulo: Unesp, 2000). Ciência Hoje, São Paulo, v. 28, n. 168, p. 68-69, jan./fev. 2001b.

PICKERING, Andrew. Constructing quarks: A Sociological History of Particle Physics. Edinburgh: Edinburgh University, 1984.

POINCARÉ, Henri. La science et l'hypothèse. Paris: Flammarion, 1902.

ROSENFELD, Léon. Selected papers. Edited by Robert S. Cohen and John Stachel. Dordrecht: Reidel, 1979.

SHAPIN, Steven. A social history of truth: civility and science in seveteenth century England. Chicago: University of Chicago Press, 1994. 
SCHILPP, Paul-Arthur [1949]. Albert Einstein: philosopher-scientist, The library of living philosophers, Open Court, Lassalle (Ill.), 1949. Reedição 1970 :

SELLERI, Franco. Quantum paradoxes and physical reality. Berlin: Springer, 2007.

SHINN, Terry. The Bellevue grand électroaimant, 1900-1940. Birth of a research-technology community. Historical Studies in the Physical Sciences, v. 24, n. 1, p. 157-187, 1993.

. Change or mutation? Reflections on the foundations of contemporary science. Social Science Information, v. 38, n. 1, p. 149-176, mar. 1999.

Formes de division du travail scientifique et convergences intellectuelles. La recherche technico-instrumentale. Revue Française de Sociologie, v. 41, n. 3, p. 447-473, 2000.

VIGIER, Jean-Pierre. Le Débat Bohr-Einstein. In: BITSAKIS, Eftichios (Ed.). The Concept of Physical Reality. Athens: Zacharopoulos, 1983. p. 51-109.

WARDEN, B. L. van der (Ed.). Sources of quantum mechanics. Amsterdam: North Holland, 1967.

WHEELER, John A.; ZUREK, Wojcieh H. (Ed.). Quantum theory of measurement. Princeton: Princeton University Press, 1983. 


\title{
O realismo de Einstein e sua crítica da Mecânica Quântica ${ }^{1}$
}

\author{
Christoph Lehner
}

\section{Introdução}

Poucos anos antes de suas mortes, o velho confidente de Albert Einstein, Michele Besso, deve ter-lhe escrito uma carta referindo-se a ele, de sua forma tipicamente entusiasmada, como um "gigante e velho amigo" (gewaltiger alter Freund). Einstein respondeu com seu próprio, não menos típico, sarcasmo:

Caro Michele,

Um velho amigo eu sou, mas à referência "gigante" só posso adicionar "coitado" [nebbish], se você está familiarizado com esta reveladora palavra de nossos antepassados. Ela expressa uma mistura de compaixão e desprezo. Cinquenta anos de ruminações conscientes não me trouxeram mais perto de uma resposta para a pergunta: "O que são quanta de luz?" Hoje em dia qualquer pé-de-chinelo pode achar que sabe, mas engana-se. ${ }^{2}$

A citação dá a avaliação um tanto desoladora do próprio Einstein de sua luta ao longo da vida com a Teoria Quântica ${ }^{3}$. Ilustra também de forma concisa dois aspectos desta luta, nos quais a presente contribuição se concentrará:

1 Em Janssen, Michel \& Lehner, Christoph (orgs.), The Cambridge Companion to Einstein. Cambridge: Cambridge University Press, no prelo. Tradução feita por Mayane da Nóbrega e Osvaldo Pessoa.

2 Albert Einstein para Michele Besso, 12 de dezembro de 1951. (SPEZIALI, 1972, p. 453)

3 Um relato detalhado com uma extensa seleção de citações de Einstein pode ser encontrado em Stachel (1986). 
a) A busca de Einstein para o entendimento dos fenômenos quânticos em um sentido forte, em oposição a uma mera descrição empiricamente adequada.

b) A crítica de Einstein de que a Mecânica Quântica, como foi formulada nos anos posteriores a 1925 (que obviamente é o reino dos pés-de-chinelo do comentário de Einstein), não nos oferece um entendimento do fenômeno, nesse sentido forte.

Estes dois aspectos estão fortemente conectados: é preciso ponderar o que estava envolvido para Einstein no elusivo conceito de "entendimento" na Física para avaliar a sua crítica do que ele próprio admitiu ser uma teoria de enorme sucesso.

A crítica de Einstein à Mecânica Quântica é naturalmente uma questão de grande interesse para o historiador interessado no pensamento dele, já que transcende as discordâncias técnicas com seus contemporâneos e concerne a suas ideias sobre o método e os objetivos da própria Física. Mas também é de grande interesse para físicos e filósofos da Física que se esforçam para a compreensão da Mecânica Quântica, já que se trata de um dos mais bem sucedidos e pensativos físicos da história e um dos pais da própria Teoria Quântica. No entanto, a crítica de Einstein era vista pela maioria de seus contemporâneos como a consequência de um ideal de ciência ultrapassado e somente nas últimas décadas filósofos e físicos a têm estudado mais de perto. Um importante papel neste desenvolvimento foi o trabalho de John S. Bell sobre a estatística de medições em estados emaranhados, que claramente demonstrou o conflito entre a Mecânica Quântica e as expectativas clássicas, e que foi construído a partir do exemplo que Einstein, Podolsky e Rosen propuseram em seu famoso experimento mental. Isto levou a um renovado interesse nas questões de fundamentos da Física Quântica, mas também ao próspero campo da preparação experimental e estudo dos estados emaranhados, exemplos paradigmáticos da estranheza do mundo quântico.

Atualmente, existe uma vasta literatura sobre a crítica de Einstein à Mecânica Quântica e a presente resenha não poderia tratar o tema em toda sua amplitude. Em vez disso, apresentarei o que vejo como o cerne da crítica de Einstein, um princípio metodológico que está na raiz de todos os seus argumentos relacionados ao entendimento da Mecânica Quântica. Este princípio é complementado por vários pressupostos físicos nos vários argumentos de Einstein, mas ele é mais geral que qualquer um destes pressupostos.

Pode-se argumentar que uma análise que buscasse encontrar um princípio básico simples para a disputa de Einstein com os vários defensores de uma leitura ortodoxa da Mecânica Quântica, necessariamente simplificaria as complexidades 
históricas e desconsideraria uma série de fatores não-teóricos que contribuíram para esta disputa. Embora, certamente, seja verdade que a história completa envolveu mais do que o debate abstrato entre duas posições teóricas, é igualmente certo que não se pode sequer começar a contar tal história completa sem compreender as questões teóricas em jogo. Por outro lado, defenderei que as questões filosóficas não podem ser compreendidas sem atenção ao contexto histórico concreto do debate.

\section{A evolução inicial das visões de Einstein}

O trabalho inicial de Einstein sobre Teoria Quântica foi acompanhado por sua esperança de finalmente chegar a uma teoria construtiva dos fenômenos quânticos, que a velha teoria quântica, antes de 1925, descrevia como um conjunto incompleto e um tanto ad hoc de condições quânticas. Einstein (1919c) explicou explicitamente o significado de "construtivo" em artigo de divulgação sobre a relatividade geral, escrito para o Times de Londres: nele, apresentou a distinção entre 'teorias de princípio', fundada em princípios gerais e bem confirmados empiricamente (como a termodinâmica, baseada na primeira e segunda leis da termodinâmica), e 'teorias construtivas', que constroem uma descrição da realidade física, a partir de partes simples, como os átomos da mecânica estatística de Boltzmann ou o campo eletromagnético da teoria de Maxwell do eletromagnetismo. Em sua comparação, Einstein deixou claro que, embora as teorias de princípio tivessem a vantagem de estar firmemente baseadas em conhecimento empírico, uma teoria física verdadeiramente fundamental deveria ser construtiva. As ideias de Einstein sobre como essa base construtiva para a Teoria Quântica poderia parecer não estão bem documentadas em suas publicações; elas têm que ser colocadas juntas a partir de observações marginais e algumas afirmações em sua correspondência. Uma vertente característica em seu pensamento era que uma modificação não-linear das equações de Maxwell poderia trazer vários benefícios: uma explicação da natureza quântica da radiação eletromagnética e uma explicação das propriedades do elétron. Por alguns anos, em volta de 1909, ele buscou vigorosamente construir tal teoria, até que desistiu temporariamente, passando a focar seus esforços na teoria relativística da gravitação, que se tornaria seu maior triunfo pessoal.

Depois de 1915, quando encontrou as equações de campo da relatividade geral após uma longa e árdua luta, duas mudanças teriam uma profunda influência no desenrolar dos acontecimentos:

Em 1913, Niels Bohr havia aplicado a Teoria Quântica ao modelo de Rutherford do átomo. Essa combinação ousada de dois novos empreendimentos teóricos - a 
Teoria Quântica e a Física Atômica - propeliu a Teoria Quântica de uma especialidade teórica um tanto obscura para a vanguarda da pesquisa em fundamentos da Física. Isto impressionou tanto Einstein que 35 anos depois ele escreveu em suas Notas autobiográficas:

Que esse fundamento inseguro e contraditório [da velha teoria quântica] fosse suficiente para permitir a um homem, com o instinto e a sensibilidade únicos de Bohr, descobrir as leis principais das linhas espectrais [...] pareceu para mim como um milagre - e até hoje parece para mim um milagre. Esta é a forma mais elevada de musicalidade na esfera do pensamento. (EINSTEIN, 1949, p. 45-47)

É plausível assumir que o sucesso de Bohr reacendeu o interesse de Einstein na Teoria Quântica. Em 1916, este publicou seu artigo sobre a emissão e a absorção de radiação pelo átomo de Bohr, conectando o novo modelo à sua velha especialidade, a hipótese do quantum de luz. Retornarei ao trabalho de Einstein sobre Teoria Quântica adiante. Antes, discutirei um segundo desenvolvimento de importância menos óbvia para as visões de Einstein sobre a Mecânica Quântica.

O sucesso da relatividade geral confirmou a conviç̧ão de Einstein na sensatez de um programa construtivo que baseasse a Teoria Quântica em uma teoria de campo; já em 1919, ele propôs uma modificação da relatividade geral com o objetivo de derivar elétrons como soluções das equações de campo. (EINSTEIN, 1919a) Este programa levaria, eventualmente, ao programa da teoria de campo unificado, no qual Einstein começou a trabalhar nos anos 20 e pelo resto de sua vida. Naquele momento, todavia, ele foi confrontado com muito ceticismo sobre sua abolição radical da realidade física do espaço e tempo. Colocado no centro das atenções da sociedade pela espetacular confirmação de suas previsões a respeito do desvio da luz do sol, mas por outro lado criticado vigorosamente pela Matemática de difícil compreensão e pela dificuldade de se intuir sua teoria, respondeu com uma série de artigos defendendo a sensatez física e epistemológica de sua teoria, tanto para seus colegas quanto para o público em geral. Isto o obrigou a pensar detidamente sobre os fundamentos e os métodos da Física e muitos dos seus mais importantes artigos filosóficos foram escritos nestes anos. (EINSTEIN, 1918c, 1918d, 1919b, 1919c, 1920, 1921)

Na próxima seção, argumentarei que, nesses anos, sob a influência dominante de sua experiência com a relatividade geral, as visões maduras de Einstein sobre a natureza e o método da Física foram formadas, especialmente seu chamado 'realismo', o princípio metodológico central na base da sua crítica à Mecânica Quântica. No restante desta contribuição, tentarei mostrar o quão profundamente este ponto de vista sobre a Física influenciou a posição de Einstein em relação à Mecânica Quântica e à pretensão desta de ser a nova base da Física. 


\section{0 realismo de Einstein}

A mais conhecida citação de Einstein sobre a Mecânica Quântica é indubitavelmente sua máxima "Deus não joga dados", expressa em uma carta a Max Born, seu colega e amigo de longa data, que se tornou um de seus principais oponentes na disputa sobre o estatuto da Mecânica Quântica ${ }^{4}$. Max Born foi um dos criadores da mecânica matricial e lhe é creditada a primeira formulação da interpretação estatística da Mecânica Quântica em seu trabalho sobre o tratamento mecânico ondulatório do processo de espalhamento. (BORN, 1926) Como muitos depois dele, Born viu o indeterminismo como a quebra fundamental da Mecânica Quântica em relação à Física clássica e entendeu a crítica de Einstein à Mecânica Quântica, como um preconceito contra a possibilidade de uma Física radicalmente indeterminista. ${ }^{5}$ Esta leitura tornou-se, em larga medida, a visãopadrão sobre a posição de Einstein: o velho revolucionário que matou o espaço e o tempo absolutos agora tornou-se conservador, agarrando-se teimosamente a suposições metafísicas antiquadas. Entretanto, este é um mal-entendido em relação à posição de Einstein, talvez compreensível do ponto de vista de Born e seu orgulho em ter feito com o determinismo o que Einstein fez com o espaço absoluto, mas demasiado simplista para fazer justiça à avaliação feita por Einstein da Mecânica Quântica. E embora historiadores da ciência com sensibilidade filosófica ${ }^{6}$ tenham apontado que as visões de Einstein eram muito mais complexas (e muito mais bem fundamentadas), a caricatura ainda se impõe fora da pequena comunidade dos estudiosos de Einstein.

Defendo esta posição com uma testemunha-chave: Wolfgang Pauli, apelidado de "a consciência da física". Sendo ele próprio um dos vigorosos defensores da Mecânica Quântica, certamente não era condescendente com Einstein. Apenas um ano antes da morte de Einstein, ele e Max Born travaram mais uma vez um debate bastante acalorado sobre a Mecânica Quântica, após a contribuição de Einstein para o Festschrift de Born, no qual criticara a Mecânica Quântica com um experimento mental discutido mais à frente (seção 7). Pauli, que na época estava em Princeton com Einstein, interveio para aplainar as crespas ondas. Ele escreveu para Born:

4 Albert Einstein para Max Born, 4 de dezembro de 1926. (EINSTEIN; BORN, 1969, p. 127)

5 Esta visão está expressa nos comentários de Born, em Einstein e Born (1969). Também Pais (1982), a biografia de Einstein geralmente muito cuidadosa, desconsidera completamente a crítica dele à Mecânica Quântica.

6 As discussões clássicas das visões filosóficas de Einstein podem ser encontradas em Jammer (1966), Howard (1984, 1985, 1993) e Fine (1996a). 
Em particular, Einstein não considera o conceito de "determinismo" tão fundamental quanto se costuma sustentar (como ele falou-me enfaticamente muitas vezes). [...] o ponto de partida de Einstein é mais "realista" do que "determinista", o que significa que seu preconceito filosófico é diferente. $^{7}$

Não surpreendentemente, é o conceito de realidade que está no coração do argumento de Einstein-Podolsky-Rosen (EINSTEIN; PODOLSKY; ROSEN, 1935) e é Mecânica quântica e realidade o título de um segundo artigo no qual Einstein apresentou uma versão mais simples do argumento. (EINSTEIN, 1948) No desenrolar de nossa discussão, encontraremos muitas evidências da preocupação de Einstein com a realidade que a Mecânica Quântica descreveria. Mas qual é o realismo que consiste no "preconceito filosófico" de Einstein? Pauli, que queria banir todas as imagens da descrição dos fenômenos atômicos, considerou-o como a tentativa ingênua e antiquada de continuar fazendo modelos mecânicos intuitivos na tradição da física do século XIX e, assim, o resultado de sua avaliação quanto à posição de Einstein não é mais positivo que o de Born. Mais tarde, comentadores de orientação mais filosófica concentraram-se na crítica de Einstein ao positivismo lógico e igualaram sua posição com a de um realismo epistemológico tradicional, que defende dever ser a ciência uma imagem fiel de "como as coisas realmente são", uma verdade independente do observador, que transcende nosso conhecimento empírico. (HOLTON, 1968) Tanto os positivistas lógicos, quanto os defensores da interpretação de Copenhagen da Mecânica Quântica, gostavam de rotular esta posição de "realismo ingênuo", implicando mais uma vez que isto significava um apego a ideias ultrapassadas sobre a possibilidade do conhecimento científico. Mas esta rejeição ignorava que Einstein, o estudante entusiasta de Hume, Mach e Poincaré, certamente não era ingênuo quando se tratava da epistemologia da ciência ${ }^{8}$. Ele aprendera, há tempos, a lição do empirismo e positivismo de que ciência não é simplesmente uma imagem do "mundo lá fora"; e não esqueceu esta lição em sua velhice, como mostra a seguinte citação:

O "real" não nos é dado de maneira alguma imediatamente, somente as experiências dos seres humanos nos são dadas. [...] A postulação do "real" como algo que existe independentemente da minha experiência é uma totalidade de construções intelectuais [...]. Nossa confiança no sistema de crença sobre a realidade repousa apenas no fato que aqueles conceitos e relações [postos como reais] estão em uma

7 Wolfgang Pauli para Max Born, 31 de março de 1954, em Einstein e Born (1969, p. 286).

8 Ver discussão em Howard (1993) 
relação de correspondência com nossa experiência; este é o único fundamento para a "verdade" de nossas afirmações. (EINSTEIN, 1951)

Einstein contrasta acentuadamente seu ponto de vista com o de Herbert Samuel, para quem a realidade é aquilo "lá fora" que a ciência deveria retratar. A verdade da ciência não está em ser uma imagem fidedigna de uma realidade independente da mente, mas no seu sucesso em contabilizar nossas experiências (aqui está o empirismo de Hume e Mach); e, de maneira mais importante para nossos propósitos, a própria realidade não é o "lá fora" independente da mente da epistemologia cartesiana, mas uma construção intelectual, posta pela ciência (aqui está o convencionalismo de Poincaré).

Se o realismo de Einstein não é um simples realismo epistemológico, o que é então? O que pode significar ser um realista sobre um construto intelectual? Arthur Fine havia proposto que Einstein "enteoriza" o realismo, significando que o realismo de Einstein não é uma tese epistemológica sobre a relação entre a ciência e a realidade independente da mente, mas sim uma tese metodológica sobre a correta estrutura interna da ciência e a escolha de seu aparato metodológico. Fine (1986, p. 86-111) vê o realismo de Einstein em um conjunto de requisitos para uma teoria fundamental satisfatória: a teoria deve falar sobre objetos independentes de observação, deve representá-los em um quadro espaço-temporal, deve consistir de leis deterministas. Fine também adicionou algumas exigências secundárias que não são tão centrais para Einstein.

Apresentando o realismo de Einstein desta forma, pode-se fazer este realismo parecer menos ingênuo, mas ele ainda parece um tanto carregado de preconceito: Einstein se apega a um conjunto de exigências a priori sobre a física e está disposto a descartar todo o bem-sucedido campo da Mecânica Quântica porque este não se encaixa nessas exigências. Tentarei fornecer um contexto histórico para as convicções metodológicas de Einstein, que mostrará que elas não são a priori, mas sim que resumem as lições que ele achou ter aprendido de seus próprios sucessos em Física teórica e que também estreitará a noção, um tanto vaga, de um conjunto de requisitos que Fine propôs para um único princípio fundamental (com alguns corolários), que proponho chamar de o realismo construtivo de Einstein. Por último, esta contextualização histórica fará com que as exigências de Einstein pareçam muito mais plausíveis, enquanto preceitos metodológicos gerais, mesmo à luz da Física contemporânea.

O contexto a ser olhado, como anunciado acima, é o período "filosófico" de Einstein, depois da publicação da Teoria da Relatividade geral, época em que ele conceituou e defendeu os princípios metodológicos que o levaram a seu maior sucesso teórico. E não há melhor lugar para começar, senão com a correspondência entre ele e Moritz Schlick, que havia escrito uma das primeiras análises 
filosóficas da relatividade geral: o artigo Raum und Zeit in der gegenwärtigen Physik (Espaço e tempo na física contemporânea). Einstein havia elogiado a sua "insuperável clareza de redação e organização". Alguns meses depois, Einstein estava estudando o livro, versão ampliada do artigo, e teceu um comentário sobre a crítica de Schlick ao positivismo de Mach. Schlick havia acrescentado um novo capítulo - Relações com a filosofia - que Einstein também achou excelente. Lá, Schlick defendeu um conceito mais amplo de realidade física, para além das sensações imediatas de Mach, e defendeu que é mais satisfatório também chamar de 'reais' os eventos físicos que não são diretamente perceptíveis. A resposta de Einstein ilustra de maneira linda sua própria visão sobre a questão do realismo, por isso vou citá-la por completo:

Sua concepção contrasta com a de Mach de acordo com o seguinte esquema:

Mach: Reais são somente as sensações.

Schlick: Reais são sensações e eventos (de natureza física).

Parece-me que a palavra "real" é entendida de duas maneiras diferentes, dependendo se é dita sobre sensações ou sobre eventos, isto é, questões de fato, no sentido da física.

Se duas pessoas fazem física independentemente uma da outra, elas criarão sistemas que certamente concordam no que diz respeito às sensações (os "elementos" no sentido de Mach). Os construtos intelectuais que ambas imaginam para conectar estes "elementos" podem diferir vastamente. Os dois construtos também não precisam concordar no que diz respeito aos "eventos", porque estes certamente pertencem aos construtos conceituais. Reais no sentido de serem "irrefutavelmente dados na experiência" são somente os "elementos" e não os "eventos".

Porém, se designarmos como "real" o que é ordenado por nós no esquema do espaço e tempo, como você fez em sua epistemologia, então, sem dúvida, são principalmente os eventos que são reais.

O que agora designamos "real" na física é, indubitavelmente, o "ordenado espaço-temporalmente", e não o "dado imediatamente". O dado imediatamente pode ser uma ilusão. Inversamente, o ordenado espaço-temporalmente pode ser um conceito estéril, que não contribui para a elucidação

9 Albert Einstein para Moritz Schlick, 6 de fevereiro de 1917, CPAE 8, doc. 297. 
das conexões entre os dados imediatamente. Eu gostaria de propor aqui uma separação clara dos conceitos..$^{10}$

Einstein está propondo aqui uma clara distinção entre uma realidade fenomênica, como a base epistemológica do nosso conhecimento (aquilo que é irrefutavelmente dado na experiência), e uma realidade física dos eventos ordenados espaço-temporalmente, que é uma construção intelectual (com a qual duas pessoas - ou cientistas - não precisam concordar). Por que Einstein propõe esta distinção? Apenas para uma clarificação metodológica? Eu prefiro supor que ele, que em frase célebre chamou a si mesmo de um "oportunista epistemológico", tinha uma questão concreta de Física na mente. E não é difícil imaginar o que isso poderia ser em 1917.

A relatividade geral tinha dilacerado de uma maneira até então inimaginável a congruência entre a postulada estrutura espaço-temporal fundamental de uma teoria física e as nossas intuições pré-teóricas sobre espaço e tempo (ou talvez apenas nossas intuições moldadas pelas teorias anteriores). Einstein tinha que defender tal escândalo, não apenas contra os filósofos - que protestavam que as leis do espaço e tempo não constituíam questão a ser decidida pela ciência empírica -, mas também contra muitos físicos - que se ressentiam de que os fundamentos da Física tornaram-se cada vez mais removidos para um nível abstrato e não-intuitivo da Física-Matemática. (É nesta situação que ele encontrou apoio no convencionalismo de Henri Poincaré, cujo postulado era de que os fundamentos da ciência não são leis empíricas nem necessidades a priori, mas convenções livres, escolhidas por conta da simplicidade e da coerência da estrutura teórica). Contra essa crítica, Einstein poderia argumentar que a separação entre os fundamentos da teoria e os fatos empíricos não era meramente uma perda, mas também a base para um novo e poderoso princípio metodológico: o princípio da covariância geral. A intenção deste princípio era tirar das coordenadas qualquer significado físico enquanto medida da distância espacial e temporal. No entanto, não significava, como popularmente, mas de modo equivocado, se achava que agora "tudo é relativo". Pelo contrário, a particular força da covariância geral é a descoberta de uma nova estrutura de invariância por trás dos fenômenos.

Esta descoberta não foi trivial, como mostra a longa luta de Einstein com a questão da covariância das equações de campo para o campo gravitacional. ${ }^{11}$ Após a descoberta no final de 1915, no entanto, Einstein pôde anunciar que todas as entidades fundamentais na relatividade geral eram, agora, grandezas com covariância geral. $\mathrm{O}$ fato de que as próprias equações de campo têm covariância

10 Albert Einstein para Moritz Schlick, 21 de maio de 1917, CPAE 8, doc. 343.

11 Ver Janssen e Renn (2007) para o complicado desenvolvimento das ideias de Einstein, durante este período. 
geral significa que a estrutura gravito-inercial (a união dos efeitos gravitacionais e inerciais, requerida pelo princípio da equivalência) não é dada por uma determinação a priori, como ocorria com o espaço absoluto newtoniano, mas sim através de um campo evoluindo dinamicamente que interage com a matéria, da mesma forma que o campo eletromagnético. Não se tratava apenas de uma descoberta física, mas também de uma novidade conceitual, como mostra a comparação com a teoria anterior, conhecida como Entwurf (esboço): nesta teoria, não estava claro o quanto da estrutura espaço-temporal era dada a priori e o quanto dela era causada dinamicamente; e Einstein lutou por um longo tempo para esclarecer essa divisão, buscando propriedades de invariância das equações de campo.

Agora, com a covariância geral, essa divisão é simples: qualquer sistema de coordenadas é igualmente admissível para a descrição do espaço-tempo. Portanto, somente entidades covariantes, como tensores e vetores, definidas independentemente de uma escolha específica do sistema descritivo (coordenado), podem ser consideradas como definidas objetivamente. As leis fundamentais (como as equações de campo) só podem ser definidas em tais objetos invariantes. A propriedade de invariância matemática da covariância geral torna-se, portanto, uma marca da objetividade no sentido de independência do observador. Por outro lado, medições físicas não revelam essas próprias entidades objetivas, mas suas representações nos sistemas de coordenadas locais, que são grandezas não-invariantes. Tais medições não são menos reais, mas são reais em um sentido diferente: sua realidade é fenomênica, dependente de um observador situado de uma maneira específica. Se medirmos a força gravitacional na superfície da Terra, esta medição faz perfeito sentido, mas ela depende da especificação do referencial de repouso, ou seja, no caso, o aparelho de medição está fixo em relação à superfície da terra.

A associação de invariantes descritivos com a realidade objetiva tornou-se um padrão metodológico na Física moderna, sendo a base conceitual não só da relatividade geral, mas de todas as teorias de calibre, também em suas formas quânticas. Ela também permeia a própria Mecânica Quântica, desde a sua formulação como teoria da transformação por London, Dirac e Jordan, que também está baseada na distinção entre fatos físicos e suas representações em diferentes sistemas de referência (aqui, as diferentes bases do que logo seria chamado espaço de Hilbert). Como tal, essa associação também se tornou um tema bem tratado na história e filosofia da Física moderna. (NORTON, 1992) Por outro lado, a associação de entidades dependentes da descrição com uma realidade fenomênica não criou muita comoção. Desta forma, olharei para um exemplo marcante do uso que o próprio Einstein fez desta associação: a interpretação dos símbolos de Christoffel da métrica do espaço-tempo a partir do campo da força gravitacional. Os símbolos de Christoffel descrevem como o movimento geodésico em uma dada métrica desvia de um movimento que é "linear" em um dado sistema de coordenadas. Eles, portanto, dependem essencialmente (não apenas covariantemente) 
da escolha do sistema de coordenadas. Por esta razão, a interpretação de Einstein (e a afirmação relacionada de que a energia do campo gravitacional é dada por uma grandeza dependente de coordenadas) foi criticada até mesmo pela maioria dos adeptos da relatividade geral ${ }^{12}$; e nas modernas apresentações livres de coordenadas da relatividade geral, o ponto de Einstein é ignorado, na maior parte das vezes. Mesmo assim, a interpretação de Einstein faz sentido físico. Trata-se exatamente do ponto do princípio da equivalência, que foi a intuição original de Einstein que o levou à relatividade geral, segundo o qual o campo gravitacional é inteiramente dependente da escolha do sistema de referência: um observador em repouso na superfície da terra sente o campo gravitacional da Terra, ao passo que um observador em queda livre (como em um satélite que circunda a terra) sente "gravidade zero". O próprio princípio da equivalência foi uma questão central para os críticos da relatividade geral, que argumentavam que Einstein confundira a diferença essencial entre o campo inercial fictício e o campo gravitacional real. Para nós, é especialmente interessante como Einstein respondeu a esta crítica:

Em primeiro lugar, devo salientar que a distinção "real" versus "não-real" não pode ser muito útil aqui. [Einstein refere-se a uma discussão anterior, sobre como a energia na física clássica é uma grandeza que depende da escolha do referencial.] Em vez de distinguir entre "real" e "não-real", façamos uma distinção mais clara entre grandezas que são inerentes ao próprio sistema físico (independente da escolha das coordenadas) e grandezas que dependem do sistema de coordenadas. Seria imediatamente plausível requerer que a física devesse introduzir em suas leis apenas grandezas do primeiro tipo. No entanto, acontece que esse caminho não é realizável na prática, como já foi mostrado pelo desenvolvimento da mecânica clássica.

[A Física] não pode ser feita sem o sistema de coordenadas e portanto tem que usar, junto com as coordenadas, grandezas que não podem ser entendidas como os resultados de medições definíveis. De acordo com a relatividade geral, as quatro coordenadas do contínuo espaço-temporal são até parâmetros escolhidos de maneira completamente livre, desprovidos de qualquer significado físico independente. Parte dessa liberdade também afeta aquelas grandezas que usamos para descrever a realidade física (os componentes do campo). [...] Assim, não se pode dizer nem que o campo gravitacional em um ponto seja algo "real", nem que seja algo "meramente fictício". ${ }^{13}$

12 Ver a discussão e referências em CPAE 8, Introdução, p. li.

13 Albert Einstein, 1918k, p. 699-700; CPAE 7, doc. 13. 
A grandeza empírica mensurável "campo gravitacional" não pode ser expressa como uma entidade puramente objetiva, pois sua medição depende essencialmente do estado do observador. Mas isso não a faz fictícia. Pelo contrário, é parte do que chamo realidade fenomênica de um observador especificamente situado.

\begin{tabular}{|c|c|}
\hline \multicolumn{2}{|c|}{ 'Eventos Físicos' } \\
\hline $\begin{array}{c}\text { Invariante } \\
\text { (independente de coordenada) } \\
\text { descrição }\end{array}$ & $\begin{array}{c}\text { Objetivo } \\
\text { (independente de observador) } \\
\text { realidade }\end{array}$ \\
\hline \multicolumn{2}{|c|}{ Exemplo: tensor métrico } \\
\hline \multicolumn{2}{|c|}{ 'Eventos Machianos' } \\
\hline $\begin{array}{c}\text { Relativo } \\
\text { (dependente de coordenada) } \\
\text { descrição }\end{array}$ & $\begin{array}{c}\text { Fenomênico } \\
\text { (dependente do observador) } \\
\text { realidade }\end{array}$ \\
\hline \multicolumn{2}{|c|}{ Exemplo: campo gravitacional } \\
\hline
\end{tabular}

Figura 1 - Realidades objetiva e fenomênica

Afirmo, então, que este é o ambiente teórico específico para a distinção de Einstein entre os dois significados de realidade, na carta para Schlick. Os 'elementos machianos' de que Einstein fala em sua carta para Schlick são reais nesse sentido fenomênico; os 'eventos físicos' são reais no sentido objetivo (Figura 1). Mas esses dois conceitos de realidade são bastante independentes de qualquer afirmação epistemológica a respeito da relação da Física com o 'mundo real'. O que Einstein aborda não é o problema cartesiano, mas a metodologia da Física: dentro da Física, é preciso distinguir entre o que a teoria afirma serem fatos objetivos (independentes da descrição) e fatos fenomênicos (dependentes da descrição). Evidentemente, essa distinção é meramente analítica e não impõe qualquer restrição sobre as teorias físicas. Mas ela motiva um princípio substancial, isto é, a seguinte exigência metodológica: somente fatos objetivos (dados pelos invariantes da descrição) podem entrar nas leis fundamentais da Física.

Pode-se chamar a essa exigência de o realismo metodológico de Einstein, tendo em mente que não tem muito a ver com o realismo epistemológico com o qual os filósofos têm se preocupado. ${ }^{14} \mathrm{O}$ fundamento desse princípio metodoló-

14 Evidentemente, essas formas do realismo não são necessariamente contraditórias entre si e pode-se argumentar que Einstein, às vezes, também defendeu um realismo epistemológico mais tradicional. No entanto, como as citações acima mostram, há evidência suficiente de que, pelo menos em seu escritos de orientação mais filosófica, ele foi bastante crítico a respeito. Mais importante, como argumentarei nas seções seguintes, é que o seu realismo metodológico é suficiente para sua crítica da Mecânica Quântica. 
gico não é o fato de que a Física é, em qualquer sentido, ingenuamente realista, uma 'imagem da realidade', mas sim uma teoria de invariantes, cujo objetivo é construir uma estrutura simples e coerente por trás da multidão vertiginosa de fenômenos. O princípio é bem semelhante aos princípios regulativos de Kant e mais tarde, em sua vida, Einstein iria reconhecer essa afinidade com um filósofo que ele inicialmente não gostava muito, enquanto defensor do conhecimento $a$ priori. ${ }^{15} \mathrm{O}$ ponto importante é que o realismo metodológico de Einstein não faz quaisquer afirmações sobre a realidade, além de sua invariância. Este é o ponto em que minha leitura de Einstein difere substancialmente de outras propostas, como as de Arthur Fine e Don Howard, que pensam que o realismo de Einstein implica determinismo ou separabilidade, respectivamente.

\section{A Teoria Quântica do átomo}

Os anos que se seguiram à proposta do modelo atômico de Bohr viram a ascensão rápida da Teoria Quântica para uma teoria cada vez mais complexa e sofisticada da microfísica e Einstein estava profundamente envolvido em seu desenvolvimento. Mesmo assim, ele estava insatisfeito com a falta de compreensão fundamental dos processos responsáveis pelos fenômenos quânticos. Havia um crescente corpo de evidência de que algumas suposições fundamentais, que formavam a base de toda a Física, teriam que ser abandonadas, mas não ficara claro quais modificações seriam necessárias para dar conta do estranho mundo dos quanta. Einstein reconhecera, há muito tempo, os problemas que a dualidade da luz introduzira para a mecânica e a eletrodinâmica, mas também na física atômica não havia no horizonte um relato consistente da dualidade de estados estacionários e saltos quânticos.

Mais uma vez, foi Einstein (1916) quem apontou uma consequência perturbadora do sucesso da teoria de Bohr. Ele conseguiu mostrar que a distribuição de energia de Planck para a radiação do corpo negro podia ser derivada do modelo atômico de Bohr, com o auxílio de algumas suposições simples sobre a probabilidade de emissão e absorção de radiação. Ele pôde ainda mostrar (EINSTEIN, 1917) que a radiação emitida tinha que ter um momento definido, ou seja, que ela era emitida em uma direção específica e não como uma onda esférica, tal como era descrito pela teoria eletrodinâmica clássica. Esta foi uma ruptura bastante radical com a visão clássica, na qual um corpo emite radiação continuamente a

$15 \mathrm{Na}$ época, Einstein expressou seus pensamentos sobre Física e realidade mais diretamente na sua palestra Motivos para pesquisa (EINSTEIN, 1918c), onde enfatizou que a busca pelo absoluto, que estaria por trás dos fenômenos variáveis, seria a motivação mais fundamental para se fazer física. 
uma determinada taxa em todas as direções. No modelo de Einstein, haveria atos individuais de emissão em direções específicas que estariam distribuídas apenas estatisticamente (como o próprio Einstein comentou, isto era semelhante à lei do decaimento radioativo). Seria o próprio ato da emissão fundamentalmente indeterminístico? Hoje em dia, esta parece ser uma conclusão bastante plausível, já que temos uma teoria de enorme sucesso que determina as probabilidades de tais eventos elementares e nada mais do que as probabilidades. Einstein, contudo, não estava pronto para abandonar o determinismo. O que teria feito a hipótese de uma lei genuinamente estatística inaceitável para Einstein? O relato-padrão defende que o comprometimento de Einstein com o determinismo seria uma crença conservadora, profundamente enraizada que ele não se dispôs a abandonar em face do aumento das evidências contrárias. Quero argumentar, no entanto, que a atitude de Einstein para com o determinismo é (1) mais complexa que uma simples crença dogmática e (2) motivada pelo que ele acreditou ter aprendido de seu bemsucedido trabalho anterior sobre os fundamentos da mecânica estatística e teoria do espaço-tempo.

Einstein considerava que sua contribuição central para a física estatística nos anos 1902-1904 fora o esclarecimento do conceito de probabilidade que entrava na definição estatística da entropia de Boltzmann: $S=k \ln W$. Ele explicou a probabilidade de um estado termodinâmico, como a fração de tempo que o sistema permanece naquele estado, em média, durante sua evolução dinâmica complexa. Isto implica que um sistema em equilíbrio não permanece simplesmente em seu estado mais provável (o estado de mais alta entropia), mas que também alcança outros estados com uma probabilidade expressa pela entropia destes. Assim, o estado do sistema flutuaria em torno do estado de equilíbrio de certa maneira bem definida. Esta teoria de flutuações em torno do equilíbrio levou Einstein a suas mais importantes contribuições, não somente em mecânica estatística (movimento browniano), mas também na nascente Teoria Quântica. O sucesso desses trabalhos deu apoio aos aspectos ainda controvertidos da mecânica estatística de Boltzmann: a segunda lei da termodinâmica não seria uma lei exata, mas apenas uma regularidade estatística, e as grandezas termodinâmicas macroscópicas não nos dariam sempre uma descrição exata do estado objetivo do sistema. Para um sistema de energia definida, por exemplo, o microestado (a especificação das posições e velocidades de todas as suas moléculas) tem que estar em uma região específica do espaço de estados (a superfície de energia), já que a energia total é simplesmente a soma de todas as energias das moléculas. Porém, um sistema a uma dada temperatura não tem uma energia definida, mas somente sua energia média é especificada. Desta forma, seu microestado também não está especificado em uma determinada região do espaço de estados e pode-se somente dizer que apresenta alta probabilidade de estar próximo da superfície energética definida pela energia média. 
Isto confirmou para Einstein uma clara divisão entre os estatutos das descrições microscópica e macroscópica de um sistema físico: somente os microestados e suas dinâmicas - cuja realidade foi demonstrada dramaticamente em 1905 pela predição de Einstein sobre o movimento browniano - fornecem uma determinação completa e objetiva de um sistema físico. A macrodescrição e suas leis termodinâmicas são somente descrições incompletas, regularidades estatísticas aproximadas, derivadas da lei dos grandes números. Grandezas macroscópicas, tais como temperatura e entropia, são médias temporais definidas somente no limite de tempo infinito, de forma que para sistemas realísticos suas definições são apenas aproximadas.

Esta divisão adquiriu peso adicional com o desenvolvimento da Teoria da Relatividade de Einstein. Quando ele anunciou que "o fisicamente real no Weltgeschehen [os acontecimentos do mundo] (em oposição ao que depende da escolha de um sistema de referência) consiste das coincidências no espaço-tempo e nada mais"16, isto teve uma implicação importante para a mecânica estatística. Dado que o fisicamente real (no sentido discutido na seção anterior) é dado pela estrutura quadrimensional atemporal dos eventos no espaço-tempo, todos os eventos tanto no passado como no futuro existem objetivamente. Assim, não haveria a possibilidade de um futuro aberto que permitiria uma genuína indeterminação de eventos futuros. Qualquer lei dinâmica probabilística é, portanto, necessariamente uma descrição incompleta de eventos futuros. Esta observação exacerba a tensão entre a direcionalidade da termodinâmica e a ausência de direção do tempo na mecânica, que preocupava os defensores da mecânica estatística no século XIX. Einstein resolveu esta tensão invocando a distinção entre as realidades objetiva e fenomênica discutidas na seção anterior. Tanto a direcionalidade temporal, quanto a indeterminação de processos macroscópicos, são partes da realidade fenomênica e assim não estão em conflito com a atemporalidade da realidade objetiva.

A descrição objetiva é dada pelos microestados. Sua dinâmica é determinística, garantindo a compatibilidade com a teoria da relatividade e sua completa especificação através de leis gerais. Macroestados, no entanto, são estados fenomênicos que dependem de um particionamento convencional do espaço de estados para sua definição. Suas leis (tais como a segunda lei da termodinâmica) não são fundamentais, mas são leis estatísticas que podem coexistir com a determinação fundamental da dinâmica. Esta identificação dos macroestados estatísticos com o sentido da realidade fenomênica, discutida na seção anterior, adquiriria importância central para a compreensão que Einstein tinha da Teoria Quântica. Há, porém, uma diferença importante entre os dois casos de estados fenomênicos (na relatividade e na mecânica estatística) que discutimos: na mecânica estatística, a

16 Einstein para Ehrenfest, 26 de dezembro de 1915, CPAE 8. 
descrição é incompleta, fornecendo apenas uma caracterização parcial do estado objetivo, ou seja, pode-se dizer que a relação entre descrição e estado é de umpara-muitos (cada descrição refere-se a muitos estados objetivos possíveis). As descrições não-invariantes da relatividade não são descrições incompletas neste sentido. Ao contrário, elas são "sobrecompletas", cada estado de coisas objetivo pode ser descrito em diferentes sistemas de referência, de forma que a relação entre descrição e estado é de muitos-para-um. Podemos dizer que a descrição não é absoluta, mas relativa a um sistema de referência. Em ambos os casos, esta relação não é biunívoca (um-para-um), mas por razões diferentes. O princípio do realismo metodológico de Einstein implica em ambos os casos que a descrição não se refere a um estado objetivo e, portanto, não pode entrar em leis fundamentais ${ }^{17}$.

A descrição da emissão e absorção de radiação, que Einstein forneceu em 1916, só poderia ser para ele uma descrição fenomênica, apesar de seu sucesso, e não uma lei dinâmica fundamental. Einstein continuou buscando esta teoria fundamental. $\mathrm{Na}$ esperança de encontrar pistas para tal teoria, ele começou a desenvolver a ideia de um "experimento crucial" que decidisse sobre a natureza do ato de emissão de luz de um átomo, na esperança de esclarecer o aspecto mais misterioso do modelo atômico de Bohr: o salto descontínuo e instantâneo entre duas órbitas atômicas, que, aliás, de acordo com Bohr, deve produzir uma onda de luz estendida de frequência constante. (Não era apenas o mecanismo do salto que era obscuro, mas o fato de que ele deveria produzir uma onda de luz comparativamente imensa parecia completamente absurda.) Einstein propôs diversos experimentos durante os anos de 1920 que deveriam forçar uma resposta sobre se o ato de emissão seria instantâneo ou espacialmente e temporalmente estendido $^{18}$. Todavia, nenhum dos experimentos produziu a resposta inequívoca que Einstein esperava. Parece que o fracasso em elaborar experimentos que reforçassem o esforço construtivo fez Einstein cada vez mais cético quanto à possibilidade de uma abordagem indutiva para a desejada teoria fundamental.

Relativamente pouco é conhecido sobre as especulações teóricas de Einstein no período compreendido aproximadamente entre 1915 e 1925, já que ele não publicou suas ideias e parecia até relutante em discuti-las em sua correspondência. Um vislumbre interessante pode ser obtido de Hendrik A. Lorentz (1927) que, tanto em uma carta a Einstein ${ }^{19}$, quanto em uma palestra dada em Pasadena em 1921, relata sobre uma teoria da luz que Einstein tentativamente considerava na época. Nesta teoria, quanta e ondas de luz coexistiriam. Enquanto os quanta

17 O importante papel da biunivocidade na relatividade geral é discutido em Howard (1992).

18 Um primeiro experimento mental é descrito em Klein (1970), outro posterior em van Dongen (2007a, 2007b).

19 H. A. Lorentz para Albert Einstein, 13 de novembro de 1921. 
seriam partículas pontuais transportando pacotes de energia necessários para explicar os efeitos dos quanta de luz, seus movimentos seriam determinados por uma onda guia, de forma muito parecida como Louis de Broglie também imaginaria alguns anos mais tarde. Einstein nunca publicou um relato de suas ideias. Wigner relatou, a partir de discussões feitas na época em Berlim, que Einstein desistira da ideia da onda guia porque esta não daria conta dos processos de espalhamento: a correlação exata dos ângulos de espalhamento exigidos pela conservação de energia e momento não poderia ser causada por duas ondas que emanam em todas as possíveis direções de espalhamento ${ }^{20}$. Era um problema semelhante ao que iria também refutar a teoria BKS proposta logo depois (próxima seção). Todavia, este cenário explica o entusiasmo inicial de Einstein para os esforços construtivos de de Broglie e Erwin Schrödinger, bem como sua percepção aguda dos seus problemas fundamentais.

Em 1923, Einstein publicou um artigo intitulado A teoria de campos oferece possibilidades para a solução do problema quântico? (EINSTEIN, 1923d), em que enunciou pela primeira vez, de maneira detalhada e programática, a esperança que ele levaria pelo resto de sua vida: derivar as propriedades das partículas elementares e seus comportamentos quânticos a partir de uma teoria de campo unificado, que estenderia a relatividade geral e a eletrodinâmica maxwelliana. Einstein propôs no artigo que as condições quânticas deveriam ser entendidas como consequência de uma sobredeterminação das equações de campo da teoria unificada. Se a teoria contivesse mais equações diferenciais do que variáveis de campo independentes, nem todo conjunto de condições iniciais seria permitido. Desta forma, ele esperava explicar tanto a existência de partículas elementares com propriedades definidas, quanto sua dinâmica quantizada. $\mathrm{O}$ truque consistiria em encontrar as equações gerais de campo e Einstein esperava poder repetir o sucesso da Relatividade geral: uma vez que a correta estrutura matemática fosse encontrada (como a geometria riemanniana, no caso da relatividade geral), toda a teoria poderia ser desenvolvida a partir de algumas poucas suposições de grande generalidade (como o princípio da equivalência). Em retrospectiva, seus anos de luta com a física do campo gravitacional ${ }^{21}$ pareciam-lhe um desvio desnecessário da estrada real da Matemática. Essa confidência está expressa muito claramente em suas Palestras Spencer de 1933, em Oxford, em que declarou: "Nossa experiência até aqui justifica nossa crença de que a natureza é a realização das mais simples ideias matemáticas concebíveis". (EINSTEIN, 1933a apud EINSTEIN, 1954, p. 274) A virada de Einstein para a teoria do campo unificado tem, portanto, uma dupla raiz: a frustração com as tentativas de construir mode-

20 Conforme relatado por Wigner (1980, p. 461), citado por Howard (1990).

21 Ver a contribuição de Janssen (2004) para um relato do papel dos argumentos físicos no desenvolvimento da relatividade geral. 
los construtivos para os quanta e os efeitos quânticos e a esperança de que a teoria que iria resolver estes problemas poderia ser encontrada diretamente através da busca da teoria de campo de "tudo" que fosse matematicamente mais simples e rigorosa. As Palestras Spencer são o ponto alto das declarações de Einstein a favor da confiança no valor heurístico da Matemática. Mas mesmo quando ele duvidou, em anos posteriores, se a teoria de campo poderia resolver o enigma quântico, permaneceu convencido de que esta era o único caminho que lhe estava aberto. Durante os anos 1920 e 1930, no entanto, suas esperanças depositadas em seu novo programa de pesquisa eram imensas. É preciso sempre manter isso em mente quando se tenta entender a reação de Einstein para com o desenvolvimento da Mecânica Quântica.

\section{A ascensão da Mecânica Quântica}

O ceticismo de Einstein decorrente de suas tentativas frustradas de encontrar um fundamento teórico para a velha Teoria Quântica é o pano de fundo que se deve ter em mente ao acompanhar suas reações a diversas tentativas de outros físicos em meados da década de 1920: primeiro, a teoria de Bohr-Kramers-Slater (BKS); depois, as mecânicas matricial e ondulatória e sua unificação na teoria da transformação, o que hoje conhecemos como mecânica quântica. Ele manteve seu interesse, mas acompanhou de fora, ficando até entusiasmado de início, no caso das mecânicas matricial e ondulatória. Mas quando os desenvolvimentos entraram em dificuldades ou em conflito com o que ele considerava princípios gerais bem estabelecidos, ele passou a ver isso como um sinal do fracasso do "programa indutivo".

A teoria BKS gerou sérios problemas, antes mesmo de ser posta à prova. A ideia básica da teoria era associar a um átomo, em um determinado estado, uma orquestra de osciladores virtuais vibrando em todas as frequências que o átomo poderia emitir naquele estado. Cada oscilador de emissão gera radiação electromagnética (virtual) em sua frequência de oscilação e esta se propaga classicamente de acordo com as equações de Maxwell. Se outro átomo, com um oscilador virtual de absorção na mesma frequência, é exposto a esta radiação, haverá uma probabilidade, determinada pela intensidade da radiação, de que o átomo salte para um estado de maior energia. Einstein discordou da teoria por diversas razões (KLEIN, 1970), entre elas a violação da conservação da energia e a violação do determinismo. Conforme escreveu para Paul Ehrenfest, "essa ideia é uma velha conhecida minha, mas eu não a considero uma coisa real." ${ }^{22}$. A teo-

22 Albert Einstein para Paul Ehrenfest, 31 de maio de 1924, citado em Klein (1970). 
ria lembrou Einstein de suas próprias tentativas com uma teoria da onda piloto da luz, assim ele estava bem ciente de seus problemas. Quando a teoria BKS foi refutada pelos experimentos de Bothe-Geiger e de Compton-Simon, Einstein só comentou laconicamente com Ehrenfest: "Nós dois não tivemos dúvidas sobre isso." ${ }^{23} \mathrm{O}$ ceticismo de Einstein ressurgiria posteriormente com suas questões críticas sobre a Mecânica Quântica, que seriam influenciadas pela experiência de fracasso dessas tentativas.

Werner Heisenberg retirou da teoria BKS não muito mais do que a ideia de osciladores virtuais, quando propôs uma nova Mecânica Quântica em 1925: ele eliminou as órbitas dos elétrons e descreveu os fenômenos atômicos inteiramente em termos da frequência e amplitude das transições entre estados. Ele não viu necessidade de substituir as órbitas dos elétrons por alguma outra descrição de estados atômicos. Max Born e Pascual Jordan mostraram que se as amplitudes de transição fossem dispostas em um arranjo bidimensional (matriz) poder-se-ia com estas matrizes realizar cálculos de forma análoga à mecânica clássica. Einstein acompanhou o desenvolvimento da mecânica matricial com interesse, mas com ceticismo. Heisenberg havia justificado a eliminação das órbitas dos elétrons com o argumento positivista de que tal órbita é, em princípio, não-observável. Como ele relata em Heisenberg (1969), Einstein protestou contra este positivismo, para grande surpresa de Heisenberg, já que este havia aceitado a difundida visão de que a Teoria da Relatividade de Einstein seria um paradigma do positivismo de Mach. Heisenberg cita Einstein, que disse: "[...] apenas a teoria decide o que se pode observar" e vê nesta conversa a semente para sua posterior ideia das relações de incerteza como uma consequência do formalismo da Mecânica Quântica. Heisenberg (1927) propôs que se compreendessem as matrizes da Mecânica Quântica como descrevendo grandezas físicas não como números precisos, mas com certo grau de indeterminação. Esta indeterminação corresponde à nossa incapacidade de observar as grandezas físicas com precisão ilimitada. Heisenberg deriva do formalismo matricial uma desigualdade, a relação de incerteza de Heisenberg, que limita a definição simultânea de duas propriedades complementares, como posição e momento de uma partícula. Em seguida, ele tenta mostrar, por meio de um experimento mental simples, que essa relação de incerteza também descreve os limites de nossas possibilidades de medições. Ele supõe que se tenta medir a posição de uma partícula através do espalhamento Compton, com um quantum de luz. Para uma medição precisa da posição, a luz tem que ter um comprimento de onda curto, e portanto, o quantum de luz tem que ter um grande momento linear. Mas isso significa que a observação perturba o momento da partícula. Assim, as precisões das medições de posição e momento se limitam mutuamente. As relações de incerteza de Heisenberg se tornariam uma das questões centrais na crítica de Einstein à Mecânica Quântica.

23 Albert Einstein para Paul Ehrenfest, 18 de agosto de 1925, citado em Klein (1970) 
A mecânica ondulatória de Schrödinger, apresentada no início de 1926, num primeiro momento pareceu para Einstein uma abordagem muito mais promissora para compreender a Teoria Quântica. Em carta a Schrödinger, ele escreveu:

Estou convencido de que você fez um progresso decisivo com sua formulação das condições quânticas, assim como estou convencido de que o caminho de Heisenberg-Born é absurdo. (PRZIBRAM, 1963, p. 24) 24 $^{24}$

A explicação das órbitas atômicas, como ondas estacionárias, prometeu o retorno a uma descrição contínua, e de acordo com uma teoria de campo, dos fenômenos quânticos, em consonância com o programa do próprio Einstein. Desde 1924, Einstein simpatizava com as ideias das ondas de matéria de de Broglie e fez uso delas no contexto de sua Teoria Quântica do gás ideal, o que por sua vez instigou a pesquisa de Schrödinger na mecânica ondulatória. Schrödinger pôde rapidamente mostrar que a mecânica ondulatória consegue reproduzir as previsões empíricas da mecânica matricial. Mas ela prometia fazer muito mais, já que fornecia um relato dinâmico dos fenômenos atômicos, em oposição à caracterização estática e abstrata dos estados atômicos na mecânica matricial. No entanto, logo se tornou claro que a mecânica ondulatória também apresentava sérios problemas de interpretação. Como o próprio Schrödinger reconheceu, a função de onda de um sistema de várias partículas não era um campo definido no espaço-tempo, mas uma função abstrata em um espaço de dimensão mais alta. Não parecia haver uma maneira de interpretar essa função em um quadro espaço-temporal. Além disso, a esperança inicial de Schrödinger - de que ele poderia representar partículas livres como pequenos pacotes de ondas -, enfrentou a dificuldade de que tais pacotes de onda espalhariam ao longo do tempo.

Diferentemente das intuições de Schrödinger, Max Born propôs entender a função de onda não como um objeto físico extenso, mas como expressando a probabilidade de uma partícula pontual estar em um lugar específico. Esta interpretação estatística forneceu uma explicação natural para a alta dimensionalidade da função de onda, característica para distribuições de probabilidades conjuntas de muitas partículas. Também resolveu o problema da instabilidade do pacote de ondas. Mas frustrou a esperança de que a mecânica ondulatória poderia dar um fundamento à Teoria Quântica em termos de teoria de campo. $\mathrm{O}$ entusiasmo de Einstein diminuiu consideravelmente. Se a mecânica ondulatória era uma teoria estatística, ele a via como uma descrição incompleta da realidade objetiva, de acordo com suas convicções de longa data sobre probabilidade. Ele não acreditava que as evidências da física atômica eram fortes o

24 Albert Einstein para Erwin Schrödinger, 26 de abril de 1926, citado em Przibram (1963, p. 24). 
suficiente para justificar o abandono do determinismo. Ao final do ano, ele escreveu para Born:

A mecânica quântica é admirável. Mas uma voz interior me diz que ainda não é a palavra final. A teoria fornece muita coisa, mas ela pouco nos aproxima dos segredos do Senhor. De qualquer forma, estou convencido de que ele não joga dados. $^{25}$

Que este juízo também incluía a mecânica ondulatória pode ser visto em uma carta a Paul Ehrenfest de janeiro de 1927, na qual diz que seu coração não se aquece com as "coisas de Schrödinger" [Schrödingerei]. (EHRENFEST apud FINE, 1996a, p. 27)

Na primavera de 1927, Einstein tentou adicionar trajetórias de partículas à mecânica ondulatória, revivendo sua ideia anterior de uma teoria dual de partículas e uma onda-piloto. Há um manuscrito não-publicado ${ }^{26}$ sobre essa tentativa, com uma nota dizendo que Walther Bothe apontou uma dificuldade sobre o esquema proposto por Einstein: no caso de um sistema composto de duas partes que não interagem, a função de onda do sistema composto pode ser representada como o produto das funções de onda das partes. Se a trajetória correspondente à função de onda de uma parte for construída, ela não será idêntica à trajetória que se obteria se a outra parte não existisse. Isso entra em conflito com a suposição de que as duas partes são não-interagentes. Einstein abandonou também esta tentativa de uma teoria da dual de ondas e partículas, mas na reunião de Solvay, de 1927, ele ainda considerava as tentativas semelhantes de de Broglie como promissoras.

\section{Os primeiros debates sobre mecânica quântica}

Bohr, assim como Einstein, tinha acompanhado o desenvolvimento da Mecânica Quântica como um espectador interessado. Ao contrário de Einstein, ele não foi detido pelas dificuldades que a mecânica matricial e a ondulatória apresentaram para uma interpretação física. Como o seu modelo atômico já tinha mostrado, ele estava disposto a considerar modelos que contivessem elementos contraditórios e o fracasso da teoria BKS confirmara sua suspeita de que a descrição espaço-temporal clássica dos processos atômico tinha de ser abandonada. A natureza abstrata da mecânica matricial parecia para ele mais uma virtude do que

25 Albert Einstein para Max Born, 4 de dezembro de 1926. (EINSTEIN; BORN, 1969, p. 127)

26 Arquivo Einstein, n“2-100. O manuscrito é discutido por Belousek (1996). 
um defeito. Embora ele também recebesse a mecânica ondulatória de Schrödinger como uma expressão adequada do dualismo onda-partícula, ele discordou fortemente da esperança de Schrödinger de que ela levaria de volta para uma descrição dos fenômenos atômicos em termos de teoria de campos. Em vez disso, Bohr imaginou que a Mecânica Quântica deveria apresentar uma simetria entre uma representação de partícula e uma de onda, tanto para a matéria, quanto para a luz. Esta visão se desenvolveria no conceito da complementaridade de Bohr, formulado pela primeira vez em sua palestra em Como, na Itália, em setembro de 1927. Esta palestra foi moldada pela disputa de Bohr com Heisenberg a respeito do artigo deste sobre a incerteza, enviado para publicação sem o consentimento de Bohr. Bohr desaprovou dois pontos no artigo de Heisenberg. Este tinha cometido um erro em seu experimento de pensamento sobre a medição da posição através de espalhamento Compton: o fato de um quantum de luz transferir momento para a partícula observada não é em si um impedimento para a determinação do momento da partícula. Poderíamos simplesmente medir o momento do quantum de luz antes e depois do espalhamento. Mais importante para Bohr: Heisenberg baseou-se inteiramente numa representação de partícula em sua interpretação da Mecânica Quântica. Bohr mostrou que uma consideração da natureza dual da luz poderia resolver o problema com o experimento mental de Heisenberg. A tentativa de determinar a posição em que o espalhamento aconteceu requereria $o$ uso de um microscópio de "raio gama", que capta a luz proveniente do ponto de espalhamento. Isto significa que agora temos de considerar a natureza ondulatória do quantum de luz. Isto impõe uma limitação, bem conhecida da óptica clássica, sobre a exatidão com que esta posição pode ser determinada. Esta é inversamente proporcional ao comprimento de onda da luz, o que salva a relação de incerteza de Heisenberg. A palestra de Bohr em Como, que passou por várias revisões antes de ser publicada no verão de 1928, contém uma discussão detalhada deste experimento mental e tornou-se a formulação canônica da interpretação da complementaridade de Bohr da Mecânica Quântica. Ela também reflete as discussões de Bohr na conferência de Solvay, em outubro de 1927.

Este encontro marca o início da crítica pública de Einstein à Mecânica Quântica. Ela vem sob a forma de uma questão aparentemente modesta de classificação que, no entanto, aponta um problema com o qual a Mecânica Quântica ainda está lutando hoje em dia: o problema da medição. Einstein propôs o seguinte experimento mental: enviemos partículas com certo momento (representado na mecânica ondulatória por um trem de ondas paralelas) através de uma fenda estreita. Atrás da fenda, a onda será difratada, emanando da fenda sob a forma de cilindros concêntricos. Coloquemos agora uma tela cilíndrica atrás da fenda para detectar as partículas. O que encontramos não são ondas, mas eventos individuais de detecção (minúsculos clarões numa tela fluorescente ou pequenos pontos pretos numa chapa fotográfica). Einstein pergunta como 
devemos pensar as ondas na Mecânica Quântica no presente caso. Ele considera duas possibilidades.

Na primeira maneira de pensar, a função de onda apenas descreve um grande número de partículas de uma forma global. O que a função de onda descreve, especificamente, é o número relativo de partículas individuais em um determinado lugar. Usualmente, essa posição tem sido equiparada com a posterior interpretação dos ensembles estatísticos de Einstein para a Mecânica Quântica (ao passo que as partículas individuais teriam trajetórias bem definidas, a função de onda fornece apenas uma descrição incompleta dessas trajetórias). ${ }^{27}$ Esta equiparação é incorreta, o que é mostrado pelo fato de que Einstein diz na sequência de seu texto: a primeira interpretação não pode dar conta da validade das leis de conservação, do resultado do experimento de Bothe-Geiger ou das trajetórias na câmara de Wilson. Estes comentários enigmáticos indicam que Einstein tinha em mente uma ideia bem diferente. Parece que o pano de fundo para sua discussão é seu pensamento sobre a estatística quântica, que ele originalmente queria apresentar em uma palestra na Conferência de Solvay. Diante desse pano de fundo, ele contempla a possibilidade de que a função de onda possa ser vista como a descrição de um coletivo real de partículas, cujo comportamento individual não é especificado. Assim, é compreensível que Einstein pense que a primeira interpretação não possa capturar as correlações entre as posições subsequentes necessárias para a explicação das trajetórias na câmara de Wilson e nem possa explicar a correlação entre as energias das partículas individuais, no experimento de Bothe-Geiger. Essa leitura também explica porque Einstein não endossa a primeira interpretação, como todos os comentadores parecem assumir.

A segunda maneira de pensar a função de onda é entendê-la como uma descrição completa de uma partícula individual, que realmente não teria uma posição definida. Assim, a função de onda descreveria probabilidades de um sentido diferente: ao passo que a partícula antes da detecção não teria uma posição definida, ela dispararia um evento de detecção em um determinado ponto na tela com a probabilidade dada pela função de onda. Conforme apontado por Einstein, deve-se pensar em uma função de onda para cada partícula individual para explicar fenômenos, como o experimento de Bothe-Geiger ou as trajetórias na câmara de Wilson. No entanto, neste caso, encontramos um problema para explicar os eventos de detecção na tela. Considere um trem de ondas correspondendo a apenas uma partícula. Sabemos que se houver um clarão em um ponto da tela, não haverá outro em nenhum outro lugar da tela. Mas como é que a tela sabe? Afinal, a onda incide de forma homogênea sobre toda a tela e se houver, digamos, uma probabilidade de $10 \%$ de que ela dispare um clarão em uma

27 Ver, por exemplo, as discussões em Fine (1996a), Howard (1990), Home e Whittaker (2007) e Bacciagaluppi e Valentini (2009). 
região da tela, e houver a mesma probabilidade de ela disparar um flash em uma segunda região diferente da tela, então deveria haver uma probabilidade de $10 \%$ $\mathrm{x} 10 \%=1 \%$ de provocar dois clarões em ambas as regiões. Mas não é isso o que a Mecânica Quântica prevê; ao contrário, ela exige sempre que ocorra apenas um único clarão.

Mas, novamente, como é que a tela sabe que deve brilhar apenas uma vez? Parece que no momento em que um clarão ocorre em um ponto, a onda tem que ser "desligada" em todos os outros lugares. Tal processo deve ser, como Einstein colocou, "um mecanismo de ação à distância muito particular, que impede que a onda continuamente repartida no espaço produza uma ação em dois lugares da tela." Einstein apontou um dilema para a nossa compreensão da Mecânica Quântica: uma interpretação como a descrição de um coletivo seria simples, mas estaria em conflito com o formalismo da Mecânica Quântica e com as evidências empíricas. Uma interpretação que descreve uma partícula individual como um objeto espacialmente estendido exigiria uma transição não-física e não-local durante a sua detecção. Este processo é nada mais do que o controvertido "colapso da função de onda", que von Neumann (1932) iria formalizar alguns anos mais tarde. A conclusão que Einstein retira desse dilema é um cauteloso endosso da proposta de de Broglie, descrevendo o processo com duas entidades: uma onda de Schrödinger espacialmente estendida e uma partícula localizada, guiada pela onda, mas que é responsável pela interação local com a tela. É este endosso que corresponde à afirmação posterior de Einstein de que a Mecânica Quântica é uma descrição incompleta dos sistemas individuais.

As várias respostas à pergunta de Einstein constituem a primeira discussão publicada do problema da medição da Mecânica Quântica e, certamente, merecem um tratamento mais detalhado do que se pode oferecer aqui. Vou me concentrar na resposta de Bohr, uma vez que ele, já neste momento, surge como o porta-voz do grupo de físicos teóricos que defendem, contra as críticas de Einstein, que a Mecânica Quântica foi finalizada. Bohr respondeu imediatamente após a contribuição de Einstein, mas a resposta foi cortada dos anais publicados, assim como todas as outras contribuições de Bohr, para ser substituída por uma tradução em francês da palestra de Bohr em Como. A resposta original de Bohr está registrada apenas nas notas um tanto fragmentadas da discussão, preservada nos Arquivos Niels Bohr. ${ }^{28}$ É plausível supor que o desejo de Bohr de substituir suas contribuições por uma reedição da palestra de Como implica que ele via a palestra como uma expressão mais ampla e coerente de suas respostas. Assim, parece aceitável usar a palestra de Como para extrapolar o significado das notas de discussão.

28 Reimpresso em parte em Bohr (1985, p. 99-106) e em Bacciagaluppi e Valentini (2009, parte $3)$. 
Bohr opõe-se ao dilema de Einstein com um argumento que ele também apresentou na palestra de Como: a Mecânica Quântica é uma coleção de métodos matemáticos adequados para descrever nossas observações. Mas temos que abandonar a esperança de que ela possa nos dar um quadro exaustivo dos processos que ocorreriam entre essas observações. "Exaustivo" aqui deve ser entendido como sendo, por um lado, uma descrição espaço-temporal que, por outro lado, corresponde ao que Bohr chama de "causalidade", ou seja, a conservação de energia e momento. Bohr argumenta que a impossibilidade de uma descrição exaustiva é devido à impossibilidade de observar os sistemas microscópicos sem uma interação entre o instrumento de medição e o objeto. As limitações específicas da Teoria Quântica resultam do fato de que essa interação envolve sempre, pelo menos, a transferência do quantum de ação de Planck.

Não é óbvio o modo como o argumento de Bohr sobre os limites de observabilidade justifica sua afirmação sobre a inaplicabilidade das descrições espaço-temporais na Mecânica Quântica. Nada no dilema de Einstein depende de um pressuposto de observabilidade sem interferência. A única observação que ocorre é a detecção do evento individual. Pelo contrário, a questão de Einstein versa sobre a descrição objetiva de processos não observados. Mesmo assim, há uma boa justificativa física por trás do repúdio de Bohr a uma representação espaço-temporal contínua dos processos atômicos: trata-se simplesmente da longa lista de tentativas frustradas de encontrar tal representação, primeiro na velha Teoria Quântica, depois na própria teoria BKS de Bohr e, finalmente, na mecânica ondulatória de Schrödinger. A justificativa epistemológica da não-classicalidade fundamental, que Bohr tenta colocar no lugar de um menos glamoroso reconhecimento de derrota, tornou-se um tema recorrente na interpretação da Mecânica Quântica. No entanto, ela não satisfez Einstein por várias razões.

Primeiro, ela está baseada em uma afirmação completamente geral sobre as possibilidades das observações empíricas, que não pode nunca ser comprovada em qualquer nível de generalidade e que foi logo contestada por Einstein, que tentou dar exemplos de medição simultânea de observáveis não-comutativas. A questão da mensurabilidade de observáveis não-comutativas tornou-se tema de discussões acaloradas entre Bohr e Einstein, durante a conferência de Solvay de 1927 e nos anos posteriores. Essas discussões informais não foram gravadas na época. Elas só foram descritas 20 anos depois, na contribuição de Bohr para o volume dedicado a Einstein na Library of living philosophers. (BOHR, 1949) Nessas discussões, Einstein tentou construir situações experimentais que permitiriam a medição simultânea de grandezas complementares. Bohr rebateu os argumentos de Einstein, aplicando as relações de incerteza também para o aparelho macroscópico de medição, o que introduziu uma influência incontrolável do aparelho de medição no objeto observado. 
Mais importante, todavia, mesmo admitindo-se a impossibilidade de certas medições de grandezas teóricas, é que isso de forma alguma implica, de maneira geral, na impossibilidade de formar uma teoria coerente e empiricamente bem sucedida a partir dessas grandezas. Portanto, Einstein não se convenceu da impossibilidade de se construir contra-exemplos à relação de incerteza. Ele podia argumentar que a Física está cheia de teorias baseadas em grandezas não observáveis. Este foi o caso da mecânica estatística no século XIX e também era verdade para muitos conceitos teóricos contemporâneos à Mecânica Quântica, tais como o potencial eletromagnético, a entropia ou mesmo o conceito onipresente de energia. Para todos esses, o fato de eles não poderem ser medidos diretamente não era visto como um motivo para limitar geralmente sua utilização teórica.

A conclusão de Einstein a partir dos debates foi que a Mecânica Quântica é uma descrição autoconsistente, mas incompleta, dos processos objetivos. Ela é fenomênica, da mesma forma que a termodinâmica é fenomênica, operando com estados que são dependentes da descrição. Para argumentar neste sentido, Einstein retornou ao tipo de argumento conceitual como o exemplo da única fenda, tentando dirigir a questão sobre a realidade física dos estados quânticos contra Bohr: neste sentido, o artigo Einstein-Podolsky-Rosen é uma continuação direta do argumento da única fenda de Einstein de 1927.

\section{$7 \mathrm{O}$ argumento do emaranhamento}

A contribuição mais famosa de Einstein para o debate sobre a Mecânica Quântica é o artigo A descrição da realidade física fornecida pela mecânica quântica pode ser considerada completa?, em coautoria com Boris Podolsky e Nathan Rosen e publicado em 1935, normalmente conhecido como Electron paramagnetic resonance (EPR). Depois de uma réplica de Bohr, que foi um tanto obscura no conteúdo, mas confiante no tom, o artigo foi em larga medida ignorado pela comunidade dos físicos. Isso só mudou com o uso, por parte de J. S. Bell, do exemplo do EPR para um argumento que foi substancialmente além do de Einstein. $\mathrm{O}$ artigo de Bell (1964) foi parte do ressurgimento de um interesse nos fundamentos da Mecânica Quântica e uma reavaliação da dominância da interpretação de Copenhague, o que também levou a uma nova apreciação das críticas de Einstein. Olharei brevemente para a relevância de Bell ao argumento de Einstein no epílogo. Motivada pela análise de Bell, uma série de análises da situação física descrita por Einstein foi apresentada nas últimas décadas. Enquanto isso, tam- 
bém historiadores e filósofos, com sensibilidade histórica, encontraram detalhes interessantes sobre o contexto histórico do argumento de Einstein. ${ }^{29}$

Uma faceta interessante da história que os historiadores têm desvelado é que foi Boris Podolsky quem escreveu o artigo e que o próprio Einstein ficou insatisfeito com a maneira como o argumento foi escrito, como ele escreveu para Schrödinger em 19 de junho de 1935: "O principal ponto ficou enterrado, por assim dizer, debaixo da erudição." Na mesma carta, ele fez uma apresentação muito mais simples do argumento, que repetiu logo depois, em um artigo intitulado Física e realidade. (EINSTEIN, 1936) Olharei primeiro para esta apresentação e depois para o argumento de EPR completo. Isso não só ajuda a entender a erudição do argumento de EPR, como também mostra uma diferença importante entre as duas versões.

$\mathrm{Na}$ carta para Schrödinger, Einstein inicia com uma explicação de sua ideia de completude. Ele começa com um exemplo simples da vida cotidiana: considere duas caixas com as tampas fechadas. Você sabe que há uma bola que você sempre vai encontrar em uma das caixas quando abrir as tampas. Você descreve o estado das caixas dizendo que a probabilidade de a bola estar em uma dada caixa é $1 / 2$. A questão agora é: será esta uma descrição completa da situação física? Se você responder não, você está supondo que há um estado de coisas objetivo a respeito da bola estar em uma ou outra caixa, mesmo que você não tenha aberto nenhuma tampa. Se você responder sim, você tem que supor que, sem o ato de abrir a tampa, não há questão de fato a respeito de onde a bola está. Só depois de você abrir uma tampa e encontrar ou não uma bola é que você causa a bola estar em uma caixa específica. Estas duas respostas, obviamente, correspondem às duas possibilidades que Einstein tinha descrito em sua questão sobre o experimento da fenda única na conferência de Solvay. Talvez por isso Einstein anacronicamente chamasse a primeira alternativa de "interpretação de Born", embora Born já tivesse se unido há muito tempo à ortodoxia de Copenhague; e a segunda alternativa, de "interpretação de Schrödinger", apesar de Schrödinger apontar, em sua resposta, que ele já ultrapassara "há muito tempo o estágio em que pensava que se pudesse ver a função $\psi$ de alguma forma direta como uma descrição da realidade." ${ }^{30}$ No entanto, o verdadeiro inimigo era Niels Bohr, cujo nome não aparece na carta, mas que é referido como "o filósofo talmudista que não dá a mínima para a realidade, o bicho-papão das mentes ingênuas”, que afirma que ambas as interpretações são diferentes apenas no palavreado e que o debate é inútil. A introdução de Einstein deixa bem claro que ele próprio não está inge-

29 Discussões bem conhecidas são as de Howard (1985), Fine (1996b) e Beller e Fine (1993). Referências adicionais podem ser encontradas no panorama apresentado por Home e Whitaker (2007).

30 Schrödinger para Einstein, 19 de agosto de 1935, EA 22-051 
nuamente adorando o bicho-papão da realidade. Ele reconhece que não temos nenhuma maneira de conhecer a realidade independentemente da sua descrição física. Portanto, não podemos comparar a descrição física diretamente com a realidade. Desta forma, não está imediatamente claro como podemos decidir qual das duas interpretações é correta. É por isso que Einstein introduz um princípio adicional que ele chama de princípio de separação: ${ }^{31}$ supondo que as caixas estão espacialmente separadas e que não há interação física entre as duas, o estado real de uma caixa e de seu conteúdo é independente do que acontece com a outra. Mas, então, abrindo a tampa de uma e verificando se existe dentro dela uma bola, não pode alterar o estado real da outra caixa. Por outro lado, após abrir a tampa de uma caixa, sabe-se se a bola está na outra ou não. Este fato sobre a outra caixa deve também, portanto, por causa do princípio de separação, ter sido verdade antes de abrir a tampa da primeira caixa. Einstein salienta que a analogia com o caso quântico é imperfeita e que o exemplo cotidiano deve somente ser visto como uma explicitação do conceito de incompletude.

A análise de Einstein do caso quântico está baseada na representação de estados de sistemas compostos na Mecânica Quântica-padrão e, especialmente, $o$ fenômeno para o qual Schrödinger (1935) cunhou mais tarde o termo "emaranhamento", em um artigo escrito como reação a Einstein. Embora esta representação esteja implícita na formulação de von Neumann da Mecânica Quântica, a questão geral da descrição de estados em sistemas compostos não tinha suscitado muito interesse até então. No formalismo padrão do espaço de Hilbert da Mecânica Quântica, existe, para qualquer observável físico $O$, um conjunto de valores $o_{\mathrm{i}}$ (os autovalores do observável) que este observável pode assumir. Há também um conjunto de autoestados $\Psi_{\mathrm{i}}$, correspondentes aos autovalores $o_{\mathrm{i}}$, definido pela equação de autovalores

$$
\hat{O} \psi_{i}=o_{i} \psi_{i}
$$

onde Ô é o operador do espaço de Hilbert correspondente ao observável O. Estes autovalores formam uma base de todo o espaço de Hilbert, ou seja, todo estado $\Psi$ no espaço de Hilbert pode ser representado como uma combinação linear

$$
\psi=\sum_{i} c_{i} \psi_{i}
$$

31 As discussões do princípio da separação de Einstein (FINE, 1996a; HOWARD, 1985) têm analisado este princípio como consistindo em dois pressupostos logicamente independentes: separabilidade, a existência de estados independentes dos dois subsistemas; e localidade, o pressuposto de que uma mudança de estado de um subsistema não influencia o estado do segundo. Ninguém na época de Einstein duvidava da localidade e Einstein sempre supôs a conjunção de ambos. Assim, geralmente falarei apenas da separabilidade como pressuposto relevante para a discussão. 
Dois observáveis diferentes $O$ e $O^{\prime}$ terão em geral diferentes conjuntos de autoestados $\Psi_{\mathrm{i}}$ e $\Psi_{\mathrm{i}}^{\prime}$ '

Novamente, Einstein considera dois sistemas A e B que estão separados um do outro e não interagem fisicamente. Para um observável $O^{A}$ em A e $O^{B}$ em $\mathrm{B}$, podemos escrever um estado $\Psi^{A B}$ do sistema composto na forma

$$
\Psi^{A B}=\sum_{i, j} c_{i j} \psi_{i}^{A} \psi_{j}^{B},
$$

onde os $\Psi_{i}^{A}$ e os $\Psi_{j}^{B}$ são as bases dos autoestados correspondentes aos observáveis $\mathrm{O}^{A}$ e $\mathrm{O}^{B}$, respectivamente. Se escolhermos um observável diferente $\mathrm{O}^{\prime A}$ para o sistema A, podemos igualmente representar $\Psi^{A B}$ na base do auto-estados $\Psi_{i}{ }_{i}^{A}$ de $\mathrm{O}^{\mathrm{A}}$ :

$$
\Psi^{A B}=\sum_{i, j} c_{i j}^{\prime} \psi_{i}^{\prime A} \psi_{j}^{B} .
$$

Note que usamos ainda a mesma base do estado para o sistema B.

Esta representação implica uma ruptura radical com as expectativas clássicas: um estado $\Psi^{\mathrm{AB}}$ que tem esta forma não pode, em geral, ser escrito como produto de um estado do sistema A e um estado do sistema B. Isto significa que a Mecânica Quântica não nos dá um estado quântico definido para cada componente individual do sistema, quando o sistema composto está em um estado emaranhado. No entanto, o postulado da redução implica em previsões definidas para os estados dos sistemas componentes individuais, se for realizada uma medição em um dos sistemas. Se medirmos, digamos, o observável $\mathrm{O}^{\mathrm{A}}$, o estado $\Psi^{\mathrm{A}}$ do sistema A depois da medição será um dos auto-estados $\Psi_{\mathrm{i}}^{\mathrm{A}}$, ao passo que o estado do sistema B será o correspondente "estado relativo" $\Psi^{B}=\sum c_{i j} \psi_{j}^{B}$. Se, ao invés disso, medirmos $\mathrm{O}^{\mathrm{A}}$, o estado $\Psi^{\prime \mathrm{A}}$ será um dos autoestados $\Psi_{\mathrm{i}}^{{ }^{\prime} \mathrm{A}}$ e o estado $\Psi_{\mathrm{i}}^{\mathrm{B}}$ será $\sum c_{i j}^{\prime} \psi_{j}{ }^{B}$, que em geral é diferente de $\Psi^{\mathrm{B}}$.

Neste ponto, Einstein aplica o princípio de separação: a situação física do sistema $B$ não pode ser afetada por uma medição no sistema $A$. Assim, essa situação física deve ser a mesma, não importando se medimos $\mathrm{O}^{\mathrm{A}}$ ou $\mathrm{O}^{\mathrm{A}}$. Isto significaria que a mesma situação física é descrita por dois estados quânticos diferentes $\Psi^{\mathrm{B}} \mathrm{e} \Psi^{\prime \mathrm{B}}$. Os estados quânticos não seriam, portanto, uma "descrição biunívoca" da realidade física (ou seja, eles não estariam em uma relação biunívoca com os elementos da realidade física). Até aqui, a argumentação de Einstein é bastante 
incontestável. Além disso, ela é um claro reflexo de seu realismo metodológico: ele não faz suposições sobre a realidade objetiva, salvo que esta seja a mesma em ambas as situações.

Mas Einstein não para neste ponto: ele logo conclui que a descrição quântica não é biunívoca, pois ela é incompleta, e que, portanto, a Mecânica Quântica deve ser uma teoria estatística. Conforme já foi discutido na seção 4, esta conclusão não se justifica logicamente. Uma descrição que não é biunívoca não é necessariamente incompleta: por exemplo, na relatividade restrita, pode-se ter descrições diferentes do mesmo estado objetivo (correspondendo a diferentes referenciais). Isto não implica que a descrição seja incompleta, mas que ela não é absoluta. Além disso, a estrutura do argumento torna óbvio que Einstein não conseguiu provar a incompletude, mas a não-absolutidão: o que ele mostrou foi que várias descrições se aplicam a uma única realidade objetiva e não que uma descrição refere-se a diversas realidades objetivas. O salto lógico injustificado é, no entanto, intuitivamente plausível se pensar-se em termos da mecânica estatística, onde ambas as formas de não-univocidade são válidas; e esta era, naturalmente, a intuição que Einstein tinha enquanto fazia o argumento.

Em mecânica estatística, pode-se fazer referência a um microestado, por meio de diferentes distribuições de probabilidade, e uma distribuição de probabilidade se refere a diferentes microestados. A diferença entre essas duas noções de não-univocidade é ilustrada nas figuras abaixo para um sistema de uma partícula que pode estar em diversos microestados $a, b, c$ etc:

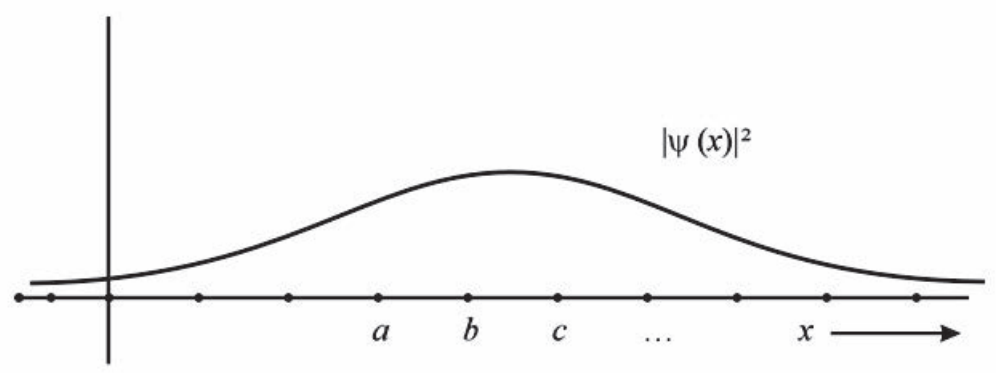

Figura 2 


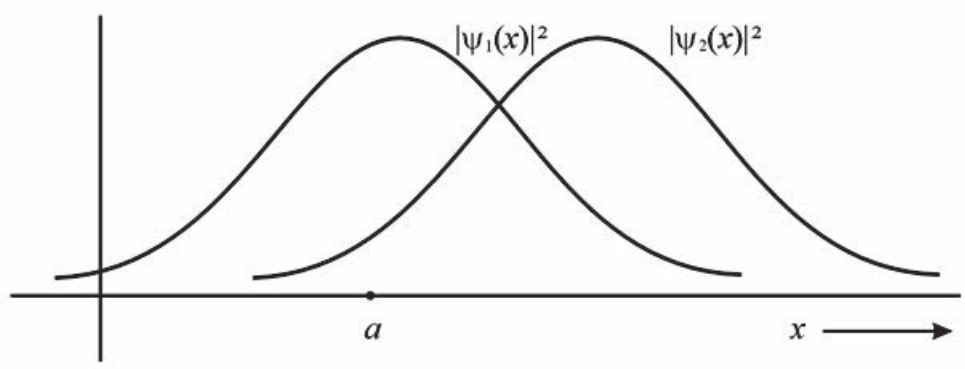

Figura 3

A grandeza $P(x)$ plotada nestas figuras dá a probabilidade de encontrar a partícula no estado $x=a$ etc. A figura superior ilustra a incompletude usual do tipo uma descrição/muitos estados. Uma e a mesma função de probabilidade $|\Psi(x)|^{2}$ é compatível com a partícula, estando em muitos estados diferentes $a, b, c$ etc. A figura inferior ilustra a não-univocidade do tipo muitas descrições/um estado, que chamamos anteriormente de não-absolutidão: diferentes funções de probabilidade - aqui $\left|\Psi_{1}(x)\right|^{2}$ e $\left|\Psi_{2}(x)\right|^{2}$ - são compatíveis com a partícula, estando em um e o mesmo estado $a$. A descrição por meio do macroestado estatístico é nãounívoca em ambos os sentidos. Einstein havia mostrado que a segunda forma de não-univocidade vale na Mecânica Quântica e inferiu que esta é uma teoria estatística. Embora a não-absolutidão também valeria em uma teoria estatística, uma descrição não-absoluta não é necessariamente estatística, como vimos no caso da relatividade.

Esta lacuna no argumento simples de Einstein é possivelmente a razão para a argumentação mais complicada no artigo EPR. Podolsky pode ter percebido a necessidade de um passo adicional que Einstein achou uma erudição desnecessária. $\mathrm{O}$ artigo tenta mostrar diretamente que a descrição quântica é incompleta (e não apenas não-biunívoca), provando que a mesma descrição pode se referir a vários estados diferentes da realidade. Mas, para isso, Podolsky precisa do controvertido "critério da realidade" que é delineado no início do artigo:

Se, sem de modo algum perturbar um sistema, pudermos prever com certeza (ou seja, com probabilidade igual à unidade) o valor de uma quantidade física, então existe um elemento de realidade física correspondente a essa quantidade física. (EINSTEIN; PODOLSKY; ROSEN, 1935, p. 91)

Este critério implica que, se um sistema quântico é descrito por um autoestado do operador correspondente a alguma grandeza física, então existe um "elemento de realidade física" correspondendo ao seu autovalor. O que EPR a 
seguir mostram é que se pode construir um tipo específico de estado emaranhado de sistemas separados, onde cada medição da posição da partícula $\mathrm{A}$ deixa também $B$ em um autoestado de posição e cada medição do momento da partícula A deixa também $B$ em um autoestado de momento. ${ }^{32}$ Então, o critério da realidade implica que se uma medição de posição for realizada em $\mathrm{A}$, há um elemento de realidade correspondendo à posição de $\mathrm{B}$; e se uma medição de momento for realizada em $\mathrm{A}$, há um elemento de realidade correspondendo ao momento de B. Mas o princípio de separação implica que esses elementos de realidade da partícula $B$ existem independentemente do que foi feito ou medido na partícula $\mathrm{A}$. Mas não há nenhum estado quântico que permitiria à partícula $\mathrm{B}$ ter, ao mesmo tempo, posição definida e momento definido. Assim, a Mecânica Quântica é incompleta no sentido estrito. O que permite EPR chegar a esta conclusão é o critério da realidade. Este critério permite concluir, a partir do resultado da medição na partícula $\mathrm{A}$, uma afirmação sobre a real situação da partícula $\mathrm{B}$. No entanto, isto implica um sentido mais forte de realismo do que o realismo metodológico de Einstein. Se alguém aceita o realismo tradicional, supondo que qualquer resultado de medição reflete um elemento da realidade, então a conclusão não é problemática. Se, como Einstein na carta a Schlick, uma distinção estrita for feita entre fenômenos e realidade física objetiva como uma construção intelectual, então não é evidente que uma medição e as previsões que seguem a partir dela fornecem realidade objetiva para a grandeza medida: o campo gravitacional na relatividade geral pode ser medido perfeitamente bem, mas isso ainda não mostra que o campo gravitacional tenha realidade objetiva na teoria fundamental. O desconforto de Einstein com o artigo de EPR também pode ter a ver com essa "bagagem metafísica" adicional. Como Einstein escreveu a Schrödinger: "A única coisa que é essencial para mim é que $\Psi^{B}$ e $\Psi^{B B}$ sejam diferentes. [...] Se $\Psi^{B}$ e $\Psi^{B}$ podem ser interpretados como autofunções de diferentes observáveis não me interessa [ist mir wurst]." E de fato, o simples argumento de Einstein é suficiente para mostrar que a Mecânica Quântica não oferece a descrição invariante que para ele era o marco da objetividade. Isso certamente foi suficiente para que ele justificasse seu programa de encontrar uma descrição mais fundamental. No entanto, isso não justifica a confiança de Einstein de que os enigmas da Mecânica

32 Este exemplo específico é um pouco infeliz, já que os autoestados de momento são completamente "delocalizados" (cada autoestado é uma onda plana que se estende por todo o espaço). Portanto, é problemático supor que as partículas possam ser separadas espacialmente. Este problema foi evitado por David Bohm (1951), que propôs pela primeira vez considerar um estado onde o spin das partículas está emaranhado. Tais estados podem ser bem-localizados, então não há problema em pensar um estado de duas partículas muito separadas e sem interagirem, que, no entanto, apresentam spin emaranhado. Discussões modernas do argumento de EPR geralmente operam com este estado. Além disso, estados emaranhados de spin, de partículas e de fótons, têm sido a realização experimental usual da montagem de EPR e se tornaram objeto de estudo experimental extensivo. Ver Bertlmann e Zeilinger (2002) para vários trabalhos sobre a história de realizações experimentais do experimento de EPR-Bohm. 
Quântica pudessem ser explicados como efeitos estatísticos dentro de uma interpretação dos ensembles estatísticos (ver seção 6).

Foi essa confiança que Schrödinger criticou. Ele enviou para Einstein uma longa carta com uma réplica a seu argumento de que a Mecânica Quântica sofre de incompletude. ${ }^{33}$. Ele argumentou que a interpretação dos ensembles estatísticos de Einstein para a função de onda fracassa se considerarmos as relações funcionais entre observáveis diferentes. Ele considera o conjunto de operadores $\mathrm{O}_{\mathrm{a}}=\left(p^{2} / a+a x^{2}\right) / \hbar$ para qualquer valor de $a$. Cada um destes operadores pode somente ter autovalores discretos $(2 n+1)$ para alguma função de onda $\Psi$ possível. Isso é fácil de ver: para um oscilador harmônico com frequência $\omega=a / m$ (onde $m$ é a massa da partícula), $O_{\mathrm{a}}$ seria o operador de número que conta o estado de excitação do oscilador. Em geral, $O_{\mathrm{a}}$ não terá este significado físico, mas ele ainda pode ser definido formalmente e terá o mesmo espectro de autovalores. Para explicar este espectro a partir de uma teoria de ensemble, temos que supor que qualquer $\Psi$ descreve uma partícula com valores definidos de $p$ e $x$, de tal forma que $O_{\mathrm{a}}$ seja inteiro para todo valor de $a$. Obviamente, se ajustamos $p$ e $x$ para que $O_{\mathrm{a}}$ seja inteiro para algum $a$, e agora variamos $a$ por uma quantidade pequena, $O_{\mathrm{a}}$ deixará de ser inteiro. Este exemplo simples mostra que não pode existir uma interpretação de ensemble que dê conta dos valores de funções de observáveis, a partir dos valores desses observáveis. ${ }^{34}$ Todavia, o ponto feito por Schrödinger não foi assimilado por Einstein. Em sua resposta, ele escreveu: "Se eu afirmasse que entendi sua última carta, seria uma grande mentira." Isto não o desencorajou. Duas sentenças depois, ele introduz suas próprias ideias sobre o assunto com bom humor: "Agora, se eu deslizar sobre tudo o que não entendi, eu não vejo porque é contraditório supor que a função $\Psi$ se refere a um ensemble estatístico."

A resposta de Bohr ao artigo de EPR veio em duas partes: um breve anúncio preliminar (BOHR, 1935a) e uma discussão um pouco mais longa. (BOHR, 1935b) Esta última também fez referência a uma vindoura exposição detalhada que, no entanto, nunca apareceu. Era óbvio que Bohr tinha de questionar o critério de realidade de $\mathrm{EPR}$, a fim de evitar o dilema do $\mathrm{EPR}$ entre a não-localidade $\mathrm{e}$ a incompletude, já que ele concordava que a Mecânica Quântica não deveria permitir um distúrbio mecânico à distância. A resposta direta seria negar que possa haver um conceito significativo de realidade objetiva na Mecânica Quântica:

33 Schrödinger para Einstein, 19 de agosto de 1935, EA 22-051.

34 Esta é uma versão mais específica do argumento de von Neumann (1932) contra variáveis ocultas, que tem sido injustamente criticada como sendo fisicamente improcedente. Schrödinger (1935) escolhe um exemplo que está ainda mais perto da observação física: em vez de $O_{a}$, ele usa o conjunto de momentos angulares $L_{\mathrm{a}}$ com relação a qualquer origem de coordenadas a. Mais uma vez, $L_{\mathrm{a}} / \hbar$ tem que ser um número inteiro em todos os instantes, mesmo que possamos mover $a$ de forma contínua. 
enquanto o formalismo nos permite fazer previsões experimentais bem sucedidas, temos que aceitar que não há uma imagem consistente da realidade que possa ser construída a partir dela. Esta seria a resposta radicalmente positivista. Contudo, Bohr não queria ir tão longe: ele queria mostrar que um senso apropriado de realismo é reconciliável com a completude da Mecânica Quântica. Portanto, ele apenas argumenta que o critério de realidade de EPR contém uma ambiguidade que a torna inaplicável no caso considerado, ao passo que uma influência física a partir da medição de uma partícula até a outra partícula é excluída, Bohr (1935b, p. 103-104) afirma que

[...] mesmo nesse estágio existe essencialmente a questão de uma influência sobre as próprias condições que definem os tipos possiveis de previsões relativas ao comportamento futuro do sistema.

Ele tenta mostrar que esse critério não é cumprido no caso de EPR, considerando uma realização experimental do estado de EPR. Bohr considera duas partículas com momentos definidos, passando simultaneamente através de duas fendas de um anteparo. Se as fendas forem suficientemente estreitas, sabemos precisamente a diferença entre as posições das duas partículas. Se medirmos o momento do anteparo antes e depois da passagem das partículas, também sabemos o momento total de ambas as partículas após a passagem. A medição do momento do anteparo nos impede saber a sua posição, portanto, as posições absolutas das duas partículas também são desconhecidas. Também não sabemos os momentos individuais das partículas, já que elas trocaram um momento indefinido durante sua passagem através das fendas. Após a passagem pelo anteparo, a medição do momento de uma partícula permite deduzir o momento da outra, já que o momento total é conhecido. Alternativamente, a medição da posição da primeira partícula permite que se deduza a posição da segunda, uma vez que a distância entre as duas é conhecida. Naturalmente, a realização de ambas as medições simultaneamente é impossível. Esse fato seria suficiente para o positivista radical negar que o argumento de EPR fosse conclusivo. Bohr, por outro lado, tenta dar um argumento físico de porque a medição de uma partícula interfere nas "condições que definem os tipos possíveis de previsões relativas ao comportamento futuro do sistema." No entanto, não está claro como este critério deve ser aplicado para a montagem experimental que Bohr idealizou. Dugald Murdoch (1987, p. 176) a analisa dizendo que

[...] não podemos significativamente atribuir uma propriedade física a um objeto a menos que as pré-condições para o uso significativo do predicado em questão estejam satisfeitas, e essas pré-condições são a presença de um arranjo experimental adequado que seja capaz de ser utilizado para medir a propriedade em questão. 
Ao contrário de Murdoch, não creio que possa haver um argumento, a partir da montagem física da situação, dizendo que essas pré-condições não foram cumpridas. $\mathrm{O}$ argumento teria que ser que a medição, digamos, da posição de uma partícula excluiria a possibilidade de medir o momento da outra partícula. Murdoch acha que a medição da posição da primeira partícula envolveria a transferência do momento da partícula para o corpo, definindo o referencial espacial comum, e que essa transferência interferiria com a medição do momento da segunda partícula. Este argumento está errado, já que o corpo que define o referencial comum pode ser tão pesado quanto se queira. Portanto, a velocidade do referencial é afetada apenas por uma quantidade que pode ser feita arbitrariamente pequena e, portanto, o corpo ainda pode ser utilizado para uma medição do momento da segunda partícula. ${ }^{35}$ Também as palavras do próprio Bohr não apoiam claramente esta leitura. Ele escreve:

[...] eliminamos, com esse procedimento, qualquer possibilidade futura de aplicar a lei de conservação da quantidade de movimento [momento] ao sistema constituído pelo diafragma [anteparo] e pelas duas partículas, e assim perdemos nossa única base para uma aplicação inequívoca da ideia de quantidade de movimento em previsões relativas ao comportamento da segunda partícula. (BOHR, 1935b, p. 103)

Se isso significa que a transferência do momento da primeira partícula para o referencial impede qualquer possibilidade de aplicar a lei da conservação do momento ao sistema total, então, a frase é verdadeira, mas irrelevante. Bohr parece supor que só podemos inferir o momento da segunda partícula através de uma aplicação da lei da conservação do momento. No entanto, podemos medir o momento da segunda partícula diretamente e isso é tudo que precisamos para a aplicação do seu próprio critério de significado ${ }^{36}$. Beller e Fine (1993) propõem um argumento mais sutil do lado de Bohr: na montagem de Bohr, a correlação entre as duas posições das partículas é válida apenas no instante da passagem através do anteparo. Imediatamente depois, como as posições das partículas espalham, esta correlação é destruída. Portanto, uma medição da posição da primeira partícula tem que acontecer imediatamente após a passagem pelo anteparo, para permitir quaisquer inferências sobre a posição da segunda partícula. Mas, neste

35 Casos semelhantes são considerados em Bohr e Rosenfeld (1933), onde Bohr corretamente reconhece a possibilidade de tais medições.

36 Se esta é a leitura correta, o erro de Bohr pode se originar da equiparação do exemplo EPR com o caso de uma medição de escolha demorada, que ele discute tanto em Bohr (1935b), quanto em discussão posterior de EPR em Bohr (1939b). No caso de uma medição da escolha demorada, a conservação do momento realmente desempenha um papel importante, já que permite a determinação do momento inicial da partícula, a partir do momento do anteparo, após a medição e do momento final da partícula. 
caso, medir a posição da primeira partícula equivale a uma medição da posição do próprio anteparo e, por conseguinte, interfere na preparação do estado, que dependia de o anteparo ter um momento definido. Beller e Fine vêm isso como a razão pela qual Bohr diz que a medição da posição da primeira partícula exclui qualquer possibilidade de aplicar a lei da conservação do momento para o sistema inteiro: a medição simplesmente interfere com a preparação do estado emaranhado em si. Sob a leitura de Beller e Fine, não é surpreendente que Bohr considere que a medição da posição de uma partícula interfira nas condições para fazer previsões sobre este sistema: ela simplesmente interfere com a preparação do estado total. Esse problema, porém, é um "artefato" (efeito espúrio) da montagem de Bohr para preparar o estado EPR. O problema subjacente é que a correlação da posição no estado de EPR só existe para um instante de tempo, já que a posição não é uma invariante do movimento. No entanto, não é necessário supor que o instante do tempo em que a correlação acontece seja o instante em que a preparação do estado foi realizada. E só neste caso é plausível supor que a medição interfere na preparação.

Embora a resposta de Bohr a EPR ainda esteja escrita usando o paradigma fundamental de que a medição leva a um distúrbio incontrolável do objeto medido, vários autores observaram que Bohr mudou o seu critério de significado após 1935, presumivelmente percebendo a natureza problemática de sua resposta. (BELLER; FINE, 1993; MURDOCH, 1987) Bohr exige um critério muito mais rigoroso de significado em Bohr (1939b): uma grandeza física pode ser significantemente atribuida a um sistema, somente quando ocorrer uma medição real da grandeza. Este critério, em geral, impedirá a possibilidade de considerar as diferentes descrições fenomênicas da mesma situação real ou de construir uma teoria de invariantes que valem para diferentes experimentos. Assim, está em conflito com o realismo metodológico de Einstein. Além disso, está em conflito com a intuição de Einstein sobre a separabilidade, já que a realidade de uma grandeza definida em um sistema dependerá de medições realizadas em outro sistema espacialmente separado. O critério rigoroso de Bohr foi considerado como uma possível objeção pelos próprios EPR:

De fato, nossa conclusão não seria alcançada se insistíssemos em que duas ou mais quantidades físicas só poderiam ser encaradas como elementos simultâneos de realidade quando pudessem ser simultaneamente medidas ou previstas. (EINSTEIN; PODOLSKY; ROSEN, 1935, p. 96)

Eles desconsideraram essa postura por causa de seu conflito com o pressuposto da separabilidade:

Isso faz as realidades de $P$ e $Q$ dependerem do processo de medida executado no primeiro sistema, o qual não perturba 
de modo algum o segundo. Nenhuma definição razoável de realidade pode permitir tal coisa.

A única reação publicada de Einstein à resposta de Bohr foi uma breve caracterização da posição de Bohr:

Não há razão para que qualquer existência (estado da realidade) mutuamente independente deva ser atribuída aos sistemas parciais A e B, vistos separadamente, nem mesmo se os sistemas parciais estiverem espacialmente separados uns dos outros no instante particular considerado. (EINSTEIN, 1949)

Retirando a acusação de que a posição de Bohr não era razoável, Einstein admitiu que tal posição é defensável em contribuição para um número da revista filosófica Dialectica, editada por Wolfgang Pauli (EINSTEIN, 1948). Neste artigo, sua última exposição detalhada do argumento do emaranhamento, ele apresenta o argumento como mostrando a incompatibilidade da suposição de que a Mecânica Quântica seja completa e do princípio de separabilidade. Ele agora tece um argumento detalhado do motivo da suposição da separabilidade, embora não seja logicamente necessário, está no fundamento de todo o nosso pensamento físico e, em especial, do conceito de um campo regido por equações de campo locais. Ela é uma condição necessária para a possibilidade de formular e testar as leis da Física. Portanto, Einstein conclui que ele não pode aceitar a completude da Mecânica Quântica.

Há um problema adicional com o critério estrito de significado de Bohr para o qual Einstein chamou a atenção: é impossível limitar seu uso aos fenômenos microscópicos. Adaptando o exemplo do gato de Schrödinger (1935), Einstein (1949) considera a seguinte situação: o decaimento de um átomo radioativo é registrado macroscopicamente por uma marca em uma tira de papel, indicando o instante de decaimento. Einstein argumenta que, neste caso, o defensor da completude está comprometido em dizer que não há questão objetiva de fato sobre a localização da marca no papel, até que uma observação tenha sido feita. Mais uma vez, Einstein admite que essa posição seja logicamente sustentável, mas "é muito pouco provável que alguém estivesse inclinado a considerá-la seriamente." Embora este argumento possa parecer um apelo ao realismo ingênuo, deve ser visto no contexto do debate com Bohr, que queria manter o realismo para a Física clássica dos objetos macroscópicos e que associava a não-classicalidade da Mecânica Quântica com o fracasso dos nossos meios de observação no mundo microscópico.

Na mesma linha deste argumento, Einstein (1953) apresenta outro exemplo, na Festschrift Born (volume em homenagem a Max Born): ele considera uma esfera 
macroscópica, perfeitamente elástica, ricocheteando entre duas paredes paralelas. Os autoestados de energia desta esfera são completamente delocalizados. Em uma interpretação estatística, isso significa apenas que a probabilidade de encontrar a esfera em um determinado local é praticamente a mesma em toda parte. Mas se quisermos manter que a descrição quântica é completa, é em princípio impossível atribuir uma posição para a esfera. Mesmo se permitíssemos apenas estados quânticos que são aproximadamente localizados (pacotes de onda) para a descrição da esfera, isso não resolveria o problema, já que estes pacotes de onda tornar-se-iam cada vez mais delocalizados ao longo do tempo. Assim, é impossível afirmar que, no limite macroscópico, a descrição quântica será aproximadamente a mesma que a descrição clássica da esfera. No debate que se seguiu (EINSTEIN; BORN, 1969), Born insistiu que o espalhamento do pacote de ondas seria uma manifestação do nosso conhecimento incompleto das condições iniciais da esfera e que, portanto, a descrição quântica espelha exatamente a descrição clássica, se uma incerteza nas condições iniciais for permitida. Born supôs que Einstein queria criticar o indeterminismo da Mecânica Quântica, expresso no espalhamento do pacote de ondas. Ele não percebeu que sua resposta concedia o ponto de Einstein de que a descrição quântica só pode ser entendida como a descrição de um ensemble estatístico e não de um caso individual. Como já foi mencionado na introdução, Pauli enviou duas cartas detalhadas sobre a discordância para Born (EINSTEIN; BORN; BORN, 1969, p. 285-291), salientando que o determinismo não era a questão na qual Einstein estava interessado. A resposta de Pauli ao argumento de Einstein foi que a ideia de realidade independente da observação tem de ser abandonada, tanto no mundo macroscópico, quanto microscópico. Pauli se opôs ao discurso de Einstein sobre descrição incompleta, já que esta implica a existência de um esquema conceitual mais completo, o que para ele refletia um preconceito metafísico. Já alguns anos antes, Einstein criticara a ideia de Pauli de que a Mecânica Quântica ofereceria um esquema conceitual autocontido para a descrição de fenômenos, em uma carta a Michele Besso:

Você também notou como foi ilógica a resposta de Pauli [para o artigo de Einstein na Dialectica]? Ele nega que essa forma de descrição [por meio de uma função de onda] é incompleta, mas diz no mesmo trecho que a função $\psi$ é uma descrição estatística do sistema, a descrição de um ensemble de sistemas. Só que isso é apenas outra forma de dizer que a descrição do sistema único (individual) é incompleta! ${ }^{37}$

Colocando a crítica de Einstein em uma forma linguística mais próxima às ideias de Pauli: falar sobre distribuições de probabilidade sobre valores possíveis de uma grandeza pressupõe que o discurso sobre os valores desta grandeza

37 Einstein para Besso, 24 de julho de 1949, em Speziali (1972, p. 403). 
seja significante. Se, em acordo com Pauli, tal significado for negado antes que uma medição seja realizada, então também a descrição quântica, por meio de uma função de onda sobre esses valores, torna-se sem sentido. Até hoje em dia, a forma padrão de pensar sobre a Mecânica Quântica consiste em uma oscilação entre uma interpretação da ignorância (há partículas cujas posições não são conhecidas com exatidão) e uma interpretação de propensão (existe uma função de onda que colapsa com a observação). Os vários experimentos mentais de Einstein são, antes de tudo, expressão da impaciência de Einstein com este tipo de indecisão teórica.

À luz da defesa de Einstein de uma interpretação da Mecânica Quântica como uma teoria incompleta, é à primeira vista surpreendente que ele tenha desconsiderado a tentativa de David Bohm de reavivar e refinar a interpretação dual de onda-partícula de de Broglie para a mecânica quântica. (BOHM, 1952) Considerando que Einstein já havia pensado longamente sobre teorias duais, tanto no início dos anos 1920 quanto em conexão com suas tentativas de compreender a mecânica ondulatória, seu ceticismo era de se esperar. A interpretação de Bohm sofreu dos mesmos problemas que fizeram as tentativas anteriores inaceitáveis para Einstein: a função de onda definida num espaço de configuração de muitas dimensões não poderia ser interpretada como um campo físico. Pelo contrário, ela estabelece correlações não-locais entre partículas distantes, dando assim a resposta menos atraente ao dilema de Einstein sobre os estados emaranhados. No Born Festschrift, Einstein (1953) acrescenta que a interpretação de Bohm também não consegue dar conta satisfatoriamente do limite macroscópico da Mecânica Quântica: na interpretação de Bohm, a esfera que deveria ricochetear entre as paredes, em um estado de energia definido, permanece absolutamente imóvel.

Em seus últimos anos, depois de muitas tentativas fracassadas para construir uma teoria do campo unificado, Einstein reconheceu a possibilidade de que a hipótese de uma descrição objetiva e local da realidade, que fundamenta a teoria de campo, talvez tenha que ser abandonada, e que um fundamento totalmente novo para a Física talvez tivesse que ser encontrado, mas para ele isso significaria um colapso total dos fundamentos da Física contemporânea: "No entanto, considero inteiramente possível que a física não possa ser fundamentada no conceito de um campo, ou seja, em construtos contínuos. Então, nada restará do meu castelo no ar, incluindo não só a teoria da gravitação, mas também todo resto da física contemporânea." Contudo, ele permaneceu convencido de que a Mecânica Quântica não poderia ser essa teoria fundamental. 


\section{Epílogo: o sonho de Einstein destruído?}

O argumento de EPR viria a desempenhar um papel importante nas discussões posteriores dos fundamentos da Mecânica Quântica. Nos anos de 1960, John Bell mostrou que é impossível recuperar a estatística prevista pela Mecânica Quântica ao assumir-se, com Einstein, que dois estados localmente separáveis determinam os resultados de medições em cada componente do estado emaranhado. (BELL, 1964) Bell mostrou que, se fosse esse o caso, as correlações dos resultados de medições em experimentos do tipo EPR deveriam satisfazer as chamadas desigualdades de Bell. As previsões da Mecânica Quântica, por outro lado, contradizem as desigualdades de Bell. Já como um experimento mental, esta prova é de grande importância porque mostra a impossibilidade da ideia de Einstein de que a Mecânica Quântica poderia ser entendida como uma descrição incompleta de uma realidade que é objetiva e localmente definida. Permaneceu uma questão empírica sobre qual das duas visões seria corroborada: a de Einstein ou a da Mecânica Quântica?

Muitos experimentos foram realizados para testar as desigualdades de Bell, desde o início dos anos 1970. (BERTLMANN; ZEILINGER, 2002) Seus resultados têm confirmado cada vez mais as previsões da Mecânica Quântica e a violação das desigualdades de Bell, apesar de alguns críticos que apontaram possíveis furos (loopholes) nas realizações experimentais (por exemplo, FINE, 1996b). Fine também argumentou que Einstein não acreditava em uma teoria de variáveis ocultas que simplesmente adiciona à Mecânica Quântica padrão um valor pré-existente para resultados de medição. No entanto, o argumento de Bell também se aplica a uma teoria de campo local como Einstein havia concebido: também um campo definido localmente é uma variável oculta local no sentido de Bell e Einstein certamente teria concordado que as previsões estatísticas da Mecânica Quântica deveriam ser deriváveis de sua teoria fundamental, pelo menos aproximadamente. Mas as desigualdades de Bell proíbem que uma teoria de campo local faça previsões que sejam mesmo aproximadamente idênticas às da Mecânica Quântica.

Apesar de a conclusão de Einstein, a partir de EPR, não parecer viável, as perguntas que ele levantou sobre a interpretação da Mecânica Quântica permanecem válidas. $\mathrm{O}$ efeito paradoxal do trabalho de Bell foi trazer essas questões de volta à consciência de mais do que uma ínfima minoria de físicos e filósofos. Além disso, a clareza conceitual do pensamento de Einstein continua sendo útil como um quadro para os debates sobre a interpretação da Mecânica Quântica. Seguindo o modo como reconstruí as críticas de Einstein à completude da Mecânica Quântica, há basicamente três suposições no argumento que poderiam ser abandonadas: 
a) Pode-se abandonar o realismo metodológico de Einstein. Isto significa que se renuncia à possibilidade de ter uma descrição de estado completa e objetiva na Mecânica Quântica: estados quânticos seriam sempre fenomênicos e não poderíamos encontrar uma descrição invariante dos fatos por trás dos fenômenos. A esperança de Bohr de que esta solução pudesse ser consistente com um realismo de senso comum sobre os objetos macroscópicos tornou-se cada vez menos plausível. Dado que o mundo quântico hoje é, de longe, não tão impenetrável experimentalmente como era nos dias de Bohr, torna-se difícil acreditar que deva ser epistemologicamente diferente do mundo macroscópico. Mas então, ter-se-ia que aceitar a posição de Pauli e desistir, de modo geral, até mesmo de um realismo metodológico mínimo. Como Einstein salientou repetidamente, esta é uma posição logicamente defensável. Ela não apenas é sustentada pelos defensores da ortodoxia de Copenhague, mas também pelos proponentes de uma abordagem de teoria da informação e provavelmente pela maioria dos adeptos de visões pragmatistas ou instrumentalistas da Mecânica Quântica. No entanto, esta posição está em desacordo com a prática da Física, tanto hoje como nos dias de Einstein: a ideia de invariantes descritivos tornou-se um dos instrumentos teóricos fundamentais em toda a Física contemporânea, especialmente na Mecânica Quântica e na teoria quântica de campo. Sem um realismo metodológico, no sentido de Einstein, esta ideia é completamente ad hoc.

b) Pode-se aceitar o realismo metodológico de Einstein (a teoria quântica precisa de algum tipo de descrição completa de um estado objetivo) e aceitar a afirmação de Einstein de que a descrição-padrão da Mecânica Quântica é incompleta. Se o argumento de Einstein para a necessidade de um realismo metodológico for seguido, aceitando-se sua afirmação de que a descrição quântica padrão (ao menos em um caso como EPR) é incompleta, então é preciso construir uma descrição mais completa, ou pela adição de variáveis físicas suplementares ou pela modificação da dinâmica para permitir um "colapso físico", ou seja, por algum mecanismo que dê realidade física aos resultados da medição, antes da sua observação. Mas, como as desigualdades de Bell têm mostrado, isto requer uma não-localidade explícita na dinâmica. Isso se aplica aos vários tipos de interpretações de variáveis ocultas, como a interpretação de de Broglie-Bohm ou a interpretação modal, e também às teorias de colapso físico, como a Mecânica Quântica não-linear ou a interpretação de Ghirardi-Rimini-Weber. Há pelo menos duas razões que tornam esta solução pouco atraente com bases físicas: como Einstein já havia salientado, aceitar a possibilidade de interações não-locais derruba a justificativa teórica de qualquer teoria de campo, incluindo a teoria 
quântica de campos. Há um argumento ainda mais forte que, até onde eu saiba, não tem sido considerado neste contexto. A própria Mecânica Quântica confirma a localidade de todos os processos físicos observáveis, como é demonstrado pelos diversos teoremas de não-sinalização, que mostram que o emaranhamento não pode ser usado para a transferência de informação. No entanto, isto significa que a não-localidade das interpretações mencionadas acima reside inteiramente na estrutura teórica e não nos fenômenos.

c) Pode-se manter tanto o realismo metodológico de Einstein quanto seu princípio da separação, rejeitando sua conclusão de que a não-univocidade da Mecânica Quântica implica sua incompletude. Como foi indicado na seção 7, a prova de EPR da incompletude da Mecânica Quântica se baseia em um sentido mais forte de realismo do que Einstein estava geralmente disposto a admitir. Mas, o argumento favorito de Einstein envolvendo o emaranhamento só pode mostrar a não-univocidade das descrições quânticas, não a sua incompletude. Haveria a possibilidade de construir uma interpretação da Mecânica Quântica que considera os estados quânticos como descrições não-absolutas, no mesmo sentido da Teoria da Relatividade? Esta possibilidade foi explorada por Hugh Everett (1973) em sua "interpretação do estado relativo" da Mecânica Quântica, aplicando a distinção de Einstein entre realidade fenomênica e realidade objetiva de um modo radicalmente novo. Everett propôs que os resultados das medições não nos dão informação direta sobre o estado objetivo, que nunca entra em colapso. Os resultados das medições são apenas refletidos em um estado relativo não-invariante, que, como as descrições dependentes de coordenadas na relatividade, descrevem uma perspectiva fenomenal não-única. Isto permite uma explicação natural do argumento simples do emaranhamento de Einstein: os dois estados quânticos para a segunda partícula que resultam da medição da primeira partícula seriam simplesmente duas perspectivas fenomênicas. Ao contrário do que foi suposto por EPR, eles não refletem elementos da realidade objetiva. Portanto, nenhuma violação do princípio da separação de Einstein é necessária para explicar as previsões na Mecânica Quântica. Embora a interpretação de Everett certamente divirja radicalmente das intuições de Einstein sobre como o mundo é, esta interpretação é, como o próprio Everett apontou, a mais fiel aos princípios metodológicos de Einstein. 


\section{Referências}

BACCIAGALUPPI, Guido; VALENTINI, Antony. Quantum theory at the crossroads: reconsidering the 1927 Solvay Conference. Cambridge: Cambridge University, 2009.

BELL, John Stewart. On the Einstein Podolsky Rosen Paradox. Physics, v. 1, p. 195-200, 1964.

BELLER, Mara; FINE, Arthur. Bohr's Response to EPR. In: FAYE, J.; FOLSE, H. J. (Org.). Niels Bohr and contemporary philosophy. Dordrecht: Kluwer, 1993. p. $1-31$.

BELOUSEK, Darrin W. Einstein's 1927 unpublished Hidden-variable theory: its background, context and significance. Studies in the History and Philosophy of Modern Physics, v. 27, p. 437-461, 1996.

BERTLMANN, Reinhold A.; ZEILINGER, Anton (Org). Quantum (un)speakables: from bell to quantum information. Berlin; Heidelberg: Springer, 2002.

BOHM, David. Quantum theory. Englewood Cliffs, NJ: Prentice-Hall, 1951.

. A suggested Interpretation of the Quantum Theory in Terms of 'Hidden' Variables. Physical Review, v. 85, p. 166-193, 1952.

BOHR, Niels. Can quantum mechanical description of physical reality be considered complete?" Physical Review, v. 48, p. 696-702, 1935b. Em português: "A descrição da realidade física fornecida pela mecânica quântica pode ser considerada completa?". Trad. C.W. Abramo. Cadernos de História e Filosofia da Ciência, v. 2, p. 97-106, 1981.

. The causality problem in atomic physics. In: New Theories in Physics (Conferência em Varsóvia). Paris: Institut International de Coopération Intellectuelle, 1939b. p. 11-38. Les nouvelles théories de la physique. Proceedings

. Collected Works, v. 6: foundations of Quantum Physics I (1926-1932).

Org. por Jørgen Kalckar. Amsterdam: North-Holland, 1985.

. Collected Works, v. 2: works on Atomic Physics (1912-1917). Org. por

Ulrich Hoyer. Amsterdam: North-Holland, 1981.

. Discussion with Einstein on Epistemological Problems in Atomic

Physics. In: SCHILPP, Paul A. (Org.). Albert Einstein: philosopher-scientist. 
Evanston, IL: Library of Living Philosophers, 1949. p. 199-242. Em português: "O debate com Einstein sobre problemas epistemológicos na física atômica". In: BOHR, N. Física atômica e conhecimento humano. Trad. Vera Ribeiro. Rio de Janeiro: Contraponto, 1995. p. 41-83.

Quantum mechanics and physical reality. Nature, v. 136, p. 65, 1939a.

BOHR, Niels; ROSENFELD, Léon. Zur Frage der Meßbarkeit der elektromagnetischen Feldgrößen. Kgl Danske Videnskabernes Selskab. Matematisk-fysiske Meddelser, v. 12, p. 1-65, 1933.

BORN, Max . Zur Quantenmechanik der Stoßvorgänge. Zeitschrift für Physik, v. 37, p. 863-867, 1926.

CPAE 7. The collected papers of Albert Einstein, v. 7: the Berlin years: writings, 1918-1921. Org. por Michel Janssen et al. Princeton: Princeton University, 2002.

CPAE 8. The collected papers of Albert Einstein, v. 8: the Berlin years: correspondence, 1914-1918 (parts A and B). Org. por Robert Schulmann et al. Princeton: Princeton University, 1998.

DONGEN, Jeroen van. Emil Rupp, Albert Einstein and the Canal Ray Experiments on Wave-Particle Duality: Scientific Fraud and Theoretical Bias. Historical Studies in the Physical and Biological Sciences, v. 37, p. 73-120, 2007a. Supplement.

. The interpretation of the Einstein-Rupp experiments and their influence on the history of quantum mechanics. Historical Studies in the Physical and Biological Sciences, v. 37, p. 121-131, 2007b. Supplement.

EINSTEIN, Albert. Äther und Relativitätstheorie. Berlin: Julius Springer, 1920.

Autobiographical notes. In: SCHILPP, Paul A. (Org.). Albert Einstein: philosopher-scientist. Evanston, IL: Library of Living Philosophers, 1949. p. 2-94. Em português: Notas Autobiográficas. Trad. A. S. Rodrigues. Rio de Janeiro: Nova Fronteira, 1982.

. Bietet die Feldtheorie Möglichkeiten für die Lösung des Quantenproblems? Preußische Akademie der Wissenschaften (Berlin). Physikalisch-Mathematische Klasse. Sitzungsberichte, p.359-364, 1923.

. Dialog über Einwände gegen die Relativitätstheorie. Die Naturwissenschaften, v. 6, p. 697-702, 1918a. Reimpresso em CPAE 7, op. cit., Doc. 13. 
. Der energiesatz in der allgemeinen Relativitätstheorie. Königlich Preußische Akademie der Wissenschaften (Berlin). Physikalisch-Mathematische Klasse. Sitzungsberichte, p. 448-459, 1918b. Reimpresso em CPAE 7, op. cit., Doc. 9.

. Elementare Überlegungen zur Interpretation der Grundlagen der Quanten-Mechanik. In: . Scientific Papers Presented to Max Born. Edinburgh: Oliver \& Boyd, 1953. p. 33-40.

. Geometrie und Erfahrung. Berlin: Julius Springer, 1921.

. Ideas and opinions. New York: Crown, 1954. Reimpressão: New York: Modern Library, 1994.

. Induktion und deduktion in der physik. Berliner Tageblatt, 25 dez. 1919b.

. Letter from Dr. Albert Einstein. In: HERBERT, L. Samuel. (Org.). Essay in Physics. Oxford: Blackwell, 1951.

. Mein Weltbild. 27. ed. Org. por Carl Seelig. Amsterdam: Querido, 1934. Em português: Como Vejo o Mundo. Trad. H.P. de Andrade. Rio de Janeiro: Nova Fronteira, 1981.

. Motive des forschens. In: WAMBURG, Emil et al. (Org.). $Z u$ Max Plancks sechzigstem Geburtstag. Karlsruhe: Karlsruhe I.B.: C.F. Müllersche Hofbuchhandlung M.B.H., 1918c. p. 29-32. Reimpresso em CPAE 7, op. cit., Doc. 7.

. Prinzipielles zur allgemeinen Relativitätstheorie. Annalen der Physik, v. 55, p. 241-244, 1918d. Reimpresso em CPAE 7, op. cit., Doc. 4.

. Physics and reality. Franklin Institute Journal, v. 221, p. 313-337, 1936.

. Quanten-mechanik und Wirklichkeit. Dialectica v. 2, p. 320-324, 1948.

. Spielen gravitationsfelder im Aufbau der materiellen

Elementarteilchen eine wesentliche Rolle? Preussische Akademie der Wissenschaften (Berlin), Sitzungsberichte, p. 349-356, 1919a.

. Strahlungs-emission und -absorption nach der quantentheorie.

Deutsche Physikalische Gesellschaft. Verhandlungen v. 18, p. 318-323, 1916. 
. Time, space, and gravitation. The Times, London, p. 13-14, 28 nov. 1919c.

. Zur Quantentheorie der Strahlung. Physikalische Zeitschrift, v. 18, p. 121-128, 1917.

.; BORN, Max; BORN, Hedwig. Briefwechsel 1916-1955. München: Nymphenburger Verlagshandlung, 1969. Em inglês: The Born-Einstein Letters, Macmillan, New York, 1971.

EINSTEIN, Albert; PODOLSKY, Boris; ROSEN, Nathan. Can quantum mechanical description of reality be considered complete?. Physical Review, v. 47, p. 777-780, 1935. Em português: "A descrição da realidade física fornecida pela mecânica quântica pode ser considerada completa?. Trad. C.W. Abram. Cadernos de História e Filosofia da Ciência, v. 2 p. 90-96, 1981.

EISENSTAEDT, Jean; KOX, Anne (Org.). Studies in the History of General Relativity. Einstein Studies. Boston: Birkhäuser, 1992.

EVERETT, Hugh. The theory of the universal wave function. In: DEWITT, Bryce; GRAHAM, Neill (Org.). The many-worlds interpretation of quantum Mechanics. Princeton: Princeton University, 1973. p. 3-140.

FINE, Arthur. Einstein's realism. (1986). In: . The shaky game: Einstein, realism and the quantum theory. 2. ed. Chicago: University of Chicago, 1996a. p. 86-111.

The shaky game: Einstein, realism and the quantum theory. 2. ed. Chicago: University of Chicago, 1996b.

HEISENBERG, Werner. Der Teil und das Ganze: Gespräche im Umkreis der Atomphysik. Munich: Piper, 1969. Em português: A parte e o todo. Trad. Vera Ribeiro. Rio de Janeiro: Contraponto, 1996.

Über den anschaulichen Inhalte der quantentheoretischen Kinematik und Mechanik. Zeitschrift für Physik, v. 43, p. 172-198, 1927.

HOLTON, Gerald. Mach, Einstein, and the Search for Reality. Daedalus, v. 97, p. 636-673, 1968. Reimpresso em: HOLTON, G. Thematic Origins of Scientific Thought: Kepler to Einstein. Cambridge, MA: Harvard University, 1988. p. 237-277.

HOME, Dipankar; WHITAKER, Andrew. Einstein's struggles with quantum theory. New York: Springer, 2007. 
HOWARD, Don. Einstein and Eindeutigkeit: a neglected theme in the philosophical background to general relativity. In: EISENSTAEDT, Jean; KOX, Anne (Org.). Studies in the History of General Relativity. Einstein Studies. Boston: Birkhäuser, 1992. p. 154-243.

. Einstein on locality and separability. Studies in History and Philosophy of Science, v. 16, p. 171-201, 1985.

. Nicht sein kann was nicht sein darf: or the Prehistory of EPR, 19091935: Einstein's Early Worries about the Quantum Mechanics of Composive Systems. In: MILLER, Arthur I. (Org.). Sixty-two Years of Uncertainty: historical, philosophical, physics inquiries into the Foundations of Quantum Physics. New York: Plenum, 1990. p. 61-111.

. Realism and conventionalism in Einstein's philosophy of science: The Einstein-Schlick correspondence. Philosophia Naturalis, v. 21, p. 616-629, 1984.

. Was Einstein really a realist?. Perspectives on Science: Historical, Philosophical, Social, v. 1, p. 204-251, 1993.

JAMMER, Max. The conceptual development of quantum mechanics. New York: McGraw-Hill, 1966.

JANSSEN, Michel. 'No Success like Failure...': Einstein's Quest for General Relativity, 1907-1920. In: JANSSEN, Michel; LEHNER, Christoph (Org.). The Cambridge Companion to Einstein. Cambridge: Cambridge University, 2010. No prelo.

.; RENN, Jürgen. Untying the Knot: how Einstein found his way back to field equations discarded in the zurich notebook." In: RENN, Jürgen (Org.). The genesis of general relativity. New York; Berlin: Springer, 2007. v. 2, p. 839-925.

KLEIN, Martin J. The first phase of the Bohr-Einstein dialogue. Historical Studies in the Physical Sciences, v. 2, p. 1-39, 1970.

LORENTZ, Hendrik A. Problems of modern physics. Boston: Ginn, 1927.

MURDOCH, Dugald. Niels Bohr's Philosophy of Physics. Cambridge: Cambridge University, 1987.

NEUMANN, Johann von. Mathematische Grundlagen der Quantenmechanik. Berlin: Springer, 1932. Em inglês: Mathematical Foundations of Quantum Mechanics. Princeton: Princeton University, 1955. 
NORTON, John D. The physical content of general covariance. In: EISENSTAEDT, Jean; KOX, Anne (Org.). Studies in the History of General Relativity. Einstein Studies. Boston: Birkhäuser, 1992. p. 281-315.

PAIS, Abraham. 'Subtle is the Lord ...' the science and life of Albert Einstein. Oxford: Oxford University, 1982. Em português: “Sutil é o Senhor...”: a ciência e a vida de Albert Einstein. Trad. F. Parente e V. Esteves. Nova Fronteira: Rio de Janeiro, 1995.

PAULI, Wolfgang. Scientific correspondence with Bohr, Einstein, Heisenberg, a.o. Vol. 1. 1919-1929. Org. por Armin Hermann, Karl von Meyenn e V. F. Weisskopf, V.F. New York: Heidelberg; Berlin: Springer, 1979.

PRZIBRAM, Karl (Org.). Briefe zur Wellenmechanik. Vienna: Springer, 1963.

SCHILPP, Paul A. (Org.). Albert Einstein: philosopher-scientist. Evanston, IL: Library of Living Philosophers, 1949.

SCHRÖDINGER, Erwin. Die gegenwärtige Situation in der Quantenmechanik. Die Naturwissenschaften, v. 23, p. 807-812, 823-828, 844-849, 1935.

SPEZIALI, Pierre (Org.). Albert Einstein - Michele Besso : correspondance 1903-1955. Paris: Hermann, 1972.

STACHEL, John. Einstein and the Quantum: fifty years of Struggle. In: COLODNY, Robert G. (Org.). From Quarks to Quasars: Philosophical Problems of Modern Physics. Pittsburgh: University of Pittsburgh, 1986b. p. 349-385.

. Einstein's Search for General Covariance, 1912-1915. In: HOWARD, D; STACHEL, J (Ed.). Einstein and the history of general relativity.. Boston; Basel: Stuttgart: Birkhäuser, 1989. (Einstein Studies, 1).

Einstein from 'B' to 'Z'. Boston: Birkhäuser, 2002. (Einstein Studies, 9).

WHEELER, J.A.; ZUREK, W. H. (Org.). Quantum theory and measurement. Princeton: Princeton University, 1983.

WIGNER, Eugene. Thirty years of knowing Einstein. In: WOOLF, H. (Org.). Some Strangeness in the Proportion: a Centennial Symposium to Celebrate the Achievements of Albert Einstein. Reading, MA: Addison-Wesley, 1980. p. 461-468. 


\title{
Bohr e o problema da medição: uma solução dualista?\#
}

\author{
Stefano Osnaghi
}

\section{Introdução}

A ideia de que a visão de Bohr sobre a Física é fundamentalmente dualista é muito comum, sendo transmitida pela exposição dos livros-textos ortodoxos, os quais enfatizam que "[...] para obter-se uma maneira de interpretar a função de onda [quântica], devemos [...], de início, postular um nível clássico de forma que os resultados obtidos de uma medida possam ser compreendidos" (BOHM, 1951, p. 626). Geralmente, considera-se que a Mecânica Quântica não pode dar conta da própria ocorrência de resultados bem definidos, a não ser assumindo um processo de "redução" do vetor de estado. De acordo com o postulado de projeção, quando uma observação for realizada, o estado de um sistema é suposto "colapsar" (num auto-estado da observável medida), em aparente contraposição com a evolução contínua governada pela equação de Schrödinger. Segundo uma interpretação bastante comum, defendida, por exemplo, por John Bell (2004, p. 217-219), "postular um nível clássico", ou seja, restringir o domínio de aplicabilidade da física quântica governada pela equação de Schrödinger a sistemas microscópicos fechados, seria a maneira excogitada por Bohr para dar conta da redução do vetor de estado dentro de um quadro teórico logicamente coerente, embora ontologicamente dualista. Uma vez que, como o próprio Bohr assinalou, a existência de resultados definidos é uma pré-condição para se realizar experimentos quânticos, e uma vez que sem a redução do estado parece não haver resultados definidos, o dualismo de Bohr é, então, geralmente considerado como uma tentativa (não bem sucedida) de se resolver um problema de consistência.

\# Traduzido por Gustavo Rocha, revisado pelo autor. 
Esta leitura é o ponto inicial de inúmeros programas de pesquisa que almejam "ir além" da abordagem de Bohr ao provar a consistência da Teoria Quântica, sem se basear em hipóteses dualistas. Um exemplo típico é dado pelo programa que pretende explicar, por meio da "descoerência" induzida pelo ambiente, as características clássicas do fenômeno macroscópico, incluindo a ocorrência de resultados de medida definidos (ver, por exemplo, ZUREK, 2003). Admito, é claro, a importância do estudo experimental e teórico dos sistemas quânticos macroscópicos. Ademais, concordo que, a fim de se fornecer uma visão consistente das teorias e do conhecimento científico, a abordagem de Bohr precisa ser elaborada e completada. Não obstante, sustento que seja enganosa a ideia de que esta tarefa possa ser atingida ao se delinear uma explicação quântica do processo de medida. A ideia de que uma tal explicação, pelo fato de preencher o fosso entre os domínios de experiência quânticos e clássicos, permitiria que nos livrássemos dos postulados dualistas de Bohr está equivocada por várias razões. Uma delas é que, como este artigo pretende demonstrar, não há postulados dualistas na abordagem de Bohr.

Na próxima seção, delinearei o cenário do problema, sintetizando as alegações de dualismo que são geralmente dirigidas contra o ponto de vista de Bohr. Em seguida, argumentarei que estas alegações, provenientes de um entendimento equivocado das ideias de Bohr, não são justificadas. Farei isto em três etapas. Em primeiro lugar, recordarei, brevemente, as próprias observações de Bohr sobre a medição. Em segundo lugar, analisarei sua definição muito precisa do que seja um vetor de estado, e as implicações de longo alcance desta definição. Em terceiro lugar, mostrarei que, baseado nesta definição, a abordagem de Bohr não implica em, ou necessita de, nenhuma das características dualistas que a ela geralmente é atribuída. Em particular, ela não proíbe o tratamento quântico dos sistemas macroscópicos e dos processos de medida e, portanto, não entra em discordância com as tentativas de se estender a Mecânica Quântica aos fenômenos que envolvem sistemas macroscópicos. Segue-se disto que estas tentativas não deveriam ser consideradas como alternativas à analise de Bohr. Igualmente, argumentarei, elas não fornecem, independentemente desta mesma analise, uma prova da consistência da Mecânica Quântica. A minha conclusão será que o "dualismo" implícito na abordagem de Bohr nos leva, simplesmente, a reconhecer a existência de diferentes modos de descrição da experiência (o formalismo quântico, a mecânica clássica, a linguagem ordinária...), cada um dos quais, insinuarei, é mais bem interpretado como um modo de predição e é bem definido dentro de uma "prática" específica. Nada impede que se estenda o domínio de aplicabilidade de um ou outro modo, contanto que a prática correspondente, que permite associar-se um significado físico inequívoco aos símbolos e às expressões linguísticas, seja ampliada também de maneira apropriada. 
Finalmente, uma última observação. A minha análise sobre o desentendimento ao redor das ideias de Bohr ressoará as conclusões de alguns estudos recentes (ver FAYE, 2008). Contudo, meu objetivo, neste artigo, não será contrastar com uma exegese precisa dos escritos de Bohr o que considero ser uma interpretação equivocada das ideias dele. Ao invés disto, tentarei responder diretamente às críticas levantadas contra a abordagem de Bohr, atacando, explicitamente, os diferentes aspectos do conhecido problema da medição e esboçando, de modo que a abordagem de Bohr possa ser enquadrada de maneira coerente, um referencial epistemológico não-dualista. Esta resposta reflete a minha elaboração do ponto de vista de Bohr, baseada numa leitura pragmática que se foca na noção de preditividade, isto é, capacidade de predição. Embora acredite que esta elaboração esteja de acordo com as intuições filosóficas mais fundamentais de Bohr, não lidarei aqui com o problema de estabelecer se ela oferece uma interpretação historicamente consistente da doutrina bohriana da complementaridade.

\section{Medição e alegações de dualismo}

O problema da medição está conexo com o chamado colapso da função de onda, o qual se supõe que ocorra quando se realiza uma observação, em contraste com a evolução contínua de um sistema fechado. Para poder ser considerada uma teoria completa, a Mecânica Quântica deveria dar conta de todos os fatores que desempenham algum papel no processo de medição (o qual pode ser entendido como apenas um tipo particular de interação física). O colapso da função de onda é tipicamente explicado pelo ato intencional de um observador consciente ou pelo caráter macroscópico do aparelho de medida. Então, dependendo da explicação do colapso adotada, a Mecânica Quântica deveria oferecer um modelo físico da mente, ou uma justificação do fato de que o aparelho de medida, e de maneira geral os objetos macroscópicos, não são encontrados numa superposição dos estados que correspondem às suas configurações "clássicas" (em contraposição ao famoso gato de Schrödinger).

O colapso da função de onda é considerado frequentemente como um "processo 'mágico' no qual alguma coisa bem drástica" acontece, "enquanto em todas as demais ocasiões supomos que os sistemas obedeçam a leis contínuas perfeitamente naturais." (Everett a Jammer, 1973, citado por OSNAGHI; FREITAS; FREIRE JR., 2009, p. 105) Quer se concorde ou não que este "processo mágico" caracteriza de forma justa "o aspecto estridente da Mecânica Quântica de Bohr" (ROVELLI, 1996, p. 1671), não surpreende que, quando entendido desta maneira, o postulado da projeção levante preocupações a respeito da consistência da teoria (ver, por exemplo, HEISENBERG, 1955, p. 23). Isto é ilustrado pelo experimento de pensamento (Gedankenexperiment) do amigo de Wigner (1961), no qual um 
observador $\mathrm{O}_{2}$ realiza uma medida sobre outro observador $\mathrm{O}_{1}$, o qual, por sua vez, mede um sistema $S$. Se supusermos que $\mathrm{O}_{1}$ e $\mathrm{S}$ formam um sistema fechado, $\mathrm{O}_{2}$ descreverá a situação de $\mathrm{O}_{1}$ e $\mathrm{S}$ através do estado emaranhado resultante da evolução contínua do conjunto $\mathrm{O}_{1}$ e S. Contudo, uma vez que $\mathrm{O}_{1}$ tenha realizado a sua medida de $S$, encontrando, por exemplo, o valor x para a observável medida, o postulado da projeção determina que o seu estado se colapsará no estado correspondente à configuração clássica "ter observado x". Isto parece nos levar a um paradoxo, a menos que estejamos preparados para, por um lado, endossar o "solipsismo" (ao tomarmos a descrição de $\mathrm{O}_{2}$ como a única válida, implicando que $\mathrm{O}_{1}$ e todos os demais observadores não têm um estado definido, apesar de afirmarem o contrário), ou para, por outro, postular que a interação do sistema com uma mente consciente é o que acarreta o colapso do seu estado (neste caso, a descrição correta seria que o relato de $\mathrm{O}_{2}$ sobre $\mathrm{O}_{1}$ seria incompleto, uma vez que este não consegue levar em consideração a mudança objetiva no estado do mundo provocada pela observação de $\mathrm{O}_{1}$ ). Tanto autores que, no debate entre as décadas de 1960 e 1970, defenderam a hipótese da influência da mente sobre o mundo físico (WIGNER, 1961), quanto os que recusaram esta solução (POPPER, 1967), fizeram-no a partir do convencimento de que "a doutrina de Copenhagen [era] logicamente inconsistente, e que esta falha deriva[va] da adoção por ela de uma filosofia subjetivista" (BUNGE, 1973, p. 89).

Contudo, embora ocasionalmente, a acusação de "idealismo" ou aquela de consentir uma influência do observador sobre o mundo físico tenham sido dirigidas contra Bohr (ver a discussão em HOWARD, 2004, e CAMILLERI, 2009), a atitude mais comum entre os críticos é argumentar que, a fim de evitar qualquer referência ao observador, Bohr endossa um tipo diferente de dualismo. Deste modo, como vimos na introdução, o aspecto geralmente considerado como a característica distintiva da abordagem de Bohr é a sua restrição da aplicabilidade da Teoria Quântica somente ao âmbito do mundo atômico (BELL, 2004, p. 188-189). Segundo Rovelli (1996, p. 1671), por exemplo, "o aspecto perturbador do ponto de vista de Bohr é a inaplicabilidade da Teoria Quântica ao mundo macroscópico". Para ele, a visão de Bohr implica que "o mundo clássico é fisicamente distinto dos sistemas microscópicos" e que devemos tratar "uma porção do mundo de maneira diferente do resto dele". Na concepção de Zurek (2003, p. 716), "a solução de Bohr era delinear uma fronteira entre o quântico e o clássico e manter determinados objetos - especialmente os instrumentos de medida e os observadores - ao lado do clássico". Desta maneira, "o princípio de superposição" era suspenso por "decreto" no domínio clássico. Para Omnès (1992, p. 340-341), estas mesmas características implicam que "a interpretação de Copenhague é incompleta, a sua consistência é muito questionável, e o seu tratamento do fenômeno é bastante superficial" (tendo em vista nossa discussão subsequente, é importante notar que Omnès (1992, p. 340-341) apresenta a sua abordagem 
como "o tipo de progresso necessário para se obter uma versão satisfatória da interpretação de Copenhague”).

A crença de que a abordagem de Bohr postula que "os sistemas macroscópicos são relativamente imunes aos efeitos quânticos", o que implicaria que "mesmo em princípio a Mecânica Quântica não pode descrever o processo da própria medição", é uma das razões pelas quais Hugh Everett, ainda estudante de doutorado, começou a desenvolver uma abordagem alternativa à Mecânica Quântica, que resultou na sua formulação dos "estados relativos" (EVERETT, 1957). Sabemos, a partir das cartas de Everett, que ele considerava a abordagem de Bohr "desesperadamente incompleta" e "um tanto quanto repugnante, uma vez que ela [levava] a uma dicotomia artificial do universo entre fenômenos ordinários e medições". Além disto, segundo Everett, tal abordagem "adere[ia] a um conceito de 'realidade' no nível clássico, enquanto renuncia[ava] o mesmo no domínio quântico”. Isto parecia para ele uma "monstruosidade filosófica" (EVERETT, 1955, p. 3; OSNAGHI; FREITAS; FREIRE JR., 2009, p. 105-106, 113).

Na tese de Everett, a abordagem de Bohr é associada a um ponto de vista mais sofisticado, o qual Everett chama de formulação do "observador externo" da Mecânica Quântica. Nas palavras de Bas van Fraassen, esta formulação resulta em assumir que

[...] a Teoria Quântica fora desenvolvida para se descrever somente situações nas quais um observador (ou pelo menos o ambiente da medida) esteja envolvido, ao mesmo tempo em que deixa esta parte fora da descrição. (FRAASSEN, 1991, p. 273)

Uma observação importante é a seguinte: nesta visão "qualquer sistema pode ser parte do sistema sob estudo, mas a linha entre o sistema sob estudo e o aparelho de medida (final) deve ser traçada em algum lugar" (FRAASSEN, 1972, p. 332). A descrição do ponto de vista de Copenhague nos termos da formulação do "observador externo" é provavelmente devida a John Wheeler. Orientador de Everett, e um dos inspiradores dos estudos sobre os fundamentos da Mecânica Quântica nas décadas de 1970 e 1980, Wheeler era um bohriano dedicado. Para ele, o objetivo da proposta de Everett não era "questionar" a abordagem ortodoxa do problema da medição, "mas aceitá-la e generalizá-la" (Wheeler para Stern, 1956, citado em OSNAGHI; FREITAS; FREIRE JR., 2009, p. 97). Entretanto, embora em comentário publicado junto com a tese de Everett, Wheeler (1957) afirmasse que a formulação do "observador externo" tinha "o grande mérito" de ser dualista, ele admitiu sucessivamente que o fato de ela "dividir o mundo em dois" levantava uma dificuldade que o perturbava profundamente (WHEELER, 2000, p. 269). Durante suas discussões com Bohr, na década de 50, Wheeler havia levantado este ponto, dizendo que ele estava preocupado, principalmente, com a 
[...] questão fundamental, a saber, se há qualquer escapatória a um formalismo como o de Everett, quando se deseja lidar com uma situação onde vários observadores são considerados e, ainda, incluir os próprios observadores no sistema a ser considerado na análise matemática. (Wheeler para Bohr, 1956, citado em OSNAGHI; FREITAS; FREIRE JR., 2009, p. 119).

A resposta do próprio Everett a esta questão era, é claro, negativa. Como ele enfatizou, a formulação da "observação externa" chegava a problemas críticos "no caso de um universo fechado", já que neste caso "não há lugar a se posicionar fora do sistema para observá-lo. Não há nada fora dele para produzir transições de um estado a outro" (EVERETT, 1957, p. 142).

A leitura que identifica a interpretação de Copenhagen com a formulação do "observador externo" continua sendo popular, assim como as preocupações a respeito da completeza e da consistência da visão de Bohr que tal leitura suscita. Deste modo, van Fraassen (1991, p. 273), por exemplo, argumenta que, na abordagem de Bohr, "uma medição, ao deixar para fora alguma ou outra coisa, é uma interação descrita de maneira incompleta". Na sua "variante de Copenhagen" da interpretação modal, ele se dispõe a "completar" a abordagem de Bohr ao fornecer uma caracterização completa e objetiva das interações que contam como medições, eliminando, desta maneira, todas as "conotações antropocêntricas" e tornando possível "pensar a Teoria Quântica como uma descrição autônoma putativa do mundo em termos físicos neutros" (FRAASSEN, 1991, p. 284; ver OSNAGHI, 2008, para discussão).

Para concluir esta seção, vale a pena sintetizar esquematicamente os aspectos da abordagem de Bohr que, nas interpretações mais comuns, implicam em algum tipo de dualismo (ver FAYE, 2008):

1. O colapso da função de onda quando se realiza uma observação, em oposição à evolução continua de um sistema fechado.

2. A necessidade de se levar em consideração processos extrafísicos (envolvendo, por exemplo, a consciência) ao se descrever a física da observação.

3. A existência de uma divisão física entre os fenômenos atômicos, governados pela física quântica, e o mundo macroscópico, governado pela física clássica.

4. A necessidade de manter as interações que constituem uma medição fora do alcance da Mecânica Quântica. 


\section{Bohr sobre o "problema observacional":}

As caracterizações dualistas do ponto de vista de Bohr e as questões relacionadas a respeito de sua completeza são justificadas? As passagens dos escritos de Bohr que lidam com aspectos do que hoje é chamado de "problema da medição" não são exatamente cristalinas (TELLER, 1981; MURDOCH, 1987; BITBOL, 1996). Mesmo assim, não há dúvida de que Bohr estava convencido de que a sua abordagem não enfrentava qualquer problema específico com relação à medição. Caso se aceitasse o uso "da palavra fenômeno exclusivamente para referir às observações obtidas sob circunstâncias específicas, incluindo uma descrição de todo o arranjo experimental", então, o "problema observacional" estaria

[...] livre de qualquer complicação especial, uma vez que, em experimentos reais, todas as observações são expressas por afirmações inequívocas com relação, por exemplo, ao registro do ponto aonde um elétron chega numa chapa fotográfica. (BOHR, 1963, p. 64).

Numa conferência de 1938, Bohr foi explicitamente chamado a comentar a respeito do postulado da projeção. Segundo as atas, ele respondeu que "a dualidade que ele encontrava na interpretação do formalismo da mecânica quântica era, em sua opinião, uma questão de se escolher a descrição mais adequada do experimento". Ele também observou que

[...] se decidirmos incluir na enumeração das condições exteriores todos os instrumentos que devam ser utilizados para o estudo do fenômeno como um todo, o único fator arbitrário remanescente será [...] a livre escolha destas condições experimentais, e, para além desta liberdade, a interpretação da solução do problema, no que diz respeito às predições relativas ao fenômeno que estamos estudando, será perfeitamente inequívoca. (BOHR, 1998, p. 107).

A resposta de Bohr ao artigo EPR foca no papel "constitutivo" do contexto da medição na definição da "realidade física". Ela contém afirmações que parecem aludir à necessidade de um "corte" na sequência de interações que constituem uma medição, embora estas afirmações, na verdade, pretendam enfatizar a necessidade de uma definição objetiva do contexto da medição. Bohr (1935, p. 701), por exemplo, enfatiza a

[...] necessidade de, em cada arranjo experimental, se discriminar entre aquelas partes do sistema físico em questão que serão tratadas como instrumentos de medida, daquelas que constituem os objetos sob investigação [...], 
e observa que esta necessidade "realmente, deve-se dizer, forma uma distinção fundamental entre as descrições, clássica e quanto-mecânica, do fenômeno físico". Da mesma forma, em outro momento, ele enfatiza

[ ] a necessidade de se descrever inteiramente em termos clássicos todos os instrumentos de medidas que, ao fim e a cabo, definem as condições externas do fenômeno, e, portanto, a necessidade de mantê-los fora do sistema, para o qual o tratamento do quantum de ação está, essencialmente, sendo levado em consideração. (BOHR, 1998, p. 104).

Contudo, ele também acentua, enfaticamente, que "é possível, é claro, que no sistema, em que é aplicado o formalismo da mecânica quântica, se inclua qualquer agente auxiliar intermediário empregado no processo da medida" (BOHR, 1998, p. 104). Estas afirmações podem parecer ambíguas. Por um lado, Bohr defende que o instrumento de medida deve, necessariamente, ser descrito classicamente. Por outro, ele reivindica que o instrumento de medida pode ser parte daquilo que, em outra passagem, chama de "sistema objeto" num experimento. Todavia, a contradição aqui é somente aparente, como se tornará claro na medida em que as afirmações precedentes forem entendidas à luz da interpretação bohriana do formalismo.

\section{A interpretação instrumentalista do formalismo}

Segundo Bohr (1948, p. 314),

[...] todo o formalismo [da Teoria Quântica] deve ser considerado como uma ferramenta para se derivar predições, de caráter determinista ou estatístico, com relação às informações obteníveis de acordo com as condições experimentais descritas [...] em linguagem ordinária adequadamente refinada pelo vocabulário da física clássica.

Esta e outras afirmações similares são frequentemente consideradas como um pouco mais do que slogans instrumentalistas, cujo ponto principal é enfatizar as limitações epistêmicas da Mecânica Quântica quando comparada com as teorias clássicas. Acredito que, pelo contrário, elas oferecem uma concepção positiva e precisa das teorias físicas, que pretende generalizar (mais do que restringir) o "ponto de vista habitual da filosofia natural" (BOHR, 1935, p. 697). Para o propósito de minha discussão, chamarei este "ponto de vista habitual" de "ponto de vista representacionalista". De maneira aproximada, este pode ser caracterizado como o ponto de vista que supõe que o fenômeno, e, portanto, nossas observações 
e os resultados de nossas medidas, seja produzido pelas propriedades de objetos cujas características não dependem da forma como investigamos a experiência. Dentro do ponto de vista representacionalista, espera-se que as teorias, em última análise, descrevam estes objetos e suas interações. Nesta perspectiva, é natural imaginar-se que o vetor de estado de um sistema reflita, mais ou menos diretamente, as propriedades objetivas do sistema, ou seja, seu "estado físico" (ver, por exemplo, EVERETT, 1973, p. 63).

A interpretação de Bohr do formalismo não pressupõe esta estrutura referencial. Ela não contém referência, seja direta ou indireta, a propriedades. As predições se referem a resultados, com nenhuma alusão implícita a algo supostamente "revelado" por eles. Isto tem duas consequências cruciais. Primeiro, as afirmações empíricas são intrinsecamente condicionais, uma vez que elas se referem ao que ocorrerá se uma medida for levada a cabo. Segundo, uma vez que os símbolos matemáticos da teoria se referem unicamente às medidas, o uso significativo de uma teoria pressupõe que se possa definir de maneira inequívoca o arranjo experimental no qual as medidas são realizadas, assim como seus possíveis resultados (BOHR, 1963, p. 5). Deste modo, se assumimos a interpretação de Bohr do formalismo, tanto a possibilidade de se definir, quanto a de se comunicar de maneira inequívoca as condições sob as quais um experimento é realizado, é condição prévia para se dotar de significado físico os modelos formais (ver BOHR, 1935, p. 700). Esta condição não deveria ser vista como uma restrição externa imposta sobre a Física. Muito pelo contrário, de um ponto de vista pragmático, ela expressa claramente uma condição de possibilidade da Física, ou seja, uma condição cujo cumprimento está implícito em qualquer atividade experimental desenvolvida dentro de um quadro teórico bem definido (STAPP, 1972; PARK, 1973; MURDOCH, 1987; BIBTOL, 1996).

\section{O dualismo revisitado}

Mantendo em mente a interpretação do formalismo acima, não é difícil perceber que a abordagem de Bohr não é dualista no sentido que caracterizam as leituras mais comuns. Estas leituras refletem um esforço mal conduzido para se levar em consideração, dentro do ponto de vista representacionalista, a natureza inerentemente pragmática dos modelos quânticos e, mais especificamente, o fato que, na medida em que estes se relacionam com os dados empíricos, os modelos pressupõem um contexto de medição bem definido.

Colapso da função de onda versus evolução contínua. Suponha que a observável A de algum sistema $S$ seja medida por um aparelho " $M_{1}$ " e então que a medida seja repetida imediatamente por um segundo aparelho " $\mathrm{M}_{2}$ " (aspas indicam que 
estamos nos referindo a um objeto da experiência ordinária, não ao seu correlato putativo dentro de algum modelo quântico). Como podemos ter certeza de que o resultado encontrado na primeira medida será confirmado na segunda? E se não podemos ter certeza, como podemos afirmar que os resultados de uma medição de A são "estáveis" e, então, objetivos?

Vamos enfatizar antes de tudo que, segundo a visão de Bohr, no caso de uma medição repetida, estamos lidando com dois experimentos diferentes (na medida em que um experimento se identifica com uma medição realizada). Ao final do primeiro experimento, o estado de $S$ é, em geral, uma superposição de autoestados de A, enquanto no início do segundo experimento, ele é o autoestado, correspondendo ao resultado encontrado na primeira medição. O problema, então, é o seguinte: como é que a abordagem instrumentalista pode justificar o fato de que o vetor de estado adequado para prever os resultados do segundo experimento é precisamente aquele determinado pelo resultado do primeiro? $\mathrm{O}$ postulado de projeção fornece uma resposta formal a esta pergunta. Contudo, segundo a definição de Bohr, é sem sentido (rigorosamente falando) dizer que o vetor de estado de $S$ sofreu um colapso. Uma vez que o vetor de estado é definido somente dentro de um contexto experimental, não estamos tratando aqui da evolução de um vetor de estado, mas sim conectando os vetores de estado referentes a dois experimentos diferentes.

Obviamente, se considerarmos um contesto experimental "mais amplo", é possível elaborar uma descrição física da repetição da medida, e analisar o que acontece, de acordo com esta descrição, entre os dois experimentos. Nesse caso, um modelo governado pela equação de Schrödinger pode dar conta, em principio, de todos os aspectos empíricos do problema. Por outro lado, a própria definição de um tal modelo (que deve incluir, além de $S$, os sistemas $M_{1}$ e $M_{2}$ que representam os dois aparelhos " $\mathrm{M}_{1}$ " $\mathrm{e}$ " $\mathrm{M}_{2}$ ") pressupõe que seja possível atribuir um vetor de estado a $S$, o que, por sua vez, requere que os resultados das medições efetuadas sobre $S$ sejam bem definidos. Se assumirmos que a estabilidade seja um elemento constitutivo dos resultados, esta ultima condição determina a própria construção do modelo (ou seja, as definições operacionais que tornam possível a identificação dos sistemas $M_{1}$ e $M_{2}$ com os aparelhos " $M_{1}$ " e " $M_{2}$ ") e não pode então ser derivada dele. Em outros termos, a legitimidade do modelo "qua modelo de medida repetida" é garantida contanto que não se pretenda testar a "objetividade" dos resultados das medidas que o modelo é suposto representar.

As conclusões da análise precedente podem ser resumidas e generalizadas da seguinte maneira. Enquanto for confinada ao domínio das asserções empiricamente testáveis, a análise dos processos de constituição da objetividade, que tornam possível a criação e o uso de modelos preditivos, não requer o postulado de projeção. Assumindo a interpretação de Bohr, a Mecânica Quântica governada 
pela equação de Schrödinger é suficiente para dar conta das situações experimentais encontradas na análise de tais processos. Por outro lado, nenhum modelo desse tipo pode fornecer uma prova de que as condições de objetividade pressupostas pela Física são efetivamente realizadas, pela simples razão que qualquer prova desse tipo deveria assumir o que ela pretende provar.

Dissolução do dualismo mente-matéria. Uma vez que na visão de Bohr não há colapso da função de onda, não há, a fortiori, nenhuma necessidade de se postular que o colapso seja causado pela mente do observador. Poder-se-ia argumentar que atribuir um vetor de estado ao sistema depois de uma medida, o que é a maneira como o colapso deveria ser entendido na visão de Bohr, implica um ato consciente. Mas isto não envolve nenhuma ação da consciência sobre os sistemas físicos. Como Bohr enfatizou, a descrição do fenômeno atômico tem "um caráter perfeitamente objetivo, uma vez que nenhuma referência explícita é feita a qualquer observador individual" (BOHR, 1963, p. 3; ver também HOWARD, 2004). A questão é simplesmente que, uma vez que os vetores de estado são símbolos que servem para antecipar os resultados obtidos num contexto bem definido, se o contexto passa por uma mudança objetiva, como acontece depois que um resultado é registrado, o mesmo acontece ao vetor de estado a ser usado para prever os resultados das observações posteriores. Claro que para poder falar de mudança objetiva no contexto, temos que pressupor a possibilidade de um acordo intersubjetivo sobre a ocorrência de um resultado (CHEVALLEY, 1995). Contudo, como este pressuposto expressa uma condição pragmática de possibilidade da Física (na medida em que ela pode prever resultados), ele não necessita (nem pode) ser explicado por algum mecanismo físico, como o colapso da função de onda. Negar esta necessidade, sem por outro lado adotar uma doutrina idealista, é uma postura perfeitamente coerente com o ponto de vista de Bohr sobre o formalismo.

Ao levarmos em consideração estas observações, podemos perceber facilmente - na linha de raciocínio do argumento supracitado com relação à redução do estado - que o paradoxo do amigo de Wigner se dissolve. Pois, se adotarmos a abordagem operacional acima delineada, as descrições dos dois observadores, no exemplo de Wigner, não se referem mais a dois "pontos de vistas" mutuamente incompatíveis sobre o mesmo evento. Mais propriamente, eles se referem a duas situações experimentais diferentes. Poder-se-ia insistir que estas duas situações podem ser vistas como parte de uma única situação e que é então legítimo perguntar se os relatos dos dois observadores coincidem. Contudo, assumindo a interpretação instrumentalista do formalismo, a resposta a esta pergunta deve e pode ser decidida através de um experimento, em que ambos os observadores são considerados parte do "sistema objeto", ou seja, são considerados dentro de um metacontexto, no qual a questão a respeito de seus supostos desentendimentos possa ser resolvida através de medições bem definidas. Obviamente, este metamodelo não deixaria de pressupor a possibilidade de um acordo intersubjetivo. 
Medições versus interações ordinárias. Como notamos, nos escritos de Bohr há passagens que parecem insinuar a necessidade de se introduzir um "corte" na descrição física, a fim de manter a parte final do processo de medição do lado clássico (MURDOCH, 1987, cap. 5). Mesmo estudiosos que podem ser contados entre os simpatizantes de Bohr identificaram a sua visão com a formulação do "observador externo". Contudo, hoje sabemos que esta caracterização foi decididamente rejeitada pelo grupo de Copenhague (OSNAGHI; FREITAS; FREIRE JR., 2009, p. 119). Léon Rosenfeld, por exemplo, um dos colaboradores mais próximos de Bohr, reconhecia, como "perfeitamente trivial", o fato de "que seja realmente possível arranjar uma função de onda para o aparelho experimental e o Hamiltoniano para a interação entre o sistema e o aparelho". Mas, por ser trivial, este fato não deixava, segundo ele, de ser também "terrivelmente traiçoeiro" (Rosenfeld a Bergmann, 1959, citado por OSNAGHI; FREITAS; FREIRE JR., 2009, p. 119). Esta atitude é confirmada por vários documentos, que mostram que, na década de 50, o grupo de Copenhague considerava profundamente enganosa toda a ideia de se construir uma Teoria Quântica da medida ao estilo de von Neumann (OSNAGHI; FREITAS; FREIRE JR., 2009).

Do ponto de vista de Bohr, o que a descrição objetiva de um experimento precisa é de uma distinção funcional entre os instrumentos de medida e o "sistema objeto" (MURDOCH, 1987, p. 97-98). Nada impede que seja estipulado um modelo de interação física que corresponda a uma medição. Não obstante, se $S$ é o sistema físico que representa o "sistema medido" e $\mathrm{M}$ é o sistema físico que representa o "aparelho da medição", os vetores de estado presentes neste modelo adquirem significado somente quando se declara o conjunto das medições, capazes de serem realizadas sobre o sistema composto $S+M$. Isto exige que se defina, operacionalmente, as observáveis do sistema composto e que se especifique, precisamente, $\mathrm{o}$ arranjo experimental em que estas observáveis podem ser medidas. Claramente, esta situação é diferente daquela na qual o aparelho funciona como um aparelho. No último caso, o aparelho é um objeto da experiência ordinária ao qual se aplicam os predicados usuais da linguagem ordinária. Por outro lado, no primeiro caso, o aparelho é um sistema quântico, ou seja, um conjunto de graus de liberdade para os quais se aplicam os protocolos experimentais da Física Quântica.

Dado que, numa perspectiva não representacionalista, um sistema é identificado, operacionalmente, com as medições que sobre ele possam ser realizadas, e dado que estas medições são diferentes nos dois casos, está longe de ser óbvio que o sistema quântico $M$ pode efetivamente ser identificado com o aparelho clássico "M". Todavia, esta identificação pode ser construída fazendo as práticas relevantes convergirem, a fim de assegurar que nosso modelo seja coerente, por um lado, com a Teoria Quântica e sua prática experimental, e, por outro, com o quadro conceitual e os fatos da experiência cotidiana (OSNAGHI, 2009; comparar com FRAASSEN, 2008, cap. 5). Claramente, este processo construtivo 
pressupõe um quadro conceitual e pragmático que funcione como referencial semântico. Consequentemente, a tentativa de se incluir o contexto experimental na descrição teórica de um experimento pode ser considerada como algo mais do que um mero exercício formal, na medida em que ela se apóia num contexto muito mais amplo.

Uma vez que se concorde com este ponto, todo elemento da sequência de sistemas que interagem em um processo de medição, incluindo o próprio observador, pode ser modelado e considerado como um "sistema objeto" de algum experimento. Pode-se até incluir no modelo todos observadores imagináveis, contanto que se dê uma definição operacional inequívoca ao termo "todos", que o conecte a quantidades observáveis. Porém, fora da perspectiva representacionalista, a fim de que este modelo "universal" tenha sentido, precisamos descrever os contextos experimentais para os quais suas predições se referem. Isto não pode ser feito a não ser de uma maneira que seja objetiva para nós, por exemplo, utilizando os termos "inequívocos" da linguagem ordinária, cujo conteúdo disposicional é reconhecível e testável por qualquer locutor competente. Portanto, falar sobre um "corte" nos parece somente uma forma pictórica, e enganosa, de se referir ao fato de que os modelos devam ser colocados num contexto experimental concreto e que este contexto deva ser passível de descrição objetiva.

Dissolução do dualismo micro-macro. Na visão de Bohr, o uso de um modelo teórico pressupõe que se possa definir de maneira inequívoca o arranjo experimental no qual as medidas são realizadas. Portanto, a exigência de que o arranjo experimental seja descrito em termos clássicos (ou seja, utilizando-se linguagem ordinária suplementada com o vocabulário da Física clássica) reflete a necessidade de se satisfazer estas condições de comunicabilidade (MURDOCH, 1987, p. 99-100). De maneira alguma isto nos leva a uma suposição física de que os sistemas macroscópicos se comportam classicamente. Nada nos impede de produzir um modelo quântico de um sistema macroscópico. Contudo, como vimos no caso dos aparelhos de medida, a questão se tal modelo representa "realmente" um determinado objeto ordinário pode ser resolvida somente pela prática.

Para ilustrar estas ideias, vamos considerar o exemplo tradicional do gato que, na situação imaginária proposta por Schrödinger (1935), ficaria suspenso entre a vida e a morte em consequência da sua interação com um sistema atômico preparado em um estado metastável. A fim de definir operacionalmente a observável $\mathrm{O}$, cujos valores correspondem ao estado biológico do gato (vivo ou morto), podemos proceder de duas maneiras.

a) Podemos associar ao estado biológico um conjunto de medições quânticas com seus possíveis resultados (ou seja, protocolos operacionais bem definidos dentro da prática da física atômica). Na prática, como se viu, isto ocorre através de um processo construtivo, cujo objetivo é 
assegurar uma transição "suave" entre os procedimentos experimentais quânticos e as observações ordinárias. Pois que a definição operacional da observável $\mathrm{O}$ envolve graus de liberdade quânticos, nesse processo ficam automaticamente definidas também as observáveis incompatíveis com O. Então, uma vez que esta construção tenha sido realizada, o fato de que gatos possam ser preparados numa superposição de dois vetores de estado, correspondendo a "morto" e "vivo" respectivamente, e que se possa observar os efeitos de interferência correspondentes, aparece sem nenhuma surpresa. Esta observação mostra apenas que a construção foi bem sucedida.

b) Alternativamente, podemos substituir os predicados "morto" e "vivo" por uns vetores de estado e definir operacionalmente estes vetores de estado através do conteúdo disposicional que aqueles predicados têm dentro da experiência ordinária. Posto isto, então, qual seria o significado operacional de uma "superposição" destes estados? Na experiência ordinária não há nenhuma observável que nos permita distinguir entre uma superposição e uma mistura estatística destes dois estados. Logo, em contraste com o caso anterior, mas também sem surpresa, desta vez não observaremos efeitos de interferência. (Esta conclusão se aplica também ao caso em que, por exemplo, estivéssemos considerando uma observável como a posição do gato. Claro que, em física atômica, existem observáveis incompatíveis com a posição, como por exemplo, o momento. Mas se consideramos unicamente os protocolos de medida da experiência ordinária, o momento do gato não é uma observável incompatível com a sua posição).

Note-se que, à luz destas considerações, a afirmação de que gatos "não podem ser encontrados" numa superposição $|V\rangle+|M\rangle$ dos estados que correspondem à vida e à morte é bastante enganosa. Pois, dependendo do modo como se define, operacionalmente, estes estados, ou não faz algum sentido operacional afirmar que o estado do gato é $|V\rangle+|M\rangle$ (o que é o nosso caso b), ou faz sentido sim (como no caso a), mas então é falsa a afirmativa de que o gato não pode ser encontrado em $|V\rangle+|M\rangle$.

O raciocínio que leva ao paradoxo descrito por Schrödinger é baseado em hipóteses representacionalistas que identificam, de maneira não problemática, o objeto-gato do discurso ordinário com um sistema quântico, e as propriedades do primeiro com os vetores de estado do segundo (como na opção b acima). De acordo com estas hipóteses, a situação descrita por Schrödinger parece paradoxal pela razão seguinte. As propriedades "estar vivo" e "estar morto" são supostas associadas a alguns vetores de estado quânticos. Por outro lado, em contextos experimentais muito particulares, é possível preparar superposições desses 
vetores de estado. Isto parece implicar que deveria existir alguma propriedade do gato que corresponderia a uma sobreposição de vida e morte. E, uma vez que esta propriedade pode ser atribuída ao gato num contexto especifico, é legitimo perguntar-se o que significaria o gato ter esta propriedade em geral. Este exemplo poderia eventualmente ser utilizado para argumentar-se que, se a Mecânica Quântica se estendesse aos objetos macroscópicos e às suas propriedades, isto determinaria um problema de consistência porque não ficaria claro como definir de maneira objetiva os contextos experimentais que, de acordo com a interpretação instrumentalista, permitem atribuir significado ao simbolismo.

A questão aparece muito diferente do ponto de vista instrumentalista. Para este, o que determina o significado tanto da descrição quântica quanto da descrição ordinária, não é o referente putativo delas, mas sim as implicações preditivas que as caracterizam dentro do respectivo domínio de experiência. O problema é então se a rede de fatos e observáveis que constituem a experiência ordinária como um todo pode ser localmente "reduzida" à rede de fatos e operações que constituem a experiência quântica, onde, por "redução", deve-se entender homomorfismo de conteúdos preditivos da primeira com alguma sobestrutura da segunda (se um "fato da experiência ordinária" $F$ implica os fatos da experiência ordinária $F_{1}, F_{2}, \ldots$ com probabilidades $p_{1}, p_{2}, \ldots$, então o "fato da experiência quântica" $F$, que corresponde a $F$, deve implicar os fatos da experiência quântica $F q_{1}, F q_{2}, \ldots$, que correspondem a $F_{1}, F_{2}, \ldots$, com as mesmas probabilidades $p_{1}, p_{2} \ldots$.). Se esta redução é ou não possível é um problema que só pode ser resolvido na prática, ou seja, através do processo construtivo descrito acima (opção $a$ ), para o qual a hipótese reducionista funciona como um princípio regulador. É através deste processo que é possível criar as condições pragmáticas que permitem interpretar determinados conjuntos de operações quânticas e ordinárias como manipulações do mesmo objeto.

\section{A Física Quântica e a experiência ordinária}

A noção de "domínio de experiência", que tenho utilizado para indicar um conjunto estruturado de observáveis operacionalmente definidas, precisaria sem dúvida de uma análise bem mais detalhada, que não pode ser desenvolvida aqui. A ideia geral, todavia, é que os domínios de experiência podem, em primeira aproximação, ser vistos como redes autoconsistentes de fatos e predições. Neste esquema, a objetividade de um fato é assegurada pelas implicações preditivas que o conectam de maneira suficientemente unívoca a um conjunto suficientemente amplo de outros fatos da rede. Assim, por exemplo, um fato da experiência ordinária é que o meu gato estava ontem no sofá, enquanto um fato da física atômica é que o átomo que eu detectei agora estava excitado. A segunda afirmação não 
denota algum fato objetivo dentro da experiência ordinária, pois na experiência ordinária as observáveis que precisariam ser medidas para confirmá-la não estão definidas. De maneira similar, a primeira afirmação não denota, a priori, algum fato objetivo dentro da prática da física atômica.

A ênfase na dimensão construtiva, tanto dos modelos teóricos quanto dos correlativos fatos empíricos, permite entender a existência de domínios de experiência distintos, sem que seja preciso postular alguma descontinuidade espaço-temporal (ligada, por exemplo, ao tamanho dos sistemas considerados, ou à sua evolução). Entretanto, uma vez que a estrutura fenomenal tem sido liberada de todo vinculo ontológico, não fica muito claro porque deveriam existir domínios de experiência distintos. Por exemplo, se a definição das observáveis e dos fatos da Física clássica é o resultado de um processo essencialmente construtivo, como é possível que, ao interior do quadro pragmático-fatual clássico, apareçam uns fenômenos, tais como os fenômenos "atômicos", que não se deixam absorver por ele?

Uma resposta possível é que precisamente o fato de não assumir uma ligação direta entre observáveis, resultados e propriedades "objetivas" elimina toda garantia a priori de que seja possível "salvar" a coerência interna de uma estrutura preditiva de fatos e observáveis, quando esta estrutura for se estendendo a situações cada vez mais complexas. Pois, fora do esquema representacionalista, a coerência da rede preditiva dos resultados não pode mais "se apoiar" na coerência interna do conjunto estruturado das propriedades dos objetos medidos, a qual é por sua vez garantida (independentemente da complexidade e da novidade das situações consideradas) pela própria existência destes objetos (na medida em que a existência implica na possibilidade lógica). A doutrina bohriana da complementaridade pode ser vista como uma maneira de lidar precisamente com esta situação, enfatizando as suas raízes pragmáticas (FRANK, 1946; PETERSEN, 1985).

Por razões similares, a justificação a priori dos programas reducionistas inspirados na visão atomista perde plausibilidade. Nenhuma ordem intrínseca da estrutura ontológica do mundo parece garantir que a experiência ordinária possa ser descrita por meio dos modelos (supostamente mais fundamentais) da física atômica.

$\mathrm{Na}$ perspectiva não representacionalista, então, os programas reducionistas aparecem desvinculados de todo suporte metafísico. Por outro lado, eles estão livres das dificuldades que este suporte comporta quando se lida com fenômenos quânticos. De um ponto de vista pragmático, nada impede de estabelecer uma "hierarquia" entre os diferentes domínios de experiência e de tentar "reduzir" todos eles a um único domínio considerado mais fundamental. A circunstância crucial para tornar praticável esta tentativa é que as estruturas preditivas utilizadas dentro do domínio quântico generalizam os modelos preditivos dados 
pela linguagem ordinária e pela Física clássica (ver, por exemplo, FRAASSEN, 1991; BITBOL, 1996). É pelo fato desta precondição ser satisfeita que o processo construtivo descrito na seção precedente, a respeito do gato de Schrödinger, pode efetivamente ser desenvolvido com sucesso, como mostrado explicitamente pelos programas de estudo experimental da descorência (ver, por exemplo, HAROCHE et al. 1997; HACKERMULLER et al., 2005).

É claro, por outro lado, que, na perspectiva pragmática, o sucesso do programa reducionista não autorizaria de maneira nenhuma a afirmar que o caráter intrinsecamente condicional das afirmações empíricas pode ser eliminado. Qualquer descrição quântica do universo, independentemente da sua capacidade de abranger todo sistema concebível, inclusive os próprios observadores, não deixa de pressupor um referencial pragmático e conceitual, e de incorporar uma referência implícita às operações de medida realizáveis por um observador. Pois a objetividade de uma descrição física depende destes pressupostos e não poderia ser definida fazendo abstração deles.

Estas considerações ajudam a entender a bem conhecida relutância de Bohr em introduzir conceitos novos e, supostamente, mais fundamentais para lidar com o fenômeno atômico (MURDOCH, 1987, p. 100-102; OSNAGHI; FREITAS; FREIRE JR., 2009, p. 116-118). O que esta atitude reflete, eu creio, é a preocupação de que a lição epistemológica da Mecânica Quântica seria obscurecida, ao invés de iluminada, por esta operação (FAYE, 1991; CAMILLERI, 2007). O alegado "conservadorismo" de Bohr a esse respeito não deveria, portanto, ser confundido com uma oposição de princípio aos programas reducionistas. Simplesmente, se adotarmos o ponto de vista dele, o objetivo mais fundamental que estes programas têm perseguido - a saber, substituir a abordagem instrumentalista por uma descrição "autônoma e objetiva" do mundo, na qual as condições pragmáticas que tornam possível o uso dos modelos físicos seriam automaticamente satisfeitas devido a alguma característica "emergente" do universo quântico - parece repousar numa ilusão.

Certamente, dizer isto não implica que as ideias de Bohr e a interpretação particular sobre elas que esbocei neste artigo não necessitam de maior investigação, uma vez que a consistência das mesmas está baseada numa teoria pragmática do significado e do conhecimento que está, obviamente, longe de ser bem estabelecida (BITBOL, 2001). Não levantei estes aspectos aqui. O meu propósito foi salientar que as tentativas de se enquadrar a abordagem de Bohr numa visão representacionalista das teorias, e então buscar uma solução física para os paradoxos que estas tentativas acarretam, não é, provavelmente, a maneira mais apropriada de proceder. A abordagem de Bohr assume, ainda que implicitamente, uma teoria pragmática do significado e do conhecimento. E me parece que todas as questões relacionadas com a sua completeza deveriam ser colocadas neste referencial, 
muito embora, é claro, isto requeira um trabalho filosófico bem maior do que aquele envolvido na construção de uma Teoria Quântica da observação.

\section{Agradecimentos:}

Este trabalho foi apoiado pelo Programa da Templeton Research Fellows "Projeto de Cooperação entre Físicos e Filósofos sobre a Natureza da Realidade Quântica" no Instituto de Informação e Óptica Quântica de Viena da Academia Austríaca de Ciências. Eu sou grato a Anton Zeilinger e seu grupo pelo apoio e pelas discussões estimulantes e proveitosas.

\section{Referências}

BELL, J. S. Speakable and unspeakable in quantum mechanics. Cambridge: Cambridge University, 2004.

BITBOL, M. Mécanique quantique: une introduction philosophique. Paris: Flammarion, 1996.

. Non-representationalist theories of knowledge and quantum mechanics. Nordic Journal of Philosophy, v. 2, p. 37-61, 2001.

BOHM, D. Quantum theory. New York: Prentice-Hall, 1951.

BOHR, N. Causality and complementarity: supplementary papers. In: J. FAYE, J.; FOLSE, H. (Ed.). The philosophical writings of Niels Bohr, Wooldbridge (CT): Ox Bow, 1998. v. 4.

. Can quantum mechanical description of physical reality be considered complete? Physical Review, v. 48, p. 696-702, 1935.

. Essays 1958-1962 on atomic physics and human knowledge. New York: Interscience, 1963.

On the notions of causality and complementarity. Dialectica, v. 2, p.

312-319, 1948. 
BUNGE, M. Philosophy of physics. Dordrecht: Reidel, 1973.

CAMILLERI, K. Constructing the myth of the Copenhagen interpretation. Perspectives on Science, v. 17, p. 26-57, 2009.

. Indeterminacy and the limits of classical concepts: the transformation of Heisenberg's thought. Perspectives on Science, v. 15, p. 178-201, 2007.

CHEVALLEY, C. On objectivity as intersubjective Agreement. In: KRUGER, L.; FALKENBURG, B. (Ed.). Physik, Philosophie und die Einheit der Wissenschaften. Heidelberg: Spektrum Akademischer, 1995. p. 333-346.

EVERETT, H. Objective vs subjective probability. Everett papers, Maryland, USA, Niels Bohr Library, Center for History of Physics, American Institute of Physics, College Park, Box 1, Folder 6, 1955.

. 'Relative State' formulation of quantum mechanics. Review of Modern Physics, v. 29, n. 3, p. 454-462, 1957. Reimpresso em WHEELER, J. A.; ZUREK, W. H. (Ed.). Quantum theory and measurement. Princeton: Princeton University, 1983. p. 315-323.

. The theory of the universal wave function. In: DEWITT, B. S.; GRAHAM, N. (Ed.). The many-worlds interpretation of quantum mechanics. Princeton: Princeton University, 1973. p. 3-140.

FAYE, J. Copenhagen interpretation of quantum mechanics. The Stanford encyclopedia of philosophy, 2008. Edição de E. N. Zalta. Disponível em: $<$ http:// plato.stanford.edu/archives/fall2008/entries/qm-copenhagen/>.

. Niels Bohr, his heritage and legacy: an anti-realist view of quantum mechanics. Dordrecht: Kluwer, 1991.

FRANK, P. Foundations of physics. International Encyclopedia of Unified Sciences, Chicago: University of Chicago,n. 7, v. 1, 1946.

FRAASSEN, B. C. van. A formal approach to the philosophy of science. In: COLODNY, R. (Ed.). Paradigms and paradoxes: the philosophical Challenge of the Quantum Domain. Pittsburgh: University of Pittsburgh, 1972. p. 303-366.

. Quantum Mechanics: an empiricist view. Oxford: Oxford University, 1991. 
. Scientific representation. Oxford: Oxford University, 2008.

HACKERMULLER, L. et al. Coherence and decoherence experiments with fullerenes. In: AKULIN, V. M. et al. (Ed.). Decoherence, entanglement and information protection in complex quantum systems. Dordrecht: Springer, 2005. p. 329-352.

HAROCHE, S.; BRUNE, M.; RAIMOND, J. M. Experiments with single atoms in a cavity: entanglement, Schrödinger's cats and decoherence. Philosophical Transactions of the Royal Society, A355, p. 2367-2380, 1997.

HEISENBERG, W. The development of the interpretation of the quantum theory. In: PAULI, W. (Ed.). Niels Bohr and the development of physics. London: Pergamon, 1955. p. $12-29$

HOWARD, D. Who invented the 'Copenhagen interpretation'? A study in mythology, Philosophy of Science, v. 71, p. 669-682, 2004.

MURDOCH, D. Niels Bohr's Philosophy of Physics. Cambridge: Cambridge University, 1987.

OMNÈS, R. Consistent interpretations of quantum mechanics. Reviews of Modern Physics, v. 64, p. 339-382, 1992.

OSNAGHI, S. The entangled roots of objective knowledge. In: BITBOL, M.; PETITOT, J.; KERSZBERG, P. (Ed.). Constituting objectivity: transcendental approaches of modern physics. Berlin: Springer, 2009. p. 359-374.

. Van Fraassen, Everett and the critique of the Copenhagen view of measurement. Principia, v. 12, n. 2, p. 155-175, 2008.

.; FREITAS, F.; FREIRE JR., O. The origin of the Everettian heresy. Studies in History and Philosophy of Modern Physics, v. 40, p. 97-123, 2009.

PARK, J. L. The self-contradictory foundations of formalistic quantum measurement Theories. International Journal of Theoretical Studies, v. 8, p. 211-218, 1973.

PETERSEN, A. The philosophy of Niels Bohr. In: FRENCH, A. P.; KENNEDY, P. J. (Ed.). Niels Bohr, a centenary volume. Cambridge, MA: Harvard University, 1985. p. 299-310. 
POPPER, K. Quantum mechanics without 'the observer'. In: BUNGE, M. (Ed.). Quantum theory and reality. New York: Springer, 1967. p. 1-12.

ROVELLI, C. Relational quantum mechanics. International Journal of Theoretical Physics, v. 35, p. 1637-1678, 1996.

SCHRÖDINGER, E. Die gegenwärtige Situation in der Quantenmechanik. Die Naturwissenschaften, v. 23, p. 807-812, 823-828, 844-849, 1935.

STAPP, H. P. The Copenhagen interpretation. American Journal of Physics, v. 40, p. 1098-1116, 1972.

TELLER, P. The projection postulate and Bohr's interpretation of quantum mechanics. In: ASQUITH, A. P.; GIERE, R. (Ed.). PSA 1980: proceedings of the 1980 Biennial Meeting of the Philosophy of Science Association. East Lansing: Philosophy of Science Foundation, Michigan State University, 1981. v. 11, p. 201223.

WHEELER, J. A. Assessment of Everett's 'Relative State' formulation of quantum theory. Review of Modern Physics, v. 29, p. 463-465, 1957. Reimpresso em WHEELER, J. A.; ZUREK, W. H. (Ed.). Quantum theory and measurement. Princeton: Princeton University, 1983.

. Geons, black holes and quantum foam. With K. W. Ford. New York: Norton, 2000.

WIGNER, E. P. Remarks on the mind-body question. In: GOOD, I. J (Ed.). The scientist speculates. London: Heinemann, 1961. p. 284-302. Reimpresso em WHEELER, J. A.; ZUREK, W. H. (Ed.). Quantum theory and measurement. Princeton: Princeton University, 1983.

ZUREK, W. H. Decoherence, einselection, and the quantum origins of the classical. Reviews of Modern Physics, v. 75n Physics, 75: 715-775. 



\title{
Algumas singularidades do pensamento de Eugene P. Wigner
}

\author{
Frederik M. dos Santos
}

\section{Introdução}

Já se tornou lugar comum nos estudos históricos dos fundamentos da mecânica quântica $(\mathrm{MQ})$ a afirmação de que as interpretações dadas ao formalismo da Teoria Quântica estão atreladas a certos valores epistêmicos. Porém, um mapeamento dos posicionamentos que influenciaram os personagens centrais neste campo ainda está sendo feito. Entre os anos de 1960 e 1963, o reconhecido físico húngaro-americano Eugene Wigner endossou (ou re-significou) uma estranha interpretação para um problema específico nos fundamentos da mecânica quântica. Uma figura quimérica ${ }^{1}$ é como esta interpretação wigneriana para o problema da medição na Teoria Quântica, pode nos parecer atualmente. Apesar de ela ter estado na ordem do dia dos debates em fundamentos durante a década de 1960, atualmente pode causar algum desconforto a muitos físicos. Longe, porém, de ter sido um delírio criativo de um grande físico do século passado, considerado místico por alguns (BAPTISTA, 2002, p. 63-74 apud FREIRE JR., 2007, nota 1; MARIN, 2009; PATY, 1995, p. 199), tal abordagem partiu de três pontos de fuga filosóficos que, no passado, construíram certo estilo de se fazer epistemologia.

1 Uma estranha figura mítica grega que, apesar de algumas variações, costuma ser apresentada como um ser de cabeça e corpo de leão, além de duas outras cabeças, uma de cobra (na ponta do rabo) e outra de cabra (no seu dorso). 
Wigner foi um físico com uma formação curiosa. Ele fez seu mestrado e doutorado ${ }^{2}$ na área de Química Orgânica na Technische Hochschule, em Berlin, na primeira metade da década de 1920, com o objetivo de ajudar a seu pai na fábrica de curtume em Budapeste, Hungria. Esta era uma escola técnica voltada a formar engenheiros e quase todo seu doutorado foi feito no laboratório. ${ }^{3}$ Porém, curiosamente, Wigner se torna mais conhecido por suas contribuições em Física Teórica, formação que ele buscou de forma autodidata. (MEHRA, 2001) Ele fez parte da segunda geração de físicos que deram grandes contribuições ao desenvolvimento formal e conceitual da Teoria Quântica. Foi um período posterior às discussões filosóficas travadas entre os físicos da primeira geração. Era uma época voltada à aplicação e desdobramento da mecânica quântica que já estava à disposição para ser utilizada. Porém, várias mudanças começam a ocorrer no período pós-guerra; dentre elas, um interesse voltado aos Fundamentos da Mecânica Quântica se reacende aos poucos. Wigner está bem atento a tais mudanças, pois no momento em que este escreve o artigo The problem of measurement, em 1963, ele apresenta, no seu início, uma boa revisão bibliográfica de artigos anteriores ao dele que tratam especificamente do problema da medição na Teoria Quântica. Foi um momento em que alguns físicos e filósofos (tais como, Henry Margenau, Bernard d'Espagnat, Paul Feyerabend e Abner Shimony) se voltaram mais uma vez a questões relacionadas à Filosofia da Física e com Wigner não foi diferente. A seguir, identificaremos alguns dos temas que estiveram no centro dos seus interesses.

Apresentaremos quatro importantes eixos com os quais se pode construir um esquema geral da visão de Wigner sobre os fundamentos da Física. Estes eixos são constituídos por: simetrias e princípios de invariância; um uso conveniente e pragmático dos conceitos físicos; um tipo de idealismo (que ele chamou de "dualista" em Two kinds of reality) derivado da interpretação-padrão da Teoria Quântica levada as suas últimas conseqüências ${ }^{4}$ e o problema da objetividade na MQ. Apesar de o primeiro eixo ser um tópico central no pensamento de Wigner, somente os três últimos eixos estão relacionados ao problema da medição. Nosso

2 Sob a orientação do químico húngaro Michael Polanyi, o mesmo que mais tarde se dedicaria quase que exclusivamente à Filosofia.

3 Esta formação em Engenharia foi crucial para Wigner no momento em que ele trabalhou no projeto do reator nuclear de Hanford, durante a Segunda Guerra Mundial. Devido ao seu trabalho neste projeto, ele foi considerado o primeiro engenheiro nuclear na história. (MEHRA, 2001)

4 Faz-se necessário atentar para aquilo que Wigner chama de visão-padrão da Teoria Quântica: "Eu acredito que o primeiro a analisar plenamente as implicações de longo alcance, das idéias de Heisenberg, foi von Neumann, mas muitos outros chegaram a conclusões similares às dele. Há um livro muito interessante, escrito por London e Bauer, que sumariza completamente aquilo que eu chamarei de visão ortodoxa". (WIGNER, 1995g, p.154, tradução livre do autor) 
trabalho não passará de sugestões sobre a maneira como ocorreram estas relações, pois nosso foco central não está em apresentar como Wigner lidou com os problemas ligados à Teoria da Medição na MQ. De fato, nosso objetivo central é a busca de uma maior compreensão das ideias wignerianas centrais sobre epistemologia, que têm recebido pouca atenção na corrente literatura filosófica.

\section{O papel heurístico dos princípios de invariância ou a lei empírica da epistemologia}

Olhando para o histórico dos seus textos filosóficos e de divulgação científica, podemos concluir que este seria um dos seus temas mais discutidos. Afinal, parte de sua fama na Física foi devido aos seus trabalhos que colocaram as leis de invariância ainda em maior evidencia. ${ }^{5}$

Dois marcos históricos da Física são recorrentes em diversos textos de Wigner. São relatados momentos em que as investigações físicas seguiram uma abordagem inspirada num determinado princípio de invariância. Estes marcos são o surgimento da Cinemática galileana e o da Teoria da Relatividade Restrita de Einstein. E, de acordo com o que se encontra no artigo The unreasonable effectiveness of mathematics in the natural science (1960), podemos extrair da história da Física diversos exemplos que

[...] deverão ilustrar a conveniência e precisão da formulação matemática das leis em termos de conceitos escolhidos para sua manipulação, as "leis da natureza" são de precisão quase fantástica, mas de alcance bem limitado. Partindo desta observação, pretendo me remeter a estes exemplos como ilustrativos de uma lei empírica da epistemologia. Junto com as leis de invariância das teorias físicas, este é um fundamento indispensável destas teorias. Sem as leis de invariância não se poderia dar fundamento de fato às teorias físicas; se a lei empírica da epistemologia não estivesse correta, nós não teríamos o encorajamento e a segurança que são emocionalmente necessários, sem os quais as "leis da natureza" não poderiam ser exploradas com sucesso. (WIGNER, 1995m, p. 233, grifo nosso)

5 As origens históricas deste interesse de Wigner ainda não estão claras. Em nenhum dos seus textos históricos, filosóficos ou autobiográficos Wigner faz menção a qualquer influência provinda dos trabalhos da matemática Emmy Noether, por exemplo. A menção a Einstein é bem mais comum. 
Estas ideias são uma tentativa de ampliar ainda mais o significado de uma declaração feita por Einstein e citada por Wigner (1995m p. 230), onde aquele teria dito que os conceitos da Matemática - que são o resultado de muita perspicácia - possuem grande beleza.

Além dessa apropriação utilitarista dos conceitos da Matemática nas teorias físicas, Wigner passa a tomar o princípio de invariância como uma linha de prumo para as leis físicas. Este princípio está no topo da hierarquização formal das teorias físicas:

[...] a progressão de eventos para leis naturais, e de leis naturais para simetrias ou princípios de invariância, é o que, para mim, significa a hierarquia do nosso conhecimento do mundo que nos rodeia. (WIGNER, 1995l, p. 313)

Então, Wigner extrai de exemplos históricos a ideia de que tal princípio foi usado em alguns momentos tacitamente e em outros, conscientemente, como uma das formas de se testar a consistência de uma determinada lei física. ${ }^{6} \mathrm{E}$ é dentro desta perspectiva e destes pressupostos que Wigner olhará para as teorias Físicas de sua época, tanto à Teoria Quântica quanto à Cosmologia - mas principalmente a primeira.

\section{O papel dos princípios de invariância na construção da "nossa ciência"}

Wigner recorre a uma metáfora ao querer definir aquilo que ele entende por Ciência7: "[...] é nosso estoque de conhecimento dos fenômenos naturais". (WIGNER, 1995d, p. 213) Porém, estoque não é visto aqui como o simples acúmulo de conhecimento ou uma mera série de livros e artigos empilhados com informações e teorias sobre o mundo natural. Ciência é como um edifício que está em constante construção e reforma. E para chamá-la de "nossa ciência" nós devemos ter pessoas capazes de aprender a se tornarem especialistas e a construírem cada parte deste edifício, utilizando sua respectiva área de conhecimento, acreditando que seu projeto não está em contradição com os outros de outras áreas, isto é, seguros de que todos esses projetos fazem uso de um todo coerente.

6 É implícita, a alguns textos filosóficos de Wigner, sua busca em justificar certos elementos do conhecimento tácito utilizado na práxis de pesquisa do físico.

7 O conceito de Ciência em seus textos vai além das ciências ditas naturais e inclui também a psicologia. Em nenhum momento Wigner mostrou qualquer interesse com o problema da demarcação entre as disciplinas científicas e não-científicas. 
Esta confiança se faz necessária porque ninguém é capaz de conhecer completamente os projetos de todos os setores. Incoerências podem aparecer, mas o fato é que "[a] seção de elasticidade deve usar a mesma imagem da estrutura de aço sobre o qual a seção sobre magnetismo está baseada." Esta estrutura é composta pelas partes do mundo vivo e inanimado (a matéria e suas interações) estudados pela Química, pela Física moderna, pela Biologia, pela Psicologia, entre outras. Apesar disso, podemos esperar certa coerência dentro de cada projeto disciplinar (uma teoria formada por um conjunto de leis físicas) e, na exigência desta coerência interna para o caso das teorias que têm a matemática como linguagem, é que Wigner utilizará o princípio da simetria ou algum princípio de invariância como parâmetro principal. Tais conceitos são utilizados da seguinte forma: "Ser a pedra de toque para as leis da natureza é provavelmente a função mais importante dos princípios de invariância." (WIGNER, 1995a, p. 330). Em outro artigo posterior ele afirma que:

Digo mais uma vez, se alguém vier com outra lei da natureza e disser, "Sua lei natural está errada", talvez eu poderia, com maior propriedade, contradizê-lo ao lembrar-lhe, "Bem, sua lei natural não obedece um reconhecido princípio de simetria." (WIGNER, 1995j, p. 384)

Quando Wigner propõe tal abordagem de ataque às leis naturais, não está apoiado somente em sua própria experiência, mas utiliza um caso crucial na história da Ciência, anterior ao seu próprio: o sucesso que Einstein teve ao criticar as leis do eletromagnetismo de Maxwell por uma quebra de simetria espacial, uma análise crítica que desembocou em um dos seus famosos artigos (Sobre a eletrodinâmica dos corpos em movimento) de 1905, que estabelece a Teoria da Relatividade Restrita. Nesta citação, Wigner não somente dá o devido crédito a Einstein como também expõe sua visão empirista de tais conceitos:

O trabalho de Einstein estabeleceu os primeiros princípios de invariância de forma tão bem fundamentada que nós precisamos constantemente ser lembrados que eles são baseados somente na experiência. Parece-nos natural tentar derivar as leis da natureza e testar sua validade através das leis de invariância, ao invés de derivar as leis de invariância daquilo que nós acreditamos ser as leis naturais. (WIGNER, 1995 b, 1995, p. 285, grifo nosso)

Na citação a seguir, Wigner é ainda mais claro e explícito: "Nossa ciência é, antes de qualquer coisa, uma exploração das regularidades que se obtêm através dos fenômenos, e uma incorporação destas regularidades - as leis da natureza - em princípios cada vez mais gerais (as teorias da física)" (WIGNER, 1995f, p. 122, grifo nosso). Ele nos leva a crer que dentro de seu quadro geral sobre a Física 
(ou as ciências formais) suas teorias ou princípios gerais se resumiriam às leis de invariância (manifestas na forma de leis de conservação). Assim, temos um movimento ascendente que parte, primeiramente, dos fenômenos e dos dados da experiência, de onde extraímos certas regularidades que nos levam para princípios mais gerais, ou seja, as teorias da Física.

A seguir, apresentaremos o fraco idealismo ${ }^{8}$ trazido pela interpretação ortodoxa da Teoria Quântica, segundo Wigner, e a necessidade de se usar pragmaticamente os conceitos físicos levando-os à "situações-limite".

\section{Tipos de realidade e os conceitos da Física}

No verão de 1961, Wigner apresenta uma conferência na Universidade de Marquette que seria a primeira apresentação em inglês de suas ideias mais fundamentais sobre percepção e realismo na Física. Two kinds of reality foi escrito pouco antes do início de seu conturbado debate com diversos físicos proeminentes sobre o problema da medição na Teoria Quântica. Seu artigo posterior, Remarks on the mind-body question, aponta para a mesma postura pragmática e idealista presente na conferência de Marquette. Wigner diz que esta visão idealista sobre a realidade física é uma consequência direta da interpretação ortodoxa da MQ:

[...] a presente discussão emerge do desejo de explicar para uma audiência de não-físicos a epistemologia na qual alguém é forçado a chegar, caso leve a teoria quântica da observação até as suas últimas conseqüências. (WIGNER, 19951, p.185)

Ele evoca alguns autores que, segundo ele, darão suporte para discorrer sobre este tema. Alguns deles são von Neumann (1955) e F. London e L. Bauer (1939) - o fim da objetividade no processo de medição na mecânica quântica -; W. Heisenberg - e sua forma de idealismo - e Henry Margenau (1950), - principalmente a ideia de construto.

Não apenas neste texto, mas aparentemente até o fim de sua vida ${ }^{9}$, Wigner se referia às entidades reais ou existentes da Física como construtos. Porém, curiosamente, ele não usa o sentido comum dos termos real e existente. Estes construtos

8 Uso este termo para contrastar com uma forma de idealismo que Wigner chama de 'absoluto', na página 192 do artigo de 1964a, onde ele diz que “[...] não há uma mundo material independente da mente, onde só existe aquilo que é percebido ou concebido por uma mente". (PESSOA JR, 2009, p. 57) - isto seria inconsistente com suas ideias.

9 Wigner discute e defende sua postura com Shimony continuamente, através de cartas, até o início da década de 80 . 
seriam entidades teóricas (cada um com seu diferente grau de abstração), historicamente datadas, que se originaram de conceitos mais próximos dos dados imediatos da percepção e que exercem uma função necessária e vital a uma determinada teoria ou mesmo para a sobrevivência do próprio ser humano. Eles são elaborações abstratas e coletivas de nossa mente dentro de um contexto histórico e utilitarista. Assim, tais construtos não são criados do nada e ao acaso; eles estão lá para servirem utilitariamente às nossas reflexões e interações com o mundo natural, assim como, à nossa comunicação intersubjetiva. Alguns exemplos destes construtos seriam os planetas, as placas tectônicas, o campo elétrico e magnético, átomos, quarks, quasares, consciência etc. Com efeito, podemos graduar o nível de abstração destes construtos que partem daqueles que são construídos através de elaborações mais próximas dos dados de minhas sensações diretas, até aqueles que são mediados por diversos aparatos teórico-matemáticos e de medição. Wigner expõe sua filiação com Margenau em relação a estas ideias:

O que estou dizendo é que, com exceção de sensações imediatas e, em geral, o conteúdo da minha consciência, tudo é um construto, no sentido em que, por exemplo, Margenau ${ }^{10}$ usa este termo, mas alguns construtos estão um pouco mais próximos das sensações diretas. (WIGNER, 1995l, p.189)

Assim como Margenau, Wigner acredita que se pode conferir exterioridade aos dados de sensações/observações diretas. Devemos, no entanto, destacar a complexidade de nossas percepções, de modo que, quando entram nos processos cognitivos superiores da nossa consciência, elas já foram sofisticadamente traduzidas de nossas sensações primárias. O status de realidade que ele confere a estes construtos é o seguinte:

A realidade do campo magnético no vácuo consiste na utilidade do conceito de campo magnético em toda parte, a realidadeé, neste caso, sinônimo da utilidade do conceito, tanto para o nosso próprio pensamento, quanto para nossa comunicação com outras pessoas (neste momento ele faz referência à BRIDGMAN, 1960). (WIGNER, 195l, p.188)

Em outro artigo, Wigner expõe sua forma de interpretar a realidade física quando se refere à natureza destes conceitos. Em suas palavras:

A afirmação que isto "existe" significa somente que: (a) isto pode ser medido, por isso pode ser univocamente definido, e (b) que seu conhecimento é útil para o entendimento de fenômenos passados e nos ajuda a prever eventos futuros. Isto pode ser colocado como constituinte de uma Weltbild. (WIGNER, 1995h, p. 173)

10 Neste momento, Wigner insere uma nota referindo-se aos capítulos 4 e 5 do livro de Margenau de 1950. 


\section{O mito da objetividade e a Mecânica Quântica}

No livro de 1932, Von Neumann e Wigner ${ }^{11}$ fazem uma breve discussão sobre a construção da objetividade, no processo de medição. Esta discussão ganha mais sentido quando refletimos dentro de sua visão idealista da realidade, que se dá de acordo com a descrição a seguir: “[...] deve ser possível, então, descrever os processos extra-físicos da percepção subjetiva como se estes estivessem, na realidade, no mundo físico". (NEUMANN, 1955, p. 419, cap. 6, grifo nosso) Os autores nos fornecem um exemplo ao falar deste processo que, em verdade, trata de uma simples medição da temperatura. Muitas vezes se diz que "a temperatura é medida pelo termômetro". Em realidade, o processo de medição se inicia na interação do termômetro com o sistema que se quer medir, porém em que momento nós podemos considerar este processo completo? Podemos falar de todo o processo termodinâmico e estatístico que leva o mercúrio a se expandir dentro do termômetro, devido à absorção de calor, provocando assim a obtenção de determinado valor dentro de um sistema de unidade térmica. Também podemos ainda descrever o caminho que os quanta de luz tomam ao se refletir no mercúrio e se dirigirem à retina do observador, momento em que a luz interage com as células nervosas que ativam circuitos cerebrais. Indo além nesta descrição, podemos tratar das reações químicas nas células nervosas no momento da apreensão desta informação. Finalmente, sempre é possível alguém afirmar que a medição só se deu realmente quando tomamos consciência da informação transmitida pela luz ao nosso sistema nervoso. Tudo isso foi evocado, entretanto, apenas no intuito de exemplificar como podemos traçar a fronteira entre o observador e o sistema a ser medido de forma arbitrária. Em dado momento de nossa descrição, tomamos a medição completada pelo termômetro. No entanto, o peso desta arbitrariedade pode ser minimizado pelo fato de que o observador não tem qualquer interferência no fenômeno medido, portanto, não é tão relevante saber em que ponto esta fronteira entre o observador e o objeto deve ser colocada, o fato é que a objetividade deste processo sempre poderá ser mantida. No caso da mecânica quântica, von Neumann e Wigner veem problemas no processo de construção desta objetividade, pois não há como separarmos o ponto de vista do observador do fenômeno observado e isto se dá porque sempre haverá a interferência deste no

11 Hoje sabemos através de Abner Shimony (1997) que Wigner trouxe grandes contribuições ao livro de von Neumann: "As primeiras contribuições importantes, de Wigner, para a teoria da medição na Mecânica Quântica ocorre em um trabalho que não levou o seu nome, o 'Mathematische Grundlagen der Quantenmechanik' de von Neumann. Wigner comentou certa vez, privadamente, comigo que tinha aprendido muito mais de von Neumann do que este último havia aprendido com ele, mas que a análise de von Neumann, do processo de medição, nos dois últimos capítulos de seu livro, deveu muito às sugestões de Wigner. Um reconhecimento específico é dado na nota 203, cap. 5, que se refere à observação macroscópica." (SHIMONY, 1997, p. 401) 
fenômeno observado. Por isso, mais tarde, Wigner se mostrou consciente do ônus implícito quando se estabelece o ato de observação como um conceito primitivo da Física:

[...] parece perigoso considerarmos o ato de observação como um ato humano, básico para a teoria dos objetos inanimados. É, no entanto, em minha opinião, uma conclusão inevitável. Se isto for aceito, temos que considerar o ato de observação como um ato mental, um conceito primitivo da física, nos termos do qual as regularidades e as correlações da Mecânica Quântica são formuladas. (WIGNER, 1995i, p. 4)

Desde o no início da década de 1960, provavelmente reanimado pelas leituras do texto de London e Bauer de 1939, Wigner retoma estas questões e passa a questionar ainda mais fortemente a objetividade no processo de medição na Teoria Quântica. Para ele, sua proposta interpretativa do formalismo desta Teoria nos ajudaria a entender melhor o porquê de não observarmos a ocorrência de sistemas mistos acoplados ad infinitum, todos sobrepostos, além de afastar resultados bizarros tirados do "paradoxo do amigo de Wigner". ${ }^{2}$ O colapso das famílias (ou pacotes) de funções de onda e o afastamento da possibilidade de qualquer cadeia ad infinitum no processo de medição ocorreriam no momento em que o observador tomasse consciência dos resultados da medição. Assim, uma reflexão sobre as limitações da Teoria Quântica da medição nos levaria a crer que a não observação de estados sobrepostos ao nosso redor se explicaria pela destruição destas superposições ao interagirem com a mente do observador. O processo natural que leva a tal destruição deveria ser explicado pelo maior desenvolvimento do estudo da cognição e da consciência; e o incentivo a tais estudos e pesquisas seria uma obsessão que faria parte dos escritos e preocupações de Wigner por toda a vida ${ }^{13}$.

12 Wigner elaborou um experimento de pensamento para destacar como ele acreditava que a interferência da consciência era necessária para explicar o processo de medida na mecânica quântica. Tal experimento parte da possibilidade, apresentada no livro de von Neumann, de um experimentalista poder preparar um estado misto com um sistema acoplado com outro experimentalista, podendo ser o sistema+aparelho+experimentalista. Se em tal situação perguntarmos ao experimentalista (amigo de Wigner) o resultado da medição, ele nos dará uma resposta que ao tomarmos consciência dela esta desconstruirá o estado misto e reduzirá a superposição. Mas note que o outro experimentalista já havia feito a medição antes do momento em que fizemos a pergunta. Então, fica a questão, em que momento se deu a redução da superposição?

13 Ao tratar da interpretação e epistemologia da mecânica quântica de Wigner, Mehra (2001, p. 940) destaca algo muito presente na argumentação deste: "É surpreendente quão nitidamente Wigner objetou a epistemologia do materialismo ao concluir que o principal argumento contra o materialismo 'é que o processo de pensamento e consciência são conceitos primários, que nosso conhecimento do mundo externo é o conteúdo de nossa consciência e que esta não pode ser negada."” 
O fato de a Teoria Quântica não abarcar o papel da mente no processo da medição leva-o a concluir que, para que a interpretação ortodoxa da Teoria Quântica seja considerada completa, é necessário trazer à tona uma importante abordagem interpretativa ao processo da medição, ou seja, a participação da consciência. Tal perspectiva permitiu à Física a possibilidade de trazer para seu interior um forte teor subjetivo.

Provavelmente o leitor já deve ter se questionado como um físico que tinha uma visão pragmática e idealista da descrição da realidade física poderia se preocupar com o problema da medição. Uma primeira resposta seria: porque o formalismo utilizado para o processo da medição tem nos levado a isso. A entrada da consciência neste processo tem sido uma exigência necessária e natural que garantiria maior coerência interna dentro do corpus teórico da mecânica quântica. O que se exemplifica pela seguinte citação:

Dar a razão para o crescente interesse dos físicos contemporâneos em problemas de epistemologia e ontologia poderia ser útil, apesar de não ser algo estritamente relevante. A razão é, em poucas palavras, que os físicos têm achado impossível dar uma satisfatória descrição dos fenômenos atômicos sem referência à consciência. Pouco pode ser feito com o freqüentemente requentado problema da dualidade onda e partícula e aludir, certamente, ao processo chamado 'redução do pacote de onda'. Este ocorre sempre que o resultado de uma observação entra na consciência do observador - ou, para ser ainda mais exageradamente preciso, minha própria consciência, desde que seja eu o único observador, todas as outras pessoas são somente objetos das minhas observações. Alternativamente, alguém poderia dizer que a Mecânica Quântica provê somente conexões de probabilidade entre o resultado de minhas observações como eu as percebo. ${ }^{14}$ Seja qual for a formulação que alguém adote, a consciência tem evidentemente um papel indispensável. (WIGNER, 1995a, p. 186)

Esta citação foi extraída da introdução do artigo Two kinds of reality, o mesmo onde Wigner apresenta suas ideias sobre os construtos físicos, realidade e idealismo. Portanto, para ele, mais importante que nos preocuparmos com uma representação realista (no sentido comumente usado na epistemologia) das teorias físicas, seria nos preocuparmos em assumir a utilização da teoria-padrão, que tem funcionado dentro de certo domínio com sucesso e, em seguida, levá-la às situações-limite, ou seja, desdobrá-la até as suas últimas consequências, tal como foi feito por ele através do paradoxo que levou o seu nome.

14 Aqui Wigner em uma nota de rodapé faz alusão a von Neumann (1955) e a Heisenberg [Daedalus, 87, 99 (1958)]. 


\section{Conclusão}

Podemos perceber através deste texto que uma avaliação mais refinada da visão epistêmica de Wigner é possível. Este nos sugere uma imagem bem menos bizarra do que parece. A imagem incoerente de uma quimera se dispersa no ar. Sua proposta no início dos anos de 1960 para o problema da medição na mecânica quântica traz todos os seus pressupostos e exigências de coerência às teorias físicas. Ele não as aplicou somente à Teoria Quântica e mesmo sua proposta para a solução do problema da medição foi temporária. Suas argumentações filosóficas alimentavam suas críticas ao materialismo ${ }^{15}$ (que para ele era indissociável do determinismo laplaciano) e sua propaganda para o investimento intelectual em pesquisas voltadas ao estudo da mente e da consciência. Finalmente, os quatro eixos destacados aqui e que foram evocados por Wigner na construção de sua filosofia da Física podem parecer incomuns para alguns físicos.

Por fim, em momento algum Wigner demonstrou ter abandonado seu interesse por temas epistemológicos, mesmo quando se distanciou de sua interpretação mentalista para o problema da medição no início da década de 1980. (cf. WIGNER, 1995c, p. 136) ${ }^{16}$ Tal afirmação está em acordo com um comentário feito por Jagdish Mehra em seu livro The golden age of theoretical physics:

A preocupação de Wigner com questões de interpretação, epistemologia e filosofia da teoria física permaneceu contínua e profunda, e uma prova clara de que sua preocupação sobre estas questões esteve significativamente presente em seu pensamento é que elas ocuparam toda a sua obra. (MEHRA, 2001, p. 940)

15 As razões que levaram Wigner a ter aversão ao materialismo dialético são discutidas no texto produzido pelo autor para os anais do $11^{\circ}$ Seminário Nacional de História da Ciência e da Tecnologia (out/2008). Uma destas razões encontra-se na longa experiência que a Hungria passou a ter com governos totalitários, começando com a ditadura do proletariado aliada à U.R.S.S., em 1919.

16 Wigner ajudou a propagar, também, várias interpretações diferentes para o problema da medição na MQ, apesar de algumas terem chamado mais a sua atenção do que outras. Esta foi uma das grandes contribuições, dadas por ele, para o amadurecimento do campo de Fundamentos da Física como disciplina nas décadas de 1960 e 1970. (FREIRE JR., 2007) (Todos os artigos em que ele apresenta estas interpretações alternativas podem ser encontrados na parte I e II do livro Philosophical reflections and syntheses.) 


\section{Referências}

BRIDGMAN, P. W. (1936). The nature of physical "knowledge". In:

FRIEDRICH, L. W. The nature of physical knowledge. Bloomington: Indiana University, 1960. Original de 1936.

FREIRE JR., Olival. Orthodoxy and heterodoxy in the research on the foundations of quantum physics: E.P. Wigner's case. In: SANTOS, Boaventura de Sousa (Org.). Cognitive justice in a global world: prudent knowledges for a decent life. Lanham, MD: Lexington Books, 2007. p. 203-224.

LONDON, F.; BAUER, E. La théorie de l'observation en mécanique quantique. Paris : Hermann et Cie, 1939.

MARGENAU, Henry. The nature of physical reality. New York: McGraw-Hill Book Co., 1950.

MARIN, J. Miguel. 'Mysticism' in quantum mechanics: the forgotten controversy. Eur. J. Phys., v. 30, p. 807-822, 2009.

MEHRA, J. Eugene Paul Wigner: Aspects of his life, work, and personality. In: . The golden age of theoretical physics. Singapore: World Scientific, 2001.

v. 2.

NEUMANN, J. von. Formulation of the Problem. cap. VI: the measuring process. In: . Mathematical Foundations of Quantum Mechanics. Princeton, NJ: Princeton University, 1955. Primeiramente publicado em alemão no ano de 1932: Mathematische Grundlagen der Quantenmechank, Berlin: Springer.

PATY, Michel. A matéria roubada. São Paulo: Edusp, 1995.

PESSOA Jr., O. A Classificação das Diferentes Posições em Filosofia da Ciência. Cognitio-Estudos, São Paulo, vol. 6, nº 1, jan. - jun., 2009, p.54-60.

SHIMONY, Abner. Wigner on foundations of quantum mechanics. In: FOUNDATIONS OF QUANTUM MECHANICS. The collected Works of Eugene Paul Wigner, part A - Vol. III: particles and fields;. Berlin: Springer, 1997. p. 401-414.

SZANTON, A; WIGNER, E. P. The recollections of Eugene P. Wigner as told to Andrew Szanton. New York: Plenum, 1992. 
WIGNER, E. P. Events, laws of nature, and invariance principles. In:

Philosophical reflections and syntheses. New York: Springer, 1995a. p. 321-333.

Original de 1964a.

. Invariance in physics theory. In: . Philosophical reflections and syntheses. New York: Springer, 1995b. p. 283-293. Original de 1949.

. The limits of determinism. In: Philosophical reflections and syntheses. New York: Springer, 1995c. p. 133-138. Original de 1983.

The limits of science. In: Philosophical reflections and syntheses. New York: Springer, 1995d. p. 523-533. Original 1950.

. On some of physics' problems. In: . Philosophical reflections and syntheses. New York: Springer, 1995e. p. 578-583. Original de 1972a.

. Physics and the explanation of life. In: . Philosophical reflections and syntheses. New York: Springer, 1995f. p. 33-47. Original de 1970.

. The problem of measurement. In: . Philosophical reflections and syntheses. New York: Springer, 1995g. p. 163-180. Original de 1963.

. Remarks on the Mind-Body question. In: Philosophical reflections and syntheses. New York: Springer, 1995h. p. 171-184. Original de 1961.

. The subject of our discussions. In: . Philosophical reflections and syntheses. New York: Springer, 1995i. p. 199-217. Original de 1971.

. Symmetry in nature. In: . Philosophical reflections and syntheses. New York: Springer, 1995j. p. 382-411. Original de 1972b.

. Two kinds of reality. In: . Philosophical reflections and syntheses. New York: Springer, 1995l. p. 33-47. Original de 1964b.

. The unreasonable effectiveness of mathematics in the natural sciences. In: WIGNER, E. P. Philosophical reflections and syntheses. New York: Springer, 1995m. p. 534-549. Original de 1960. 



\title{
Fundamentações e perspectivas para a Teoria Quântica ${ }^{1}$
}

\author{
Jhonny Alexander Castrillón Pérez
}

\section{Introdução}

Este trabalho é uma proposta epistemológica para a Física Quântica. Seu objetivo é o de construir uma definição do estado quântico, usando a ideia de perspectiva teórica, elaborada por nós e aplicada às ideias de três autores dedicados à interpretação da Teoria Quântica, Asher Peres, Leslie Ballentine e Michel Paty. Faz-se necessário introduzir a ideia de perspectiva do estado para destacar a presença de estudos históricos e críticas epistemológicas em sua enunciação e a maneira como essas práticas são essenciais na formulação ou apresentação da física quântica contemporânea. Os autores são casos particulares, mas a ideia de perspectiva é geral, generalidade que vem do formalismo físico quântico e suas predições, no sentido de que tal ideia leva em conta três problemas comuns no momento de definir a noção de estado, ou seja, o significado e sentido das observações experimentais, as leis físico-matemáticas e seus conceitos e relações. Como resultado, confirma-se que três autores contemporâneos se valem de uma perspectiva para definir o estado quântico, dando respostas a estes três problemas. Consideramos, finalmente, como a perspectiva implica no estatuto da "realidade física", que pode ser atribuído, pelo menos de direito, à noção de estado quântico.

Este trabalho é uma leitura relacional dos problemas fundamentais da Teoria Quântica. Sua ênfase é epistemológica porque pergunta pelo sentido e significado do conceito físico-matemático de vetor de estado. Esse trabalho poderia chamar-se Epistemologia das fundamentações e seu objetivo é mostrar como certos físicos quânticos encontram um significado e um alcance para a teoria.

1 Tradução de Frederik Santos, revisão de Olival Freire e Daniela dos Santos Silva. 
Escolhemos três físicos (um deles, além disso, é filósofo da ciência) que ao mesmo tempo levantavam (1) o problema da medição quântica sobre a relação ou interação entre o "sistema" mensurável e o "aparato" de medição; (2) o problema matemático que estabelece as relações entre vetores de um espaço vetorial complexo e operadores lineares autoadjuntos; e (3) o da interpretação da teoria, onde se questiona o sentido e significado físico dos conceitos envolvidos nos primeiros problemas. Nesse ponto de vista, a interpretação se refere à síntese conceitual entre observações experimentais e formulações matemáticas. Esses três físicos são Asher Peres, Leslie Ballentine e Michel Paty.

A noção de estado quântico, por exemplo, é um aspecto que aparece em um laboratório: tanto o sistema como o aparato são preparados; é um processo tecnicamente denominado de preparação de estados. Por sua vez, o estado é traduzido para o formalismo matemático, como vetor ou função de estado, em um espaço de Hilbert. Em ambos os casos, os estados evoluem e, ao final dessas evoluções, se tem novamente um estado observado na medição e um estado lido na linguagem matemática. Além disso, o estado é compreendido em uma certa interpretação e esta se refere aos fenômenos factuais e aos seguros enunciados matemáticos, à maneira que se legitimam ou se relacionam para legitimar o significado físico do estado observado e o sentido físico daquilo que pode ser lido, quer dizer, para compreender um conceito de estado quântico.

O conceito de estado quântico é essencial na teoria e, mais adiante, as referências ao significado e alcance que ela tem serão nele exemplificados. Mas os três problemas quânticos mencionados, observação, formalização e compreensão, tratam de outros aspectos quânticos, como função da probabilidade, separabilidade não-local ou emaranhamento, indistinguibilidade dos idênticos etc, bem como das relações entre eles. Na Física clássica, o estado de um sistema é o conjunto de quantidades físicas, cuja evolução é mapeada em uma função numérica. Uma lei ou princípio físico normalmente se enuncia para determinar esta função de estado. E por meio de um experimento e sua subsequente observação é possível medir o valor numérico das quantidades, precisamente os que eram preditos pela função do estado. Em física quântica, o estado também se remete ao formalismo matemático (o vetor de estado) e ao experimental (o estado de preparação), mas a correspondência entre eles já não é de um a um como no caso clássico. Além disso, o que de algum modo fez com que se formulasse uma teoria quântica foi que algumas correlações clássicas não relatavam o que ocorria na realidade, como a catástrofe ultravioleta. Quando Planck fez seu experimento, teve que modificar a maneira usual de se fazer os cálculos na física estatística, porque os fatos - e não a lei da física - exigiam. A noção de estado quântico também aparecerá em uma correspondência, mas como veremos, modificar-se-á segundo o ponto de vista de cada autor. 
Mas qual o procedimento comum para a determinação do sentido e significado do estado quântico? Quer dizer, como é que cada autor representa o que há de observável, legível e compreensível nos fenômenos quânticos?

Temos denominado como fundamentação teórica o procedimento comum a esses autores para a definição do estado quântico. Por meio de um fundamento é que os autores determinam os três níveis de estado quântico: visível, legível e conceitual. No entanto, o resultado da fundamentação é uma perspectiva. Uma perspectiva define o nível representativo dos conceitos: o estado quântico de Asher Peres remete ao laboratório, ao nível experimental. Aí é onde se encontra sua realidade objetiva. Por outro lado, o estado quântico de Ballentine aparece primeiro como uma construção matemática, com a qual é possível ler as propriedades do sistema, no estado estudado. Enquanto Paty se refere ao estado quântico como quantidade física e as relações que esta quantidade tem com suas propriedades físicas, como função de probabilidade ou indistinguibilidade. Isto é, para Paty, o estado quântico é primeiro um conceito relacional.

\section{0 método da fundamentação teórica}

O termo fundamentação está inspirado na expressão em inglês foundations of quantum physics, no qual se inserem os textos comentados. Estes são antes de tudo textos de mecânica quântica, mas esta é uma denominação muito geral. Em particular, o campo de estudos Fundamentos da Física Quântica se dedica aos problemas de interpretação dos fundamentos da teoria. Dizer que os autores trabalham em fundamentos teóricos ou em fundamentações teóricas é dizer que se dedicam a buscar os conceitos fundamentais da teoria.

Bem, o primeiro gesto fundador dos autores é um estudo histórico. Na história da teoria se encontram as razões que permitem fazer uma nova fundamentação. Esta história é diferente segundo cada autor, mas os três se fazem essa pergunta: por que na teoria do passado não existe clareza em relação à noção de estado quântico? Então, comentam os textos-chave da história da teoria e identificam neles uma possível resposta.

Para Peres, experimentos como o do corpo negro, para o qual a análise de Planck de 1900 deu solução ao problema da catástrofe ultravioleta, e para os quais a física clássica não é capaz de dar uma explicação, são evidências de que a ideia de quantidade física, como são as variáveis canônicas clássicas $\mathbf{p}$ e q, dotadas de valores numéricos precisos, não tem sentido no mundo quântico. Ele mostrará que tentativas de definir uma quantidade quântica, para remediar a perda de objetividade sofrida por $\mathbf{p}$ e $\mathbf{q}$, tal como a função de onda que sai da equação de 
Schrödinger, estão condenadas ao fracasso, já que não há evidência experimental para determinar um valor preciso da função de onda de um sistema quântico. A aleatoriedade essencial dos fenômenos, "mostrada" por Peres, permite somente falar de probabilidade nas medições quânticas, não de quantidade de valores precisos. E não tanto pela incerteza das medições, senão que é a própria ideia de quantidade física que é enganosa para o domínio quântico.

A história de Ballentine é a da evolução do formalismo matemático quântico e de como esta evolução permite falar "de maneira mais natural da teoria". Na história da Matemática de Ballentine, para se alcançar o progresso deve-se filtrar. Quer dizer, os enunciados matemáticos, quando mudam, passam a um estado de maior abstração, são cada vez mais matemáticos. Desse modo é como Ballentine se autoriza para propor um novo espaço de Hilbert, em inglês, the rigged Hilbert space, como o representante mais geral do espaço matemático dos estados quânticos e, portanto, o melhor.

Por sua vez, Paty interrogará as teorias clássicas, pela maneira como elas têm compreendido suas quantidades físicas. Em particular, pela maneira que legitimam o uso de quantidades matemáticas para descrever fenômenos físicos. É, portanto, uma história epistemológica, que busca a maneira em que o sentido e o significado do conceito de quantidade física evoluem nas teorias clássicas. Bem, Paty encontra que as quantidades matemáticas na descrição de um fenômeno correspondem um a um com as observações experimentais relacionadas com o fenômeno; mas que fazem algo mais: as quantidades também se relacionam com suas propriedades e dessas relações é possível fazer uma síntese conceitual, com a qual se compreende ou se entende o fenômeno. Apoiado nessas considerações sobre as quantidades clássicas, ele propõe o estado quântico como representante conceitual do domínio quântico, ou seja, as relações que estabelece com suas propriedades físicas, as quais são uma representação da realidade do fenômeno.

Estas são mais ou menos as linhas gerais dos estudos históricos dos autores. Notem que, já através delas, se sugerem perspectivas como a observação experimental de Peres, o formalismo axiomático de Ballentine e o realismo conceitual ou crítico de Paty.

Pois bem, de considerações históricas segue uma crítica epistemológica com a qual se decide qual é o estatuto do estado quântico, na representação dos fenômenos, e as razões que sustentam essa decisão. Deste modo, completa-se a fundamentação, apresentados os postulados ou princípios que formam o corpo teórico que descreve exatamente os fenômenos quânticos e, em particular, apresentado o significado do estado quântico. 
Voltemos aos autores. Peres assume que a noção de quantidade física não é apropriada para descrever o micromundo porque não existe evidência experimental que respalde esta hipótese. Realmente, a função de onda não é física, no sentido que não existem provas experimentais que informem quantas unidades de função de onda se observam. O que se nota são distribuições de probabilidades. Observa-se que, quando um sistema segue uma preparação experimental, os resultados de uma medição sobre esse sistema fornecerão as mesmas probabilidades cada vez que se repita e deve repetir-se muitas vezes, pois é isso que se espera do cálculo das probabilidades. Por isso, Peres irá propor que as noções primitivas ou fundamentais da teoria são as preparações e as provas experimentais que permitem observar probabilidades. E dirá que o alcance da teoria é o de calcular as probabilidades observadas em provas que seguem preparações específicas. Seus postulados são, portanto, fatos empíricos observáveis. Por essa razão, a primeira definição de estado é observacional: "Um estado é caracterizado pelas probabilidades dos vários resultados de todo teste concebível". (PERES, 1995, p. 24) ${ }^{2}$ No entanto, Peres também tem que fazer postulados matemáticos e quando dizemos que ele antes de tudo se fixa no aspecto observacional dos fenômenos, referimo-nos ao seguinte: (1) antes da matemática estão os experimentos e desta hierarquia resulta (2) que o formalismo matemático reflete a peculiaridade de tais experimentos. Em que sentido? Encontrando o significado físico dos vetores: "Qualquer vetor complexo, exceto o vetor nulo, representa um estado puro realizável.” (PERES, 1995, p. 50)3 Quer dizer, em princípio, é possível que qualquer vetor matemático seja preparado experimentalmente. Do mesmo modo, as propriedades matemáticas dos vetores, como mudança de base, remeterão a situações experimentais. O que enfatizamos é a dominância do nível observacional na definição do sentido e significado do estado quântico. Peres sustenta uma epistemologia de laboratório e seu "gosto" operacional ou instrumental está presente nos enunciados matemáticos e, como veremos, na ideia de realidade física do estado.

Como já mencionamos, Ballentine inicia sua fundamentação partindo das matemáticas. E no desenvolvimento da teoria, quando os fenômenos começam a ser lidos em tais matemáticas, percebemos que a observação encontra seu sentido sempre que pode fazer-se corresponder com uma figura matemática. No entanto, à primeira vista parece igual ao que fez Peres - relacionar os experimentos com o formalismo -, mas, em primeiro lugar, Peres parte do laboratório ao formalismo e Ballentine, o inverso; em segundo lugar, a correspondência de Ballentine é abstrata, enquanto que a de Peres é instrumental. Para esse último, as matemáticas

2 "A state is characterized by the probabilities of the various outcomes of every conceivable test."

3 "Any complex vector, except the null vector, represents a realizable pure state." 
refletem observação; para o primeiro, o que é observável necessita de uma contrapartida formal sem a qual não pode ser estudado. Por essa razão, o sentido físico observável e o significado físico legítimo do estado quântico de Ballentine é uma correspondência abstrata:

O vetor de estado não é um objeto físico. Seu significado é duplo. Primeiro, ele é objeto matemático abstrato do qual as distribuições de probabilidades das quantidades observadas pode ser calculada. Segundo, afirmar que o vetor de estado é $\Psi$ pode ser considerado como implicando que o sistema sofreu um correspondente procedimento de preparação do estado, o qual poderia ser descrito em mais detalhes mas toda a informação relevante está contida na especificação de $\Psi$. (BALLENTINE, 1986, p. 885) ${ }^{4}$

Note-se a ordem de uma definição: primeiro matemática, segundo observável. E não se trata de níveis excludentes, o observacional e o formal são, antes de qualquer coisa, coexistentes, o que difere é a perspectiva ou a ênfase. Na perspectiva é que diferenciamos as fundamentações.

Por outro lado, o que dizer do terceiro nível de Peres e Ballentine? Ou seja, o que dizer da síntese conceitual da qual se deriva a realidade objetiva do estado quântico? Antes de responder a essa pergunta, apresentamos as fundamentações de Paty, porque é precisamente nesse nível da compreensão dos fenômenos quânticos que Paty fundamenta sua perspectiva: o conceito relacional de estado quântico provê conhecimento que ao mesmo tempo se verifica em um texto matemático e se reconstitui na observação experimental. E isto é possível porque Paty faz uma extensão do uso e do significado na noção de estado quântico de maneira tal que se possa referir a ele como uma quantidade física. Isso quer dizer que o estado não é só uma distribuição de resultados em uma medição (Peres), tampouco uma mera correspondência entre o experimento e suas matemáticas (Bellentine), mas sim, o estado quântico é o sistema mesmo ou objeto físico, isto é, o puro fenômeno compreendido ou entendido e não somente observado e calculado. A maneira como Paty sustenta esta compreensão direta do fenômeno é um litígio epistemológico que basicamente afirma que, estendendo o uso e significado do vetor de estado, é possível relacionar coerentemente o vetor a suas propriedades. Esta rede relacional é precisamente a estrutura teórica cujos resul-

4 "The state vector it is not a physical object. Its significance is twofold. Firstly, it is an abstract mathematical object from which the probability distributions of observed quantities can be calculated. Secondly, to assert that state vector is $\Psi$ can be regarded as implying that the system has undergone a corresponding state preparation procedure, which could be described in more detail but all of the relevant information is contained in the specification of $\Psi$.” 
tados são a compreensão dos fenômenos. Nas palavras de Paty (2000, p. 186-187, grifo do autor):

Essa interpretação é uma afirmativa do significado físico relativo ao nosso entendimento dos fenômenos e não uma metáfora. Ela corresponde a uma modificação do pensamento usual sobre tanto os estados físicos quanto as quantidades físicas. Nós não mais confinamos estas na definição restrita de ter de corresponder a valores numéricos singulares como aqueles dados como resultados de medidas clássicas: nós ampliamos e estendemos seu significado para entidades matematicamente mais complexas expressando relações que não são restritas a tais atribuições numéricas. Pois, acima de tudo, a função essencial das quantidades físicas é expressar relações. Estas entidades são dadas como vetores de um espaço de Hilbert, invariante em mudanças de base, representando estados físicos, e operadores hermitianos lineares agindo sobre eles, expressando as quantidades com a ajuda do que se define como o sistema da base do vetor de estado. As atribuições numéricas das medidas são apenas parciais (elas são projeções) com respeito ao sistema como um todo, condicionais e contextuais (devido à preparação que escolhe a base) e devem ser relacionais através da leitura teórica delas. $^{5}$

Note-se na declaração anterior a importância que Paty atribui à compreensão dos fenômenos e como esta compreensão é uma justiça que se faz entre a observação e o cálculo.

5 "This interpretation is a statement of physical meaning regarding our understanding of the phenomena and not a metaphor. It corresponds to a modification of the usual thought of physical states and quantities. We no more confine these in the restricted definition of having to correspond to single numerical values as those given as classical measurement results : we widen and extend their meaning to mathematically more complex entities expressing relations which are not restricted to such numerical attributions. For, after all, the essential function of physical quantities is to express relations. These entities are given as vectors of a Hilbert space, invariant under basis transformations, representing physical states, and linear hermitical operators acting on them, expressing the quantities with the help of which one defines the basis system for the state vector. The numerical attributions from measurements are only partial (they are projections) with respect to the whole system state, conditional and contextual (due to the preparation that chooses the basis), and must be made relational through theoretical reading of them." 


\section{Conclusões: perspectivas e realidade objetiva}

Uma perspectiva não é uma opinião, ainda que os autores expressem ou comentem opiniões. Do mesmo modo, uma interpretação não se refere ao traço filosófico da teoria, embora as escolhas filosóficas possam ser rastreadas nesses autores. Como teoria física, a Quântica remete principalmente a medições experimentais e a predições teóricas dessas medições, as quais podem ser lidas no formalismo matemático. Não obstante a interpretação, à medida que ela procura conciliar estes dois domínios diferentes, o visível e o legível, remeterá legitimamente às considerações epistemológicas, por meio das quais se dobram os níveis ou, em outras palavras, definem-se o sentido e o significado de observações e fórmulas. Assim, temos mostrado que Peres julgava o conceito de estado quântico partindo do laboratório, Ballentine da correspondência entre matemáticas e observações e Paty do caráter relacional do conceito.

No entanto, nós ainda não apresentamos explicitamente as interpretações do vetor de estado dos dois primeiros autores. A de Paty, como vimos, aparece primeiro porque ele se instala no nível da compreensão. Mas, como é de se esperar, a de Peres invocará primeiro a observação. E assim é. Peres negou a existência da quantidade física vetor de estado, por isso o que se faz necessário compreender desta noção remeterá ao conhecimento de regularidades estatísticas. Se há algo para se interpretar são as marcas visíveis em um aparato de medição e como estes aparatos são todos macroscópicos ou clássicos, a interpretação então será a de um modelo clássico ou de um parcialmente clássico. Do outro aspecto, o quântico, diz Peres que é ilusório ou fictício. Serve, no entanto, de contexto imaginário, mas o importante está no aparato macroscópico, onde, justamente, os fenômenos quânticos ocorrem.

Um pouco antes, lemos a afirmação de Ballentine segundo a qual o vetor de estado não é um objeto físico, mas sim uma correspondência entre matemáticas e preparações. É que para ele a física do estado quântico é outra correspondência, desta vez entre um teorema da medição (o qual por sua vez, note-se, é uma correspondência entre um objeto formal - o teorema - e um observacional - a medição) e uma interpretação crítica do conceito. Deste modo, Ballentine afirma que o estado quântico representa uma coleção de sistemas quânticos identicamente preparados. Não se deve subestimar a simplicidade do enunciado, primeiramente porque Ballentine faz uma crítica teórica à interpretação ortodoxa ou de Copenhague, segundo a qual o vetor de estado representa as propriedades de um sistema físico individual; em segundo lugar, porque para chegar a ela temos que enunciar diversas correspondências entre os níveis, formal e experimental, todas as quais justificam o teorema de medição. Aqui o importante está na edificação teórica, que se sustenta na firmeza abstrata com que as matemáticas se relacio- 
nam às observações. Isto é admirável em Ballentine, o uso variado e repetido de correspondências que tornam legível o que no experimento somente é visível.

De Paty já mencionamos que sua interpretação de estado quântico remete primeiramente à característica relacional de quantidade física com suas propriedades, mas mencionemos, então, por último, a maneira como as observações se fazem legíveis. Para este fim, Paty propõe o conceito de reconstrução. Embora o vetor de estado não seja diretamente observável, porque não é uma quantidade no sentido clássico, com valores numéricos precisos, pode-se pensá-lo como uma quantidade relacional, relações que se reconstituem em uma observação. A reconstrução é uma maneira de conciliar as observações com as predições teóricas e consiste em conceber uma observação experimental como o resultado de contribuições quânticas individuais. Quer dizer que em um aparato de medição, antes de uma observação, há uma reconstrução dos constituintes quânticos que interagem com ele. A ideia mesma de reconstrução é conceitual, isto é, não é diretamente observável, mas critica a ideia segundo a qual o domínio quântico carece de realidade, pois é apenas classicamente (em aparatos clássicos) observável.

Estas são, portanto, as três perspectivas da teoria. Uma instrumental, outra matemática e a outra conceitual. E notem que as três percorrem os três níveis e isso é feito, justamente, segundo o ponto de vista de cada autor. Peres, partindo do laboratório, negará a existência de quantidades quânticas, porque não são observáveis, e a Matemática será usada para refletir as propriedades das observações. Ballentine, por sua vez, tratará de demonstrar ou justificar porque suas correspondências são legítimas. De uma observação não dirá nada se não pode ser lida em um formalismo solidamente construído e, por esta razão, sua interpretação se sustenta nas correspondências do teorema da medição. O que difere da de Peres que, antes de tudo, observa. Talvez a controvérsia seja mais notada entre Peres e Paty porque precisamente o que o primeiro nega é a potência do segundo. Peres não vê a necessidade de um modelo teórico estritamente quântico, já que a observação é sempre em aparatos clássicos, enquanto Paty critica esta ideia porque com ela se perde o caráter físico quântico que o formalismo matemático exige. Por essa razão propõe uma nova quantidade para a Física, o vetor de estado, justamente.

Mas a controvérsia das perspectivas não se refere apenas à noção de estado quântico. Por exemplo, os três afirmam que a teoria é probabilística, mas com razões diferentes. Para Peres é suficiente ver os resultados que apresentam regularidades estatísticas para afirmá-lo; Ballentine primeiro demonstra que os fenômenos quânticos cumprem os axiomas da teoria abstrata da probabilidade e então que esses fenômenos têm funções de probabilidade correspondentes. Paty por sua vez, compreenderá que a função de probabilidade é uma nova propriedade física, a qual se relaciona com a quantidade física vetor de estado. 
A controvérsia aparece, por vezes, na diferença no que o vetor de estado representa dos fenômenos (observável, legível, compreensível), mas também aparece quando se dão razões diferentes para uma mesma declaração e, seguramente, de muitas outras formas. Faltaria relacionar as perspectivas com as implicações filosóficas e inclusive políticas como fez Freire Jr. (2003).

Finalizando este trabalho, comentemos apenas o que há de real no estado quântico, segundo cada autor. Então, o que é o real de um fenômeno quântico?

Peres é direto: a única realidade é a das marcas em um aparato de medição; para Ballentine o real se expressa na pura correspondência entre observações e cálculos; e para Paty, a realidade é uma construção simbólica ou estrutural da quantidade vetor de estado e suas propriedades físico-quânticas, realidade crítica que legitima, entretanto, a ideia de uma crítica epistemológica.

Terminamos este trabalho com uma paráfrase do parágrafo 57 da Monadologia de Leibniz (2003). É de onde buscamos a ideia de perspectivas:

E, assim como a mesma cidade parece outra e se multiplica perspectivamente sendo observada de diversos lados, o mesmo sucede quando, pelas múltiplas "controvérsias" dos sistemas simples que descreve, parece haver outras tantas teorias quânticas diferentes que, no entanto, são apenas as perspectivas de uma só, segundo os diferentes pontos de vista de cada autor. ${ }^{6}$

\section{Referências}

BALLENTINE, L. Probability theory in quantum mechanics. American Journal of Physics, v. 54, p. 883-889, 1986.

Quantum mechanics: a modern development. Singapore: World

Scientific, 1988.

FREIRE JR. O. A story without an ending: the quantum physics controversy 1950-1970. Science \& Education, v. 12, p. 573-86, 2003.

LEIBNIZ, G. W. Monadología. Trad. Esp. de R Torreti. In: OLASO, E. Escritos filosóficos (\$57). Madrid: Machado Libros, 2003. Original de 1721.

6 Para a paráfrase em português, nos apoiamos na edição de Leibniz (1974, p. 69). Volume referente a Newton e Leibniz. [Nota do tradutor]. 
. A monadologia. Trad.de M. Chauí Berlinck. São Paulo: Abril Cultural, 1974. (Os pensadores).

PATY, M. The concept of quantum state: new views on old phenomena. In: Ashtekar, A. et al. (Ed.). Revisiting the foundations of relativistic physics: John Stachel Festschrift. Dordrecht: Kluwer, 2003. p. 451-478.

. The quantum and the classical domains as provisional parallel coexistents. Synthese, Boston: Kluwer, v. 125, n. 1-2, p. 179-200, 2000. Editores: S. French, D. Krause and F. Doria. In honor of Newton da Costa.

. Are quantum systems physical objects with physical properties?

European Journal of Physics, v. 20, p. 373-388, 1999.

PERES, A. Quantum theory: concepts and methods. Dordrecht: Kluwer, 1995. 



\section{Parte III}

\section{Implicações culturais e educacionais da Teoria Quântica}





\title{
O fenômeno cultural do misticismo quântico
}

\author{
Osvaldo Pessoa Jr.
}

\section{Apresentação}

A física quântica se consolidou em 1926 como a teoria que descreve átomos, moléculas, suas interações mútuas e suas interações com diferentes formas de radiação. O domínio de aplicação desta teoria geralmente é a escala subnanométrica, ou seja, abaixo de um nanometro $\left(10^{-9} \mathrm{~m}\right)$, escala típica de uma pequena molécula. Pode-se dizer que a Teoria Quântica está por trás de todos os fenômenos de nosso cotidiano, já que, afinal, tudo é composto de átomos.

No entanto, existe uma notória dificuldade em se estender a Teoria Quântica para o domínio macroscópico (do nosso cotidiano), pois o agrupamento de um grande número de átomos tende a "borrar" ou apagar os efeitos quânticos mais delicados (processo chamado "descoerência"), resultando num comportamento tipicamente "clássico", ou seja, de acordo com a física clássica pré-quântica. Para se explicar o funcionamento de uma bicicleta, por exemplo, não é necessário usar a Teoria Quântica, mesmo que se possa argumentar que, em princípio, uma descrição quântica da bicicleta seja possível. Assim, podemos dizer que a física quântica não é "necessária", não é "essencial", para se explicar uma bicicleta, no sentido de que a física clássica fornece uma explicação suficientemente boa para este meio de locomoção.

E com relação à nossa consciência, à nossa mente (o que incluiria o inconsciente), à nossa "alma" (usaremos esses termos de maneira intercambiável)? Será que nossa consciência pode ser explicada apenas a partir da biofísicoquímica? E, em caso positivo, será que a ciência clássica seria suficiente ou seria necessária a física quântica? Não trataremos especificamente dos detalhes filosóficos desta questão, mas daremos uma olhada numa ampla classe de visões de mundo que 
argumentam sobre a existência de uma conexão essencial entre física quântica e consciência. Essas visões não se limitam à tese de que a física quântica é essencial para se explicar a consciência, mas incluem outros tipos de relações entre mente e quântica (além da mais óbvia, de que a Teoria Quântica foi criada por mentes), num amplo panorama costumeiramente chamado de "misticismo quântico". (GRIM, 1990)

A questão básica deste trabalho é caracterizar o misticismo quântico que, na última década, se disseminou tão fortemente na mídia e em boa parte da sociedade. Como pano de fundo, inicia-se examinando as quatro grandes tradições naturalistas que antecederam o surgimento da física quântica e que foram por ela modificadas. Uma dessas tradições é o "naturalismo animista", que encontrou terreno fértil para o desenvolvimento do misticismo quântico. Em seguida, apresenta-se uma longa lista de teses que podem ser incluídas nesta rubrica de "misticismo quântico", agrupadas em cinco grandes grupos. Examina-se a questão ética de como a ciência estabelecida, de cunho não-místico, deve dialogar com o misticismo quântico. Após a apresentação de cinco atitudes possíveis, formula-se o dilema que todo místico deve resolver. Por fim, abordam-se questões sociológicas associadas à onda de misticismo quântico que tem marcado o início do novo milênio.

\section{As diferentes visões naturalistas}

As quatro grandes tradições naturalistas que antecederam o surgimento da física quântica são o naturalismo animista, o materialismo, o positivismo e o construtivismo neokantiano.

\subsection{Naturalismo animista}

O misticismo quântico compartilha de uma atitude, com relação à natureza, que tem uma longa tradição na história da ciência e que chamaremos de "naturalismo animista" ou romantismo. Essa atitude considera que a natureza é imbuída de uma espécie de alma, semelhante à alma humana, ou uma espécie de sentido, finalidade ou racionalidade, semelhantes aos nossos. Essa visão era bastante forte na Antiguidade, caracterizando o pitagorismo, o estoicismo, o neoplatonismo, o taoísmo, além de várias religiões como o gnosticismo, entre outras. No Renascimento europeu, houve um ressurgimento dessas tradições de magia, astrologia, alquimia e hermetismo, que caracterizavam o chamado "naturalismo renascentista" e que influenciou cientistas como Gilbert, Kepler e van Helmont. 
No século XIX, essa tradição ressurgiu com força no romantismo alemão, presente na obra de Goethe e articulada na Naturphilosophie de Schelling, que influenciou cientistas como Oken, Carus, Ritter, Oersted e os transcedentalistas franceses (liderados por E. Geoffroy Saint-Hilaire). Essa visão considerava que o "eu" e a natureza são manifestações de uma substância fundamental, que teria entre seus atributos o espírito e a matéria (uma influência do filósofo Spinoza). Assim, as leis da natureza coincidiriam em larga medida com as leis do indivíduo ("princípio de identidade") e a natureza era vista como uma totalidade orgânica. Como as leis da natureza coincidiriam com as leis do pensamento, o cientista poderia atingir a verdade sobre a natureza apenas através da sua intuição (levando assim a uma atitude menos rigorosa para com o método científico). Toda a natureza seria permeada por polaridades de forças, que seriam responsáveis pela gradual diferenciação dos entes naturais, levando à noção de transformação biológica, regida por arquétipos ou tipos ideais. (HADA, 2007, p. 53-54)

\subsection{Visões naturalistas, subjetivistas, religiosas}

É interessante fazer uma classificação geral das diferentes posições naturalistas do século XIX, anteriores ao surgimento da física quântica, divisão esta que pode ser aplicada à Filosofia da Ciência de hoje. (PESSOA JR., 2009) Por "naturalismo" entendem-se visões de mundo que tomam como ponto de partida a existência da natureza, ou de nossa experiência perceptiva desta natureza, e que concebem que a natureza possui certa unidade e segue leis próprias. Essa atitude geral, própria da ciência, pode ser contrastada com duas outras atitudes, bastante fortes ao longo da história da humanidade. As visões de mundo mitológicas e religiosas não tomam a natureza como seu ponto de partida, mas partem da suposição de que existem deuses antropomórficos, ou um Deus único, e de que o indivíduo pode ter acesso direto a um mundo sobrenatural, em muitos casos revelados pelas escrituras religiosas. Já as visões de mundo humanistas e subjetivistas tomam o homem como a medida de todas as coisas ou fundam o mundo no "sujeito epistemológico", ou seja, nas intuições primeiras do observador que conhece ou concebe o mundo. A divisão entre essas três atitudes gerais não é nítida, mas ela ajuda a entender as diferenças que há, nos dias de hoje, entre as abordagens da ciência, da religião e das filosofias subjetivistas e/ou humanistas (idealismo alemão, Husserl, Bergson, Heidegger, existencialismo, escola de Frankfurt, pós-modernismo, psicanálise etc.).

\subsection{Realismo materialista}

Concentrando-nos então nas visões naturalistas, uma primeira divisão que pode ser feita refere-se a diferentes respostas para a questão de se entidades e estruturas inobserváveis podem ser consideradas reais pela ciência. O "realismo 
de inobserváveis", ou simplesmente "realismo", defende que há bases racionais para se aceitar teses relativas a inobserváveis, ao passo que o que podemos chamar de "fenomenalismo" nega que faça sentido atribuir realidade aos inobserváveis.

Duas abordagens realistas, fortes na ciência do século XIX, assim como em outras épocas, eram o naturalismo animista (romantismo) e o materialismo. Conforme vimos acima, o primeiro atribuía à natureza uma espécie de alma, ao passo que o segundo negava que pudesse existir consciência fora de um corpo humano (ou animal) em funcionamento fisiológico. O materialismo (ou "fisicalismo realista") defende que a consciência humana é na verdade apenas uma manifestação da matéria ou de entidades físicas (energia, campos etc.), e que na morte do corpo, a alma desaparece. (PESSOA JR., 2006b) Esta concepção, que incorporava o mecanicismo newtoniano, fortaleceu-se na segunda metade do século XIX, com o desenvolvimento das áreas de Fisiologia e Biologia evolutiva. Já a Naturphilosophie romântica perdeu sua força a partir de 1830.

\subsection{Fenomenalismos}

Por outro lado, a postura antirrealista adquiriu bastante expressão na segunda metade do século XIX, com as tradições positivista e kantiana, ambas compartilhando o "fenomenalismo" definido acima. O positivismo pode ser enquadrado na tradição empirista, representada por Hume, que funda o conhecimento científico nas observações e nos experimentos, tomados como base segura para a ciência. Assim, aceitava-se que havia observações neutras na ciência, que refletiriam fielmente um aspecto da realidade ou que a ciência poderia ser construída a partir de "fatos" objetivos. O trabalho da ciência seria concatenar esses fatos ou observações, evitando-se postular entidades e mecanismos que estariam para além da capacidade de observação, o que resultaria em especulação metafísica. Por exemplo, supor que realmente existem átomos materiais não era considerado uma posição científica correta; neste caso, o que se poderia dizer era que o conceito de "átomo" é uma representação econômica para um grande número de observações em sistemas físico-químicos. Ou seja, para o "descritivismo" da tradição positivista, a veracidade de um enunciado envolvendo o conceito de "átomo" se reduziria à veracidade dos enunciados observacionais da teoria. Uma postura alternativa, dentro da tradição empirista, seria não se preocupar em nada com a questão da veracidade de enunciados não-observacionais, o que constitui o "instrumentalismo", uma forma de pragmatismo.

Outra postura que se fortaleceu continuamente ao longo do século XIX, foi a Filosofia da Ciência elaborada por Kant, um exemplo do que se pode chamar "construtivismo". Ao contrário do empirismo, que considera o fato observado como expressão pura da realidade, o construtivismo salienta que toda observação 
envolve uma construção mental, que os dados puros dos sentidos e os fatos observacionais são na verdade organizados por categorias mentais, que "projetam" conteúdos subjetivos no fato objetivo. Na Grã-Bretanha, o debate entre empirismo e construtivismo foi representado pela discussão entre Mill e Whewell. Nos países germânicos, a tradição kantiana já era forte na Biologia, a partir de sua combinação do mecanicismo newtoniano com o princípio "regulador" da teleologia ou finalismo (um princípio regulador não é "constitutivo" dos fenômenos, mas é imposto pelo cientista na organização do conhecimento). (HADA, 2007, p. 34-36) A partir de 1870, o construtivismo kantiano recebeu novo impulso com os trabalhos de Helmholtz, que estudou a fundo a fisiologia dos sentidos da visão e audição e salientou a importância da mediação dos sentidos e da atividade pensante do sujeito no crescimento do conhecimento científico. Articulou-se, também, àquela época, uma epistemologia neokantiana com Hermann Cohen.

Em oposição a essa tradição, mantinha-se o neopositivismo de Ernst Mach, que rejeitava que as teorias científicas contivessem um elemento a priori de caráter puramente formal. Para ele, a ciência era uma reflexão conceitual a partir dos fatos, cujos elementos seriam os conteúdos da consciência dados pelos sentidos (uma visão geral das filosofias da ciência de língua alemã da segunda metade do século XIX é apresentada por PRESTON, 1971, p. 73-81).

\subsection{Idealismos}

Devemos também mencionar a força que o idealismo tinha nas universidades alemãs, especialmente a metafísica de Hegel, que postulava uma racionalidade "absoluta" na natureza. Por "idealismo" entende-se a tese de que a realidade, de alguma forma, depende da mente, do sujeito cognoscente. A versão mais radical é chamada "idealismo subjetivista", que considera que a realidade é uma espécie de sonho na mente do sujeito. Ela se opõe ao "realismo ontológico", que afirma que o mundo existe independentemente de nossas mentes, de nossa observação. As visões naturalistas tendem a aceitar o realismo ontológico, de forma que se pode classificar o idealismo subjetivista como uma forma de subjetivismo.

No entanto, dentro do campo do naturalismo, há posições que podem ser consideradas idealistas, especialmente as que radicalizam o fenomenalismo, como em Kant e Mach. Na Crítica da razão pura, Kant admite a existência da coisa em si (realismo ontológico), mas como ela é inatingível para a ciência, esta trabalha em cima do campo fenomênico, estruturado pelos sentidos e pelo entendimento humano, sendo neste sentido um idealismo. Já o "monismo neutro" de Mach buscava explicitamente colocar-se num ponto intermediário entre o realismo e $\mathrm{o}$ idealismo, que seria o campo das sensações não-estruturadas. No entanto, na tradição do materialismo dialético de Lenin, as ideias de Mach eram consideradas 
idealistas - o que pode ser entendido como sinônimo de "fenomenalistas" - e tal pecha seria atribuída pelos marxistas para a interpretação da teoria quântica formulada por Bohr (também fenomenalista).

Há um sentido de "idealismo" que se aplica às visões realistas. Consiste na tese de que a mente é capaz de alterar a realidade externa diretamente, sem a intermediação da matéria. Esta tese está na base do misticismo quântico e se enquadra na tradição naturalista animista. Pode-se distinguir este "idealismo transformador" (a mente consegue transformar a realidade) do mais forte "idealismo criador" (a mente humana cria a realidade). (PESSOA JR., 2001, p. 169) A filosofia de Berkeley, com seu lema "ser é ser percebido", é usualmente classificada como um idealismo subjetivista, mas sua visão é equivalente a um realismo, já que o papel da realidade intersubjetiva é desempenhado pela percepção na mente de Deus.

\subsection{Seleção de filosofias da ciência por novas teorias científicas}

O surgimento da Teoria da Relatividade e da Teoria Quântica poria em cheque as diferentes concepções naturalistas. O materialismo mecanicista e o construtivismo kantiano encontraram grandes dificuldades de assimilar esses novos conhecimentos, ao passo que o positivismo e o instrumentalismo conseguiram sobreviver melhor, estando próximos à atitude "operacionalista" (de definir qualquer conceito científico através da especificação das operações físicas necessárias para medir o referente de tal conceito), atribuída ao trabalho inicial de Einstein sobre a Teoria da Relatividade (1905) e adotada por Pauli e Heisenberg, no início da década de 1920. No entanto, a interpretação da complementaridade elaborada por Niels Bohr se enquadra melhor na visão de mundo construtivista (KAUARKLEITE, 2004), apesar de ele não se debater com a problemática neokantiana, como fariam Cassirer e o grupo de Leipzig (Heisenberg, von Weizsäcker e Grete Hermann). Interpretações realistas como a de David Bohm podem ser classificadas como materialismo mecanicista e o materialismo certamente inspirou a abordagem soviética para a interpretação dos coletivos estatísticos (Blokhintsev). Já o enfraquecido naturalismo animista encontraria na Física quântica um campo fértil para seu ressurgimento.

\section{Principais teses do misticismo quântico}

O "misticismo quântico", em linhas gerais, consiste em interpretações da Teoria Quântica que se inserem na tradição do naturalismo animista (com seu idealismo transformador) ou que adotam um idealismo subjetivista, ou ainda que 
partem de elementos religiosos. Trata-se de uma atitude que atribui uma conexão íntima entre a consciência humana (ou a espiritualidade) e os fenômenos quânticos. Para melhor caracterizar esta atitude, apresentam-se a seguir várias teses, cada uma das quais é aceita por alguma corrente místico-quântica. A defesa de alguma dessas teses, por si só, pode não caracterizar uma atitude mística.

Dividimos as teses do misticismo quântico em cinco grupos: O) Observador participante. M) Mente quântica. C) Comunicação quântica. I) Outras interpretações. A) Aplicações. As referências bibliográficas relativas aos físicos quânticos mencionados podem ser encontradas em Jammer (1974) e Pessoa Jr. (2003, 2006a), e as relativas ao cérebro quântico em Pessoa Jr. (1994).

\subsection{Observador participante $(\mathrm{O})$}

Uma das características distintivas que passou a ser atribuída à mecânica quântica, a partir de 1927, foi o papel peculiar do observador no ato da medição.

O1) O objeto observado é inseparável do sujeito. Essa foi a atitude inicial de Niels Bohr, ao escrever em 1928 que "uma realidade independente no sentido físico ordinário não pode ser atribuída nem aos fenômenos, nem aos agentes da observação". Esta posição é própria do que chamamos acima de "fenomenalismo" (aceito tanto pelo empirismo de Hume e dos positivistas, quanto pelo construtivismo de Kant): não faria sentido, para a ciência, falar da "coisa em si", da realidade não-observada; todo objeto da ciência é um fenômeno observável e, portanto, o objeto é inseparável do sujeito observador. Esta posição, por si só, não é necessariamente mística, nem idealista, mas ela é muitas vezes mencionada por visões naturalistas animistas.

O2) O observador humano é o responsável pelo colapso da onda quântica. Esta é talvez a tese mais bem fundada das versões realistas do misticismo quântico, no sentido de que é uma tese clara e não-refutada (para uma explicação da questão, ver Pessoa Jr, 2001, 2001, cap. 6 e 9). Esta tese é atribuída a von Neumann, mas quem a apresentou em uma publicação foram Fritz London e Edmond Bauer (1939). Uma sutileza envolvendo esta tese é o estatuto atribuído à noção de "colapso da onda quântica". Se tal onda for interpretada de maneira fenomenalista (ou "epistêmica"), como uma mera representação matemática, então esta tese $\mathrm{O} 2$ torna-se trivial. É apenas quando a onda quântica é interpretada de maneira realista e quando a noção de "observação" necessariamente implica a presença de um observador consciente (ou seja, o colapso não poderia ocorrer apenas com a interação do sistema quântico, com um instrumento de medição) que essa interpretação torna-se mais "mística". 
O3) O observador escolhe se ofenômeno é onda ou partícula. Na interpretação da complementaridade, articulada por Niels Bohr, o físico experimental pode escolher se ele quer medir um fenômeno "corpuscular" (no qual se poderia determinar a trajetória passada de cada quantum detectado) ou um "ondulatório" (no qual a coleção de quanta detectados exibe um padrão de difração ou interferência). Essa escolha pode inclusive ser feita de forma "demorada", após o objeto quântico entrar no aparelho. (PESSOA JR., 2003, p. 18-22) Na perspectiva fenomenalista de Bohr, essas alternativas envolvem a liberdade do componente subjetivo da cadeia sujeito-objeto. Porém, numa perspectiva mais realista, se os fenômenos corpuscular e ondulatório forem interpretados como diferentes estados da realidade, então esta escolha passaria a ser interpretada como um poder de transformar a realidade. Em 1931, Carl von Weizsäcker introduziu um elemento adicional, ao aplicar esta situação de escolha para o caso de duas partículas interagentes (um fóton de raio gama e um elétron, no microscópio teórico de raios gama de Heisenberg, seu orientador). Neste caso, a escolha de como montar a aparelhagem afetaria o tipo do fenômeno (onda ou partícula) da partícula localizada a distância, mas a vontade humana não poderia controlar os resultados obtidos nas medições (senão ter-se-ia transmissão instantânea de informação, o que é proibido pela Teoria da Relatividade). Tal situação envolve também uma extensão de $\mathrm{O} 2$ para sistemas de dois quanta interagentes. De qualquer forma, von Weizsäcker, dentro de uma perspectiva neokantiana, concluiu que na física quântica não se pode separar sujeito e objeto (O1) e que o sujeito contribui não só com o "saber" mas também com o "querer".

O4) O observador cria a realidade. Esta é uma célebre frase escrita por Pascual Jordan, em 1929, e usada como evidência de que a nova física quântica é idealista subjetivista. O sentido intendido por Jordan para esta frase pode ser tomado como um resumo das três teses anteriores, feito num contexto fenomenalista. Num contexto do misticismo quântico, esta frase amplifica o idealismo transformador associado a $\mathrm{O} 2$ e $\mathrm{O} 3$, constituindo um "construtivismo radical".

As teses vistas acima formam um núcleo de afirmações (que poderia incluir também a primeira parte de I2, da seção 3.4) que podem ser interpretadas de maneira mais fenomenalista, o que não constituiria um misticismo (apesar de levar a agudos debates filosóficos); ou podem ser interpretadas de maneira mais realista, levando a uma concepção naturalista animista. Nem todas as interpretações da teoria quântica aceitam as teses acima, sendo rejeitadas por diversas visões realistas mais materialistas (como a de David Bohm, de 1952). 


\subsection{Mente quântica (M)}

O ressurgimento do misticismo quântico, na década de 1980, foi em grande medida estimulado por novas hipóteses a respeito da natureza do cérebro humano.

M1) A consciência é um fenômeno essencialmente quântico. Em 1986, em A mente nova do rei, Roger Penrose partiu da hipótese, bastante questionável, de que o cérebro humano seria capaz de computar funções "não-recursivas", o que o tornaria mais poderoso do que qualquer computador. Um exemplo disso, segundo o matemático inglês, seria a nossa capacidade de ter um insight e resolver um teorema matemático. Como explicar isto? Penrose é um materialista, então não aceitou a explicação dualista de que haveria uma alma inteligente separada da corpo. (PENROSE, 1994) Desenvolveu, então, a concepção de que alguma propriedade quântica, relacionada ao problema do colapso da onda quântica, seria também responsável por esta nossa grande capacidade intelectual. Juntou-se então com o anestesiologista Stuart Hameroff, que desenvolvera a hipótese de que microtúbulos presentes em todas as células (inclusive dentro de neurônios) teriam uma função cognitiva, além da reconhecida função estrutural e de transporte. A noção de que a consciência humana seria um fenômeno essencialmente quântico é consistente com posições não-místicas e mesmo materialistas, mas para o naturalista animista ela é especialmente atraente, pois embasaria o "princípio de identidade" de que as leis da natureza coincidem com as leis do indivíduo, sustentando as teses de comunicação quântica (ver seção 3.3).

M2) O livre arbitrio é garantido pelo princípio de incerteza. Em 1932, Arthur Eddington defendeu que as escolhas humanas são livres (ou seja, não são totalmente determinadas pelo estado anterior do cérebro e do ambiente), fazendo uso do princípio de incerteza formulado em 1927 por Heisenberg (apud JAMMER, 1966, p. 337):

Se o átomo tem uma indeterminação, certamente a mente humana terá uma indeterminação igual; pois dificilmente poderíamos aceitar uma teoria que faz a mente ser mais mecanicista do que o átomo.

A questão do livre arbítrio é um problema filosófico bastante discutido e a defesa de M2 não implica em misticismo, apesar de Eddington poder ser incluído na primeira geração de cientistas mais próximos do misticismo quântico, que incluiu James Jeans, John B.S. Haldane e Walter Heitler, além de London e Bauer e mais tarde Eugene Wigner. 
M3) No dualismo entre alma e corpo, a interação entre os dois se dá por processos quânticos. Vimos com Penrose uma posição materialista a respeito do cérebro quântico. No entanto, o misticismo quântico é muito próximo de posições dualistas, para as quais a alma não emerge da matéria, mas tem existência autônoma. Essa era a visão de Descartes, que postulou uma interação entre as duas numa certa glândula no cérebro. $\mathrm{Na}$ neurociência contemporânea, John Eccles é conhecido por defender uma visão dualista e por sugerir que a alma (ou mente) atuaria durante a liberação de neurotransmissores, processo probabilístico regido pela física quântica, alterando levemente essas probabilidades.

M4) Holismo quântico se manifesta no cérebro. O cérebro é um sistema altamente integrado e alguns pesquisadores têm sugerido que esta integração envolve o "emaranhamento" quântico (como o que surge nas desigualdades de Bell). No entanto, o cérebro é um sistema muito grande e quente para que o emaranhamento desempenhe um papel na integração cerebral (essa é também a razão pela qual o cérebro não poderia ser um computador quântico). Por outro lado, há um processo descrito teoricamente por Herbert Fröhlich, em 1968, que constituiria um "condensado biológico" à temperatura ambiente, semelhante aos condensados de Bose-Einstein (que só são observados a baixíssimas temperaturas). Se tal condensado de fato existisse nas membranas neuronais, ter-se-ia um comportamento ordenado de longo alcance (mas não uma não-localidade, no sentido das desigualdades de Bell, já que tais sistemas de condensados têm no máximo apenas pares próximos de partículas emaranhadas), o que excita a imaginação de muitos místicos quânticos. Alguns pesquisadores afirmam ter encontrado evidência de que tal fenômeno existe, mas não há comprovação de que tais sistemas de fato existam em sistemas biológicos.

\subsection{Comunicação quântica (C)}

As teses que caracterizam melhor o novo misticismo quântico, surgido na década de 80 , envolvem a possibilidade de duas ou mais pessoas se comunicarem instantaneamente em um nível intuitivo.

C1) Mentes quânticas interagem à distância. No esteio das investigações relativas às desigualdades de Bell e ao problemático conceito de "nãolocalidade quântica", que surgem em sistemas emaranhados de duas partículas correlacionadas, surgiu a noção de que mentes humanas são como sistemas quânticos, podem se comunicar a distância. $\mathrm{O}$ conceito de "sincronicidade", cunhado por Carl Jung para designar correlações 
acausais que estariam por trás das coincidências significativas de nossa vida (mas que para o materialista são apenas coincidências), tem sido identificado com as correlações a distância de sistemas quânticos emaranhados. Desta maneira, vários fenômenos parapsicológicos, como a alegada capacidade de sentir eventos distantes (tipicamente tragédias com familiares), passaram a ser explicados pelos místicos como sendo uma manifestação da física quântica. Esta é talvez a tese principal do novo misticismo quântico (ou psicologia quântica), difundida como "verdade científica" entre a comunidade de místicos e naturologistas.

C2) Não-localidade entre mentes permite transmissão instantânea de pensamentos. Um caso particular de C1, divulgado especialmente por Amit Goswami (2005), envolve experimentos que comprovariam a possibilidade de transmissão instantânea de pensamento, realizada pelo mexicano Jacobo Grinberg-Zylberbaum e repetida por outros pesquisadores. Tal fenômeno seria explicado como um exemplo de não-localidade quântica. Se tal efeito fosse verdadeiro, ter-se-ia uma refutação da teoria da relatividade restrita (que pró́be a transmissão instantânea de informação). Naturalmente, tais experimentos não são levados a sério pela maioria dos cientistas.

C3) O observador conseguiria influenciar a estatística de resultados quânticos. Um desdobramento da tese $\mathrm{O} 2$, de que o observador humano é responsável pelo colapso da onda quântica, e da O3, de que a escolha do observador determina o tipo de fenômeno quântico, seria que o observador poderia influenciar a estatística de resultados em um experimento quântico. Experimentos realizados pelos engenheiros Robert Jahn e Brenda Dunne (1987), da Princeton University, apontam para a existência de tal efeito "micropsicocinético". Teríamos assim mais uma evidência de que a física quântica explicaria fenômenos parapsicológicos, segundo os místicos quânticos. É desnecessário dizer que tais resultados não são aceitos pela comunidade científica, para quem se trata de um caso de autoengano ou de fraude proposital.

C4) A mente pode se acoplar ao universo, transformando-o com pensamento positivo. Esta é a tese que aparece no livro $O$ segredo, que menciona a física quântica como explicação para o poder que a mente teria em transformar a realidade diretamente, sem a intermediação do corpo. Este é o "segredo", conhecido pelos ricos e famosos de nossa história, e só agora revelado para o grande público!

C5) Há uma física quântica da alma e de Deus. Essas teses, desenvolvidas por Amit Goswami, entre outros, aproxima o misticismo quântico das visões religiosas. 


\subsection{Outras interpretações (I)}

As teses idealistas que agrupamos na seção sobre o observador participante (O) são todas próximas às interpretações ortodoxas da Teoria Quântica. No entanto, outras interpretações da mecânica quântica também suscitam extensões místicas.

I1) A alma pode viver em universos paralelos e estas contrapartidas podem se encontrar. Esta especulação, que aparece no filme e no livro Quem somos nós? (ARNTZ; CHASSE; VICENTE, 2007), é fundada na chamada interpretação dos muitos mundos, que Bryce DeWitt desenvolveu a partir da interpretação dos estados relativos de Hugh Everett, de 1957. Segundo essas visões, o próprio ser humano entraria em superposições quânticas, o que sugere que possamos ter vidas paralelas, ou que nossas diferentes potencialidades na vida de fato coexistem, o que é atraente para a visão de mundo místico (para mais, ver PESSOA JR., 2008 , texto 22 ).

I2) Atos no presente podem alterar o passado. O ato da observação atualiza o passado. Em 1972, John Wheeler desenvolveu as teses O2 e O3, no sentido de concluir que o passado associado a um experimento quântico só se torna concreto após a escolha feita pelo físico experimental no presente. $\mathrm{O}$ ato da observação "atualizaria a potencialidade" passada (para usar um jargão aristotélico introduzido por Heisenberg). Bohr teria concordado com isso dentro de uma perspectiva fenomenalista: o observador escolhe qual quadro clássico (construído por nós: onda ou partícula) deve ser associado ao passado do experimento. Wheeler, porém, não deixou claro qual o sentido filosófico preciso de sua conclusão: "O passado não tem existência enquanto ele não é registrado no presente." Interpretado de maneira realista, isso resulta numa tese própria do misticismo quântico: podemos alterar o passado! O próprio Wheeler já tinha trabalhado numa outra ideia, que também envolve uma espécie de causalidade para o passado; desenvolvida por ele e seu aluno Feynman, foi apresentada em 1986 por John Cramer como a base da interpretação "transacional" da Teoria Quântica. A ideia é que, além das "ondas retardadas" com as quais estamos acostumados e que se propagam para o futuro com energia positiva, existiria um outro tipo de onda, chamada "onda avançada", que se propagaria para o passado, com energia negativa (para mais, ver PESSOA JR., 2008, texto 31). Alguns físicos místicos usaram a Teoria Quântica para explicar o efeito que a reza teria sobre eventos passados (CALLIGARIS, 2006)! 
I3) Paradigma holográfico - cada parte contém o todo. A visão de que cada parte do universo reflete o todo é antiga nas visões naturalistas animistas como, por exemplo, a astrologia. Após a descoberta da holografia, na década de 1950, em que cada parte do holograma contém informação de todas as outras partes, diferentes interpretações passaram a trabalhar com esta ideia. Na década de 1960, David Bohm esboçou uma interpretação de "holomovimento", também conhecida como "ordem implicada", que buscava incorporar essa noção. Na mesma época, o neurologista Karl Pribram apresentou um modelo "holonômico" para o cérebro, em que as funções cerebrais são descritas por um "campo dendrítico" (ao invés da dinâmica convencional de neurônio e sinapse), que mais tarde seria matematizado por Umezawa, usando a teoria de campos quânticos. Mais recentemente, o paradigma holográfico foi explorado na abordagem mística de Michael Talbot (1991), em seu livro O universo holográfico.

\subsection{Aplicações (A)}

A1) Religiões orientais já teriam chegado às principais ideias da física moderna. Essa é a tese que se depreende do livro de Fritjof Capra, O Tao da Física, publicado em 1975 e um dos precursores do novo misticismo quântico. Um exemplo dessa conexão íntima entre ciência e filosofia oriental seriam as semelhanças entre o conceito de yin-yang do taoísmo chinês e a noção de complementaridade, de Bohr.

A2) A física quântica fundamentaria terapias alternativas. Esta tese é base da "naturologia", termo recente que designa o campo de práticas terapêuticas que não se enquadra na medicina alopática ou nas linhas clássicas de psicanálise e psicoterapia e que se utiliza de plantas medicinais, de técnicas terapêuticas tradicionais do Oriente, e de técnicas mais recentes que se caracterizam por não serem invasivas, como a iridologia, fitoterapia, aromaterapia etc. O livro A cura quântica, de D. Chopra (1990), foi um best-seller que divulgou essa "psicologia quântica".

A3) A física quântica seria o paradigma do novo milênio. Esse sentimento está por trás da aplicação da Teoria Quântica em tantos campos. Ligada à psicologia quântica, há uma abordagem para a administração de empresas, denominada "gestão quântica", que defende uma maior distribuição de poder decisório (uma "auto-organização") e o uso de técnicas motivacionais e de integração que aumentem a felicidade dos trabalhadores. (NÓBREGA, 1995) Já o "direito quântico", formulado pelo renomado jurista brasileiro Goffredo Telles (1971), não faz uso de 
analogias com a física quântica, mas consiste de uma proposta materialista que procura fundamentar o comportamento jurídico em princípios biológicos, especialmente o maquinário genético e a interação com o ambiente, reservando porém um espaço para a liberdade humana. $\mathrm{O}$ "tantra quântico" une o misticismo quântico com as técnicas sexuais do budismo tântrico. (HERBERT, 2002) Para outros usos do termo "quântico", como na arte, ver Crease (2008).

\section{Um típico argumento místico-quântico}

Para ilustrar a concepção místico-quântica, apresentarei agora um típico argumento, envolvendo quatro teses:

a) A consciência humana é essencialmente quântica (M1).

b) Assim, de (a), e por analogia a duas partículas quânticas, duas consciências podem se acoplar quanticamente a distância $(\mathrm{Cl})$.

c) A consciência humana é responsável pelo colapso da onda quântica $(\mathrm{O} 2)$.

d) No processo de medição e colapso, nossa vontade pode escolher se um fenômeno quântico é corpuscular ou ondulatório (O3).

e) Assim, de (b) e (c), e por analogia a (d), podemos escolher se outra consciência (ou mesmo objetos inanimados) terminará com "energia espiritual" positiva ou negativa (por exemplo), no processo de colapso (C4).

A crítica a este argumento se dá da seguinte forma. Primeiro, não há evidências concretas a favor de (a), especialmente devido ao ruído térmico presente no cérebro, que "borra" os efeitos quânticos (processo chamado "decoerência"). Mas como se trata de uma hipótese empírica ainda em investigação, seu uso como hipótese no argumento é aceitável.

A tese (b), porém, é muito menos plausível: mesmo que haja efeitos essencialmente quânticos em locais restritos do cérebro, quando duas pessoas se encontram não há interação física direta entre essas partes de cada cérebro. O místico teria que postular um "campo mental" que extravasaria o crânio e permitiria o acoplamento entre mentes. Mas isso foge ao que a ciência conhece hoje em dia. 
A tese (c) faz parte de uma interpretação da teoria quântica, a interpretação subjetivista de London e Bauer e nunca se conseguiu refutá-la. Assim, é legítimo seu uso no argumento, mas não se pode misturá-la com teses de interpretações conflitantes, como a dos muitos mundos. A tese (d) também é legítima, desde que se aceite as definições de "fenômenos" ondulatório e corpuscular da interpretação da complementaridade. Ela não entra em conflito com (c).

A conclusão (e) segue por analogia a (d), mas esta passagem também é infundada. Pois escolher se o fenômeno associado à partícula distante será corpuscular ou ondulatório não pode gerar nenhuma previsão sobre o resultado da medição efetuada a distância (senão, violar-se-ia o princípio relativístico de que nenhuma informação pode se propagar a uma velocidade maior do que a da luz). ${ }^{1}$ Supõe-se que incutir energia positiva em um objeto distante seja um estado de coisas distinguível da situação em que uma energia negativa é incutida. Assim, tal escolha não poderia ser controlada pela vontade de uma mente a distância, mesmo que se pudesse acoplar quanticamente duas mentes (pois, senão, poder-se-ia transmitir informação sobre o estado energético escolhido de maneira instantânea, o que violaria a Teoria da Relatividade).

\section{Diferentes atitudes frente ao misticismo quântico}

Como um cientista ou educador deve dialogar com o misticismo quântico? Analisaremos a seguir algumas atitudes que são tomadas por cientistas e humanistas com relação ao misticismo quântico.

1) Em primeiro lugar, há os adeptos do misticismo quântico, que constituem uma pequena minoria dentre os cientistas naturais, e talvez uma minoria um pouco maior nas humanidades. Este grupo é constituído, em sua maioria, por pessoas com predisposição a uma visão mística de mundo, que não entendem exatamente do que trata a Física quântica, mas confiam ou acreditam nos livros de divulgação que leram. Há também um pequeno grupo de estudiosos que conhece bem a física quântica e defende as teses místicas quânticas com melhor fundamentação, como Henry Stapp (2007) e Nick Herbert (1989).

2) Um segundo grupo não compartilha das teses do misticismo quântico, mas o respeita, assim como respeita as teses da parapsicologia e as crenças populares. Há os pós-modernistas, que negam que haja verdades

1 Este ponto não é trivial e necessitaria de maior discussão. Ver, por exemplo, Pessoa Jr. (2003, p. 88-90; 2006a, p. 292-293). 
únicas e questionam o direito que nossa cultura teria de impor verdades sobre outras culturas. Há os agnósticos, que consideram que há um valor de verdade único e bem definido para certas afirmações (ou seja, elas são $o u$ verdadeiras ou falsas), como a existência de transmissão de pensamento, mas evitam tomar uma posição definida até que as questões sejam examinadas exaustivamente pela ciência. Há também os que acreditam em mistérios que estão para além da ciência, mesmo que discordem da maioria das afirmações da parapsicologia e das religiões oficiais. (CALLIGARIS, 2006) Dentre estes, muitos já tiveram relatos ou experiências que consideram confiáveis de premonições e outros fenômenos semelhantes, mas não chegam a defender explicitamente uma visão mística.

3) A atitude mais comum, por parte dos cientistas, é simplesmente ignorar a onda de misticismo quântico, ridicularizando-o, talvez, em conversas particulares, mas sem um esforço de criticá-lo publicamente.

4) Dentre os que acham o misticismo quântico descabido, assim como a parapsicologia e outras artes místicas, há um pequeno grupo que se autodenomina "cético" e que para distinguir sua posição do ceticismo filosófico é, às vezes, chamado de "ceticismo científico". Esse grupo é bastante ativo no projeto de desmascarar fraudadores e pseudocientistas e publica seus resultados principalmente nas revistas Skeptical Inquirer e Skeptic, além de sites na internet. Procuram trafegar no terreno da racionalidade, argumentando que as atitudes pseudocientíficas são irracionais, sem, no entanto, estender esta crítica para posições religiosas. Em suas críticas à pseudociência, fazem bastante uso de conceitos da Filosofia da Ciência, por exemplo, argumentando que as visões místicas postulam entidades supérfluas e não predizem nada de novo (violando assim a navalha de Ockham). No caso do misticismo quântico, argumentam que certa interpretação mais ortodoxa e fenomenalista é melhor; e que visões idealistas devem ser descartadas por não preverem nada de novo e por violarem a navalha de Ockham. (STENGER, 1997) Um problema com esta visão é que são descartadas também todas as interpretações realistas.

5) Por fim, gostaria de apresentar uma outra atitude (PESSOA JR., 2006b), ao mesmo tempo mais pluralista e mais dogmática (um double-bind, no sentido de Gregory Bateson). A atitude pluralista, no caso da física quântica, é admitir que há dezenas de interpretações e que qualquer uma que não seja refutável e autocontraditória deve ser admitida como uma possibilidade. Ou seja, interpretações idealistas, mesmo as que terminam por construir uma física da alma e outros conceitos 
contraintuitivos, não careceriam de racionalidade. Elas são baseadas em atos de fé, mas visões realistas da ciência também o são (e eis o componente dogmático). Seguindo esta linha de pensamento, posso afirmar para um colega místico: “Tenho fé na inexistência de Deus. Tenho fé no materialismo." Posso então explicar para ele que a ciência ortodoxa é dominada pelas visões materialista e fenomenalistas (ver seção 2) e que, portanto, para essa ciência "estabelecida", teses como a de Masaru Emoto, de que é possível fotografar a influência das emoções humanas nas configurações moleculares da água, não são levadas a sério. $\mathrm{E}$ enquanto o interlocutor manifesta seu espanto, já que o filme Quem somos nós? afirmou claramente a veracidade deste efeito (ARNTZ; CHASSE; VICENTE, 2007), posso informar a ele a grande quantidade de dinheiro que o místico japonês ganha em seus workshops em cruzeiros marítimos. Enfim, é muito difícil alguém mudar sua própria visão religiosa após uns 23 anos: "Se você é místico, então você deve estudar a física quântica, pois isso trará novas perspectivas para seu misticismo; porém, a física quântica não implica misticismo, ao contrário do sugerido no filme Quem somos nós?”.

Dentro desta última abordagem, pode-se formular um dilema para o místico ou para o religioso, cuja solução envolverá uma reflexão sobre o estatuto da visão científica do mundo. O dilema do místico é o seguinte: deve-se aceitar a existência de fenômenos que vão contra o que prevê a ciência estabelecida ou deve-se aceitar apenas a existência de entidades e processos que não entram em contradição com a ciência? A primeira opção pode ser chamada de misticismo "desafiador" da ciência e o segundo, de misticismo "conciliador" com a ciência. Por exemplo, deve-se aceitar que o ser humano evoluiu a partir de outros primatas, ao longo de milhões de anos, ou deve-se acreditar que ele foi criado por Deus de forma já acabada? Alguém que acredite em Deus e em outros mistérios, mas que aceita a evolução humana, está adotando uma postura conciliadora com a ciência. Neste caso, o texto da Bíblia deve ser interpretado de maneira figurada e não de maneira literal. Já os chamados "criacionistas" adotam uma postura desafiadora da ciência.

No caso do misticismo quântico, defender que a consciência humana é reponsável por um colapso objetivo (tese $\mathrm{O} 2$ da seção 3.1) é uma atitude conciliadora com a ciência, ao passo que a tese defendida por Goswami de que existe trasmissão instantânea de pensamento (tese $\mathrm{C} 2$ da seção 3.3) é desafiadora. Apesar de o físico indiano citar diversos experimentos que teriam verificado tal fenômeno, pouquíssimos cientistas consideram que esta aposta de Goswami possa gerar mais luz do que a dos holofotes. A tese de Jahn e Dunne (C3), de que o pensamento do observador conseguiria influenciar o resultado de um experimento quântico, viola menos teses fundamentais da Física, mas é também uma 
atitude desafiadora, já que tem consequências experimentais testáveis que estão em desacordo com as previsões das visões materialistas da ciência, e que não foram reproduzidas por cientistas que trabalham em laboratórios considerados respeitáveis.

Vale mencionar que em 2003 foi fundado na Turquia o periódico NeuroQuantology, disponível on-line, que examina questões relacionadas à mente e ao cérebro, a partir da perspectiva da física quântica. O periódico não é levado a sério pela maioria dos cientistas ortodoxos e se pode dizer que ele representa pesquisa que está na zona limítrofe entre ciência e pseudociência. A maior parte dos artigos pode ser enquadrada no que chamamos "misticismo quântico" e os dois lados do "dilema do místico" estão representados nesta revista eletrônica.

\section{$6 \mathrm{O}$ ethos do neoesoterismo}

A definição de misticismo quântico apresentada até aqui - interpretações da teoria quântica que se inserem na tradição do naturalismo animista ou que adotam um idealismo subjetivista ou, ainda, que partem de elementos religiosos - estaria incompleta se não considerássemos que ela faz parte de um movimento sociocultural que ressurgiu nas décadas de 1980-1990, herdeiro da "contracultura" das décadas de 1960-1970, mas com alguns traços diferentes. Diversos sociólogos e antropólogos, como Heelas (1996) e Magnani (1999), têm estudado o fenômeno, chamado de "nova era" ou "neoesoterismo".

Ao lado dos aspectos cognitivos de uma cultura, sua "visão de mundo", costuma-se chamar de "ethos" aspectos valorativos, morais e estéticos, as atitudes e sensibilidade de uma cultura. O ethos do neoesoterismo, segundo Magnani (1999, p. 103-116), envolve os seguintes aspectos.

a) Terapias corporais. Após a difusão da psicanálise nos anos 70 , dois desdobramentos podem ser notados: a prática do lacanismo, com sua postura intelectualizada e a ênfase na palavra, e o complexo alternativo, que privilegia a emoção, a sensação e a intuição, e enfatiza o trabalho terapêutico no corpo e a "mentalização".

b) Cultivo da individualidade. O resultado das terapias corporais é uma valorização da realidade interior e dos processos de transformação espiritual, de forma que essa nova espiritualidade é marcada pelo individualismo. O ideal dos anos 1960-1970, de igualitarismo e socialização, é substituído, na era Reagan, pela valorização da individualidade, com aquilo que ela tem de singular e diferente. 
c) Comunidade: circuito urbano. O indivíduo da nova onda mística se insere numa comunidade, porém esta não é a comunidade rural alternativa da era hippie, mas geralmente uma comunidade urbana, de fim de semana, que permite "recarregar as baterias" para enfrentar o corre-corre da metrópole, com cursos, palestras, lançamentos de livros e outras vivências.

d) Noção de "energia". O conceito de energia (o chi do taoísmo) ou energia vital é central na visão de mundo e no ethos do neoesoterismo, assim como era nos anos 1960-1970. Com o misticismo quântico, essa energia se torna quântica e é considerada a entidade que carrega o fluxo de espiritualidade dentro do corpo, entre os indivíduos e com a natureza.

e) Preocupação com ecologia e natureza. Assim como nos anos 1960-1970, mantém-se a importância da natureza e da ecologia. Porém, no neoesoterismo, o indivíduo tira sua força da comunhão com a natureza e chega a se sentir capaz de curvar a sociedade a seus desejos e impulsos.

f) Redescoberta do feminino. Um último aspecto que marca o neoesoterismo é o novo papel do feminino. Não se trata do feminismo dos nos 70 , buscando a igualdade entre os gêneros, mas o reconhecimento da superioridade das qualidades femininas de intuição, sensibilidade, espontaneidade e senso comunitário, que de certa forma se cristalizam na figura da bruxa, com seus poderes mágicos.

Eis, então, alguns aspectos sociológicos ligados ao misticismo moderno, ao qual se sobrepôs uma popularização da física quântica. Seria preciso aprofundar essa análise sociológica e antropológica para incluir o fenômeno das raves, a nova situação das drogas e a influência dos computadores e das redes socias virtuais, entender as motivações econômicas e ideológicas por trás dos modismos esotéricos etc.

Um exemplo de como a difusão do misticismo quântico está ligada a aspectos econômicos e ideológicos foi apontado pela jornalista norte-americana Barbara Ehrenreich (2008), cuja análise foi resumida pelo psicanalista ítalo-brasileiro Contardo Calligaris (2008). Segundo Ehrenreich, o culto exagerado e místico do pensamento positivo, típico de $O$ segredo, estava incorporado à cultura corporativa de tomar riscos em excesso, o que acabou por levar ao colapso financeiro de 2008 . 


\section{Agradecimentos}

Agradeço os comentários de Joan Bromberg, Olival Freire Jr., José Guilherme Magnani, Fábio Freitas e Gustavo Rocha.

\section{Referências}

ARNTZ, W.; CHASSE, B.; VICENTE, M. Quem somos nós? Rio de Janeiro: Ediouro, 2007. Original em inglês: What the bleep do we know? Deerfield Beach (FL): HCI Books, 2005.

BYRNE, R. O segredo. Rio de Janeiro: Ediouro, 2007. Original em inglês: The secret. New York: Simon \& Schuster, 2006.

CALLIGARIS, C. A aritmética da crise. Folha de São Paulo, 2 out. 2008. O poder da reza. Folha de São Paulo, 2 dez. 2006.

CAPRA, F. O tao da física. São Paulo: Cultrix, 1983. Original em inglês: The tao of physics. Berkeley: Shambhala, 1975.

CHOPRA, D. A cura quântica. São Paulo: Best Seller, 1990. Original em inglês: Quantum healing. New York: Bantam, 1989.

CREASE, R. P. Quantum of culture. Physics World, v. 21, n. 9, p. 19-21, set. 2008.

EHRENREICH, B. The power of negative thinking. New York Times, 24 set. 2008.

GOSWAMI, A. A física da alma. São Paulo: Aleph, 2005. Original em inglês: Physics of the soul. Charlottesville (VA): Hampton Roads, 2001.

GRIM, P. (Org.). Philosophy of science and the occult. 2. ed. Albany: Sunys, 1990.

HADA, K.C. O ideal de ordem natural de Toulmin aplicado à biologia teleomecanicista do século XIX. 2007. Dissertação (Mestrado em Filosofia) - Faculdade de Filosofia, Letras e Ciências Humanas, Universidade de São Paulo, São Paulo.

HEELAS, P. The new age movement. Oxford: Blackwell, 1996. 
HERBERT, N. A realidade quântica. Rio de Janeiro: Francisco Alves, 1989. . Quantum tantra. Southern Cross Review, v. 16, 2002. Disponível em: $<$ http://www.southerncrossreview.org/17/tantra.htm>.

JAMMER, M. The conceptual development of quantum mechanics. New York: McGraw-Hill, 1966. . The philosophy of quantum mechanics. New York: Wiley, 1974.

JAHN, R.; DUNNE, B. Margins of reality. San Diego: Harcourt: Brace \& Jovanovich, 1987.

KAUARK-LEITE, P. Vers une critique de la raison quantique: les approches transcendantales en mécanique quantique. 2004. Tese (Docteur de l'École Polytechnique) - Centre de Recherche en Epistémologie Appliquée, École Polytechnique de Paris, Paris.

MAGNANI, J. G. C. Mystica urbe. São Paulo: Studio Nobel, 1999.

NÓBREGA, C. Em busca da empresa quântica. Rio de Janeiro: Ediouro, 1995.

PENROSE, R. A nova mente do rei. Trad. W. Dutra. Rio de Janeiro: Campus, 1994. Original em inglês: The emperor's new mind. Oxford: Oxford University, 1989.

PESSOA JR., O. A classificação das diferentes posições em filosofia da ciência. Cognitio-Estudos, v. 6, n. 1, p. 54-60, 2009.

. Conceitos da física quântica. São Paulo: Ed. Livraria da Física, 2003.v 1.

. ______. São Paulo: Ed. Livraria da Física, 2006a. v. 2.

. O dogmatismo científico de tradição materialista. In: SILVA, C.C.

(Org.). Estudos de História e Filosofia das Ciências. São Paulo: Ed. Livraria da Física, 2006b. p. 41-57.

. Física quântica. 2008. Disponível em: <http://www2.uol.com.br/vyaestelar/fisicaquantica.htm>. 
A física quântica seria necessária para explicar a consciência? In:

Questões metodológicas em ciências cognitivas. São Paulo: Instituto de Estudos Avançado/ USP, 1994. p. 184-189. (Coleção Documentos, Série Ciência Cognitiva, v. 20. Nova numeração: Série Ciência e Tecnologia, v. 37). S . O sujeito na física quântica. In: OLIVEIRA, E. C. (Org.). Epistemologia, lógica e filosofia da linguagem:ensaios de filosofia contemporânea. Feira de Santana: Núcleo de Estudos Filosóficos/ UEFS, 2001. p. 157-96.

PRESTON, D.L. Science, society, and the German Jews: 1870-1933. 1971. Tese (Doutorado em Filosofia) - University of Illinois, Urbana.

STAPP, H. Mindful universe. New York: Springer, 2007.

STENGER, V.J . Charlatanismo quântico. [1997]. Disponível em: <http://ateus. net/artigos/charlatanismo/charlatanismo_quantico.php $>$. Original em inglês: Quantum Quackery. Skeptical Inquirer, v. 21, n. 1, p. 37-40, 1997.

TALBOT, M. O universo holográfico. São Paulo: Best Seller, 1991. Original em inglês: The holographic universe. New York: Harper Collins, 1991.

TELLES JR., G. S. O direito quântico. São Paulo: Max Limonad, 1971. 


\title{
Mecânica Quântica e a cultura em dois momentos
}

\author{
Frederico Firmo de Souza Cruz
}

\section{Introdução}

A penetração da mecânica quântica nas atividades sociais e culturais mais diversas é notória e pode ser avaliada através de uma simples consulta ao Google. Uma busca exibe cerca de 9 milhões de entradas para medicina quântica; 3 milhões, para cura ou terapia quântica; 6 milhões para psicologia quântica; 3 milhões para mente quântica e quase o mesmo número para o tantra quântico. Esta presença em áreas tão diversas mostra que a mecânica quântica, além de uma teoria revolucionária é também um fenômeno sociocultural. Richard Dawkins escreveu,

Você pode comprar quantos livros quiser sobre cura quân-
tica, sem mencionara psicologia quântica, a responsabilidade
quântica, moralidade quântica, imortalidade quântica ou
teologia quântica. Eu não encontrei ainda um livro sobre
feminismo quântico, administração financeira quântica ou
teoria Afro-quântica, mas dê um tempo. (DAWKINS, 2003,
p. 147)

Na verdade, a previsão de Dawkins se confirmou, pelo menos em parte, pois Carolyn Guertin (2003), da Universidade de Toronto, apresentou uma tese cujo título tem o termo feminismo quântico. Sokal e Bricmont (1999) escreveram sobre os significados polissêmicos que resultam da apropriação equivocada de conceitos por diferentes grupos da comunidade acadêmica, mas aqui não falaremos da academia, nem pretendemos debater a chamada guerra das ciências, mas, sim, 
refletir sobre a inevitável apropriação de conhecimentos por comunidades que tem diferentes formações, objetivos e atividades, e compartilham o mesmo lugar e tempo na sociedade. $\mathrm{O}$ conhecimento científico, assim como a arte, a mitologia e outras criações culturais do espírito humano, é de domínio público. As práticas sociais, frequentemente, levam grupos a desenvolverem certa autonomia, criando fronteiras que são definidas por diferenças de conhecimento, de cultura, de linguagem, organização social... As fronteiras criadas geram uma falsa impressão de propriedade, mas são, em geral, porosas e móveis, e o conhecimento de uns é inevitavelmente apropriado por outros, podendo eventualmente adquirir novos significados e representações. A presença de um conhecimento tão sofisticado como a mecânica quântica, em ambientes sociais tão diversos, é um exemplo desta porosidade.

Neste trabalho vamos considerar a relação entre a Física moderna e a cultura, em dois períodos distintos: o primeiro, do final do século XIX até o final da Segunda Guerra Mundial, envolve o contexto da formulação da mecânica quântica em uma sociedade em grande ebulição; o segundo, dos anos 60 aos dias de hoje, viu crescer a presença da palavra quântica nas mais variadas atividades sociais e o ressurgimento das discussões de fundamentos e interpretações da mecânica quântica, em um momento onde ela está bem consolidada.

\section{Fazendo a revolução: o contexto da formulação}

A segunda metade do século XIX é marcada por uma grande agitação social, gerada por conflitos entre as velhas e novas classes, e pelas mudanças trazidas por uma sociedade cada vez mais urbana. (HOBSBAWN, 2009; LAWRENCE, 2005) É o tempo de uma classe média ascendente, que tenta se diferenciar tanto da aristocracia, quanto da classe operária. É uma sociedade em busca de novos valores, tentando compreender um mundo ampliado pelo colonialismo, diminuído pelas comunicações e transportes e sufocado nas grandes cidades, que funcionam como um concentrador de todos os males e bens do progresso. São tempos onde a expansão da educação levou à criação de profissões técnicas e científicas e onde se buscou, por uma racionalidade capaz administrar o caos urbano, as comunicações a saúde pública e a economia. A crença na ciência se manifestou tanto para administrar o que estava posto, como também para questionar. É o tempo em que o positivismo comteano e o marxismo utilizam o termo científico para fins diferentes. A ciência, marcada pela Teoria da Evolução de Darwin e pela Física clássica, havia obtido tanto sucesso que se pensou que o conhecimento físico do mundo havia sido dominado. 
Ao final do século XIX, a dinâmica social já havia demonstrado que o ideal positivista de estender os métodos e fundamentos das ciências naturais para o tratamento de problemas sociais e humanos não era realizável. (BIDDISS, 2009; HOBSBAWN, 2009, p. 282-386; MARTEL, 2006, parte 1) O ideal positivista não conseguia dar conta das necessidades materiais, intelectuais e espirituais de toda a sociedade. Tudo que dizia respeito ao sujeito, à vontade, ao desejo, ao espírito e ao livre arbítrio contrastava com a ideia de uma evolução ditada por leis naturais objetivas. Freud, com sua obra, havia evidenciado as agruras do ego individual, entre o inconsciente, demandando satisfação e prazer, e as restrições morais da sociedade vitoriana. Na sociedade urbana, a contestação de valores, os conflitos ideológicos e morais, o debate sobre a sexualidade e a religiosidade, amplificavam-se. (HALL, 2006; HOBSBAWN, 2009)

No plano da cultura e da arte, a decepção com a visão científica da vida em sociedade se manifestou através do modernismo que se contrapôs ao ideal quase científico do naturalismo e realismo de descrever fielmente o mundo (WALTZ, 2005). Porém, o modernismo não pode ser caracterizado como um estilo artístico, mas, sim, como um movimento multifacetado, congregando estilos, linguagens e formas de expressão nem sempre convergentes, como o cubismo, o expressionismo, o futurismo, o dadaísmo e o surrealismo. (CARDULLO; KNOPF, 2001; HOPKINS, 2004; SCHAFNNER, 2006) As obras literárias de pintura ou teatro expressavam a ruptura social, a contestação dos valores morais e estéticos burgueses e críticas à massificação da cultura. Defendiam a quebra da causalidade, da temporalidade; redefiniam os objetos e objetivos da arte e buscavam novas formas de perceber o mundo. Os modernistas buscavam liberar a representação artística da obrigação de ser fiel a uma realidade aparente e iniciaram uma crítica profunda à concepção ingênua de linguagem (MATAR, 2006); e, neste sentido, o modernismo é também uma expressão da "crise da representação" em que a ciência também se encontrava, devido a descobertas científicas que abalaram a crença no poder da percepção e na noção de realidade. A descoberta do raio-X gerou um impacto muito grande no meio cultural. Enxergar o invisível e desvelar um mundo, além do aparente sensível, motivou pintores, místicos, charlatões, visionários... De 1895, quando foi descoberto, até 1896, dezenas de livros e centenas de artigos e revistas de toda natureza foram publicados sobre o raio-X, com as mais diferentes interpretações. Por exemplo, foi interpretado como demonstração da existência de uma quarta dimensão, inacessível aos nossos sentidos. Segundo esta interpretação, a percepção humana comum permite-nos apenas ver as sombras projetadas em três dimensões de uma realidade quadridimensional, que podia ser revelada pelo raio-X. Os clarividentes e médiuns teriam a capacidade de perceber as manifestações desta quarta dimensão e as fotografias de raio-X seriam uma forma física de revelá-la. 
A radioatividade e a transmutação da matéria fez com que se tomasse consciência de que nem a matéria era perene. Gustave Le Bon (2008), em seu livro de divulgação científica, L'évolution de la matière, escreveu a respeito: "a matéria é uma forma estável de energia interatômica num processo gradual de desaparecimento no éter". Le Bon, médico, antropólogo, psicólogo social e cientista amador, era muito bem conceituado nos meios intelectuais e seu livro, best-seller da época, influenciou muitos artistas. As novas descobertas científicas de então estavam em ressonância com muitas ideias e concepções difundidas entre os modernistas e presentes no imaginário social, de forma marcante; e isto aparece nas pinturas de F. Kupka e M. Duchamps, analisadas em detalhe na referência. (HENDERSON, 1988)

$\mathrm{Na}$ comunidade científica, questões sociais e culturais e as características das novas radiações geraram um programa de pesquisa bastante controverso. No final do século XIX, importantes físicos britânicos se associaram e estiveram à frente da Sociedade Britânica para Pesquisas Psíquicas (SPP). Pesquisadores renomados, como Willian Crookes, William Fletcher Barrett, Oliver Lodge, J.J. Thomson, Lord Rayleigh, entre outros, se dedicaram a investigar fenômenos paranormais, como clarividência, telepatia, espiritismo. Tais supostos fenômenos eram muito difundidos pela Teosofia e outros movimentos místicos, mas os avanços do conhecimento sobre as radiações levaram os cientistas da SPP a vislumbrar a possibilidade de transformar tais fenômenos em objetos de pesquisa científica, isto é, enquadrá-los dentro do corpo da ciência positiva. Além deste objetivo tão positivista, muitos dos envolvidos estavam imbuídos de religiosidade e acreditavam na possibilidade de provar a existência da mente independente da matéria ordinária e, com isso, combater a filosofia materialista. (NOAKES, 2008)

O impacto destas descobertas no interior da comunidade científica e filosófica pode ser medido pelas palavras de um astrônomo, Camille Flammarion, que considerava que os raios-x demonstravam que: "sensação e realidade são duas coisas distintas; [...] na verdade, é o exemplo mais eloquente em favor do axioma: é não científico afirmar que as realidades se encerram nos limites de nosso conhecimento e observação", da obra L'inconnu, citado em (HENDERSON 1988). As palavras de Flammarion mostram o tamanho dos obstáculos que estas descobertas colocaram à noção de representação científica da realidade.

Representação é, de uma maneira ingênua, compreendida como uma forma de espelhar, isto é, criar uma imagem, uma descrição sobre algo exterior a nossa mente. Esta definição de representação traz à tona a pergunta fundamental; como é possível garantir que o sujeito, através de uma ação mental, adquira conhecimento e crie uma representação "verdadeira" e objetiva da realidade exterior? 
A filosofia dualista de Descartes, fundamentando-se na separação entre sujeito e objeto, argumenta que a veracidade e objetividade de um conhecimento e de sua representação é garantido pelo pensar metódico e não pelos dados sensíveis, contrariamente à visão empirista.

Na visão kantiana, o conhecimento objetivo e sua representação estão associados à noção de fenômeno. $\mathrm{O}$ fenômeno não é o dado puro da percepção, mas sim a representação do objeto exterior, obtida pela aplicação de categorias e formas $a$ priori. As categorias e formas a priori são estruturas cognitivas inatas, necessárias e universais, que instrumentalizam o pensamento e garantem a objetividade do conhecimento e da representação. A síntese kantiana, portanto, não se restringe às informações ou induções dos dados empíricos, nem ao racionalismo cartesiano. Entre as categorias e formas a priori, o espaço e o tempo são considerados formas puras da intuição, sem as quais não é possível pensar a experiência sensível. Este referencial epistemológico tem fortes ligações com a Física newtoniana, onde entender, explicar e pensar sobre qualquer objeto físico é compreender a dinâmica de evolução espaço-temporal. Para representar um fenômeno, é necessário ter equações de movimento. Partículas ou coisas extensas como ondas, campos, fluidos, radiação ou propriedades, como carga e temperatura, adquirem significado apenas quando descritos no espaço tempo. A própria noção de realidade de um objeto está associada à possibilidade de localizá-lo no espaço/tempo.

Tomando como referência Kant, a crise de representação fica mais evidente. A descoberta do mundo invisível pela Física questionou a percepção e o papel dos sentidos, na construção do conhecimento, e a Teoria da Relatividade, por sua vez, contestou a noção de espaço e tempo como forma a priori. Por sua vez, o inconsciente freudiano questionou a racionalidade do pensar. Se no campo filosófico e científico a representação estava em crise, na arte, os modernistas empreendiam uma verdadeira revolução representacional. Os pintores de vanguarda viram nas descobertas da Física um apoio inesperado contra a ideia de pintura como um espelho da realidade. As pinturas não precisavam mais ter contornos bem definidos, nem se referir apenas à superfície dos objetos, pois a matéria também não os tinha. O raio-X havia demonstrado a limitação do olho humano e liberou o pintor dos limites da luz visível. Picasso liberou as representações ao afirmar que "a arte é uma mentira que nos aproxima da verdade". A ideia de perceber através de aparelhos também questionou o conceito kantiano de fenômeno e gerou o conceito de fenomenotécnica de Bachelard. Para outros não há mais descobertas, apenas invenções; e pintores, como Paul Klee, concebem a pintura como uma forma de criar o visível e não de mostrá-lo.

Os desenvolvimentos seguintes da Física levaram do quantum de Planck à formulação final da mecânica quântica, exigindo de seus fundadores rupturas profundas com conceitos e concepções bastante arraigados. Quando Heisenberg 
formula sua mecânica matricial, ele abre mão da descrição no espaço/tempo. Tomando as transições como as únicas grandezas observáveis e o princípio da correspondência, ele cria uma descrição matricial sem se referir, em nenhum momento, a partículas, a posição ou a momento no espaço/tempo. Esta formulação marcou o abandono dos modelos pictóricos, como os de Bohr e Sommerfeld e caracterizou uma ruptura na forma de representar o mundo físico.

A nova linguagem e a mudança de referentes foram bastante perturbadoras e muitos receberam com alívio a descrição mais familiar, no espaço/tempo, que foi momentaneamente resgatada pela mecânica ondulatória de Schrödinger. Porém, a realidade das ondas de Schrödinger foi questionada e reinterpretada, como uma amplitude de probabilidade, e a dualidade, associada ao objeto quântico, foi harmonizada, através da interpretação probabilística e do principio da complementaridade, formando a base do que se entende por Interpretação de Copenhagen.

A Interpretação de Copenhagen, fruto de um longo processo dialógico dentro da comunidade científica e filosófica, gerou questões sobre o determinismo, o caráter probabilístico da natureza, a realidade do objeto quântico, o caráter da representação, o papel do observador e do ato de medida, o papel da consciência, a objetividade do conhecimento, a completeza da representação. (BELLER, 2001)

A completeza, no sentido clássico, requer que cada propriedade física real tenha uma contrapartida única na representação, o que é contrariado pela dualidade onda partícula. O principio da complementaridade foi proposto como uma solução de compromisso, que defende a completeza da teoria, incorporando, numa mesma representação, duas descrições diferentes e exclusivas sobre um mesmo objeto, o que não se enquadra dentro da noção kantiana de representação. Para Bohr, o termo fenômeno está associado à compreensão dos efeitos observados, sob condições experimentais estruturadas a priori, que levam em conta as propriedades complementares. A complementaridade permite, então, uma unificação da descrição, dando sentido e significado ao fenômeno. Bohr entendia que as formas usuais de percepção impõe limitações à linguagem descritiva e que estas limitações seriam inerentes à natureza humana, cujos processos cognitivos estariam vinculados aos limites da percepção. Em outras palavras, estamos presos à linguagem da Física clássica e por esta razão ele considerava que a linguagem formal da mecânica quântica não seria capaz de dar uma descrição semântica e teria um papel apenas instrumental. Neste ponto Heisenberg e Pauli discordavam de Bohr. Heisenberg considerava que a revolução na ciência estava ligada a uma revolução no padrão de pensamento, implicando nisto a atribuição de uma nova semântica à linguagem formal da mecânica quântica. (HICKEY, 1995, p. 151) Para vários autores, a concepção de fenômeno e o papel da linguagem clássica em Bohr é neokantiano. Para uma discussão mais 
aprofundada sobre o caráter neokantiano da obra de Bohr ver Brock (2009), D’Espagnat (2009), Falkenburg (2009) e Kaiser (1992).

O período de formulação da mecânica quântica foi cheio de debates e questões e se incorporou no clima intelectual marcado pela irreverência e iconoclastia da época. A perplexidade diante das questões postas pela nova Física fez com que, na busca de respostas, fossem mobilizados argumentos extraídos das mais variadas fontes, tornando a fronteira entre ciência e o meio cultural mais porosa. A seguinte frase de Bohr é bastante significativa,

[...] com respeito à limitada aplicabilidade das idealizações costumeiras, devemos de fato nos voltar para outros ramos da ciência, tais como psicologia, ou mesmo refletir sobre tipos de problemas epistemológicos que já foram enfrentados por pensadores como Buda e Lao Tse, quando tentaram harmonizar a nossa posição como espectadores e atores do grande drama da existência. Porém, o reconhecimento de uma analogia de caráter puramente lógico nos problemas que se apresentam em campos de interesse humano tão largamente separados não implica na aceitação na física atômica de qualquer misticismo estranho ao verdadeiro espírito da ciência. (BOHR, 1987, p. 367)

Pauli é um exemplo desta abertura para outros tipos de conhecimento. Devido a suas ligações com a psicanálise de Jung, ele entende que matéria e mente são aspectos complementares de uma mesma realidade, governada por princípios de ordenamento comum, e que o entendimento do mundo extrapola a pura racionalidade. A percepção e a compreensão do fenômeno para Pauli passam pela mobilização do inconsciente e não apenas do consciente. No caso, ele se refere ao inconsciente coletivo e aos arquétipos que são formas simbólicas que aparecem em todas as culturas, linguagens, mitos etc... Segundo Pauli, a compreensão da realidade passa necessariamente pelas formas simbólicas e os arquétipos funcionam como fatores de ordenação que auxiliam a criação de imagens fazendo a ponte entre a percepção e o entendimento.

[...] no presente momento alcançou-se um ponto onde a visão racionalista ultrapassou o seu zênite, e se descobriu muito estreita. Externamente todos os contrastes aparecem extraordinariamente acentuados. De um lado o caminho racional do pensamento leva a suposição de uma realidade que não poder ser diretamente apreendida pelos sentidos, mas que pode ser compreensível por meio de matemática e outros símbolos. Por exemplo, o átomo ou o inconsciente. Mas do outro lado os efeitos visíveis desta realidade abstrata são tão concretas quanto explosões atômicas, e não são 
necessariamente boas, na verdade em alguns momentos é exatamente o oposto. A fuga do meramente racional, onde o poder da vontade está quase sempre presente como um pano de fundo, para o seu oposto, por exemplo misticismo Cristão ou Budista é óbvio e emocionalmente compreensível. Porém eu ainda acredito que não existe nenhum outro caminho, seja para quem o racionalismo é estreito e perdeu força da convicção, seja para aqueles que a mágica da atitude mística, ..., não é efetiva o suficiente, senão o de se expor de uma forma ou de outra a estes contrastes acentuados e seus conflitos. (ATMANSPACHER; PRIMAS, 2006, p. 28)

Pauli advogava a necessidade de se redefinir a realidade incorporando os símbolos.

Quando o leigo diz realidade, ele usualmente pensa que está falando sobre alguma coisa evidente e bem conhecida; por contraste me parece que a mais importante e difícil tarefa de nosso tempo é trabalhar uma nova ideia de realidade... O que tenho em mente, com relação a esta nova ideia de realidade, é - em termos provisórios - a ideia de realidade do símbolo. De um lado, um símbolo é um produto do esforço humano, do outro indica uma ordem objetiva no cosmos do qual os humanos são apenas uma parte. (ATMANSPACHER; PRIMAS, 2006, p. 11)

Associando alguns arquétipos a certas simetrias, Pauli deu a estas um papel de relevância no desenvolvimento de teorias físicas, o que se mostrou extremamente frutífero para as gerações seguintes.

Apesar do seu entusiasmo com as questões sobre a mente, Pauli sempre foi muito ponderado com relação a conclusões e atento a extrapolações perigosas, por exemplo, com relação ao papel do sujeito na medida,

Uma vez que o observador físico tenha escolhido o arranjo experimental, ele não tem mais nenhuma influência sobre o resultado que é objetivamente registrado e acessível a qualquer outro sujeito. As propriedades subjetivas do observador e o seu estado psicológico são irrelevantes para as leis natureza sejam quânticas ou clássicas. (ATMANSPACHER; HANS PRIMAS, 2008, p. 94)

Como um intelectual e pensador, Pauli compartilhou as ideias de sua época; e de suas reflexões, criou novos instrumentos teóricos para investigação em Física. Importante frisar que não se trata de buscar uma ligação causal ou implicações diretas, mas sim, enfatizar o papel do Zeitgeist, promovendo um fluxo de ideias 
entre ciência e o meio cultural. Para alguns, este fluxo de ideias era positivo, mas para outros, negativo e preocupante. Em 1932, Schrödinger escreve um artigo com um título sugestivo, Ist die naturwinssenschaft Milieubedingt?, onde sugere que a Física havia caído vítima do Zeitgeist, caracterizado por uma iconoclastia que impunha a necessidade de algo radicalmente diferente da ordem estabelecida (SCHROEDINGER 1935,Cap V). Esta iconoclastia foi criticado por Planck em Where is science going?

[...] nós estamos vivendo um momento singular na história. É um momento de crise, no sentido literal da palavra, mensagens de uma decadência para a qual a nossa civilização está fatalmente destinada. Antes foi apenas a religião, especialmente os seus sistemas morais e doutrinais que foram alvo de ataque dos céticos. Então a iconoclastia começou a destroçar os ideais e princípios que até então eram aceitos nos domínios da arte. Agora invadiu o templo da ciência. Dificilmente se encontra um axioma científico que não seja negado nos dias de hoje. Ao mesmo tempo qualquer nonsense teórico apresentado em nome da ciência encontrará, quase com certeza, discípulos e crentes em algum ou outro lugar. (PLANCK, 1977, p. 66)

As palavras de Planck e de Schrödinger expressavam a perplexidade diante da crítica radical e da agitação no meio social. Toda esta crítica e agitação eram, de certa forma, resultado de acontecimentos traumáticos. A tragédia e a brutalidade resultante da Primeira Guerra geraram não apenas a Revolução Russa, como também uma estupefação diante do próprio homem. Se por um lado, Freud já havia mostrado como a psique humana é um amontoado de fragmentos não necessariamente integrados, por outro a revolução Russa mostrou que a sociedade não era imutável. Parecia que os fatos mostravam que nada havia de essencial na natureza humana, apenas o seu caráter social e cultural. Com a difusão do anticlericalismo e do secularismo, parecia não haver sequer Deus para garantir a essencialidade. Nietzsche já havia dito Deus está morto. Os movimentos vanguardistas se multiplicaram entre os que abraçaram totalmente o niilismo e o nonsense, e os que buscavam uma nova subjetividade e uma nova racionalidade. Ao Dadaísmo, que confrontava a arte e a sociedade espelhando o nonsense desta própria sociedade, segue-se o Surrealismo, que dá ênfase ao inconsciente e aos segredos da psique. Embora usualmente associado ao irracionalismo e ao bizarro, o Surrealismo se considera uma arte conceitual com suporte nas ideias de Freud e na Física de então. Para os surrealistas, os sonhos e o inconsciente não eram puramente irracionais, mas sim faziam parte de uma suprarracionalidade escondida, sobre a qual não temos consciência. A linguagem tortuosa do sonho não respeita tempo nem espaço, mas pode ser interpretada como uma expressão do que está escondido. 
Na França, por volta de 1920, os surrealistas foram expostos às implicações filosóficas da Relatividade e da Teoria Quântica através de livros e artigos de divulgação. No seu livro Surrealism, art and modern science, Gavin Parkinson (2008) descreve em detalhes como os nomes de físicos, como Einstein, Eddington e James Jeans, Niels Bohr, Erwin Schrödinger, Werner Heisenberg e Louis de Broglie apareceram em revistas próximas ao movimento surrealista. Parkinson também faz um estudo detalhado do papel de Bachelard que atuava como uma ponte intelectual entre as ciências e a arte. No período em que Planck e Schrodinger explicitam sua revolta e perplexidade com os caminhos da ciência, é também o período onde a arte e ciência se aproximam. Em 1934, Carl Einstein, escritor, crítico e teórico de arte e militante anarquista, escreve o livro Georges Braque, onde analisa o cubismo. Para ele, a guinada da arte para abstração foi causada pelas mesmas forças que geraram a Física moderna e a Psicanálise. Ele considerou que os traços distintivos da arte moderna, a causalidade, heterogeneidade e a linguagem da fragmentação e dispersão, tinham origem na nova epistemologia que emergia da física. Para ele, a relatividade e o cubismo eram faces de uma mesma revolução. No mesmo ano, Henri-Charles Puech, reconhecido historiador das religiões, escreve um artigo com o título Significação e representação, onde considera que a busca da ciência e da filosofia pela essência por traz das aparências pode ser realizada apenas por meios complexos e expressáveis apenas por símbolos e técnicas abstratas, o que causa uma ruptura entre o homem moderno e o cientista. Considera ainda que os novos objetos quase imateriais da Física moderna, além de sepultar a representação naturalista, impõe a necessidade de se criar uma outra representação, com base numa intuição mais mental e simbólica que unifique símbolo e realidade. Estas palavras ecoam palavras similares de Pauli e de Bachelard, embora não seja possível estabelecer aqui uma ligação direta entre Pauli e Puech.

Nos anos seguintes à formalização final da Mecânica Quântica, Wolfgang Paalen e Matta, considerados os últimos surrealistas, vão defender uma aproximação da arte com a mecânica quântica. Paalen, de forma mais teórica e reflexiva, tentou formular uma epistemologia comum à arte e às ciências. Ele entendia a arte e a ciência como complementares. Isto é, no espírito da dualidade onda corpúsculo, arte e ciência seriam representações exclusivas, mas ambas necessárias para um entendimento do mundo. Influenciado pela obra de de Broglie, Paalen desenvolveu um conhecimento aprofundado sobre a nova teoria dos quanta e em sua obra criou uma linguagem de ondas e cores espectrais. Publicou, em sua revista Dyn, vários artigos relacionando Arte e Física moderna. Pensava, com isso, fundar uma nova escola de pintura que superasse o surrealismo de Breton. Matta baseou muito do seu trabalho em suas interpretações e (mal) apropriações da geometria não-euclideana, da relatividade e da Mecânica Quântica. Sem ser teórico como Paalen, Matta ressignificou conceitos científicos de forma não muito rigorosa mas, segundo Parkinson, isto talvez tenha concorrido para a qualidade superior de seus quadros. (PARKINSON, 2008, p. 145) 
A aproximação entre a ciência moderna e o modernismo nas artes está associada a busca por uma descrição e/ou explicação de uma realidade que estava além das aparências e da percepção. Nesta busca, tanto a ciência quanto a arte se redefiniram. A necessidade de uma nova representação de mundo foi um dos ingredientes que criou esta sincronia de pensamentos e de reflexões, gerando um fluxo de ideias e significações entre Ciência, Arte e Filosofia. Pauli considerava que a aparição simultânea de novas noções em áreas diversas eram coincidências notáveis e, como Jung, relacionava esta simultaneidade ao inconsciente coletivo. $\mathrm{O}$ fluxo de ideias entre comunidades diversas se torna maior em momentos de crise. Nestes momentos, todos os tipos de conhecimento e de saberes e de práticas são mobilizados e ressignificados. No entanto, deve-se frisar que o processo de apropriação de um conhecimento se dá através da dinâmica interna de cada campo. Assim, no campo científico, passo a passo, através de ressignificações ao longo da história, os aspectos subjetivos contingentes e idiossincráticos vão sendo varridos em busca de uma objetivação. A visão arquetípica de matiz junguiano, importante para a ênfase no papel simbólico das simetrias em Pauli, influenciou-o no desenvolvimento e interpretação do formalismo da Mecânica Quântica, porém não é possível hoje se associar arquétipos aos conceitos da Mecânica Quântica.

\section{Mecânica quântica e os tempos modernos}

Após os anos efervescentes que serviram de pano de fundo para o desenvolvimento (1900-1922), a formulação (1923-1928), veio o período de (1929 a 1963) durante o qual a quântica se tornou um paradigma, se legitimando pela capacidade de gerar explicações sobre uma gama de fenômenos cada vez mais ampla como na física nuclear, na física do estado sólido, no vigoroso desenvolvimento da teoria quântica de campos e nas inovações tecnológicas. A ciência mais e mais especializada relegou para segundo plano as questões epistemológicas, ou assuntos filosóficos correlatos. As discussões sobre os fundamentos e interpretações ficaram restritas a pequenos grupos e a filósofos, até que o trabalho de John Bell recolocou as questões de fundamento num novo patamar, onde podia ser investigada também experimentalmente. (FREIRE, 2003, 2006, 2009) Este período, caracteriza-se pelo ressurgimento das interpretações: Copenhague, de Broglie-Bohm, histórias consistentes, transacional, modal, muitos mundos, muitas mentes etc...

$\mathrm{O}$ ressurgimento dos debates interpretativos teve como pano de fundo os anos 60. Após experiências brutais, como a bomba de Hiroshima e Nagasaki e o holocausto, a Segunda Guerra havia deixado sequelas marcantes e, apesar do crescimento econômico que se seguiu e o reerguimento da Europa, a insatisfação com os descaminhos da sociedade se refletiu em vários movimentos sociais que, de alguma forma, tinham algo em comum com os movimentos contestatórios do 
entre-guerras. $\mathrm{O}$ existencialismo, o movimento beat, os movimentos sociais de libertação no terceiro mundo, os movimentos pelos direitos civis, o movimento hippie são alguns dos que confluíram para criar a contracultura dos anos 60, com sua crítica libertária contra normas sociais, costumes, estética etc.. Os anos 60 , simbolizados pelo maio de 68 , foram marcantes tanto pela contestação, como pelo romantismo, isto é, a busca por um ideal libertário, utópico, que queria resgatar o ser humano de toda e qualquer opressão, econômica, cultural ou sexual. O sociólogo Michael Löwy sintetiza os movimentos de 68 como:

[...] uma rebelião contra a sociedade capitalista moderna, em nome de valores culturais e sociais pré-modernos, com um protesto contra o desencantamento do mundo, a dissolução de comunidades humanas pelo interindividualismo competitivo e contra o triunfo da mecanização, reificação, quantificação. (LÖWY, 2002)

Löwy considera este período como uma continuação dos esforços dos surrealistas, combinando a crítica marxista ao romantismo. No resgate da espiritualidade, o simbolismo, o misticismo e o orientalismo conquistaram corações e mentes.

Os anos 60 deixaram marcas indeléveis na sociedade atual, porém de lá até os dias de hoje houve mudanças significativas no Zeitgeist. As mudanças, por vezes, são ironizadas como a transição do mundo hippie para o mundo yuppie. Uma análise desta transição está fora de nosso foco, mas a forma como as concepções da Mecânica Quântica foram apropriadas e utilizadas é um reflexo dessas mudanças. Boa parte da contestação dos 60 foi absorvida pela mesma sociedade de consumo que era objeto da crítica. Pode-se dizer que houve uma destruição de significados.

Um herdeiro dos anos 60, Fritjof Capra, em 1975 lança um livro fazendo paralelos entre a Física moderna e o pensamento oriental. O Tao da física (CAPRA, 2000) é até hoje um dos livros mais vendidos e considerado por muitos como a origem do misticismo quântico moderno.

Embora o misticismo também tenha feito parte do contexto da formulação e tenha tido um romântico interlúdio nos anos 60 , hoje o imaginário social é muito diferente. No momento atual o misticismo, ou os que se dizem místicos, parecem necessitar mais da legitimação do que da significação. Numa sociedade onde os livros de autoajuda ocupam um lugar privilegiado na indústria cultural, o termo quântica é uma griffe. Uma comparação com os anos 60 mostra que, hoje em dia, não é o paralelismo dos símbolos ou a utopia da new age que importa. Acompanhemos algumas das frases do guru Maharish Mahesh ${ }^{1}$.

1 Site do guru: http://hitxp. wordpress.com /2007/09/06/ vedic-quantum-mechanics/ 
Deixe-me dar-lhes um exemplo. Seja uma partícula quântica, por exemplo, um elétron. Quase oposta a sua natureza de partícula, foi provado que o elétron se move através de duas fendas ao mesmo tempo. É como se você se movesse através de duas portas adjacentes (separadas por uma parede fina, cuja espessura é quase a mesma que o seu corpo) ao mesmo tempo. "Isto foi provado em vários experimentos". (grifos do guru)

Tome uma partícula quântica e conduza um experimento sobre ela sem olhá-la, você obterá um resultado. Agora tome a mesma partícula e realize o mesmo experimento, mas desta vez a observando, você obterá um outro resultado. Em outras palavras a partícula sabe se você a está observando ou não. "Isto foi provado em vários experimentos". (grifos do guru)

Podemos ainda seguir Amit Goswani, físico de formação e místico de profissão, que atua de forma bem mais sofisticada do que o guru, com suas frases soltas, no site indicado na nota de rodapé. No capítulo 2 de seu livro, A física da alma (GOSWAMI, 2008), ele discute as experiências de Aspect, Dalibard e Roger e conclui que "[...] os fótons do experimento estão conectados por meio de um domínio não local da consciência que transcende o espaço e tempo" e que isto é uma prova da telepatia.

Dando continuidade ao seu discurso pseudocientífico, Goswami discute o experimento da escolha retardada de Wheeler, relacionando-o com o conceito de sincronicidade de Jung e Pauli para em seguida afirmar que esta é uma das primeiras tentativas de compreender a reencarnação por meio do conceito de não localidade quântica no tempo. A seção termina com a frase “[...] o experimento da escolha retardada foi comprovado experimentalmente na década de 1980.”.

Nas frases acima, sempre seguidas de "foi provado experimentalmente", fica patente o uso dos conceitos apenas para legitimar cientificamente asserções místicas. É difícil imaginar que um físico como Goswami não esteja ciente dos problemas envolvidos na extrapolação de resultados de experimentos com poucos fótons e/ou átomos ou moléculas para seres tão complexos como o homem, constituído de zilhões de átomos. Pela mesma razão é notório o uso de frases e citações de Bohr, Pauli, Wigner, Heisenberg, Schroedinger, que são repetidas como um mantra na maioria dos livros de "alguma coisa" quântica. Frequentemente as frases são extraídas do contexto e muitas vezes são mutiladas.

Para os místicos modernos, ou quiçá pós-modernos, o objetivo é apenas a persuasão através da fala da autoridade. Não há interesse no debate conceitual, nem na crise de representação, nem no papel dos símbolos e da intuição, ou qualquer 
outro assunto que foi tão importante para os fundadores. Para eles, o conhecimento científico tem apenas um caráter instrumental, servindo de artifício ideológico ou sofístico para legitimar certas afirmações; eles estão interessados apenas em usar os mistérios quânticos como uma mercadoria.

\section{Conclusões}

O traço distintivo entre os dois momentos que tratamos é que, no contexto da formulação, uma espécie de contexto coletivo da descoberta, a arte estava em busca de novas representações e o mundo de novos valores. Este ambiente propiciou o fluxo de ideias, a partir da comunidade científica e para ela, na busca de novos significados e novas formas para compreender e representar o mundo. Já no momento atual, temos uma forte pressão da indústria cultural e a Mecânica Quântica se encontra mais próxima do contexto da justificação e como tal é utilizada, apenas como argumento de legitimação e propaganda. Apesar de certas similaridades com o período da formulação, alguns aspectos das relações entre quântica e a cultura, nos dias de hoje, se repetem quase sempre como farsa, indicando mais uma crise de significação do que de representação.

Antes de concluir, devemos mencionar que, além do misticismo quântico e outros "ismos quânticos", nas artes existem movimentos como a Estética Quântica (CARO; MURPHY, 2002), que se assemelha em muito aos movimentos da época do surrealismo e busca uma aproximação entre Arte e Ciência. $\mathrm{O}$ problema cérebro-mente ou mente e matéria que se tornou para alguns a quântica e consciência, é um tema recorrente que penetra a sociedade, ultrapassando os muros entre diferentes campos disciplinares e envolvendo cientistas e leigos. (PENROSE, 2000; STAPP, 2009; TUSZYNSKI, 2006) Não podemos esquecer que este tema também esteve presente no contexto da formulação. (MARIN, 2009) $\mathrm{O}$ ressurgimento do debate sobre as interpretações também atrai o campo filosófico e promove uma aproximação entre comunidades que já estiveram mais separadas (BITBOL; KERSZBERG; PETITOT, 2009); e para finalizar não podemos esquecer o debate sempre presente de fundo teológico. (DJUPSJÖBACKA, 2005; HODGSON, 2006)

Tudo isto demonstra que talvez os dois mundos de Snow não estejam tão separados assim e que a porosidade e consequente apropriação de conhecimentos por várias comunidades ou grupos sociais é um interessante objeto de investigação e reflexão. 


\section{Referências}

ATMANSPACHER, H.; PRIMAS, H. Pauli' s Ideas on Mind and Matter in the context of Contemporary Science. Journal of Consciousness Studies, v. 13, p. 5-50, 2006.

. Recasting reality: wolfgang Pauli's philosophical ideas and contemporary science. Dordrecht: Springer, 2008.

BELLER, M. Quantum dialogue: the making of a revolution. Chicago: University Of Chicago 2001.

BIDDISS, M. Intellectual and cultural upheaval,1890-1945. In: . Themes in Modern European History, 1890-1945. London: Routledge, 2009. p. 82-116.

BITBOL, M.; KERSZBERG, P.; PETITOT, J. (Ed.). Constituting objectivity: transcendental Perspectives on Modern Physics. Dordrecht: Springer, 2009. (The Western Ontario Series in Philosophy of Science)

BOHR, N. H. D. Niels Bohr, essays and papers. Rochester: J T Sanders, 1987.

BON, G. L. The Evolution of matter. Swift, M.A: Kessinger, 2008.

BROCK, S. Old Wine Enriched in New bottles: Kantian flavors in Bohr's viewpoint of complementarity. In: BITBOL, M.; KERSZBERG, P.; PETITOT, J. (Ed.). Constituting objectivity: transcendental Perspectives on Modern Physics. Dordrecht: Springer, 2009. (The Western Ontario Series in Philosophy of Science). p. 301-317.

CAPRA, F. The tao of physics: an exploration of the parallels between modern physics and eastern mysticism. 4th ed. Berkeley, California: Shambhala, 2000.

CARDULLO, B.; KNOPF, M. R. (Ed.). Theater of the Avant-Garde, 1890-1950: a critical anthology. New York: Yale University, 2001.

CARO, M. J.; MURPHY, J. W. The world of quantum culture. Westport, CT: Praeger, 2002.

DAWKINS, R. ,A Devil's Chaplain: Reflections on Hope, Lies, Science, and LoveBoston -New York: Houghton Mifflin Company, 2003 
D’ESPAGNAT, B. A Physicist's Approach to Kant. In: BITBOL, M.;

KERSZBERG, P.; PETITOT, J. (Ed.). Constituting objectivity: transcendental Perspectives on Modern Physics. Dordrecht: Springer, 2009. (The Western Ontario Series in Philosophy of Science). p. 481-490.

DJUPSJÖBACKA, S. Dialogue in the crisis of representation. Abo: Åbo Akademis Förlag - Åbo Akademi University, 2005.

FALKENBURG, B. A critical account of physical reality. In: BITBOL, M.; KERSZBERG, P.; PETITOT, J. (Ed.). Constituting objectivity: transcendental Perspectives on Modern Physics. Dordrecht: Springer, 2009. (The Western Ontario Series in Philosophy of Science). p. 229-252. Springer.

FREIRE, O. Philosophy enters the optics laboratory: Bell's theorem and its first experimental tests (1965-1982). Studies In History and Philosophy of Science Part $B$, v. 37, n. 4, p. 577-616, 2006.

Quantum dissidents: Research on the foundations of quantum theory circa 1970. Studies In History and Philosophy of Science Part B, v. 40, n. 4, p. 280-289, 2009.

A story without an ending: the quantum physics controversy 1950 1970. Science \& Education, v. 12, n. 5, p. 573-586, 2003.

GOSWAMI, A. A física da alma. São Paulo: Aleph, 2008.

GUERTIN, C. G.. Quantum Feminist Mnemotechnics: the archival text, digital narrative and the limits of memory. 2003. Disponível em: $<$ http://www. mcluhan.utoronto.ca/academy/carolynguertin/diss.html>.

HALL, L. Sexuality. In: MARTEL, G. (Ed.). A companion to Europe 1900-1945. Oxford,UK: Blackwell, 2006. p. 82-97.

HENDERSON, L. D. X rays and the quest for invisible reality in the art of kupca, Duchamp and the cubists. Art Journal, p. 323-340, 1988.

HICKEY, T. J. History of twentieth-century philosophy of science. [S.I.]: T.J. Hickey, 1995.

HOBSBAWN, E. A era dos impérios 1875-1914 . São Paulo: Paz e Terra, 2009. 
HODGSON, P. E. Theology and modern physics. Burlington VT: Ashgate, 2006.

HOPKINS, D. Dada and surrealism: a very short introduction. Oxford: Oxford University, 2004.

KAISER, D. More roots of complementarity: Kantian aspects and influences. Studies In History and Philosophy of Science Part A, v. 23, p. 213-239, 1992.

LAWRENCE, P. Urbanization, poverty and crime. In: MARTEL, Gordon (Ed.). A companion to Europe: 1900-1945. India: Blackwell, 2005. p. 3-18.

LOWY, M. The revolutionary romanticism of may 1968. Thesis Eleven, v. 68, n. 1, p. 95-100, 2002.

MARIN, J. M. 'Mysticism' in quantum mechanics: the forgotten controverse. European Journal of Physics, v. 30, n. 4, p. 807-822, 2009.

MARTEL, G. A companion to Europe 1900-1945. Oxford, UK: Blackwell, 2006.

MATAR, A. Modernisn and the language of philosophy. New York: Routledge, 2006.

NOAKES, R. The world of the infinitely little: connecting physical and psychical realities circa 1900. Studies In History and Philosophy of Science Part A, v. 39, p. 323-334, 2008.

PARKINSON, G. Surrealism, art and modern science. New Haven: Yale University, 2008.

PENROSE, R. The large, the small and the human mind. Cambridge: Cambridge University, 2000.

PLANCK, M. Where is science going? Norton; New YorK: AMS, 1977.

SCHAFNNER, A. C. Assaulting the order of signs. In: JONES, Dafydd (Ed.). Dada culture: critical texts on the avant-garde. Amsterdam: Rodopi, 2006. p. 117-136. (Avant-garde critical studies, v. 18)

SCHRODINGER. E. Science and the human temperament (James Murphy translator ), London: George Allen and Unwind Ltd.,1935 ,cap V. 
SOKAL, A.; BRICMONT, J. Fashionable nonsense: postmodern intellectuals' abuse of science. New York: Picador, 1999.

STAPP, H. P. Mind, matter and quantum mechanics. 3rd ed. Dordrecht:

Springer, 2009.

TUSZYNSKI, J. A. The emerging physics of consciousness. Dordrecht: Springer, 2006.

WALTZ, R. Modernism. In: MARTEL, Gordon (Ed.). A companion to Europe: 1900-1945. India: Blackwell, 2005.p. 50-65. 


\title{
Os princípios de complementaridade e de incerteza na obra Copenhague de Michael Frayn: a arte e a teoria quântica
}

\author{
Alessandro Frederico da Silveira \\ Aurino Ribeiro Filho \\ Ana Paula Bispo da Silva
}

\section{Introdução}

A obra Copenhague, escrita em 1997 pelo escritor Michael Frayn, situa-se em tempo e lugar desconhecidos. São três os personagens principais: Niels Bohr, Werner Heisenberg e Margrethe Norlungue, esposa de Niels Bohr. Os personagens estão mortos e relembram, ora no mesmo ambiente, ora em ambientes diferentes, o que Bohr e Heisenberg conversaram em um encontro real realizado entre os cientistas em 1941, em Copenhague, Dinamarca, na casa de Bohr. A conversa oscila entre dois assuntos principais: os princípios de incerteza e complementaridade e a questão nuclear. (DÖRRIES, 2005; FRAYN, 2000; SHEPHERD-BARR, 2006)

Quando o encontro ocorreu, em outubro de 1941, Heisenberg, professor de Física Teórica na Universidade de Leipzig, liderava o programa alemão para investigar a possibilidade de fabricação de uma bomba atômica. Nesse período, a Alemanha nazista já havia ocupado a Polônia, Bélgica, Holanda, Noruega, parte da França e a Dinamarca, onde Bohr se encontrava, isolado em sua casa. Heisenberg estava em Copenhague para participar de um seminário no Instituto Cultural Alemão e foi convidado por Bohr para jantar em sua casa. (DÖRRIES, 2005) Como costumeiramente acontecia nos encontros de Bohr, os dois saíram para uma caminhada para conversar, porém, pouco se sabe sobre o que conversaram. (ABDALLA, 2006; HEISENBERG, 1995; MARTINS, 2006a) 
Durante os anos de 1925 a 1927, Niels Bohr (1885-1962) e Werner Heisenberg (1901-1976) haviam trabalhado juntos em Copenhague, desenvolvendo dois dos princípios fundamentais formadores da chamada Interpretação de Copenhague, que negava a possibilidade de descrições causais microscópicas, semelhantes às da Física clássica, para os fenômenos quânticos, o princípio de incerteza e o da complementaridade. (MARTINS, 2006b)

Em 1927, Heisenberg havia chegado às relações de incerteza, baseado principalmente no papel do experimento na Teoria Quântica e no formalismo para descrever os fenômenos. (JAMMER, 1974, p. 63) Porém, as bases conceituais sobre as quais o princípio de incerteza foi estabelecido não agradaram a Bohr, apesar de ele concordar com as conclusões a que Heisenberg chegava em sua formulação. Este fato acabou gerando uma controvérsia entre os dois físicos.

A posição de Bohr estava baseada principalmente no fato de que as relações de incerteza limitavam a aplicabilidade das noções clássicas de posição ou momentum ao caso da microfísica. Além disso, havia as diferentes opiniões sobre o papel do formalismo matemático nas explicações físicas. Para Bohr, a explicação física precede o formalismo matemático, enquanto que para Heisenberg o formalismo matemático é que descreve o que ainda será observado.

Neste trabalho, apresentaremos os elementos de História da Mecânica Quântica presentes na peça; em particular, exploramos as ideias dos princípios da complementaridade e da incerteza, discutidas pelos personagens.

\section{0 princípio de incerteza}

A questão da incerteza de Heisenberg diz respeito ao processo intrínseco de medida e expressa o fato de que sempre existe uma interação não determinável entre o observador e o que é observável (BOHR, 1928; GUIMARÃES, 1996; ROBERTSON, 1929) e que, segundo Heisenberg, não podemos fazer nada para evitar esta interação ou corrigir os seus efeitos. (GUIMARÃES, 1996) No melhor dos casos sempre haverá uma imprecisão ou, mais exatamente, incertezas devidas não à imperfeição das medidas efetuadas, mas à natureza intrínseca da matéria.

Uma forma de expressar o citado princípio se refere às tentativas de medir a posição e o momentum de um objeto quântico simultaneamente. Especificamente, se, por exemplo, tratamos de localizar muito precisamente um elétron, somos forçados a renunciar à informação sobre seu momentum. Reciprocamente, podemos medir o momentum do elétron com muita precisão, mas então sua posição fica indeterminada. (HEISENBERG, 1927, 1949; MENESES, 2008a) 
Heisenberg se dedicou a mostrar que embora para cada conceito mecânico tomado individualmente não haja, nem mesmo no domínio quântico, falta de experimentos capazes de lhe conferir legitimidade física, a quantização característica desse domínio impede que a posição e o momentum possam ser determinados experimentalmente, ao mesmo tempo com precisão ilimitada. Para isso, em seu trabalho de 1927, introduz o famoso experimento de pensamento do microscópio de raios gama, para ilustrar a origem física do princípio da incerteza. (CHIBENI, 2005; GUIMARÃES, 1996; HEISENBERG, 1927, 1949; ROSENFELD, 1971 apud WHEELER; ZUREK, 1983)

Após seus estudos, Heisenberg chega à relação apresentada a seguir e

[...] contrariamente ao que ocorre na mecânica de Newton, não se pode medir simultaneamente aquelas grandezas com alta precisão arbitrariamente. De fato, o produto das duas imprecisões, em suas medidas, resultou não ser menor que a constante de Planck [...]. (HEISENBERG, 1999, p. 63)

$$
\delta \mathrm{x} \delta \mathrm{p}_{\mathrm{x}} \geq \mathrm{h}
$$

em que $\delta \mathrm{x}$ é a incerteza da posição na direção x e $\delta$ pxé a incerteza no momentum final da partícula ao longo da direção $\boldsymbol{x}$.

Pode-se dizer que tudo se passa de forma que, quanto mais precisamente se medir uma grandeza, forçosamente mais será imprecisa a medida da grandeza correspondente, chamada de canonicamente conjugada. (BOHR, 1928; FEYNMAN; LEIGHTON; SANDS, 1987; ROBERTSON, 1929)

Desta maneira, o princípio de incerteza também está relacionado com a medida da energia $\mathrm{E}$ e do tempo $t$ necessário à medida, como, por exemplo, o intervalo de tempo $\delta t$ durante o qual um fóton com incerteza na energia $\delta E$ é emitido de um átomo. Neste caso,

$$
\delta E \delta t \geq \mathrm{h}
$$

em que $\delta E$ é a incerteza no nosso conhecimento da energia $E$ de um sistema e $\delta t$ é o intervalo de tempo característico da rapidez com que ocorrem as mudanças no sistema.

Outra leitura que se pode fazer do princípio de incerteza é que existe uma complementaridade posição-momentum. Podemos escolher medir a posição de uma partícula, em cujo caso seu momentum é incerto ou podemos medir o momentum e abandonar o conhecimento de sua posição. Cada uma das propriedades - posição e momentum - constitui um aspecto complementar do objeto 
quântico. (HEISENBERG, 1999) Se conhecermos uma dessas grandezas com alta precisão, a outra não poderá ser conhecida do mesmo modo; mesmo assim, precisamos conhecer ambas as imprecisões, a fim de determinar o comportamento do sistema.

Bohr elevou essas ideias à categoria de princípio: o da complementaridade. $\mathrm{Na}$ dualidade onda-partícula, por exemplo, as propriedades ondulatória e corpuscular de um objeto quântico constituem aspectos complementares de seu comportamento. Ele argumentou que não deveríamos encontrar nunca experimentos em que estes dois comportamentos diferentes entram em conflito entre si. (HEISENBERG, 1999)

\section{O princípio de complementaridade}

Bohr apresentou as suas ideias sobre a complementaridade pela primeira vez em um Congresso na cidade de Como, na Itália, em comemoração ao centenário da morte de Alessandro Volta, no outono de 1927. (BASTOS FILHO, 2003; FREIRE JR., 1999; GREENSTEIN; ZAJONC, 1997; KRAGH, 1999; PESSOA JR., 2008; ROSENFELD, 1971a apud WHEELER E ZUREK, 1983) Nesta ocasião, ele menciona que no mundo quântico, ao contrário do mundo clássico, nunca se pode fazer a observação de um sistema sem perturbá-lo. (BOHR, 1928, 1950; FOLSE, 1985; KRAGH, 1999; SELNER, 2006)

Bohr aproveitou essa oportunidade para falar sobre os fundamentos filosóficos da Teoria Quântica. A evidente dualidade onda-partícula nos experimentos e as relações de incerteza foram descritas por Bohr como uma nova forma de entendimento desta Teoria, conforme foi enunciado por ele:

[... o quantum de ação] força-nos a adotar um novo modo de descrição designado de complementaridade no sentido de que qualquer aplicação dada dos conceitos clássicos proíbe uso simultâneo de outros conceitos clássicos os quais em uma diferente conexão são igualmente necessários para a elucidação dos fenômenos. ${ }^{1}$ (BOHR, 1961 apud GREENSTEIN; ZAJONC, 1997, p. 84)

1 "[... the quantum of action] forces us to adopt a new mode of description designated as complementarity in the sense that any given application of classical concepts precludes the simultaneous use of other classical concepts which in a different connection are equally necessary for the elucidation of the phenomena." 
Essa citação exprime o que Bohr chamou de complementaridade, em que as propriedades ondulatórias e corpusculares de um objeto quântico constituem aspectos complementares de seu comportamento. Um sistema quântico pode exibir aspectos corpusculares ou aspectos ondulatórios, dependendo do arranjo experimental, mas não ambos ao mesmo tempo. (BASTOS FILHO, 2003; BOHR, 1935; MENESES, 2008b; PESSOA JR., 2008; SELNER, 2006)

De fato, aqui novamente nós não estamos lidando com as imagens contraditórias, mas com as imagens complementares dos fenômenos as quais somente juntas oferecem uma generalização natural do modo clássico de descrição. ${ }^{2}$ (BOHR, 1928, p. 91)

Em decorrência, Bohr argumentou que nunca se encontrariam experimentos em que estes dois comportamentos diferentes pudessem ser revelados ao mesmo tempo. (BOHR, 1935; FOLSE, 1985; SELNER, 2006) A complementaridade afirma que onda e partícula são conceitos mutuamente exclusivos. Quando um experimento particular mostra um, o outro não está presente. Eles nunca aparecem juntos.

Há uma mútua exclusão entre esses tipos experimentais, como mencionado pelo próprio Bohr:

De fato, é só a exclusão mútua de qualquer um dos dois procedimentos experimentais, que permite a definição inequívoca de quantidades físicas complementares, [...] para as novas leis físicas, a tal coexistência poderia parecer irreconciliável à primeira vista com os princípios básicos da ciência. ${ }^{3}$ (BOHR, 1935, p. 700)

Assim, se fizermos um experimento no qual fique claramente caracterizada a natureza ondulatória de um objeto quântico, suas características de partícula não irão se manifestar; e vice-versa.

O princípio de complementaridade afirma que qualquer experimento com uma entidade quântica, como um elétron, pode ser compreendido ou em um quadro corpuscular, ou

2 "In fact, here again we are not dealing with contradictory but with complementary pictures of the phenomena, which only together offer a natural generalization of the classical mode of description."

3 "In fact, it is only the mutual exclusion of any two experimental procedures, permitting the unambiguous definition of complementary physical quantities, [...] for new physical laws, the coexistence of which might at first sight appear irreconcilable with the basic principles of science." 
em um ondulatório, mas nunca em ambos ao mesmo tempo. Ou seja, se observo franjas de interferência, não posso atribuir trajetórias, e vice-versa. (PESSOA JR., 2008, p. 35)

O principio de complementaridade, além de afirmar a dualidade, declarava que quanto mais um dos dois aspectos é realçado, tanto mais o seu complemento é ofuscado.

O princípio de complementaridade (que é uma das bases da interpretação de complementaridade ou interpretação de Copenhague) pode ser definido como um fator comum que pode ser encontrado em uma variedade de situações. (BOHR, 1950, p. 53) Bohr estendeu a interpretação de complementaridade para outros ramos além da Física quântica, como a Termodinâmica e a Biologia. (JAMMER, 1974, p. 87)

Existem relatos de que o princípio de incerteza foi fundamental para a complementaridade. (FOLSE, 1985; HEISENBERG, 1967 apud WHEELER; ZUREK, 1983; KRAGH, 1999; MENESES, 2008a) E que nesta relação, Heisenberg tendeu a interpretar o princípio de incerteza de modo que apoiou a ideia que a tarefa da ciência é somente desenvolver um formalismo matemático para predizer fenômenos observados. (FOLSE, 1985; JAMMER, 1974)

A abordagem de Heisenberg manteve-se próxima à matemática da Teoria Quântica, não utilizando a linguagem tradicional da Física. Ao contrário, Bohr insistiu que para resolver o dilema dessa dualidade era necessário procurar um caminho dentro das ideias e linguagens da Física clássica. ${ }^{4}$ (GREENSTEIN; ZAJONC, 1997, p.83)

Os aspectos apresentados por ambos os princípios tiveram implicações filosóficas na Ciência, em especial na causalidade e no determinismo da Física clássica, quando se percebeu que o surgimento de fenômenos subatômicos não podia ser explicado pelo seu desdobramento em causas e efeitos, como se fazia até então. (JAMMER, 1974; MENESES, 2008b; SELNER, 2006) Apenas com David Bohm, em 1952, é que se conseguiu articular uma interpretação causal da física quântica.

4 "The approach of Heisenberg was to hold closely to the mathematics of quantum theory and to forgo using the traditional language of physics. By contrast, Bohr insisted on seeking a way within the ideas and language of classical physics [...]. (GREENSTEIN; ZAJONC, 1997, p. 83) 


\section{Explorando o texto: as ideias dos personagens sobre os princípios de complementaridade e de incerteza}

Ao explorarmos o segundo ato da peça, encontramos no diálogo $0^{5}$ entre os personagens, Heisenberg e Bohr, uma primeira referência aos princípios de incerteza e complementaridade, conforme descrevemos a seguir:

BOHR: De 1924 a 1927.

HEISENBERG: Do momento em que eu cheguei a Copenhagen pra ser seu assistente...

BOHR: Até sua partida, para ocupar sua cadeira em Leipzig.

HEISENBERG: Três anos de primaveras tempestuosas e revigorantes.

BOHR : E no final nós tínhamos a mecânica quântica, nós tínhamos a teoria da Incerteza.

HEISENBERG: Nós tínhamos a Complementaridade.

BOHR: Nós tínhamos toda a Interpretação de Copenhagen! (FRAYN, 2000, p. 60-61)

Mais adiante, encontramos no diálogo, agora com a participação da Margrethe, referências específicas ao princípio de incerteza.

HEISENBERG: Minha cabeça começou a clarear e eu tive uma imagem clara de como a física do átomo deveria se parecer. De repente percebi que nós tínhamos que limitá-la às medidas que nós pudéssemos tirar, daquilo que pudéssemos de fato observar. Nós não podemos. Simplesmente não podemos ver os elétrons dentro do átomo...

MARGRETHE: Assim como Niels não pode ver os pensamentos na sua cabeça; ou você, os pensamentos dele.

HEISENBERG: Tudo que nós podemos ver são os efeitos que os elétrons produzem, através da luz que eles refletem...

BOHR: Mas os problemas que você estava tentando resolver eram aqueles mesmos que nós tínhamos explorado juntos, jantando no apartamento ou na praia.

5 Os trechos foram retirados do texto original da peça, com a nossa tradução. 
HEISENBERG: Claro, claro. Mas eu me lembro da noite em que a matemática começou a bater com o princípio. (FRAYN, 2000, p. 62)

Como já mencionamos anteriormente, tal incerteza diz respeito ao processo intrínseco de medida e expressa o fato de que sempre existe uma interação não determinável entre o observador e o que é observável.

Sobre este aspecto, Frayn nos adverte que

[...] o conceito de incerteza é uma dessas noções científicas que se tornou cunhagem comum, e generalizou-se ao ponto de perder muito de seu significado original [...]. ${ }^{6}$ (SHEPHERD-BARR, 2006, p. 96)

e ainda complementa que:

[...] pensamentos e intenções, até mesmo da própria pessoa -talvez da maioria das pessoas - se modifiquem. Não há um único pensamento ou intenção de qualquer tipo que possa ser estabelecido precisamente.? (FRAYN, 2000, p. 99)

Assim, essa visão de Frayn sobre o conceito de incerteza é usada na peça não só para explorar o próprio conceito, mas também para caracterizar os personagens Bohr e Heisenberg, cujas visões acerca da guerra e da pesquisa atômica são constantemente questionadas.

Em outro recorte do texto da peça, encontramos um diálogo entre Heisenberg e Bohr, o que a nosso ver já fora apresentado anteriormente por Jammer (1974), quando este autor enfatiza as ideias contrárias entre os dois físicos, acerca do princípio de incerteza .

BOHR: Eu disse apenas que a fórmula de ondas e a mecânica matricial são ferramentas alternativas.

HEISENBERG: Isso é uma coisa que você está sempre me acusando. "Se funciona, funciona". Não importa o que significa.

BOHR: É claro que eu me importo com o que significa.

HEISENBERG: O que significa em língua de gente.

6 "[...] the concept of uncertainty is one of those scientific notions that has become common coinage, and generalized to the point of losing much of its original meaning."

7 “[...] thoughts and intentions, even one's own-perhaps one's own most of all-remain shifting and elusive. There is not one single thought or intention of any sort that can ever be precisely established." 
BOHR: Claro, em língua de gente.

HEISENBERG: O significado de uma coisa é o que ela significa em Matemática.

BOHR: Você acha que contanto que a Matemática funcione, o sentido não tem importância.

HEISENBERG: A matemática é o sentido! Sentido é isso!

BOHR: Mas no final, no final, lembre-se bem, a gente sempre tem que ser capaz de explicar tudo para Margrethe! (FRAYN, 2000, p.64-65)

Percebemos que o personagem Bohr, ao referir-se à Margrethe, também se preocupa com a maneira como tal princípio é comunicado às "pessoas comuns", aquelas que não se encontram na academia e não discutem ciência. A explicação para Margrethe tem implícita a questão do papel do formalismo matemático na descrição de fenômenos observáveis. Ainda que a expressão matemática forneça possíveis respostas, para que haja a compreensão dos fenômenos, deve-se sempre ter em mente a questão dos observáveis. Assim, um fenômeno microscópico deveria ser possível de descrever da mesma forma que a mecânica clássica descreve os fenômenos macroscópicos, compreensíveis por Margrethe.

Ainda sobre o princípio de incerteza, abaixo apresentamos duas falas de Heisenberg, em que o mesmo estabelece uma relação do princípio com uma situação imaginária.

E foi aí que eu cheguei na Teoria da Incerteza. Andando pelo Parque, sozinho, numa noite de inverno horrível. É muito tarde, e assim que eu entro no parque, eu fico completamente sozinho no escuro. Eu começo a pensar no que você veria, se pudesse focar um telescópio em mim, lá das montanhas da Noruega. Você só me veria quando eu passasse embaixo das lâmpadas de rua, e não veria nada quando eu sumisse dentro da escuridão. De repente, outra pequena aparição minha, quando eu passasse debaixo da lâmpada no coreto. E é isso que a gente vê na câmara de nuvens. Não um rastro continuo, mas uma série de aparições momentâneas produzidas por uma série de colisões entre um elétron passando e várias moléculas de vapor de água...Eu não sei como a gente não tinha pensado nisso antes! A não ser que a gente estivesse tão ocupado discutindo, que não havia tempo pra pensar [...] (FRAYN, 2000, p. 66-67)

[...] Você nunca pode saber tudo sobre a trajetória de uma partícula, ou sobre qualquer outra coisa, nem mesmo sobre Bohr agora, zanzando pra cima e pra baixo pela sala, deste 
jeito enlouquecido dele, porque nós não podemos observar se não introduzirmos um novo elemento na situação, uma molécula de vapor de água para a partícula bater nela, um pedaço de luz, enfim, coisas que tenham energia própria, e que, justamente por isso, produzem um efeito naquilo em que batem. Um pequeno efeito, no caso de Bohr [...]. (FRAYN, 2000, p. 67-68)

Nesta fala, em particular, a peça apresenta uma visão distorcida, pois dá a entender que o princípio de incerteza teria surgido de um insight de Heisenberg. Segundo Beller $(1985)^{8}$, as limitações de medidas impostas pelo princípio de incerteza já tinham sido discutidas por Pascual Jordan.

O trecho da peça fornece subsídios para entender alguns aspectos do princípio de incerteza, tais como:

a) O comportamento das partículas é totalmente imprevisível.

b) É impossível se determinar, efetivamente, órbitas ou trajetórias para os elementos de um sistema microscópico, pois a simultaneidade das medidas de posição e momentum apresenta uma incerteza intrínseca às medidas.

c) O conhecimento mais preciso possível sobre um sistema físico não permite prever sua evolução no tempo, por causa das incertezas existentes.

Mais adiante, neste segundo ato da peça, passam a surgir as primeiras ideias dos personagens sobre a complementaridade. Abaixo, apresentamos algumas falas que dão indícios sobre tal princípio.

HEISENBERG: Escuta. Copenhagen é um átomo. Margrethe é seu núcleo.

BOHR: Sim, sim...

HEISENBERG: Agora, Bohr é um elétron. Ele está passeando pela cidade em algum lugar da escuridão, ninguém sabe aonde. Ele está aqui, ele está lá, ele está em todo lugar e em lugar algum. Lá em cima, no Parque, lá embaixo, no centro da cidade. Passando em frente à Prefeitura, pelo porto. Eu sou um fóton. Um quantum de luz. Eu sou mandado para a escuridão para achar Bohr. Eu o encontro, eu dou um jeito

8 Segundo Beller (1985, p. 347), as ideias de Jordan sobre as probabilidades de transição podem ser agrupadas em cinco pontos principais, que coincidem com as hipóteses de Heisenberg na elaboração do princípio de incerteza. Além disso, é a partir do trabalho de Jordan que Heisenberg passa a interpretar de modo diferente o significado da posição do elétron. 
de colidir com ele... Mas o que foi que aconteceu? Olha, ele ficou mais lento, ele se desviou. Ele não está mais andando enlouquecidamente como estava antes de eu ir até ele.

BOHR: Mas, Heisenberg, Heisenberg! Você também foi desviado! Se as pessoas podem ver por onde você caminhou até me encontrar, então elas podem descobrir por onde eu devo ter caminhado! O problema é saber o que aconteceu com você! Porque para entender como as pessoas te vêm, a gente tem que te tratar não como uma partícula, mas como uma onda. Eu tenho que usar não só a sua mecânica de partículas, eu tenho que usar a função de onda de Schrödinger.

HEISENBERG: Eu sei - eu coloquei isso num post-scriptum no meu artigo.

BOHR: Todos lembram do artigo - ninguém se lembra do post-scriptum. Mas a questão é fundamental. Partículas são coisas, completas em si mesmas. Ondas são perturbações em outra coisa. (FRAYN, 2000, p. 68-69)

Bohr apresenta as bases de seu princípio para quase todos os físicos envolvidos na nova Teoria Quântica, no mês de setembro do mesmo ano em que Heisenberg publica sobre as relações de incerteza. Para Bohr, as "entidades quânticas” não são nem ondas nem partículas, nem uma combinação das duas coisas. No entanto, elas podem se comportar como ondas ou partículas, dependendo da situação.

Em outros recortes de falas dos três personagens, o princípio de complementaridade também é encontrado dentro de um contexto em que os personagens utilizam situações diárias imaginárias, a fim de melhor exemplificar tal princípio.

HEISENBERG: Eu sei. Complementaridade. Está lá no postscriptum.

BOHR: Elas são uma coisa ou a outra. Ou são partículas ou são ondas. Não podem ser as duas coisas ao mesmo tempo. Nós temos que escolher uma forma ou outra de olharmos para elas. Mas na medida em que escolhemos, já não podemos saber tudo sobre elas.

HEISENBERG: Sei, sei, Complementaridade... É claro que o lugar pra onde você vai quando passeia é determinado pelos seus genes e pelas várias forças físicas agindo em você. Mas também é determinado pelo impenetrável capricho de um momento para o outro. Assim, nós não podemos compreender completamente seu comportamento, sem olhar pra você das duas maneiras ao mesmo tempo. E lá vai ele entrando em órbita outra vez. 
BOHR: Você nunca aceitou total e absolutamente a Complementaridade, aceitou? (FRAYN, 2000, p. 69-70)

É importante ressaltar que, em meio às discussões sobre quântica, o encontro se deu durante um período de tensão política em que Heisenberg representava a Alemanha e Bohr representava a oposição à Alemanha nazista.

HEISENBERG: Em absoluto - funciona. É o que importa. Funciona, funciona, funciona!

MARGRETHE: Se Heisenberg estiver no centro do Universo, então a única parte do Universo que ele não pode ver é ele mesmo, Heisenberg.

HEISENBERG: E daí...

MARGRETHE: E daí que não adianta perguntar pra ele porque é que ele veio a Copenhagen em 1941. Ele não sabe!

HEISENBERG: Eu achei, naquele preciso momento, que tinha conseguido ter uma rápida visão disso.

MARGRETHE: E aí você se virou pra ver.

HEISENBERG: E ele sumiu.

MARGRETHE: Complementaridade outra vez, certo?

BOHR: Certo, certo...

MARGRETHE: Eu datilografei isso talvez vezes... Se você está fazendo uma coisa você tem que se concentrar. Não pode ao mesmo tempo ficar pensando sobre o que faz. E se você estiver pensando sobre aquilo que está fazendo, então você não pode estar de fato fazendo aquilo. Certo? (FRAYN, 2000, p. 72)

BOHR: Meu caro Heisenberg, a sugestão é, obviamente...

HEISENBERG: Muito interessante. Tão interessante que ela nunca lhe ocorreu. Complementaridade, mais uma vez. Eu sou seu inimigo; mas eu sou também seu amigo. Eu sou um perigo para a humanidade; mas também sou seu convidado. Eu sou uma partícula; mas também uma onda. Nós temos uma série de obrigações para com o mundo em geral; e nós temos outras obrigações, que nunca podem ser conciliadas com as outras, com nossos conterrâneos, nossos vizinhos, nossos amigos, nossa família, nossos filhos. Tudo que podemos fazer é olhar depois e ver o que aconteceu. (FRAYN, 2000, p. 77-78) 
As discussões acerca da complementaridade permitem fazer algumas conjecturas sobre o papel de Heisenberg e Bohr no contexto da guerra em 1941. Usualmente, devido à associação de Heisenberg com o nazismo, sua posição política na Guerra foi, por muito tempo, encarada como "negativa". (HEISENBERG, 1995)

Apesar de não haver consenso entre historiadores, ou mesmo um conhecimento mais detalhado do que foi realmente conversado sobre a bomba nuclear no encontro, a peça serve para discutir que a versão comum sobre os fatos pode apresentar uma "complementaridade", ou seja, só é possível entender realmente como os fatos aconteceram se forem analisadas as duas posições. Apenas uma versão não fornece respostas finais, assim como apenas um comportamento da radiação (ou da matéria) não permite determinar plenamente sua natureza. De modo quase explícito, percebe-se um direcionamento, no decorrer da peça, em defesa de Heisenberg.

A exibição da peça com essa entonação acabou por gerar polêmicas sobre o encontro Bohr-Heisenberg, durante o simpósio Creating Copenhague, realizado na City University of New York, na época da apresentação da peça na Broadway.

De acordo com Dörries (2005), nesse simpósio, durante os debates sobre a peça, particularmente sobre suas implicações e relevância, a família de Niels Bohr decidiu antecipar a divulgação de cartas-documento ${ }^{9}$ que ele escrevera e nunca enviara a Heisenberg.

A revelação, que aconteceu em fevereiro de 2002, causou repercussão no meio acadêmico, tanto que para alguns historiadores e críticos, o surgimento das cartas-documento contribuiu para que o autor Michael Frayn adicionasse um pós-escrito ${ }^{10}$ a sua obra original.

Não é possível estabelecer, na peça, uma posição definitiva para Bohr, Heisenberg e mesmo Margrethe quanto aos fundamentos e consequências de seus pensamentos. O próprio fato de a peça trabalhar com os personagens após sua morte permite-lhes a escolha das consequências de seus atos do passado, sem possibilitar uma certeza quanto à sua ocorrência. (SHEPHERD-BARR, 2006)

9 Tais documentos contêm várias cartas e notas escritas por Niels Bohr, entre 1957 e 1962, e uma carta de Heisenberg para Bohr. Os originais destes documentos encontram-se publicados na obra Michael Frayn's Copenhague in Debate de Dörries (2005).

10 O pós-escrito refere-se a uma série de alterações ao texto da peça, em resposta às sugestões e críticas que Michael Frayn recebeu após a encenação da peça em Londres e depois em Nova York. 
Essa afirmação pode ser exemplificada pela fala de Heisenberg que aparece no final do primeiro ato e se repete no final do segundo ato.

HEISENBERG: Por que é que eu vim a Copenhagen? Sim, por que foi que eu vim?

BOHR: Mais um esboço, sim? Um esboço final.

HEISENBERG: E mais uma vez eu atravesso o gramado até a porta da frente da casa dos Bohr. E toco a familiar campainha. Por que é que eu vim? Eu sei perfeitamente bem. Sei tão bem que nem preciso me perguntar. Até que mais uma vez a pesada porta da frente se abre.

BOHR: Ele fica ali, na soleira da porta, piscando por causa da repentina onda de luz que vem da casa. Até esse instante seus pensamentos estiveram em todo lugar e em lugar nenhum, como partículas não observadas. Agora os pensamentos podem ser observados e analisados. (FRAYN, 2000, p. 86)

\section{Considerações finais}

A análise feita neste artigo mostra que a peça Copenhague se apresenta como um material muito rico em termos de História da Mecânica Quântica, bem como quanto à contribuição que a interpretação de Copenhague trouxe para a filosofia e para a comunidade científica em geral.

Um aspecto presente no texto de Copenhague de Michael Frayn é a ausência de causalidade: a peça não se desenvolve seguindo uma sequência linear de fatos, lugares, tempo. Do mesmo modo, apresentam-se as características principais dos princípios de incerteza e complementaridade quanto ao comportamento e descrição de movimento.

O autor não indica sequer eventuais mudanças de cena e de situação; elas acontecem no desenvolvimento da ação e cabe a nós escolhermos a sua melhor tradução cênica. Pode-se ainda mencionar que os próprios personagens se movem livres, no tempo e no espaço, num exercício radical de imaginação e raciocínio.

Quanto aos aspectos sociais, a peça mostra que a Mecânica Quântica (particularmente a Interpretação de Copenhague) foi desenvolvida dentro de um contexto amplo, que envolvia questões éticas entre cientistas. Neste sentido, a peça traz discussões sobre a história do século XX, como o nazismo, a II Guerra Mundial, a bomba atômica e a sua relação com a ciência. Apesar de se restringir 
a apenas três personagens dentro de uma teoria que apresentou inúmeras contribuições até seu estabelecimento, a peça pode servir como instrumento para uma discussão mais ampla do papel da ciência e da sua utilização na sociedade.

\section{Referências}

ABDALLA, M. C. B. Niels Bohr: o arquiteto da mecânica quântica. Scientific American Brasil-Gênios da Ciência Quânticos, São Paulo, v. 13, p. 32-43, 2006.

BASTOS FILHO, J. B. Os problemas epistemológicos da realidade, da compreensibilidade e da causalidade na teoria quântica. Revista Brasileira de Ensino de Física, v. 25, n. 2, p. 125-147, jun. 2003.

BELLER, M. Pascual Jordan's influence on the discovery of Heisenberg's indeterminacy principle. Journal Archive for History of Exact Sciences, v. 33, n. 4, p. 337-349, dez. 1985.

BOHR, N. Can quantum-mechanical description of physical reality be considered complete? Physical Review, v. 48, p. 696-702, oct. 1935. Tradução para o português: A descrição da realidade física fornecida pela mecânica quântica pode ser considerada completa? Tradução C.W. Abramo. Cadernos de História e Filosofia da Ciência, v. 2, p. 97-106, 1981.

. On the notions of causality and complementarity. Science, New Series, v. 111, n. 2873, p. 51-54, jan. 1950.

. The quantum postulate and the recent development of at atomic theory. Nature, v. 121, p. 580-590, 1928, apud WHEELER, J. A.; ZUREK, W. H. Quantum Theory and Measurement. New Jersey: Princeton University, 1983. p. 87-126. Tradução para o português: O postulado quântico e o recente desenvolvimento da teoria atômica. Tradução O. Pessoa Jr. em PESSOA JR., O. (Org.). Fundamentos da Física 1: Simpósio David Bohm. São Paulo: Ed. Livraria da Física, 2000. p. 135-159.

CHIBENI, S. S. Certezas e incertezas sobre as relações de Heisenberg. Revista Brasileira de Ensino de Física, v.27, n. 2, p. 181-192, 2005.

DÖRRIES, M. (Ed.). Michael Frayn's copenhague in debate: historical essays and documents on the 1941 meeting between Niels Bohr and Werner Heisenberg. Berkeley: Office for History of Science and Technology, 2005. 
FEYNMAN, R.; LEIGHTON, R. B.; SANDS, M. T. Lectures on physics, quantum mechanics. Delaware: Addison-Wesley Iberoamericana, 1987. v. 3. Em português: Lições de Física de Feynman: edição definitiva. Trad. A.V. Roque da Silva. Porto Alegre: Bookman, 2008.

FOLSE, H. J. The philosophy of Niels Bohr: the framework of complementarity. New York: North-Holland, 1985.

FRAYN, M. Copenhague. New York: Anchor Books Original, 2000.

FREIRE JR., O. David Bohm e a controvérsia dos quanta. Campinas: Unicamp, 1999. (Coleção CLE, v. 27).

GREENSTEIN, G.; ZAJONC, A. The quantum challenge: modern research on the foundations of quantum mechanics. Sudbury, MA: Jones and Bartlett, 1997.

GUIMARÃES, F. E. G. Ótica de campo próximo e super-resolução à luz do critério de Rayleigh e do princípio da incerteza de Heisenberg. Revista Brasileira de Ensino de Física, v. 18, n. 2, jun. 1996.

HEISENBERG, W. Física e filosofia. Tradução de Jorge Leal Ferreira. 4. Ed. Brasília: Universidade de Brasília, 1999. Original de 1958.

. The physical content of quantum kinematics and mechanics. In: WHEELER, J. A. e ZUREK, W. H. Quantum theory and measurement. Princeton: Princeton University, 1983. p. 62-84.

The physical principles of the quantum theory. Tradução de Carl Eckart e Frank C. Hoyt. New York: Dover Publications, 1949. Original de 1930.

Über den anschanlichen Inhalt der quantentheoretischen Kinematik und Mechanik. Zeitschrift für Physik, v. 43, p. 172-178, 1927.

A vida política de um apolítico: minhas lembranças de Werner

Heisenberg. Tradução de Ingeborg Fleckenstein. São Paulo: Ars Poética, 1995.

JAMMER, M. The philosophy of quantum mechanics. New York: John Wiley \& Sons, 1974.

KRAGH, H. Quantum generations: a history of physics in the twentienth century. New Jersey: Princeton University, 1999. 
MARTINS, R. A. O nascimento de uma nova Física. Scientific American BrasilGênios da Ciência Quânticos, São Paulo, v. 13, p. 6-13, 2006 a.

. Werner Heisenberg: o semeador da mecânica matricial. Scientific

American Brasil- Gênios da Ciência Quânticos, São Paulo, v. 13, p. 64-73, $2006 \mathrm{~b}$.

MENESES, R. D. B. de. A causalidade e as causalidades segundo Schlick : pelo significado do Circulo de Viena. Eikasia - Revista de Filosofía, ano 3, n. 18, p. 33-57, maio 2008b.

. A complementaridade em Niels Bohr: da mecânica quântica a filosofia. Eikasia - Revista de Filosofía, ano 3, n. 17, p. 75-126, mar. 2008a.

PESSOA JR., O. As interpretações da mecânica quântica. Ciência Hoje, v. 42, n. 250, p. 32-37, jul. 2008.

ROBERTSON, H. P. The uncertainty principle. Physical Review, v. 34, p. 63-164, 1929.

SELNER, C. Método para análise de sistemas de conhecimento, inspirado no princípio da complementaridade de Niels Bohr. 2006. Tese (Doutorado em Engenharia de Produção) - Universidade Federal de Santa Catarina, Florianópolis, 2006.

SHEPHERD-BARR, K. Science on stage: from doctor faustus to copenhague. New Jersey: Princeton University, 2006.

WHEELER, J. A.; ZUREK, W. H. Quantum theory and measurement. New Jersey: Princeton University, 1983. 



\section{Teoria da ressonância: história e ensino}

José Luis P. B. Silva,

Nídia Franca Roque

\section{Introdução}

Linus Pauling dedicou grande parte de sua carreira ao estudo da natureza da ligação química, em suas palavras, "o mais valioso conceito da química". (PAULING, 1992a, p. 521) Seu trabalho influenciou fortemente o pensamento químico e parte de suas idéias permanecem válidas, com tantos anos passados, compondo os atuais conteúdos de química dos níveis médio e superior de ensino.

Neste artigo, focaremos em uma das construções intelectuais mais importantes de Pauling, a teoria da ressonância, que costuma ser ensinada de modo pouco significativo, pela falta de apresentação da origem o do desenvolvimento das ideias que a compõem. Assim é que, no que se refere à teoria da ressonância, há uma grande diferença entre o os textos didáticos, em todos os níveis, e as ideias originais de Pauling.

Na primeira seção descreveremos, de modo breve, a elaboração histórica da teoria da ressonância. Em seguida, apresentaremos as críticas que lhe foram formuladas pelos contemporâneos de Pauling e suas réplicas. Passaremos, então, à análise de textos didáticos de importância reconhecida pela comunidade dos químicos e professores de química e, por fim, apresentaremos nossas considerações finais. 


\section{Teoria da Ressonância}

Pauling tornou-se adepto da ideia de ligação química como partilha de elétrons, em 1919, ao ler os artigos de Lewis e Langmuir que tratavam do assunto(PAULING, 1984). Estes autores propunham um modelo atômico em que os elétrons mantinham posições definidas em torno do núcleo. (LANGMUIR, 1919; LEWIS, 1916) Pauling, porém, viria a adotar uma visão dinâmica do átomo e da ligação química: em 1926, ele publicou artigo onde procurou conciliar as propostas para a ligação química de Lewis (par eletrônico compartilhado), Bohr (elétrons em movimento) e Knorr (os elétrons participantes de uma ligação orbitam em torno dos dois núcleos que ligam), no que denominou teoria da ligação química como elétrons compartilhados em órbita. (PAULING, 1926)

No período de abril de 1926 a setembro de 1927, Pauling viajou como bolsista para a Europa, com o projeto de estudar a estrutura eletrônica de átomos e moléculas e a natureza da ligação química. (PAULING, 1992b) Ali esteve em meio aos acontecimentos que geraram a nova mecânica quântica. Particularmente importante para suas ideias foi o conceito de ressonância quantum-mecânica, que viria a se tornar central no desenvolvimento de sua concepção acerca da ligação química:

[...] a principal contribuição da mecânica quântica para a química tem sido a sugestão de novas idéias, tais como a ressonância de moléculas entre várias estruturas eletrônicas com um associado aumento de estabilidade. (PAULING, 1945, p. ix)

\subsection{Ressonância quantum-mecânica}

O termo ressonância foi introduzido na mecânica quântica em 1926 por Werner Heisenberg que, para explicar os espectros de emissão dos átomos de hélio (singlete e triplete), elaborou um tratamento matemático correspondente ao de dois osciladores quânticos acoplados que trocam energia entre si, análogo à situação clássica de dois pêndulos em ressonância. Heisenberg intitulou seu trabalho Mehrkörpenproblem und Resonanz in der Quantenmechanik (Ressonância em Mecânica Quântica e o Problema de Muitos Corpos). (MEHRA; RECHENBERG, 1982)

Para se compreender o significado atribuído por Pauling à ressonância quantum-mecânica é preciso considerar o processo de resolução do problema do átomo de hélio excitado, que é o átomo que emite a radiação. Como primeira aproximação, considera-se o sistema com um elétron no nível fundamental de 
energia, $1 \mathrm{~s}$, e outro no estado excitado mais próximo, $2 \mathrm{~s}$, cada elétron interagindo com o núcleo, mas não com o outro elétron. Como o hélio possui dois elétrons, existem duas possibilidades: (a) elétron 1 no estado fundamental (1s) e elétron 2 no estado excitado (2s); e (b) elétron 2 no estado fundamental e elétron 1 no estado excitado, aos quais correspondem as seguintes funções de onda:

$$
\psi^{\mathrm{I}}(1,2)=1 \mathrm{~s}(1) 2 \mathrm{~s}(2) \text { e } \psi^{\mathrm{II}}(1,2)=2 \mathrm{~s}(1) 1 \mathrm{~s}(2)
$$

onde (1) e (2) representam as coordenadas dos elétrons. Ambas as representações do átomo de hélio excitado correspondem à mesma energia, $\mathrm{E}_{0}$, pois os elétrons são indistinguíveis. São soluções aproximadas, pois é evidente que os elétrons constituintes de um átomo estão próximos e interagem.

O segundo passo do método consiste em melhorar a representação do átomo, considerando a interação dos elétrons. Esta é introduzida como uma perturbação no sistema anterior e determinam-se os estados perturbados do átomo, considerados reais, que resultam ser combinações lineares das funções de onda não-perturbadas, $\psi^{\mathrm{I}}$ e $\psi^{\mathrm{II}}$ :

$$
\psi_{s}(1,2)=2^{-1 / 2}\left(\psi^{\mathrm{I}}+\psi^{\mathrm{II}}\right)=2^{-1 / 2}\{1 \mathrm{~s}(1) 2 \mathrm{~s}(2)+2 \mathrm{~s}(1) 1 \mathrm{~s}(2)\}
$$

e

$$
\psi_{\mathrm{a}}(1,2)=2^{-1 / 2}\left(\psi^{\mathrm{I}}-\psi^{\mathrm{II}}\right)=2^{-1 / 2}\{1 \mathrm{~s}(1) 2 \mathrm{~s}(2)-2 \mathrm{~s}(1) 1 \mathrm{~s}(2)\}
$$

Na análise de Pauling, estes resultados mostram que $\psi^{\mathrm{I}}$ e $\psi^{\mathrm{II}}$ contribuem igualmente para os estados perturbados do sistema $\left(\psi_{\mathrm{s}}\right.$ e $\left.\psi_{\mathrm{s}}\right)$. Assim, não há razão para crer que no átomo de hélio excitado um elétron esteja permanentemente localizado no nível 1s e o outro no $2 \mathrm{~s}$, mas que "[...] cada elétron ressoa entre uma órbita 1s e uma 2s”. (PAULING; WILSON JR, 1935, p. 324)

Interpretações similares são encontradas em contemporâneos de Pauling, tais como Herzberg (1945) e White (1934).

Aos dois estados perturbados do átomo de hélio excitado correspondem distintos valores de energia,

$$
\mathrm{E}_{\mathrm{c}}=\mathrm{E}_{0}+\mathrm{J}+\mathrm{Ke} \mathrm{E}_{\mathrm{d}}=\mathrm{E}_{0}+\mathrm{J}-\mathrm{K}
$$

e assim, Heisenberg pode explicar a diferença de energia entre os estados singlete e triplete, observados experimentalmente. Nestas expressões, J e K representam 
as parcelas de energia devidas à interação dos elétrons, dadas, respectivamente, por:

$$
\begin{gathered}
J=\iint 1 s(1) 2 s(2)\left(e^{2} / r_{12}\right) 1 s(1) 2 s(2) d \tau_{1} d \tau_{2} \\
e \\
K=\iint 1 s(1) 2 s(2)\left(e^{2} / r_{12}\right) 2 s(1) 1 s(2) d \tau_{1} d \tau_{2}
\end{gathered}
$$

A primeira expressão é denominada integral de Coulomb e representa a energia da interação coulombiana entre o elétron 1 no estado 1 s e o elétron 2 no estado 2 s.

A segunda integral, onde cada elétron está relacionado às duas funções de onda, representa a energia resultante da transição do elétron 1 do nível 1 s para o 2 s, ao mesmo tempo que o elétron 2 realiza a transição em sentido inverso e, por isso, é denominada integral de ressonância ou integral de troca. (PAULING, 1928a)

De acordo com a interpretação de Pauling, o fenômeno da ressonância quantum-mecânica manifesta-se através da forma da função de onda do sistema, como combinação linear das funções $\psi^{\mathrm{I}}$ e $\psi^{\mathrm{II}}$ (forma similar à da equação de movimento dos pêndulos acoplados), bem como pela expressão da energia de interação eletrônica, a integral de ressonância. Embora admita a impossibilidade de verificação experimental da ressonância, Pauling defende a importância de tal interpretação para uma "compreensão intuitiva segura e produtiva das equações da mecânica quântica e dos resultados de sua aplicação.” (PAULING; WILSON JR, 1935, p. 314-315)

No entender de Pauling (PAULING; WILSON JR, 1935), o caso dos estados do hélio excitado encaixa-se no problema mais geral de como descrever o estado resultante da interação de dois sistemas com igual energia. Um procedimento para encontrar a solução é o método de perturbação e as soluções resultam ser combinações lineares das funções não-perturbadas do sistema considerado. Nesses casos, é possível interpretar o estado do sistema com interação, como ressoando entre os estados sem interação.

\subsection{Ressonância e ligação química}

Em 1927, Heitler e London resolveram o problema da molécula do hidrogênio, cujo estado é descrito como uma combinação de dois estados não-perturbados de mesma energia, cada qual constituído por dois átomos de hidrogênio. Em artigo de revisão, Pauling (1928a) rediscutiu a molécula do hidrogênio e outros 
problemas deste tipo, sempre concluindo pelo importante papel da ressonância na explicação da ligação química.

A discussão da molécula do hidrogênio começa por considerar os estados não-perturbados, que seriam dois átomos de hidrogênio sem interação mútua, ou seja, cada próton interagindo com apenas um elétron. Há duas possibilidades, com igual energia: se o elétron 1 está ligado ao núcleo $\mathrm{A}$ e o elétron 2 está ligado ao núcleo $\mathrm{B}$, a função de onda é dada por $\psi_{\mathrm{A}}(1) \psi_{\mathrm{B}}(2)$; se o elétron 2 está ligado ao núcleo $\mathrm{A}$ e o elétron 1 está ligado ao núcleo $\mathrm{B}$, a função de onda é dada por $\psi_{\mathrm{B}}(1)$ $\Psi_{\mathrm{A}}(2)$. Ao considerar a ação de todas as quatro partículas entre si (dois elétrons e dois prótons) a resolução do problema leva às seguintes funções de onda:

$$
\begin{gathered}
\Psi_{\mathrm{s}}=\mathrm{C}_{\mathrm{s}}\left\{\Psi_{\mathrm{A}}(1) \psi_{\mathrm{B}}(2)+\psi_{\mathrm{B}}(1) \Psi_{\mathrm{A}}(2)\right\} \\
\mathrm{e} \\
\Psi_{\mathrm{a}}=\mathrm{C}_{\mathrm{a}}\left\{\psi_{\mathrm{A}}(1) \psi_{\mathrm{B}}(2)-\psi_{\mathrm{B}}(1) \psi_{\mathrm{A}}(2)\right\}
\end{gathered}
$$

onde $\mathrm{C}_{\mathrm{s}}$ e $\mathrm{C}_{\mathrm{a}}$ são constantes. Note-se que, à semelhança do átomo de hélio excitado, os estados calculados para a molécula do hidrogênio são compostos pelos estados não-perturbados - $\psi_{\mathrm{A}}(1) \psi_{\mathrm{B}}(2)$ e $\psi_{\mathrm{B}}(1) \psi_{\mathrm{A}}(2)$ - podendo ser interpretados, à moda de Pauling, como estados em que há ressonância dos elétrons entre os núcleos A e B.

A formulação da ligação química proporcionada pela mecânica quântica possibilitou Pauling (1928b, p. 359) interpretar os pares eletrônicos de Lewis em seus termos:

Com o desenvolvimento da mecânica quântica tornou-se evidente que os fatores responsáveis pela valência química são, essencialmente, o princípio da exclusão de Pauli e o fenômeno da ressonância de Heisenberg-Dirac. Mostrou-se que no caso de dois átomos de hidrogênio no estado normal, trazidos à proximidade um do outro, a autofunção que é simétrica nas coordenadas de posição dos dois elétrons corresponde a um potencial que conduz a que os dois átomos se combinem para formar uma molécula. Este potencial é principalmente devido a um efeito de ressonância que pode ser interpretado como envolvendo uma troca na posição dos dois elétrons que formam a ligação, de modo que cada elétron está parcialmente associado com um e outro núcleo. (Tradução nossa).

Pauling (1928b, p. 359) admite, de acordo com London, que "a energia de troca de dois elétrons, um pertencendo a cada um de dois átomos, é a energia da 
ligação não-polar, em geral" e interpreta que "o par de elétrons de Lewis consiste, agora, de dois elétrons que estão em estados idênticos exceto que seus spins são opostos".

Pauling chegou a considerar o trabalho de Heitler e London como a maior contribuição isolada para o conceito de valência, desde a noção de par eletrônico compartilhado, proposta por Lewis. (BROCK, 2000)

\subsection{Ressonância entre estruturas e ligações}

À ideia de ressonância de elétrons seguiu-se a de ressonância entre estruturas eletrônicas das moléculas. Para tanto foi necessário um passo decisivo: postular que a toda configuração eletrônica corresponde uma função de onda. Ocorre que, se uma estrutura é explicada como resultante de mais de uma configuração eletrônica, a autofunção correspondente a esta estrutura deverá ser uma combinação das autofunções das configurações contribuintes. (PAULING, 1932a) Uma vez que, a cada configuração eletrônica corresponde uma fórmula química, com este postulado Pauling estabeleceu a relação entre as representações química e quantum-mecânica de uma molécula.

Pauling tinha clareza de que, para várias substâncias, não havia como conciliar suas propriedades com uma única fórmula química construída pelo sistema usual de ligações covalentes (simples, duplas e triplas). Em lugar de condenar a representação usual das estruturas moleculares e criar outra, Pauling advogou em favor de sua manutenção, como uma atitude prática, introduzindo a ideia de que a estrutura correta seria híbrida das várias estruturas convencionais possíveis.

O caso mais difundido é o do benzeno, que apresenta várias possibilidades de representação:

A

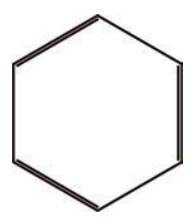

B

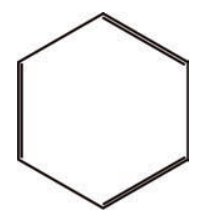

C

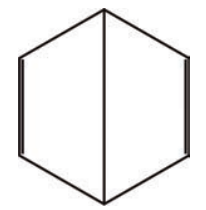

D

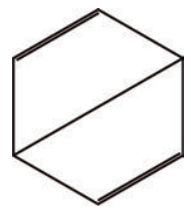

E

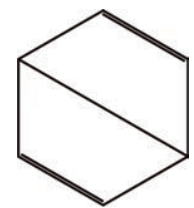

Figura 1 - Formas ressonantes do benzeno, de acordo com Pauling (1945)

De acordo com a teoria da ressonância, a estrutura do benzeno seria um híbrido de 5 estruturas possíveis, representadas pelas 5 fórmulas de ligação de valência da Figura 1, acima. Em outras palavras, estas 5 estruturas em ressonância representariam a verdadeira estrutura do benzeno. 
Pauling estendeu a noção de ressonância às ligações químicas, explicando porque distâncias interatômicas medidas situavam-se entre os valores calculados para ligações simples e duplas, como nos casos da grafita, do benzeno e de outros compostos. A ideia é que as ligações "estão ressoando entre ligações simples e duplas." (PAULING, 1932a, p. 295) Ainda nesse artigo, Pauling empregou a ressonância entre ligações para explicar qualitativamente o caráter ácido ou básico de compostos orgânicos de diversos tipos.

Nos trabalhos subsequentes da série The nature of the chemical bond, o modelo de estruturas e ligações ressonantes foi aprimorado e consolidado. Foi estabelecida uma escala de eletronegatividades associada à polaridade das ligações, resultante da ressonância entre uma estrutura iônica e outra covalente. (PAULING, 1932b) Esta escala de eletronegatividades constituiu-se num importante instrumento na análise da distribuição de cargas em estruturas ressonantes. Foram desenvolvidos procedimentos de cálculo da energia de ressonância, a partir de dados termoquímicos, e refinada a explicação da estrutura de vários compostos: dióxido de carbono, isocianatos de alquila, ácidos carboxílicos, ésteres, amidas, hidrocarbonetos aromáticos (benzeno e derivados, naftaleno, antraceno), compostos heterocíclicos, sistemas conjugados em geral etc. (PAULING; WHELAND, 1933)

A conceituação básica da teoria da ressonância estava estabelecida e explicava vários fenômenos químicos com base no movimento entre estruturas eletrônicas e no movimento de ligações no interior dessas estruturas.

De modo conciso e direto (PAULING, 1938, p. 1857-1858, tradução nossa):

A idéia de ressonância, em sua aplicação à química, é a seguinte. Se for possível escrever para uma molécula (ou outro sistema) duas ou mais estruturas eletrônicas correspondendo a aproximadamente a mesma energia e satisfazendo outras condições, então, nenhuma das estruturas isoladamente pode ser considerada como representante do estado normal da molécula que, em vez disso, é representado essencialmente por uma média de todas elas; e, além disso, a molécula é mais estável (possui um menor conteúdo energético) que poderia ser se tivesse qualquer uma das estruturas isoladas. A molécula é descrita como ressoando entre as várias estruturas e a energia de estabilização da molécula é denominada energia de ressonância [grifos do autor].

(Em termos quantum-mecânicos, diz-se que a função de onda que representa o estado normal da molécula não é 
qualquer uma das funções de onda correspondentes às várias estruturas eletrônicas, mas é uma combinação linear destas.).

\section{Críticas à Teoria da Ressonância}

O trabalho de Pauling sobre ligação química foi bem aceito pela comunidade científica. A primeira edição da obra que resumiu a teoria, The Nature of the Chemical Bond, lançada em 1939, esgotou-se rapidamente e já no ano seguinte foi lançada uma segunda edição, revista e atualizada. Este livro foi considerado pela crítica como a apresentação mais clara e unificada sobre estrutura molecular (FRENCH, 1940), um marco na história da teoria de valência (MULLIKEN, 1940) e recomendado a quem desejasse um entendimento mais profundo sobre ligação química. (KISTIAKOWSKY, 1940) Entre os reparos feitos por seus revisores, constam a ressalva à ideia de estruturas ressoando em alta frequência, (KISTIAKOWSKY, 1940) e a ausência de referências à teoria do orbital molecular. (MULLIKEN, 1940) As principais divergências e críticas à teoria da ressonância referem-se a três aspectos inter-relacionados: a analogia entre ressonância quântica e clássica, a realidade das estruturas constituintes de um sistema ressonante e a relação entre ressonância e tautomeria (equilíbrio químico).

\subsection{Problemas da analogia entre ressonância quântica e ressonância clássica}

Como visto na primeira parte deste artigo, Pauling entendia a ressonância quantum-mecânica como movimento, uma troca de posição de elétrons entre os átomos participantes da ligação. Seus escritos mostram que a analogia entre ressonância clássica e quântica tinha por base a troca de energia dos sistemas em ressonância, sugerindo uma visão clássica da ressonância quântica.

Embora cientistas importantes da época, como Herzberg (1945) e White (1934), houvessem concordado com Pauling, outros igualmente importantes, como Coulson (1952), Heitler (1956), Slater (1963), Fermi (1966), divergiram dessa interpretação.

Um crítico especial da ressonância como fenômeno foi George W. Wheland, já que foi um dos químicos que mais contribuiu para seu desenvolvimento. Entre 1932 e 1936 Wheland realizou um estágio de pós-doutorado no Caltech, onde colaborou com Pauling no desenvolvimento da teoria da ressonância. Publicaram juntos três artigos, inclusive o quinto trabalho da série The Nature of the Chemical 
Bond, que tratou do cálculo de energia de ressonância do benzeno e outros compostos aromáticos. (PAULING; WHELAND, 1933) Em 1936-1937, Wheland esteve como bolsista na Inglaterra, onde trabalhou com o grupo de Ingold, em Londres, e serviu de elo de ligação entre Pauling e os físico-químicos orgânicos ingleses. Posteriormente, esteve com Hinshelwood, em Oxford e realizou visitas a Hückel, em Munique, e a Lennard-Jones, em Cambridge (PARK, 1999), o que revela seu interesse pelos aspectos mais centrais da físico-química, além de sua aplicação aos compostos orgânicos.

Park (1999) atribui ao contato de Wheland com os físico-químicos orgânicos o desenvolvimento da percepção das críticas que poderiam ser dirigidas à teoria da ressonância. Por isso, quando da publicação de The Theory of Resonance and Its Application to Organic Chemistry, em 1944, e de seu sucessor, Resonance in Organic Chemistry (WHELAND, 1955), buscou resolver o problema de como situar-se equilibradamente entre a exposição físico-matemática e a exposição química da ressonância.

Tanto Wheland quanto Pauling reconheciam na ressonância uma ampliação da teoria estrutural clássica (pré-quântica). Entretanto, enquanto Pauling percebia a ressonância como fenômeno, Wheland considerava-a como um artifício, um método aproximativo para tratar moléculas (WHELAND, 1955, p. 25, tradução nossa, grifo do autor):

Um de tais métodos aproximativos que é conveniente, embora não seja o único, para resolver a equação de onda é baseado na consideração de que a função de onda $\psi$ pode ser expressa como uma combinação linear de funções conhecidas, do seguinte modo:

$$
\psi=\mathrm{k}_{1} \varphi_{1}+\mathrm{k}_{2} \varphi_{2}+\ldots+\mathrm{k}_{\mathrm{n}} \varphi_{\mathrm{n}}
$$

onde $\varphi_{1}, \varphi_{2}, \ldots, \varphi_{\mathrm{n}}$ são as funções conhecidas e $\mathrm{k}_{1}, \mathrm{k}_{2}, \ldots, \mathrm{k}_{\mathrm{n}}$ são constantes numéricas. [...] Quando este método de aproximação é empregado e quando as funções $\varphi_{1}, \varphi_{2},[\ldots], \varphi_{n}$ podem ser correlacionadas de algum modo com definidas estruturas da molécula em questão, então, diz-se que a molécula é um híbrido de ressonância dessas estruturas, ou, diz-se que as estruturas contribuem para o estado da molécula. As grandezas relativas dos coeficientes $k_{i}$ são medidas qualitativas dos pesos relativos atribuídos às respectivas estruturas.

Wheland considerava que o termo ressonância havia sido introduzido por Heisenberg na mecânica quântica, com a finalidade de estabelecer uma analogia 
formal com a mecânica clássica, mais familiar, possuindo significado "[...] apenas com referência a um particular método de aproximação da situação real". (WHELAND, 1955, p. 29, grifo do autor) Em vista disso, a ressonância seria

[...] um conceito artificial em um sentido mais fundamental que na maioria das outras teorias físicas. Ele não corresponde a nenhuma propriedade intrínseca da molécula, mas, em vez disso, é apenas um expediente matemático deliberadamente inventado pelo físico ou químico para sua própria conveniência. Inclusive, se o problema quantum-mecânico pudesse ser rigorosamente resolvido ou mesmo se um método aproximativo diferente fosse empregado, a idéia de ressonância não apresentar-se-ia. Portanto, se um conjunto diferente de $\varphi$ 's fosse usado na equação 1 [combinação linear, acima] a molécula cuja função de onda fosse aproximada por $\psi$ poderia ser descrita como um híbrido de um conjunto de estruturas inteiramente diferente. (WHELAND, 1955, p. 28-29, tradução nossa)

Para Wheland (1955), os análogos mecânicos clássicos das estruturas componentes do sistema seriam os movimentos independentes dos pêndulos acoplados porque, tanto uns quanto outros, podem ser empregados como artifícios para representar os estados de sistemas compostos - pêndulos acoplados ou híbridos de ressonância - através de combinações lineares.

\subsection{Estatuto ontológico das estruturas constituintes de um sistema ressonante}

Para Wheland, a ressonância era um método para descrever o estado das moléculas, de modo que, as estruturas constituintes de um sistema ressonante eram meras ficções, não podiam existir realmente. Em sua opinião, o termo estrutura não deveria ser aplicado às fórmulas utilizadas para descrever o híbrido de ressonância. Wheland tinha restrições à terminologia empregada pelos químicos da época pela imprecisão de linguagem que, acreditava, poderia gerar equívocos no entendimento do conceito de ressonância. Por isso, dedicou uma seção inteira de Resonance in Organic Chemistry (WHELAND, 1955) à discussão de termos que considerava impróprios pela ideia de fenômeno que vinculava à ressonância. Advogou contra o emprego do verbo "ressoar" e outras expressões que pudessem sugerir que

[...] as moléculas de um híbrido de ressonância estejam oscilando de um lado para o outro entre as várias estruturas e, por isso, que estas estruturas devam possuir significado físico real. (WHELAND, 1955, p. 7) 
Coulson (1952) também pensava que as estruturas componentes do sistema ressonante não tinham realidade no sentido objetivo do termo, porque as autofunções associadas não correspondem a estados estacionários permitidos. Sendo assim, seria inexato falar de ressonância entre estruturas no sentido de oscilação temporal.

Christopher Ingold foi um dos químicos britânicos a reconhecer imediatamente o valor da teoria da ressonância porque, em 1926, havia elaborado o conceito de efeito mesomérico para descrever o estado de moléculas, cuja fórmula seria intermediária entre duas fórmulas de ligação de valência, conceito similar à ressonância entre estruturas proposta por Pauling em 1931-1932. Por isso, reconheceu na ressonância "a propriedade ondulatória fundamental na teoria da valência", considerando a mesomeria como um caso particular que recebeu denominação própria em função de sua importância na química orgânica. (INGOLD, 1938, p. 314) Entretanto, como Wheland e Coulson, Ingold considerava que a analogia entre ressonância quântica e ressonância clássica era de ordem matemática apenas. Por isso desenvolveu uma crítica severa à ideia de que as estruturas ressonantes tivessem existência real. Seu argumento se baseia em que os estados não-perturbados empregados na descrição da molécula sob estudo, embora estejam relacionados a fórmulas químicas clássicas, não correspondem à realidade; é através da perturbação destes estados que se encontra a o correto estado da substância: “[...] apenas o estado mesomérico é real." (INGOLD, 1934, p. 946)

O estatuto ontológico das estruturas componentes de um sistema ressonante esteve no centro da crítica à teoria da ressonância elaborada na União Soviética. $\mathrm{Na}$ discussão sobre a teoria da ressonância, o princípio de Butlerov - a cada substância uma fórmula estrutural - foi sistematicamente empregado para contrapor-se à idéia de várias fórmulas para representar uma estrutura e a teoria da ressonância foi condenada como irreal. (GRAHAM, 1964)

\subsection{Confusão entre ressonância, mesomeria e tautomeria}

A confusão entre ressonância e tautomeria (equilíbrio químico) perdurou por um intervalo de tempo razoável. Bachelard (1990) conta que os membros de um congresso sobre mesomeria realizado na França, em 1947, foram consultados a respeito de a mesomeria ser um fenômeno real ou um método de investigação e resultou que as opiniões se dividiram. Tal situação seria corroborada na crítica de Dewar, que apontava a dificuldade dos químicos em distinguir os conceitos intuitivamente. (RUSSELL, C., 1971) Para Ingold (1934), que considerava as estruturas ressonantes como irreais, não fazia sentido confundir mesomeria com tautomeria, porque a última pressupõe que as moléculas se encontrem em um determinado intervalo de tempo, em um ou outro dos estados moleculares 
separados, ao passo que na ressonância isso não ocorre. Por isso, o termo estado não teria o mesmo sentido ao tratar-se de formas tautoméricas e ressonantes.

Outro cientista a criticar a identificação da ressonância com o tautomerismo foi Nevil Sidgwick, presidente da Chemical Society of London (atual Royal Society of Chemistry), nos anos de 1936-1937. Considerando a ressonância como o desenvolvimento mais importante desde os dias de van't Hoff, acreditava, contudo, que o termo era "ruim porque sugere que a molécula está oscilando entre dois estados, o que não é verdade". Propunha o emprego de algum outro nome não-comprometido, a exemplo do mesomerismo. (SIDGWICK, 1936, p. 535)

De acordo com Wheland (1955), ressonância e mesomeria seriam equivalentes. A ressonância distinguia-se da tautomeria porque as estruturas ressonantes não têm existência real, ao passo que as estruturas tautoméricas existem, podendo as substâncias ser isoladas e identificadas. No caso do benzeno, por exemplo, em momento algum o benzeno toma a forma das estruturas de Kekulé. Apesar de virtuais, as propriedades das estruturas componentes de um sistema ressonante, como o "cicloexatrieno", podem ser inferidas a partir de estruturas reais que possuam elementos componentes similares, como o cicloexeno e, então, serem utilizadas na construção do híbrido de ressonância.

\section{Réplicas de Pauling}

Pauling não aceitava a sinonímia (e consequente identificação) da ressonância com a mesomeria. A única crítica à teoria da ressonância que ele admitia abertamente era um elemento de arbitrariedade na escolha das estruturas componentes de um sistema ressonante, considerado de pouca importância, em vista da contribuição do conceito de ressonância na discussão de problemas químicos. (PAULING, 1945) Portanto, na conferência realizada durante a entrega do prêmio Nobel de Química de 1954 (PAULING, 1954), procurou responder às críticas à teoria da ressonância; tais réplicas foram posteriormente desenvolvidas. (PAULING, 1956)

Ressaltando a conveniência e a utilidade do conceito de ressonância na resolução dos problemas químicos, Pauling procura mostrar que a teoria da ressonância é tão arbitrária quanto a teoria estrutural clássica da química orgânica, pois ambas empregam idealização. Na descrição do benzeno pela teoria da ressonância, as estruturas de Kekulé devem ser consideradas como hipotéticas porque não é possível sintetizar moléculas com essas estruturas. De modo similar, na descrição do propano, como tendo ligações simples carbono-carbono e carbono-hidrogênio, as ligações simples são idealizações porque é impossível isolar uma porção da molécula do propano e identificá-la como uma dessas ligações. Portanto, conclui, o valor das teorias independe das idealizações e da arbitrariedade envolvidas. 
Considerando a teoria da ressonância como essencialmente idêntica à teoria estrutural clássica da química orgânica, concluiu que, se a crítica fosse consistente, seria necessário abandonar ambas as teorias, pois a teoria clássica também emprega idealizações na descrição das moléculas. (PAULING, 1956)

Pauling acreditava que a teoria da ressonância perduraria e seria desenvolvida, apesar das críticas que lhe eram feitas. Contudo, prevaleceu a posição dos seus críticos e se a ressonância tornou-se um instrumento indispensável ao trabalho dos químicos, é como um método de investigação e não como fenômeno. Prova disso é que o March's Advanced Organic Chemistry (SMITH; MARCH, 2001), um dos mais conceituados manuais de química orgânica na atualidade, empregado como referência para a pesquisa, trata a teoria da ressonância como método da ressonância.

\section{Ensino da Teoria da Ressonância}

Há toda uma problemática a cercar o conceito de ressonância que remete às concepções de molécula e representação do mundo microscópico. São questões delicadas porque a passagem do território da matéria macroscópica para o dos modelos microscópicos não é tranquila; requer um modo de raciocínio que relacione grandezas observáveis e características dos modelos, algo difícil, porém necessário a todo químico e professor de química.

Defendemos o emprego da história das ciências como coadjuvante do ensino de ciências, uma vez que pode esclarecer a formação dos conceitos científicos. (SILVA, 2002) Sendo assim, a transposição didática do conhecimento científico ao ambiente escolar deve considerar os problemas que geraram os conceitos, bem como seu desenvolvimento. (SILVA; ROQUE, 2004) Nesta seção, analisamos como a ressonância é apresentada aos químicos em materiais de estudo empregados nos diversos níveis de ensino, da pós-graduação ao ensino médio. Os materiais didáticos de ciências do ensino fundamental não incluem a discussão desse conceito.

Se Pauling passou à história como o criador da ressonância, as ideias de Wheland terminaram por definir seu significado entre os químicos. No March's Advanced Organic Chemistry (2001), que contém um texto didático introdutório de cada capítulo, a ressonância é introduzida como um modo de representar estruturas de substâncias que possuem ligações deslocalizadas. A referência apontada como definitiva é o livro de Wheland (1955).

Ainda em nível de pós-graduação, o Advanced Organic Chemistry (CAREY; SUNDBERG, 2001) segue na mesma linha: um método útil para representar a 
deslocalização de elétrons e discutir a estabilidade das estruturas de substâncias. Toda a problemática que cerca o conceito é ignorada. A importância do método se revela pela aplicação a casos exemplares.

Pontos comuns aos livros universitários de pós-graduação e de graduação são: (a) a introdução da ressonância pela citação do problema histórico original: a limitação das fórmulas de Lewis para representar estruturas de substâncias; (b) a ausência de explicação para emprego do termo ressonância e sua controversa polissemia; (c) a ausência de justificativa para a afirmação de que as fórmulas de ressonância não possuem realidade. Enquanto na pós-graduação a ressonância é discutida em termos gerais, os livros de química orgânica básica da graduação recorrem à discussão de casos: radical alila (MORRISON; BOYD, 1996); ́́on carbonato (ALLINGER et al., 1976; SOLOMONS, 1996); benzeno. (AMARAL, 1981; CAMPOS, 1976, 1980) Nos dois níveis de ensino, a representação estrutural é considerada resolvida pelo método da ressonância e a problemática em torno da ideia de ressonância não é claramente exposta.

Na química geral de ensino superior, a ressonância étambém introduzida a partir de casos particulares: ozônio e benzeno (BROWN; LEMAY; BURSTEN, 1999; CHANG, 1994; RUSSELL, J., 1994), óxidos de enxofre (BRADY; HUMINSTON, 1983), nitrato e benzeno (ATKINS; JONES, 2001), óxidos de nitrogênio, nitrato, carbonato, ozônio, benzeno. (ROZEMBERG, 2002) São apresentações curtas onde é explícita a ideia de método de representação estrutural, sem explicações da elaboração conceitual.

Nos livros didáticos tradicionais de química do ensino médio, os resultados da transposição didática da ressonância são variados. Peruzzo e Canto (2002) procuram defini-la de modo simples, como "o termo usado para descrever uma situação na qual, sem mudar a posição dos átomos, podemos escrever mais de uma fórmula estrutural diferente, mudando apenas a posição de alguns elétrons", considerando híbrido de ressonância como "um misto" de estruturas. A distinção entre ressonância e equilíbrio resume-se à diferença dos tipos de setas usadas na representação, sem qualquer discussão. Não distingue entre fenômeno e método.

Há quem apresente a ressonância como movimento eletrônico. Para Feltre (2001) "[...] as ligações duplas saltam espontaneamente de suas posições" nas fórmulas de Kekulé do benzeno. Para Fonseca (1993) os elétrons "mudam de lugar o tempo todo".

Outros livros didáticos de química do ensino médio não discutem o conceito de ressonância. Mortimer e Machado (2002) tratam o benzeno do ponto de vista da teoria do orbital molecular, ao passo que o livro do Gepeq (2000) emprega fórmulas de Kekulé. 


\section{Considerações finais}

A história do conceito de ressonância mostra que, embora a ideia tenha nascido com Pauling, com um cunho realista, associada ao movimento de elétrons, ligações e estruturas químicas, a controvérsia que se desenvolveu finalizou com a vitória da noção de instrumento teórico útil para representar estruturas.

Verificamos que os manuais didáticos empregados no ensino de química, sejam de pós-graduação, graduação e voltados para a educação básica, espelham o resultado da disputa científica, mas escondem o processo de elaboração conceitual do método da ressonância. Essa atitude equipara a ciência a outras formas de conhecimento dogmático, o que contraria a prática da pesquisa científica.

Por outro lado, várias obras fortalecem uma visão de ciência muito difundida, a de que o conhecimento provém da experiência particular e depois é generalizado. (ATKINS; JONES, 2001; FELTRE, 2001) Esta posição está em desacordo com as principais correntes da epistemologia de base histórica, que têm explicitado a construção dos conceitos científicos.

Por fim, os livros didáticos examinados apresentam alguns traços de realismo ingênuo, produzindo um ensino que abre mão da criticidade que caracteriza as ciências.

Concluímos, portanto, por uma necessidade de maior aproximação entre o ensino de química e a história da teoria quântica, de modo a produzir um ensino mais significativo e esclarecedor, tanto quanto aos conceitos, como quanto à atividade científica.

\section{Agradecimentos}

Queremos agradecer aos árbitros que, com suas críticas, contribuíram para a melhoria do artigo.

\section{Referências}

ALLINGER, Norman L. et al. Química orgánica. 2. ed. Rio de Janeiro: LTC, 1976. 2v.

AMARAL, Luciano do. Química orgânica. São Paulo: Moderna: Edusp, 1981. 
ATKINS, Peter W.; JONES, Loretta. Princípios de química. Porto Alegre: Bookman, 2001.

BACHELARD, Gaston. O materialismo racional. Lisboa: Edições 70, 1990.

BRADY, James E.; HUMINSTON, Gerard E. Química geral. Rio de Janeiro: LTC, 1983.

BROCK, William H. The chemical tree: a history of chemistry. New York: W. W. Norton, 2000.

BROWN, Theodore L.; LEMAY, H. Eugene; BURSTEN, Bruce H. Química ciência central. Rio de Janeiro: LTC, 1999.

CAMPOS, Marcello de Moura (Coord.). Fundamentos de química orgânica. São Paulo: Edgard Blücher: Edusp, 1980. . (Coord.). Química orgânica. São Paulo: Edgard Blücher: Edusp, 1976. $4 \mathrm{v}$.

CAREY, Francis A.; SUNDBERG, Richard J. Advanced organic chemistry. 4th ed. New York: Plenum, 2001.

CHANG, Raymond. Química. 5. ed. Lisboa: McGraw-Hill, 1994.

COULSON, Charles A. Valence. Oxford: Claredon, 1952.

FELTRE, Ricardo. Fundamentos da química. 3. ed. São Paulo: Moderna, 2001.

FERMI, Enrico. Molecule, crystals, and quantum statistics. New York: W. A. Benjamin, 1966.

FONSECA, Martha REIS Marques. Química integral. São Paulo: FTD, 1993.

FRENCH, Sidney J. Nature of the chemical bond. Journal of Chemical Education, v.17, n.7, p.551, 1940.

GEPEQ. Interações e Transformações. São Paulo: Edusp, 2000.

GRAHAM, Loren R. A soviet marxist view of structural chemistry. Isis, v. 55, n.179, p. 20-31, 1964. 
HEITLER, Walter. Elementary wave mechanics with applications to quantum chemistry. 2nd ed. Oxford: Clarendon, 1956.

HERZBERG, Gerhard. Atomic spectra and atomic structure. New York: Dover, 1945.

INGOLD, Christopher K. Mesomerism and tautomerism. Nature, v.133, p. 946, 1934.

. Resonance and mesomerism. Nature, v. 141, n. 3564, p. 314-318, 1938.

KISTIAKOWSKY, G. B. Journal of the American Chemical Society, v. 62, p.457, 1940.

LANGMUIR, Irving. The arrangement of electrons in atoms and molecules. Journal of the American Chemical Society. v. 41, p. 868-934, 1919.

LEWIS, Gilbert N. The atom and the molecule. Journal of the American Chemical Society. v.38, p.762-785, 1916.

MEHRA, Jagdish; RECHENBERG, Helmut. The Historical Development of Quantum Theory. New York: Springer, 1982.

MORRISON, Robert T.; BOYD, Robert N. Química Orgânica. Lisboa: Calouste Gulbenkian, 1996.

MORTIMER, Eduardo; MACHADO, Andréa Horta. Química para o ensino médio. São Paulo: Scipione, 2002.

MULLIKEN, Robert S. Nature of the chemical bond. Journal of Physical Chemistry, v.44, n.3, p.827-828, 1940.

PARK, Buhn S. Chemical translators: Pauling, Wheland and their strategies for teaching the theory of resonance. British Journal of History of Science, v. 32, p. 21-46, 1999.

PAULING, Linus C. The application of the quantum mechanics to the structure of the hydrogen molecule and hydrogen molecule-ion and to related problems. Chemical Reviews, v. 5, p.173-213, 1928 a. 
. The dynamical model of the chemical bond and its application to the structure of benzene. Journal of the American Chemical Society, v. 48, p.11321143, 1926.

. Lewis and the chemical bond. Journal of the Chemical Education, v. 61, n. 3, p.201-203, 1984.

. Modern structural chemistry. Science, v.123, n.3190, p. 255-258, 1954.

. The nature of the Chemical Bond - 1992. Journal of Chemical

Education, v. 69, n. 6, p. 519-521, jul. 1992a.

. The nature of the Chemical Bond. III: the transition from one extreme bond type to another. Journal of the American Chemical Society, v. 54, p. 9881003, mar. 1932a.

. The nature of the Chemical Bond. IV: the energy of single bonds and the relative electronegativity of atoms. Journal of the American Chemical Society, v. 54, p. 3570-3582, 1932b.

. The nature of the Chemical Bond and the structure of molecules and crystals. 2nd ed. Ithaca-NY: Cornell University, 1945.

. The nature of the theory of resonance. In: TODD, Alexander (Ed.). Perspectives in organic chemistry. New York: Interscience, 1956. p.1-8.

. The shared-electron chemical bond. Proceedings of the Academy of Sciences of the United States, v.14, p.359-362, 1928b.

. The significance of resonance to the nature of chemical bond and the structure of molecules. In: GILMAN, Henry et al. (Ed.). Organic chemistry: an advanced treatise. New York: John Wiley, 1938. p.1857-1858.

. The value if rough quantum mechanical calculations. Foundations of Physics, v. 22, n. 6, p. 829-838, 1992 b.

PAULING, Linus C.; WILSON JR, E. Bright. Introduction to quantum mechanics with applications to chemistry. New York: Dover, 1935.

PAULING, Linus C.; WHELAND, G. W. The nature of the chemical bond. V. The quantum-mechanical calculation of the resonance energy of benzene and 
naphthalene and the hydrocarbon free radicals. Journal of Chemical Physics, v.1, p.363-374, 1933.

PERUZZO, Francisco Miraglia; CANTO, Eduardo Leite do. Química: na abordagem do cotidiano. 2. ed. São Paulo: Moderna, 2002.

ROZEMBERG, I. M. Química geral. São Paulo: Edgard Blücher, 2002.

RUSSELL, Colin A. The history of valence. Leicester: Leicester University, 1971.

RUSSELL, John Blair. Química geral. 2. ed. São Paulo: Makron Books, 1994. 2v.

SANTOS, Wildson Luiz Pereira et al. Química e sociedade. São Paulo: Nova Geração, 2005.

SIDGWICK, Nevil V. Structural chemistry. Journal of the Chemical Society, p.535-538. p.335, apr. 1936.

SILVA, José Luis P. B. O valor pedagógico da história das ciências. Ideação, n.9, p.109-124, 2002.

SILVA, José Luis P. B.; ROQUE, Nídia Franca. Ordens de transposição didática. In: ENCONTRO NACIONAL DE PESQUISA EM EDUCAÇÃO EM CIÊNCIAS, 4., 2003, Bauru-SP. Atas... . Bauru: Unesp, 2004. 1 CD.

SLATER, John C. Quantum theory of molecules and solids. New York: McGrawHill, 1963. v. 1

SMITH, Michael B.; MARCH, Jerry. March's advanced organic chemistry. New Yoprk: Wiley-Interscience, 2001.

SOLOMONS, T. W. Graham. Química Orgânica. 6. ed. Rio de Janeiro: LTC, 1996.

WHELAND, George W. Resonance in organic chemistry. New York: John Wiley, 1955.

WHITE, Harvey E. Introduction to atomic Spectra. Tokyo: McGraw-Hill/ Kogakusha, 1934. p. 210. 



\title{
Ênfase conceitual e interpretações no ensino da Mecânica Quântica
}

\author{
Ileana M. Greca
}

Olival Freire Jr.

\section{Introdução}

A pesquisa sobre ensino de Mecânica Quântica (MQ), tanto no nível universitário quanto no ensino médio, vem despertando interesse cada vez maior na área de ensino de ciências, nos últimos 15 anos. (MCDERMOTT; REDISH, 1999) Até pouco tempo atrás, o maior propósito para os estudantes universitários, que não fossem físicos ou químicos, para estudar MQ era uma melhor apreciação de sua influência na forma de compreender o mundo, argumento semelhante ao esgrimido pelos defensores da introdução de tópicos de física contemporânea no ensino médio. (GIL; SOLBES, 1993; LÜHL, 1992) Assim, Muller e Weisner (2002) consideram que, sendo a MQ a teoria que forneceu um novo marco para toda a Física, cidadãos formados deveriam ter a possibilidade de poder apreciar seus estranhos aspectos e a sua beleza. Indo um pouco além nesta mesma linha, Karakostas e Hadzidaki (2005) salientam que a MQ não somente nos propõe uma visão radicalmente diferente do mundo físico, senão que dá a base conceitual para a apropriada interpretação de uma ampla variedade de fenômenos naturais. Desde uma vertente diferente, relacionada com o impacto tecnológico da $\mathrm{MQ}$, se argumenta que os estudantes não deveriam sentir um rechaço para com ela, sobretudo nos primeiros anos de ciências universitárias (GRECA; FREIRE JR., 2003), dado que é necessário dispor de mais pessoas, em áreas como as Engenharias e a Biologia, que possam desenvolver e manipular de forma apropriada tecnologia embasada em princípios de MQ. Mais ainda, Zollman (1999) enfatiza que um melhor ensino universitário de tópicos de MQ tem se tornado fundamental, pois os recentes desenvolvimentos em nanotecnologia e eletrônica 
trazem para o mundo dos engenheiros e dos negócios dispositivos que somente podem ser apreciados pelos seus princípios.

Cabe destacar que ambas as posturas são complementares. Como salienta Hadzidaki (2008a, 2008b), neste momento, em que se espera que estudantes de toda classe de campos aplicados aprendam as ideias básicas e os cálculos técnicos da MQ, não deveríamos esquecer que uma educação cientifica responsável deve ir além da preparação efetiva de futuros cientistas e técnicos e ajudar os estudantes a compreender como a ciência se relaciona com toda a cultura, darlhes o conhecimento suficiente para participar da cultura cientifica quando seja necessário e oferecer-lhes a oportunidade de pensar sobre as implicações filosóficas derivadas da Física moderna, questões que passam, umas e outras, por uma apropriada compreensão conceitual da MQ.

Para conseguir estes objetivos, várias propostas didáticas diferentes têm aparecido. Assim, centrando-nos especificamente nos primeiros anos do ensino universitário e nos cursos de formação de professores, encontramos propostas focadas em discussões conceituais, em discussões filosóficas, em abordagens históricas, no uso de experiências recentes para aprofundar aspectos conceituais fundamentais e no uso (portanto, desenvolvimentos) de softwares especiais, tanto para aprimorar a visualização de certos conteúdos de Física clássica, necessários à compreensão da $\mathrm{MQ}$, quanto para explorar características quânticas de sistemas microscópicos. ${ }^{1}$ Estas abordagens podem ser, por sua vez, identificadas em dois grupos, com ênfases radicalmente opostas: de um lado, estão aquelas que de forma proposital evitam as relações com a Mecânica Clássica e o uso de analogias clássicas ou semiclássicas; e, do outro, as que salientam a relevância de estabelecer pontes com a Mecânica Clássica. Matzkin (2002) indica que estas diferenças parecem radicar fundamentalmente na concepção que os autores têm sobre o estatuto da MQ em relação à realidade. Ampliando esta ideia, consideramos que, no fundo, estas diferenças exprimem diferentes posturas sobre a interpretação mais apropriada da Teoria Quântica.

Neste trabalho, refletimos trazendo elementos da história da ciência, sobre a necessidade que toda pesquisa na área de ensino de Mecânica Quântica ${ }^{2}$ - seja sobre formas mais eficientes de ensino ou sobre como os estudantes compreendem os conceitos quânticos - que pretenda enfatizar aspetos conceituais, parta, pelas características dessa teoria, de uma explicitação da interpretação privilegiada

1 Ver revisão de literatura em Greca e Moreira (2001). Sobre tema relacionado, revisão de literatura sobre ensino de física moderna e contemporânea no ensino médio, ver Ostermann e Moreira (2000) e Pereira e Ostermann (2009).

2 Embora nesta apresentação tomemos exemplos de cursos de graduação e pós-graduação em Física, consideramos que nosso argumento é extensível a todos os casos envolvidos no ensino de Mecânica Quântica. 
pelos autores. Embora fundamental, pois a interpretação adotada condiciona os tipos de abordagens possíveis, assim como os resultados das análises realizadas sobre a compreensão dos conceitos quânticos por parte dos estudantes, esta questão, no entanto, não é frequentemente abordada nas pesquisas na área.

\section{O ensino não-conceitual da Mecânica Quântica}

Dificuldades de compreensão de Mecânica Quântica são lendárias. Não somente os estudantes de graduação pesquisados não compreendem seus princípios básicos (AMBROSE et al. 1999; GRECA; FREIRE JR., 2003; JOHNSTON; CRAWFORD; FLETCHER, 1998; SINGH, 2001; VOKOS et al. 2000), embora seus tópicos fundamentais sejam muito repetidos - segundo Cataloglu e Robinett (2002), nos Estados Unidos, um estudante pode se encontrar com conteúdos semelhantes de MQ em até uns cinco cursos antes de se graduar -, senão que destacados físicos que têm trabalhado com ela o reafirmam. Por exemplo, John Bell expressa que "Quando era estudante, [teve] muitas dificuldades com a mecânica quântica. Foi reconfortante saber que mesmo Einstein teve dificuldades por muito tempo" (FREIRE JR, 2006); para Murray Gell-Mann (1980, p. 169-170), "A mecânica quântica é aquela misteriosa, confusa disciplina, que nenhum de nós realmente compreende mas que sabemos como usar" ou como diz Richard Feynman na sua famosa frase

Como o comportamento atômico é tão diferente da experiência ordinária, é muito difícil adquirir familiaridade com o mesmo, ele parece peculiar e misterioso para todos - tanto para o novato quanto para o físico experiente. Mesmo os especialistas não a entendem do modo como gostariam de entendê-la, e é perfeitamente razoável que isso aconteça porque toda a experiência, ou a intuição, humana direta se aplica a objetos em grande escala. (FEYNMAN, 1964, p. 1)

Além de sua estranheza, parte da dificuldade com seus conceitos, que se distanciam de conceitos culturalmente queridos como a causalidade, o determinismo ou a localidade, é sua apresentação, característica de disciplinas avançadas dos cursos de graduação, basicamente formalista, centradas na aprendizagem de métodos matemáticos de resolução de casos típicos, com pouca ou nenhuma discussão conceitual ou interpretacional. Destacamos que as disciplinas introdutórias de MQ (muitas vezes a única vez em que estudantes de carreiras de ciências diferentes da Física são expostos a esses conteúdos) tampouco tratam estas questões em profundidade: usando uma quase-história, na terminologia de Kragh (1992), com simplificações excessivas e erros, enfatizando ideias e imagens 
desenvolvidas entre 1900 e 1920, anteriores aos desenvolvimentos propriamente quânticos, provocando erros conceituais. (JONES, 1991)

Qual a origem desta abordagem didática formalista e instrumental? Quiçá a resposta que primeiro nos vem à cabeça seja que, dada a complexidade matemática da teoria, é necessário reforçar particularmente estes tópicos com os estudantes. Como destaca David Bohm na introdução do seu livro Quantum theory (1989, publicado originalmente em 1951) - livro, aliás, que em direção oposta à tendência nos Estados Unidos nessa época, tema que abordaremos adiante, discute durante muitas páginas uma e outra vez os conceitos centrais da MQ - além das ideias físicas que diferem completamente de nossa experiência cotidiana, na MQ

[...] o aparato matemático necessário para aplicar esta teoria mesmo para os exemplos mais simples é muito menos familiar que o correspondente para os problemas de mecânica clássica. Como resultado, existe uma tendência a apresentar a teoria quântica como sendo inseparável dos problemas matemáticos que aparecem nas suas aplicações. (BOHM, 1989, p. 1 )

Outro fator, relacionado com a visão da geração de físicos posteriores aos fundadores da Mecânica Quântica sobre seus princípios é o destacado por Heilbron (2001), que indica que a maioria dos físicos, além do círculo próximo a Bohr, usava a maquinaria da Mecânica Quântica para estudar o mundo microscópico, sem se preocupar com questões conceituais ou interpretacionais. No entanto, vários livros didáticos europeus de pós-graduação do período posterior à Segunda Guerra, em particular alemães e franceses, tinham seções sobre questões de fundamentos e implicações epistemológicas. (KAISER, 2007, p. 33) Este predomínio da visão da Mecânica Quântica como "maquinaria de cálculo" teria sido reforçado particularmente nos Estados Unidos. Nesse país, segundo Schweber (1986), o desenvolvimento da física teria sido marcado pela coexistência nos mesmos departamentos de físicos teóricos e experimentais - dando maior ênfase aos experimentos e aplicações - e pela tendência americana ao pragmatismo. Esta postura, basicamente instrumentalista, não exige uma compreensão conceitual profunda sobre como sucedem os fenômenos, senão que privilegia o conhecimento de como aplicar os algoritmos necessários para fazer novos cálculos, o que não é pouco, no caso da Mecânica Quântica, embora não seja suficiente.

Além destas questões, encontramos um outro fator de muita relevância para o ensino, relacionado com os livros didáticos. Segundo Kaiser, como resultado do grande aumento do número de estudantes de graduação e pós-graduação em Física nos Estados Unidos, no contexto da Guerra Fria que sucedeu a Segunda Guerra Mundial, foi necessário tomar algumas decisões pedagógicas que afetaram especialmente o ensino de Mecânica Quântica, dado que, nos anos 50, somente 
aqueles que a tivessem estudado podiam dizer que eram físicos. (KAISER, 2007) Assim, os departamentos de Física tiveram que reformular as disciplinas, acentuando aqueles elementos com os quais obtinham melhores resultados pedagógicos, como analisado por Kaiser:

Com o crescimento do tamanho das turmas, contudo, os aspectos filosóficos da mecânica quântica foram afastados das salas de aula. O objetivo da física era treinar 'mecânicos quânticos': os estudantes deveriam ser mais como engenheiros ou mecânicos do domínio atômico, que filósofos. [...] Face ao crescimento nas matrículas, a maioria dos físicos nos Estados Unidos reorganizou o conteúdo da mecânica quântica acentuando aqueles elementos que permitiam o tema ser ensinado tão rápido quanto possível, abandonando silenciosamente, ao mesmo tempo, os últimos vestígios de reflexões conceituais ou interpretativas que tanto tinham ocupado o tempo das aulas antes da guerra. (KAISER, 2007, p. 28-31)

Esta mudança de enfoque ficou expressa nos livros didáticos editados a partir de então que, de modo algum, segundo Kaiser, eram compatíveis com o espectro de posturas pedagógicas em relação à $\mathrm{MQ}$ no período entre-guerras. Um exemplo destacado é o livro de Schiff, amplamente usado na formação de físicos em todo o mundo. Kaiser nos lembra que Schiff foi aluno de Mecânica Quântica de Oppenheimer, em Berkeley, curso muito popular entre os estudantes, no qual Oppenheimer apresentava a MQ como uma solução radical a problemas filosóficos e se adentrava em discussões sobre seus mistérios. Se Schiff não considerou relevante para seu livro incluir tópicos de discussões conceituais, parece pouco provável que os físicos posteriores, futuros professores dos cursos de graduação, sem uma formação conceitual especifica sobre $\mathrm{MQ}$, ensinassem de uma forma que não fosse a instrumental. O livro muito mais conceitual de Bohm ao qual fizemos referência anteriormente, aparecido na mesma época que o do Schiff, não teve a mesma acolhida que o conhecido livro de Schiff e, de fato, não foi reeditado, pelo menos nos anos imediatos.

Entre 1951 e 1980, foram publicados nos Estados Unidos, específicamente na área de Física, 33 livros de pós-graduação sobre MQ e uns 20 livros destinados a estudantes de graduação (KAISER, 2007, p. 32) que, embora com marcantes diferenças relacionadas com a abordagem que permitiria progressos mais rápidos (se a abordagem de Schrödinger, a das matrizes de Heisenberg ou a abordagem de brackets de Dirac), todos eles eram muito semelhantes, com longas listas de problemas de complicado cálculo e poucas questões conceituais que, de fato, não passavam de perguntas para resposta curta. 
Esta tendência nos livros didáticos somente teria começado a mostrar alguma mudança em alguns livros aparecidos nos finais dos anos 60, quando o boom dos estudantes de Física nas universidades norte-americanas começou seu rápido declínio. Assim, livros como os de Eisberg e Resnick, além da longa lista de exercícios, incluíram algumas questões de discussão. No entanto, numa leitura desse livro se observa que há apenas uma página dedicada a apresentar a interpretação de Copenhague e são inexistentes questionamentos sobre os fundamentos da MQ. Como descreve Barton ainda no final do século XX, os livros-texto usuais, tanto os de nível introdutório como os mais avançados,

[...] fornecem esplêndidos métodos para realizar qualquer cálculo sobre átomos ou sobre campos quantizados, mas no que se refere a princípios e interpretação da Mecânica Quântica em si, são, quase sem exceção, simplistas e obscuros ao mesmo tempo [...]. ${ }^{3}$ (BARTON, 1997, p. 429)

De fato, uma visão rápida de cursos universitários de $\mathrm{MQ}$ nos mostra que, na maioria deles, continua-se a ensiná-la da mesma forma que há 70 e tantos anos atrás (FLETCHER; JOHNSTON, 1999) e os alunos continuam a ter essa visão de "cálculo" da MQ. (JOHNSTON; CRAWFORD; FLETCHER, 1998; REDISH; STEIMBERG, 1998; STORY, 1998) Ainda que se argumente que os físicos podem aproveitar seu conhecimento do formalismo matemático para superar as dificuldades conceituais (MULLER; WEISNER, 2002), resultados de pesquisa indicam que estudantes avançados de Mecânica Quântica, que têm aprendido a resolver a equação de Schrödinger com potenciais complicados, continuam com dificuldades conceituais em aspectos fundamentais. (GRECA; FREIRE JR., 2003; SINGH, 2001) Como indica Pospiech (2000), embora não parece ser possível uma compreensão conceitual da MQ sem um conhecimento aproximado de sua estrutura matemática, a própria complexidade do formalismo completamente desenvolvido parece impedir a muitos estudantes de obtê-la, pois este formalismo geralmente mascara aspectos filosóficos.

\section{As interpretações da Mecânica Quântica na formação dos físicos}

A Mecânica Quântica, diferentemente de outras teorias científicas, teve, desde sua origem, a característica notável de poder ser interpretada de diferentes maneiras, cada uma delas internamente consistente e, em geral, consistente

3 Embora esta caracterização corresponda aos Estados Unidos, a tradição de ensino de física em América Latina e na Ásia se embasa nela, portanto esses resultados podem ser pensados como mais gerais que para o caso norte-americano. 
com os experimentos quânticos. Por interpretação, estamos usando a definição de Pessoa Jr. (2003): conjunto de teses que se agrega ao formalismo mínimo de uma teoria e que em geral não afeta as suas previsões observacionais; se fizesse previsões novas, falar-se-ia de "teoria nova". ${ }^{4}$

Embora no seu nascedouro e logo após, tenha havido intensos debates quanto às interpretações da teoria - o mais famoso, entre Bohr e Einstein -, a interpretação dominante foi aquela que viria a ser conhecida como a de Copenhague, fato tão marcante que Jammer (1974) denominou este período de "monocracia da escola de Copenhague". ${ }^{5}$ No entanto, esta monocracia nunca se expressou nos livros-texto usados na formação dos físicos: Kragh (1999) destaca que dos 43 livros publicados entre 1928 e 1937, somente 8 mencionavam, e rapidamente, o principio da complementaridade, principio central na visão epistemológica de Bohr: "a maioria dos autores dos livros-textos, ainda que simpatizantes das idéias de Bohr, achava difícil incluir e justificar uma seção sobre complementaridade". Kragh destaca que Dirac, autor de uns dos livros mais influentes de $\mathrm{MQ}$, “[...] não via nenhuma necessidade de falar de complementaridade. Não resultava em novas equações e não podia ser usada para os cálculos que Dirac identificava com a física". (KRAGH, 1999, p. 211) Em geral, quando alguma referência aparece nos livros, isso é feito na forma da mútua exclusão das representações de onda e partícula.

A junção entre esta "monocracia", mais de discurso que de fato, e os contínuos êxitos práticos da teoria levaram à sensação que os problemas fundacionais da MQ tinham sido resolvidos pelos pais fundadores (FREIRE JR, 2006) e que questões interpretacionais da $\mathrm{MQ}$ eram assunto de filósofos e não de físicos profissionais.

Se levarmos em consideração que os livros-texto nos quais os físicos foram formados até a década de 50 não refletiam nenhuma preocupação acerca da interpretação da teoria (DE WITT; GRAHAM, 1973) ${ }^{6}$ e, a partir dali, segundo Kaiser, nos livros editados nos Estados Unidos tampouco enfatizavam questões conceituas - onde elementos interpretacionais podiam chegar a ter sentido -, pode-se concluir que os livros, em geral, privilegiaram uma visão "instrumentalista mínima" (REDHEAD, 1987): algoritmo de quantização e algoritmo estatístico, mais a premissa epistemológica (implícita) que "as teorias em física são simplesmente dispositivos para expressar regularidades entre observações".

4 Para uma apresentação mais técnica da distinção entre formalismo e interpretação, ver Jammer (1974, p. 2-19).

5 Observamos, contudo, que estudos recentes têm evidenciado tanto a diversidade de perspectivas por trás da expressão "interpretação de Copenhague", como o contexto histórico da criação desse termo. Ver: Howard (2004) e Camilleri (2009).

6 Exceção, nesse cenário, foi o já referido livro de David Bohm (1989). 
Assim, existiu um reforço mútuo entre o enfoque didático da desvalorização das questões conceituais e a visão instrumentalista, afinal, esta última eximia os autores de livros-texto de aprofundamentos conceituais.

Como indica Kuhn (1970), os físicos são formados a partir dos livros didáticos. Portanto, esta breve descrição das ausências conceituais e interpretacionais nesses livros implica que elas aparecem nos cursos de graduação, sinalizando a ênfase basicamente instrumental na sua formação. Lembrando que, por sua vez, os livros didáticos de outras áreas ou de níveis inferiores tendem a reproduzir versões simplificadas do que aparece nos livros didáticos de graduação e pós-graduação, temos então uma cadeia de ausências nos dois aspetos assinalados. Cabe assinalar, por fim, que essa tendência não é inexorável e pode ser modificada. Exemplo de tentativa nessa direção, ainda no âmbito dos livros-texto, é o livro Quantum challenge, de George Greenstein e Arthur Zajonc, físicos do Amherst College nos EUA. Esse livro foi concebido, acreditando que questões de fundamentos "[...] podem ser apresentadas com razoável rigor e honestidade intelectual em uma apresentação accessível a estudantes de graduação de ciências físicas, matemática e engenharias". (GREENSTEIN; ZAJONC, 1997, p. xv) O livro é largamente baseado em uma discussão de experimentos contemporâneos reais.

\section{O caso de John Clauser $^{7}$}

O físico norte-americano John Clauser, nascido em 1942, concluiu seu doutoramento em 1969 na Columbia University, com um trabalho experimental de medida da radiação cósmica de fundo, sob a orientação de Patrick Thaddeus. Nesse mesmo ano, ele teve seu interesse deslocado para a possibilidade de testes experimentais com o teorema de Bell, campo no qual, junto com Abner Shimony, ele teve um papel pioneiro. ${ }^{8}$ Formado no final dos anos 60 , Clauser exemplifica as dificuldades de compreensão que geram abordagens didáticas instrumentalistas da MQ para aqueles estudantes que necessitam ir além da aplicação de algoritmos de resolução de problemas. Ele se descreve como um pensador concreto, que necessita de um modelo conceitual para poder resolver problemas. E indica que uma das razões pelas quais teve que fazer três vezes um curso de pós-graduação em MQ era que a maior parte do curso era de manipulações matemáticas:

7 A apresentação desse caso está embasada na entrevista com John Clauser realizada por Joan Bromberg, 20 maio de 2002, Niels Bohr Library \& Archives, American Institute of Physics, College Park, MD USA. Disponível em <http://www.aip.org/history/ohilist/transcripts.html.. Todas as citações de Clauser foram daí extraídas.

8 Para uma análise da contribuição de Clauser ao estabelecimento do campo de pesquisas dedicado aos fundamentos da mecânica quântica, ver Freire Jr. (2006) e Freire, "Dissidentes quânticos", nesse volume. 
Uma das razões pelas quais eu não conseguia obter um $B$ [no curso Mecânica Quântica Avançada] era que muito dele era somente manipulações matemáticas, e eu não sou muito bom em matemática abstrata ou pensamento abstrato; e não entendia, não sabia porque estava fazendo aquilo. E me sentia muito desconfortável.

Por outra parte, o único modelo conceitual fornecido pelos livros de MQ estava relacionado com uma interpretação ondulatória, que somente funcionava quando se pensava numa única partícula.

Os livros fazem a MQ parecer com uma simples mecânica ondulatória, i. e., o que se observaria através de uma analogia direta com as ondas na superfície de um tanque. E mostram imagens. [...]. E ainda pior, dizem: 'OK, uma partícula, podemos representá-la como uma espécie de pacote de ondas', o que quer que isso signifique, [...] se propagando num espaço real. [...] Agora considere o caso de duas partículas. Neste caso a $\Psi$ não é mais uma função de $x, y, z$ e t. É uma função de $x, y, z, x^{\prime}, y^{\prime}, z$, e t. O espaço cresceu? [...] Se eu não posso [usar esse modelo] para o caso de quatro, três, duas partículas, não deveria poder fazê-lo tampouco para uma. O que significa toda esta idéia de pacotes de onda que todos os livros colocam?

Nos livros em que Clauser estudou as imagens fornecidas para dar uma ideia “intuitiva” da MQ parecem não ter colaborado para o seu entendimento, possivelmente porque elas não formavam parte do ideário didático dessas disciplinas - aprender a fazer cálculos. Assim, resultam em agregados, sem consistência interpretacional, ou seja, sem explorar as consequências da interpretação que se pode associar a estas imagens - uma interpretação realista ondulatória (PESSOA JR., 2003) - nos conceitos quânticos. Parecem ser justamente essas contradições as que dificultaram, no caso de Clauser, sua compreensão.

O interessante deste caso, salvando a questão das imagens ondulatórias apresentadas, é que a não adoção de uma interpretação é coerente com o tratamento "conceitual" dado: não é necessário compreender o que está acontecendo para saber aplicar as fórmulas adequadas.

De fato, Clauser coloca claramente esta questão ao indicar que na formação em Mecânica Quântica as questões conceituais parecem carecer de sentido. Os físicos treinados para trabalhar com o formalismo matemático não se importam com o significado físico das fórmulas com as que estão trabalhando.

Todos os livros estão escritos desta forma, e essa é a forma como as pessoas trabalham, e eu também. Eu não tenho a 
mais remota idéia de porque estou fazendo desse jeito. $\mathrm{E}$ de fato, você escuta uma quantidade de pessoas que dizem "Bom, você não tem que entendê-la para usá-la. Somente siga as regras”.

O que este caso nos mostra é que se pode perfeitamente estudar MQ com esta abordagem, embora isso possa significar para muitos estudantes uma tarefa sem sentido, que os levará a afastar-se dela. Como indicam Johnston, Crawford e Fletcher (1998), embora seja esta uma forte tradição nos departamentos de Física - primeiro, ensinar como fazer as contas e, depois, quando o estudante se dedicar à pesquisa, preocupar-se com o que significam - parece ser já hora de mudá-la, dada a necessidade de que a MQ seja compreendida por profissionais que não serão pesquisadores em Física.

Clauser indica que, justamente por causa de suas dificuldades para compreender a MQ na forma em que lhe era ensinada, procurou diversos livros, entre eles Nonlinear wave mechanics de de Broglie, um livro crítico com relação à interpretação de Copenhague, que o encaminhou à leitura de trabalhos de Bohm e de Von Neumann, antecedentes do teorema de Bell que posteriormente ele testou experimentalmente.

\section{As interpretações na pesquisa em ensino de ciências}

Como referido na introdução, existe um interesse crescente na área em ensino de ciências por abordagens que enfatizem os aspectos conceituais da MQ. Possivelmente, parte desse interesse esteja relacionada com uma problemática pedagógica inversa à referida por Kaiser na década de 1950, nos Estados Unidos. Naquela época, a problemática era a superpopulação de estudantes em Física e a MQ era a matéria que devia ser conhecida pelos que queriam ser físicos. Atualmente, em que a Física não é mais a única estrela do firmamento acadêmico e que deve, portanto, justificar suas ações, o número decrescente de alunos matriculados faz voltar a investir na compreensão da MQ, pois é necessário "mão- de-obra" para o desenvolvimento tecnológico por ela desencadeado (nanotecnologia, ciência dos materiais, informação quântica).

É relevante ressaltar que parte deste desenvolvimento tem sido possível justamente pela florescente pesquisa sobre os fundamentos da MQ, desenvolvida nas últimas décadas do século XX. O que, pelo menos, resulta paradoxal: aqueles problemas que na década de 1950 eram considerados meramente filosóficos resultam ser, no final do século, o eixo central de uma área de pesquisa reconhecida pelos físicos, assim como o ponto de partida para uma tecnologia de ponta, no caso, a informação quântica. 
Assim, embora o enfoque didático instrumentalista da década de 1950 não possa ser simplesmente associado a um campo amadurecido de pesquisa -, pois persistiram os problemas com o significado do formalismo quântico, somente que não tratados (sobretudo nos Estados Unidos) -, neste momento, parece, um enfoque didático mais conceitual poderia estar fortemente influenciado pelos desenvolvimentos tecnológicos de ponta, embasados justamente na retomada daquelas questões que ficaram sem solução nos primórdios da Mecânica Quântica.

O interesse em questões conceituais na área de ensino de ciências não aparece, no entanto, refletido com a mesma ênfase em questões interpretacionais, embora estejam, como estamos discutindo, indissoluvelmente associadas. Numa análise de artigos relacionados com o ensino da MQ em cursos ou disciplinas de Física, publicados entre 2000 e 2007 em revistas internacionais da área American Journal of Physics, European Journal of Physics, International Journal of Science Education, Physics Education, Science Education e Science \& Education -, pode-se observar que dos 34 artigos aparecidos, somente 8 (menos de 1/4) explicitam a interpretação adotada. ${ }^{9}$ Nesses, foram adotadas uma interpretação realista de Bohr (HADZIDAKI, 2008a, 2008b; KARAKOSTAS; HADZIDAKI, 2003); de ensembles estatísticos (MULLER; WEISNER, 2002); interpretação de Copenhague (SINGH, 2001); interpretação ortodoxa realista (GRECA; FREIRE JR., 2003); interpretação bohmiana dualista realista (PASSON, 2004); e interpretação de estados quânticos como potencialidades. (POSPIECH, 2003) Desses trabalhos, 3 pertencem ao mesmo grupo de pesquisa e 5 se encontram em uma revista com ênfase nos aportes da Historia e da Filosofia da Ciência para o ensino de ciências (Science \& Education).

Um dado interessante deste levantamento é que, à exceção de um deles, todos os trabalhos que de forma explícita adotam uma interpretação podem ser incluídos dentro do espectro das denominadas interpretações realistas - ou seja, interpretações que se afastam da postura epistemológica da interpretação de Copenhagen, atribuindo um caráter objetivo ao conceito de estado de um sistema quântico, tornando-o menos dependente dos processos de medição. Essa tendência favorável a interpretações realistas coincide com a visão epistemológica predominante entre os físicos que estiveram na origem do campo de fundamentos da Teoria Quântica na década de 1970. (FREIRE JR., 2009)

9 Num período anterior, analisado em Greca e Moreira (2001), repete-se uma tendência semelhante.

10 Pospiech considera importante que sejam conhecidas diferentes interpretações da mecânica quântica, em especial os professores e estudantes de licenciatura. Tomamos as interpretações como identificadas pelos autores das pesquisas, sem a preocupação de avaliar possíveis superposições ou mesmo duplicações. 
Voltando para a problemática das interpretações da MQ na pesquisa em ensino de ciências, a não explicitação da interpretação leva à permanência de dúvidas e ambiguidades em relação tanto às concepções dos estudantes, quanto às vantagens das abordagens didáticas propostas. Tomemos, por exemplo, uma frase que aparece em alguns questionários e também em respostas de estudantes: "O elétron é sempre uma partícula". Embora esta frase pareça uma resposta clássica, não se pode afirmar, sem explicitar a interpretação a partir da qual se faz a afirmação, que uma resposta deste tipo seja necessariamente representativa de um pensamento mecanicista, clássico e, portanto, não apropriado para a compreensão do mundo quântico. Esta resposta, isolada, poder-se-ia associar a uma interpretação da Teoria Quântica, em consonância com as variáveis escondidas propostas por David Bohm, em 1952. Poderia ser associada também à interpretação dos ensembles estatísticos que tem sido adotada por vários livros-texto e à Lógica quântica, vez que esta pressupõe uma visão corpuscular. (MONTENEGRO; PESSOA JR., 2002, p. 109) Sendo bastante comum entre estudantes que têm cursado alguma disciplina de $\mathrm{MQ}$, embora certamente de forma mais ingênua, poderia ser usada como ponto de partida para uma discussão conceitual dos princípios da MQ, sempre que se explicitassem as limitações e/ou dificuldades que ela apresenta. Obviamente, para outras interpretações, como as do tipo ondulatório ou a de Copenhague, a afirmação antes referida é incorreta.

De forma semelhante, questões referidas ao principio de incerteza podem ter várias respostas, dependendo da interpretação privilegiada. Existem pelo menos duas interpretações possíveis. (JAMMER, 1974; PESSOA JR., 2003) Uma é a defendida pela interpretação ortodoxa e pela ondulatória que considera o princípio de incerteza aplicável a objetos individuais estando, portanto, limitadas em cada objeto, as medições de duas grandezas simultaneamente incompatíveis com uma resolução tão boa quanto se queira. A outra, é aceita pela interpretação dos ensembles estatísticos e das variáveis escondidas, em que a limitação se aplica somente a ensembles de eventos ou objetos.

Por outra parte, é evidente que as estratégias didáticas serão diferentes de acordo com a interpretação adotada. Assim, por exemplo, várias pesquisas que tentam tornar "visualizáveis" os fenômenos quânticos para assim fazê-los apreensíveis para os estudantes, a partir do uso de softwares, tendem implicitamente a adotar interpretações do tipo ondulatório que, por sua natureza, podem reforçar as ligações com a Física clássica. O problema com a adoção acrítica de uma dada interpretação, o que acontece quando não é explícita, é que pode ter consequências não desejadas, se não se discutem as limitações que têm ditas interpretações. Em geral, pareceria que estas abordagens que ancoram em ideias clássicas dos estudantes as reforçam, impedindo uma melhor compreensão dos conceitos quânticos, como acontece, por exemplo, com as dificuldades que os alunos têm para substituir a ideia de onda eletromagnética pela de onda de probabilidade 
(GRECA; FREIRE JR., 2003), fazendo com que o gráfico da densidade de probabilidade seja considerado como um gráfico de movimento. Isto acontece também na Química, onde estudantes que aprendem o modelo ondulatório de átomo entendem o conceito de orbital como "campo espacial" e não como uma função matemática. (TSAPARLIS; PAPAPHOTIS, 2009) Além disto, estas interpretações tampouco conseguem dar respostas satisfatórias para uma série de fenômenos, em particular para aqueles relacionados com experiências recentes da Mecânica Quântica. Isto não quer dizer que não funcionem num dado âmbito, senão que dão uma visão que pode dificultar a compreensão do estudante em cursos posteriores, como indicado no caso de Clauser. Por isso, consideramos que o estudante deve estar consciente de que está trabalhando com uma dada interpretação da Mecânica Quântica e não com "a" sua interpretação.

Embora alguns pesquisadores considerem desejável que o estudante seja apresentado a várias interpretações da Mecânica Quântica nos seus primeiros cursos - há algumas propostas neste sentido, por exemplo, Pessoa Jr. (2003) e Pospiech (2003) - parece-nos preferível, dada a natureza tão pouco intuitiva dos conceitos quânticos, que o estudante pudesse se aprofundar neles de forma consciente desde uma determinada interpretação, para depois poder comparar com outras interpretações possíveis.

\section{Considerações finais}

Neste trabalho, buscamos argumentar no sentido de que seja qual for a estratégia didática que se pretenda desenvolver para aprimorar a compreensão dos estudantes da Mecânica Quântica, ela deve partir de uma explicitação clara sobre a forma em que os pesquisadores entendem o mundo microscópico descrito por ela. Como indica Hadzidaki (2008b), a construção de uma teoria didática deve embasar-se numa eleição explícita da interpretação adotada.

Dadas as características da $\mathrm{MQ}$, as pesquisas na área em ensino de ciências referidas ao seu ensino devem se colocar uma pergunta não usual em Física: qual é a melhor interpretação ou quais interpretações apresentar? Lamentavelmente, esta pergunta não tem resposta simples, pois depende de vários fatores, como os compromissos epistemológicos dos pesquisadores, sua própria formação, os objetivos das implementações didáticas, assim como o tipo de alunos aos quais está dirigida a implementação. Possivelmente, sequências didáticas desenhadas para aprimorar a compreensão conceitual da Mecânica Quântica para futuros professores do ensino médio precisem de interpretações diferentes daquelas desenhadas para estudantes de ciências informáticas, que vão trabalhar com a teoria quântica na elaboração de softwares para computadores quânticos, embora 
ambos precisem compreender os fundamentos da Mecânica Quântica. O que não se pode fazer é deixar a pergunta sem resposta.

Obviamente, toda esta discussão faz sentido desde que se considere importante a compreensão conceitual dos estudantes e não o treinamento de "mecânicos" quânticos. Uma visão meramente instrumentalista, como temos discutido neste trabalho, pode prescindir deste tipo de questões e, de fato, fazer mais rápido o avanço pela maquinaria quântica, embora ao preço de reduzir o alcance cognitivo da teoria, sem fazê-la mais compreensível.

\section{Referências}

AMBROSE, B. S. et al. C. An investigation of student understanding of singleslit diffraction and double-slit interference. American Journal of Physics, v. 67, n. 2, p. 146-155, 1999.

BARTON, G. Quantum dynamics of simple systems. Contemporary Physics, v. 38, n. 6, p. 429-430, 1997.

BOHM, D. Quantum theory. New York: Dover, 1989. Unabridged republication of 1951.

CAMILLERI, K. Constructing the myth of the Copenhagen interpretation. Perspectives on Science, v. 17, n. 1, p. 26-57, 2009.

CATALOGLU, E.; ROBINETT, R. Testing the development of student conceptual and visualization understanding in quantum mechanics through the undergraduate career. American Journal of Physics, v. 70, n. 3, p. 238-251, 2002.

DE WITT, B. S.; GRAHAM, N. (Ed.). The many worlds interpretation on quantum mechanics: a fundamental exposition by Hugh Everett III with papers by J. A. Wheeler [and others]. Princeton: Princeton University, 1973.

FEYNMAN, R. P.; LEIGHTON, R. B.; SANDS, M. The Feynman lectures on physics: quantum mechanics. Reading, MA: Addison-Wesley, 1964.

FLETCHER, P.; JOHNSTON, I. Quantum mechanics: exploring conceptual change. In: RESEARCH on teaching and learning quantum mechanics: Annual Meeting National Association for Research in Science Teaching. Boston: 
National Science Foundation, 1999. (Collection of papers presented). Disponível em: <www.phys.ksu.edu/perg/papers/narst $>$. Acesso em: 2010.

FREIRE JR., O. Dissidentes quânticos: pesquisa em fundamentos da teoria quântica em torno de 1970. 2009.

. The historical roots of "Foundations of Quantum Physics" as a field of research (1950-1970). Foundations of Physics, v. 34, n. 11, p. 1741-1760, 2004.

. Philosophy enters the optics laboratory: Bell's theorem and its first experimental tests (1965-1982). Studies in History and Philosophy of Modern Physics v. 3, p. 577-616, 2006.

GELL-MANN, M. Questions for the future, 8th Wolfson lecture. In: MULVEY, J. H. (Ed.). The nature of matter. Oxford; England: Clarendon, 1980. p. 169-198.

GIL, D.; SOLBES, J. The introduction of modern physics: overcoming a deformed vision of science. International Journal of Science Education, London, v. 15, n. 3, p. 255-260, 1993.

GRECA, I. M.; FREIRE JR., O. Does the emphases in the concept of quantum states enhance students' understanding of quantum mechanics? Science \& Education, v. 12, n. 5-6, p. 541-557, 2003.

GRECA, I. M.; MOREIRA, M. A. Uma revisão da literatura sobre estudos relativos ao ensino de mecânica quântica introdutória. Investigações em ensino de ciências, v. 6, n. 1, p. 7-106, jan. 2001. Disponíve em: <http://www.if.ufrgs.br/ public/ensino/revista.htm>.

GREENSTEIN, G.; ZAJONC, A. The quantum challenge: modern research on the foundations of quantum mechanics. Sudbury, MA: Jones and Bartlett, 1997.

HADZIDAKI, P. The Heisenberg microscope: a powerful instructional tool for promoting meta-cognitive and meta-scientific thinking on quantum mechanics and the "nature of science". Science \& Education, v. 17, n. 6, p. 613-639, 2008b.

. "Quantum mechanics" and "scientific explanation" an explanatory strategy aiming at providing "understanding". Science \& Education, v. 17, n. 1, p. 49-73, 2008a. 
HEILBRON, J. The earliest missionaires of the Copenhagen spirit. In:

GALISON, P.; GORDIN, M.; KAISER, D. (Ed.). Science and Society: the history of modern physical science in the twentieth century. New York: Routledge, 2001. p. 295-330. (Quantum Histories, v. 4).

HOWARD, D. Who invented the "Copenhagen interpretation"? A study in mythology. Philosophy of Science, v. 71, p. 669-682, 2004.

JAMMER, M. The philosophy of quantum mechanics: the interpretations of quantum mechanics in historical perspective. New York: John Wiley \& Sons, 1974.

JOHNSTON, I. D.; CRAWFORD, K.; FLETCHER, P. R. Student difficulties in learning quantum mechanics. International Journal of Science Education, v. 20, n. 4, p. 427- 446, 1998.

JONES, D. Teaching modern physics: misconceptions of the photon that can damage understanding. Physics Education, v. 26, n. 2, p. 93-98, 1991.

KAISER, D. Turning physicists into quantum mechanics. Physics World, p. 28-33, may 2007.

KARAKOSTAS, V.; HADZIDAKI, P. Realism vs constructivism in contemporary physics: the impact of the debate on the understanding of quantum theory and its instructional process. Science \& Education, v. 14, n. 5, p. 607-629, 2005.

KRAGH, H. Quantum generations: a history of physics in the twentieth century. Princeton: Princeton University, 1999.

. A sense of history: history of science and the teaching of introductory quantum theory. Science \& Education, v. 1, p. 349-363, 1992.

KUHN. T. S. The structure of scientific revolutions. $2^{\text {nd }}$ ed., Chicago: Chicago University, 1970.

LÜHL, J. Teaching of social and philosophical background to atomic theory. Science \& Education, v. 1, p. 193-204, 1992.

MATZKIN, A. Realism and the wave function. European Journal of Physics, v. 32, p. 285-294, 2002. 
MCDERMOTT, L.; REDISH, E. 'Resource letter: PER-1: physics education research. American Journal of Physics, v. 67, n. 9, p. 755-767, 1999.

MONTENEGRO, R.; PESSOA JR., O. Interpretações da teoria quântica e as concepções dos alunos do curso de Física. Investigações em Ensino de Ciências, v. 7, n. 2, p. 107-126, 2002.

MÜLLER, R. and WIESNER, H. Teaching quantum mechanics on an introductory level, American Journal of Physics, v. 70, n. 3, p. 200-209, 2002.

OSTERMANN, F. e MOREIRA, M. A. Uma revisão bibliográfica sobre a área de pesquisa Física Moderna e Contemporânea no ensino médio. Investigações em Ensino de Ciências, v. 5, n. 1, p. 23-48, 2000.

PASSON, O. How to teach quantum mechanics, European Journal of Physics, v. 25, p. 765-769, 2004.

PEREIRA, A. P. e OSTERMANN, F. Sobre o ensino de Física Moderna e Contemporânea: uma revisão da produção acadêmica recente. Investigações em Ensino de Ciências, v. 14, p. 393-420, 2009.

PESSOA, O. Jr. Conceitos de Física Quântica-São Paulo: Editora Livraria da Física, 2003.

POSPIECH, G. Uncertainty and complementary: the heart of quantum physics. Physics Education, v. 35, n.6, p. 393-399, 2000.

POSPIEVICH, G. Philosophy and quantum mechanics in science teaching, Science \& Education, v. 12, p. 559-571, 2003.

REDHEAD, M. Incompleteness, Nonlocality, and Realism - A Prolegomenon to the Philosophy of Quantum Mechanics, Oxford: Clarendon Press - Oxford Univ. Press, 1987.

REDISH, E., LEI, B.\& JOLLY, P. Student difficulties with energy in quantum mechanics. Oral communication AAPT Winter meeting, Phoenix, January. Disponível na Internet: www.physics.umd.edu/perg/cpt.html. 1997.

SCHWEBER, S. The empiricist temper regnant: theoretical physics in the United States 1920-1950. Part 1. Historical Studies in the Physical and Biological Sciences, v. 17, p. 55-98, 1986. 
SINGH, C. Student understanding of quantum mechanics. American Journal of Physics, v. 69, n.8, p. 885-895, 2001.

STORY, R. Bridging a quantum-mechanical barrier. IEEE Transactions on Education, v. 41, n. 1, p. 54-60, 1998.

TOULMIN, S. Regreso a la razón, Barcelona: Ediciones Península, 2001.

TSAPARLIS, G. \& PAPAPHOTIS, G. High-school students' conceptual difficulties and attempts at conceptual change: the case of basic quantum chemical concepts. International Journal of Science Education, vol. 31, n. 7, p. 895-930, 2009.

VOKOS, S., SHAFFER, P. S., AMBROSE, B. S., MCDERMOTT, L. C. Student understanding of the wave nature of matter: diffraction and interference of particles. American Journal of Physics, Supp. vol. 68, n. 7, p. S42-S51, 2000.

ZOLLMAN, D. Introduction - Research on teaching and learning quantum mechanics. Annual Meeting National Association For Research In Science Teaching, 1999, Boston. Collection of papers presented. Disponível na Internet: www.phys.ksu.edu/perg/papers/narst. 2010. 


\section{Parte IV}

Construção da Teoria Quântica história e tendências de pesquisa 



\title{
Max Planck e a Física de sistemas estocásticos
}

\author{
Sílvio Renato Dahmen
}

\section{Introdução}

Max Planck, cujo nome associa-se ao nascimento da Mecânica Quântica, desempenhou ao longo de sua vida um destacado papel no desenvolvimento da Termodinâmica. É impossível pensar sua obra sem levar em conta um fato: seus anos formativos corresponderam justamente ao período de estabelecimento da Termodinâmica enquanto área na Física e Planck, que se tornaria uma das maiores autoridades neste assunto, se não a maior autoridade entre todas, contribuiu de maneira significativa para tal. Foi a Termodinâmica que também o levou ao seu célebre trabalho de 1900 - o problema da radiação do corpo negro - abrindolhe as portas para a física quântica. Uma década mais tarde, a física quântica lhe abriria as portas de outra área - a da física de sistemas estocásticos na forma da Equação de Fokker-Planck. Embora hoje saibamos que conceitualmente o caminho tomado por Planck é incorreto, sua dedução rigorosa da equação ainda é válida e se tornou um instrumento indispensável nas mãos dos praticantes da área. Neste trabalho, discuto o papel de Planck na história dos sistemas estocásticos, do ponto de vista de suas considerações a respeito da termodinâmica e da Física Quântica, em particular sua contribuição para o estabelecimento da equação que hoje leva seu nome e o nome de Fokker¹.

1 A equação de Fokker-Planck, o tema principal deste trabalho, foi deduzida de forma geral e rigorosa em 1931 pelo matemático russo A. N. Komolgorov em um trabalho seminal acerca de equações diferenciais estocásticas. (KOLMOGOROV, 1931) Um ano antes, o matemático britânicos Sir R. A. Fisher deduziu, sem o conhecimento de trabalhos prévios, a mesma equação no contexto de mutações raras na genética. (FISHER, 1930) O nome "Equação de Fokker Planck" foi sugerido por Kolmogorov. (DAHMEN, 2008) 
Com um artigo intitulado Über einen Satz der statistischen Dynamik und seine Erweiterung in der Quantentheorie publicado nos Sitzungsberichten der Preussischen Akademie der Wissenschaften (PLANCK, 1917a) e nos artigos posteriores Zur Theorie des Rotationsspektrums. Erste und Zweite Mitteilung, publicado nos Annalen der Physik (PLANCK, 1917b, 1917c), Planck fundamentou a teoria que hoje se encontra na base da física de sistemas estocásticos. Seus objetivos eram dois: por um lado, fornecer uma dedução rigorosa da equação que Adriaan Fokker (1887-1972) havia introduzido em sua tese de doutorado alguns anos antes, sem, porém, justificá-la do ponto de vista formal. (FOKKER, 1914) A equação de Fokker era uma generalização daquela equação que Albert Einstein (1879-1955) havia utilizado em sua teoria do movimento browniano. (EINSTEIN, 1906) Mas, como Planck bem enfatizou na introdução de seu primeiro artigo, Fokker apresentou "[...] apenas a forma da equação geral, sem a prova correspondente. Esta última tarefa seria deixada para uma oportunidade posterior." (PLANCK, 1917a) Ao escrever estas linhas, três anos já haviam transcorrido sem que Fokker publicasse a prova prometida. Planck continua:

Uma vez que o teorema acima citado, em sua forma geral, é de fundamental importância para a dinâmica estatística - eu mesmo o usei em repetidas ocasiões - e dado que sua validade tem sido questionada em círculos especializados, como várias missivas a mim enviadas puderam mostrar, parece-me então justificado publicar uma prova do mesmo. Este é o primeiro objetivo deste trabalho. (PLANCK, 1917a)

O segundo objetivo que ele buscou alcançar nos trabalhos posteriores era tratar de um problema que já mantivera não apenas Fokker ocupado, mas também os mais brilhantes físicos daquela geração: o espectro rotacional de moléculas diatômicas. $\mathrm{O}$ problema geral de linhas espectrais tornou-se, com o tempo, um dos principais interesses de Planck (ECKERT, 2008), como podemos comprovar lendo seus artigos Die Quantenhypothese für Molekeln mit mehreren Freiheitsgraden e Bemerkungen über die Emission von Spektrallinien (PLANCK, 1915a, 1915b, 1915c). Arnold Sommerfeld (1868-1951) era a grande autoridade no assunto e para Planck, editor dos Annalen der Physik, os trabalhos do físico de Munique não passaram despercebidos. Além disso, Sommerfeld lhe enviara uma cópia de seu longo artigo sobre o tema e, com o objetivo de evitar disputas acerca de prioridades, Planck respondeu de maneira bastante polida:

O meu trabalho publicado no Sitz. Ber. locais ${ }^{2}$ acerca de linhas espectrais foi apenas um breve passeio por uma área por mim ainda pouco visitada e por meio do qual eu

2 Sitzungsberichte der Preussischen Akademie der Wissenschaften, os relatos das reuniões da Academia Prussiana de Ciências. 
apenas queria chamar a atenção para a relação existe entre a estrutura do espaço de fase e a fórmula de Bohr. Espero que minha publicação não suscite a impressão que há ali mais do que realmente está escrito. Vejo agora que minha preocupação era infundada, pois o problema não poderia estar em melhores mãos que as Vossas. (ECKERT, 2008)

Deste modo, foi novamente seu interesse por problemas da interação da radiação com a matéria, que há uma década haviam-no colocado no caminho da hipótese da quantização da energia, que agora o colocaria no caminho da equação de Fokker-Planck. É importante mencionar que, diferentemente do que imaginava Planck, a equação de Fokker-Planck não está de modo algum relacionada com a física quântica. No entanto, para o "revolucionário à revelia", a questão que se colocava era a dos limites de aplicabilidade da Teoria Quântica e o "salvamento" da teoria clássica de interação radiação-matéria a la Maxwell, da qual ele não queria abrir mão:

Consideremos porém que segundo a teoria quântica os fenômenos de absorção [de radiação] seguem leis ditadas única e exclusivamente pela teoria clássica, e que apenas a emissão satisfaça algumas leis quânticas, então neste caso a lei de Einstein e Fokker se mostra ser de extrema utilidade. (PLANCK, 1917a) ${ }^{3}$

Para melhor contextualizar o trabalho de Planck e entender suas consequências até os dias atuais, dividi este texto em duas seções, nas quais tento responder às perguntas: $\mathrm{O}$ que é a equação de Fokker-Planck? Como foi que Planck e seus antecessores a ela chegaram? A primeira parte do trabalho, intitulada $O$ movimento browniano e o nascimento da física de sistemas estocásticos, discute este "o quê". O movimento irregular de pequenas partículas suspensas desempenhou para a criação da física de sistemas estocásticos o mesmo papel que a radiação do corpo negro desempenhou para a física quântica. A segunda seção, Max Planck $e$ as linhas espectrais de moléculas em rotação, discute o caminho tomando por Planck para resolver o problema e o contexto de sua época. Como já mencionado anteriormente, o interesse de Planck era o de compreender os espectros de emissão e absorção de graus de liberdade rotacionais de moléculas diatômicas. Se por um lado moléculas na forma de halteres representam os construtos mais simples possíveis quando se trata de estudar rotações, por outro, medições a baixas temperaturas de hidrogênio molecular também contribuíram significativamente para o interesse de físicos por este problema.

3 As linhas espectrais do espectro de emissão já eram conhecidas experimentalmente de longa data. 
Procurou-se, ao longo do texto, manter a Física e a Matemática envolvidas em um nível acessível a leitores que se interessam pela História da Física, sem necessariamente possuírem uma formação direta na área. Algumas fórmulas são imprescindíveis, mas elas são empregadas cum grano salis e apenas na medida em que são necessárias a uma melhor compreensão do texto.

\section{O movimento browniano e o nascimento da Física De Sistemas Estocásticos}

Do ponto de vista etimológico, a palavra estocástico vem do grego clássico

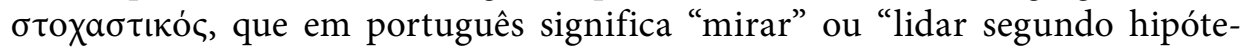

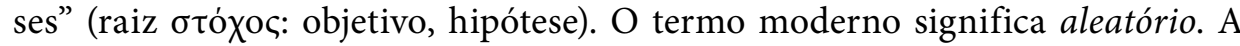
primeira pergunta que se faz é como a aleatoriedade pode entrar numa ciência exata como a Física, que usa da mais exata de todas as linguagens para se expressar: a Matemática. A aleatoriedade entra na Física de diversas maneiras (GUTTMANN, 1999): por um lado, falamos da natureza inerentemente probabilística da física quântica, cuja formulação, enquanto teoria probabilística imanente, foi completada no final dos anos 20 do século passado. Por outro, temos a aleatoriedade da física clássica de um sistema infinito de partículas. Neste caso, a probabilidade se faz presente pelo nosso desconhecimento (e a impossibilidade do conhecimento) das condições iniciais de todas constituintes do sistema. Isto tem por consequência o fato que as equações de movimento embora determinísticas em sua natureza - não podem ser integradas, o que faz necessário então que recorramos ao conceito de um ensemble estatístico. ${ }^{4} \mathrm{~A}$ dedução e o estudo deste programa metodológico levam à chamada mecânica estatística de Ludwig Boltzmann e Josiah Willard Gibbs (1839-1903) e foi de certo modo completada em $1903 .{ }^{5}$

A estocasticidade da equação de Fokker-Planck tem a mesma natureza mecânica da física estatística clássica e não está, de maneira alguma, relacionada à física quântica da teoria de emissão e absorção de moléculas, como Planck originalmente supusera. Mas, diferentemente da mecânica estatística de Maxwell, Boltzmann e Gibbs, no tratamento estocástico segundo Planck, abre-se mão de

4 Um ensemble é um conjunto infinito de sistemas idênticos, cujos valores médios de grandezas microscopicamente definidas podem ser calculados desde que certas condições físicas e matemáticas sejam respeitadas. Estes valores médios representam as grandezas mensuráveis da termodinâmica, como, por exemplo, a pressão ou temperatura.

5 A introdução de conceitos quânticos na mecânica estatística ocorreu primordialmente, nos anos de 1920 e está associada aos nomes de Albert Einstein (1879-1955), Satyendra Nath Bose (1894-1974), Enrico Fermi (1901-1954) e Paul Adrien Maurice Dirac (1902-1984). 
conceitos como espaço de fase, teorema de Liouville, bem como de toda a metodologia daquela teoria (EBELING; GUDOWSKA-NOWAK; SOKOLOV, 2008), e se imagina uma dinâmica regida por uma força irregular, ou seja, a probabilidade entra diretamente nas equações de movimento, na forma de uma força estocástica ou de um ruído (neste caso, fala-se da equação estocástica para as grandezas físicas mensuráveis) ou, o que muitas vezes é equivalente, escreve-se uma equação determinística para a distribuição de probabilidade das grandezas físicas mensuráveis. No primeiro caso, temos a chamada equação de Langevin. No segundo, a equação de Fokker-Planck.

Se nos perguntarmos qual fenômeno deu origem ao estudo de sistemas estocásticos, podemos responder sem hesitar que foi a observação do movimento irregular de pequenas partículas suspensas em um fluido. EsteS fenômenos foi pela primeira vez descrito pelo médico holandês Jan Ingenhousz (1730-1799) e discutido de maneira mais detalhada em 1827 pelo botânico escocês Robert Brown (1773-1858). ${ }^{6}$ A primeira equação usada para modelar o movimento browniano (KAMPEN, 1997) foi publicada em 1822 por Fourier, em seu famoso tratado Théorie analytique de la chaleur. Embora aplicada a um contexto diferente, a saber, o da transmissão de calor em uma dimensão, a equação de Fourier é, do ponto de vista matemático, a mesma que rege o movimento browniano:

$$
\frac{\partial T(x, t)}{\partial t}=\kappa \frac{\partial^{2} T(x, t)}{\partial x^{2}}
$$

onde $\kappa$ é a capacidade térmica do meio e $T(x, t)$, a temperatura como função da posição e do tempo. Esta equação diferencial parabólica descreve a difusão de partículas, onde devemos substituir o parâmetro $T(x, t)$ por $\mathrm{p}(x, t)$, a distribuição de probabilidade da coordenada $x$, $e k$ por $D$, a constante de difusão. Neste contexto, John William Strutt (Lord Rayleigh, 1842-1919) introduziu uma equa-

6 Jan Ingenhousz é mais conhecido pelo descobrimento do papel da luz na fotossíntese. Suas observações sobre pó de carvão suspenso em álcool passaram despercebidas para o público de língua não holandesa. (EBELING; GUDOWSKA-NOWAK; SOKOLOV, 2008). Robert Brown (1773-1858), um renomado botânico, que muito contribuiu para os estudos de morfologia de plantas e para a descrição da flora australiana, observou o movimento irregular de pólen suspenso em água. Para confirmar se o movimento seria causado pela força interna de "moléculas orgânicas" vivas, Brown conduziu experimentos com pólen armazenado há mais de 100 anos em seu herbário. (BRUSH, 1976, BD. 2 P. 658) Na realidade, este movimento já havia sido observado por vários estudiosos antes de Brown, mas ele foi o primeiro a fazer um estudo extensivo do fenômeno, descrevendo-o. Uma lista completa dos nomes mais importantes associados a estes estudos podem ser encontrados em Abbott e outros (1996). Hoje sabemos que o movimento irregular das partículas suspensas é provocado pelo choque com moléculas do líquido e representa uma prova da realidade atômica da matéria. (EINSTEIN, 1906) 
ção para a distribuição de probabilidade $W(v, t)$ da velocidade $v$ de uma partícula difúsica em um líquido (RAYLEIGH,1891):

$$
\frac{\partial W}{\partial}=\gamma\left(\frac{\partial}{\partial v}(v W)+\frac{k T \partial^{2} W}{m} \partial v^{2}\right)
$$

Nesta equação, $\gamma$ representa o coeficiente de difusão, relacionado ao número de choques moleculares aos quais uma partícula é submetida. É interessante notar neste contexto que a distribuição de Maxwell (1860)

$$
f_{0}(\not{p})=\frac{n}{(2 \pi m k T)^{3 / 2}} e^{-\left(p \vec{p}-p_{0}\right)^{2} / 2 m k T}
$$

satisfaz a equação de Rayleigh, onde $\vec{p}=m$ representa o momento de uma partícula de massa $m$ e $\kappa=1,3806503 \times 10^{-23} \mathrm{~J} \cdot \mathrm{K}^{-1}$ é a constante de Boltzmann. $T$ representa a temperatura absoluta e $p_{0}$ o valor médio de $p$. Maxwell provou que esta distribuição é estacionária e descreve assim um gás em equilíbrio termodinâmico. Uma vez que não há interação entre partículas, $f_{0}$ não depende da posição.

Em 1913, Adriaan Fokker, então doutorando de Hendrik Antoon Lorentz (1853-1928) e sem conhecimento prévio do trabalho de Lord Rayleigh, introduziu uma equação para a evolução temporal de uma distribuição de probabilidade $W(q, t)$ de uma grandeza $q$ qualquer, mas cuja dinâmica é regida por flutuações. A equação toma a forma

$$
\frac{\partial W}{\partial t}=-\frac{\partial}{\partial q}\left(h_{1}(q) W(q, t)\right)+\frac{1}{2} \frac{\partial^{2}}{\partial v^{2}}\left(h_{2}(q) W(q, t)\right)
$$

onde $h_{1}(q)$ e $h_{2}(q)$ são funções diretamente relacionadas às flutuações e dispersão do parâmetro $q$ (KUBO; TODA; HASHITSUME, 1985):

$$
\frac{\langle\Delta q\rangle}{\Delta t}=\mathrm{h}_{1}(q) ; \quad \quad \frac{\left\langle(\Delta q)^{2}\right\rangle}{\Delta t}=\mathrm{h}_{2}(\mathrm{q})
$$

7 Eu uso a notação moderna ao longo desse texto por uma questão de clareza, particularmente quando me refiro a Boltzmann, cuja notação difere daquela que se tornou "padrão" em livrostextos. 
Nesta equação $\Delta t$ deve ser tão pequeno de tal modo a $W$ não varie muito, mas grande o suficiente para que muitas flutuações de $\Delta q$ ocorram. Esta equação, que hoje responde pelo nome de Equação de Fokker-Planck, pode ser interpretada como uma generalização da equação de difusão. Este nome foi dado por Andrei Kolmogorov que, em seu importante trabalho de 1931, deduziu uma versão ainda mais geral (KOLMOGOROV, 1931):

$$
\frac{\partial}{\partial t} W(s, x, t, y)=-\frac{\partial}{\partial \gamma}[A(t, y) W(s, x, t, y)]+\frac{\partial^{2}}{\partial \gamma^{2}}\left[B^{2}(t, y) W(s, x, t, y)\right]
$$

Kolmogorov chamou sua equação originalmente de segunda equação diferencial fundamental. Na matemática ela é conhecida como equação avançada de Kolmogorov. Disto é fácil concluir que existe também uma equação retardada (chamada de primeira equação fundamental por Kolmogorov). Os termos avançada refere-se ao fato que a grandeza $W(s, x, t, y)$ apresentada acima representa a função de distribuição de uma grandeza cujo valor $x$ no tempo $s$ depende do valor $y$ num tempo anterior $t<s$. Um ano antes de Kolmogorov esta equação foi deduzida em um contexto completamente diferente, a saber na genética, mais especificamente num trabalho de Ronald A. Fisher (1930) acerca de mutações raras:

$$
\frac{\partial y}{\partial T}=\frac{1}{4 n}\left(\frac{\partial}{\partial \theta}(y \cot \theta)+\frac{\partial^{2} y}{\partial \theta^{2}}\right)
$$

Nesta equação $y$ é a função de distribuição para as taxas de frequência de mutações, $n$ é o número de acasalamentos em cada geração, $T$ o número de gerações e $\theta$ depende do quociente $p / q$ de genes que sofreram mutação em dois loci diferentes via $p / q=(1-\cos \theta) /(1+\cos \theta)$.

Para Fokker, bem como para Planck, $q$ representava o momento angular de uma molécula e $W(q, t)$ a distribuição de probabilidade do momento angular de um gás de $N$ moléculas, ou seja

$$
N x W(q, t) x d q
$$

era o número de moléculas, cujo momento angular, no tempo $t$, se encontrava entre $q$ e $q+d q$. A equação de Fokker-Planck pode ser utilizada de maneira bastante geral quando, junto à descrição macroscópica usual de uma grandeza arbitrária, queira também se levar em conta flutuações (KAMPEN, 1997). É justamente por esta universalidade que a equação de Fokker-Planck se torna atraente enquanto descrição matemática de fenômenos estocásticos. Obviamente é necessário se determinar quem são as funções $h_{1}(q)$ e $h_{2}(q)$ (ou as funções A e B na notação de 
Kolmogorov), antes de buscar uma solução. No entanto, esta tarefa não é difícil quando se conhece a dinâmica determinística (sem flutuações) da grandeza $q$ na forma de uma equação de movimento

$$
\frac{\partial q}{\partial t}=h_{1}(q)
$$

No caso determinístico, a distribuição de probabilidade é dada na forma de uma distribuição de Dirac e, ao colocar esta função na equação de Fokker-Planck, obtém-se que a função $h_{1}(q)$ da equação determinística coincide com a função $h_{1}(q)$ da equação de Fokker-Planck. Além disso, a mecânica estatística de equilíbrio fornece a distribuição estacionária da variável $q$, que coincide com a solução independente do tempo da equação de Fokker-Planck. Com isto se obtém uma relação entre $h_{1}(q)$ e $h_{2}(q)$, fixando assim o valor da segunda. (KAMPEN, 1997)

A equação de Fokker-Planck é um caso especial de uma equação mais geral, chamada equação de Chapman-Kolmogorov, a partir da qual aquela pode ser deduzida quando as variáveis espaciais e temporais são tomadas como sendo contínuas. Implícita nesta dedução está o fato que os processos que ela descreve possuem a propriedade markoviana. Isto significa que o sistema tem uma memória de curto alcance, ou seja, um estado no tempo $t_{n}$ depende somente de um estado no passo anterior $t_{n-1}$ e não de estados mais longínquos no passado. Quão extensa é a memória depende de quão grandes são os intervalos temporais escolhidos. Quando a precisão dos aparelhos de medida é maior que o tempo de relaxação dinâmico típico do sistema, então a dinâmica é puramente estocástica (cada passo não depende do passo anterior). Processos puramente estocásticos não podem, no entanto, descrever sistemas com variáveis contínuas, uma vez que para isto são necessárias mudanças infinitesimais nas variáveis. Portanto, sistemas markovianos representam os sistemas mais simples com os quais é possível modelar sistemas estocásticos com variáveis contínuas. Um sistema com memória de longo alcance pode ser descrito por equações de Fokker-Planck mais gerais. (KUBO; TODA; HASHITSUME, 1985; RISKEN, 2003)

Nossa vantagem hoje é que podemos lançar um olhar no passado e estudar todo o desenvolvimento da física de sistemas estocásticos, uma vantagem que Planck obviamente não tinha. Para ele o interesse na equação não era tanto pelos sistemas estocásticos per se, embora isto não lhe tire o mérito da grande contribuição que deu à área. Se hoje olhamos sua atuação como físico, fica claro que sua carreira foi, em grande parte, uma tentativa de melhor entender e estender conceitos termodinâmicos - em particular a entropia - a outras áreas da Física. Um problema onde esta metodologia se fez presente foi o do calor específico de moléculas diatômicas. Mais uma vez, foi o envolvimento de Planck com problemas da interação radiação-matéria, que há alguns anos lhe havia aberto as portas da física quântica, que agora lhe abririam as portas da estocasticidade. 


\section{Max Planck e o espectro de moléculas em rotação}

Todo estudante de física aprendeu, da mecânica estatística, que no equilíbrio termodinâmico à temperatura absoluta $T$, cada grau de liberdade possui, na média, uma energia no valor de

$$
\mathrm{E}=\frac{1}{2} k T
$$

onde $k$ é a constante de Boltzmann. Este resultado, conhecido como teorema da equipartição de energia, permite deduzir que a energia média de um gás ideal de $\mathrm{N}$ partículas tem um valor dado por:

$$
\mathrm{E}=\frac{3 \mathrm{~N}}{2} k T
$$

Este resultado vem do fato que cada partícula de massa $m$ de um gás ideal (não interagente) possui apenas uma energia cinética (composta das três componentes espaciais de velocidade, uma para cada direção do espaço):

$$
E_{k i n}=\frac{1}{2} m v_{x^{2}}+\frac{1}{2} m v_{y^{2}}+\frac{1}{2} m v_{z^{2}}
$$

Da $c_{v}=\frac{\partial E}{\partial T}$ segue diretamente que ovalor docalor específico de tal gásé uma constante:

$$
\mathrm{c}_{\mathrm{v}}=\frac{3}{2} \mathrm{Nk} \text {. }
$$

Para um sistema com $n$ graus de liberdade por partícula, segue a chamada lei de Dulong-Petit Gesetz de 1819:

$$
c_{v}=\frac{n}{2} N k \text {. }
$$

Uma vez que este resultado não depende da temperatura, dever-se-ia obter um valor constante de $c v$ para $T \rightarrow 0$ e, na verdade, um valor diferente de zero. Caso fosse este mesmo o caso, então de acordo com a terceira lei da termodinâmica, a entropia deveria ir a zero no zero absoluto, um resultado obviamente não físico ${ }^{8}$. Um caminho para a solução desta inconsistência foi mostrado por

Podemos escrever a entropia $S(T)$ como $S(T)=\int_{0}^{T} \frac{\delta Q}{T^{\prime}}=\int_{0}^{T} \frac{c\left(T^{\prime}\right)}{T^{\prime}} d T^{\prime}$. Para evitar que a entropi divirja no zero absoluto, temos que fazer com que o calor específico também tenda a zero neste limite. 
Einstein em 1906, com a introdução de frequências de vibração quantizadas para os átomos de uma rede cristalina. (EINSTEIN, 1906) Embora houvesse uma boa concordância dos resultados em altas temperaturas (Dulong-Petit), o comportamento do modelo de Einstein para baixas temperaturas desvia-se significativamente dos resultados experimentais. Foi somente com o trabalho de Peter Debye (1884-1966), alguns anos mais tarde, que esta inconsistência pode ser sanada. (DEBYE, 1911)

Porém, permanecia em aberto o problema que tanto a teoria de Einstein quanto a de Debye se aplicavam a corpos sólidos e não era claro se a mesma poderia ser estendida para gases. Porém, já era sabido que as linhas espectrais de moléculas, como hidrogênio, eram, segundo enfatizou Planck, "canalizadas" (quantizadas):

Embora os trabalhos pioneiros de N. Bohr, A. Sommerfeld, P. Epstein tenham mostrado de maneira inquestionável que a espectroscopia é regida por leis quânticas, a natureza da dos fenômenos que ocorrem durante a emissão e absorção de radiação encontra-se envolta pelo mais opaco véu. (PLANCK, 1917b, p. 491)

Antes de se determinar de maneira inequívoca o calor específico de gases, era necessário determinar se o espectro associado à rotação era também "canalizado" ou não, pois a ele estariam associados graus de liberdade e, portanto, uma contribuição não nula ao calor específico. Planck acreditava que, embora o espectro de emissão fosse quantizado - os experimentos eram claros quanto ao isso -, o espectro de absorção não o era, seguindo leis clássicas de absorção segundo Maxwell:

A primeira interpretação [ou seja, de um espectro de emissão e absorção quantizados] é atualmente a mais difundida, tendo sido utilizada recentemente por A. Einstein como ponto de partida de uma teoria, em muitos aspectos bem sucedida, sobre a radiação térmica. Porém existe nela uma dificuldade, a saber, que em cada salto que um oscilador que absorve energia realiza, de uma órbita estacionária de energia mais baixa para uma estacionária de energia mais alta, deve-se supor que ele tenha que absorver uma quantidade de energia do campo circundante, algo que se não condiz com uma velocidade finita de propagação da radiação e uma densidade espacial finita de radiação - uma dificuldade que desde já muito tempo levou a suposição que as órbitas estáticas não são as únicas possíveis, mas sim a únicas a partir das quais a emissão pode ocorrer. Essa suposição traz consigo a vantagem de ser condizente com as leis de absorção 
da eletrodinâmica clássica. E uma vez que estas leis são bem conhecidas, há a esperança que, ao seguirmos esta hipótese e as suas consequências, consigamos uma resposta positiva da questão, se uma pessoa que siga este caminho encontrará um resultado que contradiga os experimentos. Apenas quando esta última se provar verdadeira, aí então será inevitável deixarmos o terreno da teoria clássica da absorção. (PLANCK, 1917b)

Planck voltou-se, assim, à tarefa de entender o espectro de absorção de dipolos em rotação. Havia, apenas, um parâmetro de ajuste - o momento de inércia do dipolo - e a tarefa de calcular a função de distribuição dos momentos angulares dos dipolos, determinada a partir da equação de Fokker-Planck, e uma vez achada uma solução, utilizar a eletrodinâmica de Maxwell para estudar o movimento de um dipolo com o eixo fixo numa direção espacial (PLANCK, 1917b) e depois com um eixo que podia mudar sua orientação no espaço. (PLANCK, 1917c) Para Planck, era claro que este era o caminho a ser seguido, não obstante os resultados experimentais do espectro de emissão (Planck 1917b):

Aqui parece haver, à primeira vista, uma contradição grande entre minha hipótese a pouco introduzida e a realidade, pois o espectro de rotação é sabidamente não contínuo, mas canalizado. Ele parece ser na realidade caracterizado por máximos de absorção mais ou menos definidos em posições equidistantes dadas pelas velocidades de rotação ou frequências de oscilação $\omega_{1}, \omega_{2}, \ldots, \omega_{n}, \ldots$ e há todas as razões para se supor que por meio da rarefação do gas, quando então o efeito das colisões das moléculas é reduzido de maneira significativa, os máximos se apresentarão como linhas bem definidas. Esta imagem parece não poder ser interpretada do ponto de vista da toeria clássica senão que pelo fato que a absorção da radiação incidente só ocorre para aquelas moléculas que possuem uma velocidade de rotação $\omega_{n}$ e que de acordo com a teoria clássica de absorção certamente não estão ligadas a velocidades de rotação específicas. Disto seguiria que nenhuma outra velocidade a não ser $\omega_{n}$ se encontra presente no gas, que representa assim do ponto de vista da teoria quântica as "órbitas estáticas" das moléculas em rotação.

Esta dedução tão clara é porém inapropriada. Ela não leva em conta que uma dada molécula não possui uma velocidade de rotação específica, mas que sua velocidade muda tão logo comece a absorver. Aquelas moléculas que absorvem dentro de um intervalo temporal específico uma radiação de um intervalo espectral específico, não são idênticas àquelas 
moléculas cujas frequências de oscilação se encontravam, no início deste período, dentro do intervalo espectra; antes disso, ocorre durante todo o processo uma troca de frequeicas entre moléculas.

Planck não parecia satisfeito com a ideia dos pacotes de luz (fótons). Para ele, era necessário salvar a teoria clássica de Maxwell onde ela ainda poderia ser salva. Assim, Planck se colocou a tarefa de melhor entender a dinâmica desta troca entre moléculas em um dado intervalo espectral. Para isto, ele necessitava do resultado de Fokker acerca da energia média de rotação de dipolos, num campo eletromagnético externo (FOKKER, 1914):

$$
W(q) f(q) \tau-W(q) \bar{R}+\frac{1}{2} \frac{\partial}{\partial q}\left(W(q) \overline{R^{2}}\right)=0 .
$$

Nesta expressão, $q$ representa o momento angular de uma molécula e $W(q)$, a densidade de probabilidade; $f(q)$ é a velocidade com a qual $q$ diminui, ou seja, $d q / d t$. Finalmente, $R$ é $\Delta q$, as flutuações durante o intervalo $\tau$ devido a processos térmicos aleatórios. $\mathrm{O}$ termo do meio, no lado esquerdo da equação, é fundamental, pois sem ele se recupera a equação da difusão já obtida por Einstein (1906).

Planck considerou, inicialmente, o caso de um sistema de dipolos, cujos eixos de rotação eram fixos (o segundo da série de três artigos. No primeiro ele apenas apresentou a dedução rigorosa da equação). Sua conclusão, após longos cálculos, era, em suas próprias palavras, um tanto quanto surpreendente (einigermassen überraschend):

Se tivemos $\mathrm{N}$ moléculas de um gás e o número daquelas cujas frequências de oscilação se encontram entre $\omega$ e $\omega+\mathrm{d} \omega$ é dado por $N x W(\omega)$, de modo que $W(\omega)$ represente a "densidade de distribuição espectral", então a energia absorvida por todo o gas da radiação incidente com frequência entre $\omega$ e $\omega+d \omega$ não é proporcional à $W(\omega)$ mas simá $-\omega \frac{\mathrm{d} W(\omega W)}{\omega}$. Assim, quando num dado intervalo de frequência não há qualquer absorção, como na região entre $\omega_{n}$ e $\omega_{n+1}$, a densidade de moléculas ali é portanto diferente de zero e independe $\omega$. E no caso onde linhas bem definidas de absorção aparecem entre nos valores de $\omega_{n}$ e $\omega_{n+1}$, ali encontramos, em ambos os lugares, uma acentuada queda na distribuição de densidade $W(\omega)$ a medida que $\omega$ aumenta. 
À mesma conclusão ele chegou no artigo seguinte, onde tratou do caso de eixos de rotação móveis. A diferença do artigo anterior é simplesmente que a energia absorvida não era mais proporcional $-\omega \frac{\mathrm{d} W(\omega W)}{\omega}$ à mas $\operatorname{sim}$ à $-\omega^{2} \frac{\mathrm{d} W(\omega W)}{\omega}$.

Planck conclui seu último artigo, comparando os resultados por ele obtidos com dados experimentais medidos em moléculas de água. A concordância entre experimento e teoria não foi muito boa, resultado que ele atribuiu ao fato de moléculas de água não serem exatamente "dipolos simples". O que ele não sabia é que, com a equação por ele utilizada para se determinar a continuidade ou descontinuidade dos processos de absorção, é uma equação que se aplica a sistemas clássicos e não ao mundo quântico. As variáveis na equação de Fokker-Planck são contínuas e ela tem tanta relevância na mecânica quântica quanto esta última tem no cálculo de órbitas de planetas. (KAMPEN, 1997)

\section{Conclusão}

Entre os anos de 1915 e 1917, na tentativa de explicar o espectro rotacional de moléculas diatômicas e assim resgatar a teoria de absorção e emissão de radiação à la Maxwell, incondizente que esta era com as observações experimentais de um espectro quantizado, Planck envolveu-se com a teoria de sistemas estocásticos, tomando-o por base para explicar a aparente contradição. O resultado de Planck pode ser assim resumido: numa série de artigos, ele foi capaz de achar uma relação funcional entre a taxa de emissão e a derivada da função distribuição $f$ (densidade de moléculas) como função da frequência de rotação destas. Deste modo, a não observação de um espectro de emissão contínuo se dava não pela inexistência de moléculas distribuídas continuamente pele espectro, mas antes por haver regiões de frequência onde $f$ era constante (e, portanto, a derivada nula). A função distribuição era a solução estacionária de uma equação que Planck deduziu de maneira rigorosa, uma vez que esta era a base sobre qual seu trabalho se assentava. Hoje sabemos que esta equação não se aplica ao problema original que Planck tinha em mente. Sua dedução, porém, é válida, motivo pelo qual a equação foi mais tarde batizada de Equação de Fokker-Planck, pelo matemático russo Kolmogorov, num célebre artigo onde ele a assentou sobre bases matemáticas mais sólidas. 


\section{Referências}

ABBOTT, D. et al. Simple derivation of the thermal noise formula using window-limited fourier transforms and other conundrums. IEEE Transactions on Education, v. 39, n. 1, p. 1, 1996.

BOLTZMANN, L. E. Entgegnung auf die wärmtheoretischen Betrachtungen der Hrn. E. Zermelo. Annalen der Physik, v. 57, p. 773, 1896.

. Experimentelle Bestimmung der Dielektrizitätskonstante von Isolatoren. Wiener Berichte, v. 67, p. 17-77, 1872a.

. Experimentelle Bestimmung der Dielektrizitätskonstante einiger Gase.

Wiener Berichte, v. 69, p. 795-813, 1879.

. Über den Beweis des Maxwell'schen Geschwindigkeitsverteilungs-

gesetzes unter Gasmolecülen. Sitzungsber. d. k. bayer. Akad. d. Wiss. 24, 1894.

. Über die mechanische Bedeutung des zweiten Hauptsatzes der

Wärmetheorie. Wiener Berichte, v. 53, p. 195-220, 1866.

. Über das Wärmegleichgewicht zwischen mehratomigen

Gasmolekülen. Wiener Berichte, v. 63, p. 397-418, 1871.

. Weitere Studien über das Wärmegleichgewicht unter Gasmolekülen.

Wiener Berichte, v. 66, p. 275-370, 1872b.

. Zu Hrn. Zermelos Abhandlung, Über die mechanische Erklärung

irreversibler Vorgänge. Annalen der Physik, v. 60, p. 392-398, 1897.

BRODA, E. Ludwig Boltzmann: mensch, physiker, philosoph. Viena: Franz Deuticke, 1983.

DAHMEN, S. R. Boltzmann's works in physics. Rev. Bras. Ens. Fis., v. 28, n. 3, p. 281-295, 2006a.

. Gödel and Einstein: what if time does not withstand a friendship?. Rev. Bras. Ens. Fis., v. 28, n. 4, p. 1-10, 2006 b.

. Max Planck on Statistical Thermodynamics and Stochastic Systems. In: [Hoffmann 2008], S. $335 \mathrm{ff}$.

EBELING, W. Max Planck on entropy and irreversibility. In: [Hoffmann 2008], S. $29 \mathrm{ff}$. 
EBELING, W.; GUDOWSKA-NOWAK, E.; SOKOLOV, I.M. On stochastic dynamics in physics: remarks on history and terminology. Preprint, 2008.

ECKERT, M. Max Planck's Later Work on Quantum Theory. In: [Hoffmann 2008], S. $643 \mathrm{ff}$.

EINSTEIN, A. Zur theorie de Brownsche Bewegung. Annalen der Physik, v. 19, p. 371, 1906.

EHRENFEST, P.; EHRENFEST, T. Begriffliche Grundlagen der statistischen Auffassung in der Mechanik. Leipzig: Enzyklopädie der Mathematischen Wissenschaften, 1911. Bd. IV. Edition in English: The Conceptual Foundations of the Statistical Approach in Mechanics. Ithaca: Cornell University, Ithaca, 1959.

FISHER, R. A. The distribution of gene ratios for rare mutations. Proc. Roy. Soc. Edinburgh, v. 50, p. 205-220, 1930.

FOKKER, A. D. Die mittlere Energie rotierender elektrischer Dipole im Strahlungsfeld. Annalen der Physik, v. 43, p. 810-820, 1914.

GÖDEL, K. An example of a new type of cosmological solutions of einstein's field equations of gravitation. Rev. Mod. Phys., v. 21, p. 447-450, 1949.

GUTTMANN, Y. M. The Concept of Probability in Statistical Physics. Cambridge: Cambridge University, 1999.

HOFFMANN, D. (Hrsg.). Max Planck: annalen papers. Weinheim: Wiley-VCH, 2008.

HUANG, K. Statistical mechanics. $2^{\text {nd }}$ ed. New York: John Wiley and Sons, 1987.

KAMPEN, N. G. Die Fokker-Planck-Gleichung, Physikalische Blätter (Sonderdruck). Berlin: Wiley-VCH, 1997. p. 14.

KIRCHHOFF, G. Vorlesungen über die Theorie der Wärme. Ed. M. Planck. Leipzig: Teubner, 1894.

KLEIN, M. J. The development of Boltzmann's Statistical Ideas. In: COHEN, E. G. F.; UHLENBECK, G. (Ed.). The Boltzmann Equation: theory and application. Viena: Springer, 1973.

KOLMOGOROV, A. Über die analytischen Methoden in der Wahrscheinlichkeitsrechung. Mathematische Annalen, v. 104, p. 415-570, 1931. 
KUBO, R.; TODA, M.; HASHITSUME, N. Statistical Physics II, Nonequilibrium Statistical Mechanics. Berlin: Springer, 1985.

MAXWELL, J.C. Maxwell, illustrations of the dynamical theory of gases. Phil. Mag., v. 19, p. 19, 1860.

PLANCK, M. Absolute Entropie und chemische Konstante. Annalen der Physik, v. 66, p. 365-372, 1921.

. Bemerkungen über die Emission von Spektrallinien. Sitzungsber. d.

Preuss. Akad. d. Wiss., 1915c, 909-913.

. Die Quantenhypothese für Molekeln mit mehreren Freiheitsgraden:

Erste Mitteilung. Verh. der Deutsch. Phys. Ges., v. 17, p. 407-418, 1915 a.

. Die Quantenhypothese für Molekeln mit mehreren Freiheitsgraden:

Zweite Mitteilung. Verh. der Deutsch. Phys. Ges., v. 17, p. 438-451, 1915 b.

. Über den Beweis des Maxwell'schen

Geschwindigkeitsverteilungsgesetzes unter Gasmolecülen. Annalen der Physik, v. 55, p. 220-222, 1895. Nachd.

. Über einen Satz der statistischen dynamik und seine Erweiterung in der Quantentheorie. Sitzungsber. d. Preuss. Akad. d. Wiss., 1917a, 324-341.

. Planck, zur theorie des rotationsspektrums: Erste Mitteilung, Annalen der Physik, v. 52, p. 491-505, 1917b.

. Zur theorie des rotationsspektrums: Zweite Mitteilung. Annalen der Physik, v. 53, p. 241-256, 1917c.

RAYLEIGH, Lord. Dynamical problems in illustration of the theory of gases. Phil. Mag., v. 32, p. 424, 1891.

SCHRÖDINGER, E. The statistical law in nature. Nature, v. 153, p. 704, 1944. Original de 1938.

ZERMELO 1896a] E. Über einen Satz der Dynamik und die mechanische Wärmetheorie. Annalen der Physik, v. 57, p. 485, 1896 a.

Über mechanische Erklärungen irreversibler Vorgänge. Eine Antwort auf Hrn. Boltzmanns Entgegnung. Annalen der Physik, v. 59, p. 793, $1896 \mathrm{~b}$. 


\title{
De Louis de Broglie a Erwin Schrödinger: uma comparação
}

\author{
Roberto de Andrade Martins
}

\section{Introdução}

O trabalho de Erwin Schrödinger sobre mecânica ondulatória começou no final de 1925, como consequência do seu estudo da tese de De Broglie de 1924 . Sabe-se que a equação de onda de Schrödinger pode ser deduzida dos resultados de De Broglie, no limite clássico. Sob este ponto de vista, poderíamos pensar que a teoria de Schrödinger seria um mero desenvolvimento da teoria de De Broglie. Mas podemos realmente aceitar essa conclusão?

Este artigo compara algumas das características das teorias de De Broglie e Schrödinger. Sabe-se que, em suas primeiras tentativas de formular uma teoria quântica do átomo, Schrödinger tentou desenvolver uma teoria relativística, seguindo as ideias de De Broglie, e apenas depois começou a procurar uma equação de onda não-relativística. É muito fácil deduzir uma equação de onda para as ondas de fase de De Broglie, tanto no caso relativístico, quanto no caso nãorelativístico. $\mathrm{Na}$ sua tentativa relativística, Schrödinger realmente seguiu uma abordagem simples, usando a teoria de De Broglie. No entanto, ao desenvolver a formulação não-relativística, ele tentou produzir uma dedução independente da equação de onda, seguindo diversas linhas diferentes de argumentação, em vez de utilizar os resultados de De Broglie no limite clássico.

Primeiramente será feita uma breve apresentação das ideias de De Broglie e sua influência histórica sobre Schrödinger; depois, serão discutidas as primeiras deduções da equação de onda, enfatizando as diferenças e semelhanças entre 
as duas teorias. Será mostrado que, embora seja formalmente possível deduzir uma equação de onda a partir da teoria de De Broglie, existe uma incompatibilidade entre as duas teorias: seria impossível dar qualquer sentido às ideias de De Broglie, no caso de um corpo rígido girando, por exemplo. A abordagem de Schrödinger era, neste sentido, independente e incompatível com a teoria de De Broglie, e podia ser aplicada facilmente a muitas situações físicas diferentes.

\section{A teoria de De Broglie}

Louis de Broglie apresentou sua teoria primeiramente sob a forma de uma série de artigos publicados em 1923 e 1924 (DE BROGLIE, 1923a, 1923b, 1923c, 1923d, 1924a, 1924b, 1924c) e depois em sua tese de doutoramento (DE BROGLIE, 1924d, 1925). ${ }^{1}$ Ele tomou como ponto de partida a ideia de que todas as partículas (elétrons, quanta de luz etc.) sofriam algum processo periódico, obedecendo às equações de energia da relatividade e da teoria quântica, $E=h v$ and $E=m c^{2}$, $\mathrm{e}$ usou a relatividade especial como principal ferramenta teórica no seu trabalho. (DE BROGLIE, 1923a)

No referencial de repouso da partícula, devemos ter $E_{0}=m_{0} c^{2}=h v_{0}$ e em relação a outros referenciais, a equação correta seria:

$$
E=m c^{2}=h v
$$

No entanto, a massa aumenta com a velocidade, e a frequência diminui com a velocidade. Portanto, parecia que o uso de $E=m c^{2}=h v$ levava a uma contradição. (DE BROGLIE, 1923a, p. 507-508) Depois de lidar com essa dificuldade por algum tempo, De Broglie reconheceu que sua teoria só poderia obedecer à teoria da relatividade especial se ele concebesse todos os quanta como sistema espacialmente extensos, em vez de partículas pontuais.

$\mathrm{Na}$ sua tese, ele apresentou esta ideia fundamental de um modo muito claro. De acordo com o eletromagnetismo de Maxwell, a energia de qualquer carga (incluindo um elétron) está espalhada no espaço à sua volta, embora haja uma forte concentração de energia em torno do centro. Seguindo esta ideia, De Broglie considerou o elétron como um sistema infinito. (DE BROGLIE, 1925, p. 33-34)

1 Uma análise detalhada do trabalho de Louis de Broglie pode ser encontrada na dissertação de mestrado de Pedro Sérgio Rosa (2004). Disponível em: <http://www.ifi.unicamp.br/ ghtc/ ms-psr.htm>. 
No referencial de repouso de um elétron, supôs que toda sua estrutura (infinita) estava pulsando em sincronia, com uma frequência dada por $h v_{0}=m_{0} c^{2}$. Esse fenômeno periódico pode ser descrito por uma equação como esta:

$$
\Psi_{0}=A \operatorname{sen} 2 \pi\left(v_{0} t_{0}\right)
$$

Em relação a outros referenciais, a sincronia deste fenômeno periódico seria perdida, é claro, devido a efeitos relativistas ${ }^{2}$. A transformação de Lorentz do tempo é:

$$
t_{0}=\frac{1}{\sqrt{1-\beta^{2}}}\left(t-\frac{\beta x}{c}\right)
$$

onde $\beta=v / c$ é a velocidade da partícula dividida pela velocidade da luz no vácuo.

Aplicando a transformação de Lorentz do tempo (3) a esta pulsação (2), De Broglie mostrou facilmente que a oscilação se transformava em uma onda, em relação a outros referenciais, e obteve a velocidade, a frequência e as outras propriedades da onda. Substituindo $t_{0}$ em (2) por (3), obtemos:

$$
\Psi_{0}=A \operatorname{sen} 2 \pi\left[v_{0} \frac{1}{\sqrt{1-\beta^{2}}}\left(t-\frac{\beta x}{c}\right)\right]
$$

A fórmula geral de uma onda monocromática plana movendo-se na direção do eixo $x$ é:

$$
\Psi_{0}=A \operatorname{sen} 2 \pi\left[v\left(t-\frac{x}{V}\right)\right]
$$

2 Pode-se ver uma apresentação didática do argumento de Louis de Broglie em Martins (2008, p. 160-170). 
A comparação das equações (4) e (5) mostra que a pulsação uniforme do elétron (no referencial próprio) se transforma em uma onda plana monocromática (a "onda de fase"), em relação a outros referenciais. Identificando as quantidades correspondentes nessas duas equações, obtêm-se a frequência $v$ e a velocidade $V$ da onda associada ao elétron:

$$
\begin{gathered}
v=\frac{v_{0}}{\sqrt{1-\beta^{2}}} \\
V=\frac{c}{\beta}=\frac{c^{2}}{v}
\end{gathered}
$$

O elétron deve ter alguma posição definida, portanto, a onda uniforme infinita não pode descrevê-lo completamente. $\mathrm{O}$ elétron livre em movimento seria equivalente a um sistema extenso, com uma forte concentração de energia em torno de um centro, viajando a uma velocidade $\mathrm{v}$ e, ao mesmo tempo, atravessado por uma onda monocromática de velocidade $V=c^{2} / v$ e frequência $v=m c^{2} / h$.

Uma onda monocromática modulada é matematicamente equivalente a um grupo de ondas, mas conceitualmente a ideia de De Broglie é muito diferente, porque no referencial próprio ela tem uma única frequência bem definida, e não deveria se espalhar à medida que se desloca.

\section{Mecânica e óptica}

De Broglie apresentou sua teoria sob diferentes formas. Em algumas de suas publicações ele enfatizou as semelhanças entre a mecânica e a óptica. (DE BROGLIE, 1924a, 1925, p. 46-53) Na teoria da relatividade especial, o princípio da ação mínima de Maupertuis pode ser escrito como:

$$
\delta \int_{\mathrm{P}}^{\mathrm{Q}} \mathrm{J}_{\mathrm{i}} \mathrm{d} \mathrm{x}^{\mathrm{i}}=0
$$

onde o símbolo $J_{\mathrm{i}}$ representa as componentes do quadrivetor de momentoenergia ${ }^{3}$.

3 Ver Martins (2008, p. 164-166). 
Por outro lado, a versão relativística do princípio de Fermat pode ser escrita como:

$$
\delta \int_{P}^{Q} O_{\mathrm{i}} d x^{\mathrm{i}}=0
$$

onde o símbolo $O_{\mathrm{i}}$ representa as componentes do quadrivetor "onda de universo", com componentes correspondendo às projeções do número de onda e à frequência da onda.

A analogia entre os dois princípios (Fermat e Maupertuis) e a relação $E=h v$ que é válida para a quarta componente dos quadrivetores permitiu, então, a De Broglie estabelecer uma relação geral em quatro dimensões:

$$
O_{\mathrm{i}}=\frac{1}{h} J_{\mathrm{i}}
$$

Ela contém tanto $E=h v$ quanto $p=h / \lambda$ como casos especiais da equação relativística geral. (BROWN; MARTINS, 1984)

\section{Campos eletromagnéticos}

Se o elétron estiver se movendo em um campo eletromagnético, sua energia total $W$ (incluindo a energia potencial $e \phi$ ) permanece constante (DE BROGLIE, 1925, p. 60). De Broglie supôs que a frequência do elétron seria proporcional à energia total $W$ e, portanto, também seria constante.

$$
h \nu=W=\frac{m_{0} c^{2}}{\sqrt{1-\beta^{2}}}+e \varphi
$$

No entanto, a velocidade $V$ das ondas e o seu comprimento de onda mudariam de ponto para ponto, de acordo com uma equação muito complexa (DE BROGLIE, 1925, p. 60):

$$
V=\frac{W}{p}=\frac{\frac{m_{0} c^{2}}{\sqrt{1-\beta^{2}}}+e \varphi}{\frac{m_{0} \beta c}{\sqrt{1-\beta^{2}}}+e A_{l}}=\frac{c}{\beta} \frac{W}{W-e \varphi} \cdot \frac{1}{1+e A_{l} / G}
$$


Nesta equação, o momento do elétron contém componentes proporcionais ao potencial vetor $\boldsymbol{A}$, seguindo a teoria de Maxwell. (BORK, 1967)

De Broglie não tentou aplicar (11) e (12) a nenhuma situação específica. O único caso de partícula em um campo que ele foi capaz de tratar foi o átomo de hidrogênio. (DE BROGLIE, 1923a, p. 509-510) Ele supôs que o centro do elétron obedecia à mecânica clássica e seguia uma trajetória de Kepler. Assumiu que a onda seguiria a mesma trajetória clássica. Supondo que a onda estivesse sempre em fase com as oscilações do elétron (e não supondo que a onda fosse estacionária, como apresentado nos livros didáticos), ele provou que a regra de quantização de Bohr para o momento angular, $L=p r=n h / 2 \pi$, era uma consequência de sua própria teoria. (DE BROGLIE, 1925, p. 62-65)

A única previsão nova da teoria de De Broglie foi a difração de elétrons (DE BROGLIE, 1923b, p. 549, 1925, p. 104) e ela foi confirmada rapidamente. Experimentos com elétrons de alta energia provaram, depois de poucos anos, que o comprimento de onda da onda associada ao elétron obedecia à equação relativística, conforme previsto por De Broglie. (BROWN; MARTINS, 1984)

\section{O papel intermediário de Einstein}

Costuma-se dizer que a tese de De Broglie só foi aceita pela banca por causa da influência de Einstein sobre Paul Langevin (MEHRA; RECHENBERG, 19821987, v. 1-2, p. 604). Esta versão, baseada no testemunho do próprio De Broglie, não é correta.

Langevin contou a Einstein sobre o trabalho de De Broglie em julho de 1924 e no dia 27 do mesmo mês pediu a De Broglie que enviasse uma cópia de sua tese (ainda não defendida) a Einstein. (DARRIGOL, 1993, p. 355; WHEATON, 1983, p. 297) No entanto, Einstein não reagiu imediatamente. A tese de De Broglie foi apresentada e aprovada no dia 25 de novembro do mesmo ano. Somente no dia 16 de dezembro, Einstein escreveu cartas para Langevin e para Lorentz, elogiando o trabalho de Louis de Broglie: "Ele ergueu uma ponta do grande véu". (DARRIGOL, 1993, p. 355; MEHRA; RECHENBERG, 1982-1987, v. 1-2, p. 604) No dia 13 de janeiro, Langevin escreveu uma carta para De Broglie contando-lhe sobre a opinião favorável de Einstein. (WHEATON, 1983, p. 297)

Nessa época, Einstein estava pesquisando a teoria quântica dos gases (atualmente chamada "estatística de Bose-Einstein"). Em um artigo que publicou em fevereiro de 1925, ele comentou que o trabalho de De Broglie poderia ajudar a esclarecer o significado dessa nova teoria. (JAMMER, 1966, p. 249) 
Erwin Schrödinger leu esses trabalhos de Einstein e trocaram cartas sobre o assunto. (HANLE, 1977, 1979) Estimulado pela referência de Einstein ao trabalho de De Broglie, Schrödinger obteve uma cópia da tese (que havia sido publicada) e a leu em outubro de 1925. ${ }^{4}$ Em novembro do mesmo ano, Schrödinger escreveu cartas para Einstein e Landé que mostravam que ele estava muito excitado com as ideias de De Broglie. (MOORE, 1989, p. 192) Ele aplicou essa teoria aos gases em um artigo que completou, em dezembro de 1925. (REGT, 1997, p. 474) No entanto, ele considerou alguns aspectos da teoria de De Broglie difíceis de entender ou de aceitar - especialmente a teoria do átomo de hidrogênio.

No dia 23 de novembro de 1925, Schrödinger apresentou um seminário sobre as ideias de De Broglie. (MOORE, 1989, p. 192). Na ocasião, Peter Debye comentou que a abordagem de De Broglie era infantil e que era necessário usar uma equação de onda para descrever uma onda em três dimensões. (KRAGH, 1982, p. 157) Schrödinger concordou que as ondas deviam ser tratadas de um outro modo, no caso do átomo de hidrogênio. Ele também notou que ondas de De Broglie em órbitas keplerianas próximas produziriam uma frente de onda distorcida.

Em dezembro de 1925, Schrödinger começou a tentar produzir uma equação de onda a partir da teoria de De Broglie e aplicá-la ao átomo de hidrogênio. Em vez de ondas seguindo órbitas de Kepler, ele começou a pensar sobre ondas estacionárias em três dimensões, análogas a ondas sonoras em cavidades. A quantização surgiria como uma consequência do espectro discreto de frequências das ondas estacionárias no átomo.

\section{A equação de onda relativística de Schrödinger}

Alguns passos decisivos foram dados na época de Natal de 1925, durante uma estada de Schrödinger em Villa Herwig, nos Alpes, onde ele passou duas semanas com uma amante misteriosa. (MOORE, 1989, p. 194-195) Primeiramente, Schrödinger tentou produzir uma equação de onda relativística, seguindo a abordagem de De Broglie. (KRAGH, 1982, p. 175-178) Esta dedução não foi publicada, mas foi encontrada em um manuscrito escrito provavelmente no final de 1925. (MEHRA; RECHENBERG, 2001, v. 5.1, p. 423-430) Vamos apresentar aqui uma

4 De acordo com Heitler (1961, p. 222), muitos outros físicos estudaram De Broglie pela mesma razão, mas ninguém - exceto Schrödinger - levou a sério a ideia de ondas associadas a elétrons. Ver a análise de Raman e Forman (1969) sobre a atitude peculiar de Schrödinger em relação ao trabalho de De Broglie. 
reconstrução dessa primeira dedução da equação de onda por Schrödinger. (KRAGH, 1982, p. 180, 1984)

A equação de onda geral, válida tanto na física clássica quanto na relativística, é:

$$
\Delta \psi+\left(\frac{2 \pi}{\lambda}\right)^{2} \psi=0
$$

Para qualquer onda monocromática $\lambda=V / v$, portanto, a equação de onda geral também pode ser escrita como uma função da velocidade da onda e de sua frequência:

$$
V^{2} \Delta \psi+4 \pi^{2} v^{2} \psi=0
$$

Na teoria de De Broglie, $V=E / p$ onde $E$ é a energia total do elétron:

$$
E=h v=m c^{2}-e \phi=\left(m_{0} c^{2}\right) /\left(1-\beta^{2}\right)^{1 / 2}-e \phi
$$

Se não for necessário levar em conta campos magnéticos, o momento $p$ será:

$$
p=m v=\left(m_{0} \beta c\right) /\left(1-\beta^{2}\right)^{1 / 2}
$$

Como a energia total do elétron é igual a $h v$ (eq. 15), é possível obter $\mathrm{v}=\beta c$ como função de $v$. Substituindo esse resultado nas equações de $E$ e de $p$, pode-se computar a velocidade da onda $V=E / p$ como função da frequência $v$. Depois de algumas manipulações, a equação de onda geral (13) se torna:

$$
\frac{h^{2} c^{2}}{4 \pi^{2}} \Delta \psi+\left[(E-e \varphi)^{2}-m_{0}^{2} c^{4}\right] \psi=0
$$

Esta é uma das formas da chamada "equação de Klein-Gordon".

Note-se que a dedução de Schrödinger desta equação de onda relativística depende apenas de resultados que já haviam sido obtidos por De Broglie. Realmente, o próprio De Broglie chegou a este resultado, de forma independente. (KRAGH, 1984, p. 1025)

Schrödinger aplicou esta equação de onda ao átomo de hidrogênio e obteve resultados errados para os níveis de energia. (JAMMER, 1966, p. 257-258; 
MEHRA; RECHENBERG, 1982-1987, v. 5, p. 367-368) Depois de se debater por pouco tempo com uma teoria relativística, ele se voltou para uma abordagem não-relativística.

\section{A equação de onda clássica}

Obter uma equação de onda no caso da aproximação clássica é muito mais fácil do que no caso relativístico e diversos livros-texto apresentam tal tipo de dedução. Se aceitarmos a relação $\lambda=h / p$ entre momento e comprimento de onda e aplicarmos a dinâmica clássica, obteremos:

$$
\lambda=\frac{h}{p}=\frac{h}{m v}
$$

Na mecânica clássica, a energia cinética $K$ é:

$$
K=\frac{m v^{2}}{2}=E-U
$$

Portanto, o quadrado do comprimento de onda, no limite clássico, é:

$$
\lambda^{2}=\frac{h^{2}}{p^{2}}=\frac{h^{2}}{m^{2} v^{2}}=\frac{h^{2}}{2 m(E-U)}
$$

A equação de onda geral (clássica e relativística) é:

$$
\Delta \psi+\left(\frac{2 \pi}{\lambda}\right)^{2} \psi=0
$$

Substituindo em (21) pela expressão de (2), obtemos:

$$
\Delta \Psi+\frac{8 \pi^{2} m}{h^{2}}(E-U) \Psi=0
$$


Esta é a chamada "equação de Schrödinger independente do tempo". Portanto, usando apenas a mecânica clássica e a relação de De Broglie $\lambda=h / p$ é possível deduzir a equação de onda de Schrödinger. Note que esta dedução é muito semelhante à que Schrödinger usou no caso relativístico, embora mais simples. No entanto, Schrödinger não utilizou essa dedução tão simples. Como ele apresentou a equação de onda em seus primeiros artigos? ${ }^{5}$

\section{A equação de onda no primeiro artigo de Schrödinger}

No primeiro artigo que publicou em 1926, Schrödinger apresentou a equação de onda como uma consequência da abordagem de Hamilton-Jacobi, de um modo bastante abstrato .(SCHRÖDINGER, 1926a, p. 361-362, 1929, p. 1-2) Ele introduziu uma função desconhecida $\Psi$ e afirmou que a ação $S$ poderia ser escrita como:

$$
S=K \log \Psi
$$

Portanto, a função hamiltoniana $H$ poderia ser escrita como:

$$
H\left(q, \frac{\partial S}{\partial q}\right)=H\left(q, \frac{K}{\Psi} \frac{\partial \Psi}{\partial q}\right)=E
$$

Schrödinger, então, afirmou que no caso não-relativístico essa equação "sempre pode ser transformada de modo a se tornar uma forma quadrática (de $\Psi$ e de suas derivadas) igualada a zero" (SCHRÖDINGER, 1926a, p. 361-362; 1929, p. 1). No caso do átomo de hidrogênio (um campo coulombiano), ela se torna:

$$
\left(\frac{\partial \Psi}{\partial x}\right)^{2}+\left(\frac{\partial \Psi}{\partial y}\right)^{2}+\left(\frac{\partial \Psi}{\partial z}\right)^{2}-\frac{2 m}{K^{2}}\left(E+\frac{e^{2}}{r}\right) \Psi^{2}=0
$$

Esta é simplesmente a equação clássica da conservação da energia $p^{2}=2 m(E-V)$, pois os três primeiros termos correspondem ao quadrado do momento dividido por $(K / \Psi)$, de acordo com (24).

5 Não discutirei aqui o caminho que Schrödinger seguiu para chegar à sua equação de onda. Os trabalhos que ele publicou não apresentam suas ideias do modo como foram desenvolvidas. (KRAGH, 1982, p. 158) O que nos interessa aqui é o modo pelo qual Schrödinger decidiu publicar seus resultados e qual poderia ter sido sua motivação para apresentá-los exatamente desta forma. 
Schrödinger (1926a, p. 362, 1929, p. 2), então. afirmou: “Agora procuramos uma função $\Psi$ tal que para qualquer variação arbitrária dela a integral da acima referida forma quadrática, calculada sobre todo o espaço de coordenadas, é estacionária [...]”. A equação correspondente é:

$$
\delta J=\delta \iiint\left[\left(\frac{\partial \Psi}{\partial x}\right)^{2}+\left(\frac{\partial \Psi}{\partial y}\right)^{2}+\left(\frac{\partial \Psi}{\partial z}\right)^{2}-\frac{2 m}{K^{2}}\left(E+\frac{e^{2}}{r}\right) \Psi^{2}\right] d x \cdot d y \cdot d z=0
$$

A partir deste problema variacional, Schrödinger deduziu a equação de onda para o átomo de hidrogênio:

$$
\nabla^{2} \Psi+\frac{2 m}{K^{2}}\left(E+\frac{e^{2}}{r}\right) \Psi=0
$$

Esta dedução apresentada no primeiro artigo de Schrödinger de 1926 é completamente sem sentido, já que $\Psi$ é uma função não definida e (26) não é um princípio variacional válido na física clássica ${ }^{6}$. Sua única "justificação" é que a equação de onda leva aos níveis de energia corretos para o átomo de hidrogênio, deduzidos cuidadosamente no restante desse mesmo artigo. (SCHRÖDINGEr, 1926a, p. 362-374, 1929, p. 2-10)

\section{A dedução no segundo artigo de Schrödinger}

O próprio Schrödinger não estava muito satisfeito com essa "dedução" do primeiro artigo e apresentou uma muito diferente, no seu segundo artigo de 1926 (SCHRÖDINGER, 1926b, 1929, p. 13-40), onde apresentou pela primeira vez a equação de onda genérica independente do tempo $(m=1)$ :

$$
\Delta \Psi+\frac{8 \pi^{2} m}{h^{2}}(E-U) \Psi=0
$$

6 "A primeira dedução publicada [...] era não apenas curiosamente formal, mas explicitamente críptica. No conjunto, esta dedução parece mal justificada, sua única fundamentação sendo seu resultado [...]". (KRAGH, 1982, p. 158) 
Apresentamos aqui uma reconstrução de sua dedução, enfatizando os seus pontos principais.

A suposição fundamental de Schrödinger foi a equação de onda geral (clássica) nesta forma (SCHRÖDINGER, 1926b, p. 510; 1929, p. 27):

$$
\nabla^{2} \psi-\frac{1}{u^{2}} \ddot{\psi}=0
$$

Schrödinger já havia obtido, no mesmo artigo (1926b, p. 494-498; 1929, p. 16-20), a equação para a velocidade da onda:

$$
u=\frac{d s}{d t}=\frac{E}{\sqrt{2(E-V)}}=\frac{h v}{\sqrt{2(h v-V)}}
$$

Então, supondo que a função de onda $\Psi$ tenha a mesma forma que usualmente possui na física clássica (SCHRÖDINGER, 1926b, p. 510, 1929, p. 27):

$$
\psi=f\left(q_{k}\right) \cdot e^{2 \pi i v t}
$$

deduzimos:

$$
\ddot{\psi}=\frac{\partial^{2} \psi}{\partial t^{2}}=(2 \pi i v)^{2} \cdot f\left(q_{k}\right) \cdot e^{2 \pi i v t}=-4 \pi^{2} v^{2} \psi
$$

Substituindo (32) e (30) em (29), obtém-se imediatamente a equação de onda de Schrödinger:

$$
\nabla^{2} \psi+\frac{8 \pi^{2}}{h^{2}}(h v-V) \psi=0
$$

Como $E=h v$, ela pode também ser escrita (SCHRÖDINGER, 1926b, p. 510; 1929, p. 27):

$$
\nabla^{2} \psi+\frac{8 \pi^{2}}{h^{2}}(E-V) \psi=0
$$

7 Em vez do símbolo usual para o operador laplaciano, empregado aqui, Schrödinger escreveu div grad. 
Portanto, na dedução que apresentou no seu segundo artigo, as únicas suposições não-clássicas são $E=h$ e a fórmula para a velocidade $u$ das ondas associadas ao elétron (30) que corresponde ao limite clássico da relação $u=E / p$ de De Broglie.

No entanto, Schrödinger não tomou a fórmula de $u$ do trabalho de De Broglie. Ele apresentou sua própria dedução original e altamente abstrata dessa relação, usando a analogia entre os princípios de Huygens e Hamilton (SCHRÖDINGER, 1926b, p. 494-498, 1929, p. 16-20). Ele se referiu ao trabalho de De Broglie neste artigo, mas enfatizou que seus próprios resultados foram obtidos de um modo mais geral e de forma independente da teoria da relatividade. Depois de apresentar sua própria dedução ele comentou:

Encontramos aqui novamente um teorema para as 'ondas de fase' do elétron, que o Sr. De Broglie tinha deduzido, referindo-se essencialmente à teoria da relatividade, nessas belas pesquisas às quais devo a inspiração para meu trabalho. Vemos que o teorema em questão é de uma maior generalidade, e não surge apenas da teoria da relatividade, mas é válido para qualquer sistema conservativo da mecânica comum. (SCHRÖDINGER, 1926b, p. 498, 1929, p. 20)

Portanto, Schrödinger poderia ter utilizado o trabalho de De Broglie para deduzir a equação de onda no caso não-relativístico, mas ele não o fez. Utilizou uma fórmula para a velocidade da onda associada ao elétron, que é equivalente à de De Broglie, mas apresentou uma nova dedução dessa relação - aparentemente porque queria provar que ela era válida, independentemente de considerações relativísticas.

\section{As teorias de De Broglie e Schrödinger}

O cuidado que Schrödinger tomou em evitar fundamentar sobre o de De Broglie poderia, talvez, ser justificado da seguinte forma: primeiramente, ele havia tentado usar a abordagem relativística e havia falhado; além disso, a equação de onda que de fato levava a resultados corretos não é o limite clássico da equação de onda relativística. Portanto, era adequado apresentar uma dedução completamente independente da teoria relativística de De Broglie, para assegurar que sua própria teoria era bem fundamentada. Provavelmente, isso era parte de sua motivação. No entanto, há outros aspectos relevantes, pois há muitas diferenças profundas entre as duas teorias.

O trabalho de De Broglie estava fundamentado na relatividade especial e suas principais equações só podiam ser deduzidas para elétrons em movimento uniforme, já que ele tomou como ponto de partida a descrição da pulsação do elétron 
extenso no seu referencial próprio. Sua ampliação para o caso do movimento acelerado exigia um novo modo de pensar e uma justificação diferente.

De Broglie tentou de fato proporcionar uma base para sua teoria, no caso do movimento acelerado, usando a analogia entre os princípios de Maupertuis e Fermat - que são válidos apenas para partículas isoladas e para raios. Isso o levou a uma relação geral entre as propriedades ondulatórias e mecânicas do elétron, movendo-se em um campo eletromagnético. No entanto, o elétron de De Broglie ainda descrevia uma trajetória bem definida e a onda associada podia ser descrita por raios - uma abordagem que só é satisfatória em situações correspondentes à óptica geométrica, mas inadequada nos casos de interferência e difração. Ele aplicou suas ideias com sucesso ao átomo de hidrogênio, mas foi incapaz de estudar o oscilador harmônico e outros sistemas simples. O conceito de De Broglie sobre o elétron não podia ser aplicado de forma adequada aos casos em que as dimensões do sistema eram comparáveis ao comprimento de onda. Era também difícil perceber como sua teoria poderia ser aplicada a um sistema com diversas partículas. Além disso, sua teoria não teria significado para um sólido rígido em rotação, por exemplo8.

A abordagem de Schrödinger era muito mais geral do que a de De Broglie. Suas deduções não dependiam da teoria da relatividade e, portanto, ele podia atacar diretamente os casos de sistemas acelerados e em rotação. Além disso, na dedução apresentada no seu segundo artigo de 1926, Schrödinger apresentou sua própria teoria de modo muito geral (SCHRÖDINGER, 1926b, p. 490-491, 1929, p. 14), usando coordenadas generalizadas (abrindo assim a possibilidade de aplicá-la à rotação e outros tipos de movimento) e discutindo um sistema conservativo geral (ou seja, ele não restringiu seu tratamento a uma partícula isolada). Seu modo geral e abstrato de abordar o problema lhe permitia aplicar a equação de onda a qualquer sistema físico.

No seu segundo artigo, Schrödinger usou a analogia entre os princípios de Huygens e Hamilton (não entre Fermat e Maupertuis, como De Broglie fez) e assegurou, assim, que a relação poderia ser aplicada a casos nos quais as dimensões do sistema fossem comparáveis ao comprimento de onda. Por essas razões, apenas a teoria de Schrödinger podia ser aplicada diretamente a ondas associadas a um ou mais elétrons em três dimensões (sistemas atômicos), ao oscilador harmônico e a sólidos em rotação, como ele de fato o fez. (SCHRÖDINGER, 1926b)

8 A análise do sólido rígido quântico em rotação era muito importante na teoria dos calores específicos de gases poliatômicos. Este problema foi abordado por Schrödinger em seu segundo artigo de 1926. 


\section{Conclusões}

A equação de onda de Schrödinger pode ser deduzida dos resultados de De Broglie, no limite clássico. No entanto, a sua teoria não é uma aplicação ou desenvolvimento da teoria de De Broglie.

A teoria de Schrödinger pode ser aplicada a casos nos quais a de De Broglie não pode ser aplicada, como movimento acelerado e rotação, e para partículas em situações em que o comprimento de onda é comparável às dimensões da região que contém o elétron. Mesmo no caso de uma partícula livre, são também incompatíveis: o comprimento de onda relativístico de De Broglie foi confirmado por experimentos de difração e, portanto, o comprimento de onda clássico de Schrödinger não é válido, para velocidades altas. O valor heurístico da equação de onda de Schrödinger é outra distinção muito importante entre as duas teorias, já que a de De Broglie apenas levou a uma única predição nova: o comportamento ondulatório de elétrons em experimentos de difração. Há ainda outras diferenças entre as duas abordagens que não podem ser descritas aqui.

Embora a teoria de De Broglie tenha sido o ponto de partida do trabalho de Schrödinger e tenha tido um importante papel heurístico a esse respeito, as duas teorias são diferentes, independentes e incompatíveis.

\section{Agradecimentos}

O autor agradece o apoio recebido do Conselho Nacional de Desenvolvimento Científico e Tecnológico (CNPq) e da Fundação de Amparo à Pesquisa do Estado de São Paulo (FAPESP), sem cujo auxílio teria sido impossível desenvolver esta pesquisa.

\section{Referências}

BORK, Alfred M. Maxwell and the vector potential. Isis, v. 58, p. 210-222, 1967.

BROWN, Harvey R.; MARTINS, Roberto de A. De Broglie's relativistic phase waves and waves groups. American Journal of Physics, v. 52, p. 1130-1140, 1984.

DARRIGOL, Olivier. Strangeness and soundness in Louis de Broglie's early works. Physis: Rivista Internazionale di Storia della Scienza, v. 30, p. 303-372, 1993. 
DE BROGLIE, Louis. Ondes et quanta. Comptes Rendus de l'Académie des Sciences de Paris, 177, 507-510, 1923a.

A tentative theory of light quanta. Philosophical Magazine, v. 47, p. 446-458, 1924a.

. Les quanta, la théorie cinétique des gaz et le principe de Fermat.

Comptes Rendus de l'Académie des Sciences de Paris, 177, 630-632, 1923c.

Quanta de lumière, diffraction et interférences. Comptes Rendus de l’Académie des Sciences de Paris, v. 177, p. 548-550, 1923b.

. Recherches sur la théorie des quanta. Annales de Physique, series 10, v. 3, p. 22-128, 1925.

Sur la définition générale de la correspondance entre onde et mouvement. Comptes Rendus de l'Académie des Sciences de Paris, v. 179, p. 39-40, 1924b.

. Sur un théorème de M. Bohr. Comptes Rendus de l'Académie des Sciences de Paris, v. 179, p. 676-677, 1924c.

. Thèses : recherches sur la théorie des quanta. Paris: Masson, 1924d. . Waves and quanta. Nature, v. 112 , p. 540, 1923d.

HANLE, Paul A. Erwin Schrödinger's reaction to Louis de Broglie's thesis on the quantum theory. Isis, v. 68, p. 606-609, 1977.

. The Schrödinger-Einstein correspondence and the sources of wave mechanics. American Journal of Physics, v. 47, p. 644-648, 1979.

HEITLER, Walter. Erwin Schrödinger, 1887-1961. Biographical Memoirs of Fellows of the Royal Society, v. 7, p. 221-228, 1961.

JAMMER, Max. The conceptual development of quantum mechanics. New York: MacGraw-Hill, 1966.

KRAGH, Helge. Erwin Schrödinger and the wave equation: the crucial phase. Centaurus, v. 26, p. 154-197, 1982. 
. Equation with the many fathers. The Klein-Gordon equation in 1926. American Journal of Physics, v. 52, p. 1024-1033, 1984.

MARTINS, Roberto de A. Teoria da relatividade especial. Campinas: Grupo de História e Teoria da Ciência, 2008.

MEHRA, Jagdish; RECHENBERG, Helmut. The historical development of quantum theory. New York: Springer, 1982-1987. 5 v.

MOORE, W. J. Schrödinger: life and thought. Cambridge: Cambridge University, 1989.

RAMAN, V. V.; FORMAN, Paul. Why was it Schrödinger who developed de Broglie's ideas? Historical Studies in the Physical Sciences, v. 1, p. 291-314, 1969.

REGT, Henk W. de. Erwin Schrödinger, Anschaulichkeit, and quantum theory. Studies in History and Philosophy of Modern Physics, v. 28, p. 461-481, 1997.

ROSA, Pedro Sérgio. Louis de Broglie e as ondas de matéria. Dissertação de Mestrado em Física. Campinas: Universidade Estadual de Campinas, 2004.

SCHRÖDINGER, Erwin. Collected papers on wave mechanics. London; Glasgow: Blackie \& Son, 1929.

. Quantisierung als Eigenwertproblem (Erste Mitteilung). Annalen der Physik, series 4, v. 79, p. 361-376, 1926 .

. Quantisierung als Eigenwertproblem (Zweite Mitteilung). Annalen der Physik, series 4, v. 79, p. 489-527, 1926 b.

WHEATON, Bruce R. The tiger and the shark: empirical roots of wave-particle dualism. London: Cambridge University, 1983. 


\title{
A imagem pública de Arthur Holly Compton: um físico quântico ou clássico?
}

\author{
Indianara Lima Silva \\ Olival Freire Jr \\ Ana Paula Bispo da Silva
}

\section{Introdução}

O impacto da criação da Teoria Quântica na ciência do século XX pode ser inferido também pela terminologia que ela gerou em relação aos físicos que contribuíram para a sua criação. Tal impacto foi bem caracterizado pelo historiador Helge Kragh (1999) ao designar a sua história síntese da Física do século XX de Quantum generations. O termo físico quântico foi utilizado para referências, por exemplo, a Niels Bohr (1885-1962), Wolfgang Pauli (1900-1958) ou Werner Heisenberg (1901-1976), e ainda hoje sobrevive no léxico da Física e do senso comum. ${ }^{1}$ A expressão "pais fundadores" se tornou corrente para denominar os físicos que criaram essa teoria física. Mesmo quando se almeja matizar a contribuição de um desses "fundadores", utilizam-se expressões que ainda acentuam o caráter revolucionário atribuído a essa teoria física e à participação do físico nessa revolução. Assim é que Max Planck (1858-1947) muitas vezes é apresentado como o "revolucionário relutante", mesma expressão utilizada, por exemplo, para referenciar Martin Luther (1483-1546)² e Charles Darwin (1809-1882). Parece-

1 No Google, o número de entradas como quantum physicist (53400) perde apenas para nuclear physicist (220.000), mas supera particle physicist (49700). Outras expressões possíveis, como electromagnetic physicist, relativist physicist, mechanical physicist, e thermodynamic physicist apresentam entradas muito menores, apenas a última chegando a 1400 entradas. Acesso em 22 de setembro de 2009.

2 Em português, utiliza-se tradicionalmente o nome Martinho Lutero. 
nos, então, que estamos diante de um fenômeno que a história designa de mito de fundação. Eficaz como os mitos podem ser, eles não resistem, em geral, a uma análise histórica acurada.

A imagem pública do físico norte-americano Arthur Holly Compton (18921962), vencedor do Prêmio Nobel de 1927 "pela descoberta do efeito que leva o seu nome", está associada à ideia de um físico quântico, um dos "pais fundadores" dessa teoria. Não obstante, a análise da biografia intelectual de Compton revelanos um físico que dedicou quase todo o seu programa de investigação ao estudo do fenômeno dos raios-X e raios gama, nos marcos da Física clássica. Fruto dessa atividade foi, por exemplo, a proposição de um modelo de um "grande elétron" para explicar os efeitos observados no espalhamento dos raios-X pela matéria. A criação do efeito Compton, para explicar esse espalhamento com base nos conceitos quânticos, foi o ponto de chegada de um percurso de mais de seis anos, em que Compton trabalhou essencialmente nos marcos das teorias da Física clássica, em especial, a mecânica e a eletrodinâmica. Ainda mais, nos marcos desse programa essencialmente clássico, não há indícios de que Compton havia sido guiado ou utilizado conscientemente a ideia do quantum de luz desenvolvida por Einstein. (STUEWER, 2000, p. 986)

Mesmo depois da obtenção desse resultado e de sua premiação, Compton não se destacou pelo uso ou desenvolvimento da Teoria Quântica. Ele trabalhou com os raios cósmicos a partir de 1930, participou do Projeto Manhattan que construiu a primeira bomba atômica e, depois da guerra, abandonou a atividade científica para se dedicar à administração acadêmica, assumindo a presidência da Washington University, em 1946.

A apresentação de Compton como essencialmente um físico quântico não parece contribuir para os objetivos da generalização da educação científica. Tal imagem, cercada do heroísmo associado aos criadores da Teoria Quântica, é uma simplificação, típica dos mitos de fundação. Nessa imagem, Compton é essencialmente um revolucionário, partícipe da revolução científica, para usarmos os termos de Thomas Kuhn (1978), representada pela criação da Teoria Quântica. Essa imagem desumaniza a atividade científica efetivamente desenvolvida por Compton, desenvolvida na maior parte do seu tempo nos marcos, ainda usando os termos kuhnianos, da "ciência normal". Estudantes de Física certamente se reconhecerão mais facilmente nessa segunda imagem, mais complexa, porém mais realista, da atividade de Compton que na imagem mitificada presente nos livros-textos onde se aprende a disciplina. Parece-nos que o termo utilizado por Samuel K. Allison (1962, p. 138) é o mais adequado ao tratar do nosso personagem, Arthur Holly Compton, por físico pesquisador. 
Este artigo é uma pequena contribuição para o resgate dessa imagem mais realista das contribuições de Arthur Compton. Na primeira seção, evidenciamos quão difundida está, nos livros textos e na história da ciência, a imagem de Compton como um físico quântico. Neste sentido, faremos dois tipos básicos de críticas: (i) àqueles que descrevem Compton essencialmente como um dos pais fundadores da Teoria Quântica; (ii) àqueles que afirmam que Compton apenas aplicou a hipótese do quantum de radiação proposta por Einstein, na sua explicação do processo de espalhamento dos raios-X pela matéria. Na segunda seção, sintetizamos os resultados da dissertação de um dos autores (SILVA, 2009) na qual, apoiada tanto na análise dos artigos originais do período, quanto da literatura secundária, emerge a imagem de um Compton inserido na tradição e na comunidade de pesquisa em raios-X do início do século XX. Um Compton clássico, eventualmente contribuindo para a criação da Teoria Quântica, será a imagem que dele sintetizaremos.

\section{A imagem pública do físico Arthur Compton}

A imagem pública da trajetória científica desenvolvida por Compton é aquela presente nos livros didáticos, em particular, naqueles que contribuem para a formação de físicos e de professores de Física. Muitos estudos têm destacado que a história da ciência retratada nesses livros é uma pseudo história, muitas vezes, limitada ao relato de nomes, datas e lugares. Nesta seção, analisamos os livros didáticos mais comumente utilizados nos cursos de graduação de Licenciatura e Bacharelado em Física, os quais contribuem para formar as opiniões de físicos e professores de Física: Física moderna (TIPLER; LLEWELLY, 2006), Curso de física básica (NUSSENZVEIG, 1998) e Fundamentos de física (HALLIDAY, RESNICK; WALKER, 2007), de modo que se possa evidenciar a imagem de Compton neles difundida. Além disso, também verificamos aquela difundida pela história da ciência.

O livro Física moderna, escrito por Tipler e Llewelly (2006, p. 94), destaca que

Compton aplicou as leis de conservação do momento e da energia, em sua fórmula relativística, à colisão de um fóton com um elétron; isso lhe permitiu calcular a diferença entre os comprimentos de onda do fóton incidente e do fóton difratado. 
Os autores continuaram afirmando que

Compton verificou os seus resultados experimentalmente usando como fótons incidentes os fótons associados à linha do espectro característico de raios $\mathrm{X}$ do Molibdênio com um comprimento de onda de 0.0711 e como alvo os elétrons de um bloco de grafita. (TIPLER; LLEWELLY, 2006, p. 95)

A esse livro não se aplica a nenhuma daquelas críticas descritas, (i) e (ii), descritas anteriormente. No entanto, os autores simplificaram bastante a atividade científica desenvolvida por Compton, descrevendo apenas o produto final do saber científico. Ainda que as simplificações sejam necessárias em livros didáticos, os autores poderiam ter mencionado que Compton havia explicado o mesmo fenômeno através da teoria clássica.

Já o livro Curso de física básica, publicado pelo físico brasileiro Moysés H. Nussenzveig, apesar da familiaridade do autor com a história da ciência, afirma que "Compton levou às últimas consequências a hipótese de Einstein". (NUSSENZVEIG, 1998, p. 254) Essa afirmação não tem respaldo histórico, já que no seu artigo de 1923, Compton não fez nenhuma alusão às ideias de Einstein sobre o quantum-corpuscular. E conforme o historiador Stuewer (1975, p. 217), Compton construiu a sua Teoria Quântica para o espalhamento de modo relativamente autônomo. Segundo ele,

Não existe uma indicação de que Compton tenha lido em algum momento o trabalho do quantum de luz de Einstein de 1905. De fato, Compton também não citou o trabalho de Einstein em seu próprio trabalho de 1923, e nem mesmo mencionou o seu nome. (STUEWER, 2000, p. 986)

O interessante a notar é que se Compton foi realmente influenciado, essa influência não partiu dos estudos de Einstein sobre a radiação, mas sim dos estudos acerca dos raios-X. Afinal, a comunidade de pesquisadores com a qual Compton se relacionava diretamente era exatamente aquela dos especialistas em raios-X.

Ao abordar o efeito Compton, Nussenzveig (1998, p. 254) mencionou que a "Evidência mais direta das propriedades corpusculares da luz foi obtida entre 1919 e 1923 por Arthur Compton". Essa consideração nos induz a interpretar que Compton sempre estivera dedicado à aplicação da hipótese do quantum de luz, de 1919 a 1923, o que não é verídico historicamente, visto que as suas conjecturas iniciais estavam apoiadas na teoria eletromagnética clássica da luz. Foi apenas no final de 1922 que Compton propôs a sua abordagem quântica. Em relação aos resultados experimentais, o autor descreveu que "Compton verificou experimentalmente tanto o valor absoluto quanto sua dependência angular." 
(NUSSENZVEIG, 1998, p. 256) A abordagem clássica do efeito Compton não aparece, portanto, na obra escrita por Nussenzveig.

No livro Fundamentos de física, publicado por Halliday, Resnick e Walker, reeditado há várias décadas e influente na formação de físicos e engenheiros em todo o mundo, inicialmente os autores mencionaram o artigo de Einstein de 1916, no qual ele propõe que os fótons possuem momento. E prosseguem

Em 1923, Arthur Compton, da Washington University, em Saint Louis, executou um experimento que confirmou a previsão de que os fótons possuem energia e momento. $\mathrm{O}$ cientista fez incidir um feixe de raios-X de comprimento de onda $\lambda$ em num alvo de carbono. (HALLIDAY; RESNICK; WALKER, 2007, p. 185)

Mais uma vez, isso nos conduz a imaginar que Compton somente aplicou a hipótese de Einstein, o que não há respaldo na história da ciência, pois Compton fez toda sua carreira pesquisando em raios-X, com modelos baseados na Física clássica; e quando usou a hipótese quântica, não deixou evidências de que tenha sido influenciado diretamente pela ideia do quantum de luz de Einstein. Os autores também não se referem à abordagem clássica adotada por Compton, antes da sua descoberta do efeito que leva o seu nome.

Essa análise evidencia que os livros-texto reduzem o árduo trabalho teóricoexperimental realizado por Compton, como também desconsideram o universo clássico no qual ele viveu durante seis anos. Os livros supracitados também destacam a importância da sua atividade experimental, mas essa aparece subestimada quando comparada ao Compton teórico, evidenciando uma subestimação da Física experimental.

É preciso destacar que, neste trabalho, não se propõe que os livros didáticos abordem todo percurso trilhado pelo nosso personagem. Todavia, se eles iniciassem uma discussão do efeito Compton a partir da análise de uma das suas hipóteses clássicas, evidenciando o modo pelo qual as ideias de Compton foram construídas - partindo de um modelo clássico e chegando a um quântico - isso poderia contribuir para uma imagem mais realista do sentido da atividade científica de Compton. Desse modo, os livros didáticos poderiam contribuir para a compreensão da natureza da ciência por parte dos estudantes. Portanto, concordamos com Matthews (1994) quando afirma que o estudo da história da ciência proporciona um olhar mais aguçado sobre a natureza da ciência.

Além disso, a visão de um Compton quântico tem sido reforçada pela história da ciência, mesmo aquela elaborada por historiadores experientes. O livro de Sanchez Ron, reconhecido historiador espanhol da Física, em livro destinado ao grande público, relata a história da pesquisa sobre os raio-X, sem citar Compton como um de seus protagonistas, enquanto inclui Compton ao remeter-se à 
história da Mecânica Quântica. (RON, 2007, p. 357) Compton aparece, assim, em El poder de la ciencia - historia social, política y econômica de la ciencia (siglos $X I X$ y XX) como um físico quântico que "[...] pôs em evidência a natureza corpuscular da luz". (RON, 2007, p. 357) Em A física do século XX, obra do epistemólogo francês Michel Paty, Compton comparece em capítulo dedicado à criação da Teoria Quântica, como tendo "confirmado" o caráter corpuscular da radiação ou "observado" experimentalmente a natureza da luz como partículas, concepção formulada por Einstein em 1916. (PATY, 2009, p. 28 e 80)

No livro Quantum generations publicado por Helge Kragh (1999), Compton não é citado como protagonista nos estudos sobre raios-X, comparecendo apenas na história da construção da Teoria Quântica. Deste modo, a descoberta do Efeito Compton é abordada isoladamente, o que nos faz pensar que o interesse do nosso personagem sempre estivera associado com o desenvolvimento da velha Mecânica Quântica.

Todavia, outros historiadores têm sido mais atentos à especificidade da prática científica de Compton. O historiador J. L. Heilbron (2003), enquanto escrevia o seu verbete sobre os raios- $\mathrm{X}$, mencionou a contribuição de Compton para a pesquisa nessa área e, consequentemente, para a Teoria Quântica. A abordagem do efeito Compton escrita pelos físicos e historiadores japoneses Mituo Taketani e M. Nagasaki (2001), é um exemplo de como esse efeito poderia ser discutido. Os autores inicialmente mencionam a hipótese do grande elétron proposta por Compton e, em seguida, discutem a sua abordagem quântica. No caso do historiador Stuewer (1975), embora o título do seu livro valorize apenas a contribuição para a Teoria Quântica, ele, de fato, analisou todo o programa de pesquisa desenvolvido por Compton, antes da sua abordagem quântica para o fenômeno do espalhamento. A análise dos livros textos e dos historiadores está sintetizada no quadro 1.

\begin{tabular}{|c|c|c|c|}
\hline Autores & $\begin{array}{c}\text { Crítica } \\
\text { (i) }\end{array}$ & $\begin{array}{c}\text { Crítica } \\
\text { (ii) }\end{array}$ & Outra \\
\hline Tipler e Llewelly (2006) & & & Simplificação Excessiva. \\
\hline Nussenzveig (1998) & & $\mathrm{X}$ & \\
\hline Halliday, Resnicke Walker (2007) & & $\mathrm{X}$ & \\
\hline Sanchez Ron (2007) & $\mathrm{X}$ & & \\
\hline Paty (2009) & & $\mathrm{X}$ & \\
\hline Kragh (1999) & $\mathrm{X}$ & & \\
\hline Heilbron (2003) & & & \\
\hline Taketani \& Nagasaki (2001) & & & \\
\hline Stuewer (1975) & & & \\
\hline
\end{tabular}

Quadro 1 - Sistematização da análise 


\section{A trajetória de um físico clássico}

O interesse de Compton pela Física clássica dos raios-X iniciou em Princeton e continuou durante toda a sua carreira. (SHANKLAND, 1973, p. xxvii) Tal interesse pela teoria clássica foi influenciado por dois personagens, Karl Compton e O. W. Richardson, e ficou mais acentuado quando Compton soube da descoberta realizada por Max von Laue (1879-1960). Laue havia demonstrado, através da difração, que os raios-X poderiam ser considerados apenas ondas eletromagnéticas clássicas. (STUEWER, 1975, p. 97)

De fato, o título do seu discurso na premiação do Nobel foi X-Rays as a branch of optics, o que evidencia a cultura científica na qual Compton estava inserido. Os seus trabalhos sobre reflexão, refração, difração e polarização demonstram o seu contínuo interesse acerca da natureza ondulatória dos raios-X. (SHANKLAND, 1973, p. xxvii) Além disso, Compton publicou dois livros sobre a Física dos raios-X (X-rays and electrons e $X$-Rays in theory and experiment) escritos juntamente com Allison, que se tornaram referência sobre a Física teórica e experimental dos raios-X.

Para ilustrar o mundo clássico construído por Compton, analisamos uma das abordagens clássicas desenvolvidas por ele para explicar o processo de espalhamento dos raios-X e $\gamma$ pela matéria: a hipótese do grande elétron.

Em seu artigo de 1919, intitulado The size and the shape of the electron: I. Scattering of high frequency radiation, Compton descreveu os dois problemas que a teoria clássica não estava conseguindo resolver. O primeiro era que o valor teórico determinado pela teoria clássica para o coeficiente de espalhamento de massa para os raios-X e $\gamma$ nunca deveria ser menor do que 0.118 , no caso do alumínio. No entanto, os resultados experimentais obtidos por C. G. Barkla (1877-1944) e M. Ishino mostravam que o coeficiente de absorção do alumínio era, de fato, 0.045. O coeficiente de espalhamento de massa torna-se o coeficiente de absorção desde que o feixe primário de raio-X perca energia ao atravessar a matéria. (COMPTON, 1919, p. 21) O segundo problema referia-se à intensidade do feixe de raios-X encontrada quando eles atravessavam uma fina camada de matéria. Para a teoria clássica, a intensidade dos raios espalhados sobre os dois lados de uma placa deveria ser a mesma. Contudo, os experimentos evidenciavam que a radiação espalhada sobre o lado emergente da placa era mais intensa do que aquela espalhada no lado incidente.

Para Compton, a solução desses problemas parecia ser

[...] inexplicável de acordo com a eletrodinâmica clássica se as dimensões do elétron são consideradas ser desta ordem de magnitude [se o elétron fosse considerado uma carga 
pontual] [...] Se, de outro lado, considera-se que o elétron tem um raio comparável com o comprimento de onda da radiação incidente, uma explicação quantitativa do fenômeno de baixo espalhamento para comprimento de onda curto é óbvia. (COMPTON, 1919, p. 21, 23)

\section{1 Primeiro problema: explicação de Compton}

De acordo com Compton (1919, p. 28-29), se o diâmetro do elétron é comparável com o comprimento de onda da radiação incidente em magnitude, então, haveria uma diferença de fase entre os raios espalhados pelas diferentes partes do elétron. Essa diferença de fase é maior para raios espalhados em grandes ângulos do que para pequenos ângulos. Vamos supor que uma frente de onda $S$ incide sob um grande elétron (ver Figura 1), sendo que a radiação é espalhada pela parte do elétron em A e a outra pela parte do elétron em B. Se o diâmetro do elétron é proporcional em tamanho com o comprimento de onda da radiação incidente, logo, o caminho percorrido pela radiação espalhada em A é maior do que aquela espalhada em B. Essa diferença de fase entre os dois caminhos pode resultar em uma interferência destrutiva, devido à superposição de ondas, já que elas não possuem a mesma fase. (STUEWER, 1975, p. 99) A intensidade dos raios espalhados em P, portanto, teria um valor reduzido.

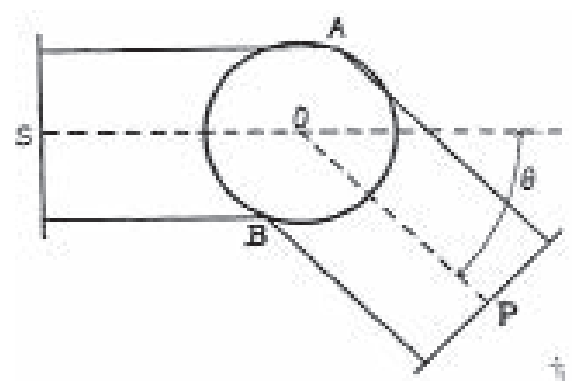

Figura 1 - Modelo do grande elétron proposto por Compton em 1919.

Fonte: Compton (1919, p. 23).

Compton (1919) também determinou o valor teórico para o coeficiente de espalhamento, $\sigma / \rho$, baseado em três modelos de elétrons: (I) uma esfera rígida de eletricidade; (II) uma casca esférica flexível de eletricidade; e (III) um fino anel flexível de eletricidade. Para Compton (1919, p. 23), considerar a forma do elétron era essencial para explicar o baixo valor encontrado para o espalhamento. Para 
cada modelo de elétron, Compton determinou uma estimativa para o seu raio por meio dos resultados experimentais de Ishino e A. W. Hull e M. Rice para o coeficiente de espalhamento. Ver Quadro 2 a seguir.

\begin{tabular}{|c|c|c|}
\hline Modelo do elétron & Expressão teórica & $\begin{array}{c}\text { Raio do elé- } \\
\text { tron }\end{array}$ \\
\hline $\begin{array}{c}\text { Uma casca esférica rígida } \\
\text { de eletricidade (incapaz } \\
\text { de rotação) }\end{array}$ & $\frac{\sigma}{\rho}=\frac{8 \pi}{3} \frac{e^{4} N}{m^{2} C^{4}} \sin ^{4}\left(\frac{2 \pi a}{\lambda}\right) /\left(\frac{2 \pi a}{\lambda}\right)^{4}$ & $\begin{array}{l}a_{1}=1.910^{-10} \mathrm{~cm} \\
a_{2}=1.710^{-10} \mathrm{~cm}\end{array}$ \\
\hline $\begin{array}{c}\text { Uma casca esférica flexí- } \\
\text { vel de eletricidade }\end{array}$ & $\frac{\sigma}{\rho}=2 \pi N L^{2} \int_{0}^{\pi} \frac{I_{0}}{l} \sin \theta d \theta$, onde \\
\hline $\begin{array}{c}\text { Um fino anel flexível de } \\
\text { eletricidade }\end{array}$ & $\frac{e^{4}\left(I+\cos ^{2} \theta\right)}{2 L^{2} m^{2} C^{4}}\left\{\sin ^{2}\left(\frac{4 \pi z}{\lambda} \sin \frac{\theta}{2}\right) /\left(\frac{8 \pi}{3} \frac{N e^{4}}{m^{2} C^{4}}\left\{\sin \frac{\theta}{2}\right)^{2}\right\}\right.$ & $\begin{array}{l}a_{1}=2.010^{-10} \mathrm{~cm} \\
a_{2}=2.110^{-10} \mathrm{~cm}\end{array}$ \\
\hline
\end{tabular}

Quadro 2 - Síntese dos resultados obtidos por Compton em 1919

Nessas expressões, $\sigma$ é a razão entre a energia espalhada e a incidente por unidade de volume do material, $\rho$ é a sua densidade, então, $\sigma / \rho$ é o coeficiente de espalhamento, $N$ é o número de elétrons em unidade de massa da substância, $e$ e $m$ são respectivamente a carga e a massa do elétron, $C$ é a velocidade da luz, $\lambda$ é o comprimento de onda do feixe incidente, $a_{1}$ é o raio do elétron determinado a partir dos resultados experimentais de Ishino para o alumínio, $a_{2}$ é o raio do elétron encontrado a partir dos experimentos de Hull e Rice para o alumínio, $\mathrm{I}_{\theta}$ é a intensidade do feixe espalhado pelo elétron em um ângulo $\theta, I$ é a intensidade do feixe incidente.

No Quadro 2, para cada modelo de elétron há o valor teórico determinado por Compton. Ele substituiu os valores experimentais para o coeficiente de espalhamento e encontrou o raio do elétron para cada modelo de elétron.

Compton, portanto, estava defendendo um elétron da ordem de $2.10^{-10} \mathrm{~cm}$, ou seja mil vezes maior que o do modelo de elétron sugerido por Thomson, cujo raio deveria ser $1.10^{-13} \mathrm{~cm}$ ou $10^{-5} \AA$ Å. (STUEWER, 1975, p. 99) É importante destacar que o tamanho do grande elétron de Compton era menor do que o tamanho do átomo proposto pela teoria atômica de Bohr. 


\section{2 Segundo problema: explicação de Compton}

De acordo com a teoria de Thomson, a intensidade dos raios espalhados sobre os lados de uma placa deveria ser a mesma. Barkla e Ayres constaram que essa explicação apenas seria aplicada quando raios-X moles e substâncias de baixo peso atômico eram utilizados. Porém, quando se utilizava raios-X e $\gamma$ duros, os resultados experimentais mostravam que a radiação espalhada sobre a face emergente de uma placa era mais intensa do que sobre a face incidente. (COMPTON, 1919, p. 27)

Quando um feixe de radiação incide em uma placa, a diferença de fase dos raios espalhados em grandes ângulos era maior do que para aqueles em pequenos. Então, a intensidade da radiação espalhada na face incidente, em grandes ângulos, seria reduzida uma vez que haveria uma interferência destrutiva entre os feixes espalhados na face incidente da placa (COMPTON, 1919, 28-29). Foi, assim, que Compton explicou os dados de observação a partir da teoria clássica.

No final de seu artigo, Compton (1919, p. 31-32) concluiu que a teoria de Thomson não era capaz de explicar o baixo valor encontrado para o coeficiente de absorção e a dissimetria observada entre a intensidade do feixe espalhado incidente e a do emergente, devido ao modelo de elétron empregado (carga elétrica pontual). No entanto, tais problemas, para ele, poderiam ser explicados através da hipótese de que o diâmetro do elétron seria da ordem de grandeza do comprimento de onda dos raios $\gamma$ muito curtos. O raio do grande elétron de Compton era de aproximadamente $2 \cdot 10^{-10} \mathrm{~cm}$. Ainda segundo Compton, também seria preciso supor que o elétron realizasse movimentos de rotação e translação.

\section{Considerações finais}

Compton duvidou da aplicabilidade do seu modelo de grande elétron para explicar o processo de espalhamento somente em 1922. O modelo apresentava inconsistências, pois os seus resultados experimentais sugeriam que seria necessário assumir que o raio do elétron deveria aumentar com o comprimento de onda da radiação de alta frequência, já que Compton utilizava o efeito de interferência, onde $a \sim \lambda$, para explicar o espalhamento dos raios-X pela matéria. (STUEWER, 1975, p. 196; TAKETANI; NAGASAKI, 2001, p. 234-235)

Apresentamos a hipótese do grande elétron para ilustrar como a abordagem clássica proposta por Compton para explicar o espalhamento dos raios-X pela matéria era sofisticada e instrumental. Para ele, considerar "o tamanho e a forma do elétron" na sua modelagem era essencial para explicar aqueles dois problemas 
que a teoria clássica não era capaz de fazer. O objetivo de Compton não era mostrar a possível incoerência entre a teoria clássica da Física utilizada por Thomson e os resultados experimentais, mas, sim, demonstrar que o problema com a abordagem de Thomson estava relacionado com o modelo de elétron empregado e não com a Física clássica.

Ademais, destacamos a imagem de Compton difundida pelos livros didáticos e pela história da ciência através de duas críticas assim categorizadas: (i) na qual Compton é mencionado como um dos fundadores da revolução quântica; (ii) a abordagem quântica do efeito Compton é descrita apenas como uma mera aplicação da hipótese do quantum de luz proposta por Einstein em 1905 e 1916. A imagem de Compton como um físico quântico é, como vimos, uma reconstrução da história. Isto é, uma visão baseada em anacronismo. Compton foi, de fato, um físico que trabalhou com a Física teórica e experimental do espalhamento de raios-X e $\gamma$ com modelos apoiados na Física clássica, em especial, na eletrodinâmica. O Efeito Compton, quântico, foi o produto de um programa de pesquisa clássico. O ensino de Física e da História da Física deveria incluir essa visão mais complexa e mais realista da história de Compton. Ao limitar o seu trabalho teórico e experimental simplesmente à descoberta do Efeito Compton, subestima-se toda a sua contribuição científica, o seu interesse e a sua motivação.

\section{Referências}

ALLISON, S. K. Arthur Holly Compton, research physicist. Science, v. 138, p. 794-797, 1962.

COMPTON, A. H. The Size and Shape of the electron: I. the scattering of high frequency radiation. Physical Review, n. 1, p. 20-43, 1919.

HALLIDAY, D.; RESNICK, R.; WALKER, J. Fundamentos de Física 4: óptica e física moderna. 7. ed. Rio de Janeiro: L.T.C., 2007.

HEILBRON, J. L. X-Rays. In: (Ed.). The Oxford Companion to the History of Modern Science. New York: Oxford University, 2003. p. 835-836.

KRAGH, H. Quantum generations: a history of physics in the twentieth century. Princeton: Princeton University, 1999.

KUHN, T. S. A estrutura das revoluções científicas. 2. ed. São Paulo: Perspectiva, 1978. 
MATTHEWS, Michael R. Science teaching: the role of history and philosophy of science. New York: Routledge, 1994.

NUSSENZVEIG, M. H. Curso de Física Básica 4: ótica, relatividade e física moderna. São Paulo: Edgard Blüche, 1998.

PATY, M. A física do século XX. Traduzido por Pablo Mariconda. São Paulo: Idéias \& Letras, 2009.

RON, J. M. S. El poder de la ciencia: historia social, política y econômica de La ciência (siglos XIX y XX). Barcelona: Crítica, 2007.

SHANKLAND, R. S. Scientific Papers of Arthur Holly Compton: X-Rays and Other Studies. Chicago: The University of Chicago, 1973.

SILVA, I. L. Do grande elétron aos quanta de luz: Arthur Holly Compton e a Física dos raios $X$ e $\gamma$. Dissertação (Mestrado em Ensino, Filosofia e História das Ciências), Instituto de Física, Universidade Federal da Bahia, Salvador, 2009.

STUEWER, R. H. The Compton effect: transition to quantum mechanics. Annalen der Physik (Leipzig), n. 9, p. 975-989, 2000. The Compton effect: turning point in physics. New York: Science History Publications, 1975.

TAKETANI, M.; NAGASAKI, M. The Formation and Logic of Quantum Mechanics: the way to quantum mechanics. New Jersey: World Scientific, 2001. v. 2.

TIPLER, P. A.; LLEWELLYN, R. A. Física Moderna. 3. ed. Rio de Janeiro: L.T.C., 2006. 


\title{
Mecânica Quântica e não-linearidade - dificuldades e possibilidades
}

\author{
Aurino Ribeiro Filho
}

\section{Introdução}

A pesquisa em torno de alternativas teóricas que tentam interpretar resultados experimentais em sistemas físicos que apresentam fenômenos não-lineares tem se intensificado nas últimas décadas e criado, além de expectativa, certa perplexidade. Por outro lado, apesar de ser um tópico que incite muitas controvérsias, em vista da seriedade com que tem sido debatido, torna-se de grande interesse a busca de certo roteiro histórico, em torno das contribuições mais discutidas e debatidas na literatura recente.

A denominada Física não-linear tem sido discutida fortemente na atualidade, graças aos avanços conseguidos em distintos ramos da Matemática (não-linear), a exemplo de sistemas de equações diferenciais não-lineares, sistemas solitônicos ou ondas solitárias, sistemas fractais, ondas cnoidais, transformadas de Fourier generalizadas (que podem ser não-linearizadas em espaços de uma e duas dimensões), ondaletas, álgebras de operadores não-lineares e outros tópicos. (CROCA, 2003; FOKAS; SING, 2005; LIMA, 2006) Tais objetos matemáticos têm dado grande ajuda para a resolução de vários problemas na Teoria da Relatividade Geral, Eletromagnetismo clássico, Mecânica de Newton, Óptica quântica, Mecânica dos fluidos, sistemas incomensuráveis, Física estatística, teoria de campos clássicos e quânticos, e outros ramos da Física.

No caso da Teoria Quântica estruturada pela escola de Copenhague, com o suporte de Niels Bohr, Werner Heisenberg, Paul Dirac, Max Born, Erwin Schrödinger e outros cientistas, surge o princípio da superposição (linear) como 
um de seus aspectos básicos. Apesar de seu grande sucesso na resolução de inúmeros problemas, em alguns casos surge a expectativa de correções não-lineares, a fim de explicar alguns dados experimentais. Com a intensa discussão em torno dos fundamentos da Física Quântica, atualmente, as questões envolvendo este ramo da Física e fenômenos não-lineares têm despertado o interesse de distintos pesquisadores.

Em 1971, Bastin editou o livro Quantum theory and beyond, onde registrou as contribuições de distintos autores sobre os fundamentos da mencionada teoria, num colóquio informal, de mesma denominação, realizado em Cambridge, em julho de 1968. Somente 25 pessoas participaram de tal evento, organizado por E. W. Bastin e D. Bohm, que teve como general Chairman O. R. Frisch. Nesse colóquio, somente um de seus participantes, H. R. Post, que apresentou o trabalho The incompleteness of quantum mechanics or the emperor's missing clothes faria a seguinte inquirição (BASTIN, 1971):

Em todo caso não esperamos que um formalismo linear tal como a mecânica quântica possa expressar a verdade sobre um universo real que abunda em tais fenômenos não-lineares como as cargas elementares, etc.

Pois bem, além de Post, outros físicos têm conjecturado sobre o tema da não-linearidade na atualidade, a partir de experimentos em distintos sistemas quânticos, (vide FINK et al., 2008) que têm sido relatados como exemplos da "não-linearidade quântica".

A pesquisa em torno de extensões não-lineares para as equações dinâmicas da Teoria Quântica foi bastante intensificada nos anos 50 do século XX. Um exemplo é a contribuição do físico brasileiro Mário Schönberg (1954) que, a partir de uma modificação na equação de Hamilton-Jacobi, ao introduzir potenciais generalizados, conseguiu descrever movimentos de ensembles clássicos de partículas e, a partir de tais cálculos, o mencionado autor, ao estendê-los para a Mecânica Quântica, obteve uma generalização da equação de Schrödinger, por meio de um sistema de equações não-lineares mostrando, também, ser possível usar a mesma metodologia e obter uma generalização não-linear para a equação de Dirac da Teoria Quântica relativística. Este trabalho, publicado na revista Nuovo Cimento, em 1954, tem sido um dos possíveis exemplos que influenciaram a discussão sobre a relação entre a Mecânica Quântica e os problemas da não-linearidade.

Bagchi (1980) em uma palestra proferida no Encontro Internacional sobre Equações de Evolução não-lineares e Sistemas Dinâmicos, realizado em Lecce, Itália, no período de 20 a 23 de junho de 1979, enfatiza que "Acredita-se geralmente que a física seja governada essencialmente por equações matemáticas não-lineares e toda medida implica numa interação não-linear." 
O mencionado autor chama a atenção de que, apesar disso, os físicos envolvidos com a Teoria Quântica ortodoxa (linear) ainda não tinham percebido, àquela época, as sérias dificuldades deste formalismo. Ele lembra que Heisenberg durante os seus últimos anos de vida tentou desenvolver uma teoria não-linear para as partículas elementares. De fato, ele se preocupou com o citado problema e afirmou que:

A conclusão atual é que não sabemos se finalmente o problema fundamental da teoria quântica de partículas elementares será um problema não-linear ou um problema linear [...] Finalmente, desejo enfatizar outra vez que o progresso da matemática não-linear, dos métodos de resolver equações não-lineares [...] pode ainda ser que cada tal problema seja individual e exija métodos individuais. Contudo, como eu disse, há definitivamente algumas características comuns e consequentemente se pode aprender comparando problemas não-lineares diferentes. (HEISENBERG, 1967)

Apesar de ter escrito tais asserções, Heisenberg afirma que não há dúvida sobre a linearidade intrínseca à Teoria Quântica convencional, pois, apesar das equações dos operadores serem não-lineares, é possível resolver a equação de Schrödinger da Mecânica Quântica não relativística a partir de certas transformações matriciais. $\mathrm{O}$ citado autor enfatiza que o caráter linear da mencionada Teoria Quântica não é aproximado, tal aspecto é fundamental para o entendimento de tal teoria e para a sua interpretação, que se fundamenta sobre uma base estatística, a fim de realizar cálculos em distintos sistemas quânticos. Em sua discussão, Heisenberg enfatiza que a linearidade na Teoria Quântica de Copenhague tem um caráter mais fundamental, quase filosófico, pois em tal teoria não se trabalha com fatos e sim com possibilidades, visto que o quadrado do módulo da função de onda de Schrödinger indica uma descrição probabilística e o princípio da superposição que envolve tal função é determinante para a fundamentação da referida teoria.

Apesar do sucesso da Mecânica Quântica linear em explicar vários fenômenos naturais, alguns problemas têm gerado controvérsias, a exemplo do dualismo onda-partícula, a relação entre determinismo e imprevisibilidade encontrada na teoria da medida. Nakamura (1994), na sua discussão sobre a caologia quântica, afirma que apesar do citado formalismo (linear) poder ser aplicável sem grandes modificações "a qualquer sistema seja ele classicamente regular ou caótico", surgem questões, a exemplo de: é possível obter-se o equivalente quantum-mecânico do caos apesar da linearidade da equação de Schrödinger dependente do tempo? 
O objetivo do presente trabalho é relembrar algumas contribuições que têm estimulado o debate em torno de possibilidades e dificuldades que envolvem a relação entre a Teoria Quântica e os sistemas não-lineares. Trata-se, portanto, de sumariar, num breve roteiro histórico, as principais contribuições a este novo ramo de pesquisa, o qual apesar de sua notória importância, ainda desperta certa expectativa na comunidade dos pesquisadores em Física, Filosofia, História da Ciência e Matemática.

\section{Dificuldades}

Apesar de Heisenberg (1967) ter afirmado que "todo problema em física teórica é governado por equações matemáticas não-lineares exceto a teoria quântica," ele ainda, no mesmo texto, afirmaria que era uma questão controvertida se tal teoria era linear ou não-linear. A questão da não-linearidade na Mecânica Quântica foi uma das grandes preocupações do príncipe francês Louis de Broglie que, ao introduzir, em 1927, a "teoria da dupla solução", que não discutiremos neste trabalho, enfatizaria que a equação de Schrödinger, da Mecânica Quântica linear, apresenta dois tipos diferentes de soluções. Neste formalismo, a função de onda $\Psi$ tem caráter estatístico e ao lado desta solução contínua e "fictícia" existiria também uma outra solução que envolve singularidades (ondas u) que, segundo de Broglie, descreveria a realidade física. (DE BROGLIE, 1953, 1956; RIBEIRO FILHO, 2000; RIBEIRO FILHO; VASCONCELOS, 2006) Em 1953, ao reexaminar tais ideias de Broglie escreveu "[...] que a verdadeira equação de propagação para a onda-u deve ser não-linear como são aquelas encontradas na teoria da gravitação de Einstein. (DE BROGLIE, 1953, p. 226)

De Broglie $(1953,1956)$ afirma que a citada onda-u satisfazia a uma indeterminada equação não-linear. Ele então conjecturou uma "teoria ondulatória não-linear", sem contudo escrever a equação diferencial não-linear para a citada onda. Para Xiao-Feng e Yuan-Ping (2005) tal teoria apresenta sérias dificuldades em descrever sistemas de muitas partículas, além de não ter verificação experimental. Apesar do apoio de Einstein, a citada teoria de de Broglie não recebeu o apoio da comunidade dos físicos, entretanto, algumas das ideias do príncipe francês tornaram-se fontes de inspiração para outros pesquisadores, a exemplo de equação não-linear para descrever uma partícula física, potencial quântico etc.

Weinberg $(1984,1989)$, em uma série de trabalhos, introduziu um formalismo matemático a fim de testar a teoria quântica linear, experimentalmente, ao introduzir correções não-lineares à mencionada teoria. O citado autor desenvolveu uma teoria generalizada da Mecânica Quântica, a qual se reduz à Mecânica 
Quântica linear quando alguns parâmetros utilizados na citada formulação tornam-se muito pequenos. Nesta formulação, as equações que determinam a dependência temporal da função de onda não são lineares, mas são do tipo hamiltoniano. Outro aspecto importante é que as funções de onda que se diferenciam por um fator constante representam o mesmo estado do sistema físico e satisfazem às mesmas equações dinâmicas de movimento.

Weinberg chama a atenção sobre as dificuldades de se encontrar generalizações logicamente consistentes para a Mecânica Quântica linear. Para o citado autor, um possível aspecto a ser generalizado é a linearidade do formalismo ortodoxo, entretanto, a simples adição arbitrária de termos não-lineares à equação de Schrödinger poderia criar dificuldades na interpretação física da nova teoria. Enfim, esta formulação tem por objetivo generalizar a Mecânica Quântica linear, a fim de usá-la em testes experimentais e para isso o princípio da superposição (linear) não é considerado. Em síntese, similarmente à Teoria Quântica linear, Weinberg define o estado quântico, $\Psi$, como o vetor pertencente a um espaço vetorial complexo e as observáveis quânticas por transformações, em geral, não-lineares. Com referência à interpretação física da teoria, ela surge quando a condição de autovalores é satisfeita: "quando um estado tem um valor definido para alguma observável”. Neste formalismo, as observáveis são representadas por funções não bilineares reais $b\left(\psi, \psi^{*}\right)$, as quais são interpretadas em termos de valores esperados, sendo que tais funções devem ser homogêneas de grau um em ambas $\psi \mathrm{e} \psi^{*}$. De fato, as citadas funções ("sem uma condição de realidade") formam uma álgebra, em que : (\#) $(\mathrm{b}+\mathrm{c})\left(\psi, \psi^{*}\right)=\mathrm{b}\left(\psi, \psi^{*}\right)+\mathrm{c}\left(\psi, \psi^{*}\right) ;(\# \#)(\beta \mathrm{b})\left(\psi, \psi^{*}\right)=$ $\beta \mathrm{b}\left(\psi, \psi^{\star}\right), \operatorname{com} \beta$ sendo um escalar complexo e, finalmente, a multiplicação entre as funções b e c, ou seja, $b^{*} c$ correspondem a uma generalização da multiplicação matricial na Mecânica Quântica linear.

A contribuição de Weinberg foi objeto de uma breve discussão de Polchinski (1991) que analisou a "mecânica quântica não-linear de Weinberg" em relação ao papel desempenhado na citada teoria pelo paradoxo Einstein-Podolsky-Rosen (EPR). Para o mencionado autor, o fato de nesta nova teoria existirem observáveis não-lineares, além de lineares, cria, do ponto de vista heurístico, a possibilidade de se obter, neste formalismo, mais informação na função de onda do que na Teoria Quântica convencional. Polchinski (1991) conjectura que

[...] aumenta a possibilidade que a violação fictícia da localidade, que ocorre no experimento de EinsteinPodolsky-Rosen (EPR) na mecânica quântica linear pode tornar-se uma violação real na teoria não-linear. Ou seja, o apparatus EPR poderia ser usado para enviar sinais instantâneos. 
Peres (1989), ao discutir a mencionada teoria de Weinberg, enfatiza não ser difícil introduzir variantes não-lineares na equação de Schrödinger, porém ele mostra que tais não-linearidades conduzem à violação da segunda lei da termodinâmica. Weinberg argumenta que:

Parece-me que esta é uma definição não apropriada da entropia em tais teorias generalizadas. Os argumentos de von Neumann, citados por Peres, são estabelecidos no contexto da mecânica quântica linear ordinária [...]. (PERES, 1989)

Czachor e Doebner (2002), calculando funções de correlação para muitas partículas na Mecânica Quântica não-linear, afirmam que:

[...] a dinâmica de estados exatamente linear é uma raridade na física. Teorias lineares são em geral aproximações para aquelas não-lineares. A exceção é a mecânica quântica [...]

Apesar de tal asserção os mencionados autores perguntam, em seu trabalho, se "é possível construir uma teoria quântica não-linear consistente que contenha a mecânica quântica como um caso especial?"

Eles concluem que tais extensões da Mecânica Quântica não são simples, pois as equações não-lineares de Schrödinger e de von Neumann podem ser justificadas mas não parecem ser permitidas na interpretação ortodoxa, bem como ainda não é clara uma interpretação probabilística para os operadores não-lineares.

\section{Matemática não-linear}

Henri Poincaré (2008) em explanação sobre

[...] as relações entre a física experimental e a física-matemática", ao discutir o papel da experiência e de sua generalização enfatiza que "a física-matemática existe e tem prestado serviços inegáveis: aí está um fato que é necessário explicar [...] É que não basta observar, é necessário nos servir de nossas observações; para tanto, é preciso generalizar [...].

Além do mencionado matemático e pensador francês, outras figuras marcantes da história da Física e da Matemática têm se envolvido no longo debate em torno das ligações entre estes dois campos do saber. A partir do século XVII, com Galilei, a Matemática foi apresentada como sendo uma linguagem apropriada para expressar as leis da natureza. Ribeiro Filho e Vasconcelos (2006), discutindo alguns aspectos matemáticos em sistemas não-lineares, na Mecânica Quântica e 
na Mecânica Clássica, relembram que, apesar dos grandes êxitos alcançados pela física-matemática na contemporaneidade, muitos autores apresentaram críticas, ao processo de matematização das teorias fisicas. Paty (1995), ao relembrar as contribuições de dois pensadores franceses a este debate, chama a atenção que o filósofo René Descartes enfatizava que a Matemática "só trata de coisas muito simples e muito gerais, sem se preocupar muito se elas estão ou não na natureza". Sobre o mesmo tema, Poincaré exclamava: "o que ela [Matemática] ganhou em rigor, perdeu em objetividade. Foi distanciando-se da realidade que ela adquiriu essa pureza perfeita".

Claro está que outros autores também se manifestaram sobre a utilização da Matemática à Física, porém, não sendo possível enumerá-los no presente trabalho, é importante enfatizar que é possível, por distintas maneiras, trabalhar matematicamente os distintos sistemas físicos, em particular os sistemas nãolineares, desde os modelos fenomenológicos, a partir de dados empíricos, até a formulação axiomática da teoria. Enfim, a exemplo de outros ramos da Física, a denominada Física não-linear tem se utilizado de novos métodos matemáticos, a fim de reproduzir teoricamente os resultados experimentais, os quais, além de busca de um melhor entendimento sobre os aspectos fenomenológicos, têm despertado o interesse de matemáticos, físicos e outros pesquisadores.

Uma das grandes descobertas da denominada Matemática não-linear foi aquela que envolveu o surgimento das ondas solitárias, pelo físico e engenheiro escocês John Scott Russell que, em 1834, observou pela primeira vez um tipo de onda que além de ser não-linear era também não dispersiva. Além de divulgar aquele aparecimento e tentar reproduzi-la em laboratório, o mencionado cientista estava introduzindo um dos objetos mais marcantes da física-matemática moderna. Ainda no final do século XIX, os holandeses Korteweg e De Vries (1895) conseguiram desenvolver os aspectos fundamentais das equações de derivadas parciais, denominadas de equações $\mathrm{KdV}$, as quais apresentam soluções do tipo ondas solitárias. Este trabalho ensejou um grande avanço na Matemática nãolinear e em estudos de hidrodinâmica. Fermi, Pasta e Ulam (1955) marcaram a história dos sistemas não-lineares ao estudarem um sistema de osciladores nãolineares, o qual despertou a comunidade dos físicos para o estudo desse tipo de sistema. Outras contribuições fundamentais para a matematização de sistemas não-lineares foram apresentadas por Perring e Skyrme (1962) que conseguiram obter, numericamente, soluções solitônicas da equação de seno-Gordon (ou equação de Klein-Gordon não-linear ou equação do pêndulo matemático). Estas soluções mantêm, antes e após uma colisão, a mesma forma e velocidade e receberam esta denominação, a partir do trabalho de Zabulsky e Kruskal (1965), em torno da família de equações de KdV. As ondas solitônicas ao lado de soluções cnoidais e demais soluções "elípticas" têm sido utilizadas bastante nos problemas não-lineares. (TORRIANI, 1986) 
De Broglie $(1953,1956)$ e Heisenberg (1967) conjecturaram a necessidade do surgimento de novos métodos matemáticos, a fim de enfrentar as dificuldades de problemas que ligam a teoria quântica e a não-linearidade. Nas últimas décadas, surgiram novos métodos de resolução de equações diferenciais parciais não-lineares, envolvendo as mencionadas soluções solitônicas, a partir do método do espalhamento inverso e outros. Muitos pesquisadores aplicaram tais soluções solitônicas ao problema das ondas de de Broglie da Teoria Quântica, originando novas questões sobre a fenomenologia das ondas de matéria, o mesmo acontecendo com o emprego de tais soluções na equação de Schrödinger não-linear. (BABY; BARUT, 1988)

Croca, no livro Towards a nonlinear quantum physics, apresenta uma epistemologia causal local, que não discutiremos aqui, como uma alternativa mais geral à Teoria Quântica de Copenhague e, para isso, utiliza uma análise local por ondaletas (wavelets). $\mathrm{O}$ citado autor acredita, com o seu formalismo, que:

Finalmente, é possível responder, agora, no referencial de uma epistemologia local, a velha questão de como conciliar as duas aparentemente contraditórias propriedades exibidas pelas entidades quânticas. Essas duas características opostas resultam dos fatos conhecidos que em certos experimentos aquelas estranhas entidades quânticas comportam-se como onda ou como corpúsculos [...]. (CROCA, 2003)

Recentemente, Araújo e colaboradores (2009) têm publicado uma série de trabalhos em que apresentam uma análise apoiada no formalismo das ondaletas (ou onduletas), em lugar da análise de Fourier utilizada na Teoria Quântica ortodoxa. Estes autores têm sugerido que, com as citadas transformações, eles têm conseguido derivar relações mais abrangentes, as quais apresentam as relações de Heisenberg como sendo casos particulares. Em síntese, esses pesquisadores afirmam ter encontrado uma alternativa não-linear causal e local para o formalismo quântico, em que é assumido um "novo compromisso ontológico, isto é, a existência de uma realidade independente do observador", e para isso é postulado, em vez da Equação de Schrödinger uma Equação Mestra Não-linear.

\section{Possibilidades}

Apesar de várias dificuldades, outras contribuições para o tópico da Mecânica Quântica versus não-linearidade têm sido descritas na literatura, porém aquela que parece singularizar-se é o formalismo introduzido por Xiao-Feng e YuanPing. Estes autores definem a Mecânica Quântica não-linear como sendo uma teoria para estudar as propriedades e o movimento de partículas microscópicas 
em sistemas não-lineares que exibam características quânticas. Eles a distinguem da Mecânica Quântica ortodoxa de Copenhague, ligada ao mesmo objetivo, porém, em sistemas lineares.

A descoberta de vários fenômenos quânticos não-lineares, a exemplo de movimentos de solitons ou ondas solitárias, alguns efeitos quânticos macroscópicos, em superfluidos, supercondutores, fibras ópticas, macromoléculas, sistemas biológicos e outros, subentendem a necessidade de uma teoria alternativa à Mecânica Quântica linear, pois ela não pode explicar satisfatorimente os resultados experimentais de tais sistemas. A partir dos avanços da Matemática não-linear, estes autores conseguiram introduzir um formalismo, sem contudo seguirem a trilha indicada por de Broglie, já mencionada antes, neste trabalho. Alguns efeitos quânticos macroscópicos, que ocorrem em alguns sistemas supercondutores e superfluido, e que são exemplos de sistemas não-lineares, motivaram esta nova formulação. Os mencionados autores indicam que a fundamentação experimental da Mecânica Quântica não-linear estabelecida por eles são os efeitos quânticos macroscópicos e os denominados efeitos coerentes. Muitos desses efeitos ocorrem em sistemas com estados coerentes, estados condensados tipo Bose, que "são formados através de transições de fase após uma quebra de simetria espontânea nos sistemas por meio de interações não-lineares".

Xiao-Feng e Yuan-Ping têm publicado intensamente sobre tais questões envolvendo a Mecânica Quântica em tais sistemas, entretanto, eles reconhecem que a Mecânica Quântica linear é muito importante, pelos seus êxitos, em interpretar inúmeros fenômenos, por ser bastante elegante e por possuir muitas vantagens analíticas na sua estruturação matemática. Para esses autores, as duas teorias (linear e não-linear) são totalmente distintas, pois a teoria proposta por eles estuda as propriedades e o movimento de micropartículas em sistemas nãolineares (que exibem características quânticas), em que tais partículas tornam-se self-localized particles ou solitons, sob a ação da interação não-linear.

Na formulação de Xiao-Feng e Yuan-Ping as partículas microscópicas em um sistema quântico não-linear são descritas por uma função de onda, em que a amplitude e a fase são funções do espaço e do tempo. Esta função, no caso não relativístico, satisfaz à equação generalizada de Schrödinger não-linear. No caso em que são considerados efeitos relativísticos, a função de onda satisfaz à equação de Klein-Gordon não-linear ou equação de seno-Gordon não-linear, cujas soluções podem ser do tipo solitônicas. Em síntese, neste formalismo a função de onda representa um soliton ou onda solitária que, em geral, é não-linear e não dispersivo. $\mathrm{O}$ conceito de operador permanece na teoria não-linear, entretanto ele é um objeto não-linear. 


\section{Conclusões}

Apesar do sucesso da Teoria Quântica linear, na resolução de inúmeros fenômenos naturais, algumas dificuldades enumeradas por distintos pesquisadores, sobre alguns de seus aspectos fundamentais, têm motivado a busca de alternativas para a melhor elucidação de alguns resultados experimentais. Como já mencionamos neste trabalho, a discussão em torno de tentativas para o estabelecimento de extensões não-lineares à teoria ortodoxa, ou seja, à Mecânica Quântica linear, não tem sido simples. Apesar disso e das controvérsias, o que se nota é que tais discussões não podem ser descartadas, em vista de evidências experimentais que apontam a necessidade de se procurar uma explicação teórica para tais fenômenos não-lineares. Neste trabalho, fizemos um sumário sobre algumas contribuições que marcaram a história da Física Quântica, a partir da contribuição de de Broglie, até aquelas mais recentes, em que a definição de outros objetos matemáticos - a exemplo de soluções solitônicas para as equações diferenciais da teoria, ondaletas e transformações não-lineares - tem motivado alguns pesquisadores na busca de elucidar o embasamento físico-matemático de alguns sistemas nãolineares. O que se pode verificar é que não há, ainda, uma concordância plena sobre a ligação entre a Mecânica Quântica e a não-linearidade. Esta constatação deve ser vista como estimuladora para a busca de futuras soluções para este quase enigma da Física Quântica.

\section{Referências}

ARAÚJO, T. et al. Ontologia de Fourier, análise local por onduletas e física quântica, pré-print. Lisboa: Centro de Filosofia das Ciências da Universidade de Lisboa, 2009.

BABY, B. V.; BARUT, A. O. Nonlinear de Broglie waves I: on nonlinear equation admitting soliton with a de Broglie phase. Trieste, Italy: International Centre for Theoretical Physics, 1988. p. 1-20. IC/88/163. Disponível em: <http://streaming. ictp.trieste.it/preprints/P/88/162.pdf>

BAGCHI, S. N. Fundamental equations of classical and of quantum physics as special cases of a nonlinear equation. In: BOITI, M.; PEMPINELLI, V.; SOLIUNI, G. (Ed). Nonlinear evolution equations and dynamical systems. Berlin: Springer, 1980. p. 358-398, 1980. (Lecture Notes in Physics, 120).

BASTIN, Ted (Ed.). Quantum Theory and Beyond. Cambridge: Cambridge University, 1971. p. 275-282. 
CROCA, J. R. Towards a nonlinear quantum physics. London: Wortld Scientific, 2003.

CZACHOR, Marek; DOEBNER, H.-D. Correlation experiments in nonlinear quantum mechanics. Phys. Letters A, v. 301, p. 139-152, 2002.

DE BROGLIE, Louis. Nonlinear wave mechanics: a causal interpretation. Amsterdam: Elsevier, 1960.

. The revolution in physics: a non-mathematical survey of quanta. Tradução de R. W. Niemayer. New York: Noonday, 1953. Tradução de La Physique Nouvelle et les Quanta.

. Une tentative d'interpretation causale et non linéaire de la mécanique ondulatoire: la théorie de la double solution. Paris. Gauthier-Villars, 1956.

FERMI, E.; PASTA, J. R.; ULAM, S. M. Studies of Nonlinear Problems. Los Alamos Sci. Lab. Rep., LA-1940, 1955. Later published in Collected Papers of Enrico Fermi, edited by E. Segre, University of Chicago Press, 1965. v. 2, p. 978.

FINK, J. M. et al. Climbing the Jaynes-Cummings ladder and observing its $\mathrm{n}^{1 / 2}$ nonlinearity in a cavity QED system. Nature, v. 454, p. 315-318, 2008.

FOKAS, A. S.; SUNG, L.-Y. Generalized Fourier Transforms, their Nonlinearization and the Imaging of the Brain. Notices of the AMS, v. 52, n. 10, p. 1178-1192, 2005.

HEISENBERG, Werner. Nonlinear Problems in Physics. Physics Today, New York, v. 20, n. 5, p. 27-32, may 1967.

KORTEWEG, D. J.; DE VRIES, C. On the change of form of long waves advancing in a rectangular channel, and on a new type of long stationary waves. Phil. Magazine, London, v. 39, n. 5, p. 442-443, 1895.

LIMA, João Paulo Camargo de. Processos de relaxação em sistemas quânticos e álgebras de operadores não-lineares. 2006. Tese (PhD) - Universidade federal de São Carlos. São Carlos (SP).

NAKAMURA, Katsuhiro. Quantum chaos: a new paradigm of nonlinear dynamics. Cambridge: Cambridge University, 1994.

PATY, Michel. A matéria roubada: A apropriação crítica do objeto da física contemporânea. Tradução: Mary Amazonas Leite de Barros. São Paulo: Edusp, 1995.

PERES, Asher. Nonlinear variants of Schrödinger equation violate the second law of thermodynamics. Phys. Rev. Letters, v. 63, n. 10, 1989. 
PERRING, J. K.; SKYRME, T, H. R. A model unified field equation. Nuclear Phys. New York, v. 31, p. 550-555, 1962.

POINCARÉ, H. Ensaios fundamentais. Tradução Vera Ribeiro. Rio de Janeiro: Contraponto: PUC-Rio, 2008.

POLCHINSKI, Joseph, Weinberg's nonlinear quantum mechanics and the Einstein-Podolsky-Rosen paradox. Phys. Rev. Letters, v. 66, n. 4, p. 397-400, 1991.

POST, R. H. The incompleteness of quantum mechanics or the emperor's missing clothes. In: BASTIN, Ted (Ed.). Quantum Theory and Beyond. Cambridge: Cambridge University, 1971. p. 275-282.

RIBEIRO FILHO, Aurino. Ondas de De Broglie e não-linearidade. In: PESSOA JR., O. (Org.). Fundamentos da Física I - Simpósio David Bohm. São Paulo: Livraria da Física, 2000. p. 79-83.

RIBEIRO FILHO, Aurino; VASCONCELOS, D. S. de. Aspectos matemáticos em sistemas não-lineares na mecânica quântica e mecânica clássica modernas. Caderno de Ciências Humanas - Especiaria, v. 9, n. 16, 2006, p. 397-410.

RUSSELL, J. Scott. Report on waves. Rep. 14th Meet. British Assoc. Adv. Sci., Edinburgh, p. 311-390, 1844.

SCHÖNBERG, Mário. A Nonlinear generalization of the Schrödinger and Dirac equations. Il Nuovo Cimento, v. 11, n. 6, 1954.

TORRIANI, H. H. Espalhamento inverso e métodos de hirota: alguns aspectos clássicos. São Paulo: IME-USP, 1986.

WEINBERG, Steven. Precision tests of quantum mechanics. Phys. Rev. Letters, v. 62, n. 5, p. $485-488,1989$.

336-386, 1984.

. Testing quantum mechanics. Annals of Physics, New York, v. 194, p.

. Weinberg replies. Phys. Rev. Letters, v. 63, n. 10, p. 1115, 1989.

XIAO-FENG, Pang; YUAN-PING, Feng. Quantum mechanics in nonlinear systems. Singapore: World Scientific, 2005.

ZABUKSKY, N.; KRUSKAL, M. Interaction of solitons in a colisionless plasma and the recurrence of initial states. Phys. Rev. Lett., New York, v. 15, p. 240-243, 1965. 


\title{
Ontologia de Fourier, análise local por onduletas e Física Quântica
}

\author{
João Araújo \\ João Cordovil \\ José Ramalho Croca \\ Rui Nobre Moreira \\ Amaro Rica da Silva
}

\section{Breve nota sobre a complementaridade}

Em linhas gerais, no plano teórico da Física clássica, imperam duas imagens dissimilares, a onda e o corpúsculo. Uma onda pode ser definida como uma flutuação num meio e associadas a ela estão noções como o comprimento de onda, frequência de vibração e interferência. Por outro lado, na Física clássica, um corpúsculo pode ser reduzido a um ponto, correspondendo ao seu centro de massa, sobre o qual se associam noções como as de posição, momento linear e trajetória. À onda, liga-se a noção do contínuo; ao corpúsculo, a do discreto. Um exemplo de objeto físico estudado a partir da concepção ondulatória seria a luz visível. No caso corpuscular, pode-se referir às bolas de uma mesa de bilhar. Enquanto os fenômenos ondulatórios são descritos eficazmente pelo Eletromagnetismo de Maxwell, os fenômenos corpusculares são descritos eficazmente pela Mecânica Newtoniana.

Assim, no contexto acima descrito, a partir do momento em que se estuda um determinado sistema físico, geralmente tem-se em mente essas distinções e identifica-se o plano teórico a ser utilizado na abordagem do problema. No caso de se estar envolvido com o estudo de corpúsculos, por exemplo, pode-se modificar o sistema das maneiras mais variadas possíveis, sem que nada ponha 
em dúvida o plano teórico a ser utilizado․․ Isso significa que, classicamente, um objeto físico comporta-se como uma onda ou como um corpúsculo, nunca como ambos, simultaneamente. Além disso, após a identificação de uma das concepções, não se faz necessário considerar a outra ao se estudar, futuramente, os fenômenos envolvendo aquele mesmo objeto físico.

Entretanto, no nível dos fenômenos da Física Quântica² ${ }^{2}$ o panorama clássico acima delineado se altera radicalmente ${ }^{3}$. É bem sabido que o edifício da Teoria Quântica ortodoxa, ou Escola de Copenhague, está fundamentado, sobretudo no pensamento de Niels Bohr, expresso pelo princípio da complementaridade. (JAMMER, 1974) No tipo de complementaridade onda/corpúsculo, a descrição de um sistema envolvendo uma mesma entidade quântica invoca as duas imagens clássicas de forma excludente, porém complementar. Ou seja, as imagens onda e corpúsculo são necessárias quando se estuda os mesmos objetos quânticos em situações distintas. Assim, diferentemente da Física Clássica, onde geralmente pode-se sugerir que um objeto físico tenha uma essência de onda ou de corpúsculo, quanto ao objeto quântico somos confrontados com um dilema: a dualidade onda/corpúsculo. Matematicamente, estas noções conceituais encontraram uma correspondência com a Análise de Fourier, cujo formalismo incorpora resultados fundamentais para a Teoria Quântica Ortodoxa, nomeadamente as conhecidas Relações de Heisenberg.

\section{Análise de Fourier, Teoria Quântica ortodoxa e relações de Heisenberg}

Em abril de 1928, Niels Bohr publicou um artigo em que deixou sutilmente marcada a importância que a Análise de Fourier tem para a Teoria Quântica ortodoxa. Naquele artigo, inicialmente, Bohr recorreu às fórmulas fundamentais da teoria dos quanta de luz (Relação de Planck) e das partículas materiais (Relação de Louis De Broglie):

$$
E \tau=p \lambda=\mathbf{h}
$$

1 Obviamente que a mudança deve ser realizada sob condições normais, de modo a preservar a identidade do corpúsculo.

2 Como se sabe, ao se considerar um mesmo objeto, como a luz, por exemplo, verifica-se uma ambiguidade. A experiência do Efeito Fotoelétrico deixa marcadamente ressaltada a necessidade de uma descrição teórica que leva em conta os aspectos corpusculares da luz, enquanto a experiência da Fenda Dupla somente é adequadamente descrita, via as considerações dos aspectos ondulatórios.

3 Consulte, por exemplo, Andrade e Silva (1995) e Pessoa Jr. (2005). 
onde $h$ denota a constante de Planck; $E$ e $p$ são a energia e o momento linear; $\tau$ e $\lambda$ são o período de vibração e o comprimento de onda. ${ }^{4}$ Partindo desta fórmula, Bohr destacou a relação complementar entre os aspectos corpusculares e ondulatórios ao ter afirmado que:

In these formulae the two notions of light and also of matter enter in sharp contrast. While energy and momentum are associated with the concept of particles, and hence may be characterized according to the classical point of view by definite space-time co-ordinates, the period of vibration and wave-length refer to a plane harmonic wave train of unlimited extent in space and time. (BOHR, 1928, p. 581)

Após referir os tijolos básicos da Análise de Fourier, isto é, as ondas planas harmônicas monocromáticas, Bohr começa a refletir sobre o problema da extensão infinita de tais objetos no espaço. Assim, indica o princípio da superposição com o objetivo de compor um pacote de ondas ou, segundo a sua terminologia, um campo de ondas (wave fields). Um pacote de ondas, então, seria uma representação matemática de uma "entidade quântica". A ideia que se quer deixar sublinhada aqui é a de que, para além do seu processo estritamente matemático de composição e decomposição de funções, a Análise de Fourier, na Teoria Quântica ortodoxa, foi promovida por Bohr a um estatuto ontológico com profundas implicações para a Física. Por isso, sugere-se chamar a concepção aqui envolvida por ontologia de Fourier. Este resultado importante torna-se claro no artigo mencionado, quando é considerada, como exemplo, a seguinte onda elementar:

$$
A \operatorname{Cos}\left[2 \pi\left(v t-x k_{x}-y k_{y}-z k_{z}+\delta\right)\right]
$$

onde $A$ e $\delta$ são a amplitude e a fase inicial da onda respectivamente, $\mathrm{v}=\frac{1}{\tau}$ é a frequência e $k_{x}, \mathrm{k}_{y}, \mathrm{k}_{z}$ são as frequências espaciais ${ }^{5}$ na direção dos eixos de coordenadas. Assim, mais adiante à fórmula (2.2) Bohr prossegue no artigo com a afirmação enfática: Rigorously speaking, a limited wave-field can only be obtained by the superposition of a manifold of elementary waves corresponding to all values of $v$ and $\sigma_{x^{\prime}}, \sigma_{y}, \sigma_{z}$ (BOHR, 1928, p. 581). Ou seja, dizer que, rigorosamente, as já mencionadas ondas elementares, e somente elas, são o caminho de se obter um pacote de ondas, é equivalente a afirmar que, nessa abordagem, as ondas planas harmônicas são as únicas que podem ter uma frequência pura (frequência espacial $k$ e frequência temporal $v$ ).

4 No artigo original, Bohr adotou a notação $l$ para referir o momento linear.

5 No artigo, Bohr denotou as frequências espaciais por $\sigma_{x^{\prime}} \sigma_{y^{\prime}}, \sigma_{z}$ e as chamou de números de onda. 
Para a representação de uma certa "entidade quântica" (ver Figura 1, à direita), utiliza-se uma sobreposição de várias ondas planas, associadas a uma certa distribuição para a frequência espacial $k$. Formalmente, uma tal composição é descrita através de uma integral (um tipo especial de soma), envolvendo vários valores da frequência espacial $k$. Esta integral representa o que se costuma chamar por Transformada de Fourier e permite realizar uma correlação entre o espaço físico em questão (variável $x$ ) e o espaço de Fourier (variável $k$ ). Ou seja, a Transformada de Fourier e a Transformada Inversa de Fourier realizam uma correlação entre os pares de variáveis conjugadas $x$ e $k$. O esquema a seguir pretende sintetizar esta noção, ou seja, a passagem recíproca de um espaço para o outro.

Espaço de Fourier $(\boldsymbol{k}) \stackrel{\text { Transformada de Fourier }}{\longrightarrow}$ Espaço Físico $(\boldsymbol{x})$

Espaço Físico $(x) \stackrel{\text { Transformada Inversa de Fourier }}{\longrightarrow}$ Espaço de Fourier (k)
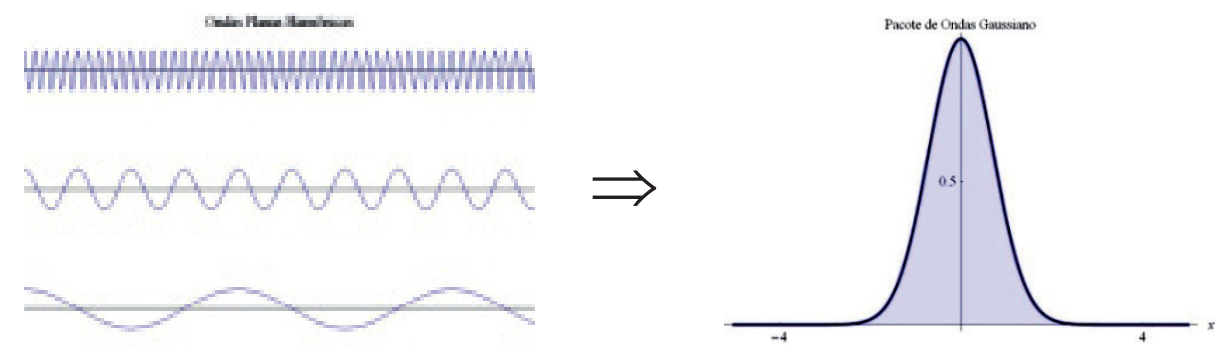

Figura 1 - Esboço gráfico explicitando a relação entre um pacote de ondas localizado e as suas ondas planas harmônicas constituintes.

Além do caráter não-local do formalismo, uma outra sutileza merece ser contrastada com o senso comum clássico. A cada uma das ondas planas harmônicas da Figura 1 à esquerda, está associada uma energia (ver as fórmulas 2.1 e 2.2). Portanto, como um pacote de ondas enfeixa uma multiplicidade de ondas elementares, ele terá uma multiplicidade de energias. Mais uma vez, ao se tentar interpretar as consequências disso através de uma concepção realista clássica, acaba-se por pensar uma "entidade quântica" como um objeto ao qual está associada, num mesmo instante, uma infinidade de energias.

Feitas essas breves notas sobre algumas das implicações a que o pensamento da Escola de Copenhague pode conduzir, um último resultado fundamental deve ser incisivamente vincado: as chamadas Relações de Heisenberg. É bem sabido que tais relações se apresentam na forma de desigualdade (fórmula 2.5) e que a sua 
derivação relaciona-se com a Transformada de Fourier. No caso em que se supõe uma distribuição gaussiana para as frequências espaciais $k$, a relação encontra o seu valor mínimo. Ou seja, a Transformada de Fourier de uma Gaussiana é também uma Gaussiana. Em consequência desse resultado, encontra-se uma relação para a largura a meia altura da distribuição nos espaços envolvidos dada a seguir:

$$
\Delta x=\frac{1}{\Delta k} \Rightarrow \Delta x \Delta k=1
$$

A síntese e a análise da Transformada de Fourier explicitam uma reciprocidade entre as larguras das representações funcionais nas variáveis conjugadas $x$ e $k$. Este exemplo simples refere-se ao caso particular ideal da distribuição gaussiana. Na versão geral das relações de Heisenberg tem-se:

$$
\Delta x \Delta k \geq 1
$$

Se a relação de Louis De Broglie (2.1) for utilizada em $\Delta k$, obtem-se uma relação com o momento linear associado à direção $x$. A inequação (2.5) define uma fronteira abaixo da qual não há, teoricamente, valores simultâneos permitidos (ver Figura 2). Ou seja, não se consegue ter uma previsão teórica simultaneamente de um resultado que será obtido por uma futura medição sobre a posição e a velocidade de uma partícula, com uma precisão que se situe fora do Espaço de Heisenberg.

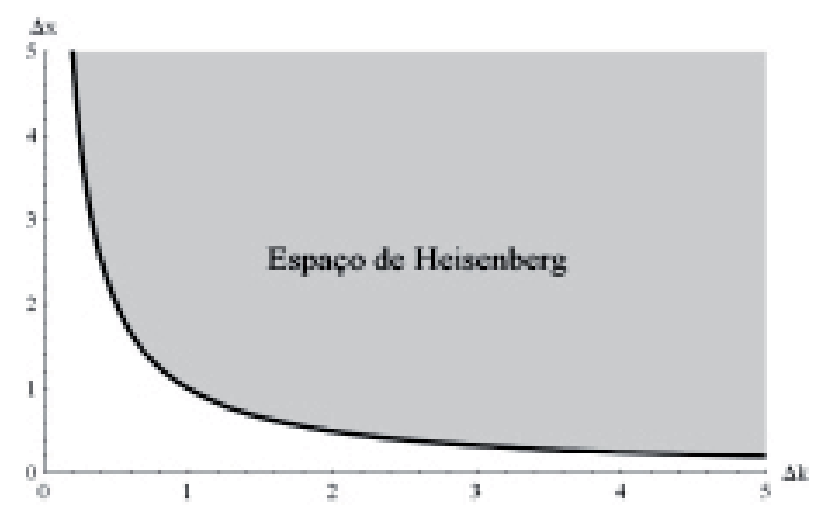

Figura 2 - Gráfico da relação $\Delta x=1 / \Delta k$ com destaque para a região em cinza definida por $\Delta x>1 / \Delta k$ A relação geral define o Espaço de Heisenberg. 


\section{A análise de onduletas}

Ao contrário da ontologia de Fourier, implicitamente assumida por Bohr (1928), será considerada, a partir desta seção, a descrição da Análise de Onduletas (CROCA, 2003). Com esta consideração, pretende-se atingir dois objetivos. Em primeiro lugar, utilizar uma abordagem não linear suportada na Análise de Onduletas. Em segundo, mostrar como tal descrição causal corresponde a toda uma nova concepção sobre a natureza dos objetos quânticos, inspirando-se, em parte, na Teoria da Dupla Solução de Louis De Broglie. Para além desta conexão histórica com a Teoria da Dupla Solução, a Análise de Onduletas é um instrumento formal poderoso que permite auxiliar no tratamento de uma Teoria Quântica Causal Não Linear. Esta descrição da realidade quântica é totalmente distinta da proposta causal, não local e linear, devida ao célebre físico David Bohm (1983). No caso da proposta de Bohm, o formalismo utilizado pressupõe a conhecida equação de Schrödinger, enquanto que na teoria causal e local a ser introduzida aqui a abordagem matemática se sustenta no pressuposto da não-linearidade.

O formalismo da Análise de Onduletas ganhou impulso na década de 1980, sendo utilizado na Geofísica como ferramenta teórica no auxílio à prospecção de petróleo. Este ramo da Matemática muito se alargou, tendo sido aplicado em uma enorme variedade de áreas e dispondo de redefinições e propriedades bastante específicas para cada caso. (CHUI, 1992; HUBBARD, 1998) É importante sublinhar que serão utilizadas aqui informações que se restringem aos objetivos traçados.

Em linhas gerais, uma onduleta é uma onda localizada. Como objeto matemático, caracteriza-se por parâmetros de dilatação e de translação, devendo cumprir com algumas restrições matemáticas. Fisicamente, tal objeto presume a existência de uma onda finita com uma frequência bem definida, diferentemente da Análise de Fourier, onde as ondas de frequências bem definidas são as ondas planas harmônicas monocromáticas, infinitas nos domínios espacial e temporal.

De forma a satisfazer os interesses aqui envolvidos, como exemplo de uma onduleta, será referida a Onduleta de Morlet. Entretanto, o raciocínio é extensivo para outros casos. A Onduleta de Morlet é caracterizada por uma frequência espacial $k_{0}$ e por uma largura, ou parâmetro de dilatação, $\sigma$. Em contraste com a Figura 1 à esquerda, que mostra três casos de ondas planas harmônicas, as representações da Figura 3 ilustram a parte real de algumas Onduletas de Morlet (isto é, para três casos da frequência $k_{0}$ ). 


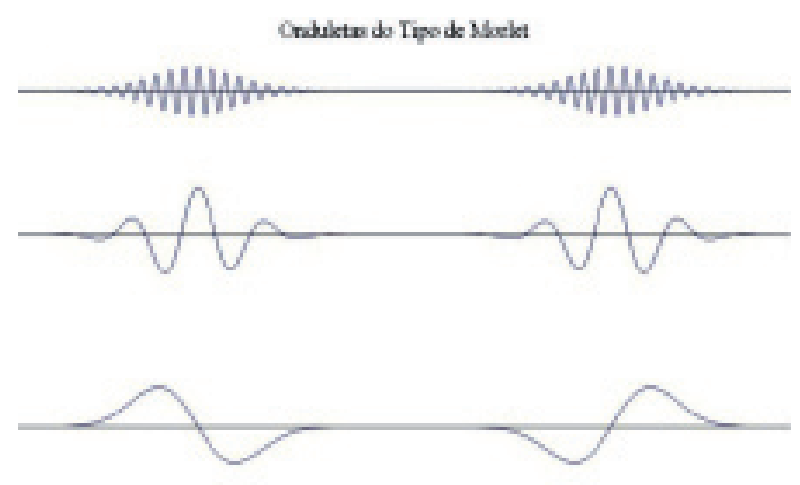

Figura 3 - Três gráficos da Onduleta de Morlet para valores distintos da frequência $k_{0}$.

Percebe-se com a Figura 3 um forte contraste com a ontologia de Fourier. Invocando novamente uma interpretação realista, desta vez para as onduletas, estas ferramentas matemáticas, por si sós, pretendem descrever alguns aspectos, de forma objetiva, característicos dos fenômenos quânticos. Contrariamente, na Análise de Fourier, um pacote de ondas, como propôs Bohr (1928), seria representado por uma superposição de infinitas ondas planas harmônicas. Dentre os aspectos caracterizadores das onduletas, fica explícita a localidade. É certo que existe uma região $\sigma$ dentro da qual a presença da onduleta é significativa. Entretanto, fora dessa região, referir uma não-localidade infinita como inerentemente a Análise de Fourier o faz, não tem, agora, qualquer sentido. Assim, a um deslocamento de tal entidade quântica, na concepção das onduletas, não há implicações no nível global do espaço (salvo o intervalo $\sigma$ onde a sua presença é significativa). Um outro contraste com a ontologia de Fourier diz respeito à energia associada a uma entidade quântica. Nela, um pacote de ondas se associa a uma infinidade de energias, cada qual relacionada com uma das suas ondas elementares constituintes. Na nova abordagem causal e não-linear, rompe-se com a ontologia de Fourier e assume-se que uma onda finita, a onduleta-mãe, pode ter uma energia bem definida.

Um resultado teórico fundamental deriva da propriedade de dilatação das onduletas, permitindo um relacionamento formal com as ondas planas harmônicas. Ou seja, quando $\sigma$, o parâmetro de dilatação, tende ao infinito, a Onduleta de Morlet tende a uma onda plana harmônica. Nesse sentido, pode-se pensar, formalmente, as ondas planas harmônicas como casos particulares das Onduletas de Morlet, no limite extremo $(\sigma \rightarrow \infty)$.

Efetivamente, em Análise de Onduletas se sobrepõe um conjunto de funçõesbase, ou seja, de onduletas-mãe. No presente caso, a base utilizada é composta 
por Onduletas de Morlet. Assim, enquanto no caso da Teoria Quântica ortodoxa tem-se uma sobreposição de ondas planas harmônicas, a formar um pacote de ondas, na Análise de Onduletas tem-se um conjunto de entidades localizadas num dado intervalo espacial (as Onduletas de Morlet), a formar um pacote de onduletas.

Na concepção da Transformada de Onduletas, tem-se nas mãos uma ferramenta, a fim de se descrever uma estatística para um ensemble de onduletas, condicionado a uma dada distribuição. Com o objetivo de realizar um estudo comparativo com os resultados obtidos pela Teoria Quântica ortodoxa ao representar o pacote de ondas, convém assumir ${ }^{6}$ a mesma distribuição gaussiana das frequências espaciais $g(k)$, caracterizada com uma largura a meia altura dada por $\Delta k$. Se isso for feito, em comparação com a expressão (2.4), obtém-se:

$$
\Delta x^{2}=\frac{\sigma^{2}}{\left(\Delta \mathrm{k}^{2} \sigma^{2}+1\right)} \Rightarrow \Delta x^{2}=\frac{1}{\left(\Delta \mathrm{k}^{2}+\frac{1}{\sigma^{2}}\right)}
$$

Essa expressão indica uma relação que contém, do ponto de vista formal, a Relação de Heisenberg como um caso particular. Contudo, do ponto de vista interpretativo, ambas as relações, (2.4) e (3.1), diferem bastante, como vem sendo exposto. Nota-se que quando o parâmetro de dilatação $\sigma$ da Onduleta de Morlet tende ao infinito, a relação entre $\Delta x$ e $\Delta k$ tende, formalmente, à Relação de Heisenberg. Um esboço claro desse resultado é mostrado nos gráficos a seguir (Figura 4):

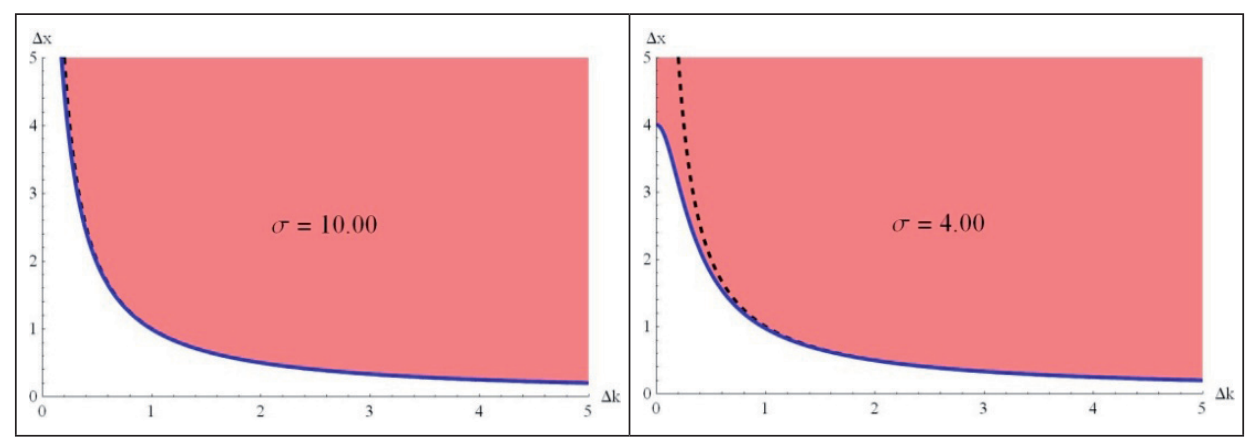

6 Outras generalizações podem ser encontradas em Croca (2003). 


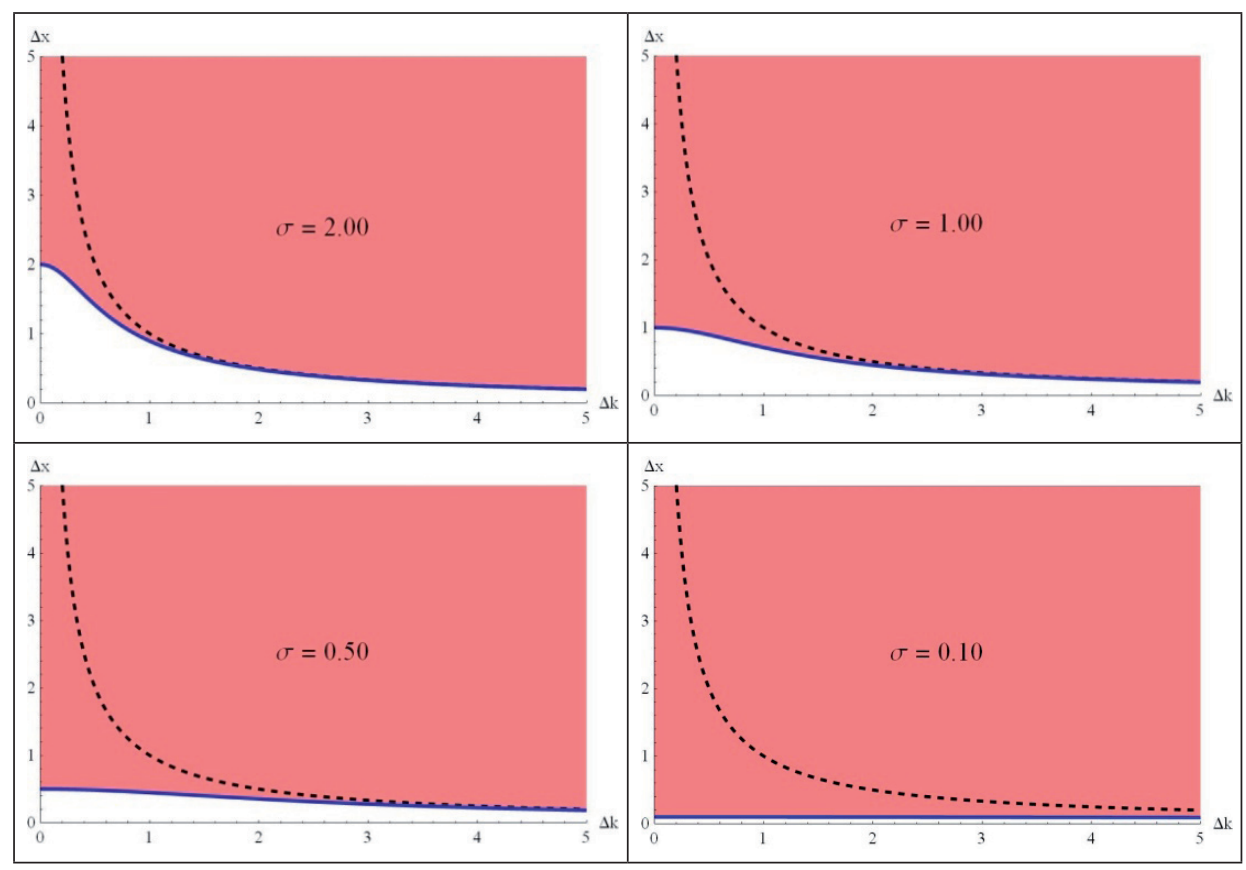

Figura 4 - Gráficos comparativos entre as Relações de Heisenberg (curva em pontilhado) e as relações mais gerais de incerteza (curva contínua).

Essa generalização permite obter uma nova previsão teórica para a distribuição das medidas sobre um conjunto de onduletas e que depende do tamanho $\sigma$ da respectiva Onduleta de Morlet utilizada (a onduleta-mãe). A nova previsão teórica preenche toda a região anteriormente proibida pelas Relações de Heinsenberg. Quanto menor for o tamanho $\sigma$ da onduleta-mãe, menor é a incerteza $\Delta x$ para qualquer valor de $\Delta k$. Na ontologia de Fourier, o limite na precisão de grandezas conjugadas não pode ser alterado, visto que se assume o formalismo da Análise de Fourier e das ondas planas harmônicas, que são independentes do parâmetro de dilatação $\sigma$. Esses resultados reforçam ainda mais o quão necessária é a Análise de Fourier dentro de todo o pensamento da Teoria Quântica Ortodoxa.?

7 A Análise de Onduletas, no contexto aqui exposto, foi apresentada pela primeira vez no formato de comunicação oral em Croca, J. R. On the uncertainty relations, comunicação ao International Symposium on Fundamental Problems in Quantum Physics, realizado em Oviedo (Espanha), em 1993. Em formato impresso, pode ser encontrado como primeiras publicações. (CROCA, 1999a, 1999b) 


\section{Uma alternativa não-linear}

Como foi visto na seção anterior, a descrição por ondas finitas, onduletas, conduz a uma mudança conceitual distinta daquela relacionada com a ontologia de Fourier proposta por Niels Bohr. Tal consideração implica na adoção de um novo compromisso ontológico e requer uma nova formulação, descontinuada do plano teórico da Teoria Quântica Ortodoxa. Serão apresentados aqui alguns aspectos gerais de um plano teórico alternativo àquele e que encontra um traço inicial comum com algumas ideias relacionadas à Teoria da Dupla Solução de Louis De Broglie (1964).

Como se sabe, o modelo causal para uma partícula quântica proposto por De Broglie é caracterizado por uma parte estendida, representando os aspectos ondulatórios, e por uma espécie de singularidade, representando os aspectos corpusculares. Neste ponto há uma distinção fundamental com relação à noção da complementaridade do tipo onda/corpúsculo desenvolvida por Bohr. Se naquela concepção, em última análise, um fenômeno seria corpuscular ou ondulatório, na concepção da Dupla Solução, em essência, um fenômeno apresenta um comportamento, simultâneo, ou seja, corpuscular $e$ ondulatório. Assim, pode-se sugerir que à perspectiva complementar de Bohr corresponderia uma perspectiva integrada de Louis De Broglie. Não faz parte deste artigo, porém, descrever em detalhes a Teoria da Dupla Solução. A sua citação aqui tem uma importância histórica, ao indicar em quais noções gerais a nova abordagem, causal e não-linear, encontra inspiração. (CROCA, 2003)

Nesta nova concepção da Física Quântica, uma partícula $\phi$ tem propriedades, essencialmente, de onda e de corpúsculo. Os aspectos ondulatórios de tal "entidade quântica" são representados por uma onduleta $\theta$, theta, associada a uma energia praticamente desprezível. O corpúsculo $\xi$, denominado acron, possui uma dada energia localizada numa pequena região. Assim, a entidade quântica integral, $\phi$, poderia ser representada matematicamente pela expressão:

$$
\phi=\theta+\xi
$$

A onda física finita, representada por uma onduleta $\theta$, constitui uma espécie de onda-guia sobre a qual o acron se desloca. Um caminho heurístico (CROCA, 2003), para propor uma Equação Mestra Não-Linear que descreva os processos envolvidos com as onduletas, baseia-se na consideração de duas equações clássicas: a Equação de Hamilton-Jacobi e a Equação da Continuidade. Com essas equações garante-se a presença formal simultânea dos dois aspectos fundamentais: o corpuscular e o ondulatório. Se a equação de Hamilton-Jacobi relaciona-se com as propriedades de localização das partículas clássicas, a equação da Continuidade, 
por sua vez, refere-se às propriedades extensas dos fluidos. A partir desse sistema de equações, consegue-se obter uma Equação Mestra Não Linear em contraste com a célebre Equação de Schrödinger.

Um resultado importante que pode ser derivado da Equação Mestra Não Linear diz respeito ao caso da partícula livre (tomando o potencial nulo). Como se sabe, a equação de Schrödinger não produz soluções de estados coerentes. No caso da dinâmica descrita pela Equação Mestra Não Linear, este fato não apresenta dificuldades. Mostra-se (CROCA, 2003) que uma solução para o caso em questão, unidimensional, é dada pela Onduleta de Morlet. Uma visualização gráfica da parte real de tal solução pode ser encontrada na Figura 5.

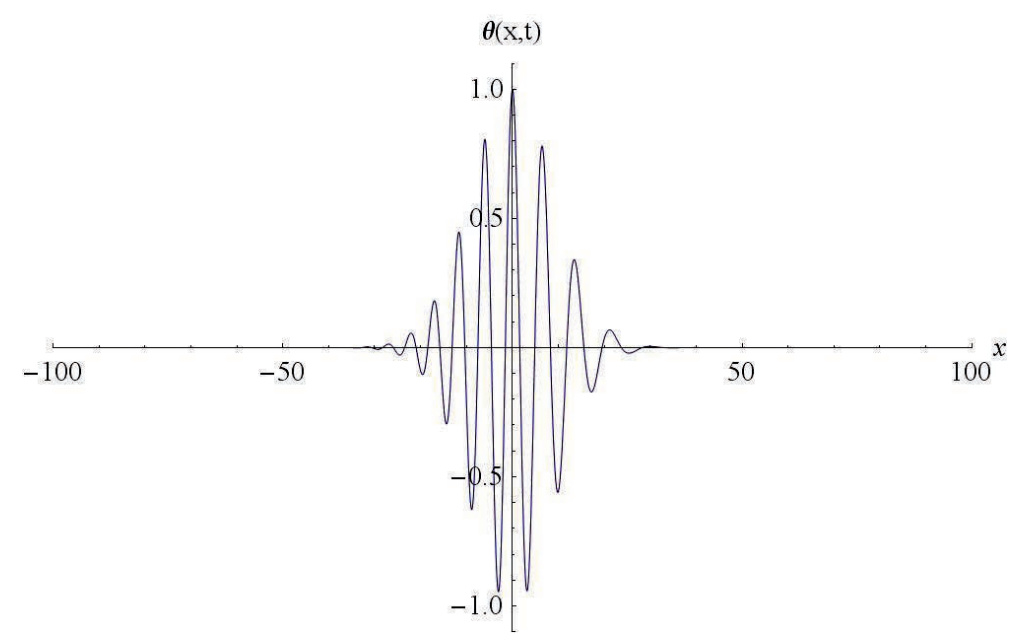

Figura 5 - Representação gráfica da parte real da solução para a partícula livre.

Com vista nesse tipo de soluções, pode-se sugerir um modelo para partícula quântica, $\phi$, levando-se em conta a fórmula (4.1). Tal modelo é constituído por uma parte ondulatória (a onduleta guia $\theta$, ou onda theta) e por uma parte corpuscular $\xi$ (o acron). Pressupõe-se, porém, que o corpúsculo possui uma amplitude muito grande relativamente à amplitude da onduleta. Além disso, o corpúsculo estaria concentrado numa região muito mais localizada do que $\theta$.

Uma solução desse tipo incorpora as duas imagens clássicas essenciais: a onda e o corpúsculo. De maneira simultânea, os aspectos de localização e de extensão são traduzidos neste modelo. A Figura 6 dá uma ideia visual de ambos os aspectos, incorporados num único objeto matemático. 
448 João Araújo / João Cordovil / José Ramalho Croca /
Rui Nobre Moreira / Amaro Rica da Silva

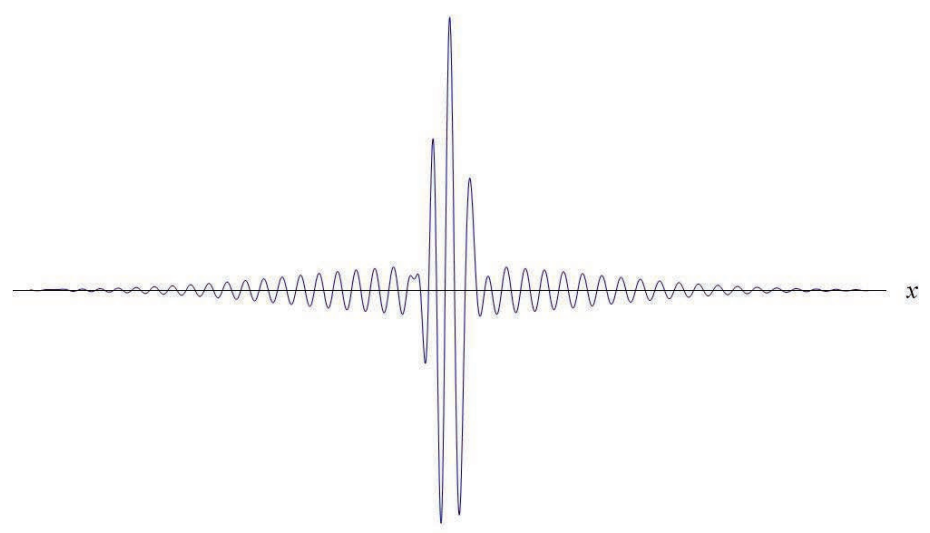

Figura 6 - Representação gráfica de uma partícula quântica livre.

Uma extensão desse modelo para uma entidade quântica pode ser realizada para duas dimensões. A Figura 7 fornece um gráfico 3D para este caso.

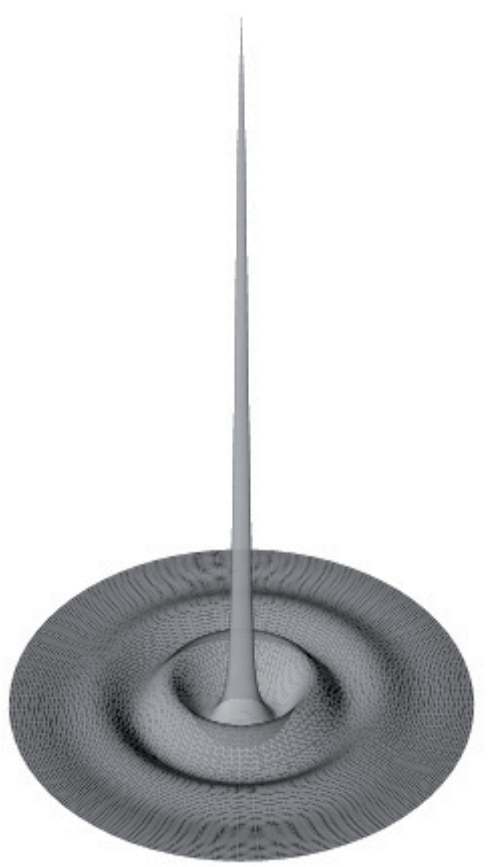

Figura 7 - Representação em 3D de uma partícula quântica livre. 


\section{A experiência da fenda dupla revisitada}

Após esta proposta expositiva sobre uma possível descrição matemática de uma entidade quântica, pode-se também realizar uma explicação intuitiva de experimentos tradicionais da Física Quântica, levando-se em consideração a natureza complexa das partículas quânticas. Partindo-se do pressuposto do modelo dado por (4.1), considera-se a célebre experiência da Fenda Dupla (Figura 8). Neste experimento, antes de encontrar as duas fendas, a entidade, emitida por uma fonte $\mathrm{S}$, é representada por um corpúsculo (o acron $\xi$, simbolizado na figura por um pequeno círculo preenchido) e por sua onduleta- guia (a onda theta, $\theta$, simbolizada pelas linhas de níveis em torno do acron). No instante em que a entidade encontra as duas fendas, a onda $\theta$, estendida espacialmente, é dividida em duas parcelas $\left(\theta^{\prime}\right.$ e $\left.\theta^{\prime \prime}\right)$, atravessando, simultaneamente, as duas fendas $\mathbf{A}$ e $\mathbf{B}$. Entretanto, ao acron, como entidade localizada, há duas opções: ou prosseguir pela fenda A ou pela fenda B (na Figura 8 escolheu-se o caminho B como ilustração). Em qualquer uma dessas opções, o acron propaga-se com uma onda-guia associada (por exemplo, a onda $\theta^{\prime \prime}$ ). Em contrapartida, a onda $\theta^{\prime}$, resultante da fenda A, é uma onda theta vazia, no sentido de ser uma entidade desprovida de acron. As duas parcelas $\theta^{\prime}$ e $\theta^{\prime \prime}$ se sobrepõem no espaço. Tal sobreposição, construtiva numas regiões e destrutiva em outras, cria as condições de propagação sobre o acron, através de processos não-lineares. $\mathrm{O}$ acron atinge pontualmente o detector $\mathbf{D}$ e, após esse processo ser realizado um número suficiente de vezes, verifica-se, progressivamente, a formação do padrão de interferência.

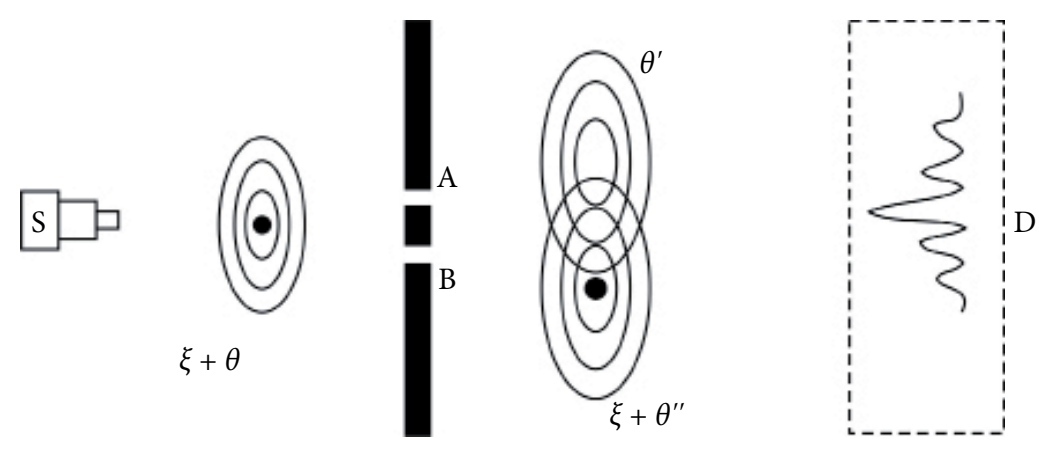

Figura 8 - Explicação causal da experiência da Fenda Dupla.

Uma observação sobre um detalhe sutil nesse experimento acaba por sugerir uma forma para se distinguir entre a perspectiva causal e local e a perspectiva ortodoxa. Na Teoria Quântica Ortodoxa, como se sabe, esse experimento é explicado considerando-se, após as duas fendas, uma função de onda total composta pelas funções de onda $\Psi_{\mathrm{A}}$ e $\Psi_{\mathrm{B}}$, associadas a cada uma das fendas A e B. Se dois 
detectores forem postos na saída de cada fenda, após uma detecção (por exemplo, no detector associado à fenda $\mathbf{B}$ ), há um colapso da função de onda total. Neste caso, a probabilidade de se encontrar $\Psi_{A}$ é nula. Em contraste com essa interpretação, na perspectiva causal e local, a ideia gira em torno do fato de que as ondas $\theta$ são entidades físicas com uma existência independente do acron. Logo, mesmo que uma detecção na fenda $\mathbf{B}$ seja realizada, o modelo supõe a existência de alguma entidade física (uma onda $\theta^{\prime}$ ) com energia praticamente desprezível a se propagar através da fenda $\mathbf{A}$.

Essa conclusão sugere a construção de aparatos experimentais que são denominados geradores de ondas theta. Na literatura, alguns trabalhos já foram publicados contendo discussões teóricas e realizações experimentais sobre essa temática. Para maiores detalhes sobre outros tipos de experimentos de geração ou de detecção de ondas theta, sugere-se ver principalmente Croca (2003); também Croca (1988), Croca e outros $(1990,1997)$ e Araújo e outros (2009a, 2009b).

\section{Referências}

ARAÚJO, J. et al. A causal and local interpretation of experimental realization of Wheeler's delayed-choice Gedanken experiment. Apeiron, v. 16, n. 2, p. 179190, 2009a.

Some experiments that question the completeness of orthodox quantum mechanics. Advanced Science Letter, v. 2, n. 4, p. 481-487, 2009b.

BOHM, D. Quantum theory. New York: Prentice-Hall, 1955. . Wholeness and the implicate order. London: Routledge, 1983.

BOHR, N. The quantum postulate and the recent development of atomic theory, Atomic Theory and the Description of Nature. Nature, v. 121, p. 580-590, 1928.

CHUI, C. K. An Introduction to wavelets. San Diego: Academic Press, CA, 1992.

Croca, J. R. Can the existence of de Broglie's empty wave be proven experimentally? In: MERWE, A. et al. (Ed.). Microphysical Reality and Quantum Formalism. Dordrecht: Kluwer Academic, 1988.

. Counter examples to the general validity of heisenberg uncertainty relations. Hadronic Journal, v. 22, p. 29-39, 1999a. 
Towards a nonlinear quantum physics. London: World Scientific, 2003.

. The uncertainty relations. Apeiron, v. 6, n. 3-4, p. 151-165, 1999 b.

CROCA, J. R. et al. Quantum-optical predictions for an experiment on de Broglie waves detection. Found. Phys. Lett., v. 3, p. 557-564, 1990.

. An experiment to test the reality of de Broglie waves. Found. Phys. Letters, v. 10, p. 441-447, 1997.

DE BROGLIE, L. The current interpretation of wave mechanics: a critical study. Amsterdam: Elsevier, 1964.

FALKENBURG, B. Particle Metaphysics: a critical account of subatomic reality. Heidelberg: Springer, 2007.

GUERET, P.; VIGIER, J. P. Lett. Nuovo Cimento, v. 38, p. 125-128, 1983.

HUBBARD, B. B. The world according to wavelets: the story of a mathematical technique in the making. 2nd. Massachusetts: AK Peters Wellesley, 1998.

JAMMER, M. The philosophy of quantum mechanics: the interpretations of quantum mechanics in historical perspective. New York: John Wiley \& Sons, 1974.

MOREIRA, R. N. Instrumentalismo versus realismo - A crise na física do século XX. In: POMBO, O.; NEPOMUCENO, A. (Ed.). Lógica e filosofia da ciência. Lisboa: Centro de Filosofia das Ciências da Universidade de Lisboa, 2008. p. 121-170.

PESSOA JR., O. Conceitos de física quântica. São Paulo: Livraria da Física, 2005. v. 1

SILVA, A. Rica da et al. Nonlinear Schrödinger equation, Burger's equation and superposition of solutions. In: JEFFERS, S. et al. (Ed.). Causality and locality in modern physics andaAstronomy. Dordrecht: Kluwer Academic, 1998. p. 421-430.

SILVA, J. Andrade e. Introdução à física moderna. Lisboa: Associação dos Estudantes da Faculdade de Ciências de Lisboa, 1995. 


\title{
Sobre os autores
}

\begin{abstract}
Alessandro Frederico da Silveira - Graduado em Física pela Universidade Estadual da Paraíba. Mestre em Engenharia Mecânica pela Universidade Federal da Paraíba. Doutorando em Ensino, Filosofia e História das Ciências pela Universidade Federal da Bahia e Universidade Estadual de Feira de Santana. Professor do Departamento de Física da Universidade Estadual da Paraíba.
\end{abstract}

Amaro José Rica da Silva - Graduado em Física pela Faculdade de Ciências de Lisboa. Doutor pela Universidade da Flórida, Estados Unidos. Professor Auxiliar do Instituto Superior Técnico, Lisboa, Portugal.

Ana Paula Bispo da Silva - Graduada e Doutora em Física pela Universidade Estadual de Campinas. Professora do Departamento de Física da Universidade Estadual da Paraíba.

Aurino Ribeiro Filho - Graduado em Física e Engenharia Civil pela Universidade Federal da Bahia. Doutor em Física Teórica pela Universidade de Essex, Inglaterra. Professor Associado do Instituto de Física da Universidade Federal da Bahia

Christian Joas - Graduado e Doutor em Física pela Universidade Livre, Berlim. Pesquisador do Instituto Fritz Haber da Sociedade Max Planck, Berlim, Alemanha.

Christoph Lehner - Graduado em Física pela Universidade Ludwig-Maximilians, Munique. Doutor em Filosofia pela Universidade de Stanford, Estados Unidos. Diretor do Projeto História da Física Quântica do Instituto Max Planck para a História da Ciência, Berlim, Alemanha.

Denis Gilbert Francis David - Graduado em Física e Doutor em Espectroscopia Atômica pela Universidade de Caen, França. Professor Adjunto do Instituto de Física da Universidade Federal da Bahia. 
Fabio Freitas - Graduado em Física pela Universidade Federal da Bahia. Mestre e Doutorando em Ensino, Filosofia e História das Ciências pela Universidade Federal da Bahia e Universidade Estadual de Feira de Santana. Professor Assistente do Instituto de Física da Universidade Federal da Bahia

Frederico Cruz - Graduado e Doutor em Física pela Universidade de São Paulo. Professor Adjunto do Centro de Ciências Físicas e Matemáticas da Universidade Federal de Santa Catarina.

Frederik Moreira Santos - Graduado em Física e Mestre em Filosofia pela Universidade Federal da Bahia. Professor Substituto do Instituto de Física da Universidade Federal da Bahia

Ileana Greca - Graduada em Matemática, Física e Cosmografia no Instituto Nacional Superior do Professorado no Paraná, Argentina. Doutora em Física pela Universidade Federal do Rio Grande do Sul. Professora da Universidade de Burgos, Espanha. Professora Visitante da Universidade Federal da Bahia e da Universidade Estadual da Paraíba.

Indianara Lima Silva - Graduada em Física pela Universidade Estadual da Paraíba. Mestre e Doutoranda em Ensino, Filosofia e História das Ciências pela Universidade Federal da Bahia e Universidade Estadual de Feira de Santana. Professora Visitante da Universidade Estadual de Santa Cruz.

Jhonny Castrillon Perez - Graduado em Física e Mestrando em Ensino de Ciências pela Universidade de Antioquia, Medellín, Colômbia.

Joan Bromberg - Graduada em Física pelo Vassar College. Doutora em Física e em História da Ciência pela Universidade de Wisconsin. Pesquisadora Visitante do Departamento de História da Ciência e da Tecnologia da Universidade Johns Hopkins, Baltimore, Estados Unidos.

João Eduardo Farias de Araújo - Graduado e Mestre em Física pela Universidade Federal de Pernambuco. Bolsista de Investigação do projeto Problemas Filosóficos da Física Quântica no Centro de Filosofia das Ciências da Universidade de Lisboa, Portugal.

João Luís de Lemos e Silva Cordovil - Graduado em Ensino da Física e Química pela Universidade de Lisboa. Doutorando em História e Filosofia das Ciências 
pela Universidade de Lisboa. É membro do Centro de Filosofia das Ciências da Universidade de Lisboa.

José Luis de Paula Barros Silva - Graduado e Doutor em Química pela Universidade Federal da Bahia. Professor Associado do Instituto de Química da Universidade Federal da Bahia.

José Nunes Ramalho Croca - Graduado e Doutorado em Física pela Faculdade de Ciências da Universidade de Lisboa. É membro fundador do Centro de Filosofia das Ciências da Universidade de Lisboa, Portugal.

Michel Paty - Graduado em Matemática pela Universidade de Bordeaux. Doutor em Física pela Universidade de Paris. Doutor em Filosofia pela Universidade de Estrasburgo. Fundador da Equipe REHSEIS e Diretor de Pesquisas Emérito do CNRS, Paris, França.

Nidia Franca Roque - Graduada em Engenharia Química pela Universidade Federal de Pernambuco. Doutora em Química Orgânica pela Universidade de São Paulo. Professora Titular do Instituto de Química da Universidade Federal da Bahia.

Olival Freire Jr. - Graduado em Física pela Universidade Federal da Bahia. Doutor em História Social pela Universidade de São Paulo. Professor Associado do Instituto de Física na Universidade Federal da Bahia. Pesquisador do CNPq.

Osvaldo Pessoa Jr. - Graduado em Física e Filosofia pela Universidade de São Paulo. Doutor em História e Filosofia da Ciência pela Universidade de Indiana, Estados Unidos. Professor do Departamento de Filosofia da Universidade de São Paulo.

Paulo Vicente Moreira dos Santos - Graduado em Física pela Universidade Federal da Bahia. Mestre em Ensino, Filosofia e História das Ciências pela Universidade Federal da Bahia e Universidade Estadual de Feira de Santana. Professor no Instituto Federal de Educação, Ciência e Tecnologia da Bahia.

Roberto de Andrade Martins - Graduado em Física pela Universidade de São Paulo. Doutor em Lógica e Filosofia da Ciência pela Universidade Estadual de Campinas. Professor Livre Docente do Instituto de Física Gleb Wataghin da Universidade Estadual de Campinas. Pesquisador do CNPq. 
Rui António Nobre Moreira - Graduado em Engenharia Mecânica pelo Instituto Superior Técnico de Lisboa. Doutorado em História e Filosofia das Ciências pela Universidade de Lisboa. Professor da Seç̧ão Autónoma da História e Filosofia da Ciência, Lisboa, Portugal.

Silvio Dahmen - Graduado em Física pela Universidade Federal de São Carlos. Doutor em Física Teórica e Matemática Aplicada pela Universität Bonn (Rheinische Friedrich-Wilhems), Alemanha. Professor Associado do Instituto de Física da Universidade Federal do Rio Grande do Sul.

Stefano Osnaghi - Graduado em Física pela Universidade de Milão. Doutor em Física pela Escola Normal Superior, Paris. Bolsista Marie Curie no Centro de Pesquisa em Epistemologia Aplicada, Escola Politécnica, Paris, França.

Wilson Fábio de Oliveira Bispo - Graduado em Física pela Universidade Federal da Bahia, Mestre em Ensino, Filosofia e História das Ciências pela Universidade Federal da Bahia e Universidade Estadual de Feira de Santana. Professor do Instituto Federal de Educação, Ciência e Tecnologia Baiano. 


\section{LIVROS EDUEPB E LATUS}

1. Pluralismo Jurídico: Para além da visão monista - Raíssa de Lima e Melo

2. Mulher, corpo e cuidado - Maria de F. de A. Silveira; e Dulce M. Rosa Gualda

3. Avaliação de serviços: um olhar na qualidade da gestão - (Orgs) Maria José Cariri Benígna; e Maria A. Amado Rivera

4. Farmacêutico na Farmácia - Rosimary S. Cunha Lima; Maria do Carmo Eutálio; e Magnólia de L. S. Targino

5. Representações sociais e saúde - Aliana Fenandes; Maria. do R de Carvalho; e Moisés Domingos Sobrinho

6. EPI Info para iniciantes - (Orgs) Sonia Maria de L. Maciel; e Pedro Henrique de A. e S. Leite

7. Ensino de lingua: do impresso ao virtual - (Orgs) Antonio de Pádua Dias da Silva; Maria de L. L. Almeida; Simone Dália de Gusmão Aranha; e Tereza. N. de Farias Campina

8. A história da mídia regional - C. B de Souza; F. G. de Oliveira; e Gorete M. Sampaio de Freitas

9. Livro de resumo de monografias - Maria Dora Ruiz Temoche

10. Planejamento tributário no campo de incidência do ICMS - Alexandre H. S. Ferreira; e Ana Maria da P. Duarte

11. 1930 - A Revolução que mudou a História do Brasil - (Orgs) João M. L. Santos; Cláudo José L. Rodrigues; Inês Caminha L. Rodrigues; e José Octávio de A. Melo

12. Curso de Direito Constitucional - Lorivaldo da Conceição

13. Fragmentos - Juarez Filgueras de Góis

14. Gênero em questão - (Org) Antonio de Pádua Dias da Silva

15. Jogos eletrônicos - Eliane de M. Silva; Filomena M. G. da S. C Moita; e Robson Pequeno de Souza

16. Nascido do Fogo, Filho da Paz - Ket Jeffson Vasconcelos Leitão

17. Política Tributária e Justiça Social - Alexandre Henrique Salema Ferreira

18. Revista Sócio-Poética - Departamento de Letras da UEPB

19. O Sábio e a Floresta - Moacir Werneck de Castro

20. Universidade e o fazer poético em prosa e poesia - (Orgs) Fabíola Nóbrega; Marcelle V. Carvalho; e Tatiana Fernandes Sant'ana

21. Sustentabilidade - um enfoque sistêmico - (Orgs) Waleska S. Lira; Helio de L. Lira; Maria José dos Santos; e Lincon Eloy de Araújo

22. Bioquímica clínica - uma abordagem geral - Sandra Reis Farias

23. Mortalidade Geral - Epidemologia - Anthonyanny A. Silva Lima; Maria J. Cariri Benigna

24. Estudos Filológicos: Literatura - Cultura - Marinalva Freire da Silva

25. Dicionário de termos relativos a gestão de pessoas - Maria Dora Ruiz Temoche

26. Práticas de Políticas Públicas - (Orgs) Marcelo A. Pereira; Maria da G. A. Pereira; Sandra. M. A de S. Celestino; Sueli Ramos de R. M. Cavalcanti; e Wíliam A. de Lacerda

27. Saúde Humana - (Org) Inácia Sátiro Xavier de França 
28. O Segredo de Pergamo - Ket Jeffson Vasconcelos Leitão

29. A queda do meteorito - Giusone Ferreira Rodrigues

30. Trajetória empreendedora: estudo de casos numa realidade local e global - (Org) Vera Lúcia Barreto Motta

31. Identidades de gênero e práticas discursivas - (Org) Antonio de Pádua Dias da Silva

32. O lugar da Educação Física - Maria José de Figueirêdo Gomes

33. O papel político dos fóruns de educação de jovens e adultos - Eduardo Jorge Lopes da Silva

34. Pesquisa histórica - resumo de monografias - (Orgs) Luíra Freire Monteiro; e Flávio Carreiro de Santana

35. Anos de luta - Waldir Porfírio

36. Mulher e violência: histórias do corpo negado - Lígia Pereira dos Santos

37. Agricultura orgânica - José Geraldo R. dos Santos; e Emmanuelly Calina X. R. Santos

38. Sobre o diálogo: introdução a uma leitura filosófica de - Julio Cesar Kestering

39. Novos cenários da Administração - (Org) maria Dora Ruiz Temoche

40. O despertar da cultura - (Org) Marinalva Freire da Silva

41. Manual básico de Radiologia Odontológica - Maria de Fátima Cavalcanti Rodrigues

42. Formas de sociabilidade e instauração da alteridade - Inácia S. Xavier de França; Lorita M. Freitag Paghuca

43. Paremiologia nordestina - Fontes Ibiapina

44. Resistência indígena no Piauí colonial 1718 - 1774 - João Renor F. de Carvalho

45. Planejando o (des)envolvimento local - Roberto Alves de Araújo; e Ana Siqueira de Araújo

46. Deuses em poéticas: estudos de Literatura e Teologia - (Orgs) Salma Farraz; Antonio Magalhães; Eli Brandão; Waldecy Tenório; Douglas Conceição

47. Campina Grande em debate - (Org) Roberto Véras de Oliveira

48. História do Direito e da violência: recortes de uma abordagem interdisciplinar - Marcelo Alves Pereira Eufrásio

49. Contos jurídicos: normas de sobredireito da Lei de Introdução ao Código Civil - Ket Jeffson Vasconcelos Leitão

50. A Bacia do Rio Gramame: Biodiversidade, uso e conservação - (Orgs) José Etam de Lucena Barbosa; e Takako Watanabe; e R. José da Paz

51. Ser criança - repensando o lugar da criança na educação infantil - (Orgs) Glória M. de Souza Melo; Soraya. M. de A. Brandão; e Marinalva. da Silva Mota

52. Estudos Sociais da Ciência e Tecnologia - (Org) Renato Dagnino

53. De portas abertas para o lazer - (Orgs) Elaine Melo de B. Costa Lemos; Eduardo Ribeiro Dantas; e Cheng Hzin Nery Chão

54. Gênero e práticas culturais - (Orgs) Charliton J. dos Santos Machado; Idalina M. F. Lima Santiago; e Maria L. da Silva Nunes 
55. Da resistência ao poder - o (P)MDB na Paraíba (1965 / 1999) - José Otávio de Arruda Mello

56. Políticas públicas e desenvolvimento regional - (Orgs) Carlos. A. Máximo Pimenta; Cecília Pescatore Alves

57. Histórias vividas e contadas no Bar do Brito - (Orgs) A. C. Barbosa de Souza; Antonio Guedes Rangel Junior; Clara M. Araújo Pinto; e Sonia Maria A. de Oliveira Brito

58. De memória e de identidade - (Orgs) Antonia M. M. da Slva; Francisco Paulo da Silva; Ivanaldo Oliveira dos Santos; e Maria Edileuza da Costa

59. A luz que não se apaga - Rômulo de Araújo Lima

60. Cálculo avançado - (Orgs) Aldo Trajano Louredo; e Alexandro M. de Oliveira; e Osmundo Alves Lima

61. Fisioterapia na gravidez - (Org) Maria do Socorro B. e Silva

62. Educação Universitária - Pedro Bergamo

63. Amora - Fidélia Cassandra

64. Educação em questão - recortando temas e tecendo ideias - (Pedro Lúcio Barboza)

65. Ciço de Luzia - Efigênio Moura

66. Zila Mamede - trajetórias literárias e educativas - Charliton José dos Santos Machado

67. A voz da infância e outras vozes - Calos Azevedo

68. A Educação da Mulher em Lima Barreto - (Jomar Ricardo da Silva)

69. Porta aberta à poesia popular - Almira Araújo Cruz Soares

70. Mulheres representadas na literatura de autoria feminina - Antonio de Pádua Dias da Silva

71. Residências terapêuticas - (Orgs) Maria de Fátima de A. Silveira e Hudson Pires de O. Santos Júnior

72. A nuvem de hoje - Braulio Taveres

73. Tecnologias digitais na educação - (Orgs) Robson Pequeno de Sousa; Filomena M. C. da S. C. Moita; e Ana Beatriz Gomes Carvalho.

74. A representação da sogra na obra de Leandro Gomes de Barros - José Itamar Sales da Silva

75. Viagem aos 80 anos da Revolta de Princesa - Janduí Dantas

76. Cidadania glocal, identidade nordestina - José Marques de Melo

77. Uma nova ciência para um novo senso comum - Marcelo Germano Gomes

78. A feira - o trovador encantado - Maria de Lourdes Nunes Ramalho

79. Nordeste como inventiva simbólica - Geralda Medeiros Nóbrega

80. Era uma vez diferente - Aline Pereira

81. Colecionismo, práticas de campo e representações - Maria Margaret Lopes e Alda Heizer. 


\section{Sobre o livro}

Este livro foi impresso na Gráfica Universitária da UEPB.

Formato: $17 \times 24 \mathrm{~cm}$

Mancha Gráfica: 12,5 x 19,5 cm.

Tipologias utilizadas: Minion Pro 11/13 pt

Papel: Apergaminhado $75 \mathrm{~g} / \mathrm{m}^{2}$ (miolo)

e Cartão Supremo 250g/m² (capa). 